\title{
Supplemental Immobilization of Hanford Low-Activity Waste: Cast Stone Screening Tests
}

\author{
PNNL \\ SRNL \\ WRPS \\ JH Westsik, Jr. \\ AD Cozzi \\ DJ Swanberg \\ GF Piepel \\ MJ Lindberg \\ WE Daniel \\ RE Eibling \\ PG Heasler \\ EK Hansen \\ TM Mercier \\ MM Reigel \\ RL Russell
}

September 2013

Richland, WA 99352

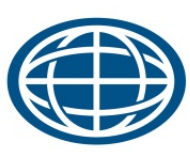

\section{Savannah River} National Laboratory ${ }^{m}$

Pacific Northwest

NATIONAL LABORATORY

Proudly Operated by Battelle Since 1965 


\section{DISCLAIMER}

This document was prepared in conjunction with work accomplished under two Contracts No. DE-AC09-08SR22470 and DE-AC05-76RL01830 both with the U.S. Department of Energy.

This work was prepared under an agreement with and funded by the U.S. Government. Neither the U.S. Government or its employees, nor any of its contractors, subcontractors or their employees, makes any express or implied: 1. warranty or assumes any legal liability for the accuracy, completeness, or for the use or results of such use of any information, product, or process disclosed; or 2. representation that such use or results of such use would not infringe privately owned rights; or 3. endorsement or recommendation of any specifically identified commercial product, process, or service. Any views and opinions of authors expressed in this work do not necessarily state or reflect those of the United States Government, or its contractors, or subcontractors.

\section{Printed in the United States of America}

Prepared for U.S. Department of Energy 


\section{ACKNOWLEDGMENTS}

The work reported here was funded by Washington River Protection Solutions (WRPS). Dave Swanberg with WRPS led the effort and provided both programmatic guidance and technical input to the project team.

These screening tests were very laboratory intensive. At Pacific Northwest National Laboratory (PNNL), Ben Williams was instrumental in preparing the Cast Stone specimens and conducting the leach tests. Don Rinehart prepared the simulants. Keith Geiszler, Steve Baum, Igor Kutnyakov, Christian Iovin, and Dennesse Smith analyzed the many samples. Stan Pitman, Mike Dahl, and Karl Mattlin conducted the compressive strength measurements. At Savannah River National Laboratory (SRNL), Vickie Williams was the cornerstone of the preparation and measurement of the Cast Stone fresh properties, Kim Wyszynski and Vickie Williams prepared the simulants, and David Best, Whitney Riley, and Beverly Wall performed the analyses.

John Harris with LaFarge graciously provided the dry blend ingredients sourced from the northwest.

Jeff Serne at PNNL and Kevin Fox at SRNL provided independent technical review of the document. Dave MacPherson from PNNL; Paul Cavanah, Dave Darling, QD Ho, Felix Miera, Gene Ramsey, Rose Russell, and Leo Thompson from WRPS; and Fred Mann also provided comments on the document. Ellen Baer and Paul Eslinger from PNNL and Kevin Fox from SRNL provided calculation and document reviews.

Susan Ennor had the challenge of editing the inputs from multiple authors into a cohesive document. Kathy Neiderhiser did an outstanding job in preparing the document for publication. 


\section{EXECUTIVE SUMMARY}

The Hanford Site has approximately 56 million gallons of radioactive waste stored in 177 underground storage tanks. The Hanford Waste Treatment and Immobilization Plant (WTP) is being constructed to treat all of the high-level waste (HLW) in the tank farms but will not have sufficient capacity to treat all of the low-activity waste (LAW) within the anticipated time frame for completion of the waste treatment mission. The LAW vitrification facility will need to be supplemented with a second LAW vitrification facility or an alternate LAW immobilization technology. A cementitious waste form known as Cast Stone is being considered to provide the required additional LAW immobilization capacity.

Hanford Tri-Party Agreement (TPA) milestone M-062-40ZZ requires the U.S. Department of Energy Office of River Protection (DOE/ORP) to submit a One-Time Hanford Tank Waste Supplemental Treatment Technologies Report by October 2014 if a technology other than a second LAW vitrification facility is proposed. The main purpose of the one-time report will be to describe the additional treatment facilities and technologies needed to treat all of Hanford's LAW. The report must describe the technologies considered, quantity of waste to be processed, quantity of final waste forms, secondary wastes, waste form performance data, technical viability, and life-cycle cost and schedule estimates. The DOE/ORP and the Washington State Department of Ecology would then have six months (until April 2015) to complete negotiations to select a final technology, and to establish milestones to implement the technology.

To support completion of the one-time report, Washington River Protection Solutions (WRPS) has contracted with Pacific Northwest National Laboratory (PNNL) and Savannah River National Laboratory (SRNL) to conduct a testing program with the following objectives:

- Determine an acceptable formulation for the LAW Cast Stone waste form.

- Evaluate the impact of different sources of dry materials for preparing the LAW Cast Stone.

- Demonstrate the robustness of the waste form for a range of LAW compositions.

- Demonstrate the robustness of the formulation for variability in the Cast Stone process.

- Provide Cast Stone contaminant release data for performance assessment and risk assessment evaluations.

The first step in determining an acceptable formulation for the LAW Cast Stone waste form was to conduct screening tests to evaluate the impact of key parameters including expected ranges in waste composition, waste stream concentrations, sources of dry materials, and mix ratios of waste (free water) to dry blend. A statistically designed test matrix was used to evaluate the effects of these key parameters on the properties of the Cast Stone as it was initially prepared and after curing. This report documents the results of these screening tests.

The screening tests comprise 26 individual Cast Stone mixes selected through the statistical design plus 12 additional tests described subsequently. The statistical experimental design included two blocks. The first block of 12 mixes plus 2 replicates was selected to estimate the main effects among the study parameters. The second block of 10 mixes plus 2 replicates 
was selected to estimate the effects of some two-parameter interactions. There was one mix in Block 1 that was replicated in Block 2. The specific parameters included the following:

- Waste simulant composition

- A single-shell tank (SST) blend based on the analyses of saltcake from six SSTs

- An overall average LAW feed composition based on Hanford Tank Waste Operations Simulator (HTWOS) flowsheet modeling

- A high-aluminum simulant based on HTWOS flowsheet modeling

- A high-sulfate simulant based on HTWOS flowsheet modeling.

- Waste concentration expressed in terms of the sodium concentration in the wastes $(5.0 \mathrm{M}$ and $7.8 \mathrm{M} \mathrm{Na})$

- Sources of dry materials for Cast Stone dry blend, also known as premix

- Class F fly ash source

- Fly ash from the Pacific Northwest - relatively high in calcium

- Fly ash from the Southeast - relatively low in calcium

- Blast furnace slag

- Pacific Northwest source

○ Southeast source

- Ordinary portland cement from the Pacific Northwest

- Mix ratio, which is the ratio of free water in the waste to the mass of dry blend in the mix. The mix ratios included 0.4 (based on previous Cast Stone secondary waste studies) and 0.6 (based on current processing experience with the Saltstone Processing Facility at the Savannah River Site).

The ratio of cement to fly ash to blast furnace slag was held constant at the nominal Cast Stone mix ratio of 8:45:47 for all 26 mixes. The different combinations of simulants, $\mathrm{Na}$ concentrations, and mix ratios yielded waste loadings ranging from $9.5 \mathrm{wt} \%$ to $20.3 \mathrm{wt} \%$ total waste solids in the Cast Stone waste form.

Each of the 26 mixes was characterized with respect to the processing properties of the wet Cast Stone slurry as it was mixed and cured, and the properties of the final Cast Stone cured waste form. Processing properties that were measured included gel and set times, slurry rheology, flow cone, fresh density, and heat generation. Processing properties were measured for 12 mixes in addition to the 26 of the screening matrix. Final waste form properties that were measured included compressive strength, porosity, cured density, Toxicity Characteristic Leaching Procedure (TCLP) leach test, and EPA Draft Method 1315 leach test.

For the processing properties, the water-to-dry-blend mix ratio was the most significant parameter in affecting the range of values observed for each property. Table ES- 1 shows the properties and their ranges at the 0.4 and 0.6 mix ratios. The method to process and dispose of the Cast Stone waste form has not yet been determined, so the function of the processing properties is to provide a potential range of property values for design input. 
Table ES-1. Cast Stone Properties and Ranges at Mix Ratios

\begin{tabular}{||l|c|c||}
\hline \multicolumn{1}{|c|}{ Property } & 0.4 Mix Ratio & 0.6 Mix Ratio \\
\hline Flow Diameter & $94-160 \mathrm{~mm}$ & $193-298 \mathrm{~mm}$ \\
\hline Gel Time & $1-15$ minutes & $12-121 \mathrm{minutes}$ \\
\hline Plastic Viscosity & $220-580$ centipoise & $54-165$ centipoise \\
\hline Bingham Plastic Yield Stress & $10-92$ Pascals & $2-24$ Pascals \\
\hline Heat Generation & $150-338 \mathrm{~J} / \mathrm{g}$ & $270-434 \mathrm{~J} / \mathrm{g}$ \\
\hline Time to Peak Heat Generation & $26-164 \mathrm{hours}$ & $16-101 \mathrm{hours}$ \\
\hline Fresh Density & $1.87-1.96 \mathrm{~g} / \mathrm{cm}^{3}$ & $1.73-1.83 \mathrm{~g} / \mathrm{cm}^{3}$ \\
\hline \hline
\end{tabular}

Compressive strengths were measured in triplicate on Cast Stone monoliths prepared at PNNL and SRNL. Compressive strengths ranged from 5.8 to $62.0 \mathrm{MPa}$ ( 850 to $8990 \mathrm{psi}$ ), excluding one sample that broke at $1.3 \mathrm{MPa}(190 \mathrm{psi})$. The target minimum compressive strength is $3.4 \mathrm{MPa}$ (500 psi), which is more than sufficient to withstand the overburden in a near-surface disposal facility, e.g., the draft waste acceptance criteria for the Hanford Integrated Disposal Facility (IDF) requires a minimum comprehensive strength of $586 \mathrm{kPa}$, or $85 \mathrm{psi}$. The lower compressive strengths tended to be from Cast Stone mixes with the $7.8 \mathrm{M} \mathrm{Na}$ simulants and the 0.6 water-todry-blend ratio. The higher compressive strengths tended to be from Cast Stone mixes with the $5 \mathrm{M}$ Na simulants and/or the 0.4 water-to-dry-blend mix ratio.

To be acceptable for disposal at the IDF on the Hanford Site, Cast Stone containing hazardous metals must pass the TCLP. Land disposal restrictions require that the concentration of the species in the leachate be below the Universal Treatment Standards (UTS) in Title 40 Code of Federal Regulations Part 268 "Land Disposal Restrictions" (40 CFR 268). The LAW is projected to include Resource Conservation and Recovery Act (RCRA) regulated metals including As, Ba, $\mathrm{Cd}, \mathrm{Cr}, \mathrm{Pb}, \mathrm{Hg}$, Se, and $\mathrm{Ag}$; and underlying hazardous constituents (UHCs) including $\mathrm{Sb}, \mathrm{Be}, \mathrm{Ni}$, and Tl. In addition, some of the dry materials used to make Cast Stone may include these same and other hazardous materials. The simulants in the screening tests were spiked with $\mathrm{Cr}, \mathrm{Pb}, \mathrm{Ni}$, and $\mathrm{Cd}$, which were the highest concentration RCRA metals projected in the HTWOS flowsheet modeling. The dry blend materials contributed As, $\mathrm{Ba}$, and Se to the Cast Stone waste forms. All of the 26 Cast Stone mixes easily met the UTS limits based on the TCLP results and total constituent analyses calculations.

Leach tests on cured Cast Stone cylinders were conducted for 91 days using EPA Method 1315 to measure the effective diffusivity of key constituents of concern including Tc, I, U, Cr, Na, and nitrates and nitrites. Effective diffusivities are used in performance assessments and risk assessments to describe the release of contaminants from the waste form. Effective diffusivities for $\mathrm{Na}$, I, nitrate, and nitrite averaged over the 28- to 91-day cumulative leach intervals were all in the same range of $1 \times 10^{-8}$ to $2 \times 10^{-9} \mathrm{~cm}^{2} / \mathrm{s}$ for all but one of the 26 Cast Stone mixes. The corresponding average leachability indices (LIs) were in the range of 8 to 8.7. Technetium effective diffusivities were in the range of $2 \times 10^{-10}$ to $6 \times 10^{-12} \mathrm{~cm}^{2} / \mathrm{s}(\mathrm{LI}=9.7$ to 11.2$)$ for the same 25 mixes and total leach interval. Chromium effective diffusivities were in the range of $9 \times 10^{-13}$ to $8 \times 10^{-15} \mathrm{~cm}^{2} / \mathrm{s}(\mathrm{LI}=12.0$ to 14.1$)$. Uranium was not detected in most of leachates from the 25 mixes, indicating that the $\mathrm{U}$ is retained in the Cast Stone and is being minimally released under the conditions of the EPA 1315 leach test.

Statistical analyses were performed for Cast Stone properties including plastic viscosity, heat generation, compressive strength, and EPA Method 1315 leach indices. The objectives of the statistical analyses were to determine whether individual test parameters and their two-parameter 
interactions have statistically significant effects on a given Cast Stone property, and to assess the relative magnitudes of these effects. Two approaches to statistical analyses of the data were performed to address these objectives. The "Full Model" approach was used to evaluate the individual effects of the five test parameters plus two-parameter interactions as used in developing the screening test matrix. The "Stepwise Model" approach used stepwise regression to build a model to identify the statistically significant individual parameter and two-parameter interaction effects. Of the five parameters varied in the screening tests, the mix ratio, fly ash source, and blast furnace slag source had the most significant effects on the Cast Stone properties. Sodium molarity and the waste simulant type were less significant variables affecting the Cast Stone. All five of the test parameters were involved in one or more statistically significant twoparameter interactions over the Cast Stone properties that were statistically analyzed, indicating that interactive effects of the parameters must be considered in future work to select optimal Cast Stone formulations.

The screening tests demonstrated that, for the ranges of parameters studied, almost all of the formulations could be processed and would provide acceptable waste forms. Of the 26 original Cast Stone mixes in the screening test matrix, all but 2 mixes had acceptable processing and waste form properties. That is, the ranges of properties measured are similar enough that a processing/disposal facility could be designed to accommodate all but two of the test compositions evaluated in the screening tests.

All of the Cast Stone mixes had acceptable properties with respect to anticipated waste acceptance criteria for the IDF. Compressive strengths exceeded the 500 psi (3.45 MPa) target. The leachates from the TCLP test met treatment standards to address Land Disposal Restrictions for hazardous chemicals in 40 CFR 268.

The next step in the planned testing program is to optimize the Cast Stone formulation. The screening test results suggest that the waste loading in the Cast Stone can be increased beyond the levels evaluated in the screening tests. Waste loading can be increased by concentrating the wastes to higher sodium concentrations and by increasing the free water-to-dry blend mix ratio. It is reasonable to conduct additional formulation optimization testing with sodium molarities in the range of $7 \mathrm{M}$ to $10 \mathrm{M}$ and free water-to-dry blend mix ratios in the range of 0.5 to 0.7 . Though there were statistically significant effects of the sources of BFS and fly ash, the impacts were not drivers to use sources other than those available in the Pacific Northwest for the Cast Stone optimization work.

Cast Stone formulation optimization provides the opportunity to investigate methods to improve the retention of Tc and I in the waste form. The use of getters, fillers to reduce porosity, and increased BFS content will be evaluated.

This work has provided a sound technical basis for the next phase of technology maturation. The primary objective for the next phase will be to develop a preferred formulation of a lowtemperature waste form for Hanford LAW based on knowledge gained during this screening test phase. The preferred formulation is expected to include formulation enhancements to improve retention of constituents of concern. Other objectives for the next phase include conducting an engineering-scale demonstration of the Cast Stone preparation process and conducting confirmatory testing with samples of real waste. 


\section{TABLE OF CONTENTS}

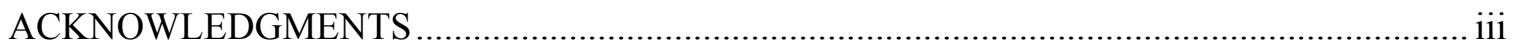

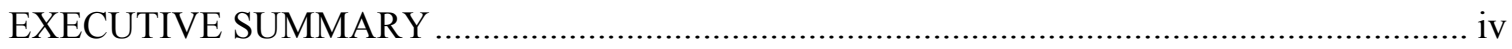

LIST OF ABBREVIATIONS AND ACRONYMS .......................................................... xvii

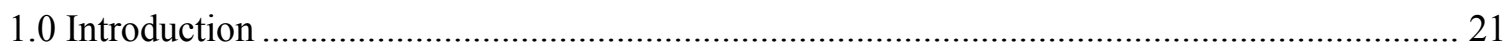

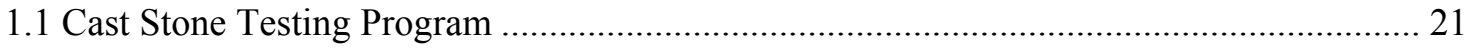

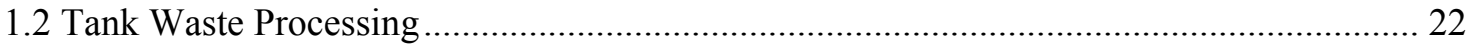

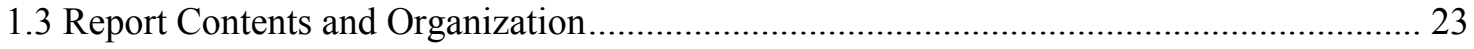

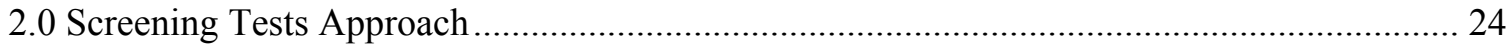

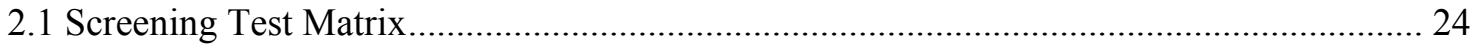

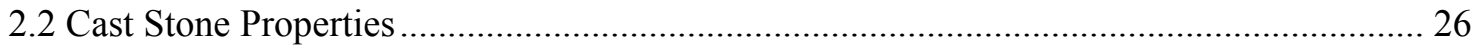

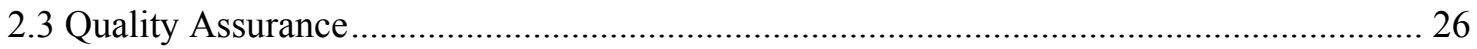

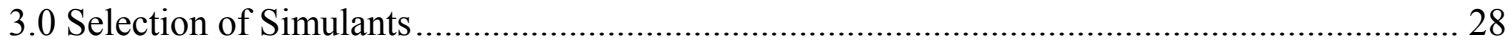

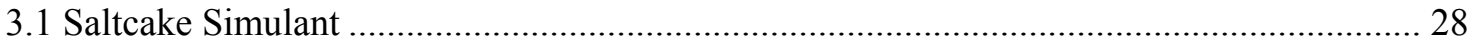

3.2 Simulants Based on System Plan 6 HTWOS Modeling ................................................... 28

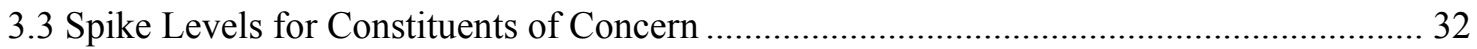

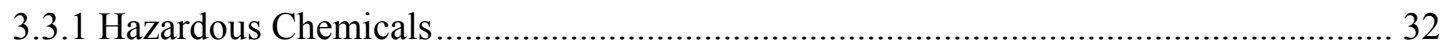

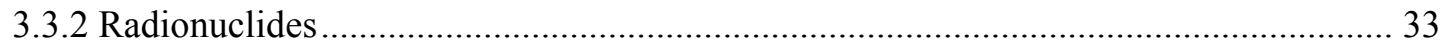

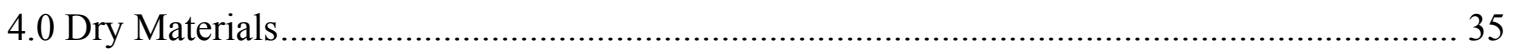

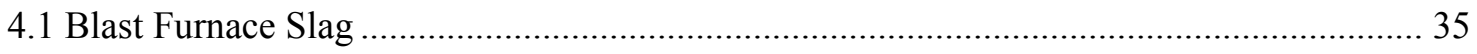

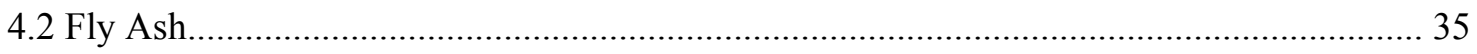

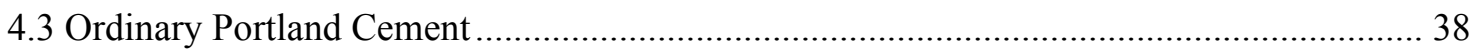

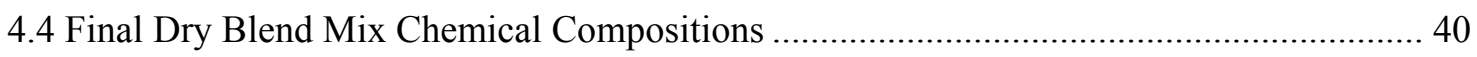

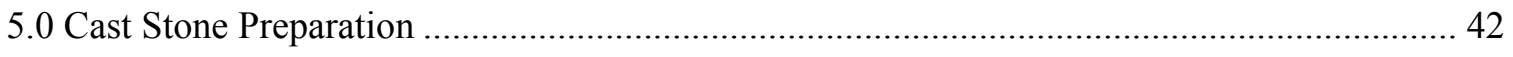

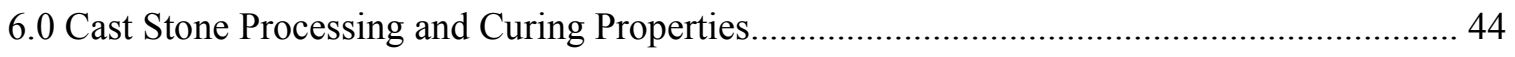

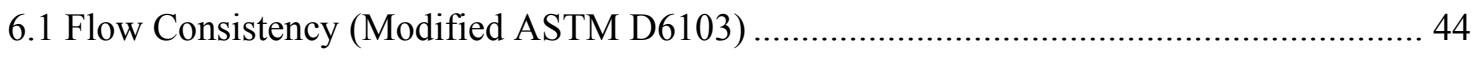

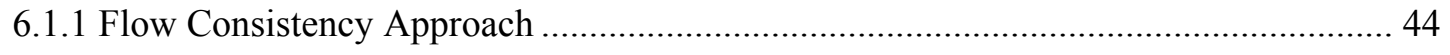

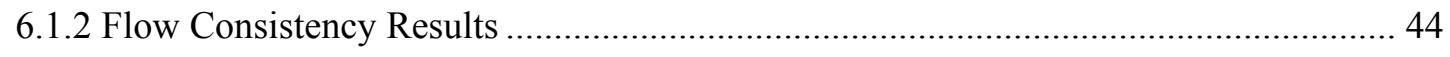

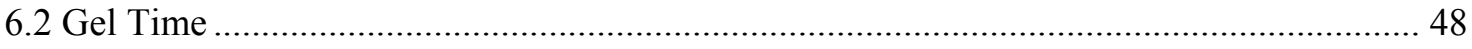

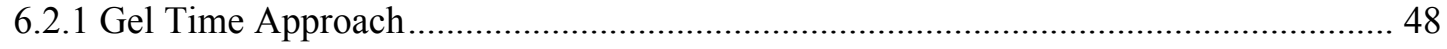

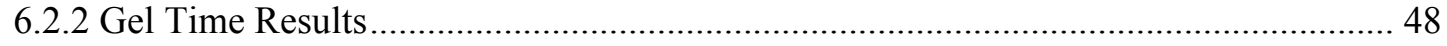




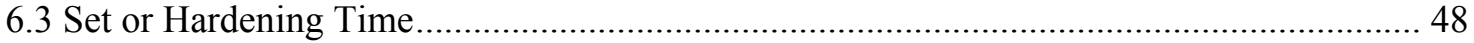

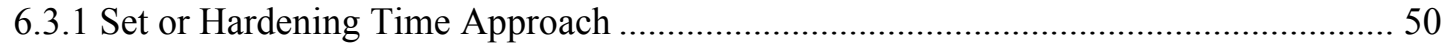

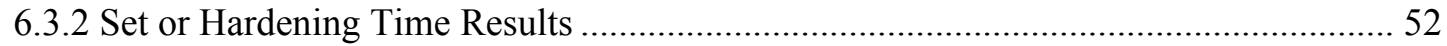

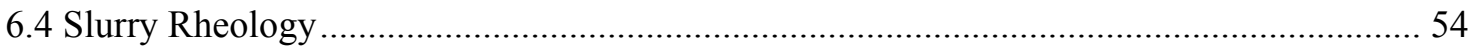

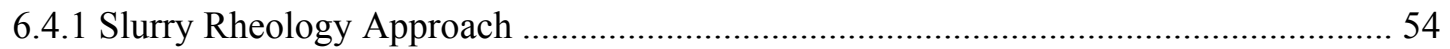

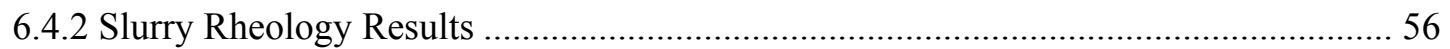

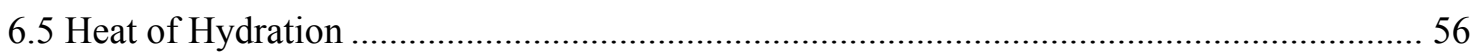

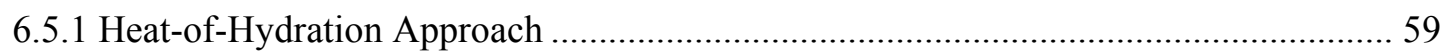

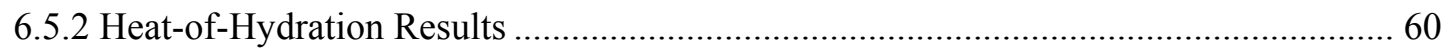

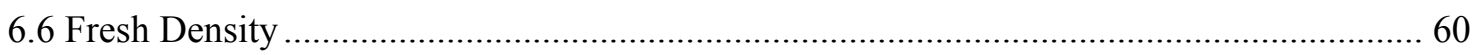

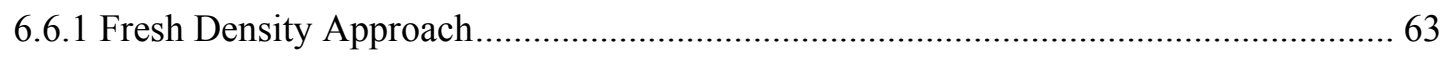

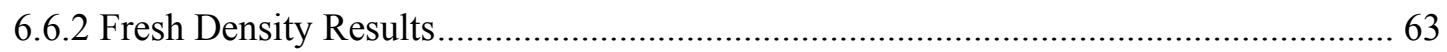

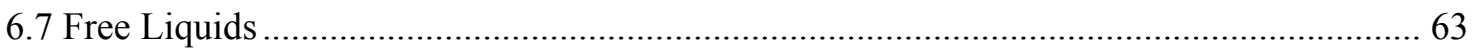

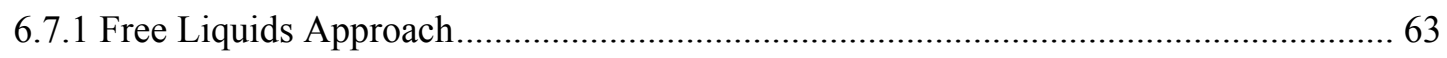

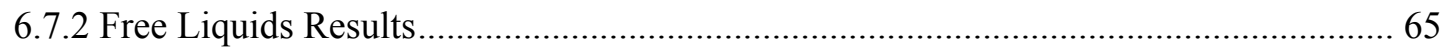

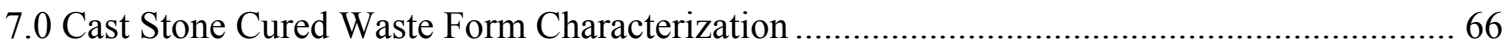

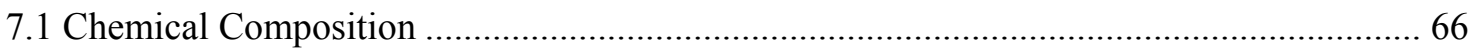

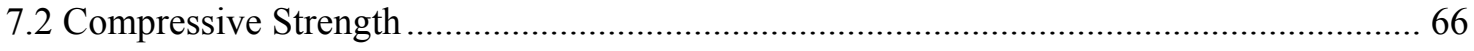

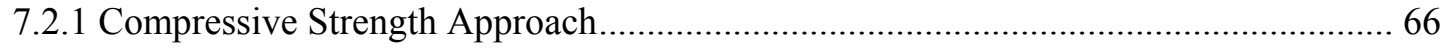

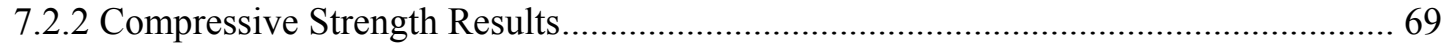

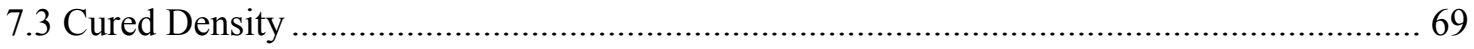

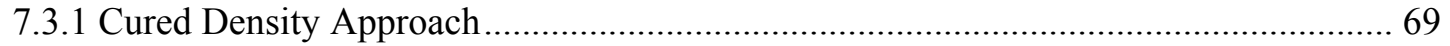

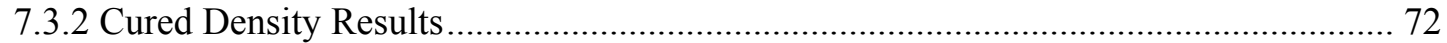

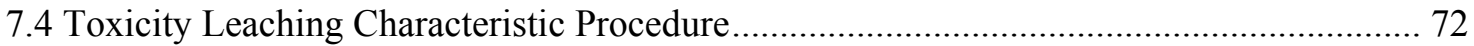

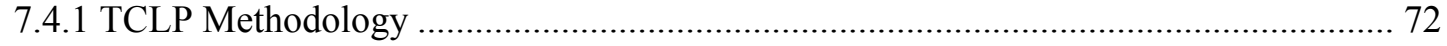

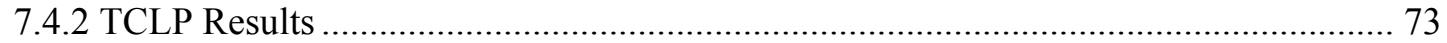

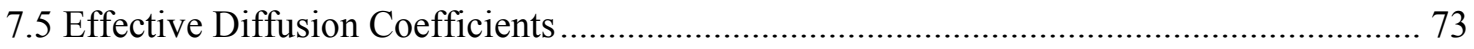

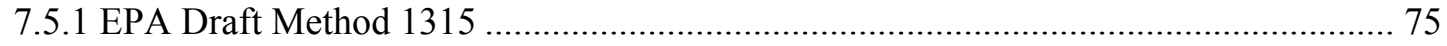

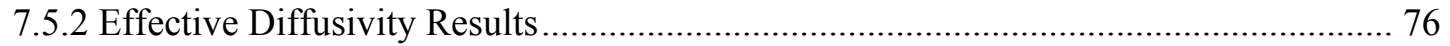

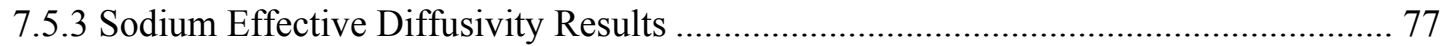

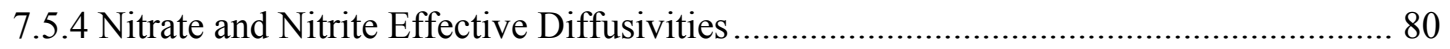

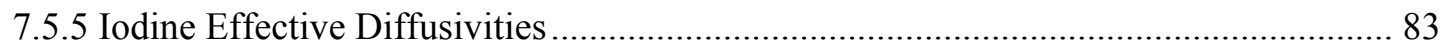

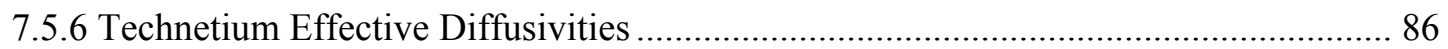




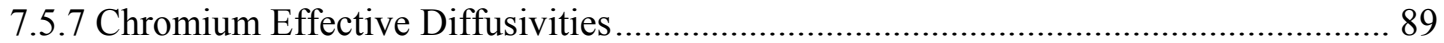

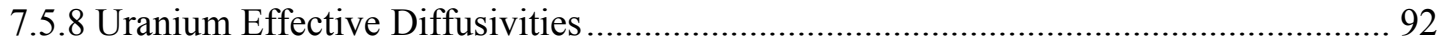

8.0 Statistical Analysis of the Effects of Screening Test Parameters on Cast Stone Properties.... 94

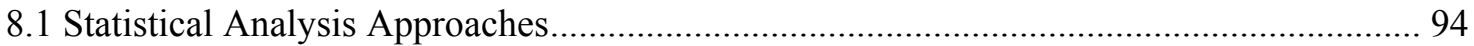

8.2 Full Model Approach to Statistical Analysis of the Screening Test Data ........................... 95

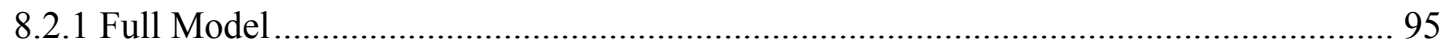

8.2.2 Fitting the Full Model and Summaries of Results......................................................... 96

8.2.3 Summary Statistics to Assess Model Adequacy ............................................................. 99

8.2.4 Estimates of Parameter Effects for the Full Model ..................................................... 100

8.2.5 Assessment of Whether the Four Simulants Have Different Effects on Cast Stone

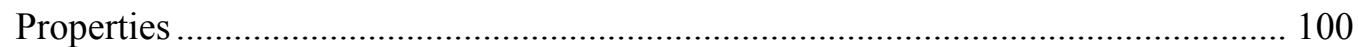

8.3 Stepwise Regression Modeling Approach, Including the Possibility of Interactions

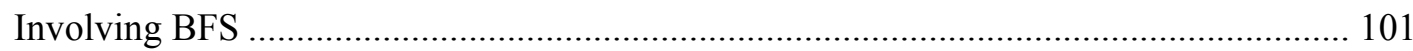

8.4 Cautions Regarding Interpreting the Results of Fitting the Full Model and Stepwise

Models 102

8.5 Estimates of Testing and Measurement Uncertainties of Cast Stone Properties from

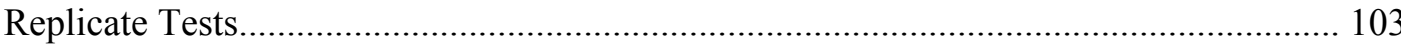

8.6 Results of Statistical Analyses - Processing Properties .............................................. 106

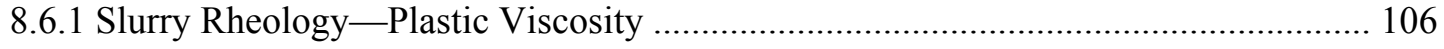

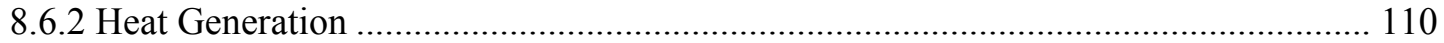

8.7 Results of Statistical Analyses - Cured Waste Form Properties ..................................... 116

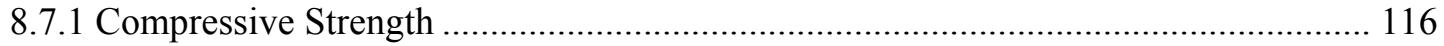

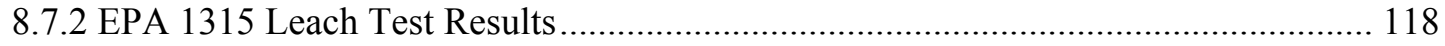

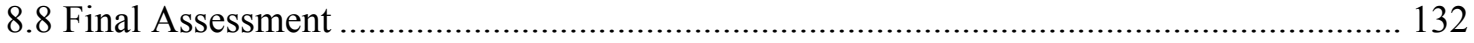

8.8.1 Assessing the Fits of the Full and Stepwise Models ................................................ 132

8.8.2 Assessing the Statistically Significant Terms in the Full and Stepwise Models ......... 134

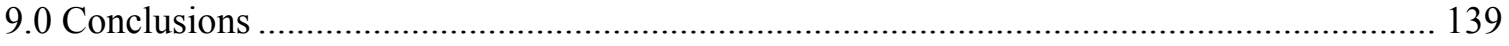

10.0 Recommendations for the Next Phase of Development .................................................... 142

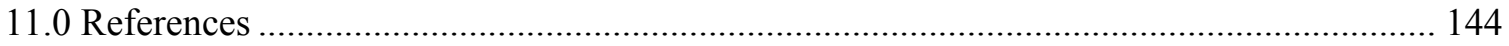

Appendix A. Statistical Design of the Screening Test Matrix .................................................. A-1

Appendix B. Dry Blend Materials Characterization .................................................................... B-1

Appendix C. Cast Stone Processing Properties Data …................................................................. C-1

Appendix D. Cured Cast Stone Properties Data.................................................................. D-1 
PNNL-22747

SRNL-STI-2013-00465

Appendix E. Data-Interaction Plots for Selected Cast Stone Properties ...................................... E-1

Appendix F. Material Certification Reports .............................................................................. 


\section{LIST OF TABLES}

Table ES-1. Cast Stone Properties and Ranges at Mix Ratios ....................................................... vi

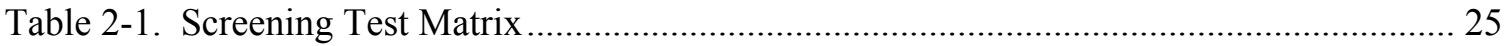

Table 3-1. Composition of the Nonradioactive Dissolved Saltcake Solution for the SST Blend

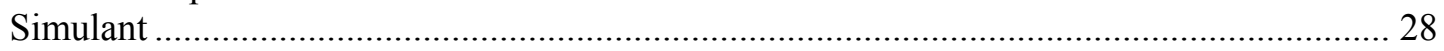

Table 3-2. Final LAW Simulants for Cast Stone Screening Tests ............................................ 32

Table 3-3. Final Spike Levels for Hazardous Constituents and Radionuclides in Simulants

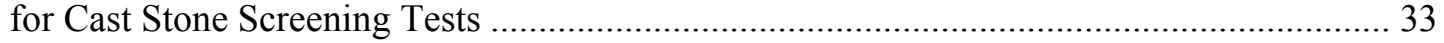

Table 4-1. Measured Chemical Composition of Blast Furnace Slags .......................................... 36

Table 4-2. Measured Chemical Composition of Fly Ashes........................................................ 38

Table 4-3. Measured Chemical Composition of Ordinary Portland Cement .............................. 40

Table 4-4. Measured Chemical Compositions of Final Dry Blend Mixes .................................. 41

Table 6-1. Twelve Mixes with BFS Sources Inadvertently Switched for Cast Stone

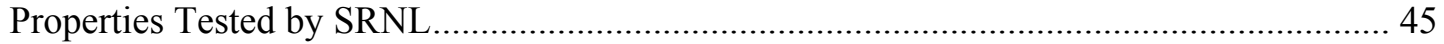

Table 6-2. Flow Curve Profile Using MV2 Geometry ............................................................... 55

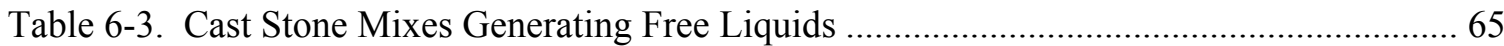

Table 7-1. Summary Table of Chemical Compositions of the 26 Mixes Spiked with

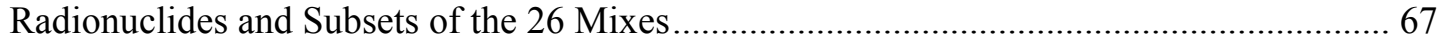

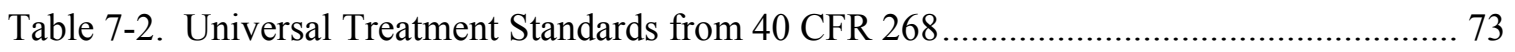

Table 7-3. Toxicity Characteristic Leaching Procedure Screening Test Results ........................ 74

Table 8-1. Summary of the Full Model Relative to Available Data............................................ 97

Table 8-2. Largest Correlations Between Pairs of Terms in the Full Model for the Property "Heat Generation at 300 hr" and Leachability Properties ..................................................... 98

Table 8-3. Estimate of All Two-Parameter Interaction Effects Associated with the NaMol*FlyAsh Interaction

Table 8-4. Complete List of Parameter Effect Estimates Associated with the "Simulant*NaMol" Interaction

Table 8-5. Replicate Property Values, Standard Deviations, and Percent Relative Standard Deviations, Along with Pooled SDs and \%RSDs Using All Replicate Pairs.....

Table 8-6. Replicate Values, Standard Deviations, and Percent Relative Standard Deviations for Effective Diffusion Coefficients from EPA 1315 Leach Tests, Along with and Pooled SDs and \%RSDs Using All Replicate Pairs 
Table 8-7. Replicate Values, Standard Deviations, and Percent Relative Standard Deviations for Leachability Index Calculated from Effective Diffusion Coefficients from EPA 1315 Leach Tests, Along with and Pooled SDs and \%RSDs Using All Replicate Pairs

Table 8-8. $\ln ($ Plastic Viscosity): Summary of Fitting the Full Model and Statistically Assessing the Effects of the Individual Test Parameters and Two-Parameter Interactions

Table 8-9. $\ln$ (Plastic Viscosity): Results of Using Stepwise Regression to Select Statistically Significant Individual Parameter and Two-Parameter Interaction Terms for the Stepwise Model

Table 8-10. Heat Generation at 300 Hours: Summary of Fitting the Full Model and Statistically Assessing the Effects of the Individual Test Parameters and TwoParameter Interactions.

Table 8-11. Heat Generation at 300 Hours: Results of Using Stepwise Regression to Select Statistically Significant Individual Parameter and Two-Parameter Interaction Terms for the Stepwise Model

Table 8-12. Time to Peak Heat Generation: Summary of Fitting the Full Model and Statistically Assessing the Effects of the Individual Test Parameters and TwoParameter Interactions.

Table 8-13. Time to Peak Heat Generation: Results of Using Stepwise Regression to Select Statistically Significant Individual Parameter and Two-Parameter Interaction Terms for the Stepwise Model

Table 8-14. $\ln$ (Compressive Strength): Summary of Fitting the Full Model and Statistically Assessing the Effects of the Individual Test Parameters and TwoParameter Interactions.

Table 8-15. $\ln$ (Compressive Strength): Results of Using Stepwise Regression to Select Statistically Significant Individual Parameter and Two-Parameter Interaction Terms for the Stepwise Model

Table 8-16. Na Leachability Index: Summary of Fitting the Full Model and Statistically Assessing the Effects of the Individual Test Parameters and Two-Parameter Interactions.....

Table 8-17. Na Leachability Index: Results of Using Stepwise Regression to Select Statistically Significant Individual Parameter and Two-Parameter Interaction Terms for the Stepwise Model

Table 8-18. $\mathrm{NO}_{3}$ Leachability Index: Summary of Fitting the Full Model and Statistically Assessing the Effects of the Individual Test Parameters and Two-Parameter Interactions.

Table 8-19. $\mathrm{NO}_{3}$ Leachability Index: Results of Using Stepwise Regression to Select Statistically Significant Individual Parameter and Two-Parameter Interaction Terms for the Stepwise Model 
Table 8-20. I Leachability Index: Summary of Fitting the Full Model and Statistically Assessing the Effects of the Individual Test Parameters and Two-Parameter Interactions.....

Table 8-21. I Leachability Index: Results of Using Stepwise Regression to Select Statistically Significant Individual Parameter and Two-Parameter Interaction Terms for the Stepwise Model

Table 8-22. Tc Leachability Index: Summary of Fitting the Full Model and Statistically Assessing the Effects of the Individual Test Parameters and Two-Parameter Interactions

Table 8-23. Tc Leachability Index: Results of Using Stepwise Regression to Select Statistically Significant Individual Parameter and Two-Parameter Interaction Terms for the Stepwise Model

Table 8-24. Cr Leachability Index: Summary of Fitting the Full Model and Statistically Assessing the Effects of the Individual Test Parameters and Two-Parameter Interactions

Table 8-25. Cr Leachability Index: Results of Using Stepwise Regression to Select Statistically Significant Individual Parameter and Two-Parameter Interaction Terms for the Stepwise Model

Table 8-26. Summary Statistics from Full Model and Stepwise Model Fits to Cast Stone Screening Study Data.

Table 8-27. Simulant Terms in the Full Model Identified as Statistically Significant by the Tukey Multiple Comparison Procedure

Table 8-28. Full Model Terms not Involving Simulant Identified as Statistically Significant

Table 8-29. Summary of Statistically Significant Terms in Stepwise Models for the Cast Stone Physical Properties.....

Table 8-30. Summary of Statistically Significant Terms in Stepwise Models for the Leachability Indices

\section{LIST OF FIGURES}

Figure 3-1. Aluminum and Chloride Concentrations from HTWOS Flowsheet Simulation ....... 30

Figure 3-2. Sulfate, Phosphate, and Fluoride Concentrations from HTWOS Flowsheet Simulations

Figure 4-1. X-Ray Diffraction Patterns Northwest and Southeast Blast Furnace Slags............... 37

Figure 4-2. X-Ray Diffraction Patterns Northwest and Southeast Fly Ashes 39 
Figure 4-3. X-Ray Diffraction Pattern of Portland Cement Used for All Cast Stone Mixes ....... 41

Figure 5-1. Overhead Mixer and Impeller for Cast Stone Preparation...................................... 42

Figure 5-2. Position of Dry Blend Addition and Vortex Formed During Mixing ........................ 43

Figure 5-3. Cast Stone Monolith in Plastic Mold and Monoliths Curing in Bucket ................... 43

Figure 6-1. Flow Consistency for Cast Stone Mixes with the Smallest and Largest Flow

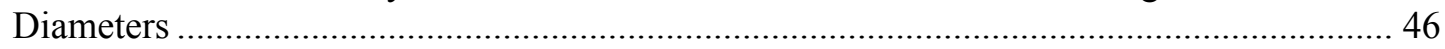

Figure 6-2. Average Flow Diameters for 38 Cast Stone Mixes ................................................. 47

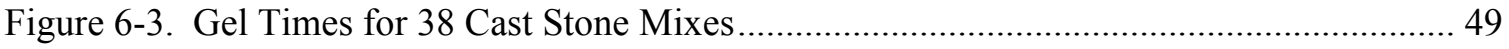

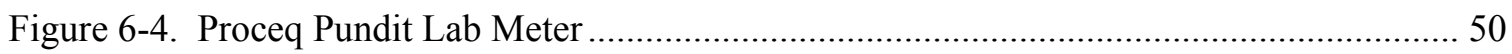

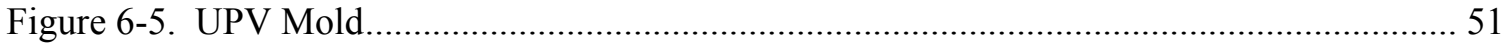

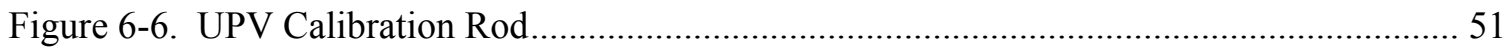

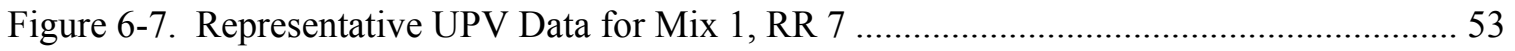

Figure 6-8. Change in UPV or P-Wave Velocity in Cement Paste ............................................ 53

Figure 6-9. Calculated Effect of Volume of Entrained Air on Sound Velocity ........................... 54

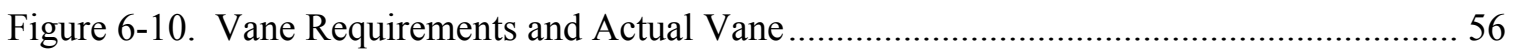

Figure 6-11. Results of Plastic Viscosity Measurements for the 38 Cast Stone Slurries ............. 57

Figure 6-12. Bingham Plastic Yield Stress for the 38 Cast Stone Slurries................................. 58

Figure 6-13. Cutaway View of a Single Channel in the Isothermal Calorimeter from

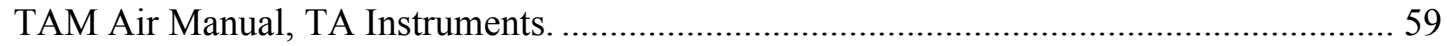

Figure 6-14. Normalized Heat Flow for Two Mixes Analyzed Using Isothermal

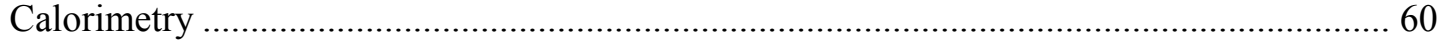

Figure 6-15. Heat Generation at 300 Hours for 38 Cast Stone Mixes........................................ 61

Figure 6-16. Time to Peak Heat Generation for 38 Cast Stone Mixes ....................................... 62

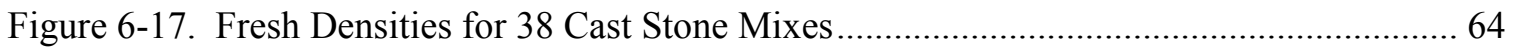

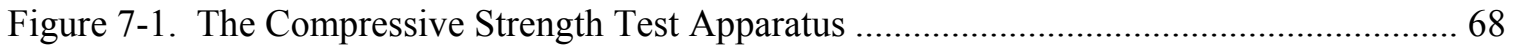

Figure 7-2. Results of PNNL Compressive Strength Measurements for 26 Cast Stone Mixes ... 70

Figure 7-3. Results of SRNL Compressive Strength Measurements for 26 Cast Stone Mixes.... 71

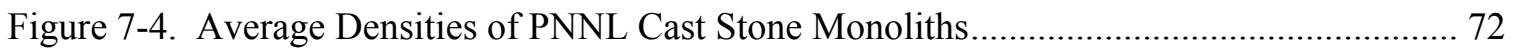

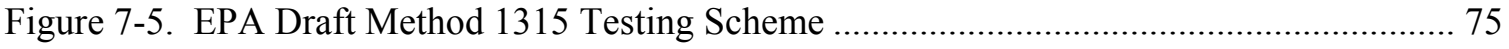


Figure 7-6. Range of Effective Diffusivities for Selected Waste Components ........................... 77

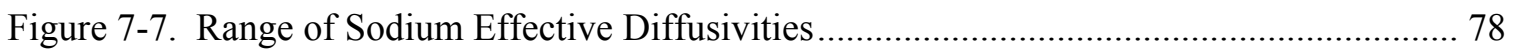

Figure 7-8. Impact of Dry Blend Mix on Sodium Effective Diffusivities.................................... 79

Figure 7-9. Impact of Waste Composition on Sodium Effective Diffusivities ............................ 80

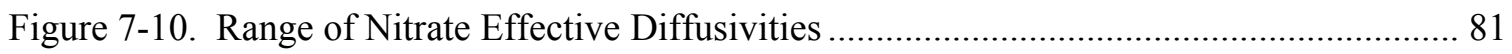

Figure 7-11. Impact of Dry Blend Mix on Nitrate Effective Diffusivities ................................... 82

Figure 7-12. Impact of Waste Composition on Nitrate Effective Diffusivities........................... 83

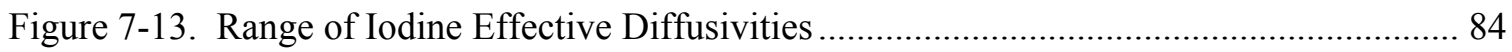

Figure 7-14. Impact of Dry Blend Mix on Iodine Effective Diffusivities ................................... 85

Figure 7-15. Impact of Waste Composition on Iodine Effective Diffusivities............................. 86

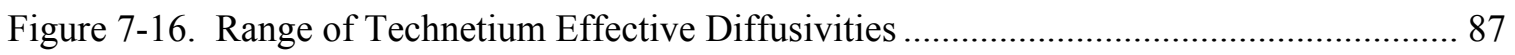

Figure 7-17. Impact of Dry Blend Mix on Technetium Effective Diffusivities .......................... 88

Figure 7-18. Impact of Waste Composition on Technetium Effective Diffusivities .................... 89

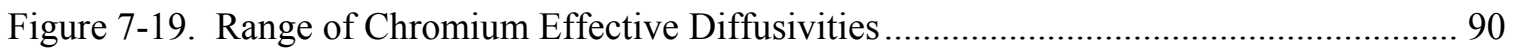

Figure 7-20. Impact of Dry Blend Mix on Chromium Effective Diffusivities........................... 91

Figure 7-21. Impact of Waste Composition on Chromium Effective Diffusivities...................... 92

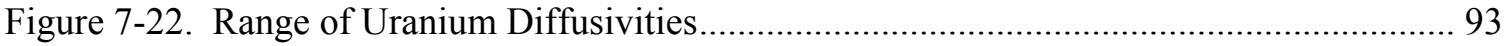

Figure 7-23. Range of Uranium Diffusivities for Specimens with Measurable Uranium

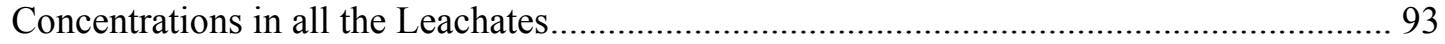

Figure 8-1. Scatterplot of Yield Stress versus Plastic Viscosity for the 38 Cast Stone Mixes

Figure 8-2. Scatterplot Matrix of Data on Three Heat Generation Properties for the 38 Cast Stone Mixes.

Figure 8-3. Scatterplot Matrix of EPA Method 1315 Leachability Indices for $\mathrm{Na}, \mathrm{NO}_{3}$, $\mathrm{NO}_{2}, \mathrm{I}, \mathrm{Tc}, \mathrm{Cr}$, and $\mathrm{U}$ 


\section{LIST OF ABBREVIATIONS AND ACRONYMS}

$\AA$

ANOVA

ANS

ANSI

ASME

BET

BFS

CAWSRP

$\mathrm{CBO}$

$\mathrm{Ci}$

CLSM

$\mathrm{cm}$

$\mathrm{cm}^{2}$

$\mathrm{cm}^{3}$

$\mathrm{COC}$

$\mathrm{cP}$

DIW

DOE

DOF

DSC

DST

EDC

EPA

FA

FY

$\mu \mathrm{g}$

$\mathrm{g}$

$\mathrm{hr}$

HASQARD

HDI

HG300

HGP angstrom(s)

analysis of variance

American Nuclear Society

American National Standards Institute

American Society of Mechanical Engineers

Brunauer-Emmett-Teller

blast furnace slag

Conducting Analytical Work in Support of Regulatory Programs

Carbon Burn Out

curie(s)

controlled low strength material

centimeter(s)

square centimeter(s)

cubic centimeter(s)

constituent of concern

centipoise

deionized water

U.S. Department of Energy

degree of freedom

differential scanning calorimetry

double-shell tank

effective diffusion coefficient

U.S. Environmental Protection Agency

fly ash

fiscal year

microgram(s)

$\operatorname{gram}(\mathrm{s})$

hour(s)

Hanford Analytical Services Quality Assurance Requirements Documents

How Do I...?

heat generation at 300 hours

heat generation at peak 


\begin{tabular}{|c|c|}
\hline HLW & high-level waste \\
\hline HSD & (Tukey's) Honestly Significant Difference \\
\hline HTWOS & Hanford Tank Waste Operations Simulator \\
\hline IC & ion chromatography \\
\hline ICDD & International Center for Diffraction Data \\
\hline ICP & inductively coupled plasma \\
\hline ICP-MS & inductively coupled plasma-mass spectroscopy or spectrometer \\
\hline ICP-AES & inductively coupled plasma-atomic emission spectrometer \\
\hline ICP-OES & inductively coupled plasma-optical emission spectroscopy \\
\hline ID & inside diameter or identification \\
\hline IDF & Integrated Disposal Facility \\
\hline in. & $\operatorname{inch}(\mathrm{es})$ \\
\hline $\mathrm{J} / \mathrm{g}$ & joule(s) per gram \\
\hline kips-force & kilo-pound force \\
\hline $\mathrm{kg}$ & kilogram(s) \\
\hline $\mathrm{kN}$ & kiloNewton(s) \\
\hline $\mathrm{kV}$ & kilovolt(s) \\
\hline $\mathrm{L}$ & liter(s) \\
\hline LAW & low-activity waste \\
\hline LI & leachability index \\
\hline $\ln$ & natural logarithm \\
\hline LOF & lack-of-fit \\
\hline$\mu \mathrm{m}$ & $\operatorname{micron}(\mathrm{s})$ \\
\hline $\mathrm{m}^{2}$ & square meter(s) \\
\hline $\mathrm{mA}$ & milliampere(s) \\
\hline $\mathrm{MCP}$ & multiple comparison procedure \\
\hline $\mathrm{mg}$ & milligram(s) \\
\hline $\min$ & minute(s) \\
\hline $\mathrm{ml}$ & milliliter(s) \\
\hline $\mathrm{mm}$ & millimeter(s) \\
\hline $\mathrm{mM}$ & millimolar \\
\hline $\mathrm{M} / \mathrm{M}$ & moles per mole \\
\hline $\mathrm{MPa}$ & megapascal(s) \\
\hline MR & mix ratio \\
\hline MS & mass spectroscopy \\
\hline
\end{tabular}




\begin{tabular}{|c|c|}
\hline $\mathrm{mW} / \mathrm{g}$ & milliwatt(s) per gram \\
\hline NIST & National Institute of Standards and Technology \\
\hline OD & outer diameter \\
\hline OED & optimal experimental design \\
\hline OLS & ordinary least squares \\
\hline $\mathrm{OPC}$ & ordinary portland cement \\
\hline ORP & Office of River Protection \\
\hline $\mathrm{Pa}$ & $\operatorname{pascal}(\mathrm{s})$ \\
\hline PA & performance assessment \\
\hline PNNL & Pacific Northwest National Laboratory \\
\hline ppm & parts per million \\
\hline psi & pounds per square inch \\
\hline QA & quality assurance \\
\hline QAP & Quality Assurance Plan \\
\hline$\%$ RSD & relative standard deviation \\
\hline RCRA & Resource Conservation and Recovery Act \\
\hline $\mathrm{rph}$ & rotations per hour \\
\hline rpm & rotations per minute \\
\hline $\mathrm{RR}$ & random run \\
\hline s & second(s) \\
\hline SD & standard deviation \\
\hline SEM & scanning electron microscopy \\
\hline SPF & Saltstone Production Facility \\
\hline SRNL & Savannah River National Laboratory \\
\hline SRS & Savannah River Site \\
\hline SST & single-shell tank \\
\hline STA & simultaneous thermal analysis \\
\hline SwRI & Southwest Research Institute \\
\hline TCLP & Toxicity Characteristic Leaching Procedure \\
\hline TGA & thermal gravimetric analysis \\
\hline TPA & Tri-Party Agreement \\
\hline TPHG & time to peak heat generation \\
\hline TRU & transuranic \\
\hline $\mathrm{UHC}$ & underlying hazardous constituent \\
\hline UPV & ultrasonic pulse velocity \\
\hline
\end{tabular}




$\begin{array}{ll}\text { UTS } & \text { Universal Treatment Standards } \\ \text { V } & \text { volt(s) } \\ \text { WC } & \text { waste concentration } \\ \text { WRPS } & \text { Washington River Protection Solutions } \\ \text { wt\% } & \text { weight percent } \\ \text { WWFTP } & \text { WRPS Waste Form Testing Program } \\ \text { WTP } & \text { Hanford Tank Waste Treatment and Immobilization Plant } \\ \text { XRD } & \text { X-ray diffraction } \\ \text { XRF } & \text { X-ray fluorescence }\end{array}$


PNNL-22747

SRNL-STI-2013-00465

\subsection{Introduction}

More than 56 million gallons of radioactive and hazardous waste are stored in 177 underground storage tanks at the U.S. Department of Energy's (DOE's) Hanford Site in southeastern Washington State. The Hanford Tank Waste Treatment and Immobilization Plant (WTP) is being constructed to treat the wastes and immobilize them in a glass waste form. The WTP includes a pretreatment facility to separate the wastes into a small volume of high-level waste (HLW) containing most of the radioactivity and a larger volume of low-activity waste (LAW) containing most of the nonradioactive chemicals. The HLW will be converted to glass in the HLW vitrification facility for ultimate disposal at an offsite federal repository. At least a portion $(\sim 35 \%)$ of the LAW will be converted to glass in the LAW vitrification facility and will be disposed of onsite at the Integrated Disposal Facility (IDF). The pretreatment and HLW vitrification facilities will have the capacity to treat and immobilize the wastes destined for each facility. However, a second LAW immobilization facility will be needed for the expected volume of LAW requiring immobilization.

A cementitious waste form known as Cast Stone is being considered to provide the required additional LAW immobilization capacity. The Cast Stone waste form must be acceptable for disposal in the IDF. The Cast Stone waste form and immobilization process must be tested to demonstrate that the final Cast Stone waste form can comply with the waste acceptance criteria for the disposal facility and that the immobilization processes can be controlled to consistently provide an acceptable waste form product. Further, the waste form must be tested to provide the technical basis for understanding the long-term performance of the waste form in the disposal environment. These waste form performance data are needed to support risk assessment and performance assessment (PA) analyses of the long-term environmental impact of the waste disposal in the IDF. The PA is needed to satisfy both Washington State IDF Permit and DOE Order requirements.

Cast Stone has been selected for solidification of radioactive wastes including WTP aqueous secondary wastes treated at the Effluent Treatment Facility (ETF) at Hanford. A similar waste form called Saltstone is used at the Savannah River Site (SRS) to solidify its LAW tank wastes.

\subsection{Cast Stone Testing Program}

A testing program was developed in fiscal year (FY) 2012 describing in detail the work needed to develop and qualify Cast Stone as a waste form for the solidification of Hanford LAW (Westsik et al. 2013). Included in the testing plan by Westsik et al. (2013) is a section on the near-term needs to address Tri-Party Agreement (TPA) Milestone M-062-40ZZ. The objectives of the testing program to be conducted in FY 2013 and FY 2014 are as follows:

- Determine an acceptable formulation for the LAW Cast Stone waste form.

- Evaluate sources of dry materials for preparing the LAW Cast Stone.

- Demonstrate the robustness of the waste form for a range of LAW compositions.

- Demonstrate the robustness of the formulation for variability in the Cast Stone process.

- Provide Cast Stone contaminant release data for PA and risk assessment evaluations.

The first step in determining an acceptable formulation for the LAW Cast Stone waste form is to conduct screening tests to evaluate the impact of key parameters including ranges in waste composition, waste stream concentrations, sources of dry materials, and mix ratios of waste (free 
water basis) to dry blend. A statistically designed test matrix was used to evaluate the effects of these key parameters on the properties of the Cast Stone as it is initially prepared and after curing.

The next phase of testing will focus on final selection of a nominal Cast Stone formulation and demonstration that Cast Stone can meet anticipated waste form requirements for disposal in the IDF. This testing is expected to use the results of the screening tests to specify a suite of tests to optimize the waste loading and waste form performance of the Cast Stone formulation.

Preparation and testing of selected LAW Cast Stone formulation(s) made with actual radioactive wastes will be conducted to provide confirmation that the results observed with LAW waste simulants in screening, waste loading, and waste form qualification testing are representative of what is expected with actual wastes.

After a preferred formulation is selected for immobilization of Hanford LAW, an engineeringscale demonstration of the Cast Stone process and containerized waste form may be conducted in FY 2014 using nonradioactive waste simulants.

\subsection{Tank Waste Processing}

The Cast Stone process is being evaluated to treat and immobilize LAW separated from the radioactive waste currently stored in underground storage tanks at Hanford. The LAW fraction of the waste is characterized as a large-volume, low-radioactivity liquid process stream stripped of most of the solids, transuranic (TRU) elements, and long-lived radionuclides. The LAW is derived from the aqueous solutions in the tanks and dissolved saltcake. The composition of the LAW will vary from tank to tank because of the variability in types and sources of wastes stored in the individual tanks and the processes used to separate the wastes into HLW and LAW fractions.

The baseline source of the LAW wastes to be treated and immobilized through the Cast Stone process is the separations processes in the WTP pretreatment facility. The liquid wastes from the tanks will pass through ultrafilters in the pretreatment facility to remove solids and insoluble radioisotopes. For some tank wastes, additional processing as part of the ultrafiltration process will remove aluminum and/or chromium from the solids destined for HLW, and the Al and $\mathrm{Cr}$ will be added to the LAW stream. Some tanks contain organic complexants that keep strontium and TRU elements in the aqueous phase. The treatment of these wastes will include a precipitation step to remove the $\mathrm{Sr}$ and TRU elements from solution prior to filtration and ion exchange. For LAW wastes with higher concentrations of complexants and other organics, it may be decided to send these wastes to the LAW vitrification facility for treatment, which would destroy the complexants and organics in the vitrification process.

The liquid filtrate from the ultrafilters will pass through ion-exchange columns to remove cesium. The effluent from the ion-exchange columns will be then concentrated in an evaporator to a specified sodium concentration depending on the waste chemistry. A recycle stream from the LAW melter off-gas submerged bed scrubbers and wet electrostatic precipitators will be blended with the ion-exchange effluent as it enters the evaporator. The concentrated solution from the evaporator will be the LAW feed for the immobilization process. The waste feed will be principally $\mathrm{Na}$ with nitrates, nitrites, carbonates and a spectrum of radioactive fission products. Minor components can include Al, K, and Si along with the chloride, fluoride, phosphate, and sulfate anions. 
To supplement WTP capacity, in-tank and near-tank separations are being considered to provide LAW feed directly to the supplemental immobilization process without processing through the WTP pretreatment facility. These processes would include a filtration step via a cross-flow filter or a rotary microfilter to remove the solids and insoluble radionuclides. Cesium would be removed through ion exchange. The separated solids and cesium would be returned to the double-shell tank (DST) system for eventual treatment and immobilization as HLW. A process for removing Tc from the LAW to be immobilized in Cast Stone is also being evaluated. The liquid effluent from the solids, Cs and Tc separation processes would become the feed to the LAW Cast Stone immobilization process.

Some tank wastes may be acceptable for direct Cast Stone processing without additional separations. These low-curie salt solutions are generated during the later stages of washing saltcake from the tanks. Experience has shown that the cesium is removed in the earlier stages of washing the saltcake such that the saltcake dissolved later is relatively free of ${ }^{137} \mathrm{Cs}$ and could be immobilized without further processing. Solid separation would be required if $>1 \mathrm{wt} \%$ solids were present. The decontamination factors have been observed in saltcake dissolution and fractional crystallization work done by PNNL and 222-S.

Therefore, the composition of LAW to be processed as Cast Stone will vary greatly, requiring testing to look at several compositions of feed. Four different chemical simulant compositions were investigated in the screening tests to assess a range of different waste compositions that may be sent to the LAW Cast Stone immobilization process.

\subsection{Report Contents and Organization}

This report summarizes the results of the screening tests conducted as the first step in determining an acceptable Cast Stone formulation for solidification of Hanford LAW. The report also summarizes the selection and development of the chemical simulants that were used in the screening tests.

The balance of the report is organized as follows. Section 2.0 describes the approach to the Cast Stone screening tests including the statistically designed test matrix and quality assurance. Section 3.0 describes the LAW simulants used to make the Cast Stone specimens, and Section 4.0 describes the sources of the blast furnace slag, fly ash, and cement used to make the Cast Stone specimens. Section 5.0 describes the preparation of the Cast Stone specimens for the screening tests. The next sections present the results of the characterization of the Cast Stone processing properties (Section 6.0) including gel and set times, slurry rheology, and heat of hydration; and final waste form properties (Section 7.0) including compressive strength, cured density, Toxicity Characteristic Leaching Procedure (TCLP) results, and leach test results. Statistical analyses of selected Cast Stone properties are presented in Section 8.0. Section 9.0 provides conclusions from the screening test work, and Section 10.0 provides recommendations for the next phase of development. Appendices contain additional information including the statistical design of the screening test matrix (Appendix A), dry blend materials characterization data (Appendix B), Cast Stone processing properties data (Appendix C), cured Cast Stone properties data (Appendix D), data-interaction plots for selected Cast Stone properties (Appendix E), and vendor material certification reports (Appendix F). 
PNNL-22747

SRNL-STI-2013-00465

\subsection{Screening Tests Approach}

Screening tests were performed to evaluate the effects of key parameters on the properties of the Cast Stone as it is initially prepared and after curing. The test parameters and their ranges that were investigated in the screening tests included

- simulants representing a range of LAW compositions (Average, single-shell tank [SST] Blend, High Al, and High $\mathrm{SO}_{4}$ [discussed in Section 3.0])

- waste concentration (5 M and $7.8 \mathrm{M} \mathrm{Na}$ )

- Class F fly ash source (NW = High Ca, SE = Low Ca)

- blast furnace slag source (NW, SE)

- free-water-to-dry-blend solids mix ratio $(0.4,0.6)$.

The four simulants are discussed in Section 3.0. The Na concentrations of $5 \mathrm{M}$ and $7.8 \mathrm{M}$ were selected to represent a range of possible waste concentrations for processing. The Class F fly ash included a relatively high-Ca content material available in the Pacific Northwest (designated NW) and a lower $\mathrm{Ca}$ content material available in the southeastern (designated SE) part of the country. Blast furnace slags (BFSs) from the northwest (designated NW) and southeast (designated SE) were also selected for the screening tests. The 0.4 and 0.6 values of the free-water-to-dry-blend solids mix ratio (henceforth referred to as "mix ratio" for convenience) were selected based on the range ( 0.35 to 0.41 grams of water per gram dry blend solids) used for the secondary waste Cast Stone formulation work (Mattigod et al. 2011) and 0.60 grams of water per gram of dry blend solids used at the Saltstone Production Facility at the SRS. The different combinations of simulants, $\mathrm{Na}$ concentrations, and mix ratios yielded waste loadings ranging from $9.5 \mathrm{wt} \%$ to $20.3 \mathrm{wt} \%$ total waste solids in the Cast Stone waste form.

The dry blend mix ratio was held constant at $8 \mathrm{wt} \%$ portland Type I/II cement, $45 \mathrm{wt} \%$ Class $\mathrm{F}$ fly ash, and $47 \mathrm{wt} \%$ Grade 100-120 BFS (Lockrem 2005). A single source of portland cement was used for all of the testing because the variability in the cement is not expected to be significant among the possible sources.

\subsection{Screening Test Matrix}

The original screening test matrix was developed in two "blocks" in case project funding might be limited and only the Block 1 tests could be performed. However, sufficient funding was provided, so both Block 1 and Block 2 of the experimental design were performed. Appendix A discusses the details of the how both blocks of the test matrix were developed.

The original test matrix for the screening tests is composed of 26 test conditions as shown in Table 2-1. The matrix was developed using statistical optimal experimental design (OED) methods and software (as described in detail in Appendix A). The test matrix includes two blocks of tests. The first block is composed of 14 tests including 12 distinct parameter combinations and 2 replicates chosen using OED to assess the effects of the individual test parameters. The second block of tests is composed of 12 tests including 10 distinct parameter combinations and 2 replicates chosen by OED to augment the first block of tests to assess the block effect and 9 selected two-parameter interactions, along with the individual parameter effects (see Appendix A). A fifth replicate pair includes one test in Block 1 and one test in 
Table 2-1. Screening Test Matrix

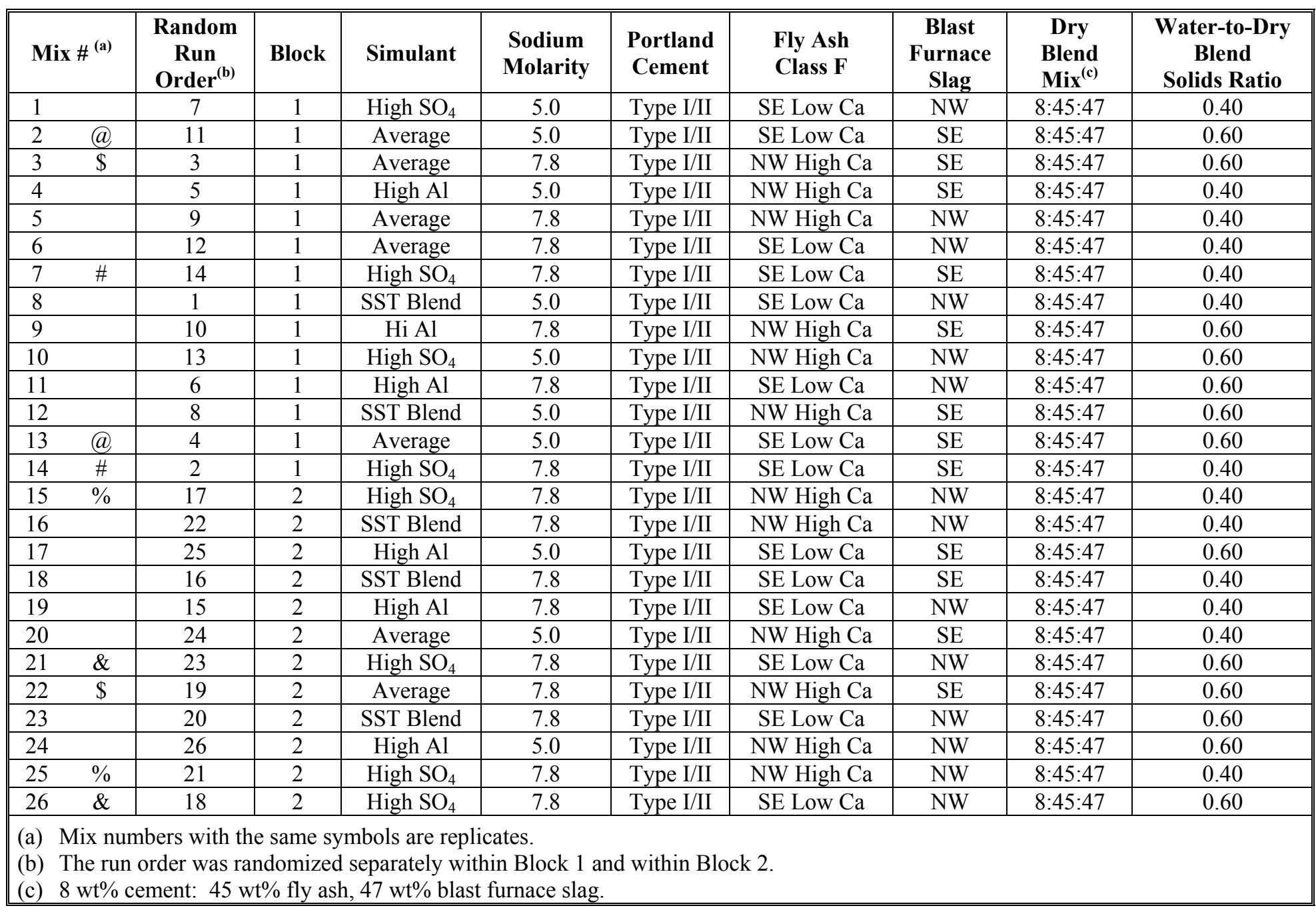


Block 2. The second column of Table 2-1 identifies the five pairs of replicate tests. The replicate tests provide for quantifying the experimental and measurement uncertainties in performing tests and measuring properties. These estimates of uncertainties also provide for statistically assessing the significance of individual parameter and two-parameter interaction effects. The order in which the test specimens were prepared within each block was based on a random run order as shown in Table 2-1. An additional 12 mixes were prepared that were not included in the test matrix in Table 2-1. These are discussed further in Section 6.0.

\subsection{Cast Stone Properties}

Cast Stone specimens for the screening tests were prepared in the laboratory and were characterized for processing properties and cured waste form properties. Processing properties include gel time (a subjective indication of when the Cast Stone slurry no longer flows freely), hardening time, slurry rheology, heat generation during curing, and residual free liquids. These processing properties were measured by Savannah River National Laboratory (SRNL) under a separate contract with Washington River Protection Solutions (WRPS).

Other properties of the solidified Cast Stone waste forms were measured after the test specimens cured for at least 28 days at room temperature in near-saturated conditions. Compressive strength was measured on Cast Stone waste forms made at both SRNL and PNNL; density and porosity were measured on the cured test specimens prepared at SRNL. The TCLP was conducted on Cast

Stone prepared at PNNL to examine the retention of Resource Conservation and Recovery Act (RCRA) metals (As, $\mathrm{Ba}, \mathrm{Cd}, \mathrm{Cr}, \mathrm{Pb}, \mathrm{Hg}$, $\mathrm{Se}$, and $\mathrm{Ag}$ ) and underlying hazardous constituents ( $\mathrm{Sb}$, $\mathrm{Be}, \mathrm{Ni}$, and $\mathrm{Tl}$ ) to address land disposal restrictions in Title 40 Code of Federal Regulations Part 268 "Land Disposal Restrictions" (40 CFR 268). Leach tests on cured Cast Stone cylinders prepared at PNNL were conducted for up to 91 days using U.S. Environmental Protection Agency (EPA) Draft Method 1315 (2012) to measure the effective diffusivity of key constituents including Tc and nitrates. Leach testing beyond 91 days is being continued on selected samples under a separate PNNL project that is providing technical data and support for preparation of a risk assessment and future, more detailed PAs. Chemical compositions and mineralogy were also determined for the cured Cast Stone specimens.

Statistical analysis of the results of the testing and characterization at PNNL and SRNL were used to assess the effects on selected Cast Stone properties of the individual test parameters and evaluate two-parameter interactions (see Section 8.0).

\subsection{Quality Assurance}

The PNNL Quality Assurance (QA) Program is based upon requirements defined in DOE Order 414.1D, Quality Assurance (DOE 2011), and Title 10 Code of Federal Regulations, Part 830, "Nuclear Safety Management", Subpart A - Quality Assurance Requirements (a.k.a. the Quality Rule) (10 CFR 830). PNNL has chosen to implement the following American Society of Mechanical Engineers (ASME) consensus standards in a graded approach:

- ASME NQA-1-2000, Quality Assurance Requirements for Nuclear Facility Applications, Part I, "Requirements for Quality Assurance Programs for Nuclear Facilities."

- ASME NQA-1-2000, Part II, Subpart 2.7, "Quality Assurance Requirements for Computer Software for Nuclear Facility Applications," including problem reporting and corrective action. 
- ASME NQA-1-2000, Part IV, Subpart 4.2, "Guidance on Graded Application of Quality Assurance (QA) for Nuclear-Related Research and Development."

The processes necessary to implement the requirements are documented through PNNL's "How Do I...? (HDI) standards-based management system.

PNNL implements the WRPS Waste Form Testing Program (WWFTP) quality requirements by performing work in accordance with the WWFTP Quality Assurance Plan (QA-WWFTP-001). ${ }^{1}$ Work is performed to the quality requirements of the NQA-1-2000 Quality Assurance Program, graded on the approach presented in NQA-1-2000, Part IV, Subpart 4.2. Data analysis is performed in accordance with the Hanford Analytical Services Quality Assurance Requirements Documents (HASQARD; DOE/RL-96-68 2007). The PNNL document for implementing HASQARD is Conducting Analytical Work in Support of Regulatory Programs (CAWSRP). ${ }^{2}$

The WWFTP addresses internal verification and validation activities by conducting an independent technical review of the final data report in accordance with WWFTP procedure QA-NSLW-0603, Independent Technical Review. Following this procedure, a technical review verifies that the reported results are traceable, that inferences and conclusions are soundly based, and that the reported work satisfies the objectives.

The SRNL work scope was performed in accordance with a Quality Assurance Program (QAP) that meets the Quality Assurance criteria specified in DOE Order 414.1D, Quality Assurance; 10 CFR 830, "Nuclear Safety Management," Subpart A, "Quality Assurance Requirements," paragraph 830.122; and also meets the requirements of ASME NQA-1-2004, Quality Assurance Requirements for Nuclear Facility Applications, including NQA-1a-2005 and NQA-1b-2007 Addenda, or later version. The SRNL work scope was performed in accordance with Savannah River Site Manual 1Q, QAP 2-3 (Control of Research and Development Activities).

WRPS has conducted an evaluation of the PNNL and SRNL QA programs and both laboratories are on their evaluated supplier list.

Certain tables and figures in this report are marked "For Information Only" because the PNNL QA procedures for calculations were not applied. The tables and figures so marked do not contain key, "quality affecting" results. The software codes used to create such tables and figures were carefully checked by the researcher, but to save considerable time and expense, were not included in the formal QA package for statistical analyses. Only the software and calculations included in the formal QA package were checked by an independent reviewer, per the applicable PNNL QA procedure.

\footnotetext{
${ }^{1}$ MacPherson, DB. 2012 as amended. WRPS Waste Form Testing Program Quality Assurance Plan. Pacific Northwest National Laboratory, Richland, Washington.

${ }^{2}$ CAWSRP - Conducting Analytical Work in Support of Regulatory Programs. 2006, as amended. Pacific Northwest National Laboratory, Richland, Washington.
} 
PNNL-22747

SRNL-STI-2013-00465

\subsection{Selection of Simulants}

For the screening tests of the Cast Stone formulations for LAW, four chemical simulants were selected to represent a range of possible LAW compositions to be solidified in the Cast Stone waste form. They included a saltcake simulant used in previous testing of LAW immobilization technologies and three chemical simulants based on the Hanford Tank Waste Operations Simulator (HTWOS) flowsheet modeling of the LAW feed that is anticipated to be sent to a supplemental immobilization facility. A detailed description of the simulant development work is provided by Russell et al. (2013).

\subsection{Saltcake Simulant}

Saltcake waste is a predominant form of the wastes in a large fraction of the SSTs at Hanford. Saltcake wastes can be dissolved, stripped of cesium, and converted to glass or an alternative waste form such as Cast Stone for disposal. To support an evaluation of supplemental treatment alternatives for immobilizing this type of LAW, a saltcake simulant waste was developed based on a blend of real waste samples from SSTs S-101, S-109, S-110, S-111, U-106, and U-109 (Rassat et al. 2003). Table 3-1 shows the nominal simulant composition, which is referred to in this report as the "SST Blend" simulant. A recipe for preparing the simulant is provided by Rassat et al. (2003). This saltcake simulant has been used in previous Cast Stone testing with Hanford LAW simulants. The composition matches the average composition of saltcake from 68 Hanford SSTs representing 85 percent of the total saltcake inventory in all Hanford SSTs and DSTs at that time (Gasper et al. 2002).

Table 3-1. Composition of the Nonradioactive Dissolved Saltcake Solution for the SST Blend Simulant (Rassat et al. 2003)

\begin{tabular}{|c|c|}
\hline Waste Constituent & $\begin{array}{c}\text { Concentration } \\
\text { (M) }\end{array}$ \\
\hline $\mathrm{Al}$ & 0.0637 \\
\hline Cs & $5.1 \times 10^{-8}$ \\
\hline $\mathrm{Cr}$ & 0.0104 \\
\hline $\mathrm{K}$ & 0.0124 \\
\hline $\mathrm{Na}$ & 5.00 \\
\hline $\mathrm{Cl}$ & 0.0438 \\
\hline $\mathrm{CO}_{3}$ & 0.475 \\
\hline $\mathrm{F}$ & 0.0316 \\
\hline $\mathrm{NO}_{2}$ & 0.424 \\
\hline $\mathrm{NO}_{3}$ & 2.51 \\
\hline $\mathrm{PO}_{4}$ & 0.0492 \\
\hline $\mathrm{SO}_{4}$ & 0.0900 \\
\hline $\mathrm{C}_{2} \mathrm{O}_{4}$ (oxalate) & 0.0118 \\
\hline Other TOCs ${ }^{(a)}$ (as carbon, from acetate) & 0.263 \\
\hline TOC Total & 0.287 \\
\hline OH Total & 0.740 \\
\hline Free $\mathrm{OH}$ & 0.485 \\
\hline
\end{tabular}

\subsection{Simulants Based on System Plan 6 HTWOS Modeling}

Three chemical simulants were developed to represent the range of LAW tank wastes that could be immobilized in a Cast Stone waste form. The chemical simulants were developed based on 
runs of the HTWOS model to support the River Protection Project System Plan, Revision 6 (Certa et al. 2011). The HTWOS model is used to track the tank waste as it moves from storage through retrieval, feed staging, and multiple treatment and immobilization processes over the life of the WTP mission. The HTWOS model can be used to forecast the quantities and compositions of primary and secondary waste streams as a result of various proposed operating scenarios (Certa et al. 2011). As one of the outputs, the HTWOS model provides the projected compositions of LAW feed to a supplemental immobilization facility over the course of the tank waste cleanup mission.

The first chemical simulant is an overall average of the 1046 weeks of modeled LAW immobilization waste feed over a 20 -year mission. Henceforth in this report, it is referred to as the "Average" simulant.

The second chemical simulant is a high- $\mathrm{Al}$, high-Cl simulant corresponding to week 235 in the HTWOS flowsheet simulation. Henceforth in this report it is referred to as the "High Al" simulant. It corresponds to the maximum $\mathrm{Al}$ concentration normalized to $\mathrm{Na}$. $\mathrm{Cl}$ is near its maximum as well. Unlike $\mathrm{SO}_{4}{ }^{2-}$ and $\mathrm{F}^{-}, \mathrm{Al}$ does not have a single spike at a high concentration but a broad region between 0.08 and 0.1 mole/mole $(\mathrm{M} / \mathrm{M})$ Na. Figure 3-1 shows the concentrations of $\mathrm{Al}$ (as $\mathrm{Al}(\mathrm{OH})_{4}{ }^{-}$) and $\mathrm{Cl}^{-}$for the 1046 weeks modeled in the HTWOS simulations. The point at week 235 is circled in green.

The third chemical simulant, referred to as the "High $\mathrm{SO}_{4}$ " simulant, was selected because sulfate and fluoride were at relatively high concentrations relative to sodium and phosphate was near its maximum. This corresponds to week 672 in the HTWOS flowsheet simulation. Figure 3-2 shows the concentrations of $\mathrm{SO}_{4}{ }^{2-}, \mathrm{PO}_{4}{ }^{3-}$, and $\mathrm{F}^{-}$for the selected point circled in red. This week was selected over the later times near the end of the mission that are predicted to have even higher spikes in sulfate and fluoride concentrations because the sources of these late spikes are not immediately clear, are due in part to low sodium concentrations, and are not representative of most of the WTP mission duration. Also, the HTWOS does not use thermodynamic models to predict solubilities. For example, it is unlikely that such high levels of phosphate and fluoride could be maintained in solution at the high $\mathrm{pH}$ and ionic strength of these wastes.

Before the simulant batches were prepared for the Cast Stone waste form screening tests, smaller 1-L batches were prepared to check for chemical interactions and solids formation (Russell et al. 2013). The $5 \mathrm{M} \mathrm{Na}$ concentration is the expected concentration for processing the LAW through ultrafiltration and ion exchange. The SST Blend saltcake and High Al simulant had only minimal solids at $5 \mathrm{M} \mathrm{Na}$. The overall Average and $\mathrm{High} \mathrm{SO}_{4}$ simulant had significant solids formation at $5 \mathrm{M} \mathrm{Na}$. These solids were determined to contain $\mathrm{Na}$ fluorophosphates similar to what had been observed earlier when the SST Blend saltcake simulant was initially developed. Therefore, the fluoride and phosphate levels were reduced in the overall Average and High $\mathrm{SO}_{4}$ simulants to levels that would result in little to no solids formation at the $5 \mathrm{M} \mathrm{Na}$ concentration. All of the simulants had solids formation at the $7.8 \mathrm{M} \mathrm{Na}$ concentration. Based on supernate analyses, all four $7.8 \mathrm{M} \mathrm{Na}$ simulants appear to have precipitated $\mathrm{Na}$ fluorophosphate solids, estimated at 1 to 3 weight percent. These solids were left in the final simulant batches used to make the Cast Stone waste forms used in the screening tests assuming that during production, pretreated LAW would be evaporated without subsequent filtration prior to immobilization in Cast Stone.

Table 3-2 shows the compositions of three chemical simulants (Average, High Al, and High $\mathrm{SO}_{4}$ ) as well as the SST Blend saltcake simulant described in Section 3.1. For comparison purposes, 
the simulants have been normalized to one-molar $\mathrm{Na}$ and are expressed as moles per mole Na. The target concentrations have been charge balanced by adjusting the anion levels in proportion to their relative concentrations.
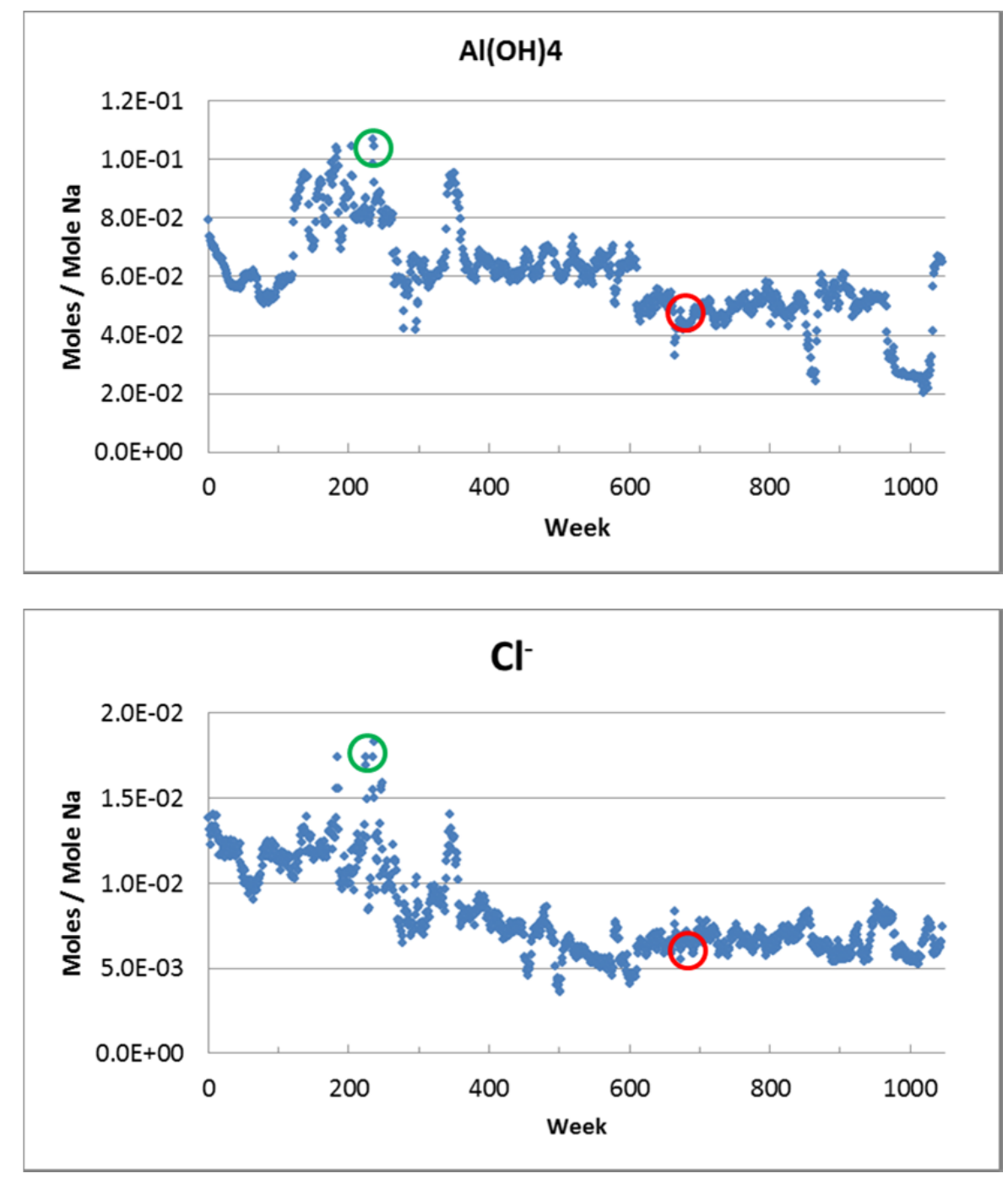

Figure 3-1. Aluminum and Chloride Concentrations from HTWOS Flowsheet Simulation. Week 235 in green circle, week 672 in red circle. 
PNNL-22747

SRNL-STI-2013-00465
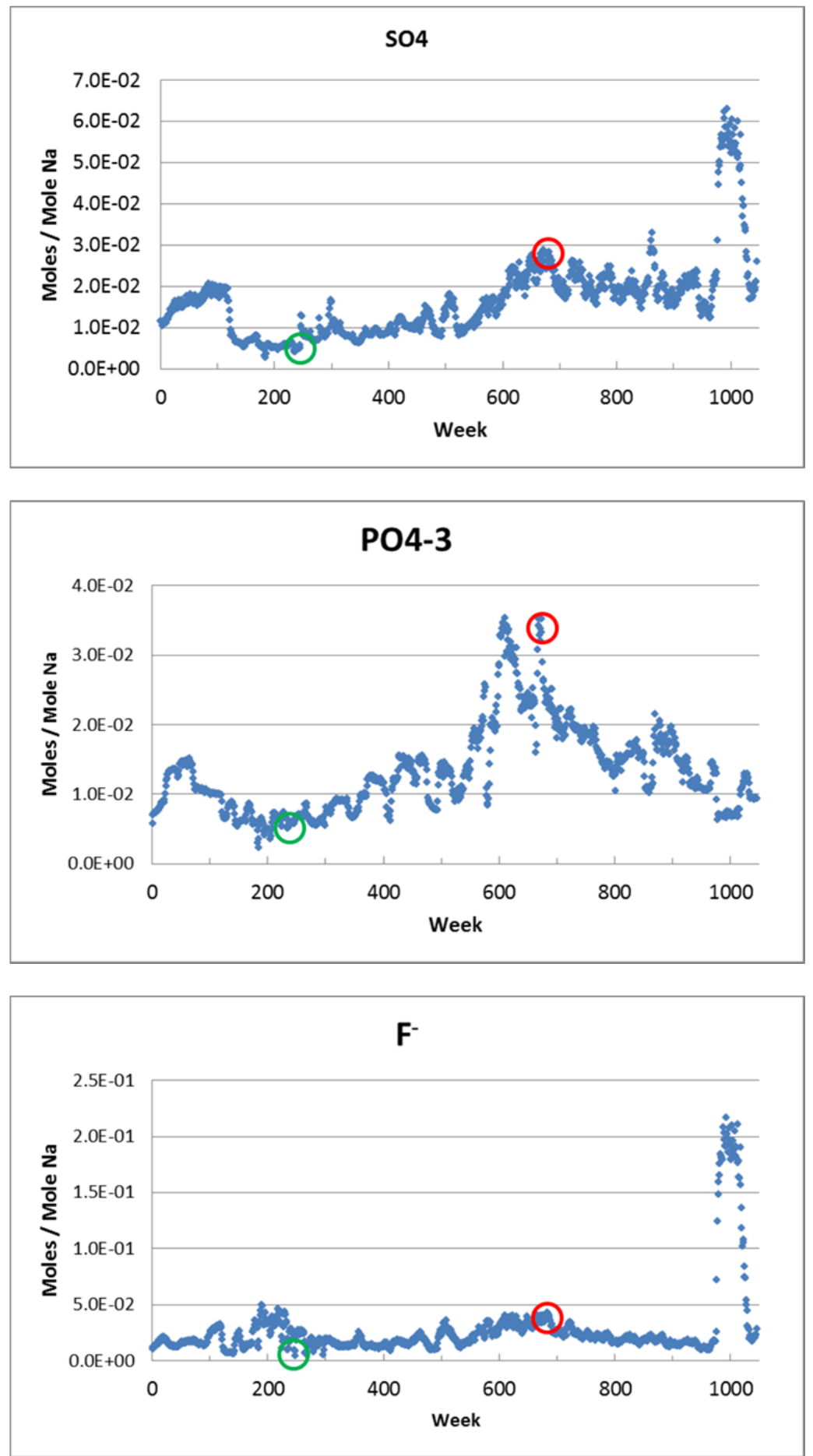

Figure 3-2. Sulfate, Phosphate, and Fluoride Concentrations from HTWOS Flowsheet Simulations. Week 672 in red circle, week 235 in green circle. 
PNNL-22747

SRNL-STI-2013-00465

Table 3-2. Final LAW Simulants for Cast Stone Screening Tests

\begin{tabular}{|c|c|c|c|c|}
\hline Waste Constituent & $\begin{array}{l}\text { SST Blend } \\
\text { Saltcake }\end{array}$ & $\begin{array}{r}\text { HTWOS } \\
\text { Overall } \\
\text { Average }\end{array}$ & $\begin{array}{c}\text { HTWOS } \\
\text { High Al }\end{array}$ & $\begin{array}{l}\text { HTWOS } \\
\text { High SO }\end{array}$ \\
\hline & \multicolumn{4}{|c|}{ Concentration (moles/mole $\mathrm{Na})^{(\mathrm{a})}$} \\
\hline $\mathrm{Na}$ & 1.000 & 1.000 & 1.000 & 1.000 \\
\hline $\mathrm{K}$ & 0.002 & 0.007 & 0.028 & - \\
\hline $\mathrm{Al}$ & 0.013 & 0.061 & 0.112 & 0.047 \\
\hline $\mathrm{Cl}$ & 0.009 & 0.008 & 0.018 & 0.007 \\
\hline $\mathrm{F}$ & 0.006 & $0.006^{(b)}$ & 0.010 & $0.012^{(\mathrm{b})}$ \\
\hline $\mathrm{SO}_{4}$ & 0.018 & 0.017 & 0.004 & 0.030 \\
\hline $\mathrm{PO}_{4}$ & 0.010 & $0.010^{(\mathrm{b})}$ & 0.005 & $0.010^{(\mathrm{b})}$ \\
\hline $\mathrm{NO}_{2}$ & 0.085 & 0.113 & 0.194 & 0.098 \\
\hline $\mathrm{NO}_{3}$ & 0.502 & 0.324 & 0.287 & 0.367 \\
\hline $\mathrm{CO}_{3}$ & 0.095 & 0.055 & 0.040 & 0.035 \\
\hline TOC Total & 0.057 & 0.015 & 0.021 & 0.007 \\
\hline Free $\mathrm{OH}$ & 0.097 & 0.312 & 0.293 & 0.306 \\
\hline \multicolumn{5}{|c|}{$\begin{array}{l}\text { (a) After charge balancing. } \\
\text { (b) Concentration of } \mathrm{F} \text { and } \mathrm{PO}_{4}{ }^{3-} \text { reduced from HTWOS values because of solids formation observed in } \\
\text { preliminary simulants. } \\
-=\text { not included }\end{array}$} \\
\hline
\end{tabular}

\subsection{Spike Levels for Constituents of Concern}

In addition to the main components of the LAW, the simulants used to make Cast Stone waste forms prepared for contaminant release testing were spiked with hazardous chemicals and/or radionuclides of interest to determine how well the Cast Stone waste form controls the release of these constituents of concern (COCs). Results in the Final Tank Closure and Waste Management Environmental Impact Statement for the Hanford Site, Richland Washington (DOE/EIS 2012) showed that only ${ }^{99} \mathrm{Tc},{ }^{129} \mathrm{I}, \mathrm{Cr}$, and $\mathrm{NO}_{3}$ had non-negligible projected groundwater concentrations from Cast Stone disposed at the IDF.

\subsubsection{Hazardous Chemicals}

Some testing required using spikes of COCs to address their retention within and release from the Cast Stone waste form. To address land disposal restrictions, including performance in the TCLP, spikes included RCRA metals and underlying hazardous constituents. The final spike levels are shown in Table 3-3 (Russell et al. 2013). For the screening tests, only $\mathrm{Cr}, \mathrm{Pb}, \mathrm{Ni}$, and $\mathrm{Cd}$ were used to test the performance of RCRA metals in the Cast Stone waste form.

An initial RCRA spike vector was selected by taking the maximum weekly batch values from the HTWOS modeling for System Plan 6 (Certa et al. 2011) for the feed to Supplemental LowActivity Waste Treatment. The list of RCRA metals to include in the simulants was reduced using total constituent analysis as allowed in Section 1.2 of EPA Method 1311 for the TCLP (EPA 1992; Russell et al. 2013). Conceptually, this analysis shows what the TCLP leachate concentrations would be if $100 \%$ of each COC were released from the waste form during the leaching procedure. This total constituent analysis screen showed $\mathrm{As}, \mathrm{Ba}, \mathrm{Se}, \mathrm{Ag}, \mathrm{Sb}, \mathrm{Be}$, and Ni levels derived from the waste feed compositions to be below Universal Treatment Standards (UTSs). None of the COCs that falls below UTS by total analysis was added to the simulants in the screening tests with the exception of Ni. Nickel was included because it contributes a significant mass to the RCRA metals vector. 
Mercury was excluded due to anticipated interactions with iodine. Mercury and silver can form highly insoluble compounds with iodine which would decrease the ability of iodine to leach from the waste form. Because the initial vector used HTWOS maximum weekly values, it would be unrealistic to test iodine performance in the presence of these other compounds that would have the effect of improving iodine performance (i.e., reduce its leaching) in the EPA Draft Method 1315 leach testing.

Table 3-3. Final Spike Levels for Hazardous Constituents and Radionuclides in Simulants for Cast Stone Screening Tests

\begin{tabular}{|c|c|c|c|}
\hline Waste Constituent & $\begin{array}{c}\text { HTWOS } \\
\text { Overall } \\
\text { Average }\end{array}$ & $\begin{array}{c}\text { HTWOS } \\
\text { Maximum }\end{array}$ & $\begin{array}{c}\text { Other } \\
\text { Considerations }\end{array}$ \\
\hline RCRA Metals and UHCs ${ }^{(\mathrm{d})}$ & moles/mole $\mathrm{Na}$ & moles/mole Na & moles/mole Na \\
\hline $\mathrm{Cd}$ & $2.78 \mathrm{E}-06$ & $3.19 \mathrm{E}-05$ & - \\
\hline $\mathrm{Cr}$ & $2.42 \mathrm{E}-03$ & $9.99 \mathrm{E}-03$ & $4.30 \mathrm{E}-03^{(\mathrm{a})}$ \\
\hline $\mathrm{Pb}$ & $1.16 \mathrm{E}-05$ & $5.13 \mathrm{E}-05$ & - \\
\hline $\mathrm{Ni}$ & $6.41 \mathrm{E}-05$ & $6.61 \mathrm{E}-04$ & - \\
\hline Radionuclides & $\mathrm{Ci} / \mathrm{mole} \mathrm{Na}$ & $\mathrm{Ci} / \mathrm{mole} \mathrm{Na}$ & $\mathrm{Ci} /$ mole $\mathrm{Na}$ \\
\hline${ }^{99} \mathrm{Tc}$ & $1.13 \mathrm{E}-05$ & $4.13 \mathrm{E}-05$ & - \\
\hline${ }^{99} \mathrm{Tc}^{(\mathrm{c})}$ & $(6.65 \mathrm{E}+02 \mu \mathrm{g} / \mathrm{mole} \mathrm{Na})$ & $(2.43 \mathrm{E}+03 \mu \mathrm{g} / \mathrm{mole} \mathrm{Na})$ & \\
\hline${ }^{129} \mathrm{I}$ & $1.44 \mathrm{E}-08$ & $8.01 \mathrm{E}-08$ & $3.54 \mathrm{E}-06^{(\mathrm{b})}$ \\
\hline${ }^{127} \mathrm{I}(\text { stable })^{(\mathrm{c})}$ & $(8.14 \mathrm{E}+01 \mu \mathrm{g} / \mathrm{mole} \mathrm{Na})$ & $(4.53 \mathrm{E}+02 \mu \mathrm{g} / \mathrm{mole} \mathrm{Na})$ & $(2.00 \mathrm{E}+04 \mu \mathrm{g} / \mathrm{mole} \mathrm{Na})$ \\
\hline${ }^{232+233+234+235+236+238} \mathrm{U}$ & $1.59 \mathrm{E}-08$ & $5.63 \mathrm{E}-08$ & - \\
\hline Natural or depleted $\mathrm{U}^{(\mathrm{c})}$ & - & $(3.56+04 \mu \mathrm{g} / \mathrm{mole} \mathrm{Na})$ & - \\
\hline \multicolumn{4}{|c|}{$\begin{array}{l}\text { (a) Cr concentration adjusted based on review of best basis inventory and previo } \\
\text { (b) Iodine concentration increased to address possible detection limits issues } \\
\text { Iodine added as nonradioactive }{ }^{127} \mathrm{I} \text {. } \\
\text { (c) These COCs were added to simulants based on mass (as shown). } \\
\text { (d) UHCs = underlying hazardous constituents }\end{array}$} \\
\hline
\end{tabular}

Thallium was not included in the screening tests because the secondary waste Cast Stone program showed satisfactory performance for thallium in TCLP leach testing (Mattigod et al. 2011). Thallium is also very close to the UTS value by total analysis $(0.36 \mathrm{mg} / \mathrm{L}$ versus $0.2 \mathrm{mg} / \mathrm{L})$ and thus would require minimal attenuation in TCLP leach testing to meet the UTS.

The HTWOS model for System Plan 6 (Certa et al. 2011) predicts a maximum Cr level in the LAW supplemental feed of $1.0 \times 10^{-2} \mathrm{M} / \mathrm{M}$ Na. The average $\mathrm{Cr}$ concentration is $2.4 \times 10^{-3} \mathrm{M} / \mathrm{M}$ $\mathrm{Na}$ and the 95th percentile for $\mathrm{Cr}$ is $4.3 \times 10^{-3} \mathrm{M} / \mathrm{M} \mathrm{Na}$. The 2003 Cast Stone work used the SST Blend saltcake simulant with a $\mathrm{Cr}$ level of $2.0 \times 10^{-3} \mathrm{M} / \mathrm{M}$ Na and the SST saltcake blend of real waste with a ratio of $3.7 \times 10^{-3} \mathrm{M} / \mathrm{M} \mathrm{Na}$ (Rapko et al. 2003). Simulants used in testing Cast Stone for the secondary waste program used a $\mathrm{Cr}$ ratio as high as $4.2 \times 10^{-3} \mathrm{M} / \mathrm{M} \mathrm{Na}$ (Sundaram et al. 2011). Based on the preceding information, a $\mathrm{Cr}$ spike level of $4.3 \times 10^{-3} \mathrm{M} / \mathrm{M} \mathrm{Na}$ corresponding to the HTWOS 95th percentile composition was selected for supplemental LAW Cast Stone waste form testing.

\subsubsection{Radionuclides}

To understand the retention and release of radionuclides of concern, spikes of ${ }^{99} \mathrm{Tc},{ }^{129} \mathrm{I}$ (substituted with nonradioactive ${ }^{127} \mathrm{I}$ ), and U were added to Cast Stone batches prepared for EPA Draft Method 1315 leach testing studies. Table 3-3 shows the spike levels for these 
radionuclides. The ${ }^{99} \mathrm{Tc}$ was spiked in all samples at the HTWOS maximum concentration. To increase the probability of being able to detect iodine in as many of the leachates as possible and at various leach intervals, the stable iodine $\left({ }^{127} \mathrm{I}\right)$ concentration in the simulants was increased to $100 \mathrm{mg} / \mathrm{L}$ for the $5 \mathrm{M} \mathrm{Na}$ simulants and $156 \mathrm{mg} / \mathrm{L}$ for the $7.8 \mathrm{M}$ simulants. These concentrations of stable iodine are 245 times larger than the average mass concentration of ${ }^{129} \mathrm{I}$ and 44 times larger than the maximum mass concentration of ${ }^{129}$ I projected by the HTWOS model to be present in LAW. 
PNNL-22747

SRNL-STI-2013-00465

\subsection{Dry Materials}

The basic Cast Stone dry blend is composed of $47 \mathrm{wt} \%$ BFS, $45 \mathrm{wt} \%$ Class F fly ash , and $8 \mathrm{wt} \%$ ordinary portland cement (OPC, Type I/II) (Lockrem 2005). This basic dry blend composition was used for all the screening tests. Two sources of BFS and two sources of fly ash were used as part of the test matrix. One of the BFS and the high-Ca fly ash were from a supplier using sources available in the Pacific Northwest. The second BFS and the low-Ca fly ash are the same materials used in the Saltstone Processing Facility at the SRS in South Carolina. A single source of portland cement from the Pacific Northwest was used in the dry blend mixes. This section describes the chemical composition and X-ray diffraction characteristics of each of the dry blend components. Additional details are available in Appendix B (Dry Blend Materials Characterization) and Appendix F (Material Certification Reports).

\subsection{Blast Furnace Slag}

The product used for one source of BFS was Lafarge NewCem ${ }^{\circledR}$ slag cement. NewCem is a finely ground BFS produced from the iron-making process. The material was obtained from LaFarge North America Inc. in Pasco, Washington. This material is referred to as the NW slag in the discussions of the Cast Stone properties. The product used for the second source of BFS was granulated BFS obtained from Holcim (US) Inc. headquartered in Waltham, Maine. This product is referred to as the SE slag in the discussions of the Cast Stone properties because it is used at SRS. Test reports from the suppliers for the two BFSs are provided in Appendix F. Table 4-1 lists the compositions of the two slags as measured at PNNL using both inductively coupled plasma (ICP) and X-ray fluorescence (XRF) and at SRNL using ICP. The analytical methods are described in Appendix B.

The NW slag is characterized as having higher concentrations of $\mathrm{Al}, \mathrm{Ca}$, and $\mathrm{S}$ and lower concentrations of $\mathrm{Mg}$ and $\mathrm{Si}$ compared to the SE slag. Figure 4-1 shows the X-ray diffractograms for the two slags. The SE slag is amorphous, while the diffractogram of the NW slag indicates that gypsum has been added. In compositions containing an abundance of Al, such as the NW slag, suppliers add gypsum to provide a soluble sulfate source that reacts with the tricalcium aluminate to form ettringite, thus preventing flash setting of the concrete mix (Ramachandran and Feldman 1995).

Additional BFS characterization information including scanning electron microscopy (SEM) micrographs, heat generation, particle size, thermal gravimetric analyses, surface area, densities, and Hausner ratio are presented in Appendix B.

\subsection{Fly Ash}

The product used for the high-Ca fly ash was a Class $\mathrm{C} /$ Class $\mathrm{F}$ fly ash produced from the combustion of coal at the Centralia Power plant in western Washington. The material was obtained from LaFarge North America Inc. in Pasco, Washington. This material is referred to as the NW fly ash in the discussions of the Cast Stone properties. The product used for the low-Ca fly ash was a thermally beneficiated Class F fly ash from the Wateree Station Carbon Burn Out (CBO) facility and was obtained from South Carolina Electric \& Gas through the SEFA Group in Lexington, South Carolina. This product is referred to as the SE fly ash in the discussions of the Cast Stone properties. Test reports from the suppliers for the two fly ashes are provided in Appendix F.

Table 4-2 lists the chemical compositions of the two sources of fly ash as measured at PNNL and SRNL. Analytical methods are described in Appendix B. 
Table 4-1. Measured Chemical Composition of Blast Furnace Slags

\begin{tabular}{|c|c|c|c|c|c|c|c|c|c|c|c|}
\hline \multirow{3}{*}{ Analyte } & \multicolumn{2}{|c|}{$\begin{array}{c}\text { NW Slag } \\
(\mu \mathrm{g} / \mathrm{g})\end{array}$} & \multicolumn{2}{|c|}{$\begin{array}{c}\text { SE Slag } \\
(\mu \mathrm{g} / \mathrm{g})\end{array}$} & \multirow{3}{*}{ Oxide } & \multicolumn{3}{|c|}{$\begin{array}{c}\text { NW Slag } \\
(w t \%)\end{array}$} & \multicolumn{3}{|c|}{$\begin{array}{c}\text { SE Slag } \\
(w t \%)\end{array}$} \\
\hline & \multirow{2}{*}{$\frac{\text { PNNL }}{\text { ICP }}$} & \multirow{2}{*}{$\begin{array}{c}\text { SRNL } \\
\text { ICP }\end{array}$} & \multirow{2}{*}{$\begin{array}{c}\text { PNNL } \\
\text { ICP }\end{array}$} & \multirow{2}{*}{$\frac{\text { SRNL }}{\text { ICP }}$} & & \multicolumn{2}{|c|}{ PNNL } & \multirow{2}{*}{$\frac{\text { SRNL }}{\text { ICP }}$} & \multicolumn{2}{|c|}{ PNNL } & \multirow{2}{*}{$\frac{\text { SRNL }}{\text { ICP }}$} \\
\hline & & & & & & ICP & XRF & & ICP & XRF & \\
\hline Aluminum & 77,700 & 67,300 & 43,300 & 45,100 & $\mathrm{Al}_{2} \mathrm{O}_{3}$ & 14.68 & 11 & 12.7 & 8.18 & 7.2 & 8.51 \\
\hline Antimony & $<2340$ & - & $<2320$ & - & & - & - & - & - & - & - \\
\hline Arsenic & $<28.6$ & - & $<28.3$ & - & & - & - & - & - & - & - \\
\hline Barium & 523 & 358 & 364 & 358 & $\mathrm{BaO}$ & 0.06 & 0.057 & 0.04 & 0.04 & 0.035 & 0.03 \\
\hline Cadmium & $<4.72$ & $<100$ & $<4.67$ & $<100$ & & - & - & - & - & - & \\
\hline Calcium & 356,000 & 304,000 & 228,000 & 240,000 & $\mathrm{CaO}$ & 49.81 & 46 & 42.6 & 31.9 & 36 & 33.6 \\
\hline Chromium & $<65.6$ & $<100$ & 69.6 & 130 & $\mathrm{Cr}_{2} \mathrm{O}_{3}$ & - & 0.01 & - & 0.01 & 0.009 & 0.02 \\
\hline Copper & $<113$ & $<100$ & $<112$ & $<100$ & & - & - & - & - & - & - \\
\hline Iron & 6,200 & 4,100 & 2,300 & 1,970 & $\mathrm{Fe}_{2} \mathrm{O}_{3}$ & 0.89 & 0.78 & 0.59 & 0.33 & 0.33 & 0.28 \\
\hline Lead & $<17.9$ & $<100$ & $<17.7$ & $<100$ & & - & - & - & - & - & \\
\hline Magnesium & 27,700 & 25,200 & 69,300 & 78,700 & $\mathrm{MgO}$ & 4.59 & 4.9 & 4.2 & 11.49 & 13 & 13.1 \\
\hline Manganese & 2,130 & 1,530 & 3,330 & 2,780 & $\mathrm{MnO}_{2}$ & 0.34 & 0.28 & 0.24 & 0.53 & 0.55 & 0.44 \\
\hline Mercury & $<15.9$ & - & $<8.63$ & - & & - & - & - & - & - & - \\
\hline Molybdenum & $<31.4$ & $<100$ & $<31.1$ & $<100$ & & - & - & - & - & - & - \\
\hline Nickel & $<488$ & $<1,000$ & $<484$ & $<1,000$ & & - & - & - & - & - & - \\
\hline Phosphorus & $<3110$ & $<1,000$ & $<3080$ & $<1000$ & $\mathrm{P}_{2} \mathrm{O}_{5}$ & - & 0.021 & - & - & 0.032 & - \\
\hline Potassium & $<9010$ & 2,800 & $<8930$ & 3,590 & $\mathrm{~K}_{2} \mathrm{O}$ & - & 0.37 & 0.34 & - & 0.43 & 0.43 \\
\hline Selenium & $<5980$ & - & $<5920$ & - & & - & - & - & - & - & - \\
\hline Silicon & 181,000 & 154,000 & 190,000 & 190,000 & $\mathrm{SiO}_{2}$ & 38.72 & 33 & 33 & 40.65 & 39 & 40.6 \\
\hline Silver & $<1.79$ & - & $<1.77$ & - & & - & - & - & - & - & - \\
\hline Sodium & $<6630$ & 1,530 & $<6570$ & 1,860 & $\mathrm{Na}_{2} \mathrm{O}$ & - & 0.52 & 0.21 & & 0.5 & 0.25 \\
\hline Strontium & 670 & - & 352 & - & $\mathrm{SrO}$ & 0.08 & 0.074 & 0.07 & 0.07 & 0.043 & 0.05 \\
\hline Sulfur & 23,800 & 16,400 & $<11100$ & 7,810 & $\mathrm{SO}_{4}$ & 7.13 & 5 & 4.9 & $(<3.33)$ & 1.69 & 2.3 \\
\hline Titanium & - & 2,300 & - & 1,580 & $\mathrm{TiO}_{2}$ & - & 0.56 & 0.36 & - & 0.35 & 0.25 \\
\hline Zinc & - & $<100$ & - & $<100$ & $\mathrm{ZnO}$ & - & - & 0.03 & - & - & - \\
\hline Zirconium & - & 183 & - & 293 & $\mathrm{ZrO}_{2}$ & - & 0.035 & - & - & 0.023 & 0.04 \\
\hline Total Carbon & 751 & - & 632 & - & $\mathrm{C}$ & - & - & - & - & - & - \\
\hline & & & & & Mass $\%$ & $116.3 \%$ & $102.6 \%$ & $99.2 \%$ & $93.2 \%$ & $99.2 \%$ & $99.9 \%$ \\
\hline
\end{tabular}



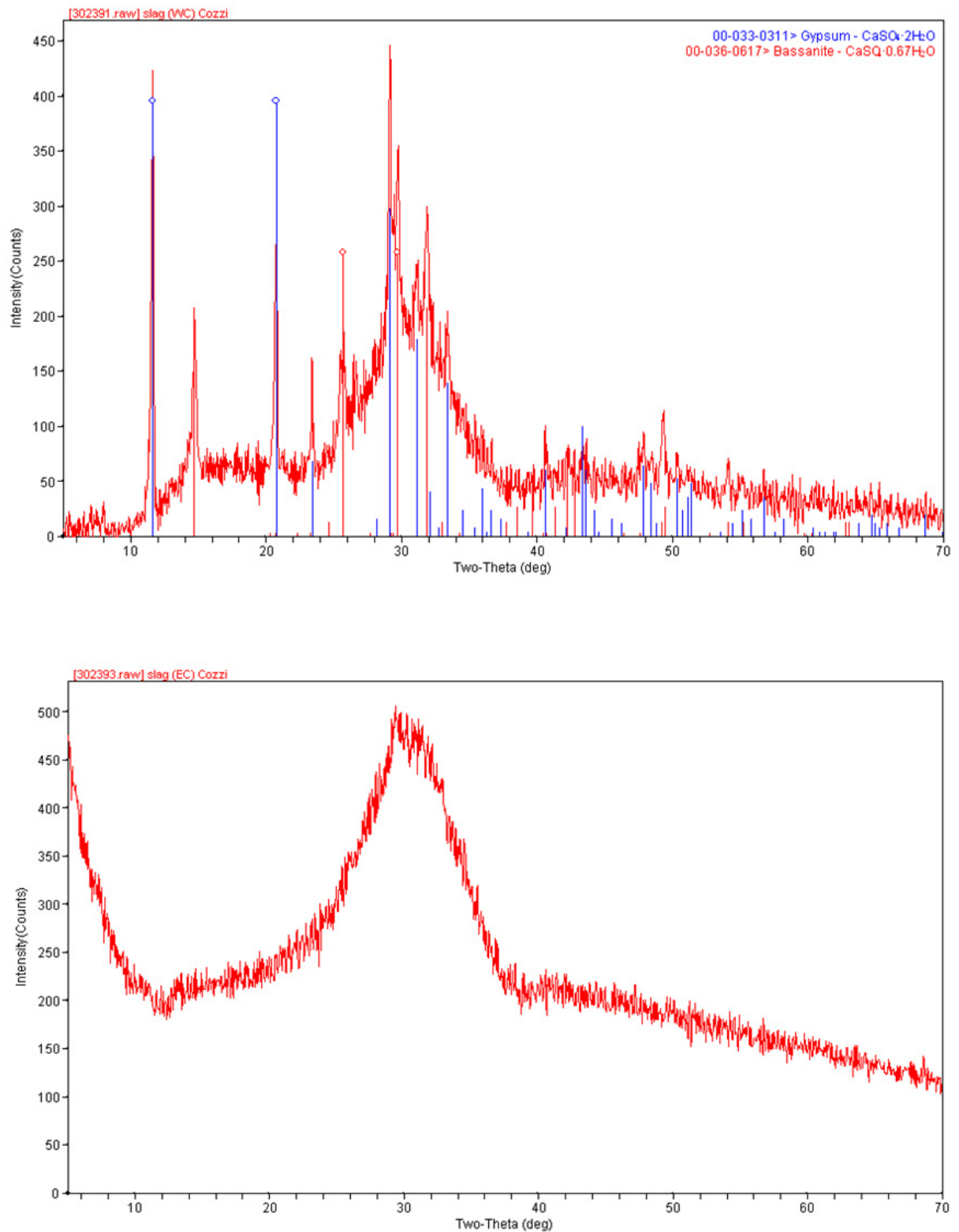

Figure 4-1. X-Ray Diffraction Patterns Northwest (top) and Southeast (bottom) Blast Furnace Slags

The NW fly ash has higher concentrations of $\mathrm{Ca}$ and $\mathrm{Mg}$ and lower concentrations of $\mathrm{Al}$ compared to the SE fly ash. Figure 4-2 shows the X-ray diffractograms for the fly ashes. The diffractograms for the NW fly ash indicated the presence of quartz, anhydrite, ${ }^{1}$ and periclase, ${ }^{2}$

${ }^{1}$ Anhydrite is anhydrous calcium sulfate $\left(\mathrm{CaSO}_{4}\right)$.

${ }^{2}$ Periclase is a cubic form of magnesium oxide $(\mathrm{MgO})$. Periclase is usually found in marble produced by metamorphism of dolomitic limestones. 
while the diffractograms for the SE fly ash identify the quartz and mullite ${ }^{1}$ crystalline phases. These results are consistent with Class $\mathrm{F}$ fly ashes from their respective regions (McCarthy et al. 1989).

Appendix B contains additional information about the properties of the fly ashes including SEM micrographs, pozzolanic activity, particle size distribution, thermal gravimetric analysis, surface areas, and densities.

Table 4-2. Measured Chemical Composition of Fly Ashes

\begin{tabular}{|c|c|c|c|c|c|c|c|c|c|}
\hline \multirow{3}{*}{ Analyte } & \multicolumn{2}{|c|}{$\begin{array}{c}\text { NW FA } \\
(\mu \mathrm{g} / \mathrm{g}) \\
\end{array}$} & \multirow{3}{*}{$\begin{array}{c}\begin{array}{c}\text { SE FA } \\
(\mu \mathrm{g} / \mathrm{g})\end{array} \\
\text { SRNL } \\
\text { ICP } \\
\end{array}$} & \multirow{3}{*}{ Oxide } & \multicolumn{3}{|c|}{$\begin{array}{c}\text { NW FA } \\
(w t \%)\end{array}$} & \multicolumn{2}{|c|}{$\begin{array}{r}\text { SE FA } \\
(w t \%) \\
\end{array}$} \\
\hline & PNNL & SRNL & & & \multicolumn{2}{|c|}{ PNNL } & SRNL & PNNL & SRNL \\
\hline & ICP & ICP & & & ICP & XRF & ICP & XRF & ICP \\
\hline Aluminum & 103,000 & 86,100 & 142,000 & $\mathrm{Al}_{2} \mathrm{O}_{3}$ & 19.46 & 16 & 16.3 & 25 & 26.8 \\
\hline Antimony & $<2,320$ & - & - & - & - & - & - & - & - \\
\hline Arsenic & $<28.3$ & - & - & - & - & - & - & - & - \\
\hline Barium & 6,960 & 4,840 & 1,240 & $\mathrm{BaO}$ & 0.78 & 0.71 & 0.54 & 0.18 & 0.14 \\
\hline Cadmium & $<4.68$ & $<100$ & $<100$ & - & - & - & - & - & - \\
\hline Calcium & 114,000 & 92,800 & 17,200 & $\mathrm{CaO}$ & 15.95 & 15 & 13 & 2.8 & 2.4 \\
\hline Chromium & $<65.0$ & 233 & 275 & $\mathrm{Cr}_{2} \mathrm{O}_{3}$ & - & 0.015 & 0.03 & 0.034 & 0.02 \\
\hline Copper & $<112$ & $<100$ & $<100$ & - & - & 0.017 & 0.02 & 0.02 & 0.04 \\
\hline Iron & 52,700 & 41,500 & 54,400 & $\mathrm{Fe}_{2} \mathrm{O}_{3}$ & 7.53 & 6.8 & 5.93 & 8.0 & 7.8 \\
\hline Lead & 31.3 & $<100$ & $<100$ & - & - & - & - & - & - \\
\hline Magnesium & 30,000 & 26,500 & 5,280 & $\mathrm{MgO}$ & 4.97 & 5.6 & 4.4 & 2.1 & 0.88 \\
\hline Manganese & 557 & 473 & 177 & $\mathrm{MnO}_{2}$ & 0.09 & 0.088 & 0.08 & 0.03 & 0.03 \\
\hline Mercury & $<15.8$ & - & - & - & - & - & - & - & - \\
\hline Molybdenum & $<31.1$ & $<100$ & $<100$ & - & - & - & - & - & - \\
\hline Nickel & $<484$ & $<1000$ & $<1000$ & - & - & - & - & - & - \\
\hline Phosphorus & $<3,080$ & $<1000$ & $<1000$ & $\mathrm{P}_{2} \mathrm{O}_{5}$ & - & 0.41 & - & 0.31 & - \\
\hline Potassium & 16,800 & 12,400 & 18,600 & $\mathrm{~K}_{2} \mathrm{O}$ & 2.02 & 1.7 & 1.49 & 2.8 & 2.2 \\
\hline Selenium & $<5,920$ & - & - & - & - & - & - & - & - \\
\hline Silicon & 270,000 & 242,000 & 260,000 & $\mathrm{SiO}_{2}$ & 57.76 & 48 & 51.8 & 56 & 55.6 \\
\hline Silver & 2.18 & - & - & - & - & - & - & - & - \\
\hline Sodium & 34,100 & 24,700 & 3,720 & $\mathrm{Na}_{2} \mathrm{O}$ & 4.6 & 3.8 & 3.3 & 0.71 & 0.5 \\
\hline Strontium & 3,730 & - & - & $\mathrm{SrO}$ & 0.44 & 0.38 & 0.3 & 0.159 & 0.12 \\
\hline Sulfur & $<11,100$ & 3,390 & 709 & $\mathrm{SO}_{4}$ & - & 1.1 & 1 & 0.2 & 0.21 \\
\hline Titanium & - & 4,760 & 7,340 & $\mathrm{TiO}_{2}$ & - & 1.2 & 0.75 & 1.7 & 1.16 \\
\hline Zinc & - & 111 & 139 & $\mathrm{ZnO}$ & - & 0.02 & 0.01 & 0.024 & 0.02 \\
\hline Zirconium & - & 336 & 338 & $\mathrm{ZrO}_{2}$ & - & 0.034 & 0.05 & 0.055 & 0.05 \\
\hline Total Carbon & 530 & - & - & $\mathrm{C}$ & - & - & - & - & - \\
\hline & & & & Mass $\%$ & $107.0 \%$ & $100.9 \%$ & $99.0 \%$ & $100.1 \%$ & $98.1 \%$ \\
\hline
\end{tabular}

\subsection{Ordinary Portland Cement}

The product used for the OPC was a portland cement Type I/II obtained from Lafarge North America Inc. in Pasco, Washington. The cement is from the LaFarge plant in Richmond, British Columbia. The vendor test report for this portland cement is provided in Appendix F.

\footnotetext{
${ }^{1}$ Mullite is a silicate mineral of post-clay genesis. It can form two stoichiometric forms $3 \mathrm{Al} 2 \mathrm{O} 3 \cdot 2 \mathrm{SiO}_{2}$ or $2 \mathrm{Al}_{2} \mathrm{O}_{3}$ •
} $\mathrm{SiO}_{2}$. It is produced during various melting and firing processes. 
Table 4-3 lists the chemical composition based on chemical analyses at PNNL and SRNL. Figure 4-3 shows the X-ray diffractogram of the cement used in this study. The phases present are consistent with OPC (Walenta 2004). The analytical methods use to characterize the OPC are described in Appendix B. This cement was used for testing at both PNNL and SRNL.

Appendix B contains additional information about the cement including SEM micrographs, heat flow and total heat, particle size distribution, thermal gravimetric analysis, surface area, and density.
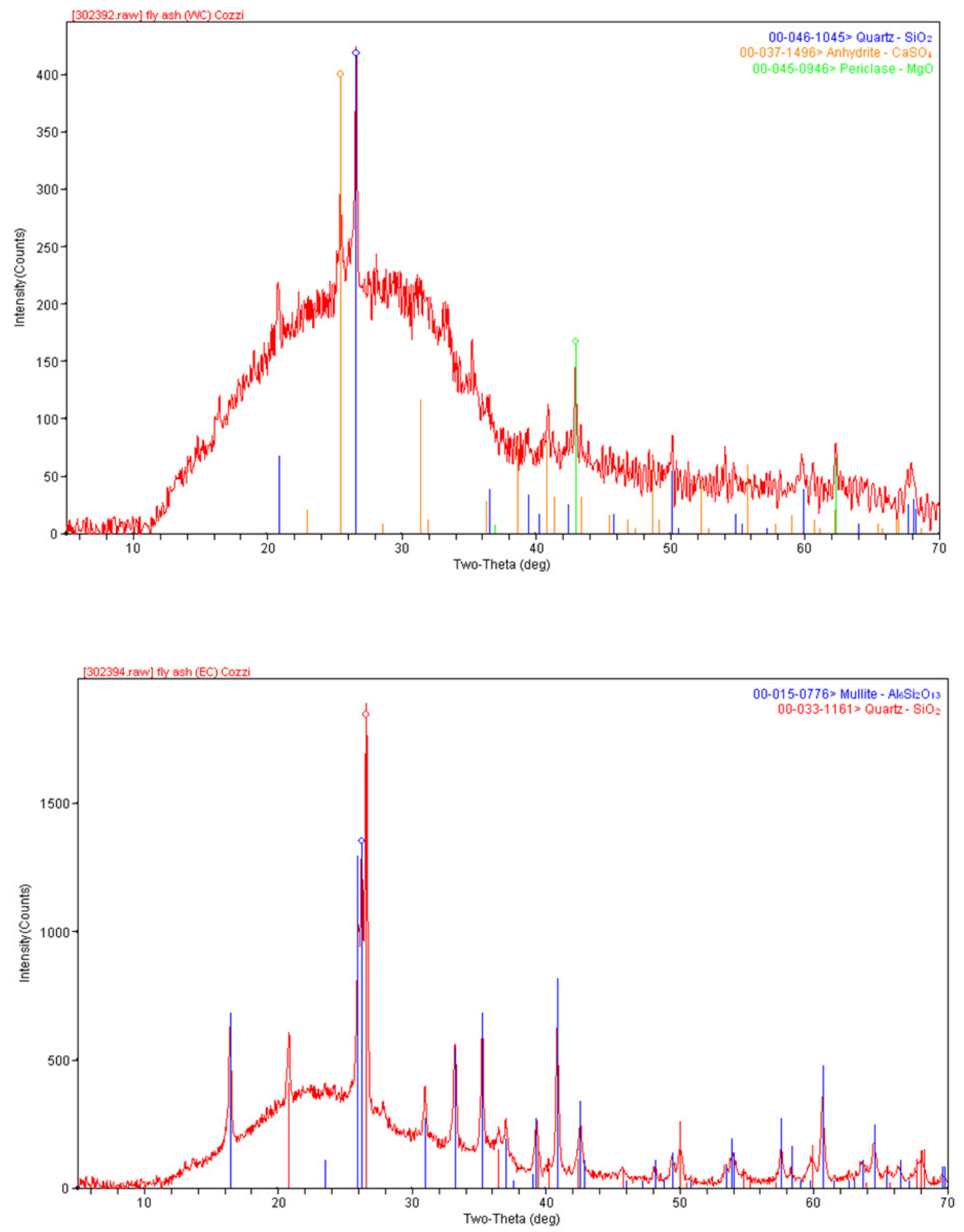

Figure 4-2. X-Ray Diffraction Patterns Northwest (top) and Southeast (bottom) Fly Ashes 
Table 4-3. Measured Chemical Composition of Ordinary Portland Cement

\begin{tabular}{|c|c|c|c|c|c|c|}
\hline \multirow{3}{*}{ Analyte } & \multirow{3}{*}{$\begin{array}{c}\begin{array}{c}\text { NW OPC } \\
(\mu \mathrm{g} / \mathrm{g})\end{array} \\
\text { PNNL } \\
\text { ICP }\end{array}$} & \multirow{3}{*}{ 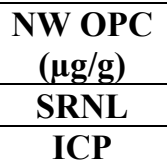 } & \multirow{3}{*}{ Oxide } & \multicolumn{3}{|c|}{$\begin{array}{c}\text { NW OPC } \\
(w t \%)\end{array}$} \\
\hline & & & & \multicolumn{2}{|c|}{ PNNL } & \multirow{2}{*}{$\begin{array}{c}\text { SRNL } \\
\text { ICP }\end{array}$} \\
\hline & & & & ICP & XRF & \\
\hline Aluminum & 27,600 & 25,600 & $\mathrm{Al}_{2} \mathrm{O}_{3}$ & 5.21 & 3.7 & 4.83 \\
\hline Antimony & $<2,320$ & - & - & - & - & - \\
\hline Arsenic & $<28.3$ & - & - & - & - & - \\
\hline Barium & 492 & 394 & $\mathrm{BaO}$ & 0.05 & 0.06 & 0.04 \\
\hline Cadmium & $<4.67$ & $<100$ & - & - & - & - \\
\hline Calcium & 486,000 & 451,000 & $\mathrm{CaO}$ & 68 & 66 & 63.1 \\
\hline Chromium & 165 & 203 & $\mathrm{Cr}_{2} \mathrm{O}_{3}$ & 0.02 & 0.03 & 0.03 \\
\hline Copper & 242 & 315 & - & 0.03 & 0.035 & 0.04 \\
\hline Iron & 27,800 & 24,900 & $\mathrm{Fe}_{2} \mathrm{O}_{3}$ & 3.97 & 3.4 & 3.55 \\
\hline Lead & 37.9 & $<100$ & - & 0.004 & - & - \\
\hline Magnesium & 5,010 & 4,050 & $\mathrm{MgO}$ & 0.83 & 1.7 & 0.69 \\
\hline Manganese & 614 & 579 & $\mathrm{MnO}_{2}$ & 0.1 & 0.1 & 0.09 \\
\hline Mercury & $<15.8$ & - & - & - & - & - \\
\hline Molybdenum & $<31.1$ & $<100$ & - & - & - & - \\
\hline Nickel & $<484$ & $<1000$ & - & - & - & - \\
\hline Phosphorus & $<3,080$ & $<1000$ & $\mathrm{P}_{2} \mathrm{O}_{5}$ & - & - & - \\
\hline Potassium & $<8,930$ & 2710 & $\mathrm{~K}_{2} \mathrm{O}$ & - & 0.34 & 0.33 \\
\hline Selenium & $<5,920$ & - & - & - & - & - \\
\hline Silicon & 110,000 & 96,100 & $\mathrm{SiO}_{2}$ & 23.53 & 19 & 20.6 \\
\hline Silver & 1.79 & - & - & - & - & - \\
\hline Sodium & $<6,570$ & 2,400 & $\mathrm{Na}_{2} \mathrm{O}$ & - & 0.54 & 0.32 \\
\hline Strontium & 1,480 & - & $\mathrm{SrO}$ & 0.18 & 0.16 & 0.16 \\
\hline Sulfur & 14,000 & 16,200 & $\mathrm{SO}_{4}$ & 4.19 & 3.63 & 4.86 \\
\hline Titanium & - & 1,480 & $\mathrm{TiO}_{2}$ & - & 0.31 & 0.23 \\
\hline Zinc & - & 1,390 & $\mathrm{ZnO}$ & - & 0.18 & 0.17 \\
\hline Zirconium & - & 233 & $\mathrm{ZrO}_{2}$ & - & 0.019 & 0.03 \\
\hline Total Carbon & 4,050 & - & $\mathrm{C}$ & - & - & - \\
\hline & & & Mass $\%$ & $106.1 \%$ & $99.2 \%$ & $99.1 \%$ \\
\hline
\end{tabular}

\subsection{Final Dry Blend Mix Chemical Compositions}

Prior to making the Cast Stone monoliths, the dry materials were pre-mixed in the four combinations needed to perform the screening tests. Table 4-4 lists the measured chemical compositions of the four dry blend mixes as measured at PNNL. Additional characterization data are presented in Appendix B. 


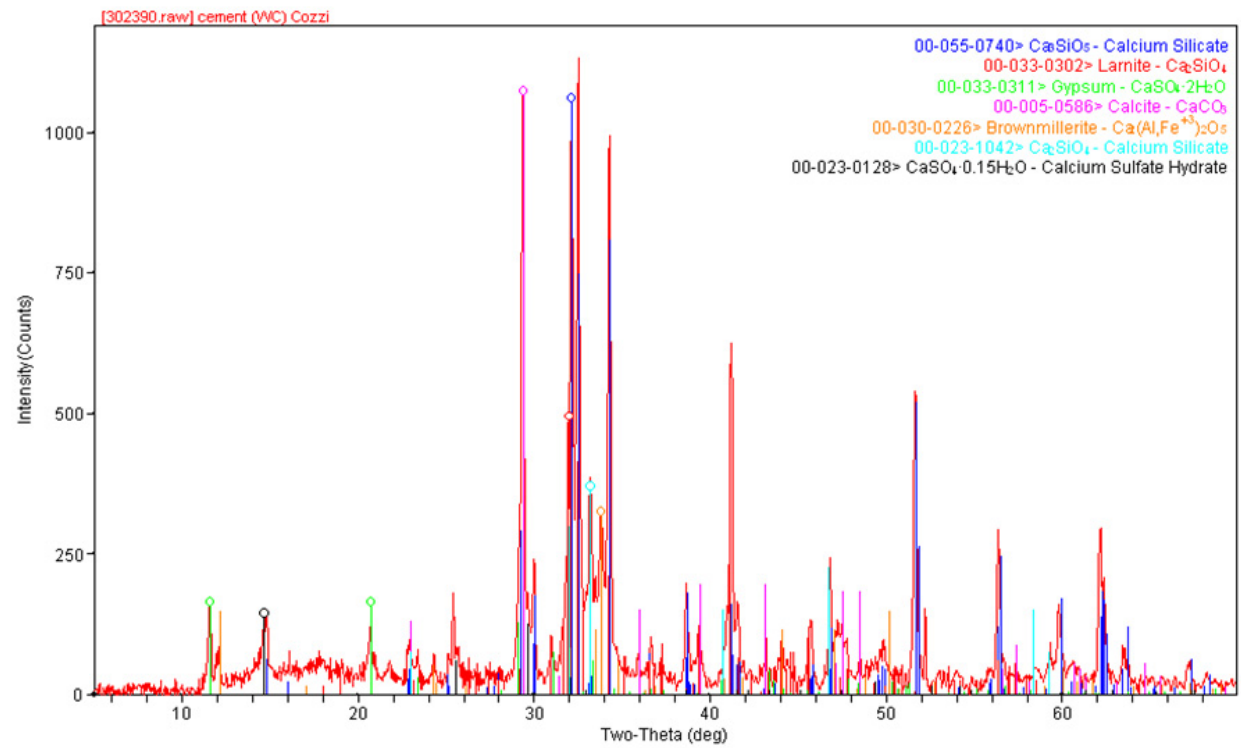

Figure 4-3. X-Ray Diffraction Pattern of Portland Cement Used for All Cast Stone Mixes

Table 4-4. Measured Chemical Compositions of Final Dry Blend Mixes

\begin{tabular}{|c|c|c|c|c|c|c|c|c|}
\hline \multirow[t]{2}{*}{ Analyte } & \multicolumn{2}{|c|}{$\begin{array}{c}\text { NW High Ca FA } \\
\text { NW BFS } \\
(\mu \mathrm{g} / g)\end{array}$} & \multicolumn{2}{|c|}{$\begin{array}{c}\text { NW High Ca FA } \\
\text { SE BFS } \\
(\mu \mathrm{g} / \mathrm{g})\end{array}$} & \multicolumn{2}{|c|}{$\begin{array}{c}\text { SE Low-Ca FA } \\
\text { NW BFS } \\
(\mu \mathrm{g} / \mathrm{g})\end{array}$} & \multicolumn{2}{|c|}{$\begin{array}{c}\text { SE Low-Ca FA } \\
\text { SE BFS } \\
(\mu \mathrm{g} / \mathrm{g})\end{array}$} \\
\hline & ICP & XRF & ICP & XRF & ICP & XRF & ICP & XRF \\
\hline Aluminum & - & 59,000 & 69,200 & 51,100 & 93,100 & 83,700 & 84,100 & 74,400 \\
\hline Arsenic & - & - & $<28.4$ & - & 43.9 & - & 37.1 & - \\
\hline Barium & - & 3,260 & 2,740 & 3,010 & 895 & 1,060 & 871 & 953 \\
\hline Calcium & - & 232,000 & 206,000 & 206,000 & 171,000 & 191,000 & 153,000 & 168,000 \\
\hline Chromium & - & 86 & 84.7 & 94 & 122 & 145 & 124 & 155 \\
\hline Copper & - & 105 & $<112$ & 93 & 114 & 126 & $<110$ & 114 \\
\hline Iron & - & 23,200 & 23,500 & 20,400 & 28,300 & 28,100 & 26,400 & 25,300 \\
\hline Lead & - & - & $<17.8$ & - & 52.2 & - & 42.4 & - \\
\hline Magnesium & - & 27,200 & 21,800 & 54,500 & 13,500 & 19,000 & 36,300 & 45,900 \\
\hline Manganese & - & 1,290 & 1,030 & 2,110 & 808 & 1,030 & 1,630 & 1,850 \\
\hline Molybdenum & - & 30.7 & $<31.2$ & 22.6 & $<31.6$ & 24 & $<30.6$ & 18.7 \\
\hline Nickel & - & 52.9 & $<486$ & 45.2 & $<492$ & 92.6 & $<477$ & 85.3 \\
\hline Phosphorus & - & 651 & $<3,100$ & 573 & $<3,130$ & 545 & $<3,040$ & 477 \\
\hline Potassium & - & 8,720 & 9,370 & 8,200 & 12,300 & 12,100 & 12,000 & 11,400 \\
\hline Silicon & - & 165,000 & 185,000 & 187,000 & 189,000 & 182,000 & 206,000 & 201,000 \\
\hline Silver & - & - & $<1.78$ & - & 2.35 & - & 1.95 & - \\
\hline Sodium & - & 12,500 & 13,200 & 12,000 & $<6,680$ & 4,080 & $<6,470$ & 4,160 \\
\hline Strontium & - & 1,710 & 1,620 & 1,580 & 891 & 944 & 824 & 853 \\
\hline Sulfur & - & 10,600 & 11,300 & 5,310 & $<11,300$ & 9,180 & $<11,000$ & 4,270 \\
\hline Titanium & - & 4,570 & 4,000 & 4,030 & 5,330 & 6,370 & 4,930 & 5,710 \\
\hline Total Carbon & - & - & 946 & - & 4,050 & - & 3,480 & - \\
\hline $\begin{array}{l}\text { \% Dry Solids } \\
\text { (\% by weight) }\end{array}$ & - & - & 99.8 & - & 99.5 & - & 99.8 & - \\
\hline
\end{tabular}




\subsection{Cast Stone Preparation}

The Cast Stone monoliths were prepared by mixing aliquots of the simulant batches and the dry blend mixes and then casting the slurry into plastic molds to cure. Batches of each of the four simulants were prepared ahead of time as described in Section 3.0. Similarly, 26 individual $1.75-\mathrm{kg}$ batches of the dry blend mixes were prepared ahead of time by weighing the cement, fly ash, and BFS at a ratio of 8:45:47, and mixing the materials by hand in a large plastic bag. The Cast Stone monoliths were prepared in the sequence as indicated by the random run order shown in Table 2-1 or Table C-1, depending on the property. To reduce the impact of inter-laboratory sample preparation, the mixing method developed at SRNL for fresh properties was used at PNNL for sample preparation.

At PNNL, the monoliths were prepared as follows. Simulants were aliquoted for each respective batch into a 2-L plastic beaker. The beaker containing the simulant was placed under the overhead mixer. A Caframo model BDC1850 overhead mixer with a 3.5-in. outer diameter (OD) elliptical impeller (Figure 5-1) was used to mix the simulants and blend the Cast Stone mixture. The beaker was positioned such that the impeller was $0.5 \mathrm{in}$. from the front of the beaker and $1 \mathrm{in}$. off the bottom, and the impeller rotation was as shown in Figure 5-1. The appropriate mass of simulant was placed in the 2-L plastic beaker and the mixer was started with an agitator speed of $200 \mathrm{rpm}$. When agitation was started, the ${ }^{99} \mathrm{Tc}$ and $\mathrm{U}$ radionuclide spikes were added to the simulant. After approximately 1 minute of agitation, the pre-mixed dry material was added to the beaker over a time period of 4.5 to 7 minutes in the location indicated in Figure 5-2. The agitation speed was adjusted to maintain a slight vortex (Figure 5-2). The wet slurry was stirred for 15 minutes from the start of addition of the dry blend. At the completion of mixing, the Cast Stone material was poured into 2 -in. $\times 4$-in. forms. The forms were agitated to release any potential entrained air and capped with a perforated lid as shown in Figure 5-3. The capped monoliths were placed in racks within a 5-gal bucket (Figure 5-3) containing $\sim 1$ in. of water at the bottom to provide a humidified curing environment. The racks with the Cast Stone monoliths were above the 1-in. water layer. The bucket was closed and the monoliths were allowed to cure at room temperature for 28 days before testing.

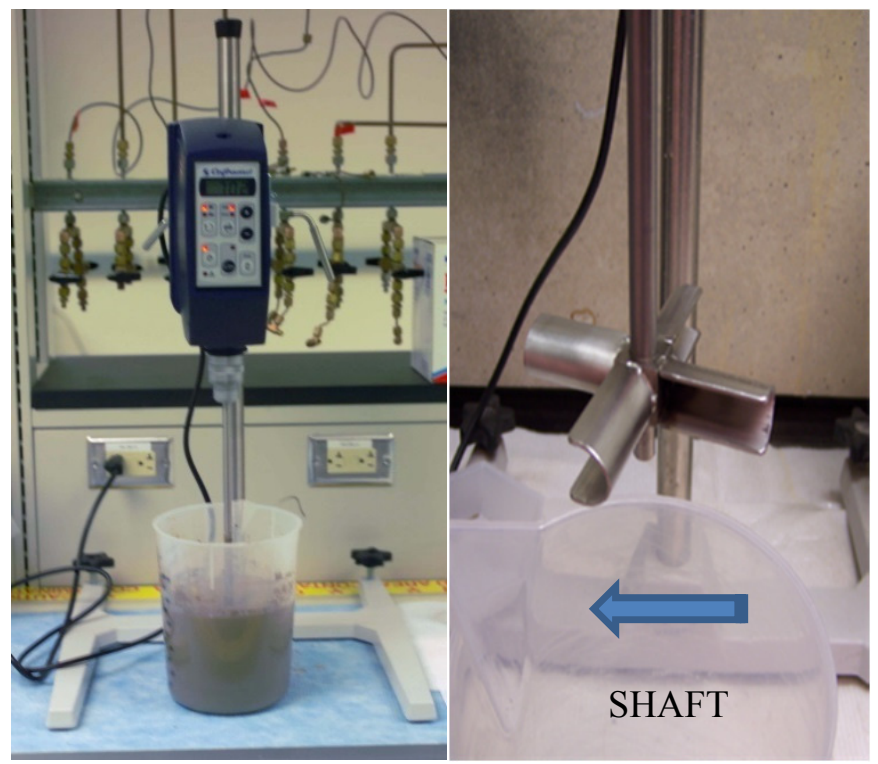

Figure 5-1. Overhead Mixer and Impeller for Cast Stone Preparation 

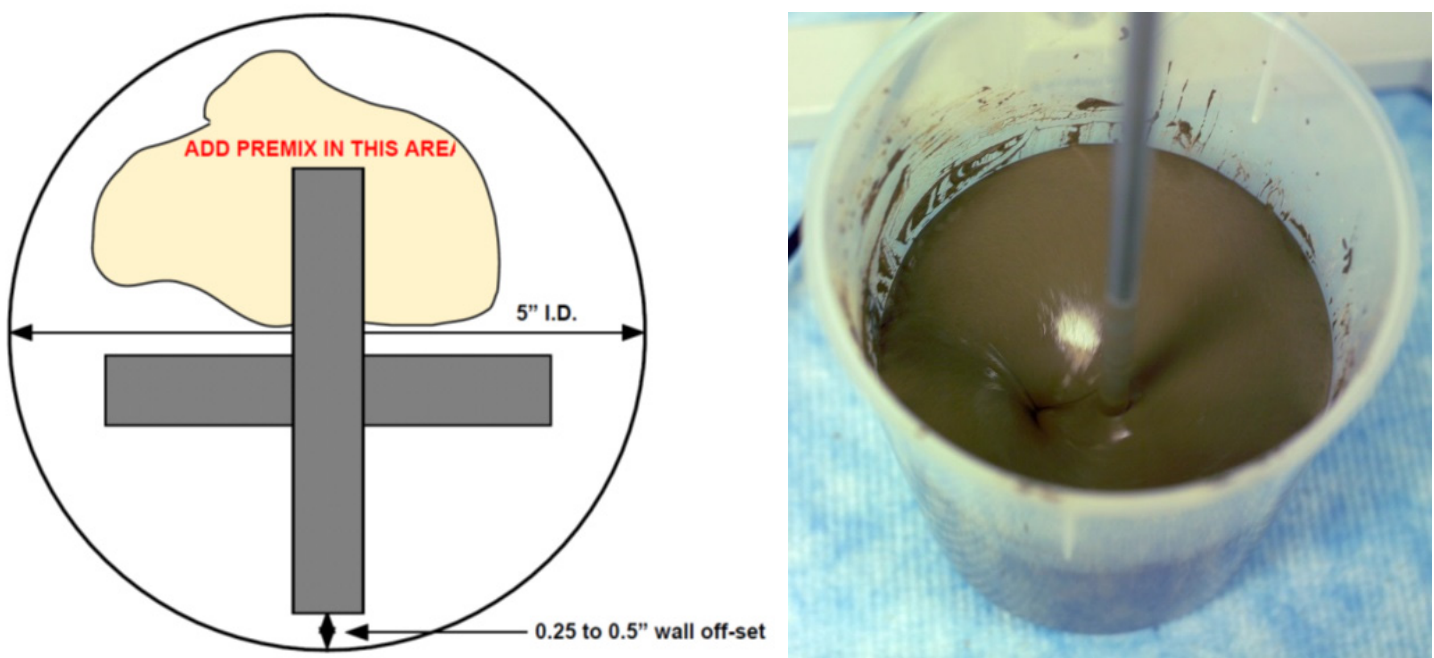

Figure 5-2. Position of Dry Blend Addition and Vortex Formed During Mixing

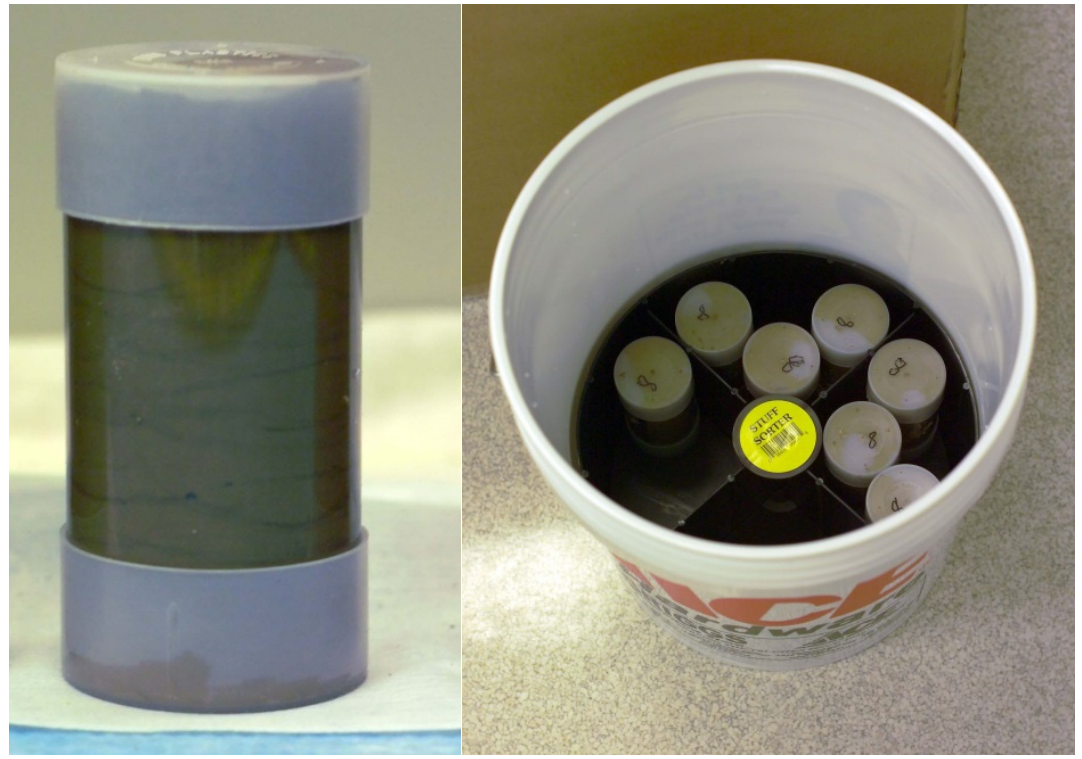

Figure 5-3. Cast Stone Monolith in Plastic Mold and Monoliths Curing in Bucket

The setup used at SRNL was the same as shown in Figure 5-1. A Caframo model BDC3030 overhead mixer was used with the same impellers that SRNL fabricated for the PNNL mixing step. The volume of the batch varied depending on the properties to be measured. The size of the plastic beaker was chosen to be approximately twice the volume of the mix being prepared. The initial agitator speed was $200 \mathrm{rpm}$ and the initial temperature of the salt solution was recorded. As the dry blend was added, the agitator speed was increased to incorporate the dry blends. All of the dry blend materials were added within 2 minutes. After the dry blend was incorporated, the temperature of the slurry was recorded. Mixing continued for a total of 15 minutes. The agitator speed was adjusted to maintain a vortex as shown in Figure 5-2. At the conclusion of mixing, the temperature of the slurry was recorded. 
PNNL-22747

SRNL-STI-2013-00465

\subsection{Cast Stone Processing and Curing Properties}

The freshly prepared Cast Stone was characterized for properties relevant to the mixing, pouring, flow, and heat generation during curing. These properties were measured at SRNL using Cast Stone slurries prepared at SRNL. The properties are discussed in the order in which the samples were cast. Additional information is available in Appendix C.

After the processing properties of the initial 26 Cast Stone mixes had been characterized, SRNL discovered that the sources of slag in two of the four possible fly ash and slag combinations had been transposed on the laboratory preparation batch sheets. This occurred at about the same time the project changed terminology for describing these materials from "Source 1" and "Source 2" for the slag to "NW" and "SE" and from "High Ca" and "Low Ca" for the fly ash to "NW" and "SE." SRNL researchers investigated and confirmed, by comparing analyzed chemical compositions to compositions calculated from the dry blend and simulant compositions, that 12 of the 26 mixes were affected. They also confirmed that the remaining 14 mixes had been properly batched. As a corrective action, SRNL repeated the 12 mixes with the correct dry blend combinations and measured all of the properties that had previously been measured with the exception of compressive strength, cured density, and porosity. The mis-batched samples were assigned mix numbers 27 through 38 and, where appropriate, the data were included in the statistical analysis and presented in this report. Table 6-1 shows the test conditions for the additional 12 mixes. Table $\mathrm{C}-1$ and Table $\mathrm{C}-2$ in Appendix $\mathrm{C}$ shows the entire test matrix with the 38 mixes.

\subsection{Flow Consistency (Modified ASTM D6103)}

The flow consistency test is a demonstrative method of expressing the measured rheological properties (yield stress and plastic viscosity) available in field conditions. The ASTM International Standard D6103, Standard Test Method for Flow Consistency of Controlled Low Strength Material (CLSM) (ASTM D6103 2004), was developed to provide an accepted, consensus method of measuring the flow characteristics of CLSM. CLSM is much more fluid than concrete so that it readily fills voids and spaces. This test method provides a procedure to quantify the flow characteristics.

\subsubsection{Flow Consistency Approach}

An open-ended cylinder was placed on a flat, level surface and filled with fresh Cast Stone slurry. The cylinder was raised quickly so that the slurry flowed into a patty. The average diameter of the patty was determined and compared to mixes of the same or similar mix compositions. A cylinder of smaller proportions than those specified by the ASTM method was used $(77 \mathrm{~mm}$ height $\times 43 \mathrm{~mm}$ inside diameter [ID] rather than the $150 \mathrm{~mm} \times 76 \mathrm{~mm}$ specified in the method). This was done based on historical data indicating that some of the mixes tested would flow a distance that could not be easily measured or contained when the larger cylinders were used.

\subsubsection{Flow Consistency Results}

Flow diameters for the 38 Cast Stone mixes (Table C-1) ranged from $93.5 \mathrm{~mm}$ (Mix 1) to $298.3 \mathrm{~mm}$ (Mix 12). Figure 6-1 presents photographs of samples with the smallest and largest flow diameters. Figure 6-2 shows the flow diameters for the 38 mixes. Note that the colored circles in this and future figures at zero value represent test conditions that were not included in the screening test matrix. The results are tabulated in Appendix C. All of the mixes with a waterto-dry-blend solids ratio of 0.60 resulted in a flow diameter greater than the mixes with a waterto-dry-blend solids ratio of 0.40 (see Table C-3 in Appendix C). 
Table 6-1. Twelve Mixes with BFS Sources Inadvertently Switched for Cast Stone Properties Tested by SRNL

\begin{tabular}{|c|c|c|c|c|c|c|c|c|c|}
\hline $\begin{array}{c}\text { Mix } \\
\text { Number }^{(a)}\end{array}$ & $\begin{array}{l}\text { Random } \\
\text { Run } \\
\text { Order }^{(b)}\end{array}$ & $\underset{\text { (c) }}{\text { Block }}$ & Simulant & $\begin{array}{l}\text { Sodium } \\
\text { Molarity }\end{array}$ & $\begin{array}{c}\text { Portland } \\
\text { Cement }\end{array}$ & $\begin{array}{l}\text { Fly Ash } \\
\text { Class F }\end{array}$ & $\begin{array}{c}\text { Blast } \\
\text { Furnace } \\
\text { Slag }\end{array}$ & $\begin{array}{c}\text { Dry } \\
\text { Blend } \\
\text { Mix }^{(d)}\end{array}$ & $\begin{array}{c}\text { Water-to-Dry } \\
\text { Blend } \\
\text { Solids Ratio }\end{array}$ \\
\hline $27(3 a)$ & 3 & 1 & Average & 7.8 & Type I/II & NW High Ca & NW & $8: 45: 47$ & 0.60 \\
\hline $28(4 a)$ & 5 & 1 & High Al & 5.0 & Type I/II & NW High Ca & NW & $8: 45: 47$ & 0.40 \\
\hline $29(5 a)$ & 9 & 1 & Average & 7.8 & Type I/II & NW High Ca & SE & $8: 45: 47$ & 0.40 \\
\hline $30(9 a)$ & 10 & 1 & $\mathrm{Hi} \mathrm{Al}$ & 7.8 & Type I/II & NW High Ca & NW & $8: 45: 47$ & 0.60 \\
\hline $31(10 a)$ & 13 & 1 & High $\mathrm{SO}_{4}$ & 5.0 & Type I/II & NW High Ca & $\mathrm{SE}$ & $8: 45: 47$ & 0.60 \\
\hline $32(12 a)$ & 8 & 1 & SST Blend & 5.0 & Type I/II & NW High Ca & NW & $8: 45: 47$ & 0.60 \\
\hline $33(15 a)$ & 17 & 2 & High $\mathrm{SO}_{4}$ & 7.8 & Type I/II & NW High Ca & $\mathrm{SE}$ & $8: 45: 47$ & 0.40 \\
\hline 34 (16a) & 22 & 2 & SST Blend & 7.8 & Type I/II & NW High Ca & $\mathrm{SE}$ & $8: 45: 47$ & 0.40 \\
\hline $35(20 a)$ & 24 & 2 & Average & 5.0 & Type I/II & NW High Ca & NW & $8: 45: 47$ & 0.40 \\
\hline $36(22 a)$ & 19 & 2 & Average & 7.8 & Type I/II & NW High Ca & NW & $8: 45: 47$ & 0.60 \\
\hline $37(24 a)$ & 26 & 2 & High Al & 5.0 & Type I/II & NW High Ca & $\mathrm{SE}$ & $8: 45: 47$ & 0.60 \\
\hline $38(25 a)$ & 21 & 2 & High $\mathrm{SO}_{4}$ & 7.8 & Type I/II & NW High Ca & $\mathrm{SE}$ & $8: 45: 47$ & 0.40 \\
\hline
\end{tabular}

(a) The mis-batched mixes were numbered 27-38. Following those numbers in parentheses are the original intended mix numbers followed by an "a", so that the relationship to the intended mix numbers is clear. Mix numbers with the same symbols are replicates.

(b) The random run order used for Mixes 27-38 (3a, 4a, .., 25a) tested by SRNL were the same as for Mixes 3, 4, .., 25 tested by PNNL.

(c) The mis-batched mixes were run in the original Block 1 and Block 2 sets of tests.

(d) $8 \mathrm{wt} \%$ cement: $45 \mathrm{wt} \%$ fly ash, $47 \mathrm{wt} \%$ blast furnace slag. 

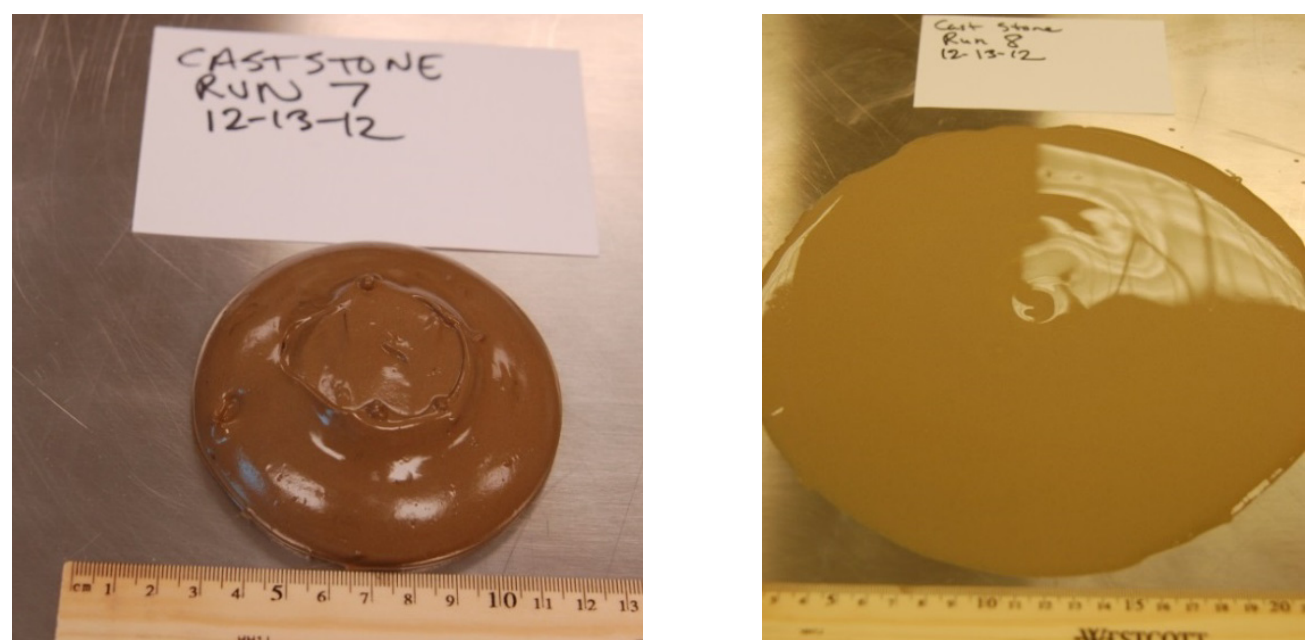

Figure 6-1. Flow Consistency for Cast Stone Mixes with the Smallest (Mix 1) and Largest (Mix 12) Flow Diameters 


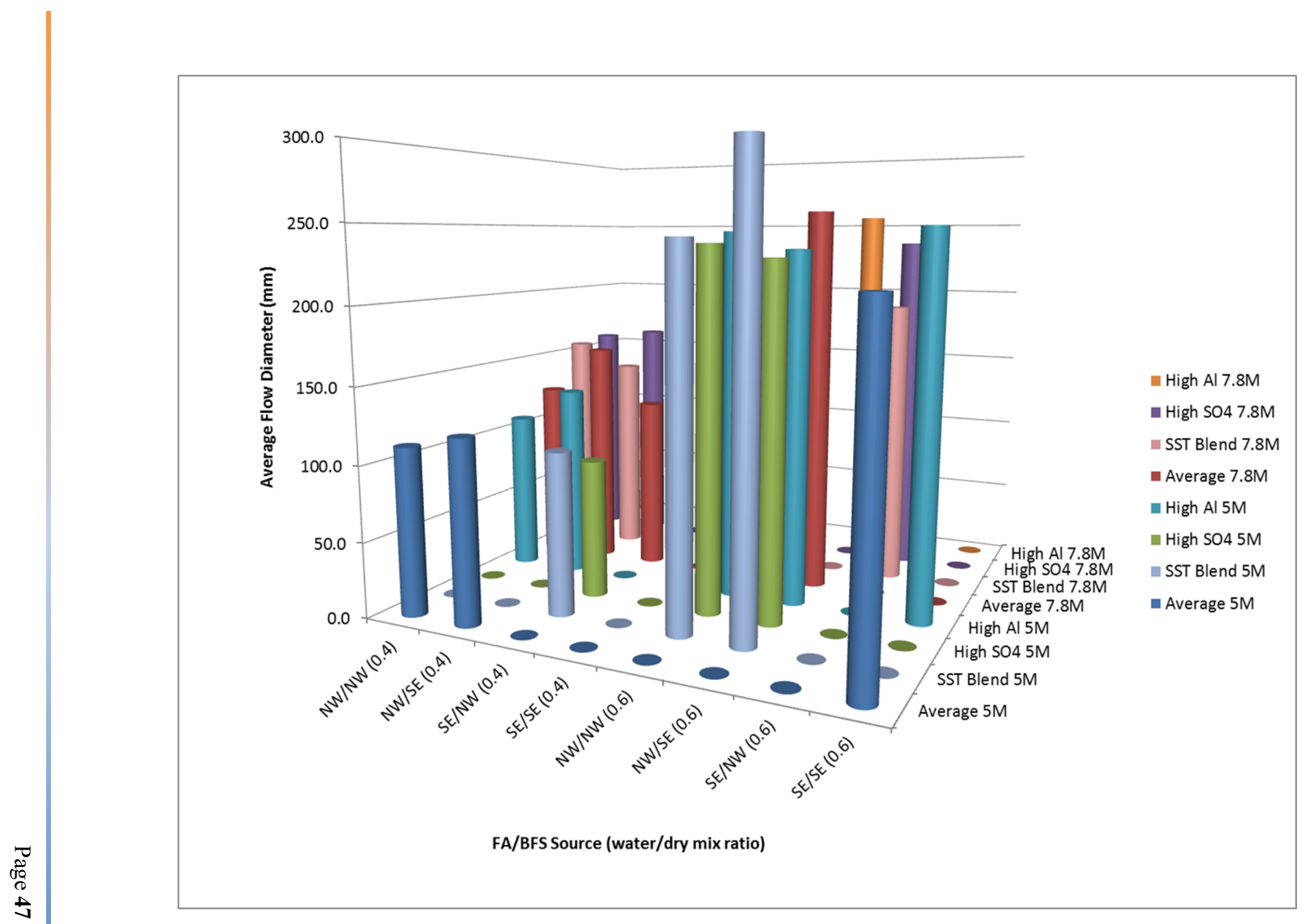

Figure 6-2. Average Flow Diameters for 38 Cast Stone Mixes 
PNNL-22747

SRNL-STI-2013-00465

\section{2 $\underline{\text { Gel Time }}$}

Gel time is a subjective method of determining the duration of slurry flowability. In a continuous process, the gel time is an indication of the time after an interruption in Cast Stone production that is available to restart the process before it becomes necessary to perform a cleanup/shutdown sequence. Gel time is also an indication of how long the placed Cast Stone (in a waste container) can maintain flowability to reach the boundaries of the waste container. However, formulations with gel times greater than the time necessary to reach the boundaries of the waste container have the potential for settling of the denser components - cement and slag-resulting in a layered waste form. Cozzi and Pickenheim (2012) evaluated saltstone grout mixes prepared with greater than normal water content and cast into standing water. Densities of cast cylinders were cut into sections and were measured individually to determine the effect of excess water on settling. Samples prepared with excess water and cast into standing water resulted in density gradients of approximately $10 \%$ through the 4 -in. samples with a trend of decreasing density from the bottom section of the cylinder to the top. Cylinders prepared with typical water content of $0.6-0.64$ water/dry mix ratio showed density variation of $1 \%$ or less.

\subsubsection{Gel Time Approach}

Gel time was measured by partially filling a series of $\sim 100 \mathrm{ml}$ containers (\#VL25H, LAContainer, Yorba Linda, CA) with fresh Cast Stone slurry. After 5 to 10 minutes, a container was deliberately poured out and the flowability was evaluated. This process continued, with the time interval determined by the flowability of the prior pour, until the Cast Stone would no longer flow from the container when tilted to the pouring position. For each of the mixes prepared, five vials were approximately $75 \%$ filled with fresh Cast Stone slurry, and a timer was started. The initial pour time was determined by the operator based on the flow consistency measurement as described in Section 6.1. Subsequent pour intervals were determined by the operator based on the observed flowability in the previous pour.

\subsubsection{Gel Time Results}

Measured gel times for the 38 Cast Stone mixes (Table C-1) ranged from 1 minute to more than 2 hours (see Figure 6-3). For Mix 22, the gel test could not be completed with the number of samples available. The pours gave the operator the sense of gelation, but the mix continued to pour, leaving insufficient material to attain gel. With the exception of some overlap at the gel time of 15 minutes, mixes prepared with a water-to-dry-blend solids ratio of 0.60 exhibited longer gel times than mixes prepared with a water-to-dry-blend solids ratio of 0.40 . Gel times tended to be highest for the $0.6 \mathrm{mix}$ ratio and the $7.8 \mathrm{M}$ simulant concentrations. The results are tabulated in Table C-4 of Appendix C.

\subsection{Set or Hardening Time}

Set time is measured by ASTM C191 Standard Test Methods for Time of Setting of Hydraulic Cement by Vicat Needle (ASTM C191 2008). A modified version of the final set described in the ASTM procedure was used to allow for up to $2 \mathrm{~mm}$ of penetration; the initial set is not currently used for Saltstone waste forms. The measurement time unit for the Cast Stone mixes was in days rather than minutes as in the ASTM procedure due to the retardation of the hydration reactions caused by the high concentrations of salts in the solutions being solidified. The set time of Saltsone was initially used to determine the time required between pours to prevent excessive hydraulic head on the vault walls at the SRS Saltsone Disposal Facility. The set time has since been used for estimating material at risk for deflagration calculations. Set time corresponds to the development of structure from hydration reactions and may be used as a process control point for 


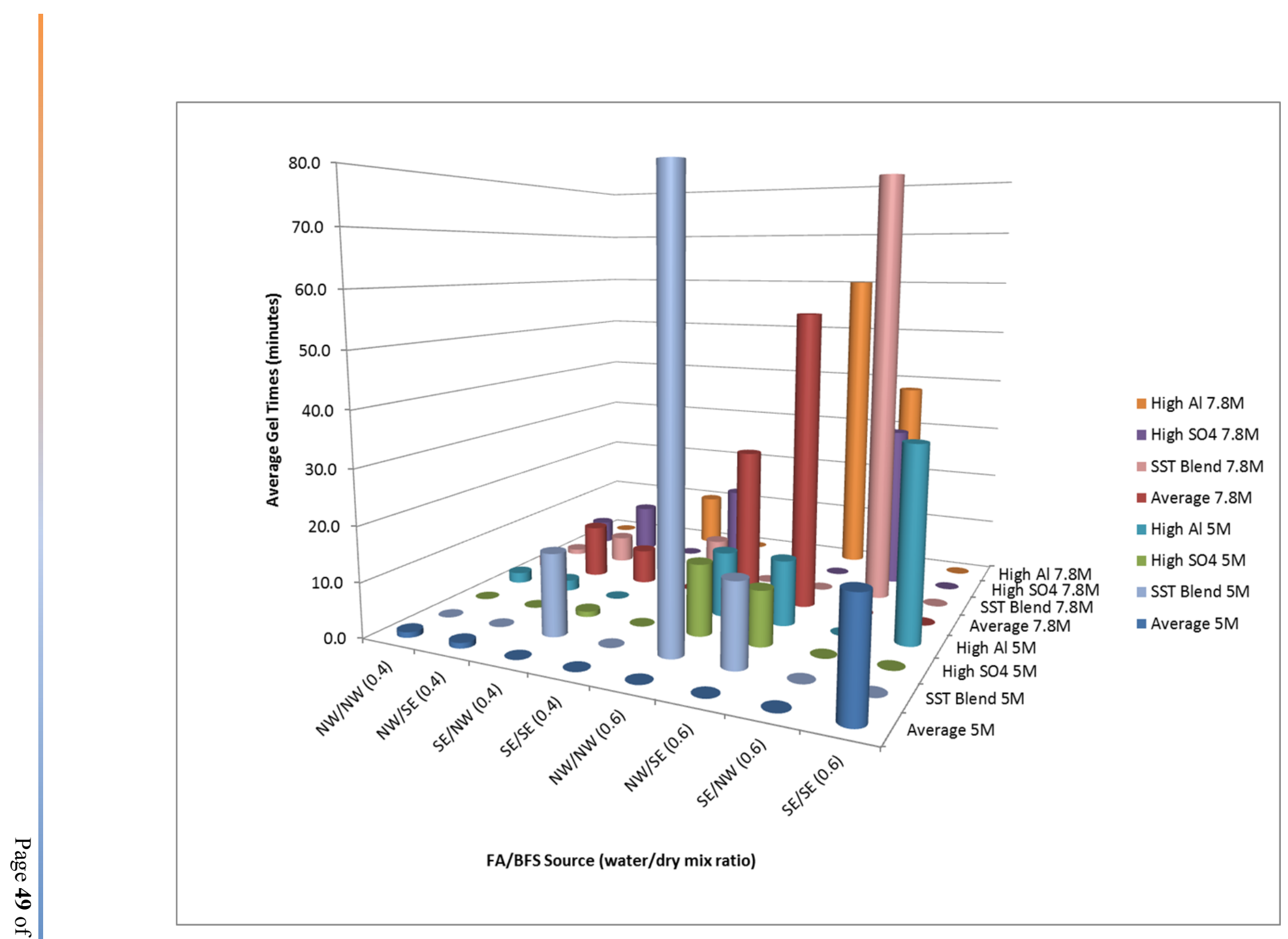

Figure 6-3. Gel Times for 38 Cast Stone Mixes 
allowing the movement of Cast Stone waste packages from the production facility to interim storage or the disposal facility. The gel time and set time are milestones that occur during the curing of cementitious materials. Both provide an indication of the extent to which the curing process has progressed at that point in time. Because curing continues as long as there is humidity and unreacted material available, the term "curing" or "cured" only have meaning when defined for the specific use.

\subsubsection{Set or Hardening Time Approach}

To measure the set time of a Cast Stone waste form, fresh slurry is cast into a container to a depth of approximately $35 \mathrm{~mm}$ and the cast time is noted. The container is sealed and placed in a ziptop bag with a moistened towel to provide a humid environment. Each day, the sample is removed from the bag and the needle penetration is measured with a Vicat tester (\#H-3050, Humboldt Mfg. Co., Schiller Park, IL). When the needle penetration is $<2 \mathrm{~mm}$, the sample is defined as set, and the time is noted. The set time is the elapsed time between the cast and set time.

In an effort to correlate the set time to other Cast Stone properties, slurry samples were cast into a mold for monitoring ultrasonic pulse velocity (UPV). A Pundit Lab meter (Proceq USA, Aliquippa, PA) (see Figure 6-4) was used to monitor the pulse velocity of an ultrasonic sound wave passed through a freshly cast sample. Two 150-kHz transducers (a transmitter and a receiver) were butted up against polycarbonate sheets separated by a rubber mold (see Figure 6-5). A standard polycarbonate cylinder with a known time of flight was used to calibrate and check the meter and transducer system (see Figure 6-6). The sample distance was corrected for the thickness and attenuation of the polycarbonate sheets. An ultrasonic couplant was used on the transducer ends to ensure a continuous path through the sample. When the sample for Vicat testing was cast, the UPV mold was filled with fresh slurry. The Proceq Pundit Lab meter was set with a pulse amplitude of $500 \mathrm{~V}$. After casting, a sampling frequency of 1 second was used for the initial 10 velocity measurements. The sampling frequency was then reduced to 10 minutes for the remainder of the test. With each Vicat penetration test, the UPV through the sample was logged. The Cast Stone was declared set via the Vicat test when the penetration was $2 \mathrm{~mm}$ or less, then the velocity sampling frequency was reduced to 1 second for 10 iterations and the UPV run was terminated. The ultrasound velocity system was then checked with a calibration polycarbonate cylinder with a known travel time.

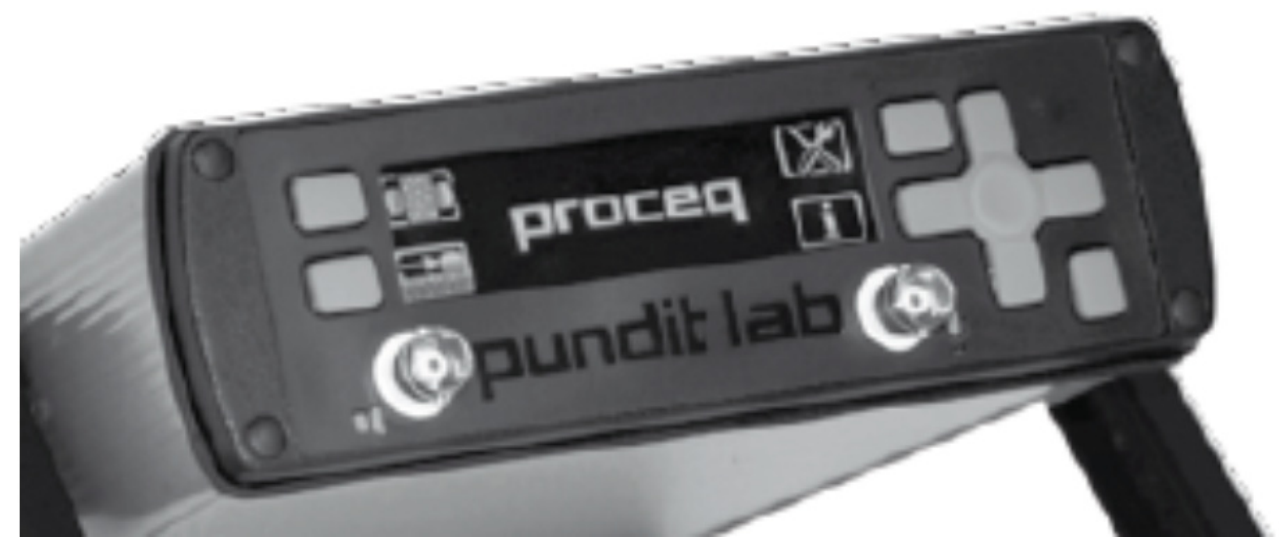

Figure 6-4. Proceq Pundit Lab Meter 
PNNL-22747

SRNL-STI-2013-00465

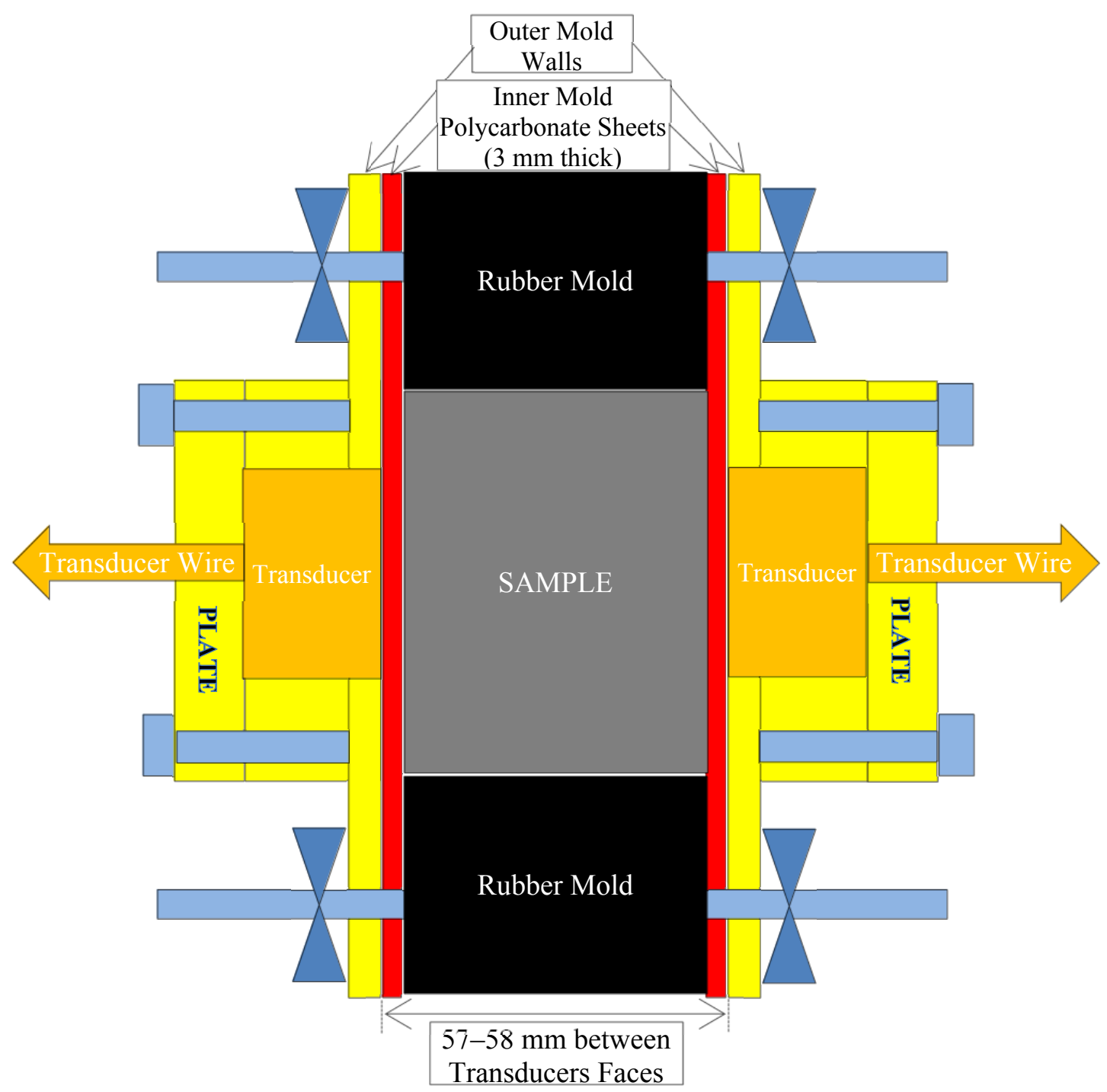

Figure 6-5. UPV Mold

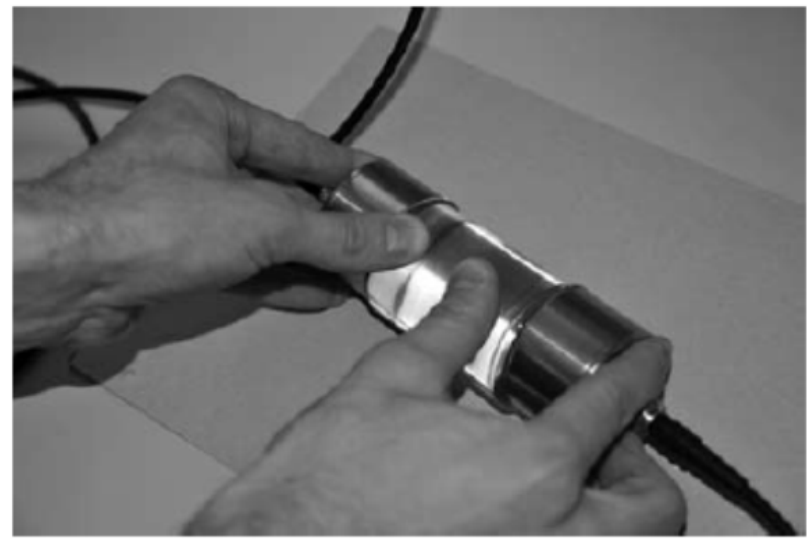

Figure 6-6. UPV Calibration Rod 
PNNL-22747

SRNL-STI-2013-00465

\subsubsection{Set or Hardening Time Results}

A representative UPV measurement is shown in Figure 6-7. Also on the plot are the Vicat results when it was noted that the sonic velocity was increasing. The two points plotted show the penetration of the needle fully extending to $35 \mathrm{~mm}$ at 24.7 hours and not penetrating at 28.8 hours, indicating "set." The UPV generally rises, levels out, and then may rise again. It is believed the UPV measurements can be related to the Vicat measurements by performing special runs where the Vicat measurements are taken every 30 minutes. Either the onset of increased velocity, the inflection in the curve, or the return to a level signal corresponds to setting characteristics and also isothermal calorimeter events. The qualitative evidence implies that there is a set velocity corresponding to the Vicat set indication. This hypothesis could be validated with more planned experiments where Vicat measurements are taken frequently to capture its curve. The remaining UPV traces with the associated Vicat data are in Section C.3 of Appendix C.

The pulse velocity of the fresh Cast Stone mixes was significantly lower than the pulse velocity of either the simulant salt solution or the set Cast Stone. Robeyst (2008) calculates the impact of dissolved or entrained air on the measurement of the UPV. The impact of entrained air on the UPV or P-wave velocity measurement for cement paste is shown in Figure 6-8. This figure illustrates that a small change in the entrained air results in a significant change in the P-wave velocity or UPV. Similar calculations were performed for the SRS saltstone mixes using a bulk modulus of the salt solution calculated from the equation reported by de Korte and Brouwers (2011) using the measured density and sound velocity of the salt solution (Cozzi et al. 2013):

$$
K=c^{2} \cdot \rho
$$

where $K$ is the bulk modulus, $\mathrm{Pa}$; $c$ is the velocity of sound, $\mathrm{m} / \mathrm{s} ; \rho$ is the density of mix, $\mathrm{kg} / \mathrm{m}^{3}$; and an estimate of the bulk modulus for the premix of $30 \mathrm{GPa}$. Figure 6-9 is the calculated effect of entrained air on the clean cap and saltstone mixes using the equations from de Korte (2011):

$$
c_{e}^{2}=\left[\left(\varphi_{t} \frac{1}{K_{f}}+\left(1-\varphi_{t}\right) \frac{1}{K_{S}}\right) \times\left(\frac{\rho_{f}\left(\rho_{s}\left(\varphi_{t}+\left(1-\varphi_{t}\right) S\right)+\rho_{f} S \varphi_{t}\right)}{\rho_{s} \varphi_{t}^{2}+\rho_{f}\left(S+\varphi_{t}\left(1-\varphi_{t}\right)\right)}\right)\right]^{-1}
$$

where $c_{e}$ is the effective wave velocity and $\rho$ is the density with the subscript " $\mathrm{f}$ " referring to the fluid, "s" to the solid, and $\phi_{t}$ to the fluid volume fractions, respectively. The parameter, $\mathrm{S}$, is a shape factor approximated for spherical particles by the equation from de Korte and Brouwers (2011) by

$$
S=\frac{1}{2}\left(\frac{1+2\left(1-\varphi_{t}\right)}{\varphi_{t}}\right)
$$




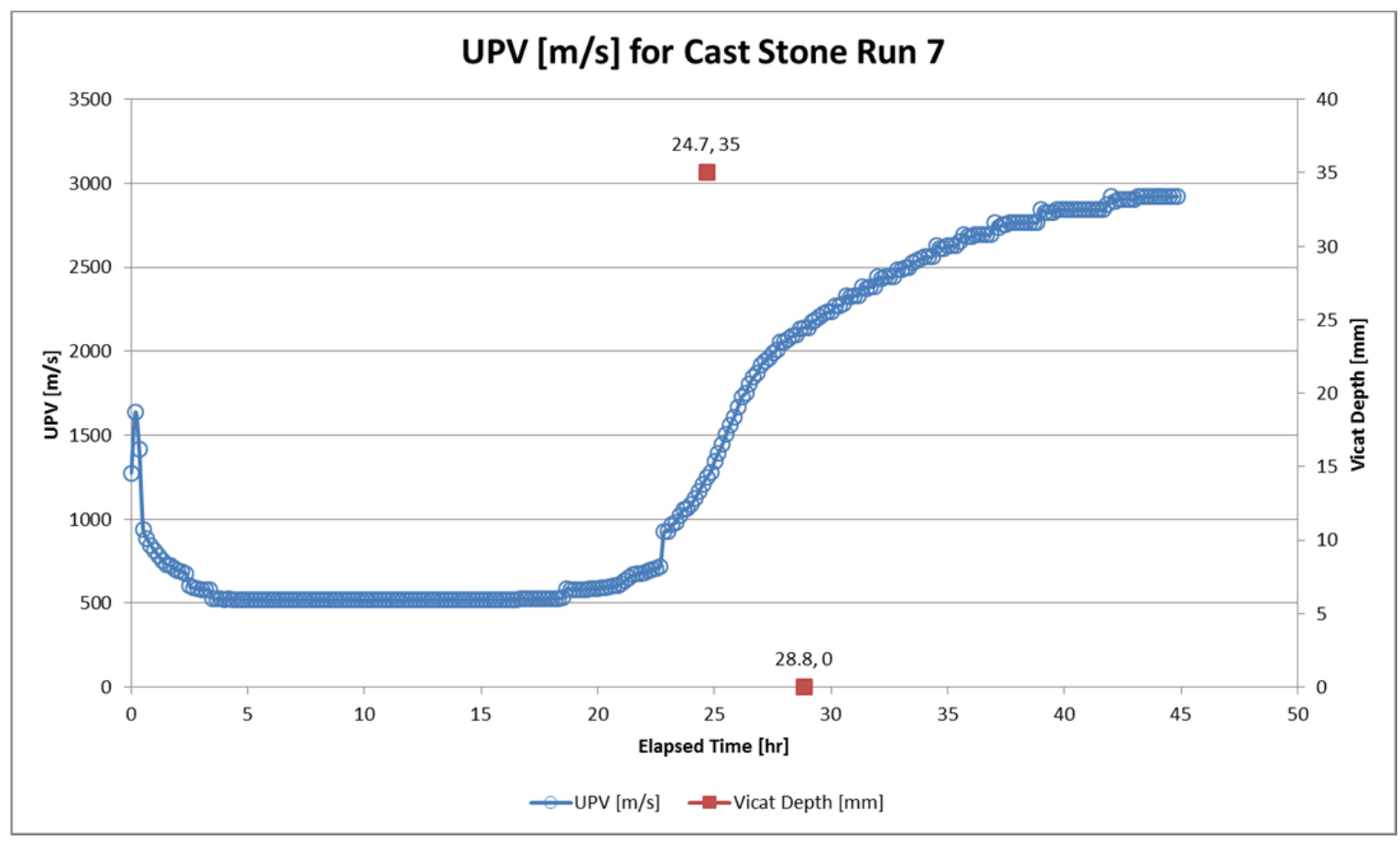

Figure 6-7. Representative UPV Data for Mix 1, RR 7

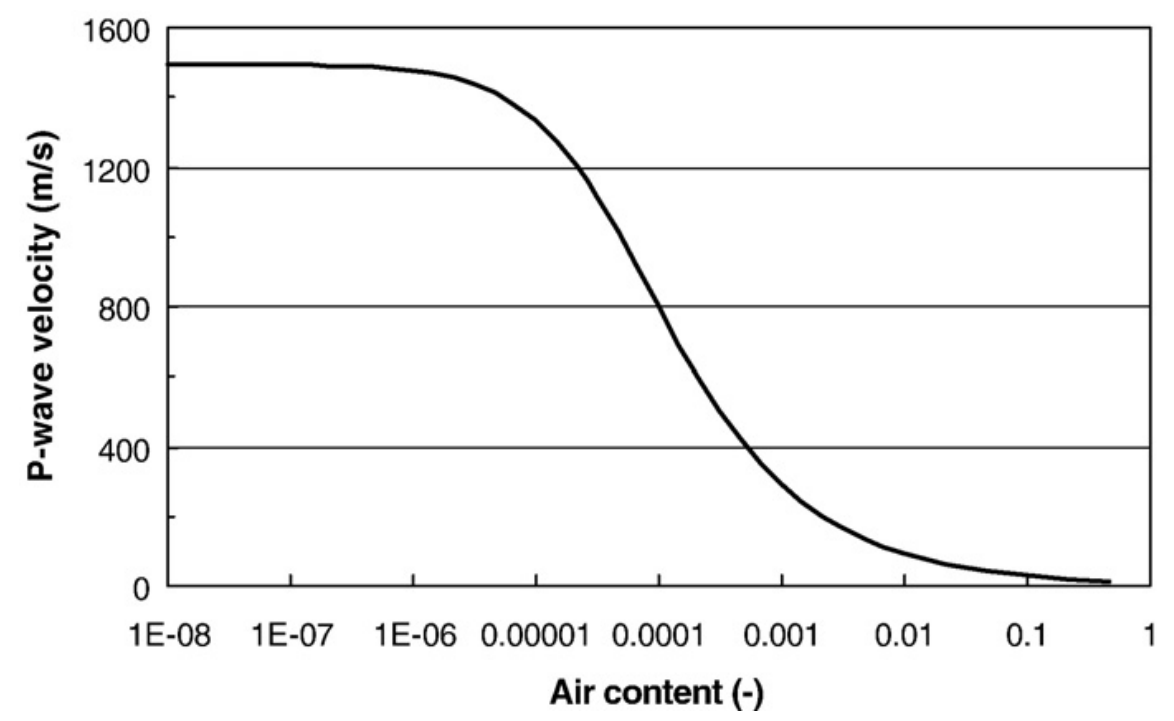

Figure 6-8. Change in UPV or P-Wave Velocity in Cement Paste $(W / C=0.5)($ Robeyst 2008) 


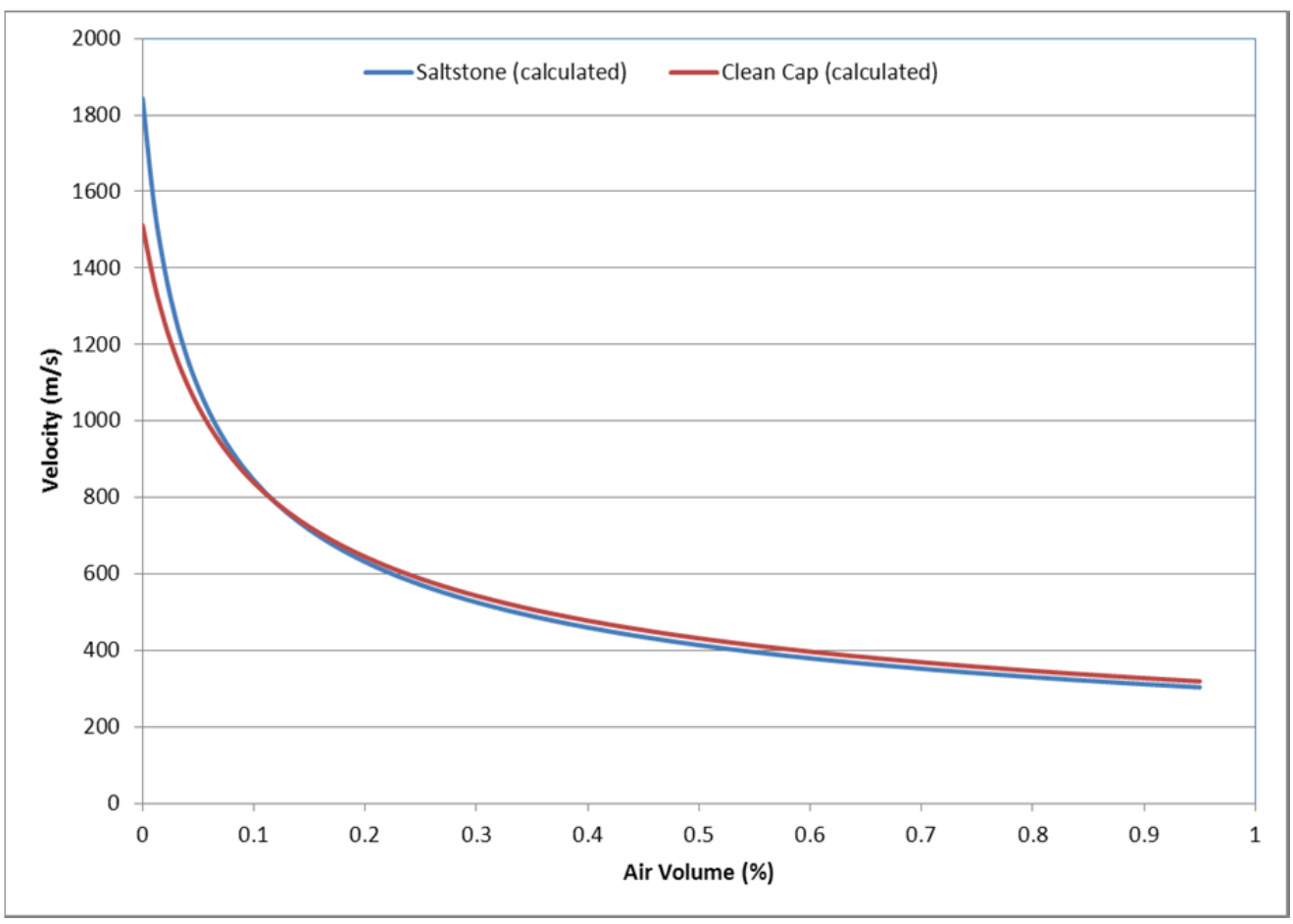

Figure 6-9. Calculated Effect of Volume of Entrained Air on Sound Velocity

\subsection{Slurry Rheology}

Rheological properties of freshly prepared Cast Stone specimens were measured using two different methods, shear stress as a function of shear rate and yield stress. For the first method, a Haake VT550 rotoviscometer was used to measure the flow properties of the Cast Stone slurry. The VT550 was used to obtain a flow curve (shear stress versus shear rate data) using a concentric geometry bob and cup. The data were analyzed using a Bingham Plastic rheological model (Macosko 1994), providing yield stress and plastic viscosity values. The flow curve profile used for this activity was the same one used to assess fresh Saltstone slurries. The second measurement method used a vane and cup configuration (model Haake RS6000, ThermoFisher, Waltham, MA). The vane has been extensively used by SRNL to measure the yield stress of sludges and grouts (Hansen et al. 2012). For these screening tests, the vane/cup configuration was used to determine whether it could assess the changes in the developing stress in the Cast Stone slurry as it cures. This second method is experimental and is still not fully developed.

\subsubsection{Slurry Rheology Approach}

All the flow curves were obtained with a rotoviscometer (Haake VT550, ThermoFisher, Waltham, MA), using the MV2 cylindrical rotor and cup configuration. The MV2 bob was selected given its range of measurement and design (e.g., the only shearing surface is the cylinder itself). The functionality of the VT550 was checked using a National Institute of Standards and Technology (NIST)-traceable N35 Newtonian viscosity oil standard at $25^{\circ} \mathrm{C}$ at the beginning of each day when flow curve measurements were required. The VT550 was considered functional if the resulting flow curve, analyzed as a Newtonian fluid, was within $\pm 10 \%$ of the NIST viscosity value. The flow curve used to quantify the rheological properties of the slurry is shown in Table 6-2. These measurements were obtained at the temperature of the slurry (i.e., the temperature as measured at the end of the mixing activities). This flow curve was developed for 
the Saltstone slurries analyzed by SRNL given gel time issues, hence the short time to obtain the flow curve profile. Potential issues are over-estimating the properties on the up curve and underestimating the properties on the down curve due to the MV2 inertia effects, if the fluid is very thin. However, these issues were not observed for this data set. Thixotropic response was expected, given that some of the slurries will start developing structure when shearing (mixing) stops.

Table 6-2. Flow Curve Profile Using MV2 Geometry

\begin{tabular}{|c|c|c||}
\hline \multicolumn{2}{|c||}{ Shear Rate and Time of Measurement } \\
\hline Up Curve & Hold & Down Curve \\
\hline 0 to $300 \mathrm{~s}^{-1}$ linearly in 2 minutes & $300 \mathrm{~s}^{-1}$ for $30 \mathrm{~seconds}$ & 300 to $0 \mathrm{~s}^{-1}$ linearly in 2 minutes \\
\hline
\end{tabular}

The Haake software converts the rotational rate of the rotating surface of the bob into a shear rate assuming the material being measured is a Newtonian fluid. This shear rate and range are when modeling the flow curve as a Bingham Plastic fluid. Both the up curve and down curve are fitted to the Bingham Plastic model

$$
\tau=\tau_{o}+\eta_{\infty} \dot{\gamma}
$$

where $\quad \tau=$ measured shear stress $(\mathrm{Pa})$

$\tau_{o}=$ Bingham Plastic Yield Stress $(\mathrm{Pa})$

$\eta_{\infty}=$ plastic viscosity $(\mathrm{Pa} \cdot \mathrm{s})$

$\dot{\gamma}=$ shear rate $(1 / \mathrm{s})$.

The Haake RS6000 was used to perform the vane measurements. The functionality of the RS6000 was checked using a NIST-traceable N35 Newtonian viscosity oil standard at $25^{\circ} \mathrm{C}$, using the Z38 bob and cup configuration, at the beginning of each day when vane measurements were required. The RS6000 was considered functional if the resulting flow curve, analyzed as a Newtonian fluid, was within $\pm 10 \%$ of the NIST viscosity value. The vane used in this task was the Haake FL22 vane (Figure 6-10), and the vane was positioned such that all the geometric requirements specified on the left side of Figure 6-10 were satisfied. Unlike normal vane measurements, where the rotational speed can range from 0.01 to 1 revolution per minute (rpm), the vane was rotated at one revolution per hour (rph) for up to two hours. This very slow rotational rate allows for the Cast Stone structure to develop. Measurements were obtained every second. The measurement was stopped when the shear stress reached $200 \mathrm{~Pa}$ or the program reached completion at two hours. The reported yield stress data were related to the gel data, when the Cast Stone was considered gelled. 
PNNL-22747

SRNL-STI-2013-00465

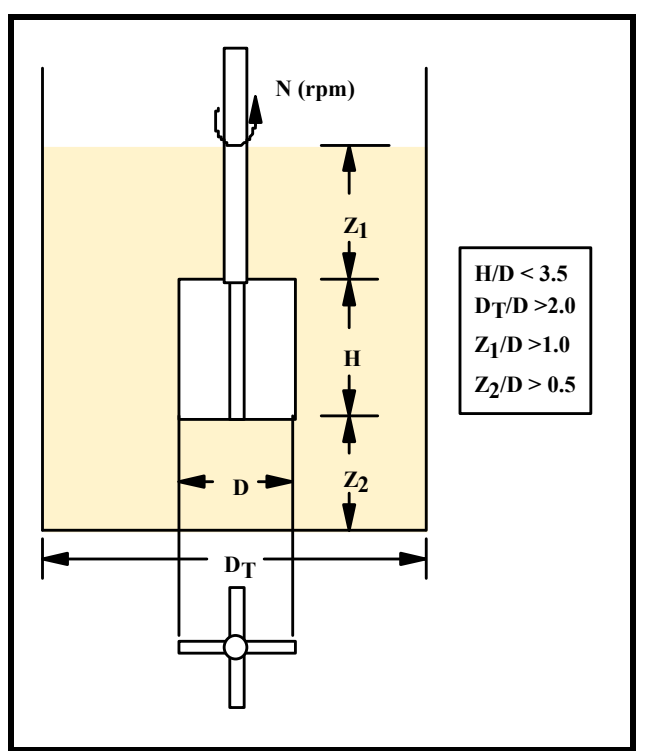

Geometric Requirements

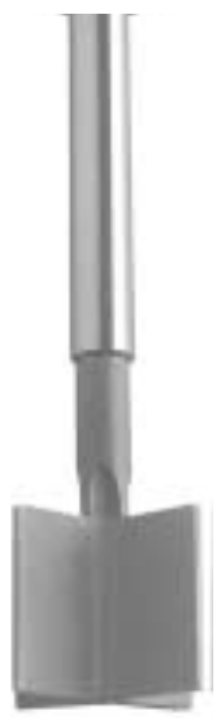

Actual FL-22 Vane

Figure 6-10. Vane Requirements and Actual Vane

\subsubsection{Slurry Rheology Results}

Figure 6-11 shows the plastic viscosity results for the 38 Cast Stone mixes in Table C-1. As expected, the mixes with the 0.4 mix ratio are more viscous than the mixes with the higher water content at a mix ratio of 0.6 . Plastic viscosities were in the range of 220 to 580 centipoise (cP) for the 0.4 mixes and 54 to 165 for the 0.6 mixes. There appears to be a smaller trend with the mixes prepared with the SE fly ash being more viscous than those prepared with the NW fly ash. No data were obtained for Mix 1 because it had set before the test could be completed. Results of the plastic viscosity and yield stress measurements are tabulated in Table C-5 of Appendix C.

Figure 6-12 shows the Bingham Plastic yield stress for the 38 Cast Stone mixes. The mixes with the 0.4 mix ratio generally have higher yield stresses when compared to the mixes with the 0.6 mix ratio. Yield stresses were in the range of 10 to 92 pascals for the 0.4 mixes and 2 to 24 pascals for the 0.6 mixes. The highest yield stresses were associated with the mixes with the 0.4 mix ratio and $5 \mathrm{M}$ sodium simulants.

\subsection{Heat of Hydration}

The isothermal heat of hydration for the Cast Stone mixes was measured in accordance with ASTM C1679, Standard Method for Measuring Hydration Kinetics of Hydraulic Cementitious Mixtures Using Isothermal Calorimetry (ASTM C1679 2009). This measurement is used to compare the hydration kinetics of salt solutions and dry mix blends. Salt solution components can affect either the energy produced during hydration, or to a greater extent, the time frame over which the energy is released. The composition of dry blend components and composition and amount of additives can also affect the magnitude and timing of hydration heat development. In large pours, the energy (heat) produced can alter the mineralogy and microstructure developed in the waste form and influence cured properties. 


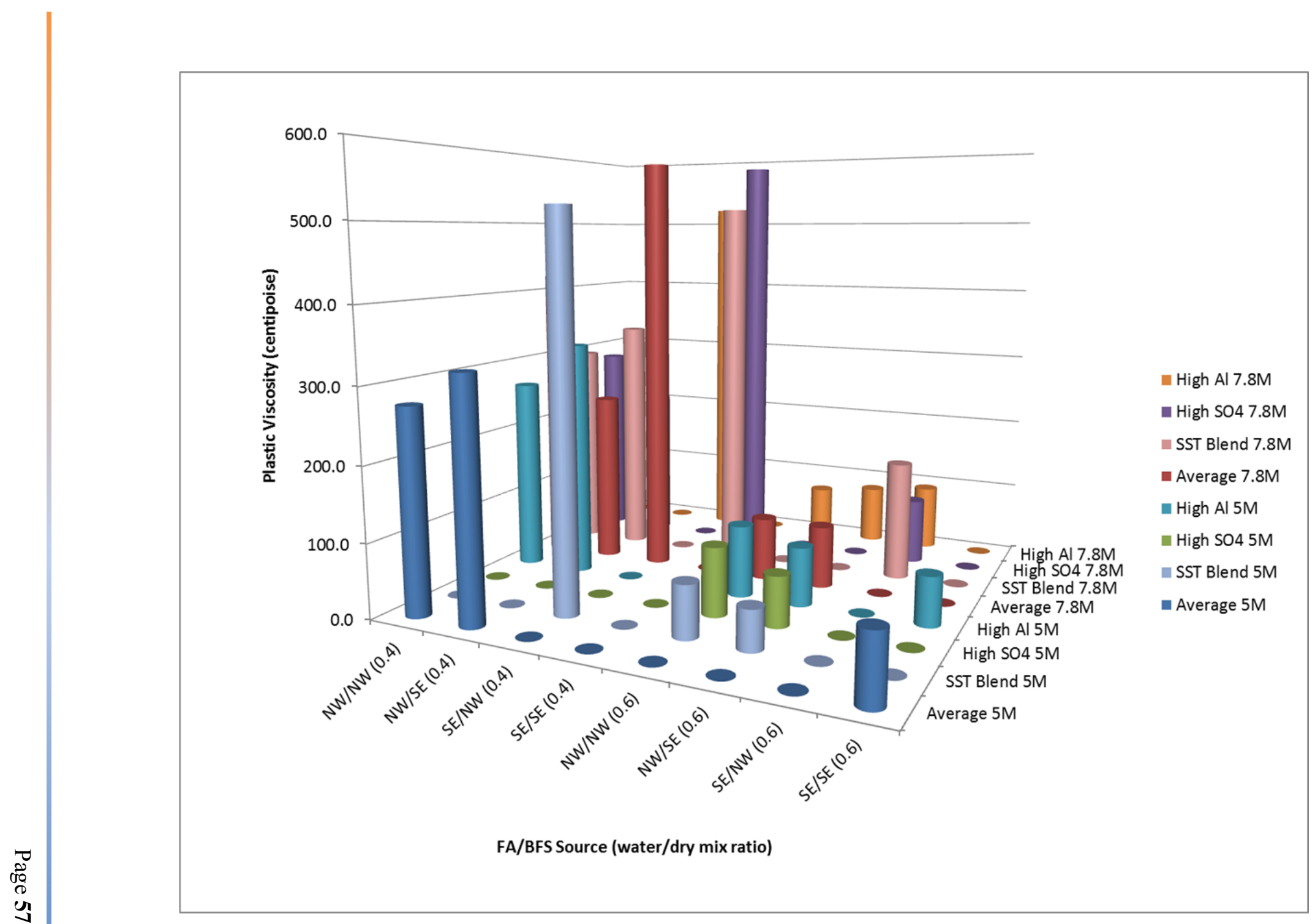

Figure 6-11. Results of Plastic Viscosity Measurements for the 38 Cast Stone Slurries 


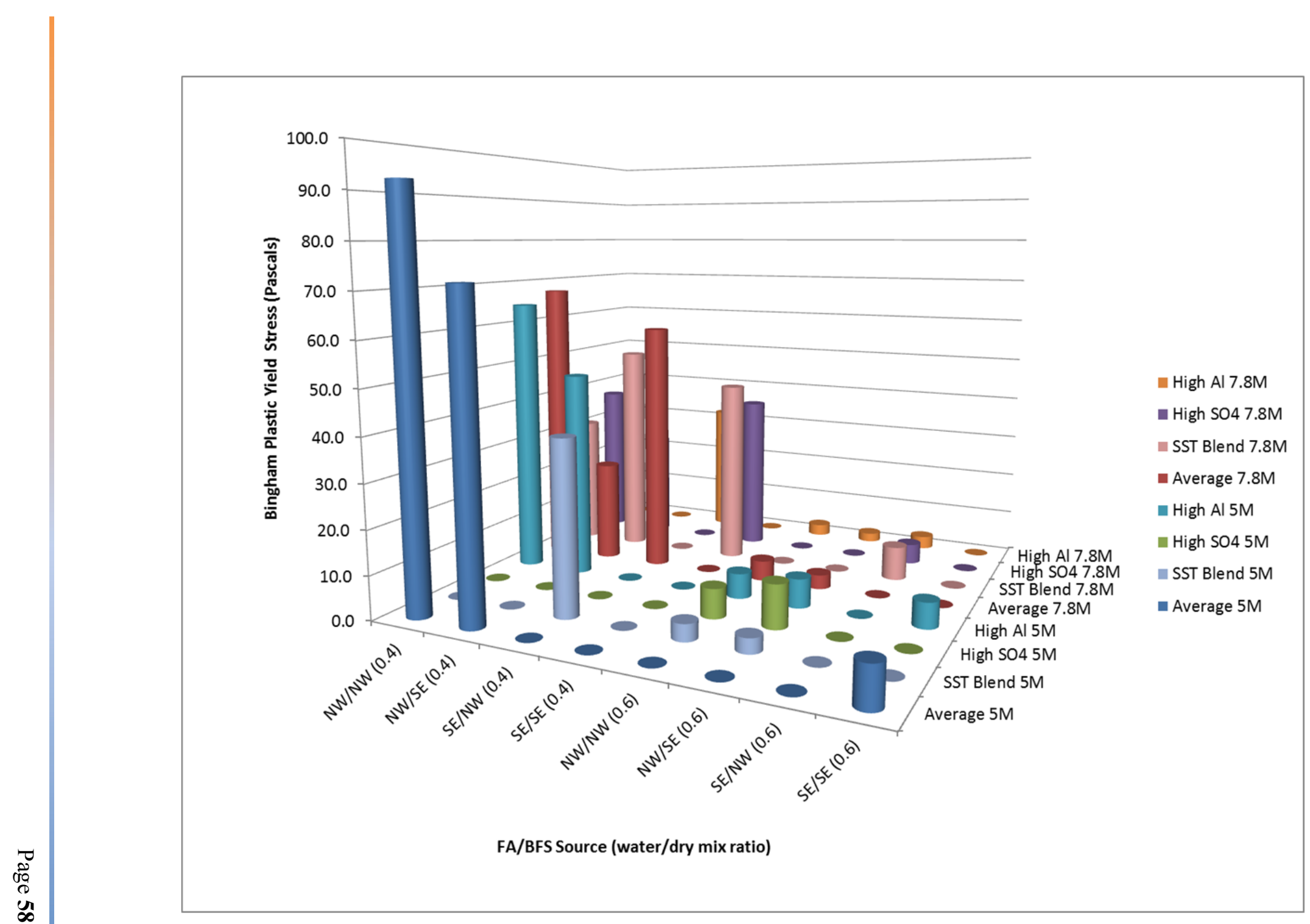

Figure 6-12. Bingham Plastic Yield Stress for the 38 Cast Stone Slurries 


\subsubsection{Heat-of-Hydration Approach}

An eight-channel isothermal calorimeter (TAM Air, TA Instruments, Newcastle, DE) was used to collect the heat generation rate and total energy generated for each of the mixes. Each channel consists of a twin configuration with one side for the sample and the other side for the reference material. Figure 6-13 depicts the configuration of one of the calorimeter channels. The reference ampoule was balanced with $20 \mathrm{~g}$ of quartz sand to approximate the heat capacity of the Cast Stone mixes. The isothermal calorimeter was maintained at $25^{\circ} \mathrm{C}$ for all of the testing.

An 18-g sample (dry blend + salt solution) of each of the Cast Stone screening test compositions was mixed using resonant acoustic mixer (LabRAM, Resodyne ${ }^{\mathrm{TM}}$ Acoustic Mixers, Inc., Butte, MT). After the dry blend was incorporated into the waste simulant solution, the materials were mixed for an additional minute. The mix was transferred to the calorimeter and the test initiated. After 300 hours, the test was terminated. The total energy produced, normalized per gram of dry blend material, was determined at 300 hours. The maximum heat generation rate (heat flow) and the elapsed time to attain this rate were also determined. Figure 6-14 shows examples of total energy and heat flow curves.

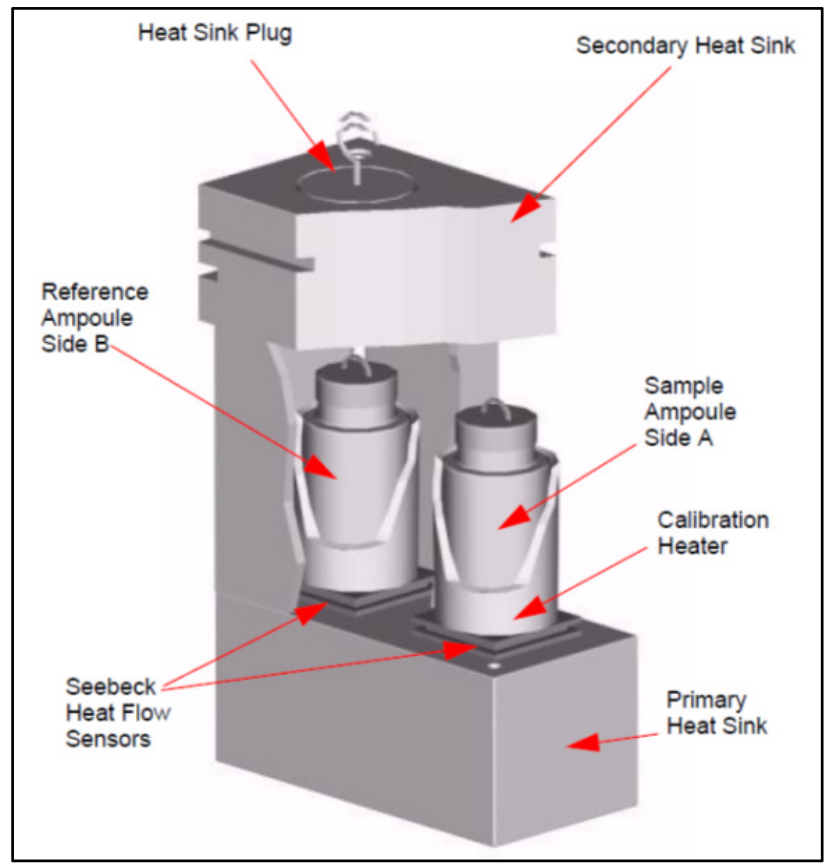

Figure 6-13. Cutaway View of a Single Channel in the Isothermal Calorimeter from TAM Air Manual, TA Instruments. 

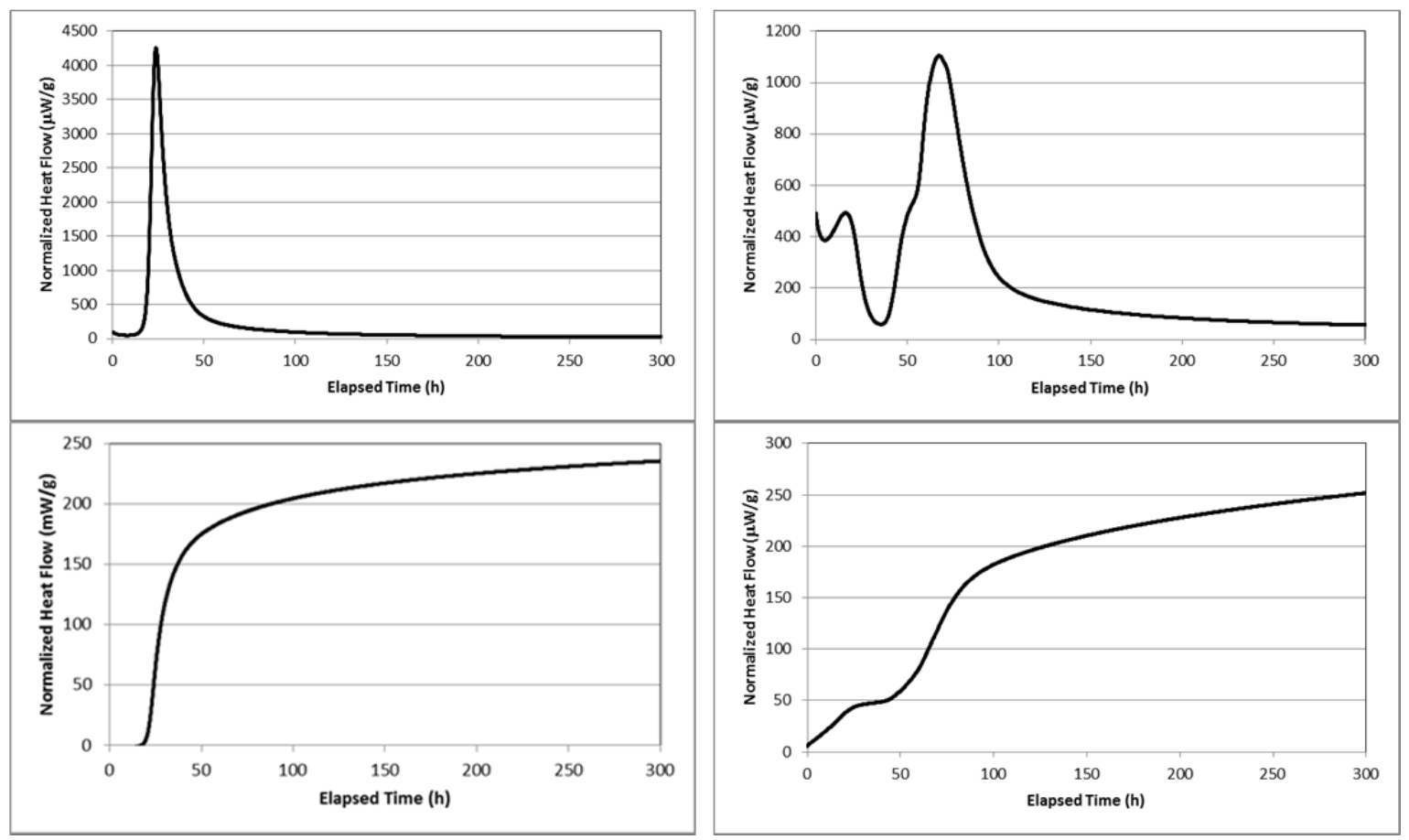

Figure 6-14. Normalized Heat Flow for Two Mixes Analyzed Using Isothermal Calorimetry. Left: Mix 1, RR7; Right: Mix 19, RR15.

\subsubsection{Heat-of-Hydration Results}

The heat-of-hydration results include the total energy generated over 300 hours of testing, the maximum heat flow, and the elapsed time to reach the maximum heat flow. These properties are referred to as "Heat Generation at 300 Hours", "Heat Generation at Peak", and "Time to Peak Heat Generation" in the balance of the report. The heat generation results for the 38 Cast Stone mixes are tabulated in Table C-8 of Appendix C. Figure 6-15 shows the heat generated over the 300 hours for the 38 Cast Stone mixes. The heat generated was in the range of 150 to 434 joules/gram $(\mathrm{J} / \mathrm{g})$ of dry blend material. There appears to be a trend of higher heat generation for the 0.6 mix ratio mixes compared with the 0.4 mix ratio mixes. Figure 6-16 shows the time to reach the peak heat generation rate. The time to peak ranged from 16 to 164 hours.

\subsection{Fresh Density}

The density of freshly prepared Cast Stone was measured with mini weight per gallon sample cups (model \#WG-SS-8.32, Gardco, Pompano Beach, FL) using a simplified ASTM D1475, Standard Test Method For Density of Liquid Coatings, Inks, and Related Products (ASTM D1475 1998). The density of fresh grout can also be calculated from density measurements of the individual dry materials and the salt solution and the known percentages of each component in the final mix. However, the fresh density can be affected by air entrainment; thus, the actual measurement is made using the ASTM D1475 method. 


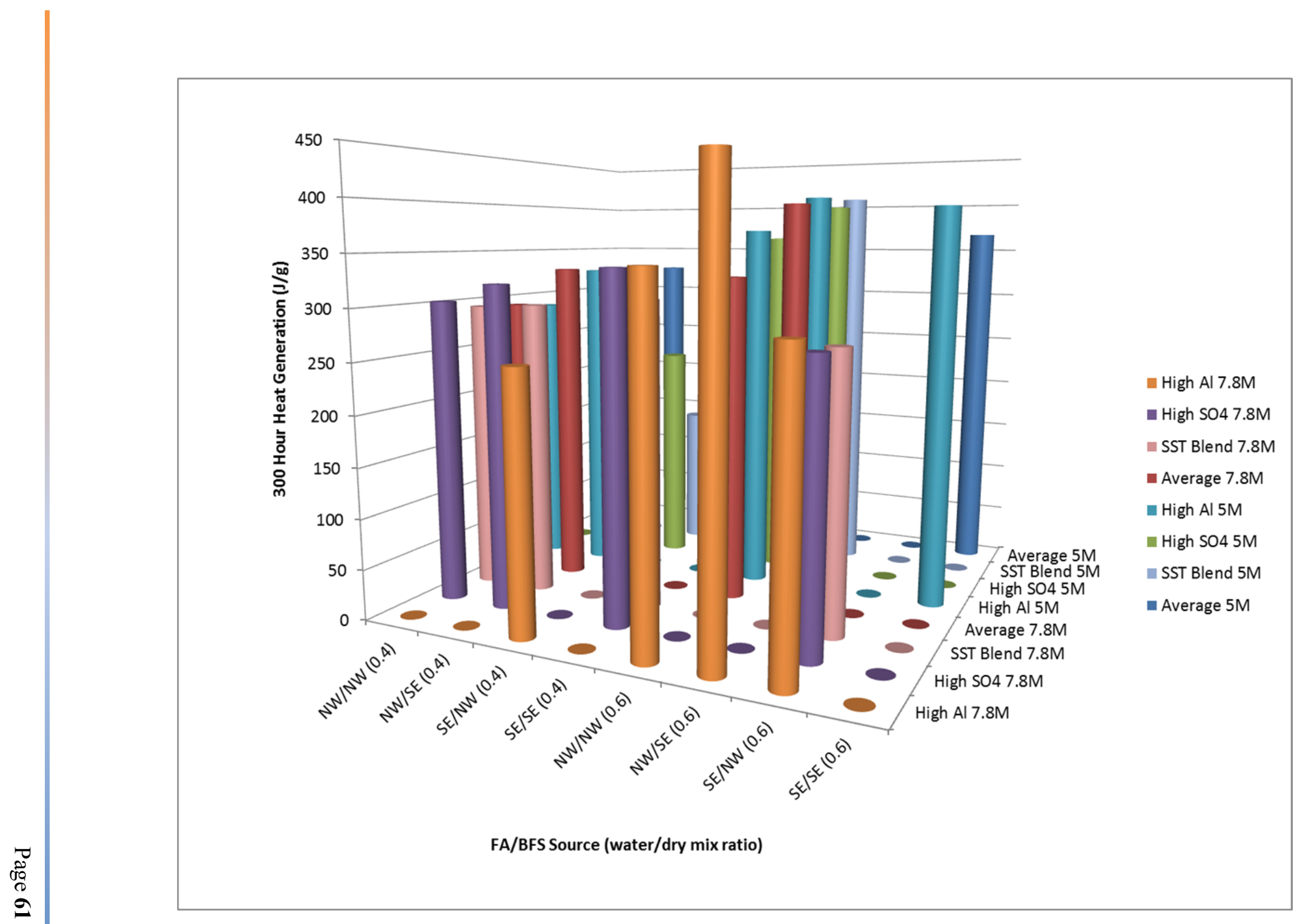

Figure 6-15. Heat Generation at 300 Hours (J/g) for 38 Cast Stone Mixes 


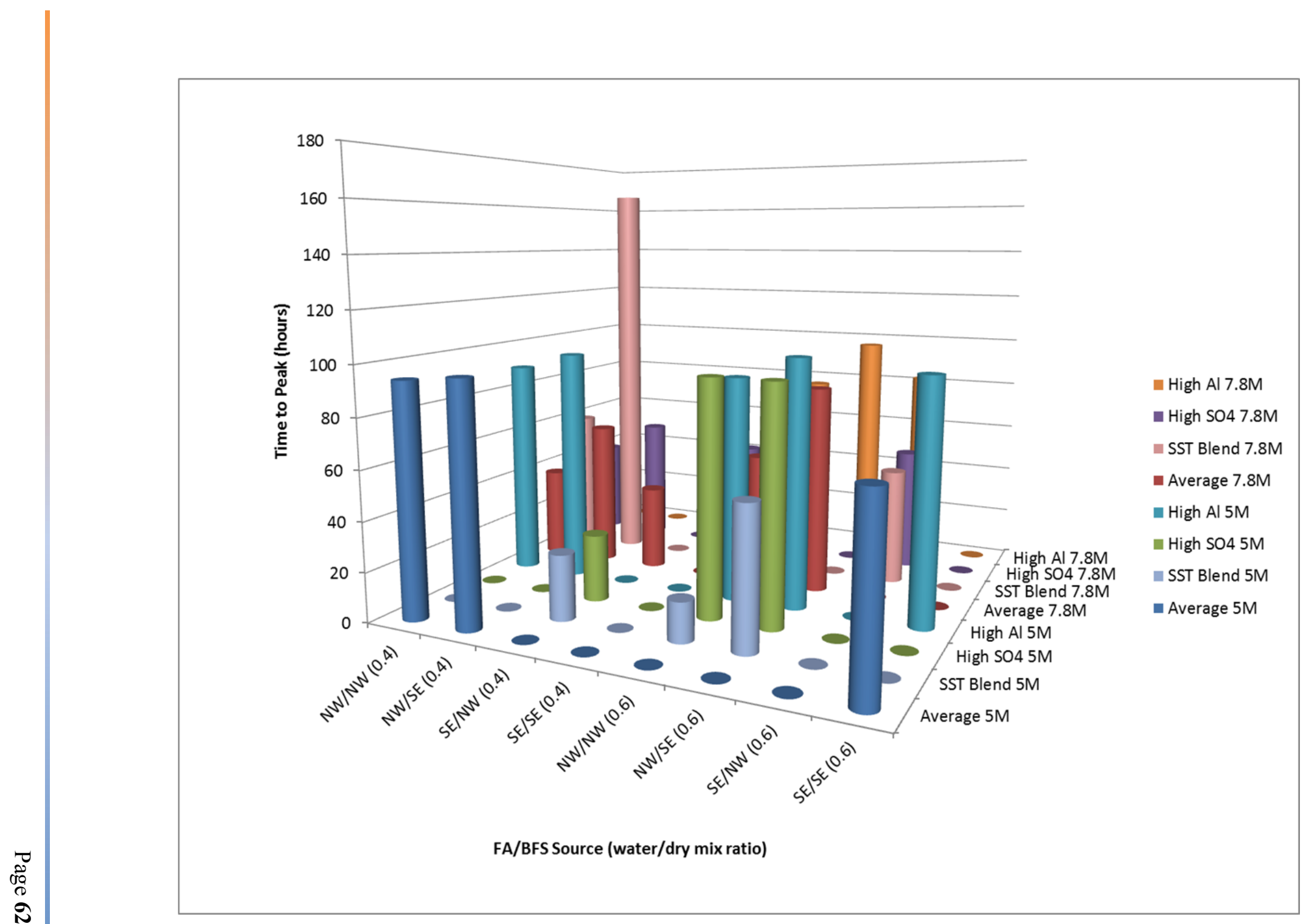

Figure 6-16. Time to Peak Heat Generation (hours) for 38 Cast Stone Mixes 
PNNL-22747

SRNL-STI-2013-00465

\subsubsection{Fresh Density Approach}

Prior to testing, the volume of the sample cup was verified with ASTM Type I water at room temperature following the calibration steps in the ASTM D1475 method. After the initial calibration check, only the tare weight of the cup was recorded assuming that the volume of the stainless steel cup remained constant throughout the testing period.

To measure the fresh density, the sample cup was filled with fresh slurry to form a meniscus. The container was capped and the excess material expressed from the overflow was wiped away. The sample cup was wiped to remove any material from the outer surfaces and then was placed on a balance to obtain the mass of the sample. The fresh density is calculated from the mass of the sample divided by the known volume of the sample cup using the equation

$$
\rho=\frac{W-w}{V}
$$

where

$$
\begin{aligned}
\rho & =\text { density of the fresh slurry, } \mathrm{g} / \mathrm{ml} \\
\mathrm{W} & =\text { mass of the filled sample cup, } \mathrm{g} \\
\mathrm{W} & =\text { mass of the empty sample cup, } \mathrm{g} \\
\mathrm{V} & =\text { volume of the sample cup, ml. }
\end{aligned}
$$

\subsubsection{Fresh Density Results}

Figure 6-17 shows the measured fresh densities for the 38 Cast Stone mixes in Table C-1. The results are tabulated in Table C- 9 of Appendix C. The fresh densities are highest for the 0.4 mix ratio mixes and are in the range of 1.87 to $1.96 \mathrm{~g} / \mathrm{cm}^{3}$. Fresh densities for the 0.6 mix ratio mixes are in the range of 1.73 to $1.83 \mathrm{~g} / \mathrm{cm}^{3}$.

\subsection{Free Liquids}

Free liquids (standing water) were determined by measuring the residual liquid remaining after predetermined curing time periods, typically 24 hours and 3 days. The volume of the liquid was calculated from the mass of the recoverable liquid. The density of the liquid was either measured or assumed to be the same as the waste simulant salt solution used to prepare the Cast Stone mix. The density of standing water remaining after 3 days was previously determined to be similar to that of the initial salt solution (Hansen et al. 2006). The standing water calculation is reported as the volume of fluid collected over the volume of hardened Cast Stone. The presence of standing water is a preliminary indication that settling may have occurred within the mix. This may or may not be an indication of preferential settling (segregation). The standing water generally is reabsorbed into the Cast Stone waste form with time (e.g., within a few days).

\subsubsection{Free Liquids Approach}

The method ASTM C232 Standard Test Methods for Bleeding of Concrete (ASTM C232 2004) was modified to accommodate the smaller test samples available and the longer time associated with gel and set. To measure the residual free liquids for the prepared Cast Stone slurries, fresh slurry was poured into two 100-ml snap-top vials (\#VL25H, LA Container, Yorba Linda, CA) to approximately three-quarters full. If the slurry did not self-level, the vial was tapped to level the surface. The vials were capped and placed in a zip-top bag with a moist cloth to mitigate evaporation. The bagged vials were set upright to maintain a level surface. After approximately 24 hours of setting, the vials were removed from the bag and inspected for free liquids. If liquid 


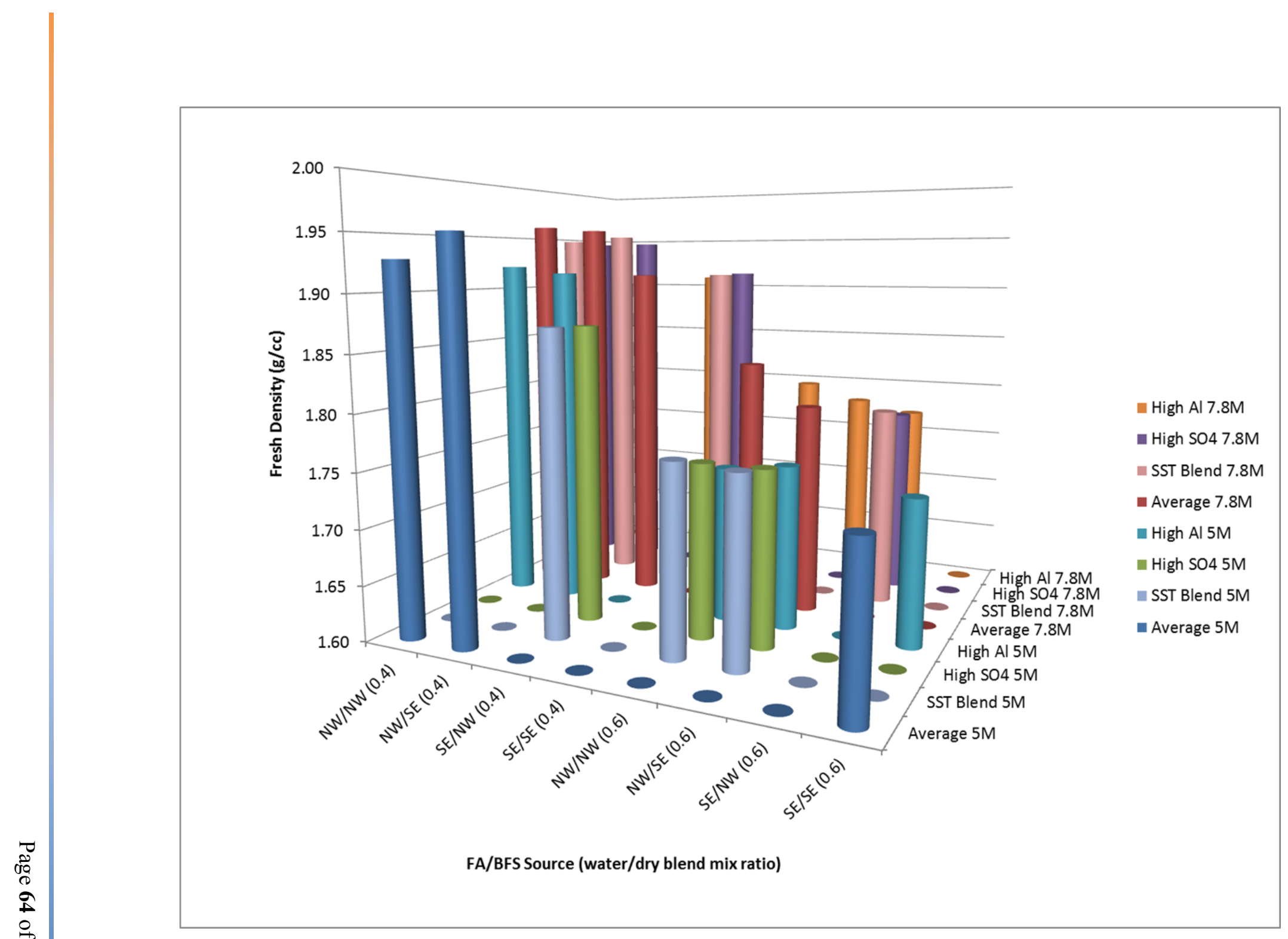

Figure 6-17. Fresh Densities for 38 Cast Stone Mixes

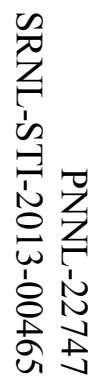


was present, the vial was wiped dry and weighed. A tared pipette was used to draw off the free liquid. The pipette was weighed with the liquid. The liquid was returned to the vial and the vial was reweighed, capped, and returned to the bag. The process was repeated after an additional 2 days of setting ( 3 days from casting).

\subsubsection{Free Liquids Results}

Five of the 38 screening test mixes prepared resulted in samples with free liquids after 24 hours. Three of the mixes (Mixes 17, 23, and 32) all produced free liquid that persisted to 3 days. Free liquids generated by the other two mixes were reabsorbed between the 1-day and 3-day measurement. Table 6-3 shows the free liquid results for the five mixes generated from duplicate samples cast from the same mix after 1 and 3 days of setting. The full set of data for all 38 mixes is listed in Table C-10 of Appendix C.

Table 6-3. Cast Stone Mixes Generating Free Liquids

\begin{tabular}{|c|c|c|c|c|c|}
\hline \multirow{2}{*}{ Mix Number } & \multirow{2}{*}{$\begin{array}{c}\text { Random Run } \\
\text { Order }\end{array}$} & \multicolumn{4}{|c|}{ Free Liquid (Vol\%) } \\
\cline { 3 - 6 } & & \multicolumn{3}{|c|}{ Day 1 } & \multicolumn{2}{c|}{ Day 3 } \\
\cline { 3 - 6 } & 29 & 1.09 & 1.11 & 0.00 & 0.00 \\
\hline 12 & 31 & 0.45 & 0.40 & 0.00 & 0.00 \\
\hline 9 & 20 & 2.33 & 2.39 & 2.43 & 2.20 \\
\hline 23 & 36 & 0.84 & 0.68 & 0.00 & 0.00 \\
\hline 16 & 25 & 0.52 & 0.45 & 0.28 & 0.21 \\
\hline 17 & 8 & 5.84 & 5.91 & 4.47 & 4.46 \\
\hline $32(12 \mathrm{a})$ & \multicolumn{5}{|l}{} \\
\hline
\end{tabular}


PNNL-22747

SRNL-STI-2013-00465

\subsection{Cast Stone Cured Waste Form Characterization}

After curing for 28 days, the Cast Stone waste form monoliths were characterized with respect to chemical composition, compressive strength, density, TCLP, and contaminant leachability. The characterization work was conducted at both PNNL and SRNL. Porosity data are in Appendix D.

\subsection{Chemical Composition}

This section provides the chemical compositions of the Cast Stone monoliths as measured at PNNL for the 26 radioactive Cast Stone mixes used in the EPA Draft Method 1315 leach tests. The chemical composition of each of the 26 Cast Stone mixes was determined by dissolving a piece from a hardened (cured 28 days) cylinder of each of the 26 radioactive batches using microwave digestion. The resulting solutions were characterized using inductively coupled plasma-mass spectroscopy (ICP-MS) and inductively coupled plasma-optical emission spectroscopy (ICP-OES) (see Appendix B for a description of the analytical methods). The first three columns of Table 7-1 show the overall averages and ranges for the compositions of the 26 Cast Stone mixes. Appendix D contains the analyzed composition of each of the mixes.

Table 7-1 also shows the average compositions for subsets of the 26 mixes segregated by different parameters in the screening matrix, including the Na molarity of the simulants, dry blend mix, and the High Al simulant. Within the analytical uncertainties, the Na concentrations are higher for the monoliths prepared with the $7.8 \mathrm{M}$ Na simulants than for the $5 \mathrm{M}$ Na simulants, but the ratio is only 1.15 compared to the value of 1.56 that one can calculate from the ratio of the 7.8 M Na simulants and 5.0 M Na simulants. The $\mathrm{Na}$ in the cured Cast Stone is tempered by the $\mathrm{Na}$ present in the NW fly ash, which contains about an order of magnitude more sodium that the SE fly ash (see Table 4-2). The average Al concentrations in the three samples prepared with the High Al simulants at $5 \mathrm{M} \mathrm{Na}$ are lower than the average for the three samples prepared with the Average simulants at $5 \mathrm{M} \mathrm{Na}$. This is because the Al variability is driven more by the variability in the $\mathrm{Al}$ concentrations among the dry blend ingredients, as seen in the columns in Table 7-1 showing the average compositions for the monoliths prepared with the four different dry blend mixes, than by the $\mathrm{Al}$ variability in the simulants.

\subsection{Compressive Strength}

Compressive strength was measured for the Cast Stone on as-cured monoliths after 28 days at both SRNL and PNNL. All compressive strength tests were conducted on nonradioactive monoliths prepared at both laboratories. After curing for a minimum of 28 days, three 2-in.diameter $\times 4$-in.-high cylinders of each Cast Stone mix were subjected to the ASTM C39 Standard Test Method for Compressive Strength of Cylindrical Concrete Specimens (ASTM C39 2012).

\subsubsection{Compressive Strength Approach}

According to the ASTM C39 test method, a sample is loaded into the testing apparatus so that the axis of the monolith is aligned with the center of thrust of the testing apparatus. Before testing the monolith, the load indicator is set to zero. The load is applied continuously without any shock at a stress rate of $0.25 \pm 0.05 \mathrm{MPa} / \mathrm{s}(35 \pm 7 \mathrm{psi} / \mathrm{s})$. The designated rate of loading should be maintained at least during the latter half of the anticipated loading phase. The loading is maintained until the load indicator starts to decrease steadily, and the monolith displays a welldefined fracture pattern as illustrated in the C39/C39M test method. The compressive strength is calculated by dividing the maximum load imposed on the monolith during the test by the average cross-sectional area of the monolith. The result is typically expressed to the nearest $0.1 \mathrm{MPa}$ or 10 psi. 
Table 7-1. Summary Table of Chemical Compositions of the 26 Mixes Spiked with Radionuclides and Subsets of the 26 Mixes

\begin{tabular}{|c|c|c|c|c|c|c|c|c|c|c|c|c|}
\hline \multirow{3}{*}{ Analyte } & \multirow{3}{*}{ Units } & Average & Max & Min & $\begin{array}{c}\text { Average } \\
5 \mathrm{M} \mathrm{Na}\end{array}$ & $\begin{array}{l}\text { Average } \\
7.8 \mathrm{M} \mathrm{Na}\end{array}$ & $\begin{array}{r}\mathrm{Hi} \mathrm{Al} \\
5 \mathrm{M} \mathrm{Na}\end{array}$ & $\begin{array}{c}\mathrm{Hi} \mathrm{Al} \\
7.8 \mathrm{M} \mathrm{Na} \\
\end{array}$ & $\begin{array}{l}\text { NW FA, } \\
\text { NW BFS } \\
\end{array}$ & $\begin{array}{l}\text { NW FA } \\
\text { SE BFS }\end{array}$ & $\begin{array}{r}\text { SE FA } \\
\text { NW BFS } \\
\end{array}$ & $\begin{array}{c}\text { SE FA } \\
\text { SE BFS }\end{array}$ \\
\hline & & \multicolumn{11}{|c|}{ Mixes } \\
\hline & & All & All & All & $2,13,20$ & $3,5,6,22$ & $4,17,24$ & $9,11,19$ & $\begin{array}{r}5,15,16 \\
25,10,24\end{array}$ & $\begin{array}{c}4,20 \\
3,9,12 \\
22\end{array}$ & $\begin{array}{c}1,6,8,19 \\
11,21,23 \\
26\end{array}$ & $\begin{array}{l}7,14,18 \\
2,13,17\end{array}$ \\
\hline Aluminum & $\mu \mathrm{g} / \mathrm{g}$ & 62,400 & 83,900 & 42,500 & 63,800 & 61,300 & 59,400 & 66,500 & 56,400 & 48,700 & 72,300 & 68,800 \\
\hline Barium & $\mu \mathrm{g} / \mathrm{g}$ & 1,360 & 2,280 & 575 & 1,340 & 1,370 & 1,540 & 1,020 & 2,100 & 2,010 & 828 & 682 \\
\hline Cadmium & $\mu \mathrm{g} / \mathrm{g}$ & 10 & 13 & 6 & 10 & 10 & - & 12 & 10 & 13 & 11 & 6 \\
\hline $\begin{array}{l}\text { Calcium } \\
\end{array}$ & $\mu \mathrm{g} / \mathrm{g}$ & 139,000 & 167,000 & 115,000 & 142,000 & 136,000 & 135,000 & 129,000 & 157,000 & 137,000 & 137,000 & 125,000 \\
\hline Cesium & $\mu \mathrm{g} / \mathrm{g}$ & 4 & 5 & 2 & 4 & 3 & 3 & 4 & 3 & 2 & 4 & 5 \\
\hline Chromium & $\mu \mathrm{g} / \mathrm{g}$ & 574 & 976 & 246 & 496 & 631 & 503 & 701 & 560 & 633 & 574 & 528 \\
\hline Iron & $\mu \mathrm{g} / \mathrm{g}$ & 19,300 & 25,600 & 13,900 & 20,100 & 18,700 & 18,300 & 18,300 & 18,200 & 16,200 & 21,100 & 21,100 \\
\hline Lead & $\mu \mathrm{g} / \mathrm{g}$ & 57 & 80 & 29 & 52 & 60 & 46 & 67 & 48 & 42 & 70 & 60 \\
\hline Magnesium & $\mu \mathrm{g} / \mathrm{g}$ & 21,000 & 36,600 & 8,860 & 22,700 & 19,800 & 24,800 & 15,600 & 16,500 & 32,000 & 10,900 & 28,100 \\
\hline Manganese & $\mu \mathrm{g} / \mathrm{g}$ & 990 & 1,570 & 465 & 1,070 & 931 & 1,080 & 795 & 765 & 1,360 & 640 & 1,310 \\
\hline Mercury & $\mu \mathrm{g} / \mathrm{g}$ & 12 & 12 & 12 & 12 & - & - & - & - & - & 12 & - \\
\hline Nickel & $\mu \mathrm{g} / \mathrm{g}$ & - & - & - & - & - & - & - & - & - & - & - \\
\hline Phosphorus & $\mu \mathrm{g} / \mathrm{g}$ & - & - & - & - & - & - & - & - & - & - & - \\
\hline Potassium & $\mu \mathrm{g} / \mathrm{g}$ & 12,600 & 13,200 & 11,500 & 12,300 & 13,200 & 13,000 & 13,200 & - & - & 12,400 & 13,000 \\
\hline Silicon & $\mu \mathrm{g} / \mathrm{g}$ & 149,000 & 172,000 & 127,000 & 155,000 & 144,000 & 149,000 & 136,000 & 142,000 & 148,000 & 145,000 & 163,000 \\
\hline Silver & $\mu \mathrm{g} / \mathrm{g}$ & 6 & 8 & 4 & 6 & - & - & - & - & - & 8 & 4 \\
\hline Sodium & $\mu \mathrm{g} / \mathrm{g}$ & 72,200 & 101,000 & 43,100 & 66,400 & 76,500 & 75,700 & 86,800 & 72,300 & 76,900 & 74,400 & 64,700 \\
\hline Strontium & $\mu \mathrm{g} / \mathrm{g}$ & 944 & 1,330 & 577 & 952 & 937 & 985 & 802 & 1,247 & 1,162 & 757 & 671 \\
\hline Titanium & $\mu \mathrm{g} / \mathrm{g}$ & 3,430 & 4,740 & 2,300 & 3,570 & 3,320 & 3,180 & 3,340 & 3,070 & 2,690 & 3,900 & 3,890 \\
\hline Technetium-99 & $\mu \mathrm{g} / \mathrm{g}$ & 7 & 10 & 4 & 6 & 8 & 6 & 8 & 7 & 7 & 8 & 7 \\
\hline Iodine-127 & $\mu \mathrm{g} / \mathrm{g}$ & 68 & 149 & 25 & 62 & 73 & 61 & 65 & 65 & 70 & 79 & 56 \\
\hline Uranium-238 & $\mu \mathrm{g} / \mathrm{g}$ & 144 & 1,050 & 46 & 87 & 185 & 89 & 123 & 107 & 244 & 125 & 104 \\
\hline \% Dry Solids & $\begin{array}{l}\text { \% by } \\
\text { Weight }\end{array}$ & 77 & 83 & 72 & 75 & 78 & 75 & 77 & 78 & 77 & 77 & 77 \\
\hline
\end{tabular}


At PNNL, the compressive strength tests were conducted using the servo-hydraulic universal test machine (MTS servo-hydraulic system with Instron ${ }^{\circledR}$ data acquisition and control system) shown in Figure 7-1. This apparatus has a maximum load capacity of 20 kilo-pound force (kips-force), which is equivalent to $88.96 \mathrm{kN}$ (kilo-newtons). The compressive load was applied until the complete fracture of the specimens was observed. The loading rate was set at $0.25 \mathrm{MPa} / \mathrm{s}$ (29.4375 kN/min) as specified by ASTM C39 (ASTM C39 2012). Three cylinders (2-in. diameter by 4-in. long) of nonradioactive Cast Stone specimens were tested for of each of the 26 test mixes. Before testing, some of the cylinders were capped with an epoxy to provide a smooth surface. In all tests, unbonded neoprene caps were used as described in ASTM C1231, Standard Practice for Use of Unbonded Caps in Determination of Compressive Strength of Hardened Concrete Cylinders (ASTM C1231 2012). Commercially available neoprene pads with a Shore A Durometer Hardness of 70 were used in the tests. The pads were inspected prior to each test and replaced more frequently than the maximum 50 reuses allowed in the ASTM method.

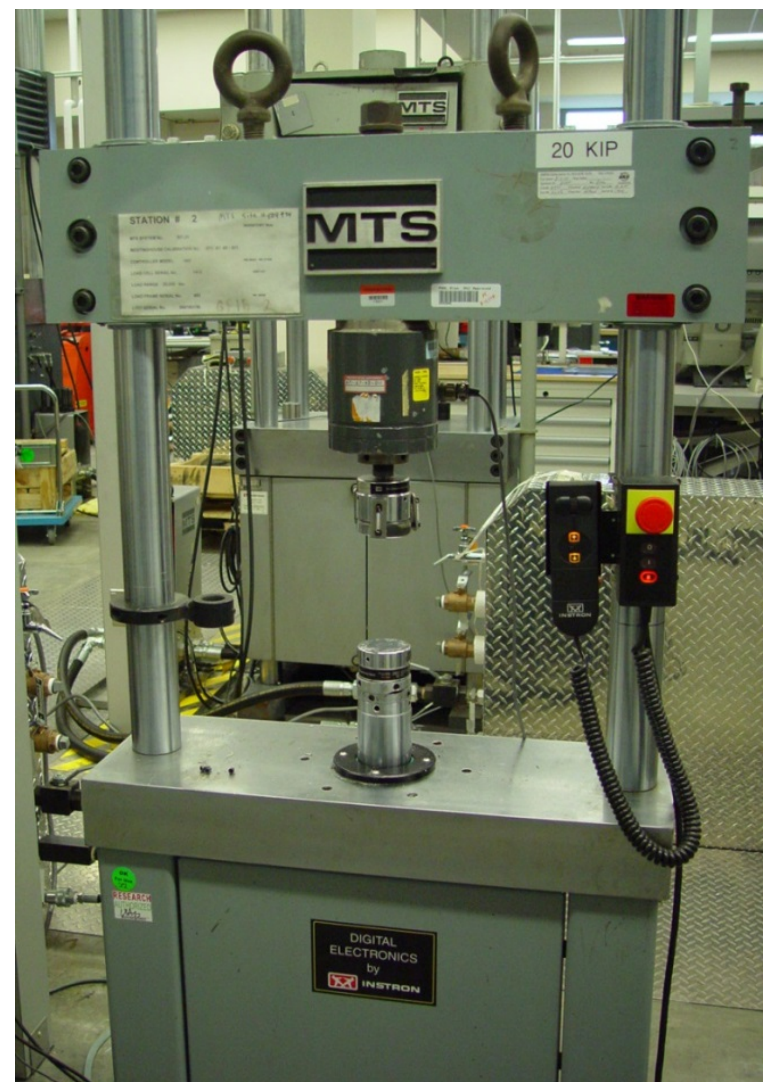

Figure 7-1. The Compressive Strength Test Apparatus

At SRNL, the compressive strength tests were conducted using a hydraulic compression test machine (Humboldt Manufacturing, Schiller Park, IL, model \#HCM-0300 with Test Mark Industries, LXI data acquisition system). This apparatus has a maximum load capacity of 300 kilo-pound force (kips-force), which is equivalent to $1334 \mathrm{kN}$. The compressive load was applied until the load indicated by the equipment was reduced to $75 \%$ of the maximum load applied to the specimen. The loading rate was set at approximately $0.25 \mathrm{MPa} / \mathrm{s}(29.4 \mathrm{kN} / \mathrm{min})$ as specified by ASTM C39 (ASTM C39 2012). Three cylinders (2-in. diameter by 4-in. long) of 
nonradioactive Cast Stone specimens were tested for 14 of the 26 screening test mixes in Table 2-1. Compressive strength was also measured for the 12 additional mixes shown in Table 6-1. In all tests, unbonded neoprene caps were used as described in ASTM C1231 (ASTM C1231 2012). Commercially available neoprene pads with a Shore A Durometer Hardness of 70 were used in the tests. The pads were inspected prior to each test and replaced more frequently than the maximum 50 reuses allowed in the ASTM method.

\subsubsection{Compressive Strength Results}

The results of the compressive strength measurements are shown in Figure 7-2 and Figure 7-3 for the PNNL and SRNL tests, respectively. These are the means of triplicate measurements. Note that the colored circles in the figures at zero compressive strength represent conditions that were not tested. Compressive strengths of the triplicate samples ranged from 5.8 to $62.0 \mathrm{MPa}$ (850 to $8990 \mathrm{psi})$, excluding one sample that broke at $1.3 \mathrm{MPa}(190 \mathrm{psi})$. The other two monoliths from that mix (\#23) broke at 11.6 and $9.4 \mathrm{MPa}$ (1683 and $1360 \mathrm{psi}$ ). For the 14 mixes tested by both PNNL and SRNL, the PNNL compressive strength measurements tended to be slightly higher than the SRNL results. The target minimum compressive strength is $3.4 \mathrm{MPa}(500 \mathrm{psi})$. The results are tabulated in Table D-2 and Table D-3 of Appendix D. Those tables also present the means and SDs of the values over the triplicate samples. The lower compressive strengths tended to be from mixes with the $7.8 \mathrm{M} \mathrm{Na}$ simulants and the 0.6 water-to-dry-blend mix ratio. The higher compressive strengths tended to be from mixes with the $5 \mathrm{M} \mathrm{Na}$ simulants and/or those with the 0.4 water-to-dry-blend ratio. Mix 26 at PNNL was prepared with 14\% less dry blend than planned ( 0.7 water-to-dry-blend ratio). At an average of $6.5 \mathrm{MPa}$, the Mix 26 specimens still passed the minimum compressive strength requirement, though the compressive strength was lower than that of its replicate, Mix $21(9.4 \mathrm{MPa})$.

\subsection{Cured Density}

The densities of the cured Tc and U-spiked Cast Stone samples produced at PNNL were determined using the measured weight and physical dimensions of each of the 28-day cured specimens. At SRNL, the cured density was measured on fractured pieces from compression specimens using helium pycnometry.

\subsubsection{Cured Density Approach}

To determine the cured density of each monolith, the diameter was measured at the top, middle, and bottom of each monolith. Then the overall length was measured at three locations. The average value of the diameter measurements and the average value of the overall length measurements were used to determine the volume of the monolith. Each monolith was weighed to determine its mass. The mass of the monolith was divided by the determined volume resulting in the cured density. At SRNL, a gas pycnometer (model \# MVP-5DC, Quantachrome Corp., Boyton Beach, FL), using helium as the fill gas was used to measure the volume of the specimen using procedure Manual L29, ITS-0168. A piece from each of the compression samples was weighed and the volume measured in triplicate. The density of the sample was calculated from the measured mass and the average of the triplicate volume measurements. The reported measured density for each mix was the average of the calculated density of the triplicate compression samples. 


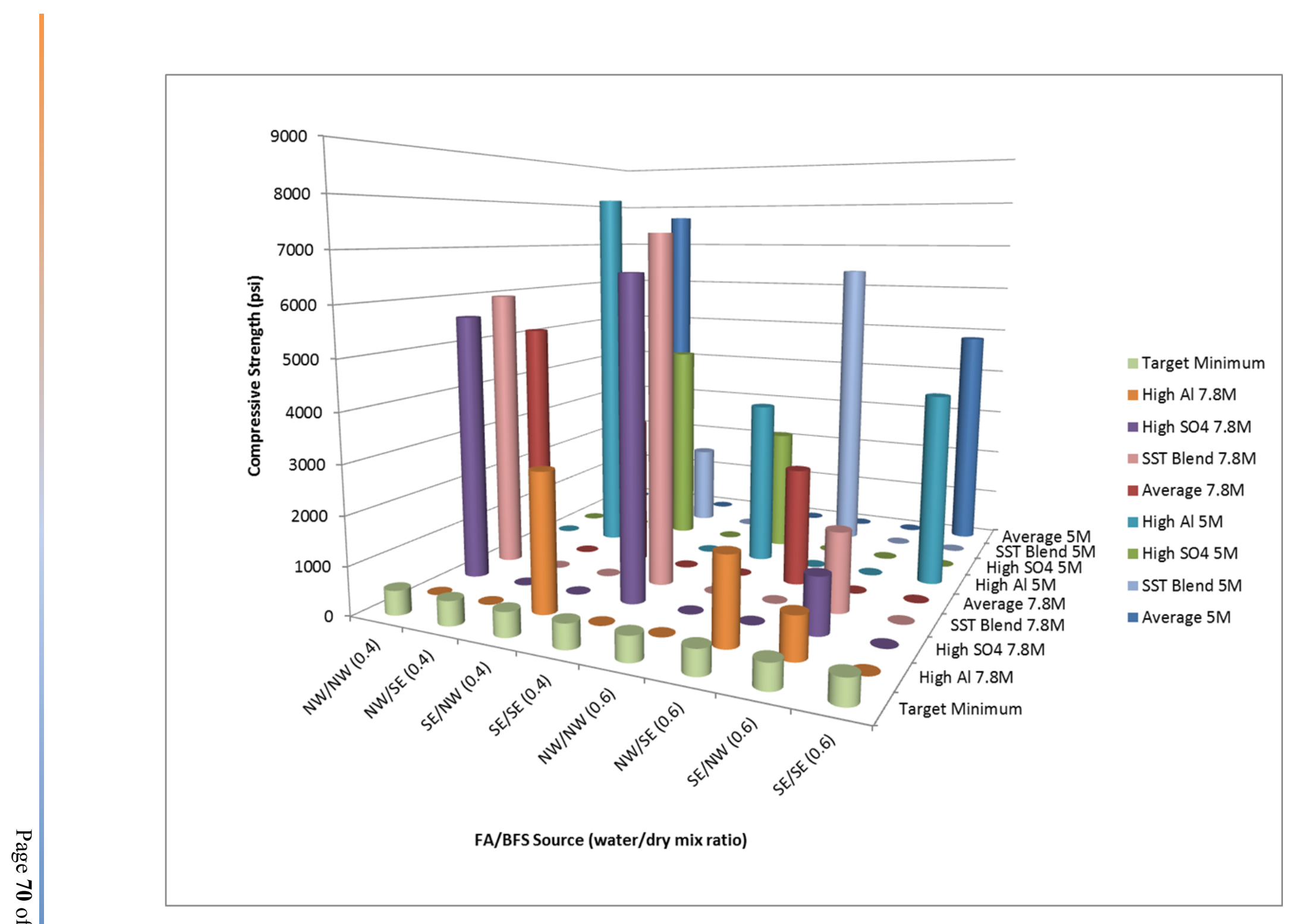

Figure 7-2. Results of PNNL Compressive Strength Measurements for 26 Cast Stone Mixes 


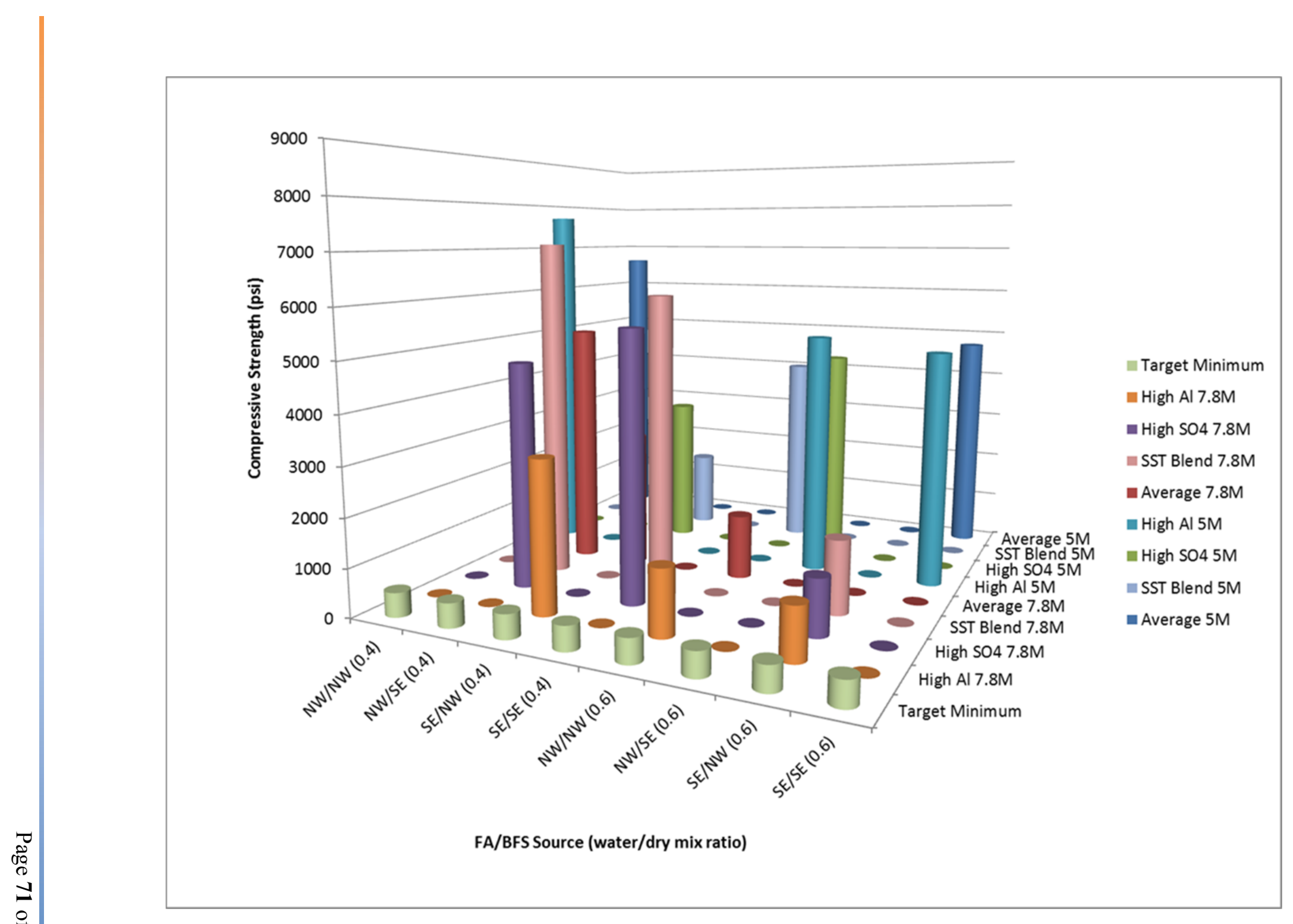

Figure 7-3. Results of SRNL Compressive Strength Measurements for 26 Cast Stone Mixes 
PNNL-22747

SRNL-STI-2013-00465

\subsubsection{Cured Density Results}

Densities were measured by PNNL on each of six specimens from each of the 26 Cast Stone mixes in Table 2-1. Densities ranged from 1.68 to $2.04 \mathrm{~g} / \mathrm{cm}^{3}$. Figure $7-4$ shows the averages of the six measurements and Appendix D has a tabulation of all of the values (see Table D-4). Note that the "flat" colored circles in the figure at densities $<1.7 \mathrm{~g} / \mathrm{cm}^{3}$ represent conditions that were not included in the screening test matrix. Table D-5 in Appendix D also lists the densities measured using a pycnometer at SRNL. Generally, densities were higher for the 0.4 water-todry-solids mix ratio mixes than for the 0.6 water-to-dry-solids mix ratio mixes. There is a less pronounced trend for higher densities with the $7.8 \mathrm{M} \mathrm{Na}$ simulants than for the $5 \mathrm{M} \mathrm{Na}$ simulants.

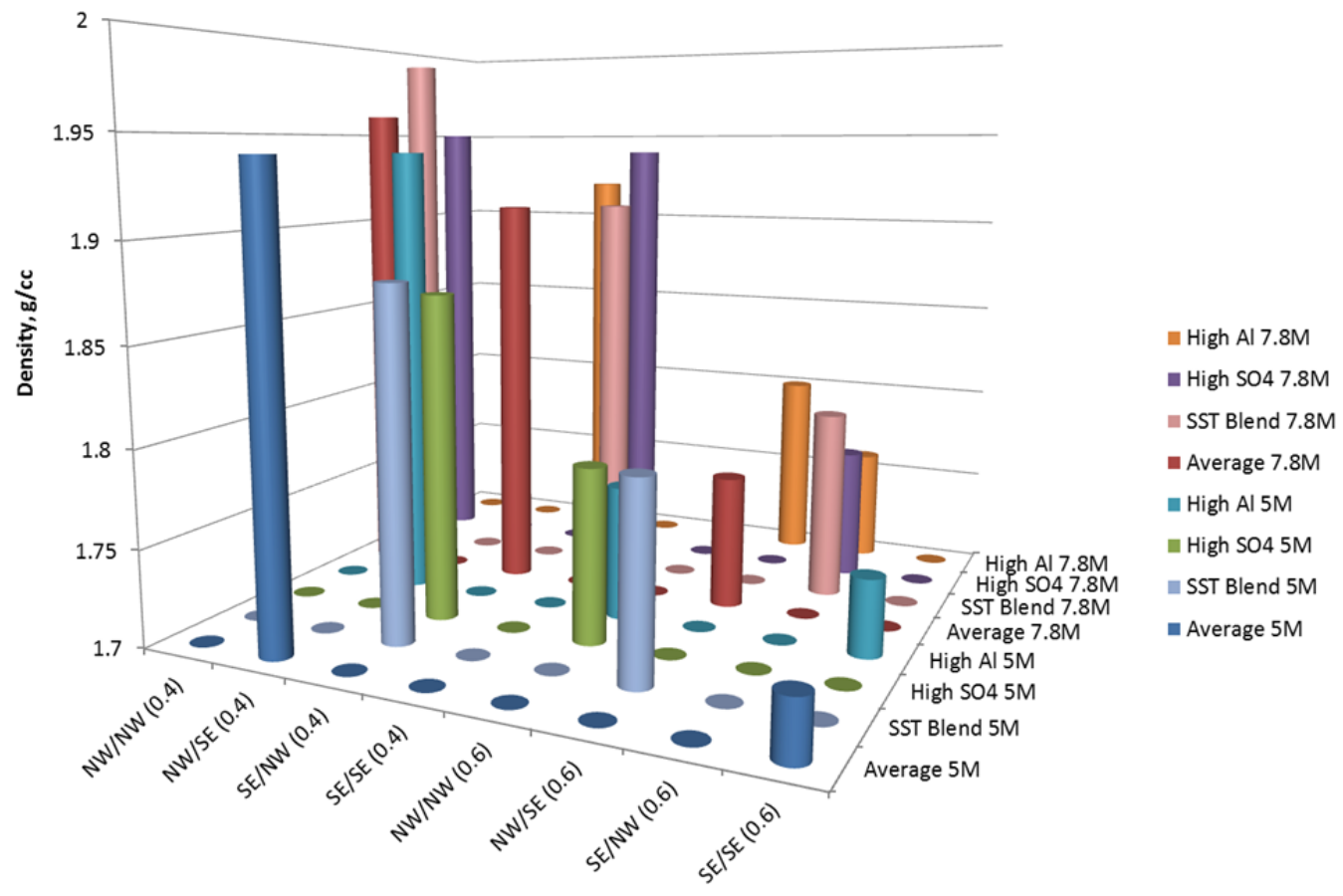

FA/BFS Source (water/dry mix ratio)

Figure 7-4. Average Densities of PNNL Cast Stone Monoliths

\subsection{Toxicity Leaching Characteristic Procedure}

The TCLP, EPA Method 1311 (EPA 1992), was conducted to demonstrate that the Cast Stone screening test formulations will meet RCRA land disposal restrictions for hazardous wastes. The LAW is projected to include RCRA metals including $\mathrm{As}, \mathrm{Ba}, \mathrm{Cd}, \mathrm{Cr}, \mathrm{Pb}, \mathrm{Hg}, \mathrm{Se}$, and $\mathrm{Ag}$; and underlying hazardous constituents (UHCs) including $\mathrm{Sb}, \mathrm{Be}, \mathrm{Ni}$, and $\mathrm{Tl}$. In addition, some of the dry materials may include these same and other hazardous materials. The results are compared with the UTS limits in 40 CFR 268, Land Disposal Restrictions, as shown in Table 7-2.

\subsubsection{TCLP Methodology}

TCLP testing was conducted at the Southwest Research Institute (SwRI) in San Antonio, Texas. SwRI is one of PNNL's evaluated suppliers and the work was conducted in accordance with the Hanford HASQARD requirements. A 2-in.-diameter by 4-in.-long cylinder of each of the 26 Cast Stone test mixes prepared at PNNL was sent to SwRI with the appropriate chain of custody. 
PNNL-22747

SRNL-STI-2013-00465

Table 7-2. Universal Treatment Standards from 40 CFR 268

\begin{tabular}{||c|c|c|}
\hline Constituent Category & Regulated Constituent & $\begin{array}{c}\text { Allowable Concentration in } \\
\text { TCLP Leachate (mg/L) }\end{array}$ \\
\hline RCRA Metals & Arsenic & 5.0 \\
\hline & Barium & 21 \\
\hline & Cadmium & 0.11 \\
\hline & Chromium & 0.60 \\
\hline & Lead & 0.75 \\
\hline & Mercury & 0.025 \\
\hline & Selenium & 5.7 \\
\hline Underlying Hazardous Constituents & Silver & 0.14 \\
\hline & Antimony & 1.15 \\
\hline & Beryllium & 1.22 \\
\hline & Nickel & 11 \\
\hline & Thallium & 0.20 \\
\hline
\end{tabular}

In the EPA 1311 method, for wastes containing $\geq 0.5 \%$ solids, the liquid, if any, is separated from the solid phase and stored for later analysis. The Cast Stone samples were $100 \%$ solid. The particle size of the solid phase is reduced by crushing to a particle size less than $1 \mathrm{~cm}$. The solid phase is extracted with an amount of extraction fluid equal to 20 times the weight of the solid phase. The extraction fluid used is a function of the alkalinity of the solid phase of the waste. For the Cast Stone samples, extraction fluid \#2 was used. This is a mixture of $5.7 \mathrm{ml}$ of glacial acetic acid $\left(\mathrm{CH}_{3} \mathrm{CH}_{2} \mathrm{OOH}\right)$ per liter of water. The $\mathrm{pH}$ of this extraction fluid is 2.88. After extraction, the liquid extract is separated from the solid phase by filtration through a $0.6-\mu \mathrm{m}$ to $0.8-\mu \mathrm{m}$ glass fiber filter. The resulting solution is chemically analyzed for the RCRA metals and UHCs.

\subsubsection{TCLP Results}

The results of the TCLP testing are shown in Table 7-3 (note that the table is populated with only values above the reporting [detection] limit). As described in Section 3.3, the simulants used in the Cast Stone specimens were spiked with only $\mathrm{Cr}, \mathrm{Pb}, \mathrm{Ni}$, and $\mathrm{Cd}$. Neither $\mathrm{Pb}$ nor $\mathrm{Cd}$ was detected in any of the TCLP extracts. Chromium and Ni were measured in most but not all of the extracts. The As, $\mathrm{Ba}$, and $\mathrm{Se}$ were not included in the simulants. They are present in the dry materials used to make the Cast Stone. Even with a $100 \%$ contribution from the dry materials, the TCLP results for As and Se would be below the UTS limits. For the values in Table 7-3, all of the 26 Cast Stone mixes easily met the UTS limits.

\subsection{Effective Diffusion Coefficients}

The Cast Stone monoliths were subjected to the draft EPA Draft Method 1315, Mass Transfer Rates of Constituents in Monolithic or Compacted Granular Materials Using as Semi-Dynamic Tank Leaching Test (EPA 2012). ${ }^{1}$ Two monoliths for each of the 26 screening test formulations

\footnotetext{
${ }^{1}$ These screening tests used the EPA Draft Method 1315 cited. As this report was being prepared, the EPA 1315 method became a formally accepted EPA method. It is available on the EPA website at http://www.epa.gov/epawaste/hazard/testmethods/sw846/new_meth.htm\#1315.
} 
Table 7-3. Toxicity Characteristic Leaching Procedure Screening Test Results

\begin{tabular}{|c|c|c|c|c|c|c|c|c|c|c|c|c|c|}
\hline \multirow{3}{*}{$\underset{\#}{\operatorname{Mix}}$} & Element & $\mathbf{S b}$ & As & $\mathbf{B a}$ & $\mathbf{B e}$ & $\begin{array}{c}\begin{array}{c}\text { Cd } \\
\text { (spike) }\end{array} \\
\end{array}$ & $\begin{array}{c}\mathrm{Cr} \\
\text { (spike) }\end{array}$ & $\begin{array}{c}\begin{array}{c}\text { Pb } \\
\text { (spike) }\end{array} \\
\text { (spiks }\end{array}$ & Hg & $\begin{array}{c}\mathbf{N i} \\
\text { (spike) }\end{array}$ & Se & Ag & Tl \\
\hline & UTS Limits, $\mu \mathrm{g} / \mathrm{L}$ & 1150 & 5000 & 21000 & 1220 & 110 & 600 & 750 & 25 & 11000 & 5700 & 140 & 200 \\
\hline & Reporting Limits, $\mu \mathrm{g} / \mathrm{L}$ & $<\mathbf{2 0}$ & $<10$ & $<5$ & $<5$ & $<5$ & $<5$ & $<10$ & $<0.2$ & $<5$ & $<10$ & $<5$ & $<25$ \\
\hline 1 & & - & 16.4 & 312 & - & - & 11.4 & - & - & 43.8 & 40.7 & - & - \\
\hline 2 & & - & 30.6 & 1120 & - & - & - & - & - & 7.3 & 30.0 & - & - \\
\hline 3 & & - & - & 311 & - & - & 8.0 & - & - & - & 34.7 & - & - \\
\hline 4 & & - & - & 735 & - & - & - & - & - & - & 27.4 & - & - \\
\hline 5 & & - & - & 136 & - & - & 8.2 & - & - & - & 38.0 & - & - \\
\hline 6 & & - & 30.0 & 421 & - & - & 11.4 & - & - & 19.1 & 68.1 & - & - \\
\hline 7 & & - & 35.6 & 958 & - & - & - & - & - & 22.9 & 26.7 & - & - \\
\hline 8 & & - & 21.0 & 288 & - & - & - & - & - & 68.8 & 57.2 & - & - \\
\hline 9 & & - & - & 471 & - & - & 10.6 & - & - & - & 31.4 & - & - \\
\hline 10 & & - & - & 163 & - & - & 28.3 & - & - & 5.7 & 27.3 & - & - \\
\hline 11 & & - & - & 346 & - & - & 14.8 & - & - & 7.0 & 37.4 & - & - \\
\hline 12 & & - & - & 360 & - & - & - & - & - & 27.6 & 19.9 & - & - \\
\hline 13 & & - & 20.3 & 691 & - & - & - & - & - & 14.1 & 15.7 & - & - \\
\hline 14 & & - & 26.9 & 492 & - & - & - & - & - & 33.0 & 15.8 & - & - \\
\hline 15 & & - & - & 135 & - & - & 23.9 & - & - & 16.2 & 29.2 & - & - \\
\hline 16 & & - & - & 225 & - & - & - & - & - & 155 & 25.4 & - & - \\
\hline 17 & & - & 13.1 & 780 & - & - & - & - & - & 6.6 & 24.8 & - & - \\
\hline 18 & & - & 45.1 & 942 & - & - & - & - & - & 119 & 39.7 & - & - \\
\hline 19 & & - & - & 382 & - & - & 10.0 & - & - & 26.8 & 50.7 & - & - \\
\hline 20 & & - & - & 542 & - & - & - & - & - & 7.6 & 26.5 & - & - \\
\hline 21 & & - & 12.1 & 397 & - & - & 47.5 & - & - & - & 67 & - & - \\
\hline 22 & & - & - & 337 & - & - & 7.6 & - & - & - & 32.2 & - & - \\
\hline 23 & & - & 27.7 & 392 & - & - & - & - & - & 71.6 & 42.9 & - & - \\
\hline 24 & & - & - & 174 & - & - & 13.2 & - & - & - & 29.9 & - & - \\
\hline 25 & & - & - & 151 & - & - & 20 & - & - & 23.6 & 30.4 & - & - \\
\hline 26 & & - & - & 101 & - & - & 106 & - & - & - & 33.8 & - & - \\
\hline
\end{tabular}


were tested. The monoliths were prepared with simulants spiked with ${ }^{99} \mathrm{Tc}$, stable I as iodide, $\mathrm{U}(\mathrm{U}(\mathrm{VI}))$, and selected RCRA metals and UHCs, as shown in Table 3-3. Deionized water (DIW) was used as the leachant. The tests were conducted at ambient room temperature. The leach tests were conducted on 2-in.-diameter $\times 4$-in.-high cylinders. Surface areas of the Cast Stone monoliths are based on the geometric surface area of the monoliths.

\subsubsection{EPA Draft Method 1315}

The EPA Draft Method 1315 (EPA 2012) is a semi-dynamic leach test that consists of submerging a monolithic sample in DIW at a fixed liquid-volume to solid-geometric-surface-area ratio. The sampling was done at fixed periods of time at cumulative leaching times of $0.08,1,2$, 7, 14, 28, 42, 49, and 63 days (EPA 2012). For these screening tests, two additional samplings were conducted at cumulative leaching times of 77 and 91 days. At each sampling interval, all the leaching fluid was removed and replaced with fresh fluid. A schematic of this process is shown in Figure 7-5.

At each of the predetermined leaching intervals, the monolith mass is recorded, and the leaching solution is changed. This method is similar to ANSI/ANS 16.1, Measurement of the Leachability of Solidified Low-Level Radioactive Wastes by a Short-Term Test Procedure (ANSI 2003), but the leaching intervals are modified, and the developers of this method claim that the process of mass transfer can be interpreted by more complex release models that account for physical retention of the porous medium and chemical retention at the pore wall through geochemical speciation modeling.

In the screening tests described in this report, cylindrical monolith samples ( $\sim 2$-in. diameter by $\sim 4$-in. in height) were placed into the centers of leaching vessels containing sufficient DIW to maintain a solution-to-solid surface area ratio of $9 \pm 1 \mathrm{ml}$ of leachant per square centimeter of sample geometric surface area. The geometric surface area is used in this test method and is calculated from the dimensions of the cylindrical monolith. Sample stands and holders were used to maximize the contact area of the monolith sample with the leaching solution. In between the sampling/replacement intervals, the leach vessels were covered with lids. Solution $\mathrm{pH}$ and electrical conductivities were measured within the leach vessel at each leaching interval. Then unfiltered leachate aliquots were removed and submitted for chemical analyses.

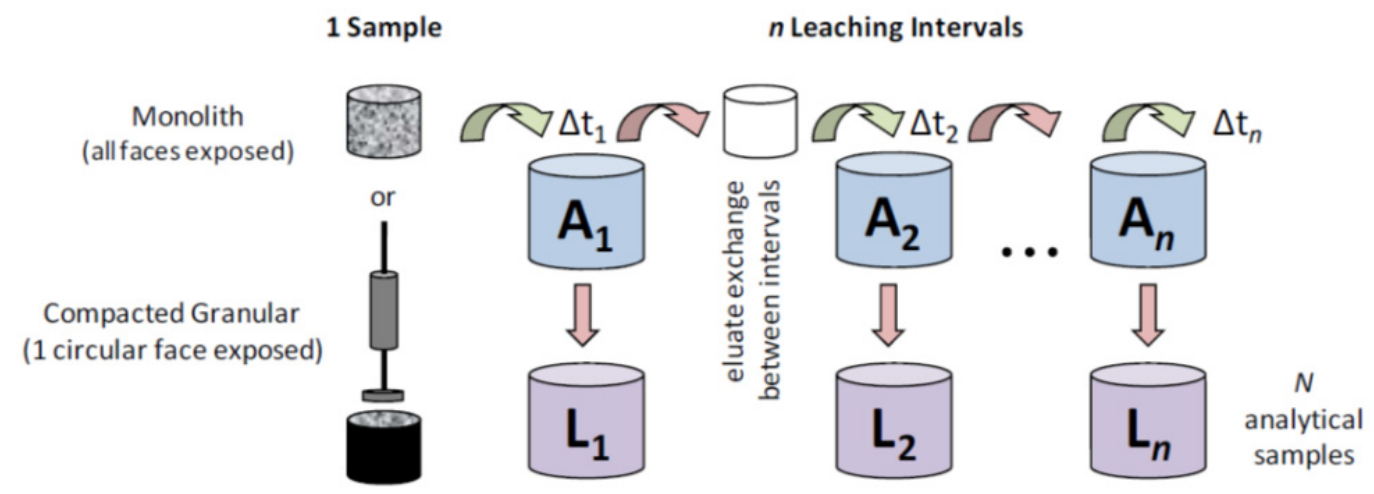

Figure 7-5. EPA Draft Method 1315 Testing Scheme (EPA 2012) 
The observed diffusivity for each constituent was calculated using the analytical solution for simple radial diffusion from a cylinder into an infinite bath as presented by Crank (1975)

$$
D_{i}=\pi\left[\frac{M_{t i}}{2 \rho C_{0}\left(\sqrt{t_{i}}-\sqrt{t_{i-1}}\right)}\right]^{2}
$$

where

$$
\begin{aligned}
& \mathrm{D}_{i}= \begin{array}{l}
\text { mean observed diffusivity of a specific constituent for leaching interval, } i \\
\left(\mathrm{~m}^{2} / \mathrm{s}\right)
\end{array} \\
& \mathrm{M}_{\mathrm{ti}}=\begin{array}{l}
\text { mass released per unit area of the monolith during leaching interval } i \\
\left(\mathrm{mg} / \mathrm{m}^{2}\right)
\end{array} \\
& \mathrm{t}_{i}=\text { cumulative contact time after leaching interval, } i(\mathrm{~s}) \\
& \mathrm{t}_{i-1}=\text { cumulative contact time after leaching interval, } i-1(\mathrm{~s}) \\
& \mathrm{C}_{0}=\text { initial leachable content }(\mathrm{mg} / \mathrm{kg}) \\
& \rho= \text { sample density }\left(\mathrm{kg} / \mathrm{m}^{3}\right) .
\end{aligned}
$$

The leachability index (LI), a parameter derived directly from immersion test results, evaluates diffusion-controlled contaminant release with respect to time. The LI was calculated using

$$
L I_{n}=-\log \left[10,000 D_{i}\right] \text {, }
$$

where $\mathrm{LI}_{\mathrm{n}}$ is the leachability index for each leach interval and $D_{i}$ is the effective diffusivity for elements of interest $\left(\mathrm{m}^{2} / \mathrm{s}\right)$ during the leach interval $n$. Note that the units of $\mathrm{D}_{i}$ in Equation (7-1) are square meter(s) per second, and the 10,000 multiplier in Equation (7-2) converts the units to square centimeter(s) per second $\left(\mathrm{cm}^{2} / \mathrm{s}\right)$ prior to calculating the LI. In general, the LIs for each time interval are averaged for each COC to calculate an average LI. The average LI is used as a criterion to assess whether solidified/stabilized waste is likely to be acceptable for subsurface disposal in waste repositories.

For purposes of the statistical analyses of the screening test results, the effective diffusivities and LIs for the 28-, 42-, 49-, and 63-day intervals were averaged for each COC to calculate an average effective diffusivity and an average LI for each of the two duplicate samples of a given Cast Stone mix. Then, the average effective diffusivities and LI values for the two duplicates were used to calculate means and standard deviations.

\subsubsection{Effective Diffusivity Results}

The EPA Draft Method 1315 leach tests were conducted for a total of 91 days with additional leachant changes at 77 and 91 cumulative days, which were 14 and 28 days beyond the standard 63 days of the EPA Draft Method 1315 but similar in duration to the ANSI/ANS 16.1 method. Figure 7-6 shows the resulting effective diffusivities for Na, nitrate, nitrite, I (added as iodide), Tc (added as pertechnetate), $\mathrm{Cr}$ (added as chromate), and $\mathrm{U}$ (added as uranyl) for Cast Stone Mix 5 (Average 7.8 M Na simulant mixed with NW/NW dry blend and a free-water-to-dry-blend ratio of 0.4). The figure shows the relative leaching performance of the different constituents with $\mathrm{Na}$, nitrate, nitrite, and I having comparable effective diffusivities and with $\mathrm{Tc}, \mathrm{Cr}$, and $\mathrm{U}$ having increasingly lower effective diffusivities. As is discussed further below, many of the U leachate concentrations were below detection limits so the $U$ diffusivity values shown represent 
maximums. As will be more evident in the figures below showing the leach results for the individual species, the effective diffusivities for $\mathrm{Na}$, I, nitrate, and nitrite appear to continue to decrease over time, while the effective diffusivities for $\mathrm{Tc}$ and $\mathrm{Cr}$ are relatively constant for the duration of the test. This is due in part to the $\mathrm{Na}$, I, nitrate, and nitrite being more leachable such that the semi-infinite solid boundary conditions associated with Equation (7-1) are not strictly met when the cumulative fraction leached of the species exceeds approximately 20 percent of the initial inventory (ANSI/ANS 16.1 2003). This can occur within the first 7 to 28 days for these more leachable species.

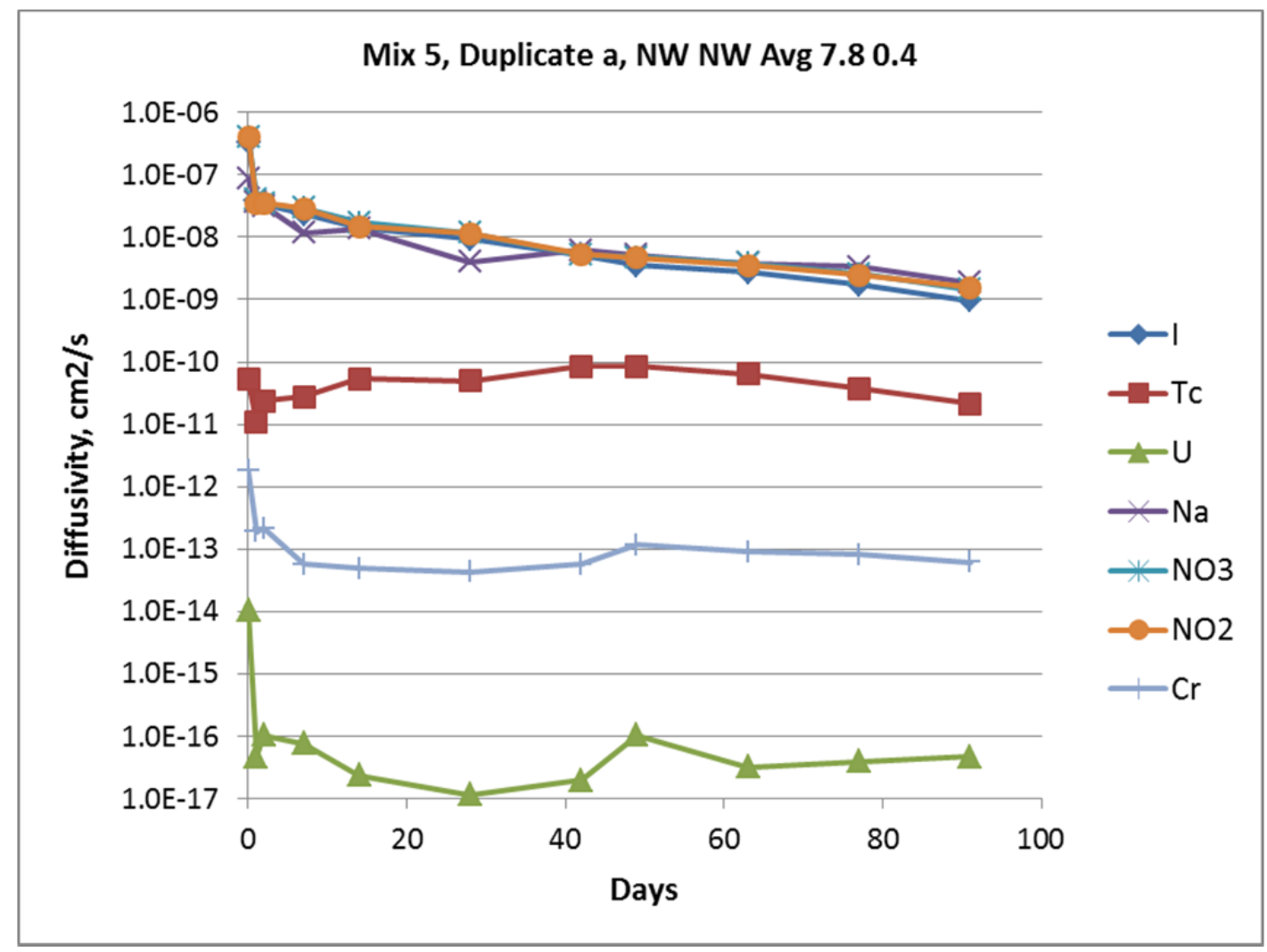

Figure 7-6. Range of Effective Diffusivities for Selected Waste Components

Each of the waste constituents' leach properties is discussed further in the sections that follow. Figures show the range of effective diffusivities across the 26 Cast Stone mixes. As discussed in the processing properties discussions of Section 6.0, some of these 26 formulations are not viable from a processing perspective and would not be used in production operations. The figures also show some of the impacts of waste composition and the dry blend mix. Detailed discussion of the statistical analyses of the leach test results follows in Section 8.0. Calculated effective diffusivities for $\mathrm{Na}$, nitrate, nitrite, iodine, $\mathrm{Tc}, \mathrm{Cr}$, and $\mathrm{U}$ are provided in Tables $\mathrm{D}-7$ through $\mathrm{D}-13$ in Appendix D.

\subsubsection{Sodium Effective Diffusivity Results}

Figure 7-7 shows the range of Na effective diffusivities observed among the 26 Cast Stone mixes in the screening test matrix (Table 2-1). The mix designations "a" and " $b$ " refer to the duplicate 


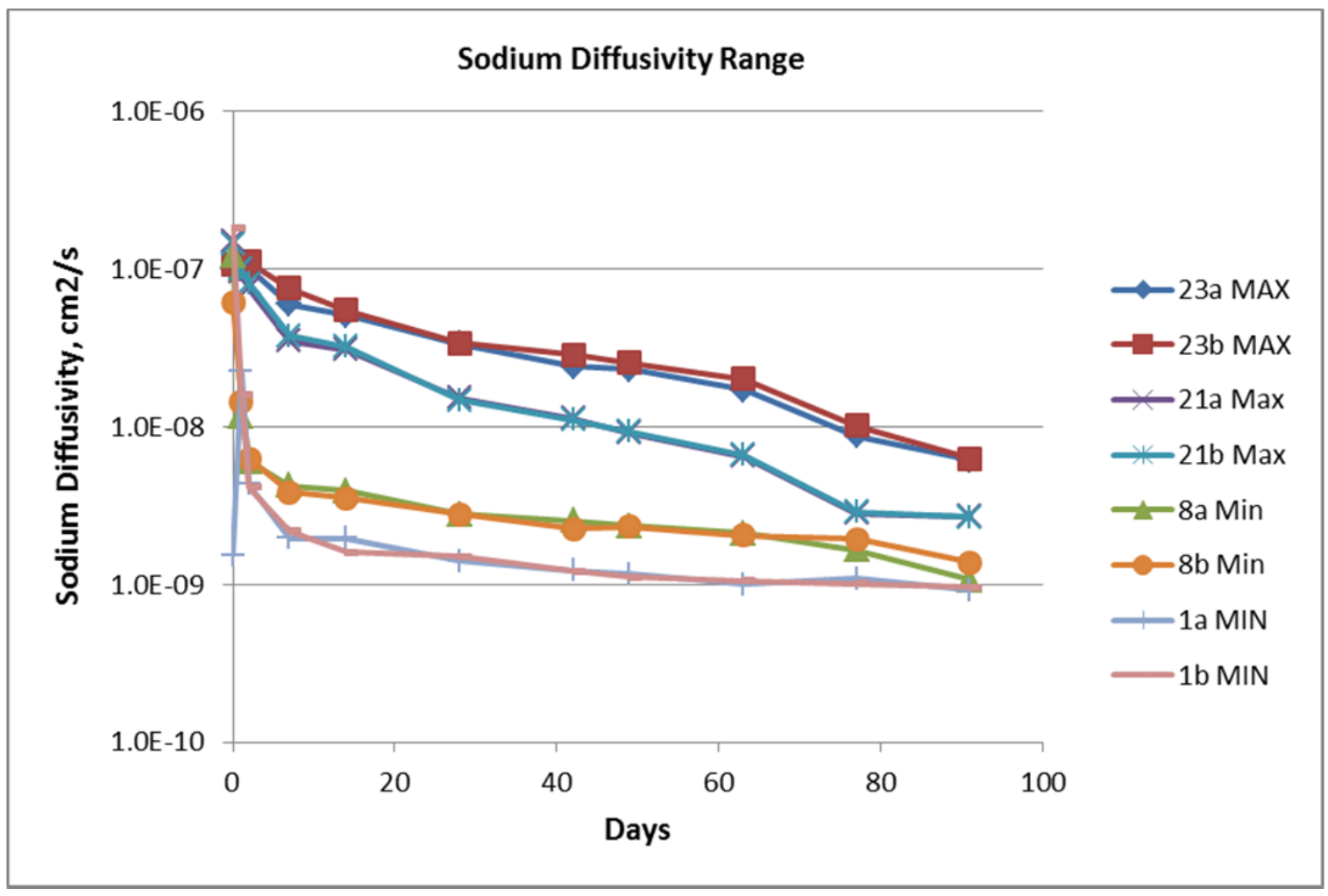

Figure 7-7. Range of Sodium Effective Diffusivities

samples of each Cast Stone mix. At the extremes, the Na diffusivities are bounded by Mix 23 on the high end and Mix 1 on the low end. Because of processing properties (i.e., Mix 1 set up immediately, Mix 23 set too slowly), neither of these mixes would be considered for actual production. Excluding these two mixes, the Na diffusivities are approximately bounded by Mixes 21 and 8. At 63 days, the range of $\mathrm{Na}$ effective diffusivities among the remaining 24 mixes is between $1.7 \times 10^{-9}$ and $8.0 \times 10^{-9} \mathrm{~cm}^{2} / \mathrm{s}$ (Mixes 19 and 24 , respectively).

Figure 7-8 compares the effective diffusivities for mixes with the NW dry blend components and mixes with the SE dry blend components for the High $\mathrm{SO}_{4}$, High Al, and SST Blend simulants at the same Na molarities and water-to-dry-blend solids ratios. There appears to be some impact of the source of the dry blend components; the NW dry blend components yield Cast Stone mixes with slightly higher Na effective diffusivities than the SE dry blend components.

Figure 7-9 shows the Na effective diffusivities for the NW dry blend components and the four simulants used in the screening test matrix. The different simulant compositions appear to have no impact on the Na diffusivity. All three Na diffusivity figures show that the effective diffusion coefficients for the duplicate samples ( $a$ and $b$ ) for each mix yield very similar values. 

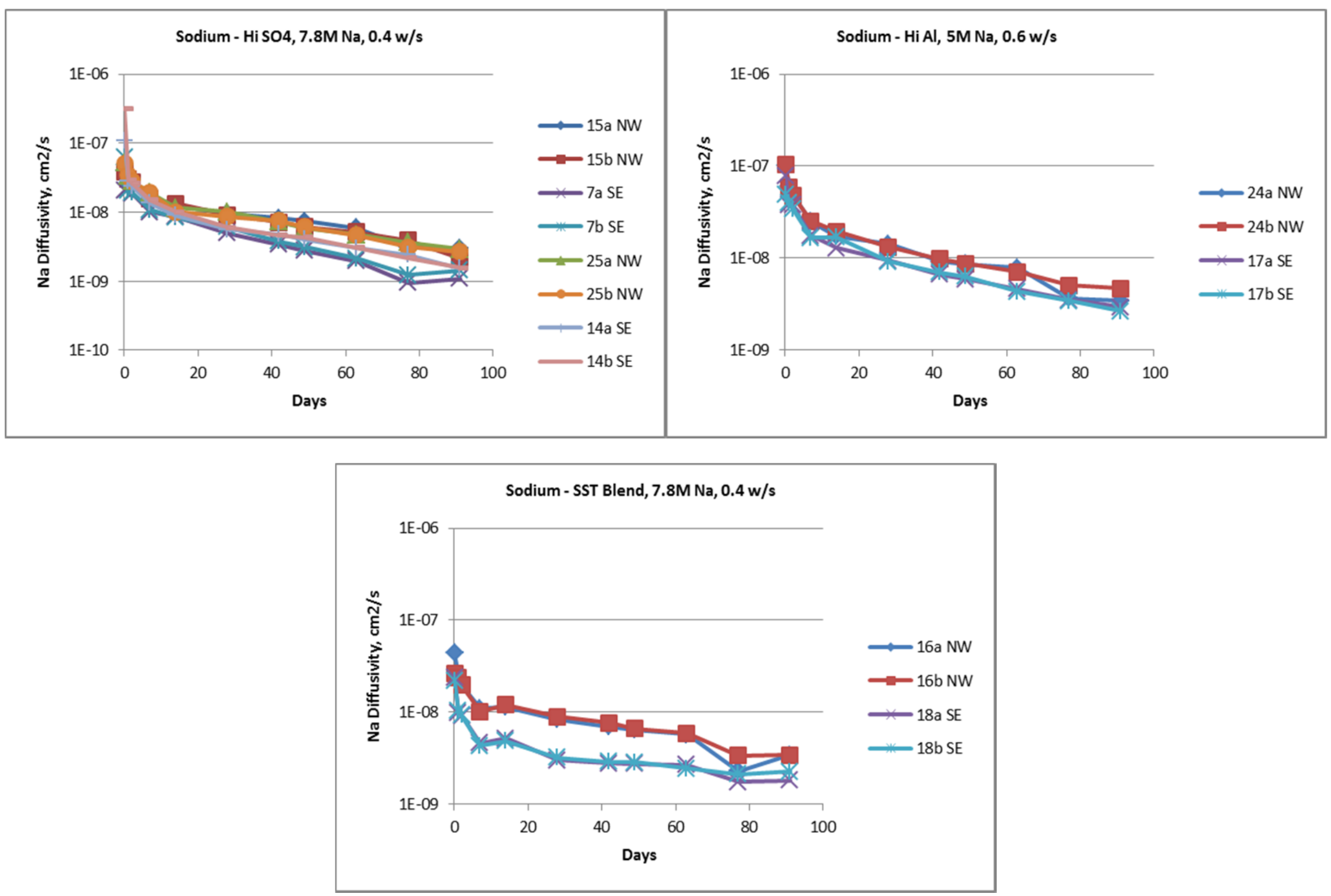

Figure 7-8. Impact of Dry Blend Mix on Sodium Effective Diffusivities 

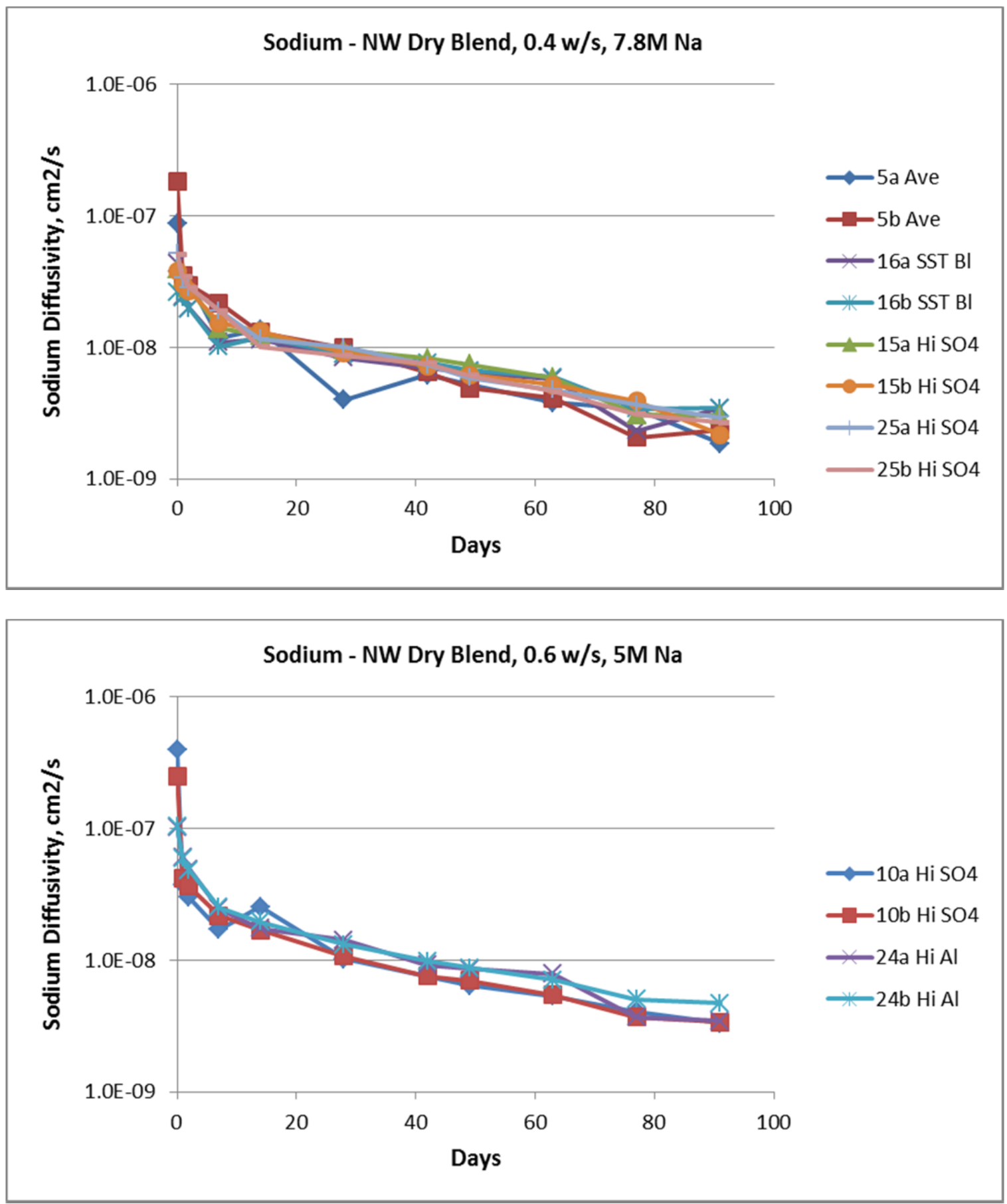

Figure 7-9. Impact of Waste Composition on Sodium Effective Diffusivities

\subsubsection{Nitrate and Nitrite Effective Diffusivities}

Statistical analysis of the leach test results for nitrate and nitrite showed that the effective diffusivities of these two constituents were highly correlated (see Figure 8-3 in Section 8). Therefore, this section covers both anions and the discussion focuses on nitrates as representing 
both species. Figure 8-3 also shows that the Na leach test results are strongly correlated with the nitrate and nitrite leach test results, so the results described here are very similar to those for $\mathrm{Na}$ described above.

Figure 7-10 shows the range of nitrate effective diffusivities observed among the 26 Cast Stone mixes in the screening test matrix. As with $\mathrm{Na}$, at the extremes, the nitrate and nitrite diffusivities are bounded by Mix 23 on the high end and Mix 1 on the low end. Because of processing properties, neither of these mixes would be considered for actual production. Excluding these two mixes, the nitrate and nitrite diffusivities are bounded by Mixes 21 and 8. At 63 days, the range of nitrate effective diffusivities among the remaining 24 mixes is between $2.3 \times 10^{-9}$ and $1.0 \times 10^{-8} \mathrm{~cm}^{2} / \mathrm{s}$ (Mixes 19 and 21, respectively). For nitrite, the range of effective diffusivities for these remaining 24 mixes at 63 days is between $2.2 \times 10^{-9}$ and $9.6 \times 10^{-9} \mathrm{~cm}^{2} / \mathrm{s}$ (Mixes 8 and 11 , respectively).

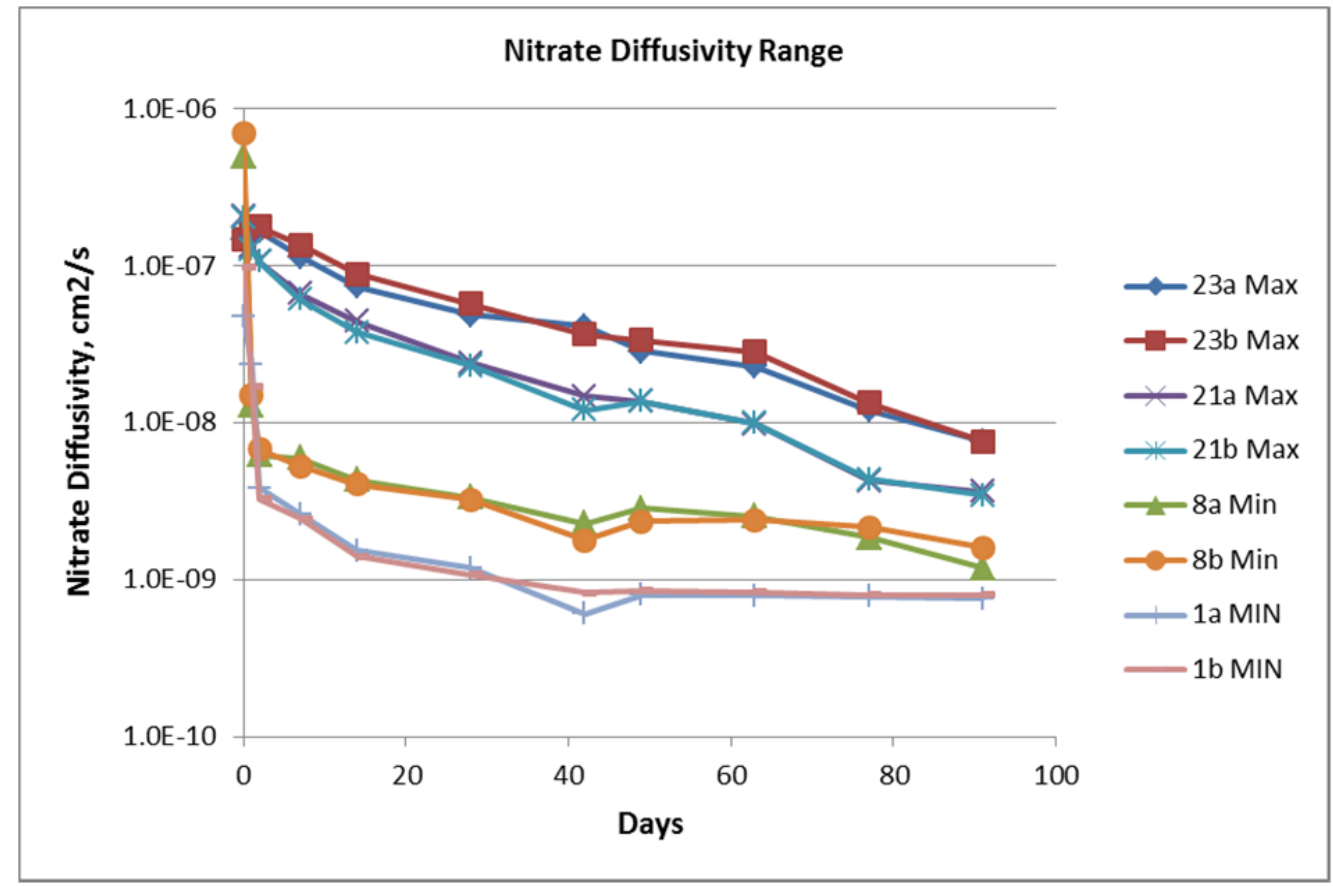

Figure 7-10. Range of Nitrate Effective Diffusivities

Figure 7-11 compares the effective diffusivities for mixes with the NW dry blend components and mixes with the SE dry blend components for the High $\mathrm{SO}_{4}$, High Al, and SST Blend simulants at the same Na molarities and water-to-dry-blend solids ratios. Other than for the SST Blend, the source of the dry blend components does not appear to have any significant impact on the nitrate diffusivity values. For the SST Blend, the Cast Stone monoliths prepared with the NW-NW dry blend appear to leach slightly more nitrate than the Cast Stone made with SE-SE dry blend.

Figure 7-12 shows the nitrate effective diffusivities for the NW dry blend components and the four simulants used in the screening test matrix. The different simulant compositions do not appear to have any impact on nitrate diffusivity. All three nitrate diffusivity figures show that the nitrate effective diffusion coefficients for the duplicate samples ( $a$ and $b$ ) for each mix yield very similar values. 

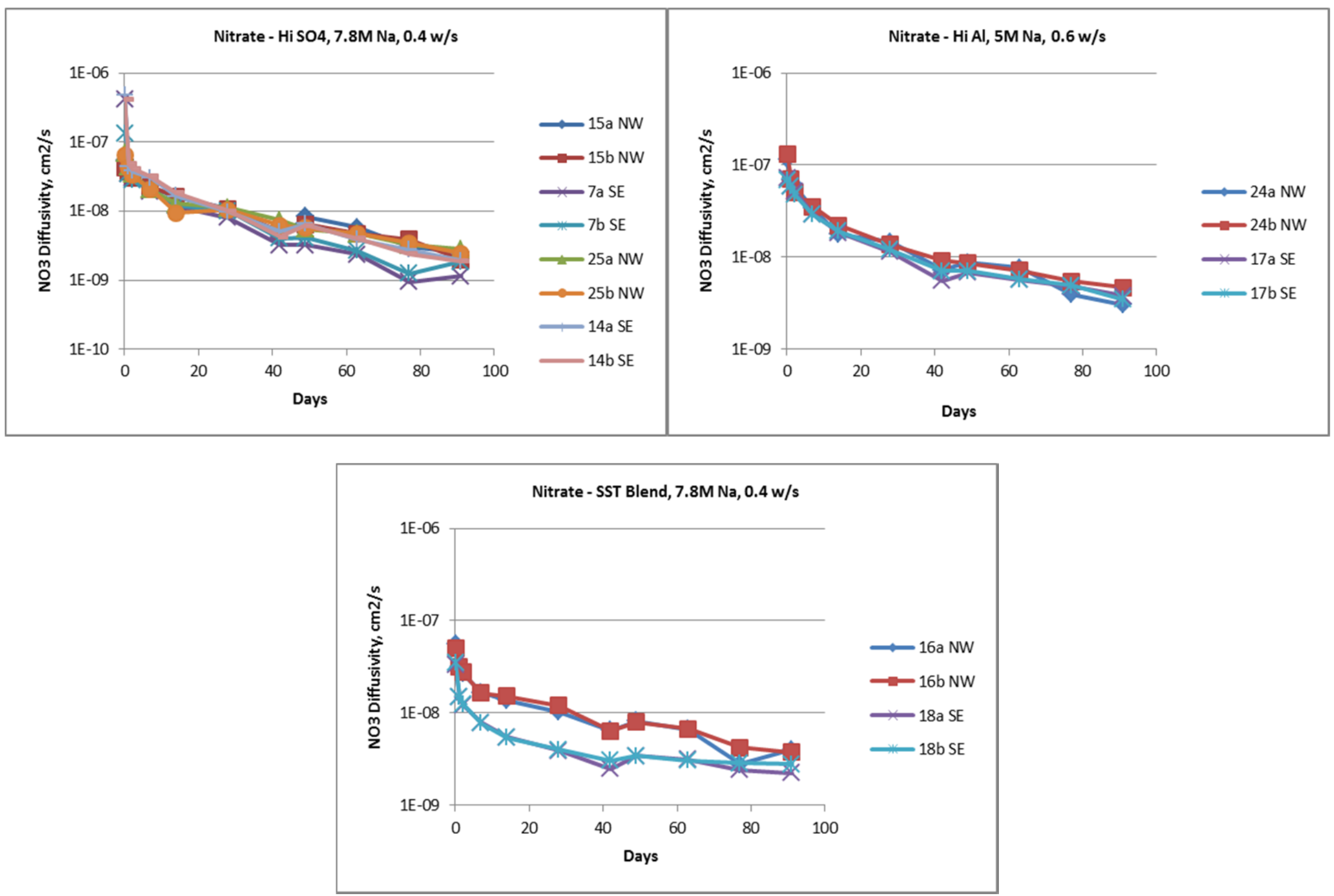

Figure 7-11. Impact of Dry Blend Mix on Nitrate Effective Diffusivities 

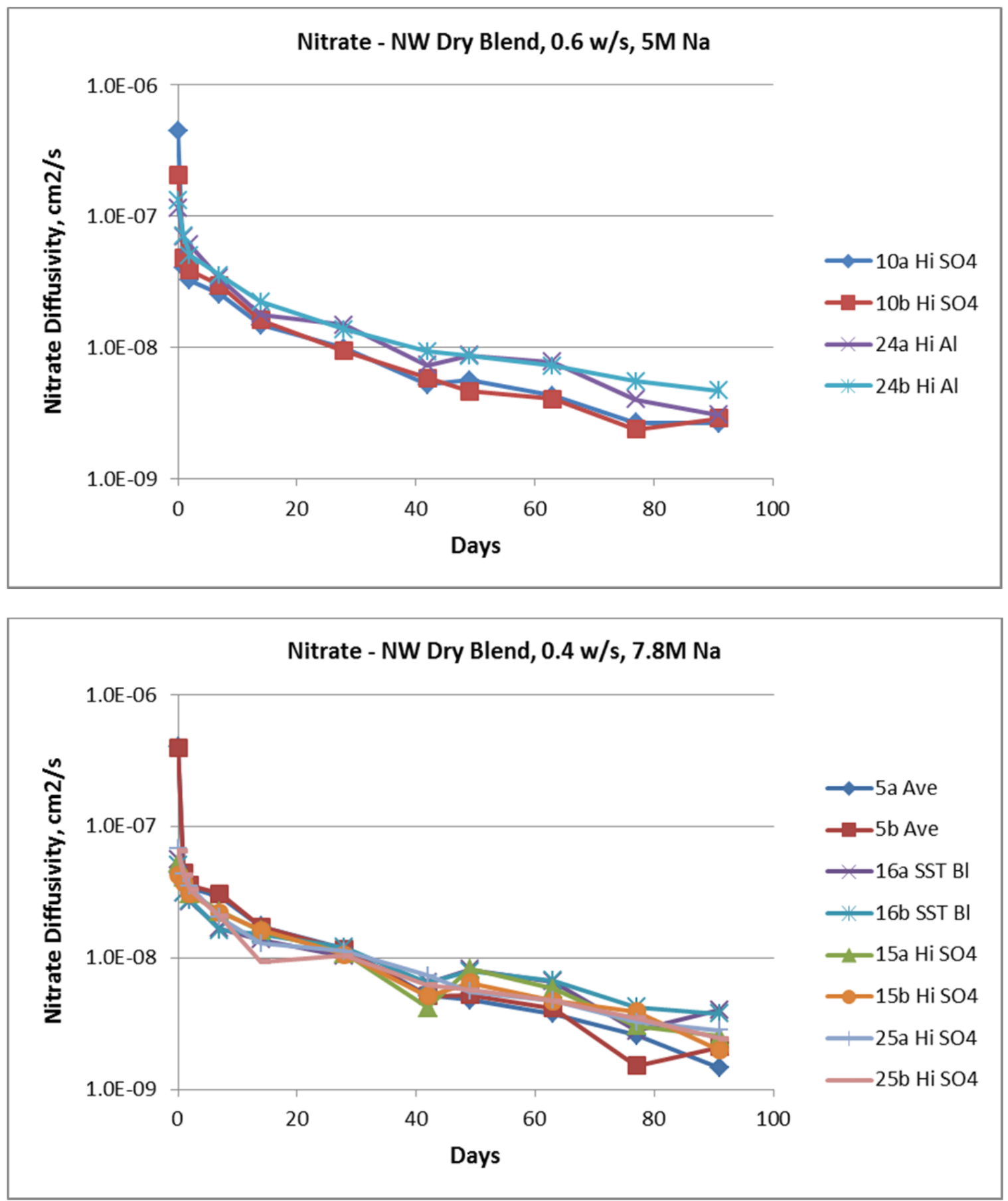

Figure 7-12. Impact of Waste Composition on Nitrate Effective Diffusivities

\subsubsection{Iodine Effective Diffusivities}

Figure 7-13 shows the range of I (added as iodide) effective diffusivities observed among the 26 Cast Stone mixes in the screening test matrix. As with $\mathrm{Na}$, nitrate, and nitrite discussed above, the I diffusivities are bounded by Mix 23 on the high end and Mix 1 on the low end. Because of processing properties, neither of these mixes would be considered for actual production. 
Excluding these two mixes, the I diffusivities are approximately bounded by Mixes 21 and 8 . At 63 days, the range of I effective diffusivities among the 24 remaining mixes is between $2.0 \times 10^{-9}$ and $1.2 \times 10^{-8} \mathrm{~cm}^{2} / \mathrm{s}$ (Mixes 7 and 11 , respectively).

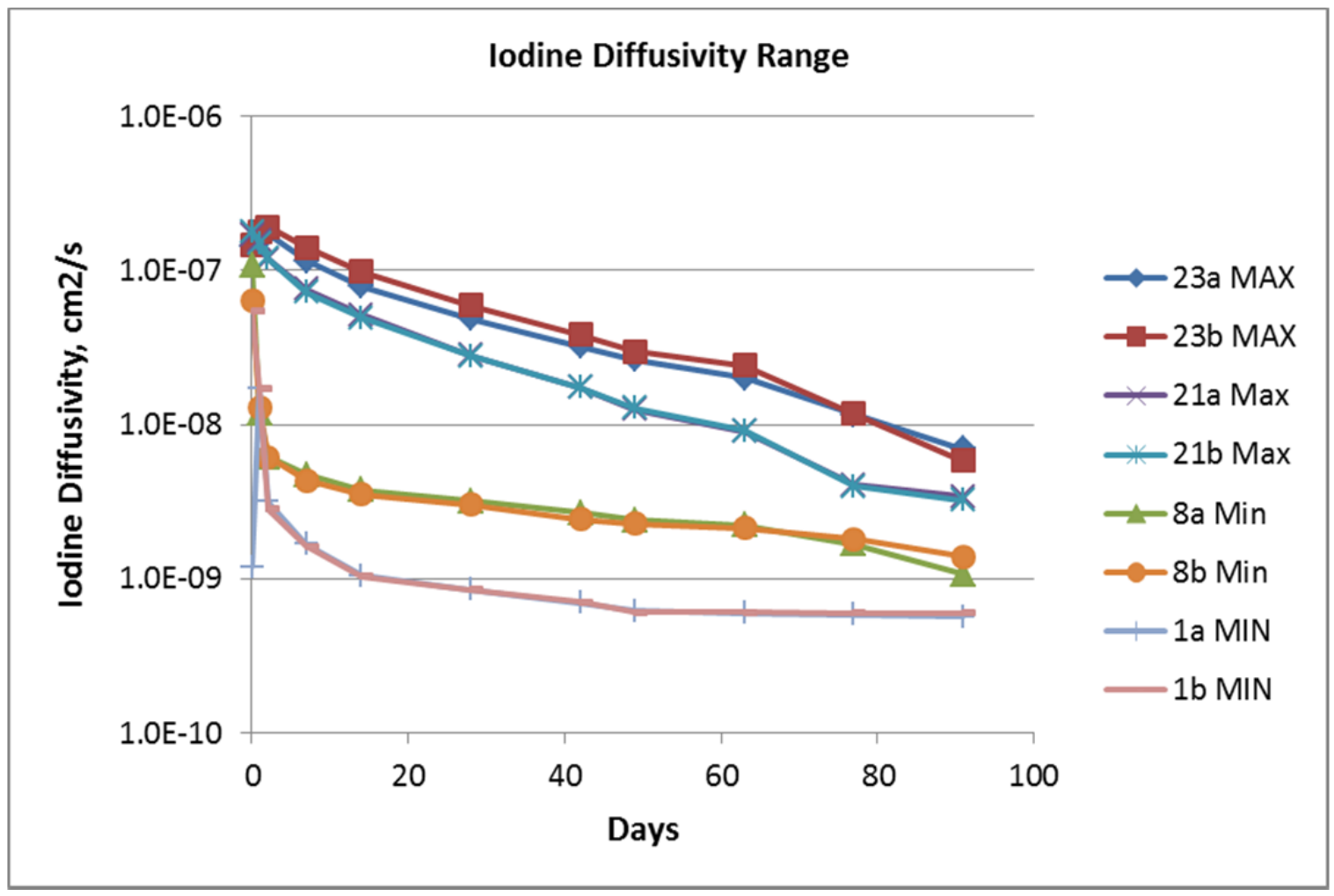

Figure 7-13. Range of Iodine Effective Diffusivities

Figure 7-14 compares the iodide effective diffusivities for mixes with the NW dry blend components and mixes with the SE dry blend components for the High $\mathrm{SO}_{4}$, High Al, and SST Blend simulants at the same $\mathrm{Na}$ molarities and water-to-dry-blend solids ratios. Other than for the SST Blend, the source of the dry blend components does not appear to have any impact on the iodide effective diffusivities. For the SST Blend, the NW-NW dry blend Cast Stone monoliths appear to leach slightly more I than the Cast Stone made with SE-SE dry blend.

Figure 7-15 shows the I effective diffusivities for the NW dry blend components and the four simulants used in the screening test matrix. The different simulant compositions do not appear to have any impact on the I diffusivity at $7.8 \mathrm{M} \mathrm{Na}$. There appears to be a slight difference in the I effective diffusivities between the High $\mathrm{SO}_{4}$ and $\mathrm{High} \mathrm{Al}$ wastes at $5 \mathrm{M} \mathrm{Na}$. All three iodine diffusivity figures show that the I effective diffusion coefficients for the duplicate samples (a and b) for each mix yield very similar values. 

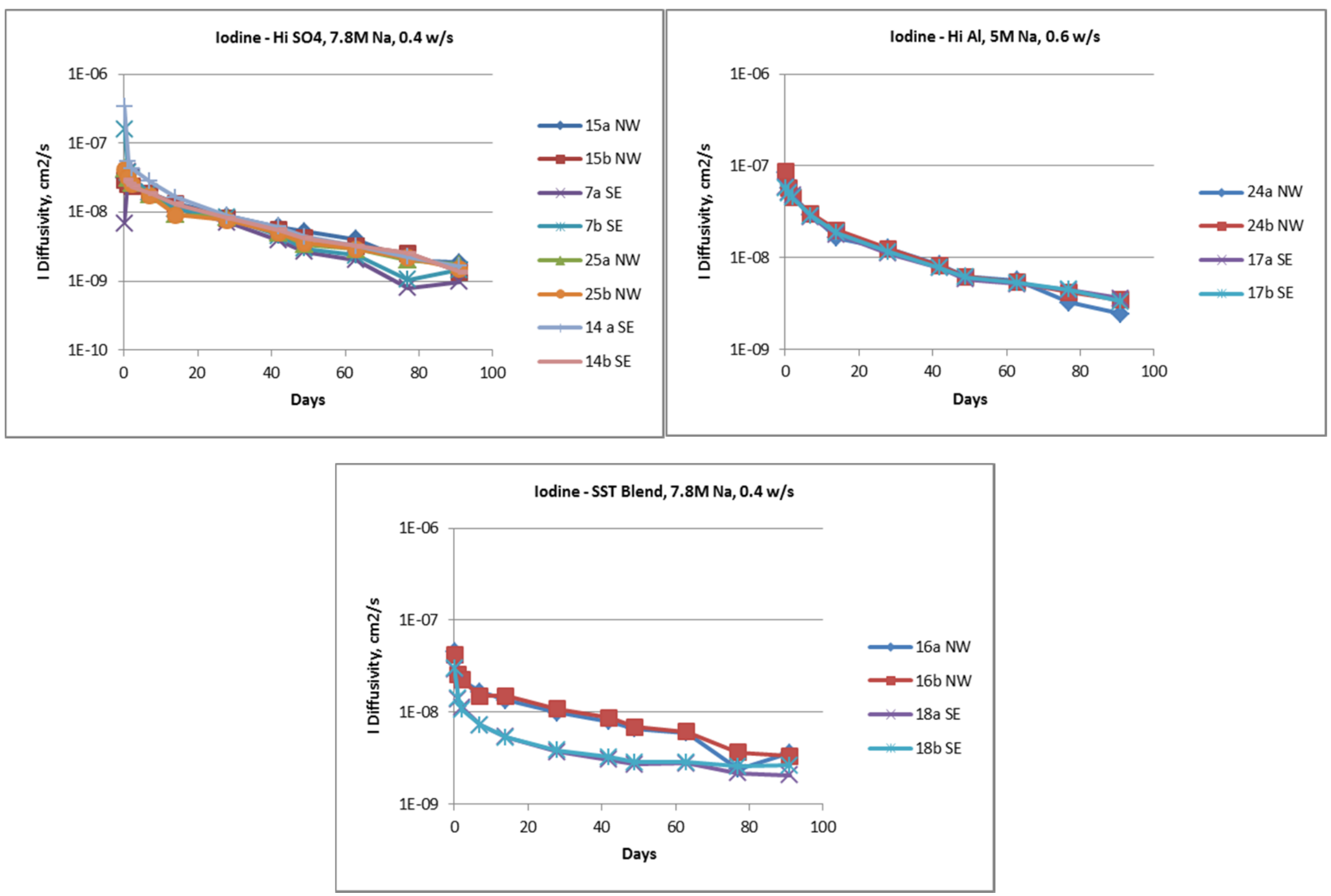

Figure 7-14. Impact of Dry Blend Mix on Iodine Effective Diffusivities 

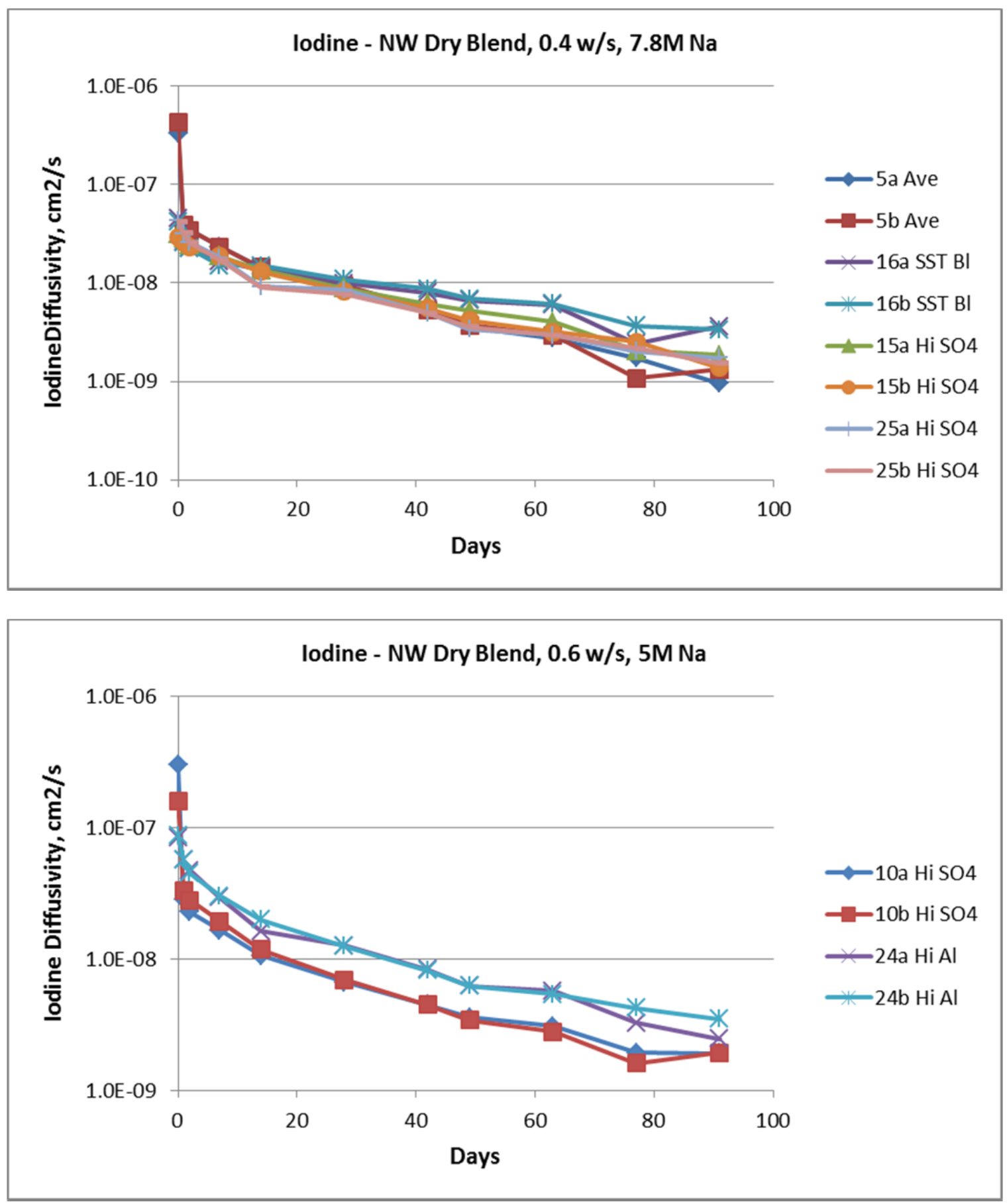

Figure 7-15. Impact of Waste Composition on Iodine Effective Diffusivities

\subsubsection{Technetium Effective Diffusivities}

Figure 7-16 shows the range of Tc effective diffusivities observed among the 26 Cast Stone mixes in the screening test matrix. Mix 23 had the highest Tc diffusivities of the 26 mixes. Because of processing properties, this mix would not be considered for actual production. Unlike the $\mathrm{Na}$, nitrate/nitrite, and I diffusivities discussed above where Mix 1 represented a lower bound, 
Mix 18 had the lowest Tc diffusivities from 28 through 63 days. At 63 days, the range of Tc effective diffusivities among the 25 mixes is between $6.8 \times 10^{-12}$ and $2.3 \times 10^{-10} \mathrm{~cm}^{2} / \mathrm{s}$ (Mixes 18 and 8 , respectively).

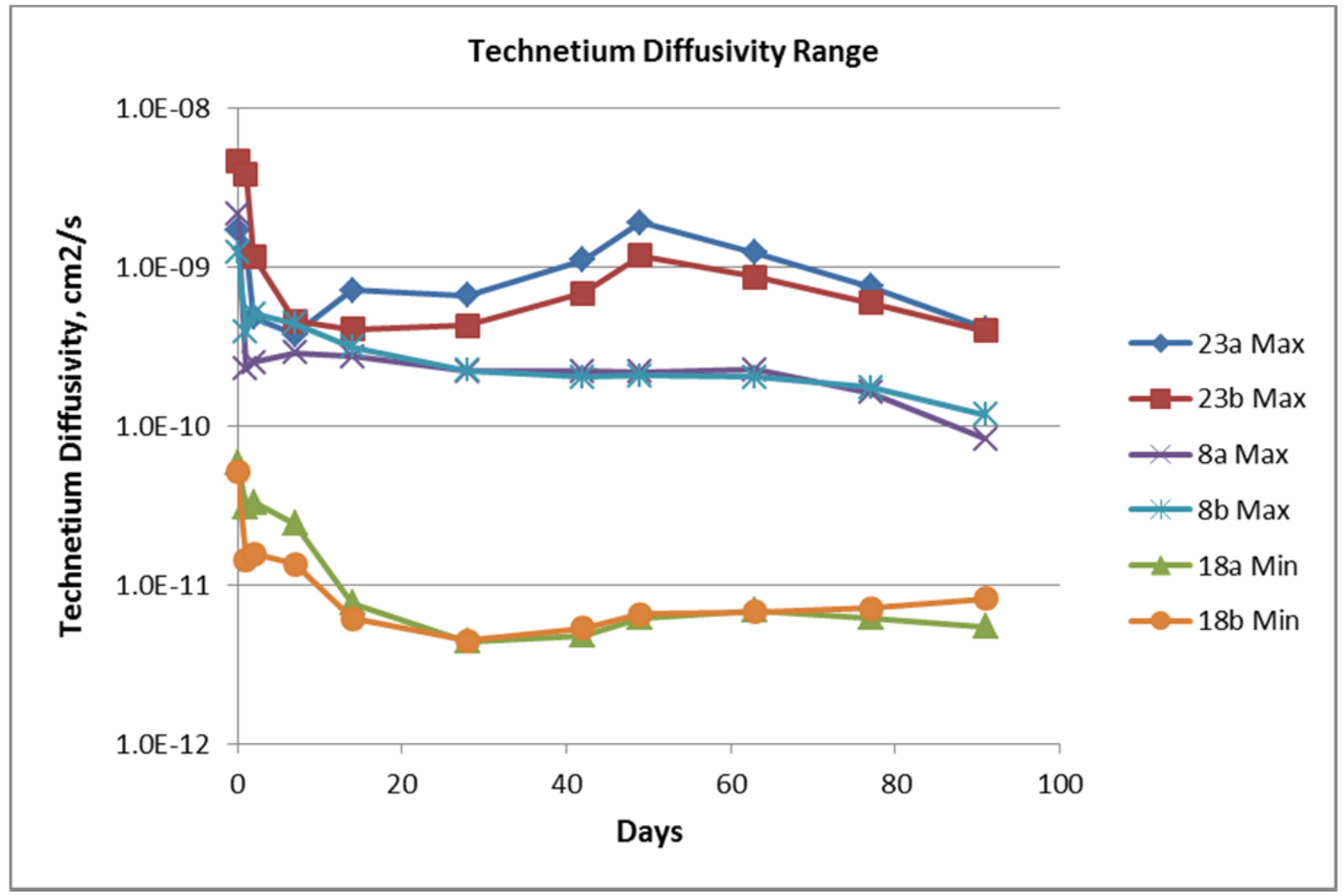

Figure 7-16. Range of Technetium Effective Diffusivities

Figure 7-17 compares the effective diffusivities for mixes with NW dry blend components and mixes with the SE dry blend components for the High $\mathrm{SO}_{4}$, High Al, and SST Blend simulants at the same Na molarities and water-to-dry-blend solids ratios. The source of the dry blend components appears to have an impact, but the trend is not consistent across the three simulants. Technetium diffusivities are lower for the SE dry blend components with the High $\mathrm{SO}_{4}$ and SST Blend simulants. However, for the High Al simulant, the Tc diffusivities are lower Cast Stone prepared with the NW dry blend ingredients.

Figure 7-18 shows the Tc effective diffusivities for the NW dry blend components and the four simulants used in the screening test matrix. All three Tc diffusivity figures show in general that the Tc effective diffusion coefficients for the duplicate samples ( $a$ and $b$ ) for each mix yield very similar values. The Tc effective diffusion coefficient values for a few of the mixes at particular leach times show some variation between the two duplicates, but the differences are small and show no time or mix consistency and thus are not considered practically important. 

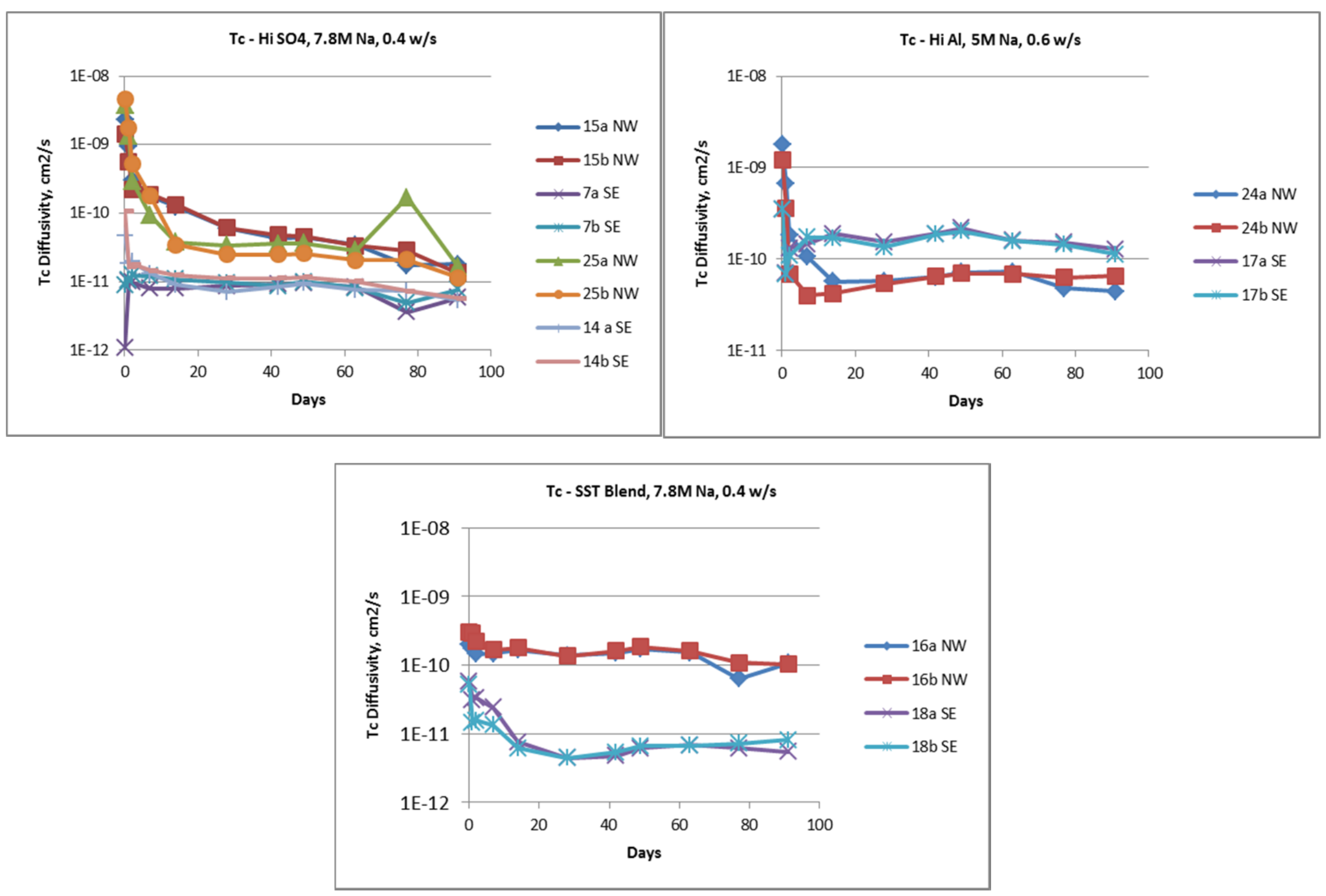

Figure 7-17. Impact of Dry Blend Mix on Technetium Effective Diffusivities 

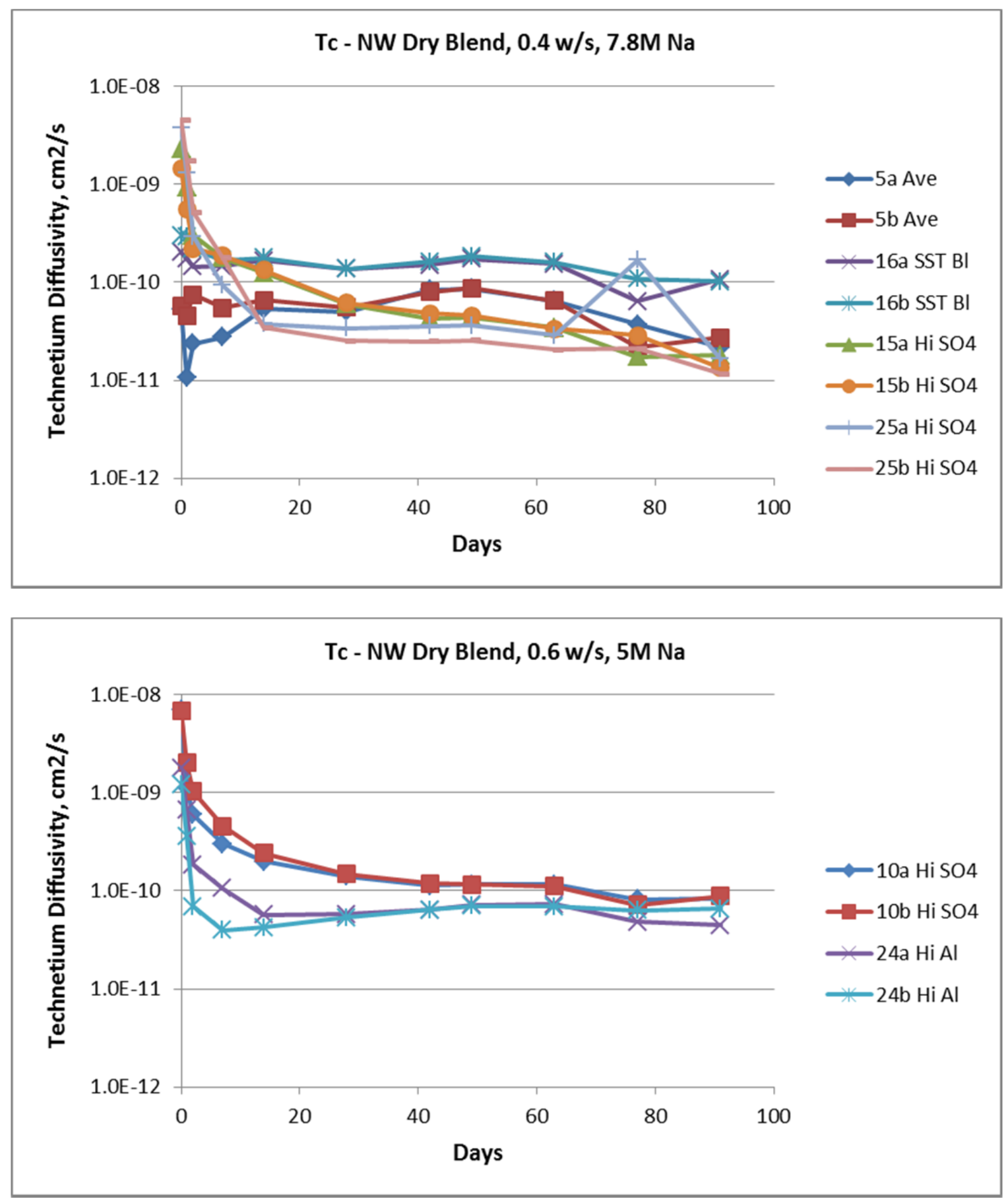

Figure 7-18. Impact of Waste Composition on Technetium Effective Diffusivities

\subsubsection{Chromium Effective Diffusivities}

Figure 7-19 shows the range of Cr effective diffusivities observed among the 26 Cast Stone mixes in the screening test matrix. At longer times, Mix 23 has the highest $\mathrm{Cr}$ diffusivities, but the differences between the next highest mixes ( 8 and 10) are not as great as those observed for the other species leached. As mentioned previously, Mix 23 would not be considered a viable recipe 
for producing Cast Stone on a full scale. One replicate pair of mixes (\#7 and \#14) had the lowest $\mathrm{Cr}$ diffusivities. At 63 days, the range of $\mathrm{Cr}$ effective diffusivities among the 24 viable mixes is between $1.0 \times 10^{-14}$ and $8.3 \times 10^{-13} \mathrm{~cm}^{2} / \mathrm{s}$ (Mixes 7 and 10 , respectively).

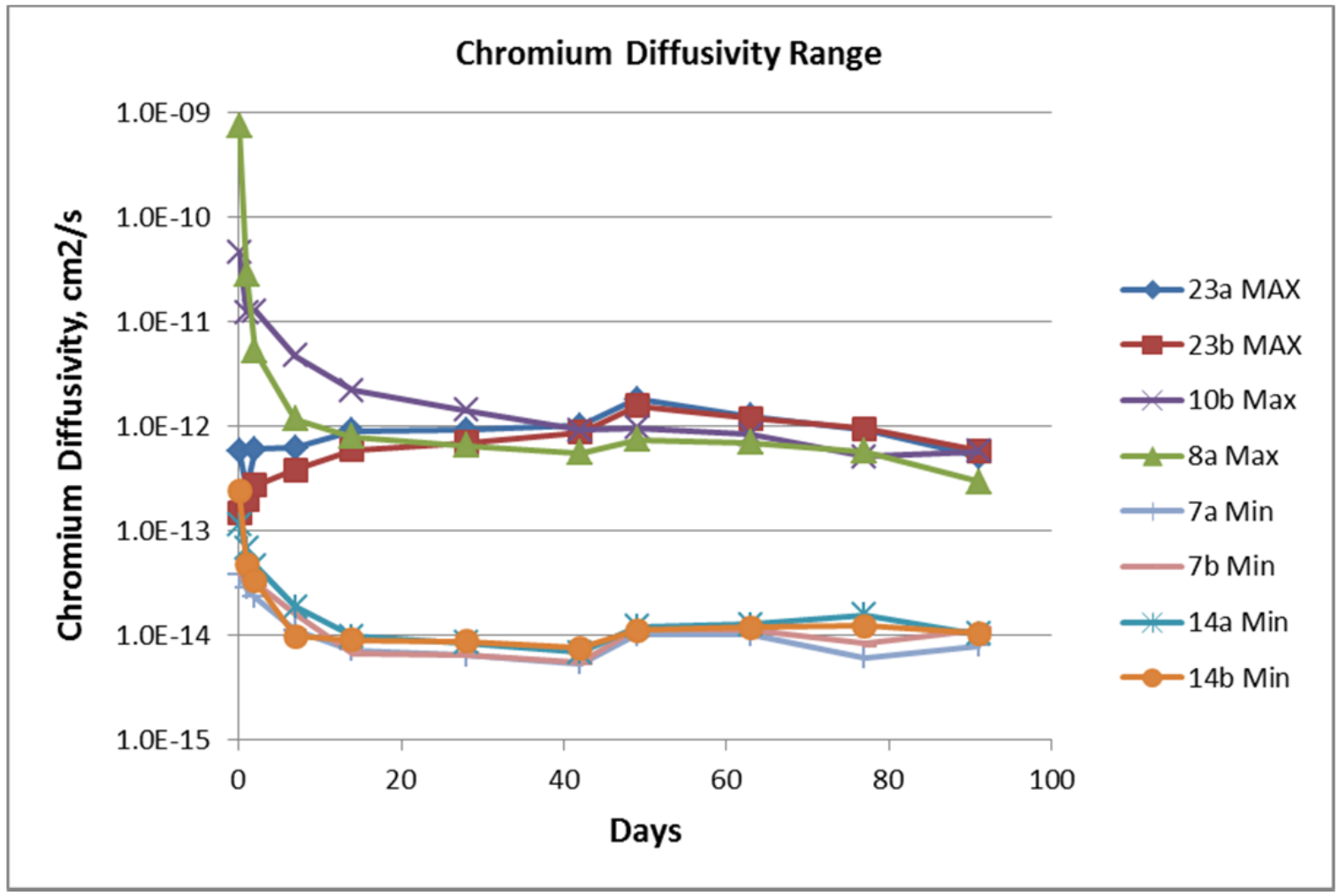

Figure 7-19. Range of Chromium Effective Diffusivities

Figure 7-20 compares the effective diffusivities of mixes with the NW dry blend components and mixes with the SE dry blend components for the High $\mathrm{SO}_{4}$, High Al, and SST Blend simulants at the same $\mathrm{Na}$ molarities and water-to-dry-blend solids ratios. The source of the dry blend components appears to have an impact, but the trend is not consistent across all the simulants. Chromium diffusivities are lower for the SE dry blend components with the High $\mathrm{SO}_{4}$ and SST Blend simulants. However, for the High Al simulant, the $\mathrm{Cr}$ diffusivities are indistinguishable between the two dry blend mixes. It should be noted that for the SST Blend, the 49- and 63-day Cr concentrations for the Mix 18 leachates were below analytical detection limits.

Figure 7-21 shows the Cr effective diffusivities for the NW dry blend components and the four simulants used in the screening test matrix. Although there are differences in the $\mathrm{Cr}$ diffusivities during the early part of the leach tests, at 49 and 63 days there does not appear to be any significant difference due to the simulant compositions at $7.8 \mathrm{M} \mathrm{Na}$. There appears to be a slight difference in the $\mathrm{Cr}$ effective diffusivities between the High $\mathrm{SO}_{4}$ and High Al wastes at $5 \mathrm{M} \mathrm{Na}$. All three $\mathrm{Cr}$ diffusivity figures show that the effective diffusion coefficients for the duplicate samples ( $a$ and $b$ ) for each mix beyond the first 21 days of leaching yield very similar values. 

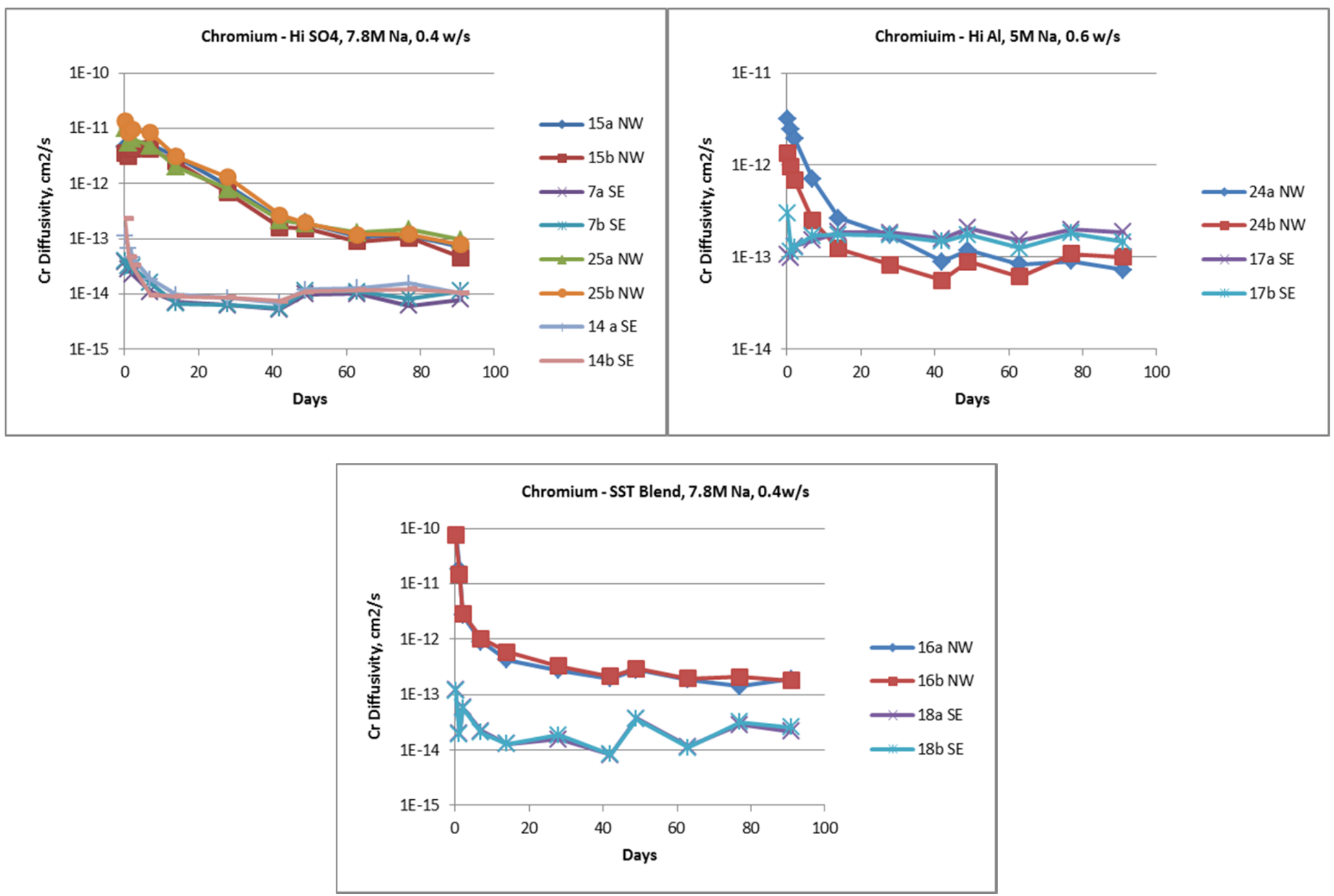

Figure 7-20. Impact of Dry Blend Mix on Chromium Effective Diffusivities 

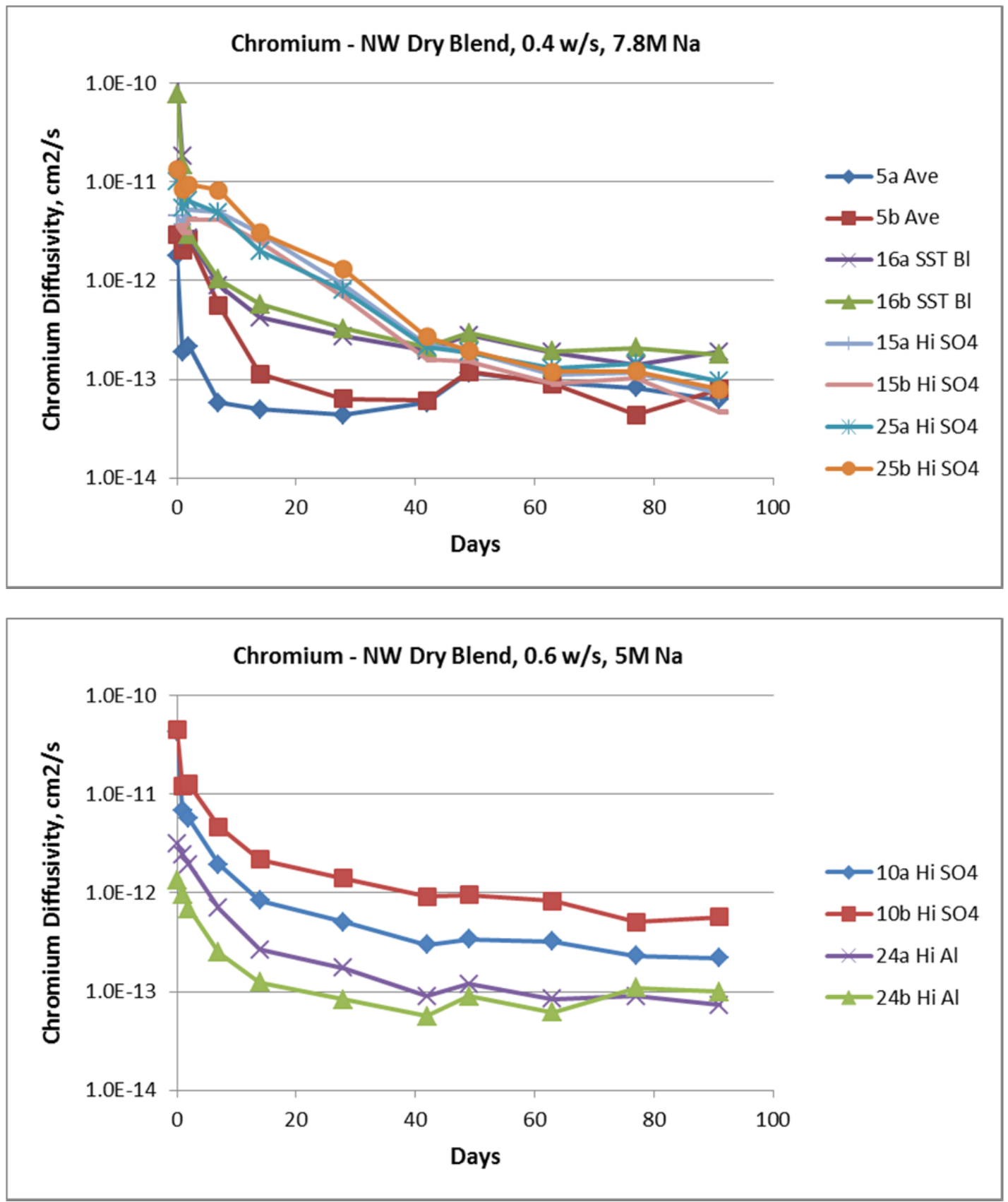

Figure 7-21. Impact of Waste Composition on Chromium Effective Diffusivities

\subsubsection{Uranium Effective Diffusivities}

Figure 7-22 shows the range of $U$ calculated effective diffusivities observed among the 26 Cast Stone mixes in the screening test matrix. Uranium was not detected in most of the leachates through 91 days of testing for the 26 mixes. The curves labeled " $U<$ Min a" and " $U<$ Min b" are the minimum effective diffusivities calculated from the analytical detection limits for $U$ in the tests. Only Mixes 1, 8, 16, 18, and 23 had measureable $U$ concentrations for the leachates for the entire 91 days of the test. Figure 7-23 shows the U effective diffusivities for these five mixes. At 63 days, the diffusivities were in the range of $1.1 \times 10^{-16}$ and $6.0 \times 10^{-16} \mathrm{~cm}^{2} / \mathrm{s}$. As mentioned, 
Mix 23 had processability issues and would not be a candidate for full production of Cast Stone. All three $U$ diffusivity figures show that the effective diffusion coefficients for the duplicate samples $(a$ and $b$ ) for each mix yield very similar values.

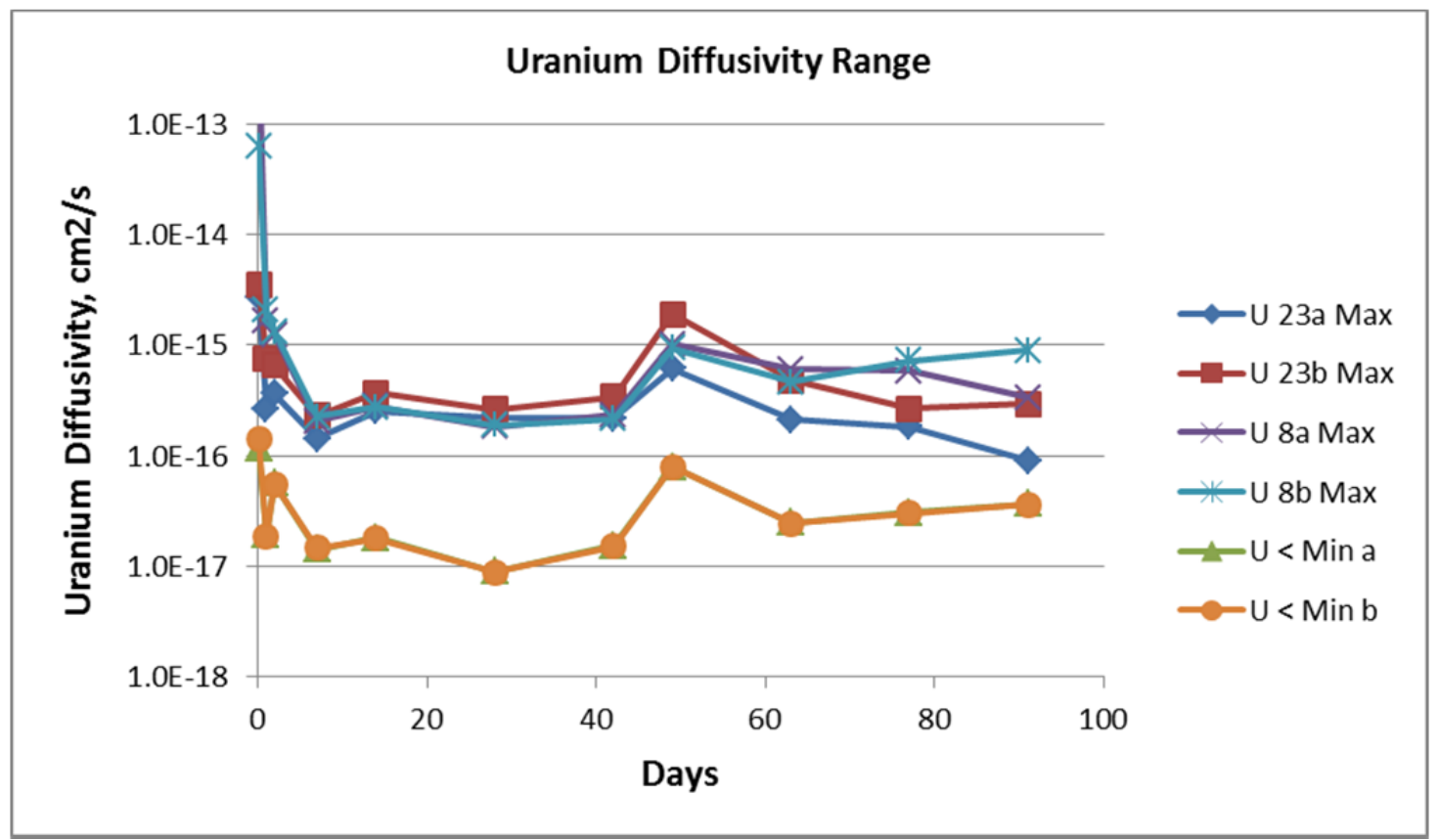

Figure 7-22. Range of Uranium Diffusivities

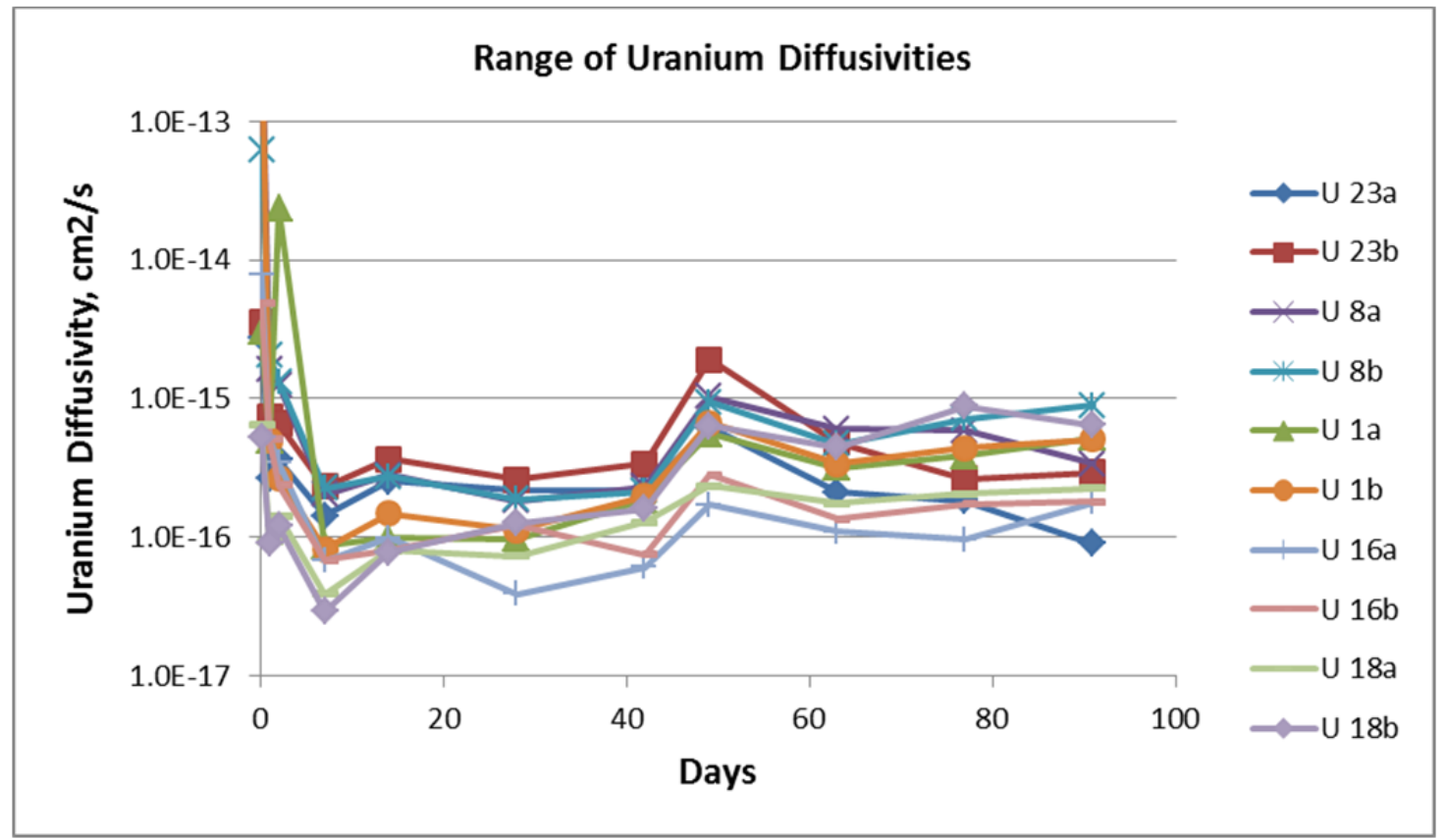

Figure 7-23. Range of Uranium Diffusivities for Specimens with Measurable Uranium Concentrations in all the Leachates 
PNNL-22747

SRNL-STI-2013-00465

\subsection{Statistical Analysis of the Effects of Screening Test Parameters on Cast Stone Properties}

Statistical analyses were performed for several Cast Stone processing and cured waste form properties. The objectives of the statistical analyses were to 1) determine whether individual test parameters and their two-parameter interactions have statistically significant effects on a given property, and 2) assess the relative magnitudes of these effects. Sections 8.1 to 8.3 describe the background and two approaches used for statistical analyses of data from the Cast Stone screening tests. Section 8.4 discusses cautions that should be kept in mind when considering results of the two statistical analysis approaches described in Sections 8.2 and 8.3. Section 8.5 presents estimates of the experimental and measurement uncertainties in Cast Stone properties based on the five pairs of replicate tests. The results of applying the two statistical data analysis approaches are discussed for Cast Stone processing properties in Section 8.6 and cured properties in Section 8.7. Finally, Section 8.8 summarizes the results of the statistical analyses.

\subsection{Statistical Analysis Approaches}

Typically in screening experiments, the goal of the data analysis is to determine which test parameters have statistically significant effects and which do not. Fortunately, the total number of tests that could be performed in the test matrix was sufficient to assess not only the individual effects of the parameters, but also the effects of some pre-specified two-parameter interactions. By pre-specifying some two-parameter interactions of interest, it was assumed the remaining twoparameter interactions (as well as higher-order interactions) were not significant. As described in Section A.3 in Appendix A, some individual-parameter effects and two-parameter interactions were assumed to be not significant, and then the test matrix was developed to support estimating the remaining individual-parameter effects and two-parameter interactions.

Assessing individual-parameter effects and some two-parameter interactions with a limited number of experimental tests comes with a price. The price is that the parameter effects (individual and/or interaction) assumed to be not significant are partially aliased (i.e., confounded) with the parameter effects assumed to be significant. If the assumptions about nonsignificant effects are wrong, the results of the statistical data analyses could be misleading.

As discussed in Appendix A, the screening test matrix in Table 2-1 was developed under the following assumptions:

A. There is no difference in the effects of the Average and SST Blend simulants on Cast Stone properties.

B. Interactions of the Average and SST Blend simulants with other test parameters are not significant.

C. Interactions of BFS with other test parameters are not significant.

These assumptions were assessed as part of the data analysis methods described in Sections 8.2 and 8.3. As discussed subsequently, the critical assumption that the BFS interactions are not significant is not supported by the statistical analyses performed.

Two approaches to statistical analyses of the data were performed to assess whether the test parameters and their two-parameter interactions have statistically significant effects on each of several Cast Stone properties. The first approach involved fitting (for each property) a "Full Model" that allows for individual effects of the five test parameters (simulant, sodium molarity, 
fly ash source, BFS source, and mix ratio) and two-parameter interactions of all parameters except those involving BFS. Hence, the Full Model is larger than the model used to develop the experimental design, and provides for assessing Assumptions A and B above. The Full Model approach to statistical analyses of the Cast Stone screening test data is described in Section 8.2.

The second approach to statistical analysis involves using stepwise regression to build a model consisting of statistically significant individual parameter effects and two-parameter interaction effects. This second approach allows for selecting two-parameter interactions involving BFS as well as other two-parameter interactions. Hence, the second approach provides for assessing Assumption $\mathrm{C}$ above. This second approach to statistical analyses of the Cast Stone screening test data, referred to as the "Stepwise Model" approach, is described in Section 8.3.

\subsection{Full Model Approach to Statistical Analysis of the Screening Test Data}

This section discusses the Full Model and the corresponding data analysis approach.

\subsubsection{Full Model}

With screening test data collected according to Table $2-1$ or Table C-1, it is possible to fit a statistical model that includes 1) all individual parameter effects, and 2) all two-parameter interactions, except those involving the BFS source. This model is given by

$$
\begin{aligned}
y_{h i j k m} & =\mu+\operatorname{Sim}_{h}+\mathrm{NaMol}_{i}+F A_{j}+\mathrm{BFS}_{k}+\mathrm{MR}_{m}+\left(\operatorname{Sim}_{h} * \mathrm{NaMol}_{i}\right) \\
& +\left(\operatorname{Sim}_{h} * F A_{j}\right)+\left(\operatorname{Sim}_{h} * M R_{m}\right)+\left(\mathrm{NaMol}_{i} * F A_{j}\right) \\
& +\left(\mathrm{NaMol}_{i} * M R_{m}\right)+\left(\mathrm{FA}_{j} * M R_{m}\right)+\varepsilon_{h i j k m}
\end{aligned}
$$

where $\quad y_{h i j k m}=$ measured response value for the $h^{\text {th }}$ level of Sim, $i^{\text {th }}$ level of NaMol, $j^{\text {th }}$ level of $F A, k^{\text {th }}$ level of $B F S, m^{\text {th }}$ level of $M R$, and a random error

$\mu=$ true, unknown mean of the response $(y)$ over all combinations of the test parameters

$\operatorname{Sim}_{h}=$ effect of the $h^{\text {th }}$ level of simulant type, with four levels (Average, Blend, $\mathrm{HiAl}$, and $\mathrm{HiSO}_{4}$ )

$\mathrm{NaMol}_{i}=$ effect of the $i^{\text {th }}$ level of sodium molarity, with two levels (low $=5.0$, high $=7.8)$

$F A_{j}=$ effect of the $j^{\text {th }}$ level of fly ash, with two levels (low Ca, high Ca)

$B F S_{k}=$ effect of the $k^{\text {th }}$ level of blast furnace slag, with two levels (NW, SE)

$M R_{m}=$ effect of the $m^{\text {th }}$ level of mix ratio, with two levels $($ low $=0.4$, high $=0.6)$

$\varepsilon_{h i j k m}=$ random error in performing a test combination for the $h^{\text {th }}$ level of Sim, $i^{\text {th }}$ level of $N a M o l, j^{\text {th }}$ level of $F A, k^{\text {th }}$ level of $B F S$, and $m^{\text {th }}$ level of $M R$ and measuring the response value. The random errors are assumed to be normally distributed with mean 0 and standard deviation $\sigma$.

and the notation "P1 * $\mathrm{P} 2$ " denotes the two-parameter interaction involving parameters $\mathrm{P} 1$ and $\mathrm{P} 2$. 
The model of Equation (8-1) is referred to as an analysis of variance (ANOVA) model in which the effects associated with each model term sum to zero. The parameters NaMol, FA, BFS, and $M R$ each only have two levels. Hence, the effect of one level of each test parameter must be equal to the negative of the effect of the second level. Because Sim has four levels, the sum of the effects of those four levels must sum to zero. The effects of two-parameter interactions must also sum to zero over each of the two parameters. The subsets of parameter effects summing to zero is necessary to have an effect for each level of each parameter or interaction component, given that the model contains an overall mean term.

Note that the model in Equation (8-1) has a few differences compared to the model in Equation (A-2) in Appendix A.

- The model is written as an ANOVA model rather than a regression model. In the regression model of Equation (A-2), the parameters are either numeric or coded to take numeric values, and every model term has a numeric coefficient that can be estimated from experimental data. In the ANOVA model in Equation (8-1), each level of a parameter or component of an interaction has a numeric effect, but the effects must sum to zero for a given parameter and for each of the two parameters in a two-parameter interaction.

- The model does not assume that the Average and Blend simulants have the same effect on the Cast Stone properties and that the difference between these two simulants does not depend on (i.e., interact with) other test parameters. In this sense the model in Equation (8-1) is larger than the model in Equation (A-2).

- The model does not contain a Block term (see Appendix A for the explanation of the two blocks in the testing). Preliminary data analyses considered models with Block terms, but there was no strong evidence of a block effect for any of the Cast Stone properties statistically analyzed. Hence, the final models used for the data analyses do not contain such terms.

The model in Equation (8-1) is referred to as the Full Model because it provides for estimating and evaluating all the parameter effects thought to be significant plus effects involving differences between the Average and Blend simulants (which were assumed to be nonsignificant in developing the test matrix). In addition, the Full Model allows evaluating the correctness of Assumptions A and B discussed in Section 8.1.

\subsubsection{Fitting the Full Model and Summaries of Results}

The relationship between each response variable and the five test parameters is quantified with a fit of the Full Model to the experimental data using ordinary least squares (OLS). OLS rest on two key assumptions:

- Errors are independent and identically distributed (i.e., have constant variance).

- The two-parameter interactions involving BFS (which were excluded from the Full Model) and higher-order interactions have no significant effects on the response variables, as emphasized in Section 8.1.

For each Cast Stone property, the structure of the errors was evaluated with diagnostic plots, BoxCox transformations, and Levene's test for homogeneity of variance (Draper and Smith 1998). In 
addition, the fact that the run order of the experiment was randomized provides some assurance of error independence. Diagnostic evaluations indicated that log-transformations on two properties (plastic viscosity and compressive strength) produce a more constant variance (see discussion of the results for those properties in Sections 8.6.1 and 8.7.1, respectively).

Table 8-1 provides an overview of the Full Model relative to the number of data points available to estimate the effects of individual parameters and two-parameter interactions depending on whether a Cast Stone property has data corresponding to Table 2-1 (26 mixes) or Table C-1) (38 mixes). When a property has data corresponding to Table 2-1 with 26 tests, the Full Model will almost be fitted exactly (except for replicate variation) because it contains 20 free parameter effects $^{1}$ to be estimated using 21 distinct data points (because 5 of the 26 data points in the test matrix are replicates). Hence, there is only one degree of freedom (DOF) for assessing model lack-of-fit (LOF). For some Cast Stone Properties, a missing property value or removing one outlier led to a data set with 25 tests, in which case there are no DOF for assessing model LOF. For the Cast Stone properties with data for 38 mixes, there are 11 DOF for assessing model LOF. The five replicates for data according to Table 2-1, and the seven replicates for data according to Table C-1, provide for estimating the pure-error standard deviation (denoted in this report as RMSE $\left.E_{\mathrm{PE}}\right)$.

Table 8-1. Summary of the Full Model Relative to Available Data

\begin{tabular}{|c|c|c|c|c|}
\hline \multirow[b]{2}{*}{ Model Term } & \multirow{2}{*}{$\begin{array}{c}\text { \# Model } \\
\text { Effects }\end{array}$} & \multicolumn{3}{|c|}{ DOF $^{(\mathbf{a})}$} \\
\hline & & $\begin{array}{c}\text { Table } 2-1 \text {, } \\
26 \text { Tests }\end{array}$ & $\begin{array}{c}\text { Table } 2-1, \\
25 \text { Tests }\end{array}$ & $\begin{array}{c}\text { Table } 2-1 \text {, Table } \mathrm{C}-1 \text {, } \\
38 \text { Tests }\end{array}$ \\
\hline$\mu($ mean $)$ & 1 & 1 & 1 & 1 \\
\hline \multicolumn{5}{|c|}{ Individual Parameter Effects } \\
\hline Sim & 4 & 3 & 3 & 3 \\
\hline NaMol & 2 & 1 & 1 & 1 \\
\hline FA & 2 & 1 & 1 & 1 \\
\hline BFS & 2 & 1 & 1 & 1 \\
\hline MR & 2 & 1 & 1 & 1 \\
\hline \multicolumn{5}{|c|}{ Two-Parameter Interactions } \\
\hline Sim*NaMol & 8 & 3 & 3 & 3 \\
\hline Sim*FA & 8 & 3 & 3 & 3 \\
\hline Sim*MR & 8 & 3 & 3 & 3 \\
\hline NaMol*FA & 4 & 1 & 1 & 1 \\
\hline NaMol*MR & 4 & 1 & 1 & 1 \\
\hline $\mathrm{FA} * \mathrm{MR}$ & 4 & 1 & 1 & 1 \\
\hline \multicolumn{5}{|l|}{ Error } \\
\hline Lack of Fit & - & 1 & 0 & 11 \\
\hline Replicates & - & 5 & 5 & 7 \\
\hline Total & 49 & $26^{(b)}$ & 25 & 38 \\
\hline \multicolumn{5}{|c|}{$\begin{array}{l}\text { (a) DOF }=\text { degrees of freedom. The DOF are less than the number of effects because of } \\
\text { subsets of effects summing to zero. } \\
\text { (b) Total DOF }=\text { the number of data points. }\end{array}$} \\
\hline
\end{tabular}

\footnotetext{
${ }^{1}$ As mentioned in Section 8.1 and subsequently illustrated with examples in Section 8.2.4, subsets of parameter effects sum to zero in the Full Model. The number of "free parameter effects" is the number obtained by subtracting from the total number of parameter effects the number of sum-to-zero constraints that apply to the parameter effects.
} 
The test matrices in Table 2-1 and Table C-1 do not ensure that estimates of the effects in the Full Model are orthogonal, which means that two or more effects in the model may have some degree of linear relationship (referred to as collinearity). Use of OLS attempts to account for the collinearities that exist between the model effects, but may not be entirely successful. The possible negative consequences of collinearities include 1) inflating uncertainties of effect estimates, and 2) causing one effect to be assessed as statistically significant when it is actually one or more other effects that are the true (unknown) significant effects. Table 8-2 lists the largest (in absolute value) pairwise correlations among the terms included the Full Model. As seen in Table 8-2, several terms exhibit pairwise correlations greater in absolute value than 0.50 . However, it should be noted the vast majority of the pairwise correlations are below 0.33 .

Table 8-2. Largest Correlations Between Pairs of Terms in the Full Model for the Property "Heat Generation at 300 hr" and Leachability Properties. Correlations for other properties differ slightly from these because of missing values and different data sets for different properties. (For Information Only)

\begin{tabular}{|c|c|c|c|c|c|}
\hline \multicolumn{3}{|c|}{ Heat Generation at 300 Hours } & \multicolumn{3}{|c|}{ Leachability Indices } \\
\hline $\begin{array}{c}\text { Pairwise } \\
\text { Correlation }\end{array}$ & \multicolumn{2}{|c|}{ Pairs of Model Terms ${ }^{(a)}$} & $\begin{array}{c}\text { Pairwise } \\
\text { Correlation }\end{array}$ & \multicolumn{2}{|c|}{ Pairs of Model Terms ${ }^{(b)}$} \\
\hline-0.75 & SimHiSO4*NaMol & FlyAsh*MixRatio & 0.81 & SimBlend*NaMol & SimBlend*MixRat \\
\hline 0.75 & SimSO4*NaMol & FlyAsh*MixRatio & -0.78 & SimBlend*NaMol & SimHiAl*NaMol \\
\hline-0.72 & SimBlend*NaMol & FlyAsh*MixRatio & -0.78 & SimBlend*MixRat & SimHiAl*MixRat \\
\hline-0.72 & SimBlend*NaMol & SimHiAl*NaMol & -0.77 & SimHiPSF*NaMol & FlyAsh*MixRat \\
\hline 0.71 & NaMol*FlyAsh & FlyAsh*MixRatio & 0.77 & MixRat & SimBlend*MixRat \\
\hline-0.70 & SimHiAl*NaMol & SimHiSO4*NaMol & -0.73 & SimBlend & SimBlend*MixRat \\
\hline-0.69 & SimHiSO4*MixRatio & NaMol*FlyAsh & 0.70 & SimHiAl*NaMol & FlyAsh*MixRat \\
\hline-0.68 & SimBlend*MixRatio & NaMol*FlyAsh & -0.69 & SimBlend & MixRat \\
\hline-0.65 & SimHiSO4*FlyAsh & NaMol*MixRatio & 0.68 & SimHiAl*NaMol & NaMol*MixRat \\
\hline 0.63 & SimHiAl*NaMol & SimHiAl*FlyAsh & \begin{tabular}{|l|}
-0.68 \\
\end{tabular} & SimHiPSF*FlyAsh & NaMol*MixRat \\
\hline \multicolumn{6}{|c|}{$\begin{array}{l}\text { (a) The notation SimHiAl denotes the high Al simulant, with similar notation for the SST Blend and high } \mathrm{SO}_{4} \\
\text { simulants. }\end{array}$} \\
\hline
\end{tabular}

A fit of the Full Model to data for a Cast Stone property produces three sets of outputs for evaluation.

- Estimates of individual-parameter effects and two-parameter interactions, standard deviations of the estimates, and the statistical significance of the effect estimates.

- Summary statistics that quantify the adequacy of the Full Model fit.

- Table of effect differences that provides for assessing which two-level parameters have statistically significant effects and which of the four simulants have statistically different effects.

Each of these sets of outputs is discussed in the following subsections. In Sections 8.6 and 8.7, all three sets of output are summarized in one table (e.g., see Table 8-10 in Section 8.6.1). 


\subsubsection{Summary Statistics to Assess Model Adequacy}

Several statistics used to summarize the adequacy of a model fit to data are discussed in this subsection. These statistics apply to fitting any model, including the Full Model (discussed in Section 8.2) and a Stepwise Model (discussed in Section 8.3).

The root mean squared error (RMSE) is given by

$$
R M S E=\left(\frac{\sum_{i=1}^{n}\left(y_{i}-\hat{y}_{i}\right)^{2}}{n-p}\right)^{0.5}
$$

where $y_{i}$ is the property value for the $i^{\text {th }}$ data point, $\hat{y}_{i}$ is the model-predicted property value for the $i^{\text {th }}$ data point, $n$ is the number of data points used to fit the model, and $p$ is the number of coefficients (or free parameter effects, see Section 8.2.2). If a property is mathematically transformed to satisfy the OLS regression assumptions (see Section 8.2.2), then the transformed values are used in Equation (8-2) as well as the following equations. RMSE includes variation due to model LOF as well as variation among replicate tests (referred to as pure error).

The RMSE for pure error is given by

$$
R M S E_{P E}=\left(\frac{\sum_{k=1 i=1}^{K} \sum_{k=1}^{n_{k}}\left(y_{k i}-\bar{y}_{k}\right)^{2}}{\sum_{k=1}^{K}\left(n_{k}-1\right)}\right)^{0.5}
$$

where $y_{k i}$ is the property value for the $i^{\text {th }}$ data point in the $k^{\text {th }}$ set of replicates, $\bar{y}_{k}$ is the mean of the property values for the $k^{\text {th }}$ set of replicates, and $n_{k}$ is the number of replicates in the $k^{\text {th }}$ set of replicates.

The $\mathrm{R}^{2}$ statistic is defined by

$$
R^{2}=1-\frac{\sum_{i=1}^{n}\left(y_{i}-\hat{y}_{i}\right)^{2}}{\sum_{i=1}^{n}\left(y_{i}-\bar{y}\right)^{2}}
$$

where $\bar{y}$ is the mean of the property values over all $n$ data points, and the other notation is as defined following Equation (8-2). $\mathrm{R}^{2}$ quantifies the fraction of variation in values of a response variable for a data set that is accounted for by a model fitted to the data. Hence, $\mathrm{R}^{2}$ takes values between 0 and 1 . $\mathrm{R}^{2}$ cannot equal 1 when there are replicate data (a model can never account for replicate variability). However, $\mathrm{R}^{2}$ will increase and approach its maximum possible value as the number of parameter effects in a model approaches the number of distinct data points (i.e., without counting replicate pairs twice). 
PNNL-22747

SRNL-STI-2013-00465

\subsubsection{Estimates of Parameter Effects for the Full Model}

As discussed in Section 8.2.2, there are 20 free parameter effects out of a total of 49 in the Full Model. Evaluating the results of fitting the Full Model is therefore simplified by concentrating on the free parameter effects. For all individual parameter effects and two-parameter interactions not involving the Simulant parameter, each model term is described by only one free parameter effect. Hence, determining the statistical significance of one of these model terms reduces to an evaluation of its one free parameter effect. For example, Table 8-8 in Section 8.6.1 contains the results for fitting the Full Model to $\ln$ (Plastic Viscosity) data. In Table 8-8, the estimate of the free parameter effect associated with MixRatio is 0.770 . This estimate actually refers to the first level of MixRatio, so 0.770 really represents the estimated effect of MixRatio $=0.4$ on $\ln$ (Plastic Viscosity). The estimate for MixRatio $=0.6$ is therefore -0.770 , the negative of the effect for the first level (see the discussion of why these effects must sum to zero in Section 8.2.1). For a twoparameter interaction, such as NaMol*FlyAsh, the estimate is associated with the first level of each of the two parameters. Thus the estimate of -0.023 in Table 8-8 actually represents the effect of NaMol $=5.0$ and FlyAsh $=$ NW. Estimates of all two-parameter interaction effects associated with NaMol*FlyAsh are as shown in Table 8-3.

\section{Table 8-3. Estimate of All Two-Parameter Interaction Effects Associated with the NaMol*FlyAsh Interaction}

\begin{tabular}{||c|c|c||}
\hline & \multicolumn{2}{|c|}{ FlyAsh } \\
\hline NaMol & NW & SE \\
\hline $\mathbf{5 . 0}$ & -0.023 & 0.023 \\
\hline $\mathbf{7 . 8}$ & 0.023 & -0.023 \\
\hline
\end{tabular}

For model terms that involve the Simulant parameter (either individually or in interactions), the interpretations are more complex. For the Simulant model term, four estimated effects are produced (see Table 8-8), each associated with one of the four simulants. These effect estimates are constrained to sum to zero as discussed in Section 8.2.1. For an interaction involving Simulant, half the estimates (four of eight) are produced. For example, the four estimates listed in Table 8-8 for "Simulant*NaMol" are associated with the first level of NaMol $=5.0$. The complete list of parameter effect estimates is obtained by taking the negatives of listed estimates as shown in Table 8-4.

Table 8-4. Complete List of Parameter Effect Estimates Associated with the "Simulant* NaMol" Interaction

\begin{tabular}{||c|c|r|r|c||}
\hline \multirow{2}{*}{ NaMol } & \multicolumn{4}{|c|}{ Simulant } \\
\cline { 2 - 5 } & Average & Blend & HiAl & HiSO $_{4}$ \\
\hline $\mathbf{5 . 0}$ & -0.053 & -0.173 & -0.026 & 0.251 \\
\hline $\mathbf{7 . 8}$ & 0.053 & 0.173 & 0.026 & -0.251 \\
\hline
\end{tabular}

\subsubsection{Assessment of Whether the Four Simulants Have Different Effects on Cast Stone Properties}

Because the Simulant parameter has four levels (i.e., four simulants), it is not sufficient to examine the statistical significance of the effect of each simulant individually. It is of interest to know whether the effects of the four simulants on a Cast Stone property are statistically different. 
To accomplish this, all pairwise differences of effects of the four simulants are considered and p-values ${ }^{1}$ are calculated to determine which simulants have statistically different effects. Because there are six pairwise comparisons of four estimates, a multiple comparison procedure (MCP) is used to produce the p-values that limit the probability of a wrong decision over all six of the comparisons. The MCP procedure used is a generalization of the Tukey Honestly Significant Difference (HSD) procedure, which is discussed by Bretz et al. $(2010,2013)$ and Hothorn et al. (2013). A generalization of the standard version of the Tukey HSD procedure was used because the assumptions of the standard version (independent estimates, equal variances) are not satisfied.

The last column of Table 8-10 illustrates a high-level summary of the results from the Tukey HSD procedure for the "Heat Generation at 300 Hours" property. Simulants with the same letter (A and B) are not statistically different with the probability 0.05 of an incorrect conclusion of a difference over all six pairwise differences. Hence, simulants that do not share any of the letters listed have statistically different effects. As an example, consider the summary of the results for the individual effects of the four simulants. The simulants with the letter A (Average, SST Blend, and $\mathrm{Hi} \mathrm{SO}_{4}$ ) do not have statistically different effects on "Heat Generation at 300 Hours". Similarly, the simulants with the letter B (Average, $\mathrm{Hi} \mathrm{Al}$, and $\mathrm{Hi} \mathrm{SO}_{4}$ ) do not have statistically different effects on the property. Only the SST Blend and Hi Al simulants do not share any of the letters listed, so they have statistically different effects on the property. This is consistent with the effect estimate for "SST Blend" having the largest negative effect among the simulants $(-25.86)$ and "Hi Al" having the largest positive effect (17.97).

\subsection{Stepwise Regression Modeling Approach, Including the Possibility of Interactions Involving} $\underline{\text { BFS }}$

To evaluate the validity of Assumption $\mathrm{C}$ in Section 8.1 (that no interactions involving BFS are statistically significant), stepwise regression (Draper and Smith 1998) was used. Stepwise regression is a procedure that starts with no terms in a model or some terms forced into the model, and iteratively builds a model by adding or removing the term that most improves the optimality criterion being used to quantify the model goodness-of-fit.

One significant difference in a regression model (e.g., a Stepwise Model) compared to an ANOVA model (e.g., the Full Model) is that all of the parameters in a regression model must have numeric values and not have exact constraints (such as groups of parameter effects summing to zero as occur with the Full (ANOVA) model). Because the four possible simulants (Average, SST Blend, $\mathrm{Hi} \mathrm{Al}$, and $\mathrm{Hi} \mathrm{SO}_{4}$ ) are categorical values of the Simulant parameter, it is not possible for them to all appear in a regression model at the same time. The Stepwise Models for Cast Stone properties were constructed by omitting all terms involving the Average simulant. Hence, the individual effect of the SST Blend, Hi Al, or Hi SO4 that is statistically significant actually corresponds to that simulant having a statistically different effect than the Average simulant.

For the Cast Stone screening data, the model terms corresponding to all individual parameter effects (except the Average simulant) were forced into the model, and all two-parameter interactions (including those with BFS as one of the parameters and those involving the Average simulant) were candidates for addition to the model. During each iteration of the stepwise regression, the term that most improves the model fit is added to the model, provided the

\footnotetext{
${ }^{1}$ A p-value is the probability of being wrong in concluding a parameter effect is not statistically significant. Small p-values (e.g., < 0.05) involve a small probability of incorrectly concluding a parameter effect is not statistically significant. Hence, parameter effects with p-values $<0.05$ are declared as statistically significant.
} 
coefficient of the term is statistically significant ( $p$-value $\leq 0.05$ ). After a term is added to the model in an iteration, all of the terms added to the model are statistically assessed to make sure they are still statistically significant. Because of collinearities between model terms resulting from a particular test matrix, it is possible that a term that was statistically significant when first added to the model during an earlier iteration may no longer be statistically significant at a later iteration. If this occurs, the term is removed from the model and the stepwise regression process continues with the next iteration of adding the best remaining term. The stepwise regression process terminates when no statistically significant term can be added and all terms in the model are statistically significant. The stepwise model development was performed using the R software (R Core Team 2013, Crawley 2007).

An example of the output of the stepwise modeling approach is given in Table 8-9, which is discussed in Section 8.6.1. The statistics discussed in Section 8.2.3 for summarizing the model fit to the data are included in the results table for each stepwise regression model in this report.

\subsection{Cautions Regarding Interpreting the Results of Fitting the Full Model and Stepwise Models}

This section discusses cautions regarding interpreting the results of fitting a Full and Stepwise Models to Cast Stone property data.

There are two main cautions associated with interpreting the results of a fitted Full Model.

Caution FM1: For Cast Stone properties that had 26 mixes tested, some properties had missing data for one test or one outlier was removed before fitting models. In such cases, the number of free parameter effects (as discussed in Section 8.2.5) in the Full Model is exactly the same as the number of distinct mixes tested (20) and $\mathrm{R}^{2}$ will achieve its maximum possible value. It is impossible to statistically assess the model LOF in this case. For Cast Stone properties that had 26 mixes tested without a missing data point or a removed outlier, the number of free parameter effects in the Full Model is one less than the number of distinct mixes tested $(21)$ and $\mathrm{R}^{2}$ will be very close to its maximum possible value. While it is possible to statistically assess the model LOF in this latter case, it is less likely that the LOF will be statistically significant with only one "extra" distinct mix. Hence, it must be recognized in assessing the results of fitting the Full Model to Cast Stone properties with data for 26 or 25 mixes that the $\mathrm{R}^{2}$ value will be very close or equal to its maximum possible value and LOF tests may be of limited value or not possible.

Caution FM2: The tabular outputs of fitting the Full Model and a Stepwise Model to each Cast Stone property (for which statistical modeling was conducted) include p-values for assessing the statistical significance of each model term. The Full Model may include many terms associated with parameters or two-parameter interactions that are not statistically significant. Not only can this inappropriately inflate $\mathrm{R}^{2}$, it can cause terms with statistically significant effects to appear to have statistically nonsignificant effects. The latter can occur because of collinearities (i.e., correlations) among parameter individual effects and two-parameter interactions. However, if terms in a fitted Full Model are statistically significant, it generally can be believed that they do have significant effects. 
There are also two main cautions associated with interpreting the results of a fitted Stepwise Model.

Caution SM1: There are collinearities (correlations) among the individual parameter terms and two-parameter interaction terms selected for a Stepwise Model, and these depend on the number of tests and the parameter combinations tested. Hence, a resulting Stepwise Model may not contain all of the true (unknown) individual parameter and twoparameter interaction terms with significant effects. Instead, a Stepwise Model could contain terms that are correlated with the true, unknown parameter effects.

Caution SM2: Stepwise regression procedures tend to include too many terms in models that are not among the true (unknown) terms.

One way to "protect" against SM2 is to use a tighter criterion to control model terms that are added to or remain in a model. In this report a p-value $<0.05$ is used to both determine what terms are added to a model and which terms are removed. However, the results of Stepwise Models in this report include the p-values of terms in the model, so the viewer can always impose a tighter constraint (e.g., p-value $<0.01$ ) to increase the chance that terms declared statistically significant correspond to true (unknown) effects of parameters on a Cast Stone property.

There are both pros and cons to the Full Model and Stepwise Model approaches chosen to statistically analyze selected Cast Stone properties. The Full Model approach avoids the concerns SM1 and SM2 associated with stepwise regression, but has the Caution FM1 and FM2 concerns. On the other hand, the stepwise regression approach avoids the Caution FM1 and FM2 concerns by building models that only contain statistically significant terms, but then has the concerns SM1 and SM2. Ultimately, both the Full Model and Stepwise Model approaches are useful, provided that the respective concerns are kept in mind when considering the model fits to Cast Stone property data (in Sections 8.6 and 8.7). The results of both approaches should be considered along with subject matter knowledge and experience to reach conclusions about which individual parameter effects and two-parameter effects are statistically significant and also meaningful from a subject matter perspective.

\subsection{Estimates of Testing and Measurement Uncertainties of Cast Stone Properties from Replicate $\underline{\text { Tests }}$}

As discussed in Section 2.1, there are five pairs of replicate tests for Cast Stone properties for which 26 tests were performed (see Table 2-1), and there are seven pairs of replicate tests for Cast Stone properties for which 38 tests were performed (see Table C-1). The replicate pairs provide for calculating the uncertainty of Cast Stone property values due to the testing and measurement processes. Before presenting and discussing quantitative estimates of the combined testing and measurement uncertainties for Cast Stone properties, it is important to emphasize the difference between replicates, and what in this report are referred to as repeats. More specifically, for some locations in the report, repeats are referred to as duplicates or triplicates.

Repeats (which are different than replicates) are tests performed on two or three samples of a given Cast Stone mix. That is, the mix was made up only once, and two or three samples of it were tested to provide duplicate or triplicate results. On the other hand, replicates involved completely remaking a Cast Stone mix and measuring properties at a different time in the run order of tests. Typically, replicates are expected to have additional uncertainty over and above the uncertainty from repeats, because of making a mix and measuring properties in different 
periods of time, potentially with different personnel and/or equipment. For Cast Stone properties that had repeat tests, the means and standard deviations of the repeat property values are listed in tables of Appendices $\mathrm{C}$ and $\mathrm{D}$. The means over repeats were used as the property values in statistical data analyses.

Table 8-5 to Table 8-7 summarize (for each Cast Stone property) the uncertainties as SDs and $\%$ RSDs for each replicate pair, and also pooled (i.e., combined) over the five or seven replicate

Table 8-5. Replicate Property Values, Standard Deviations (SDs), and Percent Relative Standard Deviations (\%RSDs), Along with Pooled SDs and \%RSDs Using All Replicate Pairs (For Information Only)

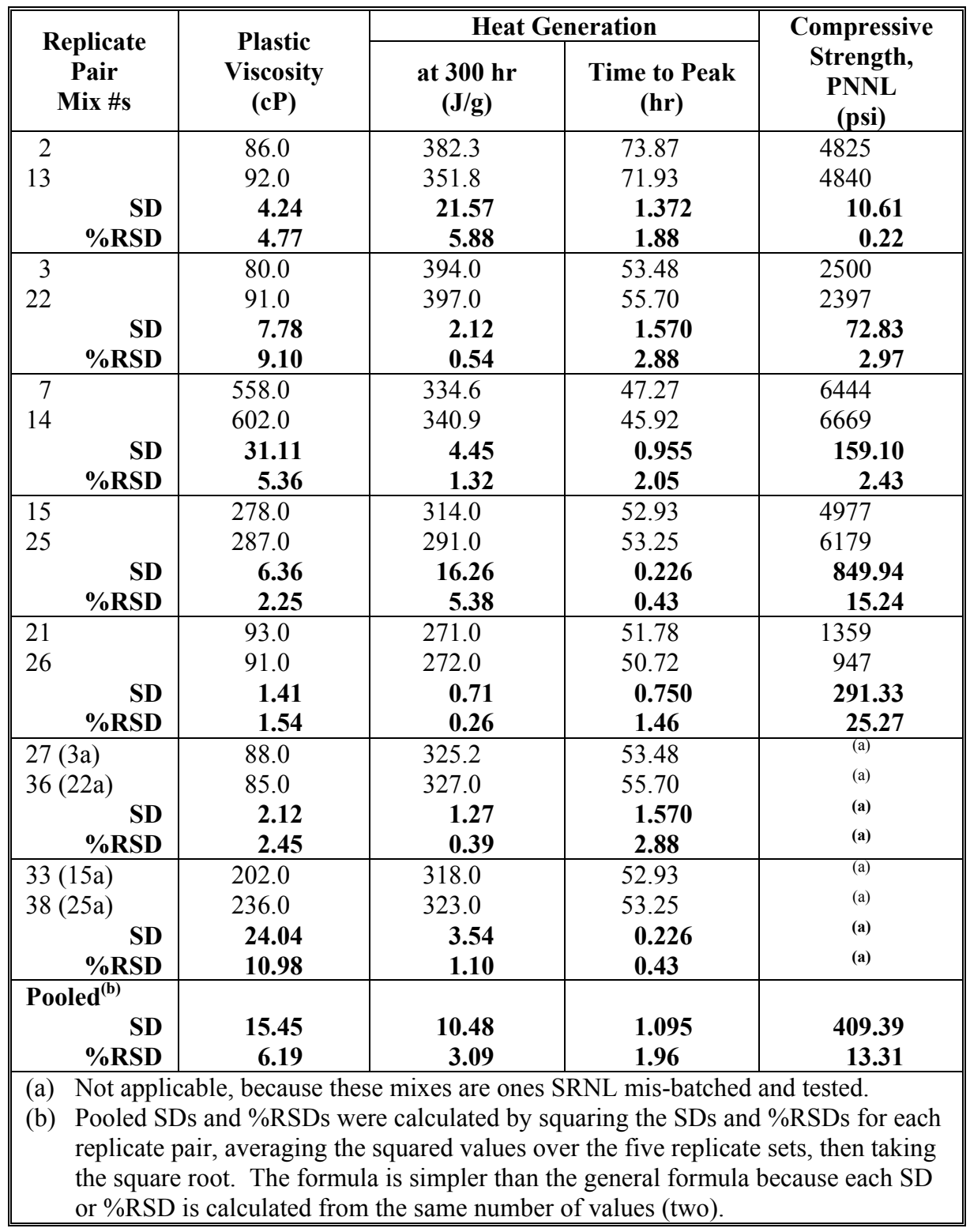


pairs (as applicable for a given property). The SDs and \%RSDs are useful as quantitative measures of the uncertainty inherent in the Cast Stone property data from testing, and also provide the basis for assessing whether the effects of parameters on properties are statistically significant. Table 8-5 presents the replicate property values and uncertainties for all properties that were chosen for statistical analysis except properties associated with EPA Method 1315. Table 8-6 and Table 8-7 present replicate property values and uncertainties for effective diffusion coefficients and leachability indices, respectively, associated with EPA Method 1315 for leach intervals between 28 and 63 days cumulative time.

Table 8-6. Replicate Values, Standard Deviations (SDs), and Percent Relative Standard Deviations (\%RSDs) for Effective Diffusion Coefficients from EPA 1315 Leach Tests, Along with and Pooled SDs and \%RSDs Using All Replicate Pairs (For Information Only)

\begin{tabular}{|c|c|c|c|c|c|c|}
\hline \multirow{2}{*}{$\begin{array}{l}\text { Replicate } \\
\text { Pair } \\
\text { Mix \#s } \\
\end{array}$} & \multicolumn{6}{|c|}{ Effective Diffusion Coefficient $\left(\mathrm{cm}^{2} / \mathrm{s}\right)$} \\
\hline & I & Te & $\mathrm{Na}$ & $\mathrm{NO}_{3}$ & $\mathrm{NO}_{2}$ & $\mathrm{Cr}$ \\
\hline 2 & $7.02 \mathrm{E}-09$ & $5.99 \mathrm{E}-11$ & $6.92 \mathrm{E}-09$ & $6.65 \mathrm{E}-09$ & $7.50 \mathrm{E}-09$ & $8.22 \mathrm{E}-14$ \\
\hline \multirow{3}{*}{$\begin{array}{r}\text { SD } \\
\% \text { RSD }\end{array}$} & $8.48 \mathrm{E}-09$ & $8.27 \mathrm{E}-11$ & $6.44 \mathrm{E}-09$ & $8.75 \mathrm{E}-09$ & 7.47E-09 & $5.51 \mathrm{E}-14$ \\
\hline & 1.03E-09 & 1.61E-11 & 3.39E-10 & 1.48E-09 & 2.12E-11 & $1.92 \mathrm{E}-14$ \\
\hline & $1.33 E+01$ & $2.26 \mathrm{E}+01$ & $5.08 \mathrm{E}+00$ & $1.93 E+01$ & 2.83E-01 & $2.79 \mathrm{E}+01$ \\
\hline 3 & 4.98E-09 & $3.47 \mathrm{E}-11$ & 4.99E-09 & 4.60E-09 & $5.44 \mathrm{E}-09$ & $1.64 \mathrm{E}-13$ \\
\hline \multirow{3}{*}{$\begin{array}{r}\text { SD } \\
\% \text { RSD }\end{array}$} & $4.42 \mathrm{E}-09$ & $2.48 \mathrm{E}-11$ & 4.84E-09 & $4.32 \mathrm{E}-09$ & 4.14E-09 & $1.79 \mathrm{E}-13$ \\
\hline & $3.96 \mathrm{E}-10$ & $7.00 \mathrm{E}-12$ & $1.06 \mathrm{E}-10$ & $1.98 \mathrm{E}-10$ & $9.19 \mathrm{E}-10$ & $1.06 \mathrm{E}-14$ \\
\hline & $8.43 E+00$ & $2.35 \mathrm{E}+01$ & $2.16 E+00$ & $4.44 E+00$ & $1.92 \mathrm{E}+01$ & $6.18 E+00$ \\
\hline 7 & $4.25 \mathrm{E}-09$ & $9.06 \mathrm{E}-12$ & $3.52 \mathrm{E}-09$ & $4.72 \mathrm{E}-09$ & $4.68 \mathrm{E}-09$ & $8.28 \mathrm{E}-15$ \\
\hline & $5.70 \mathrm{E}-09$ & $9.61 \mathrm{E}-12$ & 4.44E-09 & $6.26 \mathrm{E}-09$ & $5.93 \mathrm{E}-09$ & $9.90 \mathrm{E}-15$ \\
\hline \multirow{2}{*}{$\begin{array}{r}\text { SD } \\
\% \text { RSD }\end{array}$} & 1.03E-09 & $3.89 \mathrm{E}-13$ & $6.51 \mathrm{E}-10$ & 1.09E-09 & 8.84E-10 & $1.15 E-15$ \\
\hline & $2.06 \mathrm{E}+01$ & $4.17 E+00$ & $1.63 \mathrm{E}+01$ & $1.98 \mathrm{E}+01$ & $1.67 E+01$ & $1.26 \mathrm{E}+01$ \\
\hline \multirow{2}{*}{$\begin{array}{l}15 \\
25\end{array}$} & $5.67 \mathrm{E}-09$ & $4.62 \mathrm{E}-11$ & 7.33E-09 & $7.01 \mathrm{E}-09$ & $7.17 \mathrm{E}-09$ & $3.16 \mathrm{E}-13$ \\
\hline & 4.87E-09 & $2.88 \mathrm{E}-11$ & $6.86 \mathrm{E}-09$ & $6.99 \mathrm{E}-09$ & $5.80 \mathrm{E}-09$ & $4.02 \mathrm{E}-13$ \\
\hline \multirow{2}{*}{$\begin{array}{r}\text { SD } \\
\% \text { RSD }\end{array}$} & $5.66 \mathrm{E}-10$ & $1.23 \mathrm{E}-11$ & 3.32E-10 & $1.41 \mathrm{E}-11$ & $9.69 \mathrm{E}-10$ & $6.08 \mathrm{E}-14$ \\
\hline & $1.07 E+01$ & $3.28 \mathrm{E}+01$ & $4.68 \mathrm{E}+00$ & 2.02E-01 & $1.49 \mathrm{E}+01$ & $1.69 \mathrm{E}+01$ \\
\hline & $1.68 \mathrm{E}-08$ & $9.44 \mathrm{E}-11$ & $1.05 \mathrm{E}-08$ & $1.52 \mathrm{E}-08$ & $1.38 \mathrm{E}-08$ & $1.51 \mathrm{E}-13$ \\
\hline & 7.30E-09 & $1.66 \mathrm{E}-10$ & 8.07E-09 & $7.85 \mathrm{E}-09$ & 7.09E-09 & $1.02 \mathrm{E}-13$ \\
\hline \multirow{2}{*}{$\begin{array}{r}\text { SD } \\
\% R S D\end{array}$} & $6.72 \mathrm{E}-09$ & $5.06 \mathrm{E}-11$ & $1.72 \mathrm{E}-09$ & $5.20 \mathrm{E}-09$ & 4.74E-09 & $3.46 \mathrm{E}-14$ \\
\hline & $5.57 \mathrm{E}+01$ & $3.89 \mathrm{E}+01$ & $1.85 E+01$ & $4.51 \mathrm{E}+01$ & $4.54 \mathrm{E}+01$ & $2.74 \mathrm{E}+01$ \\
\hline \multicolumn{7}{|l|}{ Pooled $^{(a)}$} \\
\hline SD & 3.09E-09 & $2.46 \mathrm{E}-11$ & 8.50E-10 & 2.47E-09 & 2.24E-09 & $3.28 E-14$ \\
\hline$\%$ RSD & $2.79 E+01$ & $2.71 \mathrm{E}+01$ & $1.15 E+01$ & $2.37 \mathrm{E}+01$ & $2.42 \mathrm{E}+01$ & $2.01 \mathrm{E}+01$ \\
\hline \multicolumn{7}{|c|}{$\begin{array}{l}\text { Pooled SDs and \%RSDs were calculated by squaring the SDs and \%RSDs, averaging the } \\
\text { squared values over the five replicate sets, then taking the square root. The formula is } \\
\text { simpler than the general formula because each SD or \%RSD is calculated from the same } \\
\text { number of values (two). }\end{array}$} \\
\hline
\end{tabular}


Table 8-7. Replicate Values, Standard Deviations (SDs), and Percent Relative Standard Deviations (\%RSDs) for Leachability Index Calculated from Effective Diffusion Coefficients from EPA 1315 Leach Tests, Along with and Pooled SDs and \%RSDs Using All Replicate Pairs (For Information Only)

\begin{tabular}{|c|c|c|c|c|c|c|}
\hline \multirow{2}{*}{$\begin{array}{l}\text { Replicate } \\
\text { Pair } \\
\text { Mix \#s }\end{array}$} & \multicolumn{6}{|c|}{ Leachability Index $\left(-\log _{10}\left(\mathrm{~cm}^{2} / \mathrm{s}\right)\right)$} \\
\hline & I & Tc & $\mathrm{Na}$ & $\mathrm{NO}_{3}$ & $\mathrm{NO}_{2}$ & $\mathrm{Cr}$ \\
\hline 2 & 8.180 & 10.230 & 8.200 & 8.200 & 8.170 & 13.090 \\
\hline \multirow{3}{*}{$\begin{array}{r}\text { SD } \\
\% \text { RSD }\end{array}$} & 8.090 & 10.090 & 8.210 & 8.090 & 8.140 & 13.270 \\
\hline & 0.0636 & 0.0990 & 0.0071 & 0.0778 & 0.0212 & 0.1273 \\
\hline & 0.7823 & 0.9744 & 0.0862 & 0.9550 & 0.2601 & 0.9657 \\
\hline 3 & 8.300 & 10.460 & 8.320 & 8.340 & 8.270 & 12.800 \\
\hline \multirow{3}{*}{$\begin{array}{r}\text { SD } \\
\% \text { RSD }\end{array}$} & 8.360 & 10.630 & 8.320 & 8.370 & 8.390 & 12.770 \\
\hline & 0.0424 & 0.1202 & 0.0000 & 0.0212 & 0.0849 & 0.0212 \\
\hline & 0.5093 & 1.1400 & 0.0000 & 0.2539 & 1.0186 & 0.1659 \\
\hline 7 & 8.430 & 11.050 & 8.480 & 8.380 & 8.380 & 14.110 \\
\hline 14 & 8.270 & 11.030 & 8.360 & 8.230 & 8.250 & 14.020 \\
\hline \multirow{2}{*}{$\begin{array}{r}\text { SD } \\
0\end{array}$} & 0.1131 & 0.0141 & 0.0849 & 0.1061 & 0.0919 & 0.0636 \\
\hline & 1.3549 & 0.1281 & 1.0078 & 1.2771 & 1.1055 & 0.4525 \\
\hline \multirow{2}{*}{$\begin{array}{l}15 \\
25\end{array}$} & 8.270 & 10.340 & 8.140 & 8.180 & 8.170 & 12.650 \\
\hline & 8.340 & 10.550 & 8.180 & 8.180 & 8.250 & 12.560 \\
\hline \multirow{2}{*}{$\begin{array}{r}\text { SD } \\
\% \text { RSD }\end{array}$} & 0.0495 & 0.1485 & 0.0283 & 0.0000 & 0.0566 & 0.0636 \\
\hline & 0.5960 & 1.4217 & 0.3466 & 0.0000 & 0.6890 & 0.5049 \\
\hline $\begin{array}{l}21 \\
26\end{array}$ & 7.810 & 10.160 & 8.000 & 7.850 & 7.880 & 12.860 \\
\hline & 8.170 & 9.880 & 8.110 & 8.130 & 8.160 & 13.030 \\
\hline & 0.2546 & 0.1980 & 0.0778 & 0.1980 & 0.1980 & 0.1202 \\
\hline \%RSD & 3.1860 & 1.9759 & 0.9656 & 2.4780 & 2.4687 & 0.9286 \\
\hline \multicolumn{7}{|l|}{ Pooled $^{(a)}$} \\
\hline SD & 0.1311 & 0.1309 & 0.0531 & 0.1067 & 0.1082 & 0.0885 \\
\hline$\%$ RSD & 1.6256 & 1.2799 & 0.6443 & 1.3227 & 1.3339 & 0.6756 \\
\hline \multicolumn{7}{|c|}{$\begin{array}{l}\text { (a) Pooled SDs and \%RSDs were calculated by squaring the SDs and \%RSDs, } \\
\text { averaging the squared values over the five replicate sets, then taking the square } \\
\text { root. The formula is simpler than the general formula because each SD } \\
\text { or \%RSD is calculated from the same number of values (two). }\end{array}$} \\
\hline
\end{tabular}

\subsection{Results of Statistical Analyses - Processing Properties}

The results of the statistical analysis methods described in Sections 8.1 to 8.3 are presented and discussed in Section 8.6.1 for plastic viscosity and in Section 8.6.2 for two heat-generation properties.

\subsubsection{Slurry Rheology_Plastic Viscosity}

Two slurry/paste rheology properties (Yield Stress and Plastic Viscosity) were measured for the 38 Cast Stone mixes listed in Table C-1, with the data summarized in Table C-5 in Appendix C. No values of the two properties were obtained for Mix 1 because the Cast Stone paste was too thick. A scatterplot of the data for these two properties is shown in Figure 8-1. It is not clear whether there is 1) a fairly strong curvilinear relationship between these two properties with the data for Mix/Test 20, 28, and 35 being outliers, or 2) a strong linear relationship for lower values of the two parameters, but essentially no relationship for large values. Note that Mixes 20, 28, and 35 are more clearly potential outliers for Yield Stress (since they are the largest values observed). Because only Plastic Viscosity was selected for statistical analyses, and Mixes 20, 28, 
and 35 have values of that property in the middle of its range of values, they are less likely to be outliers, but it is still possible. SRNL who performed the Plastic Viscosity tests found no clear reason for these tests to be questionable, so they were retained in the statistical data analyses.

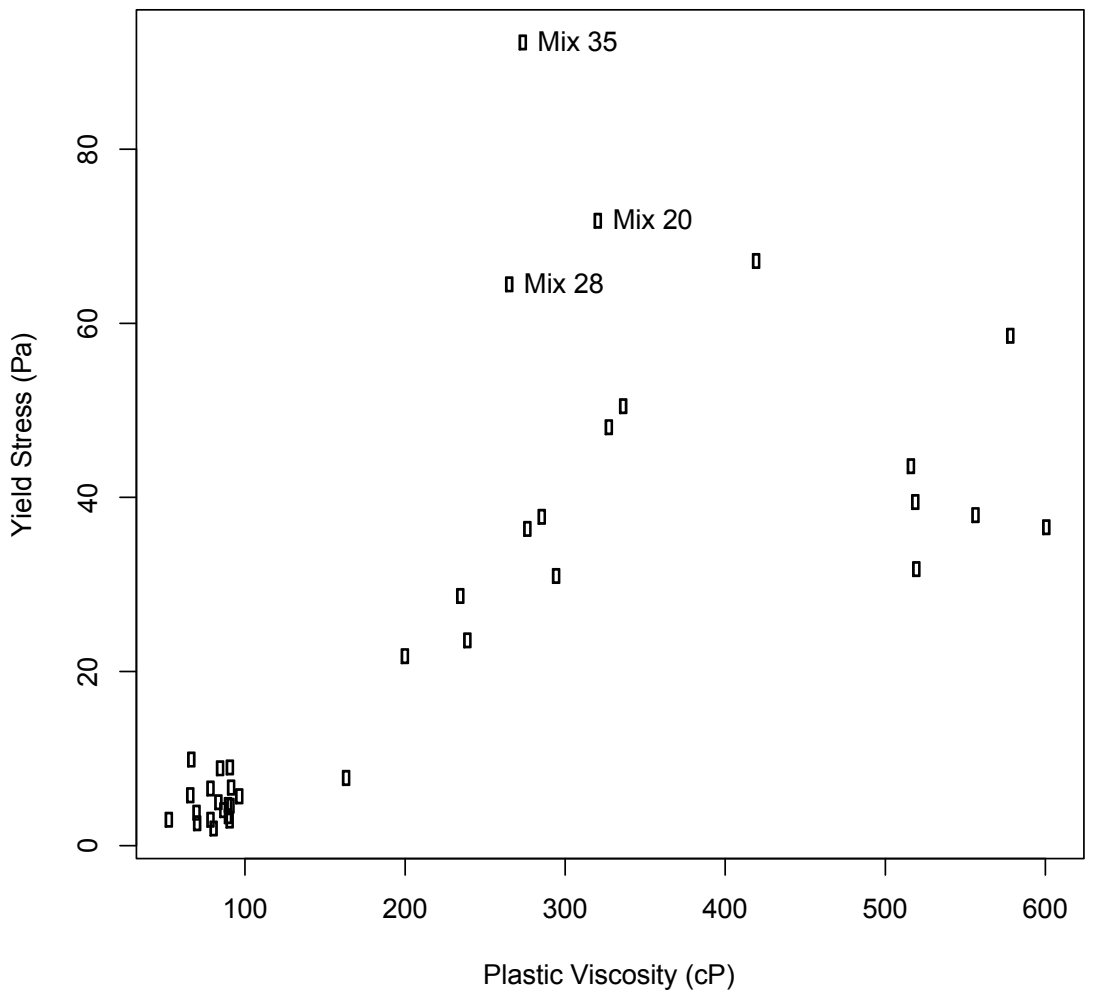

Figure 8-1. Scatterplot of Yield Stress versus Plastic Viscosity for the 38 Cast Stone Mixes. Outlying data points are labeled with the mix/test number. (For Information Only)

The Plastic Viscosity values for the 38 Cast Stone mixes listed in Table C-5 range from 54 to $602 \mathrm{cP}$ with a mean of $228 \mathrm{cP}$. Table 8-5 lists the Plastic Viscosity values for the seven replicate pairs and presents uncertainties in the plastic viscosity values as calculated from the replicates. The pooled (i.e., combined) uncertainty estimates using all replicate pairs are $\mathrm{SD}=15.45 \mathrm{cP}$ and $\%$ RSD $=6.19$. The range in Plastic Viscosity values (over a factor of 10 ) must be a result of variations in the test parameters, because the pooled \%RSD is about $6 \%$. The balance of this section presents and discusses for Plastic Viscosity the results of applying the statistical analysis methods described in Sections 8.1 to 8.3. Note that the natural logarithm of Plastic Viscosity [denoted $\ln$ (Plastic Viscosity)] was statistically analyzed because modeling diagnostics indicated that the transformation was necessary to satisfy the constant variance assumption for OLS regression (see Section 8.2.2). Viscosities of many kinds of materials are traditionally modeled using the natural logarithm transformation.

Table 8-8 summarizes the results of fitting the Full Model to the $\ln$ (Plastic Viscosity) data and statistically assessing the effects of individual parameters and two-parameter interactions (except 
Table 8-8. In(Plastic Viscosity): Summary of Fitting the Full Model and Statistically Assessing the Effects of the Individual Test Parameters and Two-Parameter Interactions

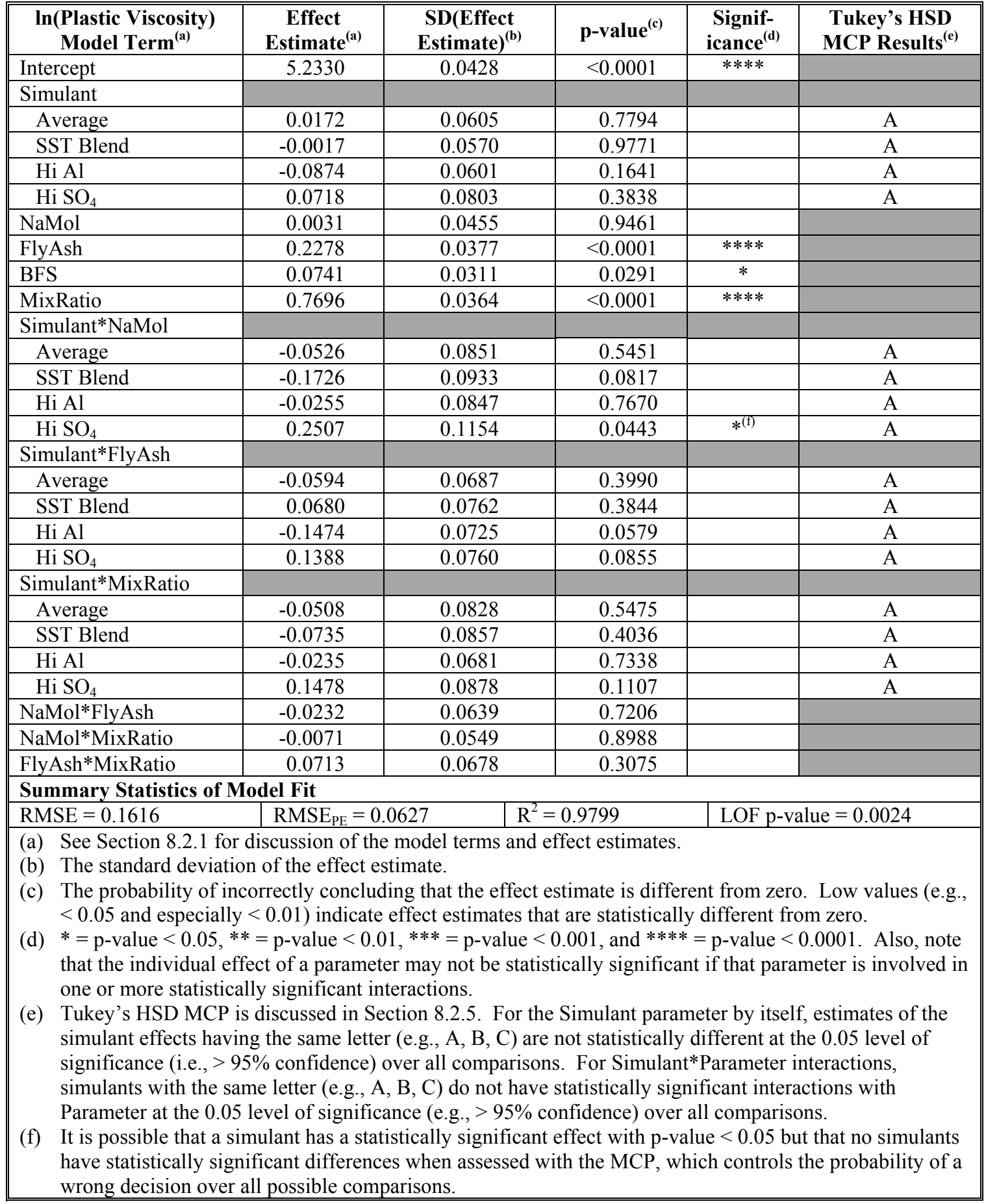


interactions involving BFS), as discussed in Section 8.2. Keep in mind that the Caution FM2 discussed in Section 8.4 applies to the discussion of the results in Table 8-8. The Full Model fits the $\ln$ (Plastic Viscosity) data very well, accounting for a high fraction of the variation in the data $\left(\mathrm{R}^{2}=0.9799\right)$. However, the RMSE $=0.1616$ is significantly larger than the $\mathrm{RMSE}_{\mathrm{PE}}=0.0627$, and hence the model LOF is statistically significant (p-value $=0.002$ ). Still, the Full Model with $\mathrm{R}^{2}=0.9799$ can be used to assess which parameters have statistically significant effects on Plastic Viscosity. Table 8-8 shows that FlyAsh and MixRatio have highly significant effects (p-values $<0.001$ confidence) and that the effect of BFS is significant (p-value $<0.05)$. The $\left(\mathrm{SimHiSO}_{4}\right)^{*} \mathrm{NaMol}$ interaction is also statistically significant (p-value $<0.05$ ). The last column in Table 8-8 shows that there are no statistically significant differences between the simulants for either individual effects or for interactions of other parameters with simulant.

Table 8-9 summarizes the results of using the stepwise regression approach described in Section 8.3. That approach allows all two-parameter interactions to enter the model, including interactions involving BFS. Keep in mind that cautions SM1 and SM2 discussed in Section 8.4 apply to the results in Table 8-9. The Stepwise Model fits the $\ln$ (Plastic Viscosity) data reasonably well, accounting for a high fraction of the variation in the data $\left(R^{2}=0.9572\right)$. This $R^{2}$ is smaller than for the Full Model $\left(\mathrm{R}^{2}=0.9799\right)$, but that may be because the latter value is inflated per SM2. The RMSE $=0.1835$ is significantly larger than the $\mathrm{RMSE}_{\mathrm{PE}}=0.0627$, and hence the model LOF is highly statistically significant ( $p$-value $=0.0016)$. Still, the Stepwise Model in Table 8-9 with $\mathrm{R}^{2}=0.9572$ can be used to assess the parameters that have statistically significant effects on plastic viscosity. Table 8-9 shows that several individual parameters have statistically significant effects, including FlyAsh and MixRatio (p-values $<0.0001)$. The only interaction that is statistically significant is FlyAsh*MixRatio (p-value $<0.001$ ). No interactions involving BFS are statistically significant, suggesting that BFS interactions do not appear to affect Plastic Viscosity.

Table 8-9. In(Plastic Viscosity): Results of Using Stepwise Regression to Select Statistically Significant Individual Parameter and Two-Parameter Interaction Terms for the Stepwise Model $^{(a)}$

\begin{tabular}{|c|c|c|c|c|c|}
\hline $\begin{array}{l}\text { In(Plastic Viscosity) } \\
\text { Model Term }^{(a)}\end{array}$ & $\begin{array}{l}\text { Coefficient } \\
\text { Estimate }^{(a)}\end{array}$ & $\begin{array}{l}\text { SD(Coeff. } \\
\text { Estimate) }^{(\mathbf{b})}\end{array}$ & t value & $\begin{array}{c}\text { p-value } \\
\operatorname{Pr}(>|\mathbf{t}|)^{(\mathbf{c})}\end{array}$ & $\begin{array}{c}\text { Statistical } \\
\text { Significance }^{(\mathrm{d})}\end{array}$ \\
\hline Intercept & 5.2110 & 0.0331 & 157.47 & 0.0000 & $* * * *$ \\
\hline SimBlend & 0.0206 & 0.0589 & 0.35 & 0.7289 & \\
\hline SimHiAl & -0.0145 & 0.0548 & -0.26 & 0.7932 & \\
\hline SimHiSO4 & -0.0610 & 0.0531 & -1.15 & 0.2604 & \\
\hline NaMol & -0.0341 & 0.0335 & -1.02 & 0.3170 & \\
\hline FlyAsh & 0.2054 & 0.0322 & 6.38 & 0.0000 & $* * * *$ \\
\hline BFS & 0.0535 & 0.0308 & 1.74 & 0.0932 & \\
\hline MixRatio & 0.7577 & 0.0330 & 22.96 & 0.0000 & $* * * *$ \\
\hline FlyAsh*MixRatio & 0.1178 & 0.0321 & 3.67 & 0.0010 & $* * *$ \\
\hline \multicolumn{6}{|c|}{ Summary Statistics for Model Fit } \\
\hline RMSE $=0.1835$ & \multicolumn{2}{|c|}{\begin{tabular}{l|l|l} 
& RMSE $_{\mathrm{PE}}=0.0627$ \\
\end{tabular}} & $\mathrm{R}^{2}=0.9572$ & \multicolumn{2}{|c|}{ LOF p-value $=0.0016$} \\
\hline \multicolumn{6}{|c|}{$\begin{array}{l}\text { (a) See Section } 8.3 \text { for discussion of the model terms and why there are no terms involving the Average } \\
\text { simulant. } \\
\text { (b) The standard deviation of the coefficient estimate. } \\
\text { (c) The probability of incorrectly concluding that the coefficient estimate is different from zero. Low values } \\
(\text { e.g., }<0.05 \text { and especially }<0.01) \text { indicate coefficient estimates that are statistically different from zero. } \\
\text { (d) } *=\text { p-value }<0.05, * *=\text { p-value }<0.01, * * *=\text { p-value }<0.001 \text {, and } * * * *=\text { p-value }<0.0001 \text {. Also, note } \\
\text { that the individual effect of a parameter may not be statistically significant if that parameter is involved in } \\
\text { one or more statistically significant interactions. }\end{array}$} \\
\hline
\end{tabular}




\subsubsection{Heat Generation}

The results of statistical analyses for two heat-generation properties are discussed in this subsection. Heat Generation at 300 Hours (HG300) is covered in Section 8.6.2.1, while Time to Peak Heat Generation (TPHG) is covered in Section 8.6.2.2. A third property, Heat Generation at Peak (HGP), was also measured but was not statistically analyzed. The values of all three properties for 38 Cast Stone mixes given in Table C-1 are listed in Table C-8 in Appendix C. Figure 8-2 shows a scatterplot matrix graph of the three heat-generation properties. This figure shows no strong correlations between pairs of the three properties when all data are considered. However, if the outlying data points are ignored, the property pairs (HG300, TPHG) and (HG300, HGP) do exhibit positive correlations. See Section 6.4 for further discussion of the approach and results from measuring these properties.

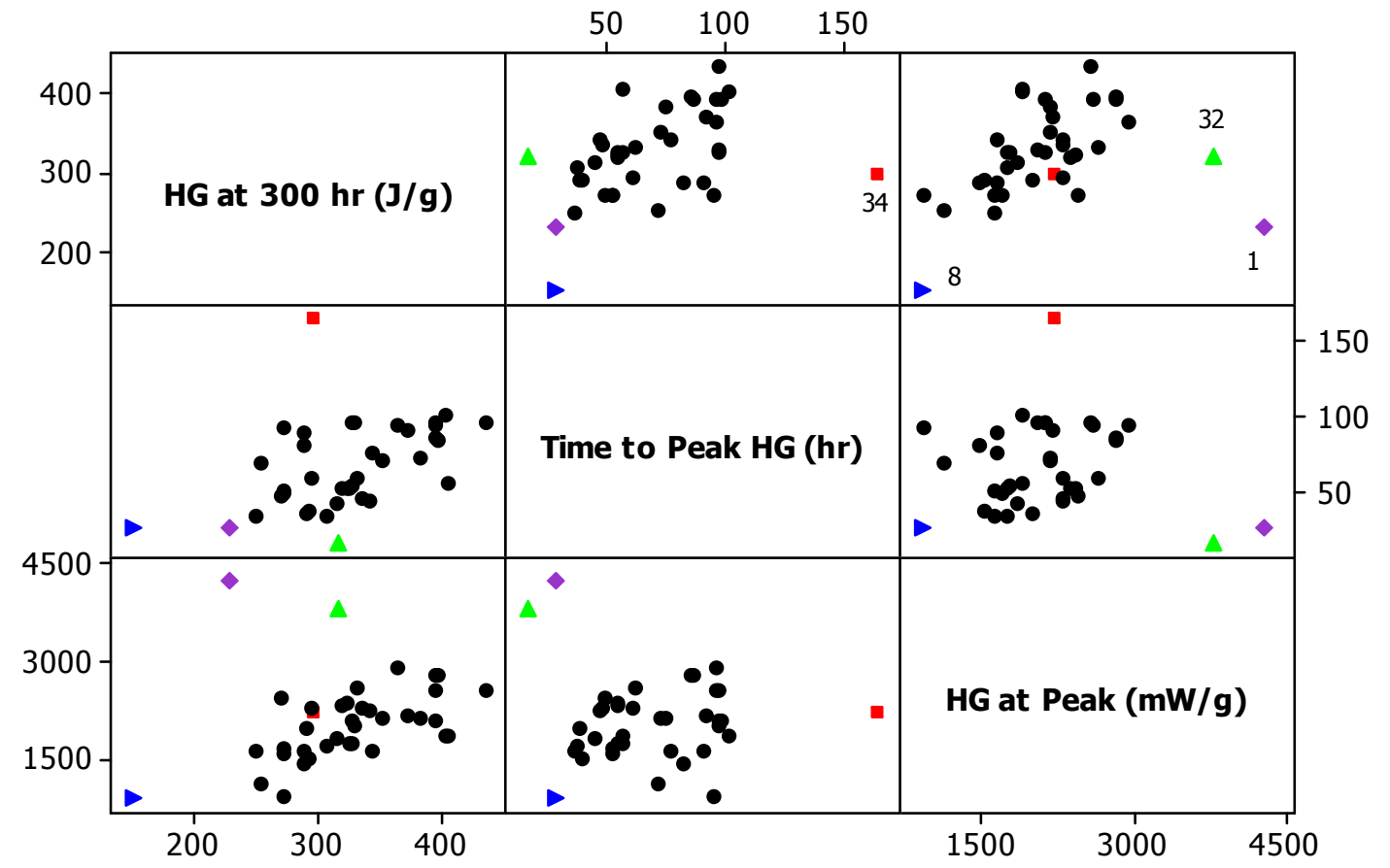

Figure 8-2. Scatterplot Matrix of Data on Three Heat Generation (HG) Properties for the 38 Cast Stone Mixes. Certain outlying points are plotted with color symbols and their mix numbers are identified in one of the plots. (For Information Only)

\subsubsection{Heat Generation at 300 Hours}

Table C-8 in Appendix C lists the HG300 values for 38 Cast Stone mixes in Table C-1, which range from 150 to $434 \mathrm{~J} / \mathrm{g}$. Figure 8-2 shows the distribution of the HG300 values. Table 8-5 lists the HG300 values for the seven replicate pairs and presents uncertainties in the HG300 values as calculated from the replicates. The pooled (i.e., combined) uncertainty estimates using all replicate pairs are $\mathrm{SD}=10.48 \mathrm{~J} / \mathrm{g}$ and $\% \mathrm{RSD}=3.09$, which are relatively small. The range in HG300 values (nearly a factor of three) must be a result of variations in the test parameters, because the pooled \%RSD is only 3\%. The balance of this section presents and discusses the results of the statistical analysis methods described in Sections 8.1 to 8.3. 
Table 8-10 summarizes the results of fitting the Full Model to the HG300 data and statistically assessing the effects of individual parameters and their two-parameter interactions, as discussed in Section 8.2. Keep in mind that Caution FM2 discussed in Section 8.4 applies to the results in Table 8-10. The Full Model fits the HG300 data moderately well, accounting for a large fraction of the variation in the data, indicated by $\mathrm{R}^{2}=0.9298$. However, the RMSE $=21.716$ is approximately twice the RMSE $E_{\mathrm{PE}}=10.478$, and hence the model LOF is statistically significant ( $\mathrm{p}$-value $=0.0107)$. However, the $\mathrm{R}^{2}$ is large enough that the Full Model in Table 8-10 can be used to assess which parameters have statistically significant effects. Table 8-10 shows that the individual parameter effects for FlyAsh, BFS, and MixRatio are highly statistically significant (p-values $<0.0001)$. Also statistically significant are the effects for the SST Blend (p-value $<0.01$ ) and Hi Al simulants ( $p$-value $<0.05$ ). As noted in Section 8.3, this means that the SST Blend and $\mathrm{Hi}$ Al simulants have statistically different effects than the Average simulant. None of the two-parameter interaction terms are statistically significant (i.e., all p-values $>0.05$ ).

Table 8-11 summarizes the results of using the stepwise regression approach described in Section 8.3. That approach allows all two-parameter interactions to enter the model, including interactions involving BFS. Keep in mind that cautions SM1 and SM2 discussed in Section 8.4 apply to the results in Table 8-11. Because more terms are available for the fit, the Stepwise Model fits the HG300 data better than the Full Model, producing a higher $\mathrm{R}^{2}=0.9526$ and a model LOF that is just barely significant ( $\mathrm{p}$-value $=0.0452$ ). However, the $\mathrm{R}^{2}$ is large enough that the Stepwise Model in Table 8-11 can be used to assess which parameters have statistically significant effects. Table 8-11 shows that the individual parameter effects for FlyAsh, BFS, and MixRatio are highly statistically significant ( $\mathrm{p}$-values $<0.0001)$. Also statistically significant are the effects for the SST Blend and Hi Al simulants (p-values < 0.01). As noted above, this means that the SST Blend and Hi Al simulants have statistically different effects than the Average simulant. The Stepwise Model also shows that two two-parameter interaction terms are statistically significant: FlyAsh*BFS (p-values $<0.01$ ) and NaMol*MixRatio (p-value < 0.05).

The principal objective for fitting the Stepwise Model was to evaluate the importance of twoparameter interactions involving BFS. Only one such interaction term is statistically significant. Still, this indicates that BFS has both an individual effect as well as an interactive effect on HG300. 
Table 8-10. Heat Generation at 300 Hours: Summary of Fitting the Full Model and Statistically Assessing the Effects of the Individual Test Parameters and Two-Parameter Interactions

\begin{tabular}{|c|c|c|c|c|c|}
\hline $\begin{array}{c}\text { Heat Generation } \\
\text { at } 300 \text { hr } \\
\text { Model Term }^{(a)}\end{array}$ & $\begin{array}{c}\text { Effect } \\
\text { Estimate }^{(a)}\end{array}$ & $\begin{array}{c}\text { SD(Effect } \\
\text { Estimate) }^{(b)}\end{array}$ & p-value $e^{(c)}$ & $\begin{array}{c}\text { Signif- } \\
\text { icance }^{(\mathrm{d})}\end{array}$ & $\begin{array}{l}\text { Tukey's HSD } \\
\text { MCP Results }\end{array}$ \\
\hline Intercept & 313.2296 & 4.4728 & $<0.0001$ & $* * * *$ & \\
\hline \multicolumn{6}{|l|}{ Simulant } \\
\hline Average & 6.0579 & 7.2914 & 0.4170 & & $\mathrm{AB}$ \\
\hline SST Blend & -25.8594 & 7.3297 & 0.0024 & ** & A \\
\hline $\mathrm{Hi} \mathrm{Al}$ & 17.9693 & 7.6501 & 0.0304 & $*$ & $\mathrm{~B}$ \\
\hline $\mathrm{Hi} \mathrm{SO}_{4}$ & 1.8323 & 6.7630 & 0.7895 & & $\mathrm{AB}$ \\
\hline NaMol & -4.5302 & 4.2384 & 0.2993 & & \\
\hline FlyAsh & -21.9614 & 4.1933 & 0.0001 & $* * * *$ & \\
\hline BFS & -27.7803 & 4.0530 & $<0.0001$ & $* * * *$ & \\
\hline MixRatio & -32.6905 & 4.1331 & $<0.0001$ & $* * * *$ & \\
\hline \multicolumn{6}{|l|}{ Simulant*NaMol } \\
\hline Average & 13.4088 & 10.7610 & 0.2287 & & A \\
\hline SST Blend & -20.1723 & 11.3380 & 0.0921 & & A \\
\hline $\mathrm{Hi} \mathrm{Al}$ & 5.4440 & 11.2370 & 0.6339 & & A \\
\hline $\mathrm{Hi} \mathrm{SO}_{4}$ & 1.3196 & 10.8555 & 0.9046 & & A \\
\hline \multicolumn{6}{|l|}{ Simulant*FlyAsh } \\
\hline Average & -2.5102 & 9.2256 & 0.7886 & & A \\
\hline SST Blend & -5.0343 & 9.4196 & 0.5996 & & A \\
\hline $\mathrm{Hi} \mathrm{Al}$ & 0.5534 & 9.6513 & 0.9549 & & A \\
\hline $\mathrm{Hi} \mathrm{SO}_{4}$ & 6.9911 & 8.5171 & 0.4225 & & A \\
\hline \multicolumn{6}{|l|}{ Simulant*MixRatio } \\
\hline Average & 3.1876 & 11.1304 & 0.7778 & & A \\
\hline SST Blend & -12.6828 & 10.5125 & 0.2433 & & $\mathrm{~A}$ \\
\hline $\mathrm{Hi} \mathrm{Al}$ & 2.0524 & 8.9021 & 0.8203 & & $\mathrm{~A}$ \\
\hline $\mathrm{Hi} \mathrm{SO}_{4}$ & 7.4427 & 9.6008 & 0.4483 & & A \\
\hline NaMol*FlyAsh & 1.2445 & 8.0205 & 0.8784 & & \\
\hline NaMol*MixRatio & -13.8591 & 6.9293 & 0.0608 & & \\
\hline FlyAsh*MixRatio & 9.0312 & 9.1049 & 0.3344 & & \\
\hline \multicolumn{6}{|c|}{ Summary Statistics of Model Fit } \\
\hline RMSE $=21.716$ & \multicolumn{2}{|c|}{$\mathrm{RMSE}_{\mathrm{PE}}=10.478$} & 0.9298 & \multicolumn{2}{|c|}{ LOF p-value $=0.0107$} \\
\hline \multicolumn{6}{|c|}{$\begin{array}{l}\text { (a) See Section } 8.2 .1 \text { for discussion of the model terms and effect estimates. } \\
\text { (b) The standard deviation of the effect estimate. } \\
\text { (c) The probability of incorrectly concluding that the effect estimate is different from zero. Low values } \\
\text { (e.g., }<0.05 \text { and especially }<0.01 \text { ) indicate effect estimates that are statistically different from zero. } \\
\text { (d) } *=\text { p-value }<0.05, * *=\text { p-value }<0.01, * * *=\text { p-value }<0.001 \text {, and } * * * *=\text { p-value }<0.0001 \text {. Also, } \\
\text { note that the individual effect of a parameter may not be statistically significant if that parameter is } \\
\text { involved in one or more statistically significant interactions. } \\
\text { (e) Tukey's HSD MCP is discussed in Section } 8.2 .5 \text {. For the Simulant parameter by itself, estimates of } \\
\text { the simulant effects having the same letter (e.g., A, B. C) are not statistically different at the } \\
0.05 \text { level of significance (i.e., }>95 \% \text { confidence) over all comparisons. For Simulant*Parameter } \\
\text { interactions, simulants with the same letter (e.g., A, B, C) do not have statistically significant } \\
\text { interactions with Parameter at the } 0.05 \text { level of significance (e.g., }>95 \% \text { confidence) over all } \\
\text { comparisons. }\end{array}$} \\
\hline
\end{tabular}


PNNL-22747

SRNL-STI-2013-00465

Table 8-11. Heat Generation at 300 Hours: Results of Using Stepwise Regression to Select Statistically Significant Individual Parameter and Two-Parameter Interaction Terms for the Stepwise Model ${ }^{(a)}$

\begin{tabular}{|c|c|c|c|c|c|}
\hline $\begin{array}{c}\text { Heat Generation } \\
\text { at } 300 \text { hr } \\
\text { Model Term }\end{array}$ & $\begin{array}{l}\text { Coefficient } \\
\text { Estimate }^{(a)}\end{array}$ & $\begin{array}{l}\text { SD(Coeff. } \\
\text { Estimate) }^{(\mathbf{b})}\end{array}$ & t value & $\begin{array}{c}\text { p-value } \\
\operatorname{Pr}(>|\mathbf{t}|)^{(\mathbf{c})}\end{array}$ & $\begin{array}{c}\text { Statistical } \\
\text { Significance }^{(\mathrm{d})}\end{array}$ \\
\hline Intercept & 315.939 & 3.237 & 97.61 & $<0.0001$ & $* * * *$ \\
\hline SimBlend & -20.599 & 5.780 & -3.56 & 0.0013 & ** \\
\hline SimHiAl & 18.235 & 5.378 & 3.39 & 0.0021 & $* *$ \\
\hline SimHiSO4 & 3.022 & 5.070 & 0.60 & 0.5559 & \\
\hline NaMol & -4.228 & 3.121 & -1.35 & 0.1863 & \\
\hline FlyAsh & -19.727 & 3.071 & -6.42 & $<0.0001$ & $* * * *$ \\
\hline BFS & -34.737 & 3.404 & -10.21 & $<0.0001$ & $* * * *$ \\
\hline MixRatio & -31.335 & 3.071 & -10.20 & $<0.0001$ & $* * * *$ \\
\hline FlyAsh*BFS & -11.658 & 3.404 & -3.43 & 0.0019 & $* *$ \\
\hline NaMol*MixRatio & -8.632 & 3.611 & -2.39 & 0.0238 & * \\
\hline \multicolumn{6}{|c|}{ Summary Statistics for Model Fit } \\
\hline \multicolumn{3}{|c|}{\begin{tabular}{|l|l|}
$\mathrm{RMSE}=17.930$ & $\mathrm{RMSE}_{\mathrm{PE}}=10.478$ \\
\end{tabular}} & $\mathrm{R}^{2}=0.9526$ & \multicolumn{2}{|c|}{ LOF $p$-value $=0.0452$} \\
\hline \multirow{3}{*}{\multicolumn{6}{|c|}{$\begin{array}{l}\text { (a) See Section } 8.3 \text { for discussion of the model terms and why there are no terms involving the Average } \\
\text { simulant. } \\
\text { (b) The standard deviation of the coefficient estimate. } \\
\text { (c) The probability of incorrectly concluding that the coefficient estimate is different from zero. Low } \\
\text { values (e.g., }<0.05 \text { and especially }<0.01) \text { indicate coefficient estimates that are statistically different } \\
\text { from zero. }\end{array}$}} \\
\hline & & & & & \\
\hline & & & & & \\
\hline \multicolumn{6}{|c|}{$\begin{array}{l}\text { (d) } *=p \text {-value }<0.05, * *=p \text {-value }<0.01, * * *=p \text {-value }<0.001 \text {, and } * * * *=p \text {-value }<0.0001 \text {. Also, } \\
\text { note that the individual effect of a parameter may not be statistically significant if that parameter is } \\
\text { involved in one or more statistically significant interactions. }\end{array}$} \\
\hline
\end{tabular}

\subsubsection{Time to Peak Heat Generation}

Table C-8 in Appendix C lists the TPHG values for 38 Cast Stone mixes in Table C-1, which range from 15.97 to $164.07 \mathrm{hr}$. Figure 8-2 shows the distribution of the TPHG values. The largest TPHG value of $164.07 \mathrm{hr}$ (for Mix 34) is considerably larger than the next largest value of $100.90 \mathrm{hr}$ (for Mix \#37). Because Mix 34 was identified as a significant outlier in preliminary fits of the Full Model and Stepwise Model, the TPHG value for Mix 34 was removed for the model fits presented in this section. Table 8-5 lists the TPHG values for the seven replicate pairs and presents uncertainties in the TPHG values as calculated from the replicates. The pooled (i.e., combined) uncertainty estimates using all replicate pairs are $\mathrm{SD}=1.10 \mathrm{hr}$ and $\% \mathrm{RSD}=1.96$, which are relatively small. The range in TPHG values (over a factor of 10) must be a result of variations in the test parameters, because the pooled \%RSD is about $2 \%$. The balance of this section presents and discusses the results of the statistical analysis methods described in Sections 8.1 to 8.3 .

Table 8-12 presents the results of fitting the Full Model to the TPHG data and statistically assessing the effects of individual parameters and their two-parameter interactions, as discussed in Section 8.2. Keep in mind that Cautions FM1 and FM2 discussed in Section 8.4 apply to the results in Table 8-12. The Full Model fits TPHG data with RMSE $=9.926$, which is over four times $\mathrm{RMSE}_{\mathrm{PE}}=2.125$. Hence, the model has a highly statistically significant LOF ( $\mathrm{p}$-value $=$ 
Table 8-12. Time to Peak Heat Generation: Summary of Fitting the Full Model and Statistically Assessing the Effects of the Individual Test Parameters and Two-Parameter Interactions

\begin{tabular}{|c|c|c|c|c|c|}
\hline $\begin{array}{c}\text { Time to Peak Heat } \\
\text { Generation } \\
\text { Model Term }^{(a)}\end{array}$ & $\begin{array}{c}\text { Effect } \\
\text { Estimate }^{(a)}\end{array}$ & $\begin{array}{c}\text { SD(Effect } \\
\text { Estimate) }^{(\mathbf{b})}\end{array}$ & p-value ${ }^{(c)}$ & $\begin{array}{c}\text { Signif- } \\
\text { icance }^{(d)}\end{array}$ & $\begin{array}{l}\text { Tukey's HSD } \\
\text { MCP Results }^{(e)}\end{array}$ \\
\hline Intercept & 64.969 & 2.102 & $<0.0001$ & $* * * *$ & \\
\hline \multicolumn{6}{|l|}{ Simulant } \\
\hline Average & 3.315 & 3.368 & 0.3389 & & A \\
\hline SST Blend & -21.794 & 3.505 & $<0.0001$ & $* * * *$ & $\mathrm{~B}$ \\
\hline $\mathrm{Hi} \mathrm{Al}$ & 21.963 & 3.511 & $<0.0001$ & $* * * *$ & $\mathrm{C}$ \\
\hline $\mathrm{Hi} \mathrm{SO}_{4}$ & -3.483 & 3.099 & 0.2766 & & $\mathrm{~A}$ \\
\hline NaMol & 3.053 & 1.979 & 0.1413 & & \\
\hline FlyAsh & -8.099 & 1.972 & 0.0007 & **** & \\
\hline BFS & -7.982 & 1.899 & 0.0006 & $* * *$ & \\
\hline MixRatio & -4.215 & 1.935 & 0.0437 & $*$ & \\
\hline \multicolumn{6}{|l|}{ Simulant*NaMol } \\
\hline Average & 11.845 & 4.922 & 0.0278 & $*$ & A \\
\hline SST Blend & -16.273 & 5.303 & 0.0070 & ** & $\mathrm{B}$ \\
\hline $\mathrm{Hi} \mathrm{Al}$ & 5.070 & 5.164 & 0.3399 & & $\mathrm{AB}$ \\
\hline $\mathrm{Hi} \mathrm{SO} 4$ & -0.643 & 4.977 & 0.8988 & & $\mathrm{AB}$ \\
\hline \multicolumn{6}{|l|}{ Simulant*FlyAsh } \\
\hline Average & -0.323 & 4.308 & 0.9411 & & A \\
\hline SST Blend & -4.199 & 4.722 & 0.3862 & & $\mathrm{~A}$ \\
\hline Hi Al & 10.671 & 4.469 & 0.0288 & $*(\mathrm{t})$ & A \\
\hline $\mathrm{Hi} \mathrm{SO} 4$ & -6.148 & 3.908 & 0.1340 & & A \\
\hline \multicolumn{6}{|l|}{ Simulant*MixRatio } \\
\hline Average & 2.883 & 5.087 & 0.5783 & & A \\
\hline SST Blend & 5.677 & 4.889 & 0.2616 & & A \\
\hline $\mathrm{Hi} \mathrm{Al}$ & 0.691 & 4.083 & 0.8676 & & $\mathrm{~A}$ \\
\hline $\mathrm{Hi} \mathrm{SO}$ & -9.250 & 4.425 & 0.0519 & & $\mathrm{~A}$ \\
\hline NaMol*FlyAsh & -2.149 & 3.672 & 0.5662 & & \\
\hline NaMol*MixRatio & 5.853 & 3.195 & 0.0845 & & \\
\hline FlyAsh*MixRatio & 3.173 & 4.161 & 0.4562 & & \\
\hline \multicolumn{6}{|c|}{ Summary Statistics of Model Fit } \\
\hline RMSE $=9.926$ & \multicolumn{2}{|c|}{$\mathrm{RMSE}_{\mathrm{PE}}=2.125$} & 0.9226 & \multicolumn{2}{|c|}{ LOF $p$-value $=4.38 \mathrm{E}-05$} \\
\hline \multicolumn{6}{|c|}{$\begin{array}{l}\text { (a) See Section } 8.2 .1 \text { for discussion of the model terms and effect estimates. } \\
\text { (b) The standard deviation of the effect estimate. } \\
\text { (c) The probability of incorrectly concluding that the effect estimate is different from zero. Low values } \\
(\text { e.g., }<0.05 \text { and especially }<0.01) \text { indicate effect estimates that are statistically different from zero. } \\
\text { (d) } *=\text { p-value }<0.05, * *=\text { p-value }<0.01, * * *=\text { p-value }<0.001 \text {, and } * * * *=\text { p-value }<0.0001 \text {. Also, } \\
\text { note that the individual effect of a parameter may not be statistically significant if that parameter is } \\
\text { involved in one or more statistically significant interactions. } \\
\text { (e) Tukey's HSD MCP is discussed in Section } 8.2 .5 \text {. For the Simulant parameter by itself, estimates of } \\
\text { the simulant effects having the same letter (e.g., A, B. C) are not statistically different at the } 0.05 \\
\text { level of significance (i.e., }>95 \% \text { confidence) over all comparisons. For Simulant*Parameter } \\
\text { interactions, simulants with the same letter (e.g., A, B, C) do not have statistically significant } \\
\text { interactions with Parameter at the } 0.05 \text { level of significance (e.g., }>95 \% \text { confidence) over all } \\
\text { comparisons. } \\
\text { (f) It is possible that a simulant has a statistically significant effect with p-value }<0.05 \text { but that no } \\
\text { simulants have statistically significant differences when assessed with the MCP, which controls the } \\
\text { probability of a wrong decision over all possible comparisons. }\end{array}$} \\
\hline
\end{tabular}


4.38E-05). Still, the Full Model accounts for a substantial portion of variability in the TPHG data (after removing the data for Mix 34), as indicated by $\mathrm{R}^{2}=0.9226$. Table 8-12 shows that the individual parameter effects for FlyAsh and BFS are statistically significant (p-value $<0.001$ ) as is the effect for MixRatio ( $p$-value $<0.05$ ). For the individual simulant effects, the effects of the SST Blend and Hi Al simulants are statistically significant (p-values $<0.0001$ ). The last column of Table 8-12 shows that the effects of SimAve and SimHiSO4 are not statistically different, but that SimBlend, SimHiAl, and pair of SimAve and SimHiSO4 have statistically different effects. Three two-parameter interaction terms involving simulants have statistically significant effects: SimBlend*NaMol (p-values $<0.01)$, SimAve*NaMol ( $p$-value $<0.05)$, and SimHiAl*FlyAsh (p-value $<0.05$ ). The last column of Table 8-12 for the Simulant*NaMol interaction shows that only SimAve and SimBlend have statistically different effects.

Table 8-13 summarizes the results of using the stepwise regression approach described in Section 8.3. That approach allows all two-parameter interactions to enter the model, including interactions involving BFS. Keep in mind that cautions SM1 and SM2 discussed in Section 8.4 apply to the results in Table 8-13. The Stepwise Model for TPHG has $\mathrm{R}^{2}=0.8958$ that is smaller than for the Full Model (0.9226), but that may be a result of the latter being inflated per Caution $\mathrm{FM} 2$ in Section 8.4. Also, $\mathrm{RMSE}=9.498$ is much larger than $\mathrm{RMSE}_{\mathrm{PE}}=2.125$, such that the Stepwise Model LOF is highly significant $(\mathrm{p}$-value $=8.72 \mathrm{E}-05)$. Table 8-13 indicates that six

Table 8-13. Time to Peak Heat Generation: Results of Using Stepwise Regression to Select Statistically Significant Individual Parameter and Two-Parameter Interaction Terms for the Stepwise Model $^{(\mathbf{a})}$

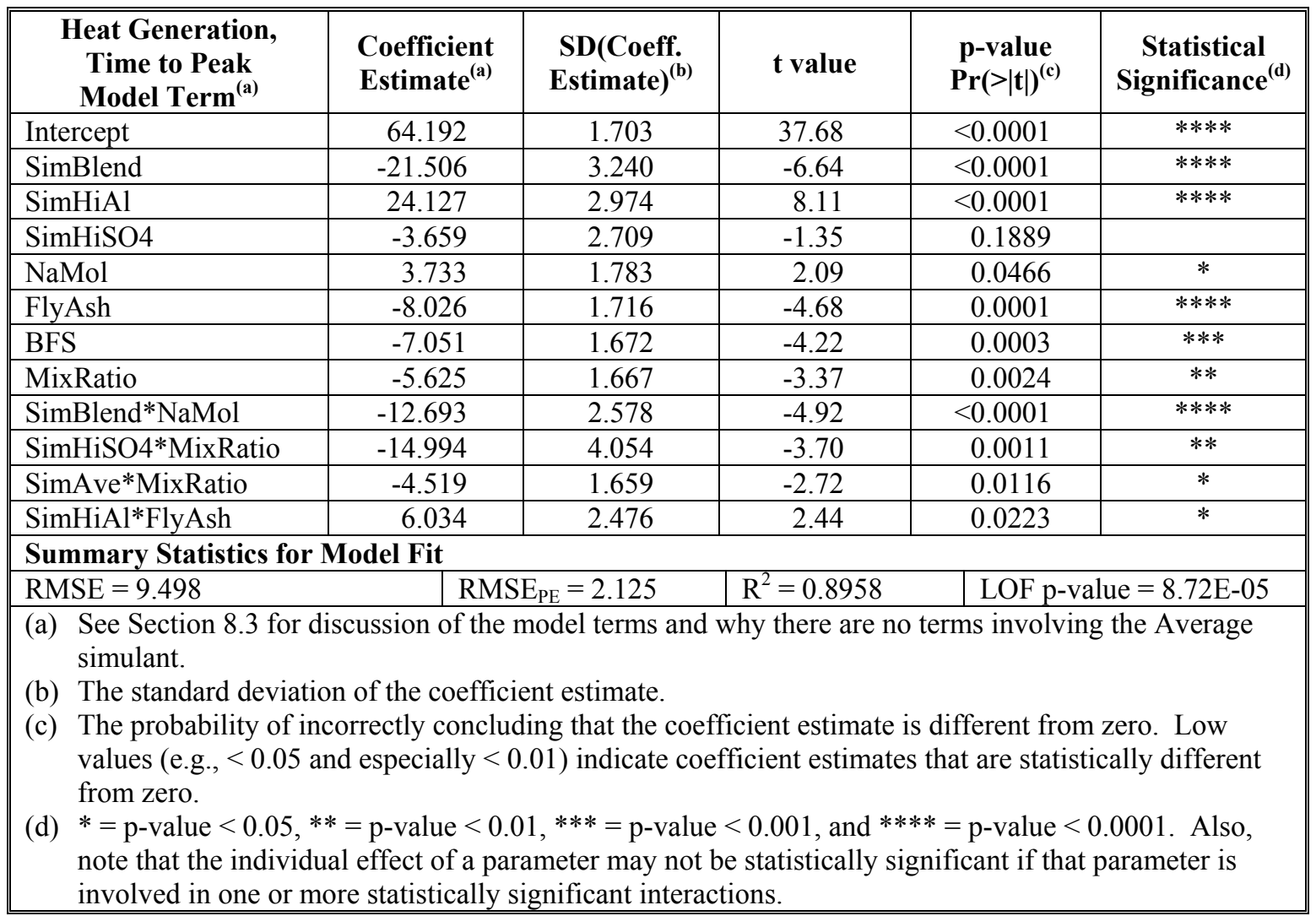


individual parameter effects are statistically significant, including SimBlend, SimHiAl, and FlyAsh (p-values $<0.0001$ ), BFS (p-value $<0.001$ ), MixRatio (p-value $<0.01$ ), and NaMol (p-value $<0.05)$. The statistically significant two-parameter interaction terms are SimBlend*NaMol (p-value $<0.0001$ ), SimHiSO4*MixRatio (p-value $<0.01$ ), SimAve*MixRatio ( $\mathrm{p}$-value $<0.05$ ), and SimHiAl*FlyAsh (p-value $<0.05$ ). Finally, no interactions involving BFS are statistically significant, suggesting that BFS interactions do not appear to affect TPHG.

\subsection{Results of Statistical Analyses - Cured Waste Form Properties}

The results of the statistical analysis methods described in Sections 8.1 to 8.3 are presented and discussed in Section 8.7.1 for compressive strength and in Section 8.7.2 for EPA Method 1315 leach results.

\subsubsection{Compressive Strength}

PNNL measured compressive strength on triplicate cylindrical samples made using each of the 26 mixes in the Cast Stone screening test matrix in Table 2-1, as discussed in Section 7.2. The means and SDs of Compressive Strength values over triplicate specimens for each of the 26 Cast Stone mixes are listed in Table D-2 in Appendix D. The means of Compressive Strength over the triplicate specimens vary from 857 to 8034 psi with a mean of 4159 psi. Table 8-5 presents uncertainties in the Compressive Strength values (means over triplicate specimens) as calculated from replicates. The estimated uncertainties using all replicate pairs are SD $=409.4$ psi and $\% \mathrm{RSD}=13.3$. The natural logarithm of Compressive Strength was statistically analyzed because the standard deviation seemed to be proportional to the magnitude of values. The balance of this section presents and discusses the results of the statistical analysis methods described in Sections 8.1 to 8.3 .

Table 8-14 presents the results of fitting the Full Model to the $\ln$ (Compressive Strength) data and statistically assessing the effects of individual parameters and their two-parameter interactions, as discussed in Section 8.2. Keep in mind that Cautions FM1 and FM2 discussed in Section 8.4 apply to the results in Table 8-14. The Full Model accounts for a large portion of the variability in the $\ln$ (Compressive Strength) data, as indicated by $\mathrm{R}^{2}=0.9826$. Also, RMSE $=0.1759$ is close to $\mathrm{RMSE}_{\mathrm{PE}}=0.1342$, such that the model LOF is not statistically significant ( $\mathrm{p}$-value $=0.0696$ ). Table 8-14 indicates that individual parameter effects for four parameters are statistically significant, including MixRatio (p-value $<0.001$ ) and NaMol, FlyAsh and BFS (p-values $<0.01$ ). None of the terms involving simulant are statistically significant. The only statistically significant two-parameter interaction term is NaMol*MixRatio ( $\mathrm{p}$-value $<0.01$ ).

Table 8-15 summarizes the results of using the stepwise regression approach described in Section 8.3. That approach allows all two-parameter interactions to enter the model, including interactions involving BFS. Keep in mind that cautions SM1 and SM2 discussed in Section 8.4 apply to the results in Table 8-15. The Stepwise Model for $\ln$ (Compressive Strength) has $\mathrm{R}^{2}=$ 0.9455 that is smaller than for the Full Model (0.9826), but that may be a result of the latter being inflated per Cautions FM1 and FM2 in Section 8.4. Also, RMSE $=0.1967$ is not enough larger than $\mathrm{RMSE}_{\mathrm{PE}}=0.1342$, such that the Stepwise Model LOF is nonsignificant ( $\mathrm{p}$-value $=0.1404$ ). Table 8-15 indicates that four individual parameter effects are statistically significant, including MixRatio and BFS (p-values < 0.0001) and NaMol and FlyAsh (p-values < 0.01). The statistically significant two-parameter interaction terms are NaMol*MixRatio (p-value $<0.0001$ ), SimBlend*NaMol (p-value $<0.01$ ), and SimHiAl*NaMol (p-value $<0.05$ ). Finally, no interactions involving BFS are statistically significant, suggesting that BFS interactions do not appear to affect Compressive Strength. 
Table 8-14. In(Compressive Strength): Summary of Fitting the Full Model and Statistically Assessing the Effects of the Individual Test Parameters and Two-Parameter Interactions

\begin{tabular}{|c|c|c|c|c|c|}
\hline 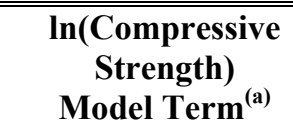 & $\begin{array}{c}\text { Effect } \\
\text { Estimate }^{(a)}\end{array}$ & $\begin{array}{c}\text { SD(Effect } \\
\text { Estimate) }^{(b)}\end{array}$ & p-value $e^{(c)}$ & $\begin{array}{c}\text { Signif- } \\
\text { icance }^{(\mathrm{d})}\end{array}$ & $\begin{array}{l}\text { Tukey's HSD } \\
\text { MCP Results }^{(\mathrm{e})}\end{array}$ \\
\hline Intercept & 8.1770 & 0.0418 & $<0.0001$ & $* * * *$ & \\
\hline \multicolumn{6}{|l|}{ Simulant } \\
\hline Average & 0.0192 & 0.0762 & 0.8094 & & A \\
\hline SST Blend & 0.0685 & 0.0705 & 0.3690 & & $\mathrm{~A}$ \\
\hline $\mathrm{Hi} \mathrm{Al}$ & -0.1150 & 0.0710 & 0.1563 & & $\mathrm{~A}$ \\
\hline $\mathrm{Hi} \mathrm{SO}_{4}$ & 0.0273 & 0.0762 & 0.7327 & & A \\
\hline NaMol & 0.1666 & 0.0404 & 0.0062 & ** & \\
\hline FlyAsh & -0.1663 & 0.0396 & 0.0057 & ** & \\
\hline BFS & -0.2483 & 0.0536 & 0.0036 & ** & \\
\hline MixRatio & 0.3381 & 0.0396 & 0.0001 & $* * *$ & \\
\hline \multicolumn{6}{|l|}{ Simulant*NaMol } \\
\hline Average & 0.0387 & 0.1151 & 0.7482 & & A \\
\hline SST Blend & -0.2288 & 0.1069 & 0.0760 & & A \\
\hline $\mathrm{Hi} \mathrm{Al}$ & 0.1155 & 0.1025 & 0.3030 & & $\mathrm{~A}$ \\
\hline $\mathrm{Hi} \mathrm{SO}_{4}$ & 0.0746 & 0.1089 & 0.5186 & & A \\
\hline \multicolumn{6}{|l|}{ Simulant*FlyAsh } \\
\hline Average & -0.0308 & 0.0856 & 0.7310 & & A \\
\hline SST Blend & -0.0497 & 0.0913 & 0.6058 & & A \\
\hline $\mathrm{Hi} \mathrm{Al}$ & -0.0383 & 0.0943 & 0.6989 & & $\mathrm{~A}$ \\
\hline $\mathrm{Hi} \mathrm{SO}_{4}$ & 0.1188 & 0.0835 & 0.2048 & & A \\
\hline \multicolumn{6}{|l|}{ Simulant*MixRatio } \\
\hline Average & -0.0558 & 0.1011 & 0.6012 & & A \\
\hline SST Blend & -0.1586 & 0.0913 & 0.1331 & & $\mathrm{~A}$ \\
\hline $\mathrm{Hi} \mathrm{Al}$ & 0.0538 & 0.0774 & 0.5129 & & $\mathrm{~A}$ \\
\hline $\mathrm{Hi} \mathrm{SO}_{4}$ & 0.1606 & 0.0835 & 0.1030 & & $\mathrm{~A}$ \\
\hline NaMol*FlyAsh & -0.0191 & 0.0703 & 0.7955 & & \\
\hline NaMol*MixRatio & -0.2663 & 0.0668 & 0.0072 & $* *$ & \\
\hline FlyAsh*MixRatio & -0.0656 & 0.0893 & 0.4904 & & \\
\hline \multicolumn{6}{|c|}{ Summary Statistics of Model Fit } \\
\hline $\mathrm{RMSE}=0.1759$ & \multicolumn{2}{|c|}{$\mathrm{RMSE}_{\mathrm{PE}}=0.1342$} & .9826 & \multicolumn{2}{|c|}{ LOF $p$-value $=0.0696$} \\
\hline \multicolumn{6}{|c|}{$\begin{array}{l}\text { (a) See Section } 8.2 .1 \text { for discussion of the model terms and effect estimates. } \\
\text { (b) The standard deviation of the effect estimate. } \\
\text { (c) The probability of incorrectly concluding that the effect estimate is different from zero. Low values } \\
\text { (e.g., }<0.05 \text { and especially }<0.01 \text { ) indicate effect estimates that are statistically different from zero. } \\
\text { (d) } *=\text { p-value }<0.05, * *=\text { p-value }<0.01, * * *=p \text {-value }<0.001 \text {, and } * * * *=p \text {-value }<0.0001 \text {. Also, } \\
\text { note that the individual effect of a parameter may not be statistically significant if that parameter is } \\
\text { involved in one or more statistically significant interactions. } \\
\text { (e) Tukey's HSD MCP is discussed in Section } 8.2 .5 \text {. For the Simulant parameter by itself, estimates of } \\
\text { the simulant effects having the same letter (e.g., A, B. C) are not statistically different at the } 0.05 \\
\text { level of significance (i.e., }>95 \% \text { confidence) over all comparisons. For Simulant*Parameter } \\
\text { interactions, simulants with the same letter (e.g., A, B, C) do not have statistically significant } \\
\text { interactions with Parameter at the } 0.05 \text { level of significance (e.g., }>95 \% \text { confidence) over all } \\
\text { comparisons. }\end{array}$} \\
\hline
\end{tabular}


PNNL-22747

SRNL-STI-2013-00465

Table 8-15. In(Compressive Strength): Results of Using Stepwise Regression to Select Statistically Significant Individual Parameter and Two-Parameter Interaction Terms for the Stepwise Model ${ }^{(a)}$

\begin{tabular}{|c|c|c|c|c|c|}
\hline $\begin{array}{c}\text { In(Compressive } \\
\text { Strength) }^{(a)} \\
\text { Model Term }^{(a)}\end{array}$ & $\begin{array}{l}\text { Coefficient } \\
\text { Estimate }^{(a)}\end{array}$ & $\begin{array}{l}\text { SD(Coeff. } \\
\text { Estimate) }^{(\mathbf{b})}\end{array}$ & t value & $\begin{array}{c}\text { p-value } \\
\operatorname{Pr}(>|\mathbf{t}|)^{(\mathbf{c})}\end{array}$ & $\begin{array}{c}\text { Statistical } \\
\text { Significance }^{(\mathrm{d})}\end{array}$ \\
\hline Intercept & 8.1795 & 0.0409 & 199.90 & $<0.0001$ & $* * * *$ \\
\hline SimBlend & 0.0201 & 0.0753 & 0.27 & 0.7931 & \\
\hline SimHiAl & -0.1245 & 0.0708 & -1.76 & 0.0990 & \\
\hline SimHiSO4 & 0.0776 & 0.0668 & 1.16 & 0.2635 & \\
\hline NaMol & 0.1579 & 0.0417 & 3.78 & 0.0018 & ** \\
\hline FlyAsh & -0.1640 & 0.0410 & -4.00 & 0.0012 & $* *$ \\
\hline BFS & -0.2827 & 0.0428 & -6.60 & $<0.0001$ & $* * * *$ \\
\hline MixRatio & 0.3519 & 0.0413 & 8.51 & $<0.0001$ & $* * * *$ \\
\hline NaMol*MixRatio & -0.2394 & 0.0409 & -5.85 & $<0.0001$ & $* * * *$ \\
\hline SimBlend*NaMol & -0.2400 & 0.0718 & -3.34 & 0.0044 & $* *$ \\
\hline SimHiAl*NaMol & 0.1569 & 0.0680 & 2.31 & 0.0357 & $*$ \\
\hline \multicolumn{6}{|c|}{ Summary Statistics for Model Fit } \\
\hline \multicolumn{3}{|c|}{\begin{tabular}{|l|l} 
RMSE $=0.1967$ & $\mathrm{RMSE}_{\mathrm{PE}}=0.1342$ \\
\end{tabular}} & $\mathrm{R}^{2}=0.9455$ & \multicolumn{2}{|c|}{ LOF $p$-value $=0.1404$} \\
\hline \multicolumn{6}{|c|}{$\begin{array}{l}\text { (a) See Section } 8.3 \text { for discussion of the model terms and why there are no terms involving the Average } \\
\text { simulant. } \\
\text { (b) The standard deviation of the coefficient estimate. } \\
\text { (c) The probability of incorrectly concluding that the coefficient estimate is different from zero. Low } \\
\text { values (e.g., }<0.05 \text { and especially }<0.01 \text { ) indicate coefficient estimates that are statistically different } \\
\text { from zero. } \\
\text { (d) } *=\text { p-value }<0.05, * *=\text { p-value }<0.01, * * *=p \text {-value }<0.001 \text {, and } * * * *=p \text {-value }<0.0001 \text {. Also, } \\
\text { note that the individual effect of a parameter may not be statistically significant if that parameter is } \\
\text { involved in one or more statistically significant interactions. }\end{array}$} \\
\hline
\end{tabular}

\subsubsection{EPA 1315 Leach Test Results}

The primary results from the EPA Method 1315 leach tests are effective diffusion coefficients (EDC) calculated as described in Section 7.5. In addition, leachability index (LI) values were calculated from EDCs using the transformation in Equation (7-2). One of the requirements of OLS model fitting methods used in the statistical analysis methods (see Section 8.1) is that the uncertainties in the property values must be relatively constant for all tests. This requirement is met for LI values but not EDC values. Hence, in this section it is the LI data that are statistically analyzed.

Table D-15 in Appendix D contains the duplicate (i.e., repeat) LI values for $\mathrm{Na}, \mathrm{NO}_{3}, \mathrm{NO}_{2}, \mathrm{I}, \mathrm{Tc}$, $\mathrm{Cr}$, and $\mathrm{U}$, along with means and SDs of the duplicate values, for each of the 26 Cast Stone mixes in Table 2-1. The duplicate LI values were calculated by applying Equation (7-2) to the duplicate EDCs in Table D-14. Table D-15 lists the means and SDs calculated from duplicate LI values for each mix. The mean LI values are used as the property values for each of the 26 Cast Stone mixes for the balance of the data analyses in this subsection.

Figure 8-3 shows a scatterplot matrix of the LI values for $\mathrm{Na}, \mathrm{NO}_{3}, \mathrm{NO}_{2}, \mathrm{I}, \mathrm{Tc}, \mathrm{Cr}$, and $\mathrm{U}$. Note that several components are strongly correlated, with the strongest correlation being for $\mathrm{NO}_{3}$ and $\mathrm{NO}_{2}$. Because of that, only the $\mathrm{NO}_{3}$ data and not the $\mathrm{NO}_{2}$ data are statistically analyzed 
subsequently. Note that $\mathrm{Na}$ and $\mathrm{I}$ are also highly correlated with $\mathrm{NO}_{3}$ and $\mathrm{NO}_{2}$. $\mathrm{Na}$ and I are also strongly correlated with each other, but not quite to the same degree as the other pairs of components discussed so far.

Also of note in Figure 8-3 are the results for Mix 1 (blue triangles) and Mix 23 (red closed squares). Mix 23 is the bottom-left-most data point in every plot in Figure 8-3, which indicates it has the lowest LI for every component. Equivalently, that means Mix 23 has the highest EDC for every component. Mix 23 has the most free-liquid (i.e., bleed water) of any of the 26 Cast Stone mixes for which it was measured, and is a poor mix that would not be used in reality. For that reason, it was decided to exclude Mix 23 from the statistical data analyses. Mix 1 has the highest $\mathrm{LI}$ values for $\mathrm{Na}, \mathrm{NO}_{3}, \mathrm{NO}_{2}$, and I, but intermediate values for other components. Hence, it was decided to retain Mix 1 in the data for statistical analyses.

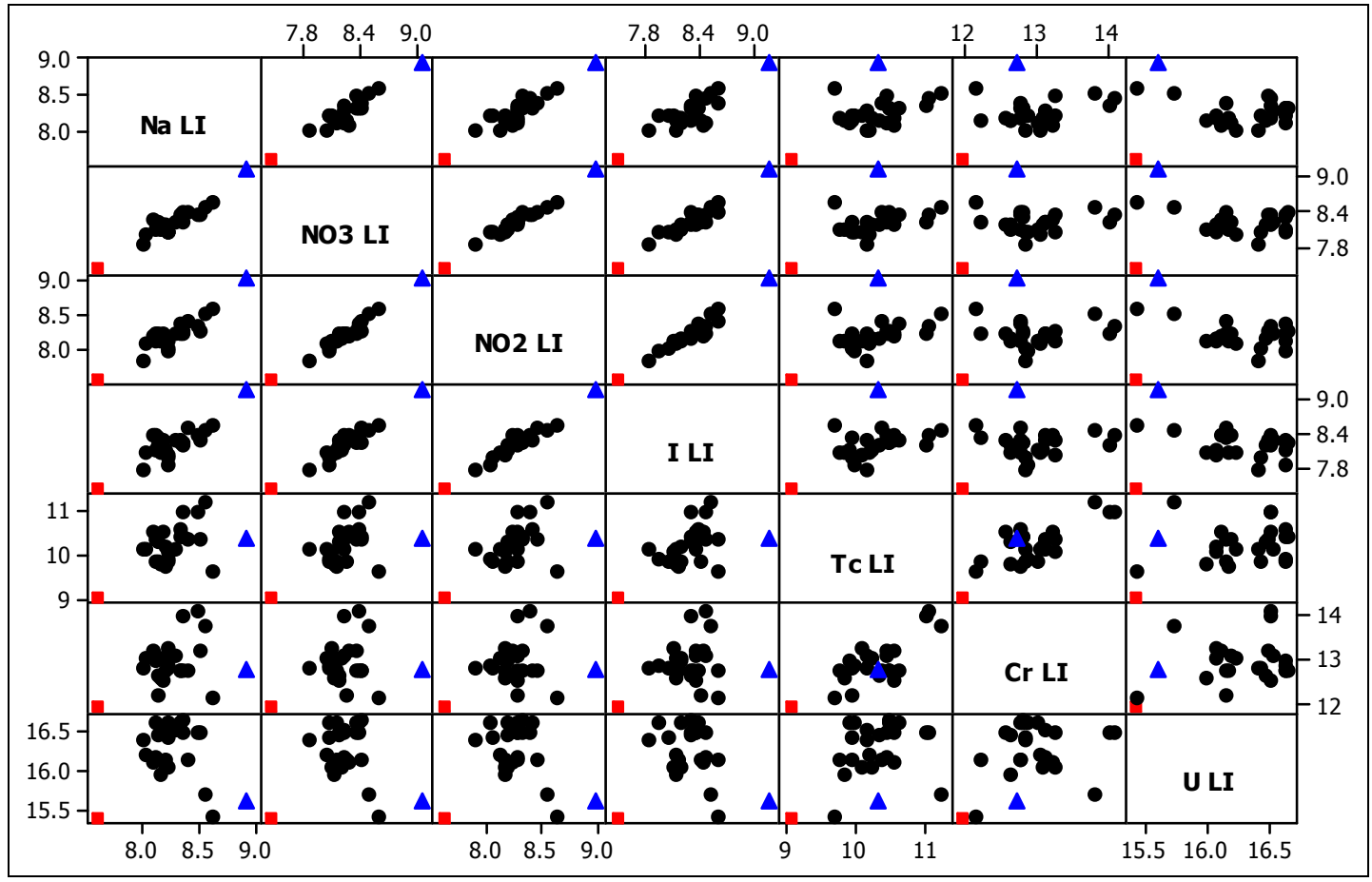

Figure 8-3. Scatterplot Matrix of EPA Method 1315 Leachability Indices for $\mathrm{Na}, \mathrm{NO}_{3}, \mathrm{NO}_{2}$, $\mathrm{I}, \mathrm{Tc}, \mathrm{Cr}$, and $\mathrm{U}$. The red squares are the results for Mix 23, while the blue triangles are the results for Mix 1. (For Information Only)

As mentioned previously, it was decided to only statistically analyze $\mathrm{NO}_{3}$ and not $\mathrm{NO}_{2}$ because of how strongly correlated those two components are. Further, because the uranium concentrations in most of the leachates were below analytical detection limits and thus the EDCs were calculated as less-than values (LI as greater-than values), it was decided not to statistically analyze the U LI data. Hence the following subsections contain results of the statistical analyses discussed in Section 8.1 only for the LI data on $\mathrm{Na}, \mathrm{NO}_{3}, \mathrm{I}, \mathrm{Tc}$, and $\mathrm{Cr}$.

\subsubsection{Na Leachability Index from EPA Method 1315}

For the 26 Cast Stone mixes in Table 2-1, the means of Na LI values over duplicate (i.e., repeat) tests are given in Table D-15 in Appendix D. The mean values were used for the statistical 
analyses reported in this section. Excluding the Na LI value for Mix 23, the remaining Na LI values range from 8.00 to 8.92 with a mean of 8.28. Table 8-7 lists the Na LI values for the five replicate pairs and presents uncertainties in the Na LI values as calculated from the replicates. The pooled (i.e., combined) uncertainty estimates using all replicate pairs are SD $=0.053$ and $\% \operatorname{RSD}=0.64$, which are small. For one replicate pair (Mixes 3 and 22) the replicate values are identical, which may contribute to these values being underestimates of the uncertainties. The balance of this section presents and discusses the results of the statistical analysis methods described in Sections 8.1 to 8.3.

Table 8-16 presents the results of fitting the Full Model to the Na LI data and statistically assessing the effects of individual parameters and their two-parameter interactions, as discussed in Section 8.2. Keep in mind that the Cautions FM1 and FM2 discussed in Section 8.4 apply to the results in Table 8-16. The Full Model accounts for a large portion of the variability in the $\mathrm{Na}$ LI values, as indicated by the $\mathrm{R}^{2}=0.9865$. The dropped data point for Mix 23 means that the Full Model fits the data exactly except for replicate variation, so it was not possible to assess the model LOF (see the discussion in Section 8.2.2). (Note that because the LI data for Mix 23 was omitted for all components, the Full Model LOF cannot be assessed for any of the component LIs.) Table 8-16 shows that of the non-simulant individual parameter effects, only FlyAsh is statistically significant ( $\mathrm{p}$-value $<0.001$ ). The Average and SST Blend simulants have statistically significant effects (p-values $<0.01$ ). Further, based on the last column of Table 8-16, the Average and SST Blend simulants have statistically different effects, as do the SST Blend and Hi Al simulants. There are six statistically significant two-parameter interaction terms of specific simulants with NaMol, FlyAsh, and MixRatio.

Table 8-17 summarizes the results of using the stepwise regression approach described in Section 8.3 to model Na LI. That approach allows all two-parameter interactions to enter the model, including interactions involving BFS. Keep in mind that the cautions SM1 and SM2 discussed in Section 8.4 apply to the results in Table 8-17. The Stepwise Model for Na LI has $\mathrm{R}^{2}=0.8930$ that is smaller than $\mathrm{R}^{2}=0.9865$ for the Full Model, but that may be a result of the latter being inflated per Cautions FM1 and FM2 in Section 8.4. The RMSE $=0.0927$ is somewhat larger than $\mathrm{RMSE}_{\mathrm{PE}}=0.0531$, but still the LOF for the Na LI Stepwise Model is nonsignificant ( $\mathrm{p}$-value $=0.0617$ ). Table 8-17 indicates that three individual parameter effects are statistically significant, including MixRatio and FlyAsh (p-values $<0.01$ ) and SimBlend (p-value $<0.05)$. There are four statistically significant two-parameter interaction terms, all involving simulants, including SimHiAl*NaMol and SimAve*NaMol (p-value $<0.0001$ ), and SimHiSO4*MixRatio (p-value $<0.01$ ), and SimHiSO4*FlyAsh (p-value $<0.05$ ). Finally, no interactions involving BFS are statistically significant, suggesting that BFS interactions do not appear to affect $\mathrm{Na} \mathrm{LI}$. 
Table 8-16. Na Leachability Index: Summary of Fitting the Full Model and Statistically Assessing the Effects of the Individual Test Parameters and Two-Parameter Interactions

\begin{tabular}{|c|c|c|c|c|c|}
\hline $\begin{array}{c}\text { Na Leachability } \\
\text { Index Model Term }^{(a)}\end{array}$ & $\begin{array}{c}\text { Effect } \\
\text { Estimate }^{(a)}\end{array}$ & $\begin{array}{c}\text { SD(Effect } \\
\text { Estimate) }^{(\mathbf{b})}\end{array}$ & p-value ${ }^{(c)}$ & $\begin{array}{c}\text { Signif- } \\
\text { icance }^{(d)}\end{array}$ & $\begin{array}{l}\text { Tukey's HSD } \\
\text { MCP Results }{ }^{(\mathrm{e})}\end{array}$ \\
\hline Intercept & 8.3316 & 0.0166 & $<0.0001$ & $* * * *$ & \\
\hline \multicolumn{6}{|l|}{ Simulant } \\
\hline Average & -0.1141 & 0.0237 & 0.0048 & $* *$ & A \\
\hline SST Blend & 0.1822 & 0.0365 & 0.0041 & ** & $\mathrm{B}$ \\
\hline $\mathrm{Hi} \mathrm{Al}$ & -0.0478 & 0.0225 & 0.0874 & & A \\
\hline $\mathrm{Hi} \mathrm{SO}_{4}$ & -0.0203 & 0.0286 & 0.5094 & & $\mathrm{AB}$ \\
\hline NaMol & 0.0047 & 0.0151 & 0.7687 & & \\
\hline FlyAsh & 0.1147 & 0.0155 & 0.0007 & $* * *$ & \\
\hline BFS & 0.0075 & 0.0191 & 0.7114 & & \\
\hline MixRatio & 0.0122 & 0.0202 & 0.5720 & & \\
\hline \multicolumn{6}{|l|}{ Simulant*NaMol } \\
\hline Average & -0.0053 & 0.0397 & 0.8987 & & $\mathrm{AB}$ \\
\hline SST Blend & -0.0603 & 0.0488 & 0.2717 & & A \\
\hline $\mathrm{Hi} \mathrm{Al}$ & -0.0891 & 0.0357 & 0.0549 & & A \\
\hline $\mathrm{Hi} \mathrm{SO}_{4}$ & 0.1547 & 0.0329 & 0.0053 & $* *$ & $\mathrm{~B}$ \\
\hline \multicolumn{6}{|l|}{ Simulant*FlyAsh } \\
\hline Average & -0.1166 & 0.0269 & 0.0075 & $* *$ & A \\
\hline SST Blend & 0.1159 & 0.0359 & 0.0232 & $*$ & $\mathrm{~B}$ \\
\hline $\mathrm{Hi} \mathrm{Al}$ & -0.0503 & 0.0291 & 0.1445 & & $\mathrm{AB}$ \\
\hline $\mathrm{Hi} \mathrm{SO}_{4}$ & 0.0509 & 0.0269 & 0.1169 & & B \\
\hline \multicolumn{6}{|l|}{ Simulant*MixRatio } \\
\hline Average & 0.0153 & 0.0358 & 0.6866 & & $\mathrm{AB}$ \\
\hline SST Blend & -0.2234 & 0.0619 & 0.0154 & * & A \\
\hline $\mathrm{Hi} \mathrm{Al}$ & 0.0791 & 0.0308 & 0.0500 & & $\mathrm{AB}$ \\
\hline $\mathrm{Hi} \mathrm{SO}_{4}$ & 0.1291 & 0.0303 & 0.0080 & ** & $\mathrm{B}$ \\
\hline NaMol*FlyAsh & 0.0800 & 0.0225 & 0.0164 & $*$ & \\
\hline NaMol*MixRatio & 0.0031 & 0.0215 & 0.8903 & & \\
\hline FlyAsh*MixRatio & 0.0519 & 0.0274 & 0.1172 & & \\
\hline \multicolumn{6}{|c|}{ Summary Statistics of Model Fit } \\
\hline RMSE $=0.0531$ & \multicolumn{2}{|c|}{\begin{tabular}{|l|l}
$\mathrm{RMSE}_{\mathrm{PE}}=0.0531$ & $\mathrm{R}$ \\
\end{tabular}} & 0.9865 & \multicolumn{2}{|c|}{ LOF $p$-value $=\mathrm{NA}^{(\mathrm{f})}$} \\
\hline \multicolumn{6}{|c|}{$\begin{array}{l}\text { (c) The probability of incorrectly concluding that the effect estimate is different from zero. Low values } \\
\text { (e.g., }<0.05 \text { and especially }<0.01) \text { indicate effect estimates that are statistically different from zero. } \\
\text { (d) } *=\text { p-value }<0.05, * *=p \text {-value }<0.01, * * *=p \text {-value }<0.001 \text {, and } * * * *=p \text {-value }<0.0001 \text {. Also, } \\
\text { note that the individual effect of a parameter may not be statistically significant if that parameter is } \\
\text { involved in one or more statistically significant interactions. }\end{array}$} \\
\hline \multicolumn{6}{|c|}{$\begin{array}{l}\text { (e) Tukey's HSD MCP is discussed in Section 8.2.5. For the Simulant parameter by itself, estimates of } \\
\text { the simulant effects having the same letter (e.g., A, B. C) are not statistically different at the } \\
0.05 \text { level of significance (i.e., }>95 \% \text { confidence) over all comparisons. For Simulant*Parameter } \\
\text { interactions, simulants with the same letter (e.g., A, B, C) do not have statistically significant } \\
\text { interactions with Parameter at the } 0.05 \text { level of significance (e.g., }>95 \% \text { confidence) over all }\end{array}$} \\
\hline \multicolumn{6}{|c|}{$\begin{array}{l}\text { (f) The data value for Mix } 23 \text { was judged an outlier and not used in the model fit. Hence, it was not possible } \\
\text { to statistically assess the model LOF. }\end{array}$} \\
\hline
\end{tabular}




\section{Table 8-17. Na Leachability Index: Results of Using Stepwise Regression to Select Statistically Significant Individual Parameter and Two-Parameter Interaction Terms for the Stepwise Model ${ }^{(a)}$}

\begin{tabular}{|c|c|c|c|c|c|}
\hline $\begin{array}{c}\text { Na Leachability } \\
\text { Index Model Term }^{(a)}\end{array}$ & $\begin{array}{l}\text { Coefficient } \\
\text { Estimate }^{(a)}\end{array}$ & $\begin{array}{l}\text { SD(Coeff. } \\
\text { Estimate) }^{(\mathbf{b})}\end{array}$ & t value & $\begin{array}{c}\text { p-value } \\
\operatorname{Pr}(>|\mathbf{t}|)^{(\mathbf{c})}\end{array}$ & $\begin{array}{c}\text { Statistical } \\
\text { Significance }^{(\mathrm{d})}\end{array}$ \\
\hline Intercept & 8.2929 & 0.0200 & 415.26 & $<0.0001$ & $* * * *$ \\
\hline SimBlend & 0.1001 & 0.0398 & 2.52 & 0.0258 & $*$ \\
\hline SimHiAl & -0.0399 & 0.0341 & -1.17 & 0.2623 & \\
\hline SimHiSO4 & 0.0207 & 0.0369 & 0.56 & 0.5842 & \\
\hline $\mathrm{NaMol}$ & 0.0430 & 0.0207 & 2.08 & 0.0581 & \\
\hline FlyAsh & 0.0723 & 0.0197 & 3.66 & 0.0029 & ** \\
\hline BFS & -0.0263 & 0.0261 & -1.01 & 0.3317 & \\
\hline MixRatio & 0.0790 & 0.0205 & 3.86 & 0.0020 & $* *$ \\
\hline SimHiAl*NaMol & -0.2912 & 0.0502 & -5.80 & & $* * * *$ \\
\hline SimHiSO4*MixRatio & 0.1065 & 0.02 & 3.75 & & $* *$ \\
\hline SimHiSO4*FlyAsh & 0.0651 & 0.02 & 2.31 & 0.0377 & * \\
\hline SimAve*NaMol & -0.1369 & 0.0214 & -6.39 & $<0.0001$ & $* * * *$ \\
\hline \multicolumn{6}{|c|}{ Summary Statistics for Model Fit } \\
\hline \multicolumn{3}{|c|}{\begin{tabular}{|l|l|}
$\mathrm{RMSE}=0.0927$ & $\mathrm{RMSE}_{\mathrm{PE}}=0.0531$ \\
\end{tabular}} & $\mathrm{R}^{2}=0.8930$ & \multicolumn{2}{|c|}{ LOF p-value $=0.0617$} \\
\hline \multirow{2}{*}{\multicolumn{6}{|c|}{$\begin{array}{l}\text { (a) See Section } 8.3 \text { for discussion of the model terms and why there are no terms involving the Average } \\
\text { simulant. } \\
\text { (b) The standard deviation of the coefficient estimate. }\end{array}$}} \\
\hline & & & & & \\
\hline \multicolumn{6}{|c|}{$\begin{array}{l}\text { (c) The probability of incorrectly concluding that the coefficient estimate is different from zero. Low } \\
\text { values }(\text { e.g., }<0.05 \text { and especially }<0.01) \text { indicate coefficient estimates that are statistically different } \\
\text { from zero. }\end{array}$} \\
\hline \multicolumn{6}{|c|}{$\begin{array}{l}\text { (d) } * \text { p-value }<0.05, * *=p \text {-value }<0.01, * * *=p \text {-value }<0.001 \text {, and } * * * *=p \text {-value }<0.0001 . \text { Also, } \\
\text { note that the individual effect of a parameter may not be statistically significant if that parameter is } \\
\text { involved in one or more statistically significant interactions. }\end{array}$} \\
\hline
\end{tabular}

\subsubsection{2 $\mathrm{NO}_{3}$ Leachability Index from EPA Method 1315}

For the 26 Cast Stone mixes in Table 2-1, the means of $\mathrm{NO}_{3} \mathrm{LI}$ values over duplicate (i.e., repeat) tests for the 26 Cast Stone mixes are given in Table D-15 in Appendix D. The mean values were used for the statistical analyses reported in this section. Excluding the $\mathrm{NO}_{3} \mathrm{LI}$ value for Mix 23, the remaining $\mathrm{NO}_{3} \mathrm{LI}$ values range from 7.85 to 9.07 with a mean of 8.27. Table 8-7 lists the $\mathrm{NO}_{3}$ LI values for five replicate pairs and presents uncertainties in the $\mathrm{NO}_{3} \mathrm{LI}$ values as calculated from the replicates. The pooled (i.e., combined) uncertainty estimates using all replicate pairs are $\mathrm{SD}=0.107$ and $\% \mathrm{RSD}=1.32$, which are small. For one replicate pair (Mixes 15 and 25) the replicate values are identical, which may contribute to these values being underestimates of the uncertainties The balance of this section presents the results of the statistical analysis methods described in Sections 8.1 to 8.3.

Table 8-18 presents the results of fitting the Full Model to the $\mathrm{NO}_{3}$ LI data and statistically assessing the effects of individual parameters and their two-parameter interactions, as discussed in Section 8.2. Keep in mind that Cautions FM1 and FM2 discussed in Section 8.4 apply to the results in Table 8-18. The Full Model accounts for a large portion of the variability in the $\mathrm{NO}_{3} \mathrm{LI}$ values, as indicated by the $\mathrm{R}^{2}=0.9562$. The dropped data point for Mix 23 means that the Full Model fits the data exactly except for replicate variation, so it was not possible to assess the 
Table 8-18. $\mathrm{NO}_{3}$ Leachability Index: Summary of Fitting the Full Model and Statistically Assessing the Effects of the Individual Test Parameters and Two-Parameter Interactions

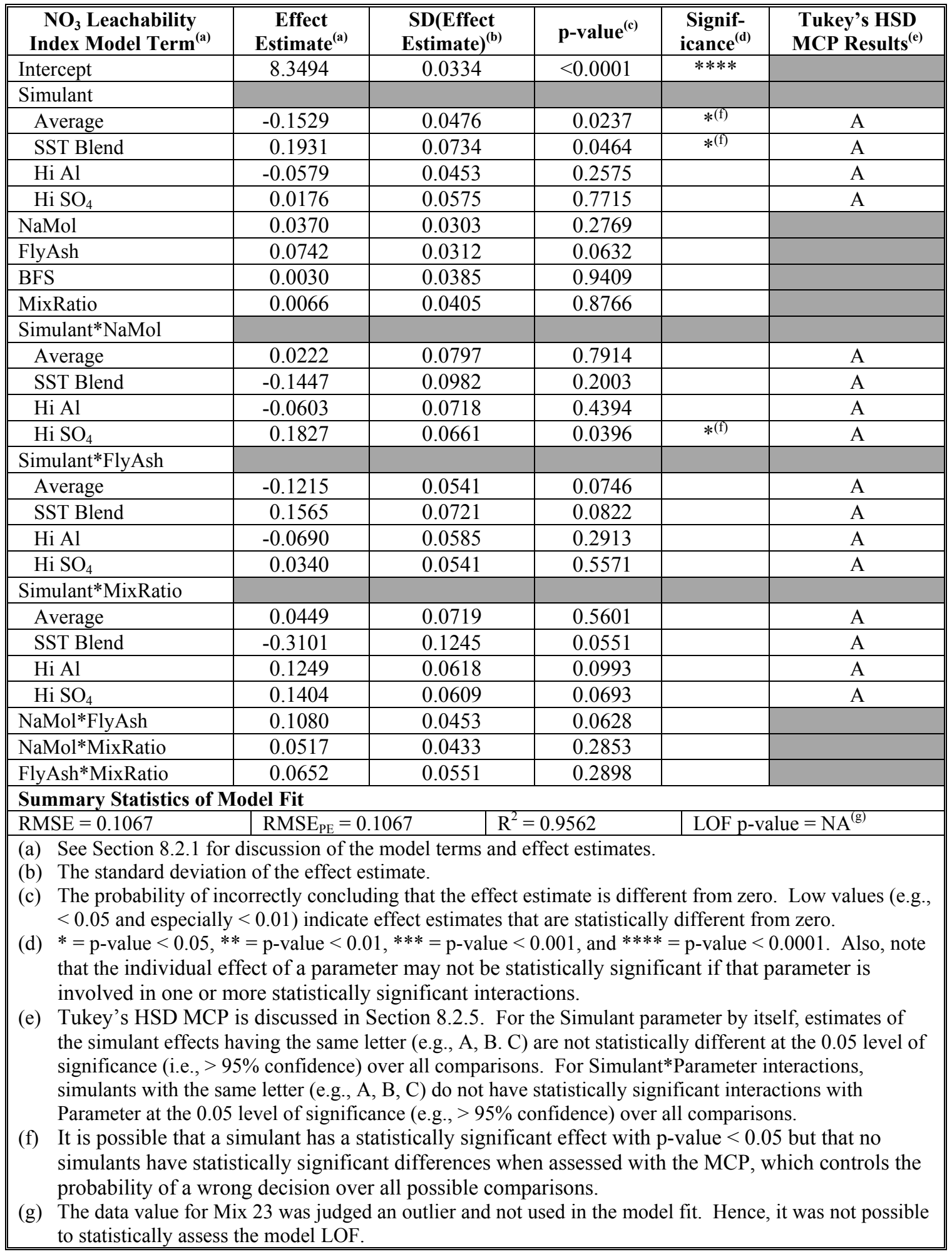


model LOF. Table 8-18 shows that only three terms have statistically significant effects (p-values < 0.05) on $\mathrm{NO}_{3}$ LI. Two of these terms correspond to the individual effects of the Average and SST Blend simulants (p-values $<0.05)$. The third term is an interaction of the $\mathrm{HiSO}_{4}$ simulant with $\mathrm{NaMol}(\mathrm{p}$-value $<0.05)$.

Table 8-19 summarizes the results of using the stepwise regression approach described in Section 8.3 to model $\mathrm{NO}_{3}$ LI. That approach allows all two-parameter interactions to enter the model, including interactions involving BFS. Keep in mind that the cautions SM1 and SM2 discussed in Section 8.4 apply to the results in Table 8-19. The Stepwise Model for $\mathrm{NO}_{3} \mathrm{LI}$ has $\mathrm{R}^{2}=0.6801$ that is smaller than $\mathrm{R}^{2}=0.9562$ for the Full Model, but that may be a result of the latter being inflated per Cautions FM1 and FM2 in Section 8.4. The RMSE $=0.1664$ is somewhat larger than $\mathrm{RMSE}_{\mathrm{PE}}=0.1067$, but still the LOF for the Na LI Stepwise Model is nonsignificant $(\mathrm{p}$-value $=0.1087)$. Table 8-19 indicates that three individual parameter effects are statistically significant, including SimHiSO4, MixRatio, and BFS (p-values $<0.05$ ). There are two statistically significant two-parameter interaction terms, SimHiSO4*NaMol (p-value $<0.001)$ and SimHiAl*NaMol (p-value < 0.05). Finally, no interactions involving BFS are statistically significant, suggesting that BFS interactions do not appear to affect $\mathrm{NO}_{3} \mathrm{LI}$.

Table 8-19. $\mathrm{NO}_{3}$ Leachability Index: Results of Using Stepwise Regression to Select Statistically Significant Individual Parameter and Two-Parameter Interaction Terms for the Stepwise Model ${ }^{(a)}$

\begin{tabular}{|c|c|c|c|c|c|}
\hline $\begin{array}{l}\mathrm{NO}_{3} \text { Leachability } \\
\text { Index Model Term }\end{array}$ & $\begin{array}{l}\text { Coefficient } \\
\text { Estimate }^{(a)}\end{array}$ & $\begin{array}{l}\text { SD(Coeff. } \\
\text { Estimate) }^{(b)}\end{array}$ & t value & $\begin{array}{c}\text { p-value } \\
\operatorname{Pr}(>|\mathbf{t}|)^{(\mathbf{c})}\end{array}$ & $\begin{array}{c}\text { Statistical } \\
\text { Significance }^{(\mathrm{d})}\end{array}$ \\
\hline Intercept & 8.3096 & 0.0355 & 234.10 & 0.0000 & $* * * *$ \\
\hline SimBlend & 0.0417 & 0.0708 & 0.59 & 0.5651 & \\
\hline SimHiAl & -0.0671 & 0.0611 & -1.10 & 0.2895 & \\
\hline SimHiSO4 & 0.1565 & 0.0644 & 2.43 & 0.0282 & $*$ \\
\hline NaMol & 0.0611 & 0.0357 & 1.71 & 0.1078 & \\
\hline FlyAsh & 0.0234 & 0.0352 & 0.66 & 0.5173 & \\
\hline BFS & -0.1035 & 0.0389 & -2.66 & 0.0178 & $*$ \\
\hline MixRatio & 0.0925 & 0.0361 & 2.56 & 0.0216 & $*$ \\
\hline SimHiSO4*NaMol & 0.2605 & 0.0587 & 4.44 & 0.0005 & $* * *$ \\
\hline SimHiAl*NaMol & -0.1333 & 0.0565 & -2.36 & 0.0323 & $*$ \\
\hline \multicolumn{6}{|c|}{ Summary Statistics for Model Fit } \\
\hline \multicolumn{3}{|c|}{\begin{tabular}{|l|l|} 
RMSE $=0.1664$ & $\mathrm{RMSE}_{\mathrm{PE}}=0.1067$ \\
\end{tabular}} & $\mathrm{R}^{2}=0.6801$ & \multicolumn{2}{|c|}{ LOF $p$-value $=0.1087$} \\
\hline \multicolumn{6}{|c|}{$\begin{array}{l}\text { (a) See Section } 8.3 \text { for discussion of the model terms and why there are no terms involving the Average } \\
\text { simulant. } \\
\text { (b) The standard deviation of the coefficient estimate. } \\
\text { (c) The probability of incorrectly concluding that the coefficient estimate is different from zero. Low } \\
\text { values (e.g., }<0.05 \text { and especially }<0.01 \text { ) indicate coefficient estimates that are statistically different } \\
\text { from zero. } \\
\text { (d) } *=\text { p-value }<0.05, * *=\text { p-value }<0.01, * * *=\text {-value }<0.001 \text {, and } * * * *=p \text {-value }<0.0001 \text {. Also, } \\
\text { note that the individual effect of a parameter may not be statistically significant if that parameter is } \\
\text { involved in one or more statistically significant interactions. }\end{array}$} \\
\hline
\end{tabular}


PNNL-22747

SRNL-STI-2013-00465

\subsubsection{Iodine Leachability Index from EPA Method 1315}

For the 26 Cast Stone mixes in Table 2-1, the means of I LI values over duplicate (i.e., repeat) tests for the 26 Cast Stone mixes are given in Table D-15 in Appendix D. The mean values were used for the statistical analyses reported in this section. Excluding the I LI value for Mix 23, the remaining I LI values range from 7.81 to 9.16 with a mean of 8.30. Table 8-7 lists the I LI values for five replicate pairs and presents uncertainties in the I LI values as calculated from the replicates. The pooled (i.e., combined) uncertainty estimates using all replicate pairs are SD = 0.131 and $\% \mathrm{RSD}=1.63$, which are small. The balance of this section presents the results of the statistical analysis methods described in Sections 8.1 to 8.3.

Table 8-20 presents the results of fitting the Full Model to the I LI data and statistically assessing the effects of individual parameters and their two-parameter interactions, as discussed in Section 8.2. Keep in mind that Cautions FM1 and FM2 discussed in Section 8.4 apply to the results in Table 8-20. The Full Model accounts for a large portion of the variability in the I LI values, as indicated by the $\mathrm{R}^{2}=0.9471$. The dropped data point for Mix 23 means that the Full Model fits the data exactly except for replicate variation, so it was not possible to assess the model LOF. Table 8-20 shows that only two terms have statistically significant effects on I LI. One is an individual parameter effect of the Average simulant, while the other is an interactive effect of the SST Blend simulant with MixRatio (p-values < 0.05).

Table 8-21 summarizes the results of using the stepwise regression approach described in Section 8.3 to model I LI. That approach allows all two-parameter interactions to enter the model, including interactions involving BFS. Keep in mind that the cautions SM1 and SM2 discussed in Section 8.4 apply to the results in Table 8-21. The Stepwise Model for I LI has $\mathrm{R}^{2}=$ 0.6812 with $\mathrm{RMSE}=0.1798$ that is not much larger than $\mathrm{RMSE}_{\mathrm{PE}}=0.1311$. Hence, the LOF for the I LI Stepwise Model is nonsignificant ( $\mathrm{p}$-value $=0.1869$ ). Table 8-21 indicates that four individual parameter effects are statistically significant, including MixRatio (p-value $<0.01$ ) as well as SimHiSO4, NaMol, and BFS (p-values $<0.05$ ). There is only one statistically significant two-parameter interaction term, SimHiSO4*NaMol (p-value $<0.01$ ). Finally, no interactions involving BFS are statistically significant, suggesting that BFS interactions do not appear to affect I LI. 
Table 8-20. I Leachability Index: Summary of Fitting the Full Model and Statistically Assessing the Effects of the Individual Test Parameters and Two-Parameter Interactions

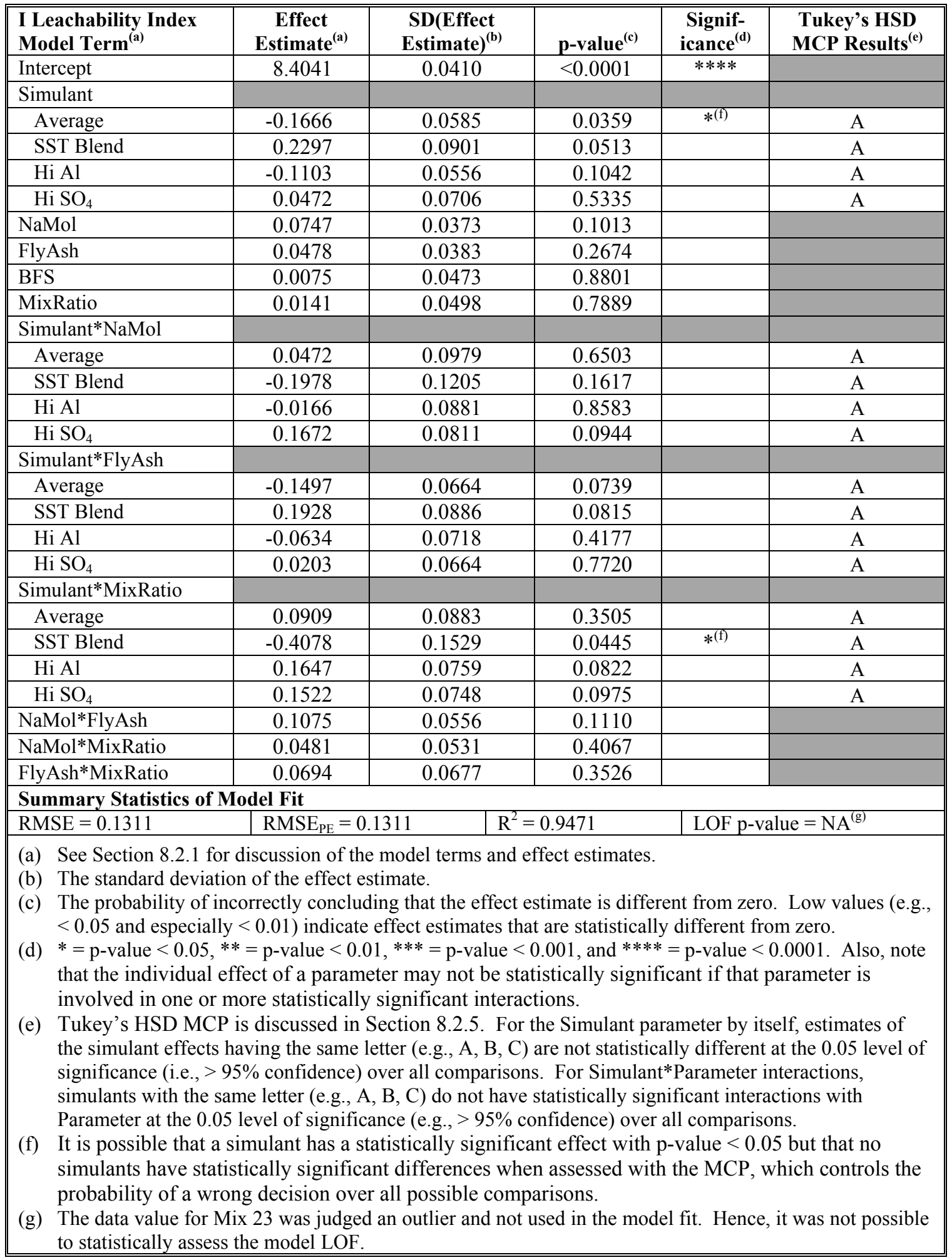


Table 8-21. I Leachability Index: Results of Using Stepwise Regression to Select Statistically Significant Individual Parameter and Two-Parameter Interaction Terms for the Stepwise Model ${ }^{(a)}$

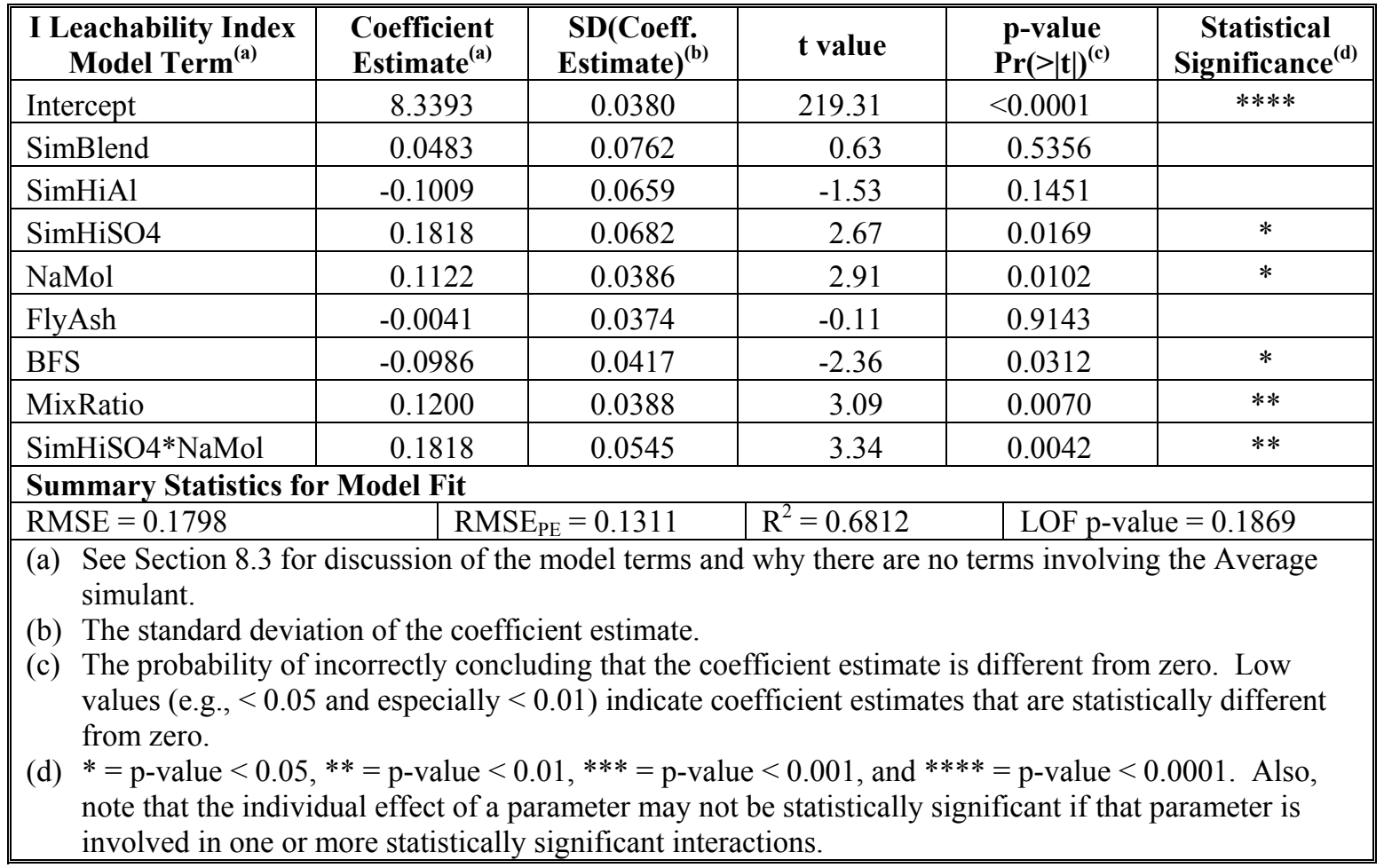

\subsubsection{Tc Leachability Index from EPA Method 1315}

For the 26 Cast Stone mixes in Table 2-1, the means of Tc LI values over duplicate (i.e., repeat) tests for the 26 Cast Stone mixes are given in Table D-15 in Appendix D. The mean values were used for the statistical analyses reported in this section. Excluding the Tc LI value for Mix 23, the remaining Tc LI values range from 9.66 to 11.25 with a mean of 10.30 . Table 8-7 lists the Tc LI values for five replicate pairs and presents uncertainties in the Tc LI values as calculated from the replicates. The pooled (i.e., combined) uncertainty estimates using all replicate pairs are SD = 0.131 and $\% \mathrm{RSD}=1.28$, which are small. The balance of this section presents and discusses the results of the statistical analysis methods described in Sections 8.1 to 8.3.

Table 8-22 presents the results of fitting the Full Model to the Tc LI data and statistically assessing the effects of individual parameters and their two-parameter interactions, as discussed in Section 8.2. Keep in mind that Cautions FM1 and FM2 discussed in Section 8.4 apply to the results in Table 8-22. The Full Model accounts for a large portion of the variability in the Tc LI values, as indicated by the $\mathrm{R}^{2}=0.9784$. The dropped data point for Mix 23 means that the Full Model fits the data exactly except for replicate variation, so it was not possible to assess the model LOF. Table 8-22 shows that the only significant individual parameter effect is NaMol (p-value $<0.01$ ). The Simulant*NaMol, Simulant*FlyAsh, and Simulant*MixRatio groups of interaction terms each have one, three, and three statistically significant terms, respectively. The last column of Table 8-22 indicates which simulants are involved in the interactions. For the 
Table 8-22. Tc Leachability Index: Summary of Fitting the Full Model and Statistically Assessing the Effects of the Individual Test Parameters and Two-Parameter Interactions

\begin{tabular}{|c|c|c|c|c|c|}
\hline $\begin{array}{c}\text { Tc Leachability } \\
\text { Index Model Term }^{(a)}\end{array}$ & $\begin{array}{c}\text { Effect } \\
\text { Estimate }^{(a)}\end{array}$ & $\begin{array}{c}\text { SD(Effect } \\
\text { Estimate) }^{(\mathbf{b})}\end{array}$ & p-value ${ }^{(\mathrm{c})}$ & $\begin{array}{c}\text { Signif- } \\
\text { icance }^{(\mathrm{d})}\end{array}$ & $\begin{array}{c}\text { Tukey's HSD } \\
\text { MCP Results }{ }^{(\mathrm{e})}\end{array}$ \\
\hline Intercept & 10.3153 & 0.0409 & $<0.0001$ & $* * * *$ & \\
\hline \multicolumn{6}{|l|}{ Simulant } \\
\hline Average & -0.1118 & 0.0584 & 0.1137 & & A \\
\hline SST Blend & 0.2034 & 0.0900 & 0.0733 & & A \\
\hline $\mathrm{Hi} \mathrm{Al}$ & -0.0706 & 0.0556 & 0.2600 & & A \\
\hline $\mathrm{Hi} \mathrm{SO}_{4}$ & -0.0211 & 0.0705 & 0.7772 & & A \\
\hline NaMol & -0.1942 & 0.0372 & 0.0034 & $* *$ & \\
\hline FlyAsh & 0.0267 & 0.0383 & 0.5167 & & \\
\hline BFS & -0.1155 & 0.0472 & 0.0582 & & \\
\hline MixRatio & -0.0594 & 0.0497 & 0.2855 & & \\
\hline \multicolumn{6}{|l|}{ Simulant*NaMol } \\
\hline Average & 0.1868 & 0.0978 & 0.1144 & & $\mathrm{AB}$ \\
\hline SST Blend & -0.3212 & 0.1204 & 0.0445 & * & A \\
\hline $\mathrm{Hi} \mathrm{Al}$ & 0.0106 & 0.0880 & 0.9092 & & $\mathrm{AB}$ \\
\hline $\mathrm{Hi} \mathrm{SO}$ & 0.1238 & 0.0811 & 0.1872 & & $\mathrm{~B}$ \\
\hline \multicolumn{6}{|l|}{ Simulant*FlyAsh } \\
\hline Average & -0.2638 & 0.0663 & 0.0106 & * & A \\
\hline SST Blend & 0.4657 & 0.0885 & 0.0033 & $* *$ & $\mathrm{~B}$ \\
\hline $\mathrm{Hi} \mathrm{Al}$ & -0.2451 & 0.0718 & 0.0189 & $*$ & A \\
\hline $\mathrm{Hi} \mathrm{SO}_{4}$ & 0.0432 & 0.0663 & 0.5437 & & A \\
\hline \multicolumn{6}{|l|}{ Simulant*MixRatio } \\
\hline Average & -0.0696 & 0.0882 & 0.4662 & & $\mathrm{AB}$ \\
\hline SST Blend & -0.5133 & 0.1527 & 0.0201 & * & A \\
\hline $\mathrm{Hi} \mathrm{Al}$ & 0.2142 & 0.0758 & 0.0369 & $*$ & $\mathrm{AB}$ \\
\hline $\mathrm{Hi} \mathrm{SO}_{4}$ & 0.3687 & 0.0747 & 0.0043 & $* *$ & $\mathrm{~B}$ \\
\hline NaMol*FlyAsh & -0.0955 & 0.0555 & 0.1462 & & \\
\hline NaMol*MixRatio & -0.0686 & 0.0531 & 0.2526 & & \\
\hline FlyAsh*MixRatio & 0.0166 & 0.0676 & 0.8156 & & \\
\hline \multicolumn{6}{|c|}{ Summary Statistics of Model Fit } \\
\hline RMSE $=0.1309$ & \multicolumn{2}{|c|}{\begin{tabular}{|l|l}
$\mathrm{RMSE}_{\mathrm{PE}}=0.1309$ & $\mathrm{~F}$ \\
\end{tabular}} & 0.9784 & \multicolumn{2}{|c|}{ LOF $p$-value $=\mathrm{NA}^{(\mathrm{f})}$} \\
\hline \multicolumn{6}{|c|}{$\begin{array}{l}\text { (c) The probability of incorrectly concluding that the effect estimate is different from zero. Low values } \\
\text { (e.g., }<0.05 \text { and especially }<0.01) \text { indicate effect estimates that are statistically different from zero. } \\
\text { (d) } *=\text { p-value }<0.05, * *=p \text {-value }<0.01, * * *=p \text {-value }<0.001 \text {, and } * * * *=p \text {-value }<0.0001 \text {. Also, } \\
\text { note that the individual effect of a parameter may not be statistically significant if that parameter is } \\
\text { involved in one or more statistically significant interactions. }\end{array}$} \\
\hline \multicolumn{6}{|c|}{$\begin{array}{l}\text { (e) Tukey's HSD MCP is discussed in Section 8.2.5. For the Simulant parameter by itself, estimates of } \\
\text { the simulant effects having the same letter (e.g., A, B. C) are not statistically different at the } 0.05 \\
\text { level of significance (i.e., > } 95 \% \text { confidence) over all comparisons. For Simulant*Parameter } \\
\text { interactions, simulants with the same letter (e.g., A, B, C) do not have statistically significant } \\
\text { interactions with Parameter at the } 0.05 \text { level of significance (e.g., }>95 \% \text { confidence) over all } \\
\text { comparisons. }\end{array}$} \\
\hline
\end{tabular}


Simulant*NaMol interaction, the SST Blend and HiSO4 simulants have statistically different effects depending on the level of NaMol. For the Simulant*FlyAsh interaction, the SST Blend simulant has statistically different effects depending on the level of NaMol. For the Simulant*MixRatio interaction, the SST Blend and HiSO4 simulants have statistically different effects depending on the level of MixRatio. Note that SST Blend interacts with NaMol, FlyAsh, and MixRatio.

Table 8-23 summarizes the results of using the stepwise regression approach described in Section 8.3 to model Tc LI. That approach allows all two-parameter interactions to enter the model, including interactions involving BFS. Keep in mind that cautions SM1 and SM2 discussed in Section 8.4 apply to the results in Table 8-23. The Stepwise Model for Tc LI has $\mathrm{R}^{2}=0.9358$ that is smaller than $\mathrm{R}^{2}=0.9784$ for the Full Model, but that may be a result of the latter being inflated per Cautions FM1 and FM2 in Section 8.4. The RMSE $=0.1351$ is slightly larger than $\mathrm{RMSE}_{\mathrm{PE}}=0.1309$, such that the LOF for the Tc LI Stepwise Model is highly nonsignificant ( $\mathrm{p}$-value $=0.4844$ ). Table 8 -23 shows statistically significant individual effects of MixRatio and BFS (p-values $<0.0001$ ), SimHiSO4 (p-value $<0.001$ ), FlyAsh p-value $<0.01$ ) and SimBlend and NaMol (p-values <0.05). As discussed in Section 8.3, the significant effects of SimHiSO4 and SimBlend actually correspond to the $\mathrm{Hi} \mathrm{SO}_{4}$ and SST Blend simulants having different effects than the Average simulant on Tc LI. There are three statistically significant interaction terms, two of which include BFS interacting with simulants (p-values $<0.0001$ ). Hence, it appears BFS has a statistically significant effect individually and has statistically significant interaction effects involving simulants.

\section{Table 8-23. Tc Leachability Index: Results of Using Stepwise Regression to Select Statistically Significant Individual Parameter and Two-Parameter Interaction Terms for the Stepwise Model ${ }^{(a)}$}

\begin{tabular}{|c|c|c|c|c|c|}
\hline $\begin{array}{c}\text { Tc Leachability } \\
\text { Index Model Term }^{(a)}\end{array}$ & $\begin{array}{l}\text { Coefficient } \\
\text { Estimate }^{(a)} \\
\end{array}$ & $\begin{array}{l}\text { SD(Coeff. } \\
\text { Estimate) })^{(\mathbf{b})}\end{array}$ & t value & $\begin{array}{c}\text { p-value } \\
\operatorname{Pr}(>|\mathbf{t}|)^{(\mathbf{c})}\end{array}$ & $\begin{array}{c}\text { Statistical } \\
\text { Significance }^{(d)} \\
\end{array}$ \\
\hline Intercept & 10.2574 & 0.0294 & 349.32 & $<0.0001$ & $* * * *$ \\
\hline SimBlend & -0.1879 & 0.0662 & -2.84 & 0.0132 & $*$ \\
\hline SimHiAl & 0.0373 & 0.0506 & 0.74 & 0.4733 & \\
\hline SimHiSO4 & 0.2482 & 0.0480 & 5.17 & 0.0001 & $* * *$ \\
\hline NaMol & -0.0751 & 0.0318 & -2.36 & 0.0333 & $*$ \\
\hline FlyAsh & -0.0907 & 0.0293 & -3.10 & 0.0079 & $* *$ \\
\hline BFS & -0.3306 & 0.0303 & -10.91 & $<0.0001$ & $* * * *$ \\
\hline MixRatio & 0.2092 & 0.0312 & 6.69 & $<0.0001$ & $* * * *$ \\
\hline SimHiAl*BFS & 0.2985 & 0.0490 & 6.10 & $<0.0001$ & $* * * *$ \\
\hline SimBlend*BFS & -0.4183 & 0.0710 & -5.89 & $<0.0001$ & $* * * *$ \\
\hline SimBlend*MixRatio & 0.2018 & 0.0674 & 2.99 & 0.0097 & $* *$ \\
\hline \multicolumn{6}{|c|}{ Summary Statistics for Model Fit } \\
\hline $\mathrm{RMSE}=0.1351$ & & $\mathrm{RMSE}_{\mathrm{PE}}=0.1309$ & $\mathrm{R}^{2}=0.9358$ & \multicolumn{2}{|c|}{ LOF $p$-value $=0.4844$} \\
\hline \multicolumn{6}{|c|}{$\begin{array}{l}\text { (a) See Section } 8.3 \text { for discussion of the model terms and why there are no terms involving the Average } \\
\text { simulant. } \\
\text { (b) The standard deviation of the coefficient estimate. } \\
\text { (c) The probability of incorrectly concluding that the coefficient estimate is different from zero. Low values } \\
(\text { e.g., }<0.05 \text { and especially }<0.01) \text { indicate coefficient estimates that are statistically different from zero. } \\
\text { (d) } *=\text { p-value }<0.05, * *=p \text {-value }<0.01, * * *=p \text {-value }<0.001 \text {, and } * * * *=p \text {-value }<0.0001 \text {. Also, note } \\
\text { that the individual effect of a parameter may not be statistically significant if that parameter is involved in } \\
\text { one or more statistically significant interactions. }\end{array}$} \\
\hline
\end{tabular}


PNNL-22747

SRNL-STI-2013-00465

\subsubsection{Cr Leachability Index from EPA Method 1315}

For the 26 Cast Stone mixes in Table 2-1, the means of Cr LI values over duplicate (i.e., repeat) tests for the 26 Cast Stone mixes are given in Table D-15 in Appendix D. The mean values were used for the statistical analyses reported in this section. Excluding the Cr LI value for Mix 23, the remaining Cr LI values range from 12.15 to 14.11 with a mean of 12.98 . Table 8-7 lists the Cr LI values for five replicate pairs and presents uncertainties in the Cr LI values as calculated from the replicates. The pooled (i.e., combined) uncertainty estimates using all replicate pairs are $\mathrm{SD}=$ 0.088 and $\% \mathrm{RSD}=0.67$, which are small. The balance of this section presents and discusses the results of the statistical analysis methods described in Sections 8.1 to 8.3.

Table 8-24 presents the results of fitting the Full Model to the Cr LI data and statistically assessing the effects of individual parameters and their two-parameter interactions, as discussed in Section 8.2. Keep in mind that Cautions FM1 and FM2 discussed in Section 8.4 apply to the results in Table 8-24. The Full Model accounts for a large portion of the variability in the Cr LI values, as indicated by the $\mathrm{R}^{2}=0.9926$. The dropped data point for Mix 23 means that the Full Model fits the data exactly except for replicate variation, so it was not possible to assess the model LOF. Table 8-24 shows that three individual parameter effects are statistically significant, namely NaMol, FlyAsh, and BFS (p-values $<0.01$ ). Interactions not involving Simulant that are statistically significant include NaMol*MixRatio (p-value $<0.001$ ), NaMol*FlyAsh (p-value $<0.01$ ), and FlyAsh*MixRatio ( $p$-value $<0.05$ ). The significant interactions involving Simulant include Simulant*NaMol, Simulant*FlyAsh, and Simulant*MixRatio. For Simulant*NaMol, only HiSO4 has a significant effect, but no simulants have statistically different effects based on Tukey's HSD MCP results (see Section 8.2.5) shown in the last column of Table 8-24. For the interaction Simulant*FlyAsh, the simulants $\mathrm{SST}$ Blend and $\mathrm{HiSO}_{4}$ interact differently with FlyAsh than the other two simulants. For the interaction, Simulant*MixRatio, the Average simulant interacts differently with MixRatio than the other three simulants, while the $\mathrm{HiSO}_{4}$ simulant interacts differently with MixRatio than the other three simulants.

Table 8-25 summarizes the results of using the stepwise regression approach described in Section 8.3 to model Cr LI. That approach allows all two-parameter interactions to enter the model, including interactions involving BFS. Keep in mind that cautions SM1 and SM2 discussed in Section 8.4 apply to the results in Table 8-25. The Stepwise Model for Cr LI has $\mathrm{R}^{2}=0.9834$ that is smaller than $\mathrm{R}^{2}=0.9926$ for the Full Model, but that may be a result of the latter being inflated per Cautions FM1 and FM2 in Section 8.4. The RMSE $=0.0935$ is similar in magnitude to $\mathrm{RMSE}_{\mathrm{PE}}=0.0885$, such that the LOF for the Cr LI Stepwise Model is highly nonsignificant ( $\mathrm{p}$-value $=0.4127$ ). Table $8-25$ shows statistically significant individual effects of MixRatio and BFS (p-values $<0.0001$ ), NaMol and FlyAsh (p-values $<0.001$ ), and SimBlend and SimHiAl (p-values < 0.01). Based on the discussion in Section 8.3, the SimBlend and SimHiAl effects actually correspond to significant differences in the effects on Cr LI of the SST Blend and Hi Al simulants compared to the Average simulant. There are seven statistically significant interaction terms (see Table 8-25), three of which include BFS (interacting with MixRatio, SimHiAl, and SimBlend). Hence, it appears BFS has a statistically significant individual effect and has statistically significant interaction effects. 
Table 8-24. Cr Leachability Index: Summary of Fitting the Full Model and Statistically Assessing the Effects of the Individual Test Parameters and Two-Parameter Interactions

\begin{tabular}{|c|c|c|c|c|c|}
\hline $\begin{array}{c}\text { Cr Leachability } \\
\text { Index Model Term }^{(a)}\end{array}$ & $\begin{array}{c}\text { Effect } \\
\text { Estimate }^{(a)}\end{array}$ & $\begin{array}{l}\text { SD(Effect } \\
{\text { Estimate })^{(b)}}\end{array}$ & p-value ${ }^{(c)}$ & $\begin{array}{c}\text { Signif- } \\
\text { icance }^{(\mathrm{d})}\end{array}$ & $\begin{array}{l}\text { Tukey's HSD } \\
\text { MCP Results }{ }^{(\mathrm{e})}\end{array}$ \\
\hline Intercept & 12.8516 & 0.0277 & $<0.0001$ & $* * * *$ & \\
\hline \multicolumn{6}{|l|}{ Simulant } \\
\hline Average & 0.0607 & 0.0395 & 0.1849 & & A \\
\hline SST Blend & -0.0791 & 0.0609 & 0.2507 & & A \\
\hline $\mathrm{Hi} \mathrm{Al}$ & 0.0869 & 0.0376 & 0.0686 & & A \\
\hline $\mathrm{Hi} \mathrm{SO}_{4}$ & -0.0686 & 0.0477 & 0.2101 & & A \\
\hline NaMol & -0.1148 & 0.0252 & 0.0060 & $* *$ & \\
\hline FlyAsh & 0.1198 & 0.0259 & 0.0057 & $* *$ & \\
\hline BFS & -0.1530 & 0.0319 & 0.0049 & ** & \\
\hline MixRatio & 0.0456 & 0.0336 & 0.2334 & & \\
\hline \multicolumn{6}{|l|}{ Simulant*NaMol } \\
\hline Average & 0.0299 & 0.0662 & 0.6699 & & A \\
\hline SST Blend & -0.0231 & 0.0814 & 0.7884 & & A \\
\hline $\mathrm{Hi} \mathrm{Al}$ & -0.1513 & 0.0595 & 0.0518 & & A \\
\hline $\mathrm{Hi} \mathrm{SO}_{4}$ & 0.1444 & 0.0548 & 0.0463 & $*^{(t)}$ & A \\
\hline \multicolumn{6}{|l|}{ Simulant*FlyAsh } \\
\hline Average & -0.3132 & 0.0449 & 0.0009 & $* * *$ & A \\
\hline SST Blend & 0.2588 & 0.0598 & 0.0075 & $* *$ & $\mathrm{~B}$ \\
\hline $\mathrm{Hi} \mathrm{Al}$ & -0.3394 & 0.0485 & 0.0009 & $* * *$ & A \\
\hline $\mathrm{Hi} \mathrm{SO}_{4}$ & 0.3938 & 0.0449 & 0.0003 & $* * *$ & B \\
\hline \multicolumn{6}{|l|}{ Simulant*MixRatio } \\
\hline Average & -0.2008 & 0.0597 & 0.0200 & * & A \\
\hline SST Blend & -0.0421 & 0.1033 & 0.7007 & & $\mathrm{AB}$ \\
\hline $\mathrm{Hi} \mathrm{Al}$ & 0.0079 & 0.0513 & 0.8831 & & $\mathrm{AB}$ \\
\hline $\mathrm{Hi} \mathrm{SO}_{4}$ & 0.2349 & 0.0505 & 0.0056 & $* *$ & $\mathrm{~B}$ \\
\hline NaMol*FlyAsh & -0.2380 & 0.0376 & 0.0014 & $* *$ & \\
\hline NaMol*MixRatio & -0.3011 & 0.0359 & 0.0004 & $* * *$ & \\
\hline FlyAsh*MixRatio & -0.1746 & 0.0457 & 0.0124 & $*$ & \\
\hline \multicolumn{6}{|c|}{ Summary Statistics of Model Fit } \\
\hline RMSE $=0.0885$ & \multicolumn{2}{|c|}{ RMSE $_{\mathrm{PE}}=0.0885$} & 0.9926 & \multicolumn{2}{|c|}{ LOF $p$-value $=\mathrm{NA}^{(\mathrm{g})}$} \\
\hline \multicolumn{6}{|c|}{$\begin{array}{l}\text { (a) See Section 8.2.1 for discussion of the model terms } \\
\text { (b) The standard deviation of the effect estimate. }\end{array}$} \\
\hline \multicolumn{6}{|c|}{$\begin{array}{l}\text { (c) The probability of incorrectly concluding that the effect estimate is different from zero. Low values } \\
\text { (e.g., }<0.05 \text { and especially }<0.01) \text { indicate effect estimates that are statistically different from zero. } \\
\text { (d) } *=\mathrm{p} \text {-value }<0.05, * *=\mathrm{p} \text {-value }<0.01, * * *=\mathrm{p} \text {-value }<0.001 \text {, and } * * * *=\mathrm{p} \text {-value }<0.0001 \text {. Also, } \\
\text { note that the individual effect of a parameter may not be statistically significant if that parameter is } \\
\text { involved in one or more statistically significant interactions. }\end{array}$} \\
\hline \multicolumn{6}{|c|}{$\begin{array}{l}\text { (e) Tukey's HSD MCP is discussed in Section 8.2.5. For the Simulant parameter by itself, estimates of } \\
\text { the simulant effects having the same letter (e.g., A, B. C) are not statistically different at the } \\
0.05 \text { level of significance (i.e., }>95 \% \text { confidence) over all comparisons. For Simulant*Parameter } \\
\text { interactions, simulants with the same letter (e.g., A, B, C) do not have statistically significant } \\
\text { interactions with Parameter at the } 0.05 \text { level of significance (e.g., }>95 \% \text { confidence) over all }\end{array}$} \\
\hline \multicolumn{6}{|c|}{$\begin{array}{l}\text { (f) It is possible that a simulant has a statistically significant effect with p-value }<0.05 \text { but that no } \\
\text { simulants have statistically significant differences when assessed with the MCP, which controls the } \\
\text { probability of a wrong decision over all possible comparisons. }\end{array}$} \\
\hline \multicolumn{6}{|c|}{$\begin{array}{l}\text { (g) The data value for Mix } 23 \text { was judged an outlier and not used in the model fit. Hence, it was not possible } \\
\text { to statistically assess the model LOF. }\end{array}$} \\
\hline
\end{tabular}


Table 8-26. Summary Statistics from Full Model and Stepwise Model Fits to Cast Stone Screening Study Data

\begin{tabular}{|c|c|c|c|c|c|c|c|c|c|c|}
\hline Property & $\begin{array}{c}\text { RMSE } \\
\text { Pure } \\
\text { Error }\end{array}$ & $\begin{array}{c}\text { RMSE } \\
\text { Full } \\
\text { Model }\end{array}$ & $\begin{array}{c}\text { RMSE } \\
\text { Stepwise } \\
\text { Model }\end{array}$ & $\begin{array}{l}\text { \# Terms } \\
\text { in } \\
\text { Stepwise }^{\text {Model }} \\
\text { (a) }^{2}\end{array}$ & $\begin{array}{c}\text { \# Data } \\
\text { for } \\
\text { Fitting } \\
\text { Models } \\
\end{array}$ & $\begin{array}{c}\mathbf{R}^{2} \\
\text { Main } \\
\text { Effects } \\
\text { Model }^{(\mathbf{b})} \\
\end{array}$ & $\begin{array}{c}\mathbf{R}^{2} \\
\text { Full } \\
\text { Model }^{(\mathbf{c})}\end{array}$ & $\begin{array}{c}\mathbf{R}^{2} \\
\text { Stepwise } \\
\text { Model }\end{array}$ & $\begin{array}{c}\text { p-value } \\
\text { LOF } \\
\text { Full } \\
\text { Model }^{(d)} \\
\end{array}$ & $\begin{array}{c}\text { p-value } \\
\text { LOF } \\
\text { Stepwise } \\
\text { Model }^{(d)} \\
\end{array}$ \\
\hline $\begin{array}{l}\text { Plastic } \\
\text { Viscosity }\end{array}$ & 0.063 & 0.162 & 0.183 & 9 & $37^{(\mathrm{e})}$ & 0.9366 & 0.9799 & 0.9572 & $0.0024^{*}$ & $0.0016^{*}$ \\
\hline $\begin{array}{l}\text { Heat Generation } \\
\text { at } 300 \text { Hours }\end{array}$ & 10.478 & 21.716 & 17.930 & 10 & 38 & 0.8468 & 0.9298 & 0.9256 & $0.0107^{*}$ & $0.0452 *$ \\
\hline $\begin{array}{l}\text { Time to Peak } \\
\text { Heat Generation }\end{array}$ & 2.125 & 9.926 & 9.498 & 12 & $37^{(\mathrm{f})}$ & 0.4458 & 0.9226 & 0.8958 & $<0.0001 *$ & $<0.0001 *$ \\
\hline $\begin{array}{l}\text { Compressive } \\
\text { Strength }\end{array}$ & 0.134 & 0.176 & 0.197 & 11 & 26 & 0.7508 & 0.9826 & 0.9455 & 0.0696 & 0.1404 \\
\hline $\begin{array}{l}\text { Na Leachability } \\
\text { Index }\end{array}$ & 0.053 & 0.053 & 0.093 & 12 & $25^{(\mathrm{g})}$ & 0.3403 & 0.9865 & 0.8930 & $\mathrm{NA}^{(\mathrm{h})}$ & 0.0617 \\
\hline $\begin{array}{l}\mathrm{NO}_{3} \text { Leachability } \\
\text { Index }\end{array}$ & 0.107 & 0.107 & 0.166 & 10 & $25^{(\mathrm{g})}$ & 0.2592 & 0.9562 & 0.6801 & NA & 0.1087 \\
\hline $\begin{array}{l}\text { I Leachability } \\
\text { Index }\end{array}$ & 0.131 & 0.131 & 0.180 & 9 & $25^{(\mathrm{g})}$ & 0.4591 & 0.9471 & 0.6812 & NA & 0.1869 \\
\hline $\begin{array}{l}\text { Tc Leachability } \\
\text { Index }\end{array}$ & 0.131 & 0.131 & 0.135 & 11 & $25^{(\mathrm{g})}$ & 0.6972 & 0.9784 & 0.9358 & NA & 0.4844 \\
\hline $\begin{array}{l}\text { Cr Leachability } \\
\text { Index }\end{array}$ & 0.089 & 0.089 & 0.094 & 15 & $25^{(\mathrm{g})}$ & 0.6321 & 0.9926 & 0.9834 & NA & 0.4127 \\
\hline
\end{tabular}

(a) The number of terms includes the intercept and all seven individual parameter effects, regardless of whether the latter are statistically significant or not.

(b) The "main effects" model contains only terms for individual effects of the parameters, that is, no interaction terms.

(c) As discussed in Section 8.4, these $\mathrm{R}^{2}$ values may be inflated because of nonsignificant terms being in the Full Model.

(d) * denotes the model LOF is statistically significant with $\mathrm{p}$-value $<0.05$.

(e) Models were fit to 37 data points because the paste for Mix 1 was too thick to measure plastic viscosity.

(f) Models were fit to 37 data points because the value for Mix 34 was an outlier that substantially changed the statistical results.

(g) Models were fit to 25 data points for these properties (because the data for Mix 23 were judged to be outliers and were not used in the model fits.

(h) NA = not applicable. The model LOF cannot be assessed because the Full Model contains the same number of free parameter effects as distinct data points (see Section 3.6.2). 
Table 8-26 shows that the Full Model produces very high $\mathrm{R}^{2}$ values for the nine Cast Stone properties. However, these values tend to be inflated because of containing many nonsignificant terms (see Cautions FM1 and FM2 in Section 8.4). For Compressive Strength in Table 8-26, the Full Model contains 20 independent parameters, but there are only 21 distinct mixes with data used to fit the model. For the component LIs (Na, NO3, I, Tc, and $\mathrm{Cr}$ ) in Table 8-26, there are only 20 distinct mixes with data to fit the model because of eliminating an outlier. Hence, there is only one DOF to assess LOF of the Full Model for Compressive Strength (which is not statistically significant) and no DOF to assess LOF of the Full Model for the LI components. There are sufficient DOF to assess LOF of the Full Model for $\ln ($ Plastic Viscosity), HG300, and TPHG. There are also sufficient DOF to assess the LOF of the Stepwise Models for all Cast Stone properties.

The results in Table 8-26 show that Stepwise Models have $\mathrm{R}^{2}$ values ranging from 0.6801 to 0.9834 for the LI components, and from 0.8958 to 0.9572 for the other four properties. Table 8-26 also shows the Stepwise Models for Compressive Strength and the component LIs do not have statistically significant LOFs and hence are adequate approximations of the relationships between these properties and the test parameters. However, the results also show that the Stepwise Models (as well as the Full Models) for Plastic Viscosity, HG300, and TPHG have statistically significant LOFs. Ultimately though, the Full and Stepwise Models fit the data well enough to assess which components have significant effects (individual and interaction) on the Cast Stone properties.

\subsubsection{Assessing the Statistically Significant Terms in the Full and Stepwise Models}

Table 8-27 and Table 8-28 provide an overview of the Full Model terms that are statistically significant for each Cast Stone property that was modeled. The p-values presented in these two tables originate from the Full Model fit summaries presented previously in Table 8-8 through Table 8-24. The p-values $<0.05$ are marked with an asterisk $(*)$, which means the corresponding terms are statistically significant with $>95 \%$ confidence. While terms marked with an $*$ are likely significant, as discussed in Section 8.4 terms not so marked may still be statistically significant if nonsignificant model terms were removed. That is one of the reasons the Stepwise Models were fit to the Cast Stone property data. All individual parameter effects and all except two two-parameter interaction effects are statistically significant in the Full Model for at least one property in Table 8-27 and Table 8-28. One exception is the individual effect of HiSO4 in Table 8-27, but that may not be significant as a result of significant interactions involving HiSO4. The other exception is the SimHiAl*NaMol interaction, although it is close to being significant for $\mathrm{Na} \mathrm{LI}$ and Cr LI.

Discussion of Caution SM2 in Section 8.4 noted that one way to protect against the tendency of stepwise regression to include too many terms in a model is to use a more stringent threshold for assessing the statistical significance of terms. Suppose a more stringent threshold (than the $\mathrm{p}<0.05$ used in Table 8-27 and Table 8-28) for statistical significance was adopted for both the Full and Stepwise Models. With a p-value $<0.01$ threshold, the SimAve*NaMol, SimAve*MixRatio, SimBlend*MixRatio, and FlyAsh*MixRatio terms in the Full Model would not be statistically significant for any property (see those columns in Table 8-27 and Table 8-28). 
Table 8-27. Simulant Terms in the Full Model Identified as Statistically Significant by the Tukey Multiple Comparison Procedure. Table contains p-values for statistically testing the hypothesis that the "Term $=0$ ".

\begin{tabular}{|c|c|c|c|c|c|c|c|c|c|c|c|c|c|c|c|c|}
\hline \multirow{2}{*}{ Property $^{\text {(a) }}$} & \multicolumn{4}{|c|}{ Simulant } & \multicolumn{4}{|c|}{ Simulant*NaMol } & \multicolumn{4}{|c|}{ "Simulant*FlyAsh } & \multicolumn{4}{|c|}{ "Simulant*MixRatio } \\
\hline & Ave. & Blend & HiAl & HiSO4 & Ave. & Blend & HiAl & \begin{tabular}{|l|} 
HiSO4 \\
\end{tabular} & Ave. & Blend & HiAl & HiSO4 & Ave. & Blend & HiAl & HiSO4 \\
\hline PV & 0.779 & 0.977 & 0.164 & 0.384 & 0.545 & 0.082 & 0.767 & 0.044* & 0.399 & 0.384 & 0.058 & 0.086 & 0.548 & 0.404 & 0.734 & 0.111 \\
\hline HG300 & 0.417 & 0.002* & 0.030* & 0.790 & 0.229 & 0.092 & 0.634 & 0.905 & 0.789 & 0.600 & 0.955 & 0.422 & 0.778 & 0.243 & 0.820 & 0.448 \\
\hline TPHG & 0.339 & $<0.001 *$ & $<0.001 *$ & 0.277 & $0.028^{*}$ & $0.007^{*}$ & 0.340 & 0.899 & 0.941 & 0.386 & 0.029* & 0.134 & 0.578 & 0.262 & 0.868 & 0.052 \\
\hline $\mathrm{CS}$ & 0.809 & 0.369 & 0.156 & 0.733 & 0.748 & 0.076 & 0.303 & 0.519 & 0.731 & 0.606 & 0.699 & 0.205 & 0.601 & 0.133 & 0.513 & 0.103 \\
\hline $\mathrm{Na} \mathrm{LI}$ & $0.005 *$ & $0.004 *$ & 0.087 & 0.509 & 0.899 & 0.272 & 0.055 & 0.005* & $0.007 *$ & $0.023 *$ & 0.144 & 0.117 & 0.687 & 0.015* & 0.050* & $0.008 *$ \\
\hline $\mathrm{NO}_{3} \mathrm{LI}$ & $0.024 *$ & $0.046 *$ & 0.257 & 0.772 & 0.791 & 0.200 & 0.439 & $0.040^{*}$ & 0.075 & 0.082 & 0.291 & 0.557 & 0.560 & 0.055 & 0.099 & 0.069 \\
\hline I LI & $0.036^{*}$ & 0.051 & 0.104 & 0.534 & 0.650 & 0.162 & 0.858 & 0.094 & 0.074 & 0.082 & 0.418 & 0.772 & 0.350 & 0.044* & 0.082 & 0.098 \\
\hline Tc LI & 0.114 & 0.073 & 0.260 & 0.777 & 0.114 & 0.044* & 0.909 & 0.187 & 0.011* & 0.003* & 0.019* & 0.544 & 0.466 & $0.020 *$ & $0.037 *$ & $0.004 *$ \\
\hline Cr LI & 0.185 & 0.251 & 0.069 & 0.210 & 0.670 & 0.788 & 0.052 & $0.046^{*}$ & 0.001* & $0.008^{*}$ & 0.001* & $<0.001 *$ & $0.020 *$ & 0.701 & 0.883 & $0.006 *$ \\
\hline
\end{tabular}


PNNL-22747

SRNL-STI-2013-00465

Table 8-28. Full Model Terms not Involving Simulant Identified as Statistically Significant. Table contains p-values for statistically testing the hypothesis that the "Term $=0$ ".

\begin{tabular}{|c|c|c|c|c|c|c|c|}
\hline Property & NaMol & FlyAsh & BFS & MixRatio & $\begin{array}{l}\text { NaMol * } \\
\text { FlyAsh }\end{array}$ & $\begin{array}{c}\text { NaMol* } \\
\text { MixRatio }\end{array}$ & $\begin{array}{c}\text { FlyAsh* } \\
\text { MixRatio }\end{array}$ \\
\hline Plastic Viscosity & 0.9461 & $<0.0001 *$ & 0.0291* & $<0.0001 *$ & 0.7206 & 0.8988 & 0.3075 \\
\hline Heat Generation at $300 \mathrm{hr}$ & 0.2993 & $<0.0001 *$ & $<0.0001 *$ & $<0.0001 *$ & 0.8784 & 0.0608 & 0.3344 \\
\hline Time to Peak Heat Generation & 0.1413 & 0.0007* & 0.0006* & $0.0437 *$ & 0.5662 & 0.0845 & 0.4562 \\
\hline Compressive Strength & $0.0062 *$ & $0.0057 *$ & $0.0036 *$ & $0.0001 *$ & 0.7955 & $0.0072 *$ & 0.4904 \\
\hline Na Leachability Index & 0.7687 & $0.0007 *$ & 0.7114 & 0.5720 & $0.0164 \%$ & 0.8903 & 0.1172 \\
\hline $\mathrm{NO}_{3}$ Leachability Index & 0.2769 & 0.0632 & 0.9409 & 0.8766 & 0.0628 & 0.2853 & 0.2898 \\
\hline I Leachability Index & 0.1013 & 0.2674 & 0.8801 & 0.7889 & 0.1110 & 0.4067 & 0.3526 \\
\hline Tc Leachability Index & $0.0034 *$ & 0.5167 & 0.0582 & 0.2855 & 0.1462 & 0.2526 & 0.8156 \\
\hline Cr Leachability Index & $0.0060 *$ & $0.0057 *$ & 0.0049* & 0.2334 & 0.0014* & $0.0004 *$ & 0.0124* \\
\hline
\end{tabular}

Table 8-29 and Table 8-30 summarize the statistically significant terms in the Stepwise Model for each of the nine Cast Stone properties that were statistically analyzed. The results in each table are discussed in turn.

The following observations about individual parameter effects are based on Table 8-29: 1) FlyAsh and MixRatio have statistically significant effects for all four properties, 2) BFS has a statistically significant effect for HG300, TPHG, and Compressive Strength, and 3) SimBlend and SimHiAl have statistically significant effects for HG300 and TPHG. The individual effects of SimBlend and SimHiAl may not be statistically significant for Compressive Strength because of interaction terms involving those two simulants. Table 8-29 also shows that a total of eight different interaction effects are statistically significant for one or more of the four properties. As explained in Caution SM1 of Section 8.4, the interactions in the Stepwise Models may be present because the two parameters interact, or because of correlations among the possible individual and interaction terms. Still, note that each of the four simulants and each of the remaining parameters (NaMol, FlyAsh, BFS, and MixRatio) is present in at least one interaction. MixRatio appears in four interactions, NaMol and FlyAsh each appear in three interactions, and BFS only appears in one interaction (HG300). As for the simulants, SimHiAl appears in two interactions, while SimAve, SimBlend, and SimHiSO4 each appear in one interaction. 
Table 8-29. Summary of Statistically Significant Terms in Stepwise Models for the Cast Stone Physical Properties

\begin{tabular}{|c|c|c|c|c|}
\hline Stepwise Model Term ${ }^{(a)}$ & $\begin{array}{l}\text { In(Plastic } \\
\text { Viscosity) }\end{array}$ & $\begin{array}{c}\text { Heat } \\
\text { Generation } \\
\text { at } 300 \text { hr } \\
\end{array}$ & $\begin{array}{c}\text { Time to } \\
\text { Peak Heat } \\
\text { Generation }\end{array}$ & $\begin{array}{c}\ln (\text { Compressive } \\
\text { Strength) }\end{array}$ \\
\hline SimBlend & & $* *$ & $* * * *$ & $(\mathrm{c})$ \\
\hline SimHiAl & & $* *$ & $* * * *$ & (c) \\
\hline SimHiSO4 & & & (c) & \\
\hline NaMol & & (c) & $*$ & $* *$ \\
\hline FlyAsh & $* * * *(\mathrm{~b})$ & $* * * *$ & $* * * *$ & $* *$ \\
\hline BFS & & $* * * *$ & $* * *$ & $* * * *$ \\
\hline MixRatio & $* * * *$ & $* * * *$ & $* *$ & $* * * *$ \\
\hline SimBlend*NaMol & & (c) & $* * * *$ & $* *$ \\
\hline SimHiAl*NaMol & & & & $*$ \\
\hline SimHiAl*FlyAsh & & & $*$ & \\
\hline SimAve*MixRatio & & & $*$ & \\
\hline SimHiSO4*MixRatio & & & $* *$ & \\
\hline NaMol*MixRatio & & $*$ & & $* * * *$ \\
\hline FlyAsh*MixRatio & $* * *$ & & & \\
\hline FlyAsh*BFS & & $* *$ & & \\
\hline $\mathrm{R}^{2}$ & 0.9572 & 0.9256 & 0.8958 & 0.9455 \\
\hline RMSE & 0.1835 & 17.930 & 9.498 & 0.1967 \\
\hline $\mathrm{RMSE}_{\mathrm{PE}}$ & 0.0627 & 10.478 & 2.125 & 0.1342 \\
\hline Model LOF p-value & 0.0016 & 0.0452 & $8.72 \mathrm{E}-05$ & 0.1404 \\
\hline \multicolumn{5}{|c|}{$\begin{array}{l}\text { (a) As discussed in Section } 8.3 \text {, the individual term for the Average simulant (SimAve) was not possible } \\
\text { in the Stepwise Models. } \\
\text { (b) } *=\mathrm{p} \text {-value }<0.05, * *=\mathrm{p} \text {-value }<0.01, * * *=\mathrm{p} \text {-value }<0.001 \text {, and } * * * *=\mathrm{p} \text {-value }<0.0001 \text {. } \\
\text { (c) The individual effect of a parameter may not be statistically significant if that parameter is } \\
\text { involved in one or more statistically significant interactions. }\end{array}$} \\
\hline
\end{tabular}

The following observations about individual parameter effects on the component LIs are based on Table 8-30: 1) MixRatio has a statistically significant effect for all five component LIs, 2) BFS has a statistically significant effect for all except Na LI, 3) FlyAsh has a statistically significant effect for $\mathrm{Na}$, Tc, and Cr LIs, 4) NaMol has statistically significant effects on I, Tc, and Cr LIs, 5) SimHiSO4 has statistically significant effects on $\mathrm{NO}_{3}$, I, and Tc LIs and 6) SimBlend has statistically significant effects on Na, Tc, and Cr LIs. The (c) footnote in Table 8-30 marks other individual parameter effects that may not be statistically significant for component LIs because of interaction terms involving those parameters. Table 8-30 also shows that a total of 12 different interaction effects are statistically significant for one or more of the component LIs. As explained in Caution SM1 of Section 8.4, the interactions in the Stepwise Models may be present because the two parameters interact, or because of correlations among the possible individual and interaction terms. Still, note that each of the four simulants and each of the remaining parameters (NaMol, FlyAsh, BFS, and MixRatio) is present in at least one interaction. MixRatio appears in five interactions, NaMol appears in four interactions, while FlyAsh and BFS each appear in three interactions. As for the simulants, SimHiAl and SimHiSO4 each appear in three interactions, SimBlend appears in two interactions, and SimAve appears in only one interaction. 
Table 8-30. Summary of Statistically Significant Terms in Stepwise Models for the Leachability Indices (LI)

\begin{tabular}{|c|c|c|c|c|c|}
\hline Stepwise Model Term ${ }^{(a)}$ & Na LI & $\mathrm{NO}_{3} \mathrm{LI}$ & I LI & Tc LI & Cr LI \\
\hline SimBlend & $*$ & & & $*$ & $* *$ \\
\hline SimHiAl & (c) & & & (c) & $* *$ \\
\hline SimHiSO4 & (c) & $*$ & $*$ & $* * *$ & (c) \\
\hline NaMol & (c) & (c) & $*$ & $*$ & $* * *$ \\
\hline FlyAsh & $* *$ & & & $* *$ & $* * *$ \\
\hline BFS & & $*$ & $*$ & $* * * *$ & $* * * *$ \\
\hline MixRatio & $* *$ & $*$ & $* *$ & $* * * *$ & $* * * *$ \\
\hline SimAve*NaMol & $* * * *$ & & & & \\
\hline SimHiAl*NaMol & $* * * *$ & $*$ & & & \\
\hline SimHiSO4*NaMol & & $* * *$ & $* *$ & & \\
\hline SimHiAl*FlyAsh & & & & & $* * *$ \\
\hline SimHiSO4*FlyAsh & $*$ & & & & $* * * *$ \\
\hline SimBlend*MixRatio & & & & $* *$ & \\
\hline SimHiSO4*MixRatio & $* *$ & & & & \\
\hline NaMol*MixRatio & & & & & $* * * *$ \\
\hline FlyAsh*MixRatio & & & & & $*$ \\
\hline SimBlend*BFS & & & & $* * * *$ & $* *$ \\
\hline SimHiAl*BFS & & & & $* * * *$ & $* * *$ \\
\hline BFS*MixRatio & & & & & $* *$ \\
\hline $\mathrm{R}^{2}$ & 0.8930 & 0.6801 & 0.6812 & 0.9358 & 0.9834 \\
\hline RMSE & 0.0927 & 0.1664 & 0.1798 & 0.1351 & 0.0935 \\
\hline $\mathrm{RMSE}_{\mathrm{PE}}$ & 0.0531 & 0.1067 & 0.1311 & 0.1309 & 0.0885 \\
\hline Model LOF p-value & 0.0617 & 0.1087 & 0.1869 & 0.4844 & 0.4127 \\
\hline
\end{tabular}

(a) As discussed in Section 8.3, terms involving the Average simulant (SimAve) were excluded from the stepwise models.

(b) $*=$ p-value $<0.05, * *=$ p-value $<0.01, * * *=$ p-value $<0.001$, and $* * * *=$ p-value $<0.0001$.

(c) The individual effect of a parameter may not be statistically significant if that parameter is involved in one or more statistically significant interactions.

The objective of the Cast Stone screening study was to identify which parameters (individually or in interactions) affect which Cast Stone properties. Ideally, some parameters would be identified as not affecting any of the more important properties that were statistically analyzed, so that those parameters could be removed from consideration for future Cast Stone optimization studies. However, as noted in the preceding discussions of Table 8-29 and Table 8-30, every parameter has individual as well as interaction effects for at least one property. This includes BFS, which was believed not to interact with other parameters during the test matrix development (see Appendix A). Even though parameters like BFS and FlyAsh have statistically significant individual and interactive effects, the test results and statistical analyses of those results provide a basis for choosing a source of BFS and a source of FlyAsh to eliminate one or both of those parameters from a future formulation optimization study. Further, the statistical analyses in this section provide a basis for choosing the simulants and ranges of the NaMol and MixRatio parameters for a future formulation optimization study. 
PNNL-22747

SRNL-STI-2013-00465

\subsection{Conclusions}

The LAW Cast Stone screening tests were a successful first step in developing and optimizing the Cast Stone waste form for immobilization of Hanford LAW. The screening tests included 26 mixes identified through a statistical experimental design and included four Hanford LAW simulants, two different sources each of fly ash and BFS used as dry blend ingredients, water-todry-blend mix ratios of 0.4 and 0.6 , and waste concentrations for $5 \mathrm{M}$ and $7.8 \mathrm{M}$ sodium. An additional 12 Cast Stone mixes were investigated at SRNL. The freshly prepared Cast Stone slurry was characterized with respect to rheology, set time, hardening time, heat generation during curing, fresh density, and free liquids. The final Cast Stone cured specimens were characterized with respect to cured density, compressive strength, porosity, TCLP for meeting land disposal restrictions, and leachability of $\mathrm{Na}, \mathrm{NO}_{3}, \mathrm{NO}_{2}$, iodine, technetium, chromium, and uranium. Statistical analyses of the rheology, heat generation, compressive strength, and leachability were conducted to determine whether individual test parameters and their twoparameter interactions have statistically significant effects on a given property, and to assess the relative magnitudes of these effects.

Plastic viscosity and Bingham Plastic yield stress were measured on the fresh Cast Stone slurry paste. Mix ratio and fly ash source were the primary contributors to the variations observed in the plastic viscosity, with both individual effects and the two-parameter interaction being statistically significant. Mixes with the 0.4 mix ratio were more viscous than the mixes with the higher water content at a mix ratio of 0.6 . Plastic viscosities were in the range of 220 to $580 \mathrm{cP}$ for the 0.4 mixes and 54 to 165 for the 0.6 mixes. Mixes prepared with the SE fly ash were more viscous than those prepared with the NW FA. There were no statistically significant differences in the plastic viscosities due to the different waste simulants.

Isothermal calorimetry was used to determine the heat of hydration of the Cast Stone slurries as the mixes cured. Heat generated over 300 hours was in the range of 150 to $434 \mathrm{~J} / \mathrm{g}$. Higher heat generation was observed for the $0.6 \mathrm{mix}$ ratios than for the $0.4 \mathrm{mix}$ ratios. The greater heat generated from the 0.6 mix ratios may indicate that there was not enough water in mixes with the lower mix ratio to fully hydrate the dry materials. Statistical analyses indicated that, in addition to mix ratio, the BFS and fly ash sources had statistically significant effects on both heat generation properties that were statistically analyzed (Heat Generation at 300 Hours, and Time to Peak Heat Generation). The time to reach the peak heat generation rate ranged from 16 to 164 hours. This property can affect the processing strategy for a given waste container if there are temperature limits associated with the chosen waste form.

Gel times for the Cast Stone slurries ranged from 1 minute to more than 2 hours. The gel times were typically higher for mixes with the $0.6 \mathrm{mix}$ ratio than mixes with the $0.4 \mathrm{mix}$ ratio and were highest for the $0.6 \mathrm{mix}$ ratio and $7.8 \mathrm{M} \mathrm{Na}$ simulants. Gel times can be useful in the design and implementation of the waste form to ensure even distribution in the container.

Densities were measured for both the "as prepared" Cast Stone slurry (fresh density) and after curing 28 days (cured density). The fresh densities were highest for mixes with the 0.4 mix ratio and were in the range of 1.87 to $1.96 \mathrm{~g} / \mathrm{cm}^{3}$. Fresh densities for mixes with the 0.6 mix ratio were in the range of 1.73 to $1.83 \mathrm{~g} / \mathrm{cm}^{3}$. Cured densities were in the range of 1.87 to $1.96 \mathrm{~g} / \mathrm{cm}^{3}$ for Cast Stone specimens with the $0.4 \mathrm{mix}$ ratio and 1.73 to $1.80 \mathrm{~g} / \mathrm{cm}^{3}$ for specimens with the 0.6 mix ratio. 
Residual free liquids were observed in 6 of the 38 mixes one day after preparation and only 3 of the 38 mixes had any residual free liquids after three days. The residual free liquid is an indication of settling that results from a longer gel time and lower Bingham Plastic yield stress. Settling is undesirable because the denser slag and cement can separate from the fly ash introducing a layered structure with variable properties.

Compressive strengths ranged from 5.8 to $62.0 \mathrm{MPa}$ ( 850 to $8990 \mathrm{psi}$ ), and easily met the target minimum compressive strength of $3.4 \mathrm{MPa}(500 \mathrm{psi})$. Statistical analyses indicated that the mix ratio, simulant sodium molarity, and sources of the fly ash and BFS were statistically significant parameters. The two-parameter interaction involving sodium molarity and mix ratio was also highly statistically significant. Lower compressive strengths tended to be from mixes with the $7.8 \mathrm{M} \mathrm{Na}$ simulants and the 0.6 water-to-dry-blend mix ratio. The higher compressive strengths tended to be from mixes with the $5 \mathrm{M} \mathrm{Na}$ simulants and/or the 0.4 water-to-dry-blend ratio.

The EPA Method 1315 was used to measure the effective diffusivities of Tc, I, U, Cr, Na, and nitrates and nitrites. Effective diffusivities for $\mathrm{Na}$, I, nitrate, and nitrite averaged over 28 to 91 days of leaching were all in the same range of $1 \times 10^{-8}(\mathrm{LI}=8)$ to $2 \times 10^{-9}(\mathrm{LI}=8.7) \mathrm{cm}^{2} / \mathrm{s}$ for all but one of the 26 Cast Stone mixes. Technetium effective diffusivities were in the range of $2 \times 10^{-10}(\mathrm{LI}=9.7)$ to $6 \times 10^{-12}(\mathrm{LI}=11.2) \mathrm{cm}^{2} / \mathrm{s}$ for the same 25 mixes and total leach interval. The sodium and technetium results are consistent with previous testing of Cast Stone waste forms with secondary waste simulants at $6 \mathrm{M} \mathrm{Na}$. Leach indices were 8.7 for sodium and 10.0 for technetium (Mattigod et al. 2011). Chromium effective diffusivities were in the range of $9 \times 10^{-13}$ $(\mathrm{LI}=12.0)$ to $8 \times 10^{-15}(\mathrm{LI}=14.1) \mathrm{cm}^{2} / \mathrm{s}$. Uranium was not detected in most of leachates from the 26 mixes, indicating that the $U$ is retained in the Cast Stone and is not being released under the conditions of the leach test. The results of these leach tests are generally consistent with ANS/ANSI 16.1 test results reported by Lockrem (2005). Limited statistical analyses were conducted on the effective diffusivities, while more extensive statistical analyses (modeling) were performed for $\mathrm{Na}, \mathrm{NO}_{3}$, I, Tc, and Cr LIs, both averaged over 28 to 63 days of cumulative leaching (the standard duration of the EPA method). The statistical analyses showed that the effective diffusivity results for $\mathrm{Na}$, iodine, nitrates, and nitrites are strongly correlated. The statistical Stepwise Models for $\mathrm{Na}, \mathrm{NO}_{3}, \mathrm{I}, \mathrm{Tc}$, and $\mathrm{Cr}$ LIs all had statistically non-significant lack-of-fits (see Table 8-30), indicating that they account for the variation in the test data after accounting for replicate testing and measurement uncertainty. Mix ratio has a statistically significant effect for all five component LIs, while the source of BFS has a statistically significant effect on all LIs except Na. The sodium molarity has individual or interaction effects on all five component LIs. The different simulants also were involved in statistically significant individual or two-parameter effects on all five component LIs.

The TCLP test was conducted to demonstrate that the Cast Stone waste form will meet land disposal restrictions. The simulants were spiked with $\mathrm{Cr}, \mathrm{Pb}, \mathrm{Ni}$, and $\mathrm{Cd}$, and the dry blend materials contributed $\mathrm{As}, \mathrm{Ba}$, and $\mathrm{Se}$ to the Cast Stone. All of the 26 mixes easily met the Universal Treatment Standards in 40 CFR 268.

Generally, for the properties for which statistical analyses were conducted, the most significant parameters in the screening test matrix were the mix ratio and the sources for the fly ash and BFS. The sodium molarity and simulant compositions were less significant unless interaction terms are considered (see Table 8-29 and Table 8-30). 
The screening tests demonstrated that for the range of parameters studied, the formulations could be processed and would provide acceptable waste forms. With the exception of two mixes, the formulations have shown good processing and waste form properties and have not touched any unacceptable waste form boundaries. Mix 1 at the mix ratio of 0.4 set quickly and would not be considered an acceptable formulation. The other mix (Mix 23) at the 0.6 mix ratio had generally poorer waste form properties than the other formulations and would not be considered for use. The screening test results suggest that there are opportunities to increase waste loading by increasing the mix ratio and increasing the waste concentration. 
PNNL-22747

SRNL-STI-2013-00465

\subsection{Recommendations for the Next Phase of Development}

The Cast Stone LAW screening tests documented in this report are the first step in a program to provide information to support the One-Time Hanford Tank Waste Supplemental Treatment Technologies Report and to support potential future implementation of Cast Stone to immobilize Hanford LAW. The next steps in the program include 1) optimization of the Cast Stone formulation, 2) waste form qualification to demonstrate that the optimized Cast Stone can meet anticipated waste acceptance criteria for the IDF, 3) demonstrating on an engineering scale the Cast Stone preparation process and characterizing the resulting large-scale casting of the Cast Stone waste form, 4) preparing and characterizing Cast Stone specimens with actual radioactive waste samples, and 5) conducting longer-term tests and characterizing the long-term performance of the Cast Stone waste form to support future performance assessment analyses. This program is well designed and should be continued as long as Cast Stone is being considered for the solidification of Hanford LAW.

The next step is to further optimize the Cast Stone formulation. The screening tests revealed opportunities to further increase the waste loading in the Cast Stone. Of the 26 original Cast Stone mixes in the screening test matrix, all but two mixes had acceptable processing and waste form properties. That is, the ranges of properties measured are similar enough that a processing/disposal facility can be designed to accommodate all but two of the tests compositions with the current experience. This suggests that the waste loading in the Cast Stone can be increased beyond the levels achieved in the screening tests. Waste loading can be increased by concentrating the wastes to higher sodium concentrations and by increasing the free water-to-dry blend mix ratio. It is reasonable to conduct additional formulation optimization testing with sodium molarities in the range of $7 \mathrm{M}$ to $10 \mathrm{M}$ and free water-to-dry blend mix ratios in the range of 0.5 to 0.7 .

Cast Stone formulation optimization provides the opportunity to investigate methods to improve the retention of Tc and I in the waste form. One approach is to add "getter" materials to the Cast Stone mix. Getters are typically inorganic materials that selectively adsorb the specific contaminant of interest. Pierce et al. (2010) identify several potential getters including layered bismuth hydroxides, argentite $\left(\mathrm{Ag}_{2} \mathrm{~S}\right)$, silver-impregnated carbon, and Ag-zeolites as I getters; and nanoporous tin phosphates, $\mathrm{Sn}$ (II)-treated apatite, nano zero-valent iron (nano ZVI), and ground BFS as ${ }^{99} \mathrm{Tc}$ getters. Another approach is to add a material such as silica fume or a concrete waterproofing additive that effectively fills the porosity in the Cast Stone to effectively slow the diffusion processes. A third approach is to increase the slag content at the expense of the cement and a portion of the FA. The increased reactivity associated with additional slag could improve the physical properties of the Cast Stone and provide additional reductive capacity for retaining Tc.

One concern with the leach testing to date is that, in order to have measurable concentrations of iodine in the leachates, the iodine concentration in the Cast Stone specimens must be spiked to two orders of magnitude higher than the projected average concentration in the waste. This may lead to higher leach rates. Leach tests with a combination of iodine radiotracers and low concentrations of stable iodine representing the projected concentrations of ${ }^{129} \mathrm{I}$ in the waste would help resolve this issue. Alternative analytical methods of natural iodine detection are also available for investigation to reduce the initial concentration needed to provide detectability.

The optimization work should also consider different cement:FA:BFS dry-blend ratios. Testing to date has been at a fixed 8:45:47 blend ratio. Testing at blend ratios around this point is needed 
to further demonstrate the robustness of the Cast Stone formulation to variability inherent in process control and potential process upsets. Testing could also consider a broader range of dry blend mixes. For example, if Tc is separated from the LAW, then there may not be a need for as much BFS, which could result in a cost saving if fly ash is substituted for some of the BFS in the dry blend. A program is under way to evaluate blends using less BFS to support Tc removal (Fox 2013).

To support the performance assessment for the IDF, long-term leach test data on the Cast Stone waste form are needed. The leach testing conducted as part of the screening tests provides an early opportunity to extend leach tests to longer times. Selected leach tests are being extended beyond the 91 days documented in this report. At the conclusion of the leach tests, the specimens should be characterized with respect to changes in chemical composition, mineralogy, and reductive capacity. Additional leach tests should be conducted with leachants representative of the pore waters expected to actually contact the waste forms in the disposal environment. The deionized water used in the screening test leach tests is thought to be more aggressive than what would be expected in the IDF disposal system. In addition to saturated leach testing, the effect of oxygen infiltration in IDF soil would provide data to evaluate retention/release behavior of redoxdependent constituents. Multi-component leach tests where Cast Stone is surrounded by IDF vadose zone sediments and leached in flow-through columns at unsaturated water conditions should be performed to simulate the actual IDF burial environment. McGrail et al. (2003) describe a strategy for assessing the performance of Cast Stone in the IDF.

To support the selection of Cast Stone as the supplemental waste form, future work should consider further evaluation of the engineering scale test. Additional testing at the engineering scale can be used to evaluate processing conditions and disposal options. 
PNNL-22747

SRNL-STI-2013-00465

\subsection{References}

This list contains references for sources cited in the main text and in the appendixes.

10 CFR 830. Code of Federal Regulations, Title 10, Energy, Part 830, "Nuclear Safety Management."

40 CFR 268. Code of Federal Regulations, Title 40, Protection of Environment, Part 268, "Land Disposal Restrictions."

Amidon GE, PJ Secreast, and D Mudie. 2009. "Particle, Powder and Compact Characterization." Chapter 8 in Developing Solid Oral Dosage Forms: Pharmaceutical Theory \& Practice, Y Qiu, Y Chen, GGZ Zhang, L Liu, and W Porter (eds.), Academic Press (Elsevier), Burlington, Massachusetts, pp. 163-186.

ANSI/ANS 16.1-2003. Measurement of the Leachability of Solidified Low-Level Radioactive Wastes by a Short-Term Test Procedure. American National Standards Institute-American Nuclear Society, New York.

ASME NQA-1-2000. 2001. Quality Assurance Program for Nuclear Facilities, American Society of Mechanical Engineers, New York.

ASME NQA-1-2004. 2004. Quality Assurance Program for Nuclear Facilities, American Society of Mechanical Engineers, New York.

ASTM C39. 2012. Measuring Hydration Kinetics of Hydraulic Cementitious Mixtures Using Isothermal Calorimetry. ASTM International, West Conshohocken, Pennsylvania.

ASTM C191. 2008. Standard Test Methods for Time of Setting of Hydraulic Cement by Vicat Needle. ASTM International, West Conshohocken, Pennsylvania.

ASTM C232. 2004. Standard Test Methods for Bleeding of Concrete. ASTM International, West Conshohocken, Pennsylvania.

ASTM C1231. 2012. Standard Practice for Use of Unbonded Caps in Determination of Compressive Strength of Hardened Concrete Cylinders. ASTM International, West Conshohocken, Pennsylvania.

ASTM C1679. 2009. Standard Method for Measuring Hydration Kinetics of Hydraulic Cementitious Mixtures Using Isothermal Calorimetry. ASTM International, West Conshohocken, Pennsylvania.

ASTM D1475. 1998. Standard Test Method for Density of Liquid Coatings, Inks, and Related Products. ASTM International, West Conshohocken, Pennsylvania.

ASTM D6103. 2004. Standard Test Method for Flow Consistency of Controlled Low Strength Material (CLSM). ASTM International, West Conshohocken, Pennsylvania. 
PNNL-22747

SRNL-STI-2013-00465

ASTM E1915-01. 2001. Standard Test Methods for Analysis of Metal Bearing Ores and Related Materials by Combustion Infrared Absorption Spectrometry. ASTM International, West Conshohocken, Pennsylvania.

Atkinson AC and AN Donev. 1992. Optimal Experimental Design, Oxford University Press, New York.

Bretz F, T Hothorn, and P Westfall. 2010. Multiple Comparisons Using R. Chapman \& Hall/CRC, Boca Raton, Florida.

Bretz F, T Hothorn, and P Westfall. 2013. On Multiple Comparisons in R. Available at http://ftp.auckland.ac.nz/software/CRAN/doc/vignettes/multcomp/Rmc.pdf.

Brunauer S, PH Emmett, and E Teller. 1938. “Adsorption of Gases in Multimolecular Layers." J. Am. Chem. Soc. 60:309.

Certa PJ, PA Empey, and MN Wells. 2011. River Protection Project System Plan. ORP-11242, Revision 6, Washington River Protection Solutions, LLC, Richland, Washington.

Cozzi AD, WE Daniel, and EK Hansen. 2013. Sonic Velocities and other Properties of Fresh SRS Saltstone Grout. SRNL-L3100-2013-00062, Revision 0, Savannah River National Laboratory, Aiken, South Carolina.

Cozzi AD, and BR Pickenheim. 2012. Impact of Standing Bleed Water on Saltstone Placement. SRNL-STI-2012-00546, Revision 0, Savannah River National Laboratory, Aiken, South Carolina.

Crank, J. 1975. The Mathematics of Diffusion, 2nd edition, Oxford University Press, New York.

Crawley MJ. 2007. The $R$ Book. John Wiley \& Sons, Ltd, The Atrium, Southern Gate, Chichester, West Sussex, England.

de Korte ACJ and HJH Brouwers. 2011. "Ultrasonic sound speed analysis of hydrating calcium sulphate hemihydrate." Journal of Materials Science 46(22):7228-7239.

DOE. 2011, as amended. Quality Assurance. Order 414.1D, U.S. Department of Energy, Washington, D.C.

DOE. 2012. Final Tank Closure and Waste Management Environmental Impact Statement for the Hanford Site, Richland, Washington. DOE/EIS-0391, U.S. Department of Energy, Washington, D.C.

DOE/RL. 2007. Hanford Analytical Services Quality Assurance Requirements Documents. DOE/RL-96-68, Rev 3, U.S. Department of Energy Richland Operations Office, Richland, Washington.

Draper NR and H Smith. 1998. Applied Regression Analysis. Third Edition, John Wiley and Sons, Inc., New York, NY. 
PNNL-22747

SRNL-STI-2013-00465

EPA. 1992. "Toxicity Characteristic Leaching Procedure." EPA Method 1311, Revision 0. In Test Methods for Evaluating Solid Waste: Physical/Chemical Methods. EPA SW 846, U.S. Environmental Protection Agency, Washington, D.C. Available at http://www.epa.gov/epawaste/hazard/testmethods/sw846/pdfs/1311.pdf.

EPA. 1996. "Microwave Accelerated Acid Digestion of Siliceous and Organically Based Matrices." EPA Method 3052 Rev. 0. In Test Methods for Evaluating Solid Waste: Physical/Chemical Methods. EPA SW 846, U.S. Environmental Protection Agency, Washington, D.C. Available at http://www.epa.gov/epawaste/hazard/testmethods/sw846/pdfs/3052.pdf.

EPA. 2007a. "Inductively Coupled Plasma-Atomic Emission Spectroscopy." EPA Method 6010C. In Test Methods for Evaluating Solid Waste: Physical/Chemical Methods. EPA SW 846, U.S. Environmental Protection Agency, Washington, D.C. Available at http://www.epa.gov/epawaste/hazard/testmethods/sw846/pdfs/6010c.pdf.

EPA. 2007b. "Inductively Coupled Plasma-Mass Spectrometry." EPA Method 6020A. In Test Methods for Evaluating Solid Waste: Physical/Chemical Methods. EPA SW 846, U.S. Environmental Protection Agency, Washington, D.C. Available at http://www.epa.gov/epawaste/hazard/testmethods/sw846/pdfs/6020a.pdf.

EPA. 2012. Mass Transfer Rates of Constituents in Monolith or Compacted Granular Materials Using a Semi-Dynamic Tank Leaching Test. EPA Draft Method 1315, U.S. Environmental Protection Agency, Washington, D.C. Current version available at http://www.epa.gov/epawaste/hazard/testmethods/sw846/pdfs/1315.pdf.

Fox KM. 2013. Cast Stone Formulation at Higher Sodium Concentrations. SRNL-STI-201300499, Revision 0, Savannah River National Laboratory, Aiken, South Carolina.

Gasper KA, KD Boomer, ME Johnson, GW Reddick, Jr., AF Choho, and JS Garfield. 2002. Recommendation for Supplemental Technologies for Potential Mission Acceleration, RPP-11261, Revision 0, CH2M HILL Hanford Group, Inc., Richland, Washington.

Hansen EK, DT Herman, and VJ Williams, 2006. Saltstone Sheet Drain Performance Results. WSRC-TR-2006-00058, Revision 0, Savannah River National Laboratory, Aiken, South Carolina.

Hansen EK, AD Marzolf, and KR Hera. 2012. 2012 SRNL-EM Vane Rheology Results. SRNL-STI-2012-00519, Revision 0, Savannah River National Laboratory, Aiken, South Carolina.

Harbour JH, VJ Williams, and TB Edwards. 2007. Heat of Hydration of Saltstone MixesMeasurement by Isothermal Calorimetry. WSRC-STI-2007-00263, Rev. 0, Savannah River National Laboratory, Aiken, South Carolina.

Hothorn T, F Bretz, and P Westfall. 2013. Package 'multcomp' - Simultaneous Inference in General Parametric Models. Available at http://cran.rproject.org/web/packages/multcomp/multcomp.pdf. 
Lockrem LL. 2005. Hanford Containerized Cast Stone Facility Task 1-Process Testing and Development Final Report. RPP-RPT-26742 Revision 0, CH2M Hill Hanford Group, Inc., Richland, Washington.

Macosko CW. 1994. "Plastic Behavior." In Rheology Principles, Measurements, and Applications, Macosko CW (ed.). Advances in Interfacial Engineering Series; Wiley-VCH Inc., New York, New York; pp. 92-108.

Mattigod SV, JH Westsik, Jr, CW Chung, MJ Lindberg, and KE Parker. 2011. Waste Acceptance Testing of Secondary Waste Forms: Cast Stone, Ceramicrete and DuraLith. PNNL-20632, Pacific Northwest National Laboratory, Richland, Washington.

McCarthy GJ, JK Solem, OE Manz, and DJ Hasset. 1989. "Use of a Database of Chemical, Mineralogical and Physical Properties of North American Fly Ash to Study the Nature of Fly Ash and Its Utilization as a Mineral Admixture in Concrete." In MRS Proceedings 178:3, Cambridge University Press.

McGrail BP, DH Bacon, RJ Serne, and EM Pierce. 2003. A Strategy to Assess Performance of Selected Low-Activity Waste Forms in an Integrated Disposal Facility. PNNL-14362, Pacific Northwest National Laboratory, Richland, Washington.

Pierce EM, SV Mattigod, RJ Serne, JP Icenhower, RD Scheele, W Um, N Qafoku, and JH Westsik, Jr. 2010. Review of Potential Candidate Stabilization Technologies for Liquid and Solid Secondary Waste Streams. PNNL-19122, Pacific Northwest National Laboratory, Richland, Washington.

R Core Team (2013). R: A Language and Environment for Statistical Computing. R Foundation for Statistical Computing, Vienna, Austria. ISBN 3-900051-07-0, URL http://www.Rproject.org/.

Ramachandran VS and RF Feldman. 1995. "Concrete Science." In Concrete Admixtures Handbook Properties, Science and Technology, Second Edition, VS Ramachandran (ed)., Building Materials Science Series; Noyes Publications, Park Ridge, New Jersey; pp. 1-60.

Rapko BM, SI Sinkov, and TG Levitskaia. 2003. Removal of ${ }^{137}$ Cs from Dissolved Hanford Tank Saltcake by Treatment with IE-911. PNNL-14250, Revision 1, Pacific Northwest National Laboratory, Richland, Washington.

Rassat SD, LA Mahoney, RL Russell, SA Bryan, and RL Sell. 2003. Cold Dissolved Saltcake Simulant Development, Preparation, and Analysis. PNNL-14194, Rev 1, Pacific Northwest National Laboratory, Richland, Washington.

Resource Conservation and Recovery Act of 1976. 1976. Public Law 94-580, as amended, 42 USC 6901 et seq. and 42 USC 6927(c) et seq.

Robeyst N, E Gruyaert, CU Grosse, and N De Belie. 2008. "Monitoring the setting of concrete containing blast-furnace slag by measuring the ultrasonic p-wave velocity." Cement and Concrete Research 38:1169-1176. 
PNNL-22747

SRNL-STI-2013-00465

Russell RL, JH Westsik Jr, DJ Swanberg, RE Eibling, A Cozzi, MJ Lindberg, GB Josephson, and DE Rinehart. 2013. Letter Report: LAW Simulant Development for Cast Stone Screening Tests. PNNL-22352, Pacific Northwest National Laboratory, Richland, Washington.

Savannah River National Laboratory (SRNL). 2010. Lithium Tetraborate Fusion Method (U) Revision 1. Procedure Manual L29, ITS-0070, Aiken, South Carolina.

Savannah River National Laboratory (SRNL). 2010. Operation of the Quantachrome Multipycnometer Revision 0. Procedure Manual L29, ITS-0168, Aiken, South Carolina.

Stat-Ease. 2010. Design-Expert Version 8.0.7.1. Stat-Ease, Inc., Minneapolis, Minnesota.

Sundaram SK, KE Parker, ME Valenta, SG Pitman, J Chun, C-W Chung, ML Kimura, CA Burns, W Um, and JH Westsik, Jr. 2011. Secondary Waste Form Development and Optimization-Cast Stone. PNNL-20159, Rev. 1, Pacific Northwest National Laboratory, Richland, Washington.

Walenta $\mathrm{G}$ and T Füllmann. 2004. "Advances in Quantitative XRD Analysis for Clinker, Cements, and Cementitious Additions. Advances in X-ray Analysis 47:287-296.

Westsik JH Jr., RJ Serne, EM Pierce, AD Cozzi, C Chung, and DJ Swanberg. 2013 Supplemental Immobilization Cast Stone Technology Development and Waste Form Qualification Testing Plan. PNNL-21823, Rev 1, Pacific Northwest National Laboratory, Richland, Washington. 
PNNL-22747

SRNL-STI-2013-00465

Appendix A. Statistical Design of the Screening Test Matrix 
This appendix discusses how the screening test matrix was developed using statistical experimental design methods and software. The screening test matrix was developed in two "blocks" in case project funding might be limited and only the Block 1 tests could be performed. However, sufficient funding was provided, so both Block 1 and Block 2 of the experimental design were performed.

Section A.1 describes the optimal experimental design (OED) methodology used to develop the test matrix. Sections A.2 and A.3 describe how the two blocks of the test matrix were developed.

\section{A.1 Optimal Experimental Design}

The test matrix (both the Block 1 and Block 2 portions) was selected using OED methods (Atkinson and Donev 1992) implemented using the Design-Expert software (Stat-Ease 2010). OED seeks to select the tests in a test matrix so as to minimize or maximize a statistical criterion based on some measure of goodness of the test matrix. The optimality criteria considered in developing the Cast Stone screening experimental design (both Block 1 and Block 2) included

- D-optimality: Minimize $\left|\left(\mathbf{X}^{\prime} \mathbf{X}\right)^{-1}\right|$

- I-optimality: Minimize Average $\left(\mathbf{x}^{\prime}\left(\mathbf{X}^{\prime} \mathbf{X}\right)^{-1} \mathbf{x}\right.$

where $\mathbf{X}$ denotes the test matrix with columns expanded in the form of terms in a specified model form, the prime denotes matrix transpose, the superscripted -1 denotes the matrix inverse, the vertical bars denote the determinant of a matrix (a scalar), and $\mathbf{x}$ denotes a vector of test combinations (expanded in the form of the specified model) within the allowable set (referred to as the candidate set) of test combinations. The D-optimality criterion seeks to reduce the size of the confidence ellipsoid on estimates of the model coefficients, while the I-optimality criterion seeks to minimize the average variance of property predictions made with the specified model. For categorical parameters (or numeric parameters with discrete values), the average is over the allowable discrete combinations. For numeric parameters with continuous values allowed, the average is over the whole space of numeric combinations.

OED methods rely on optimization algorithms that do not guarantee "the" optimal solution on a given "try." Hence, software typically makes many "tries" from different random starting designs and selects the best design from all the tries according to the chosen optimality criterion.

\section{A.2 Screening Test Matrix, Block 1}

The Block 1 test matrix focused on a screening assessment of the effects of the five individual test parameters discussed in Section 2.0. To enable the use of OED methods and software to develop the Block 1 test matrix, the following model for individual effects of the test parameters was specified:

$$
\begin{aligned}
y & =\beta_{0}+\beta_{1}\left(S_{\text {SSTBlend }-A v g}+\beta_{2} S_{\text {HighAl-Avg }}+\beta_{3} S_{\text {HighSO4-Avg }}+\beta_{4} W C\right. \\
& +\beta_{5} F A+\beta_{6} B F S+\beta_{7} M R+\varepsilon
\end{aligned}
$$

where $\quad y=$ a measured property (possibly mathematically transformed, e.g., logarithm transformation) of a Cast Stone waste form

$S_{\text {SSTBlend-Avg }}=1$ for the SST Blend simulant, $=0$ otherwise

$S_{\text {HighAl-Avg }}=1$ for the High Al simulant, $=0$ otherwise 


$$
\begin{aligned}
& S_{\text {HiSO4-Avg }}=1 \text { for the High } \mathrm{SO}_{4} \text { simulant, }=0 \text { otherwise } \\
& \mathrm{WC}=\text { waste concentration, quantified as } \mathrm{Na} \text { molarity, where } 5 \mathrm{M} \text { was coded as } \\
& 0 \text {, and } 7.8 \mathrm{M} \text { was coded as } 1 \\
& \mathrm{FA}=\text { fly ash, where } \mathrm{SE}(\text { low } \mathrm{Ca})=0, \mathrm{NW}(\text { high } \mathrm{Ca})=1 \\
& \mathrm{BFS}=\text { blast furnace slag, where } \mathrm{NW}=0, \mathrm{SE}=1 \\
& \mathrm{MR}=\text { mix ratio, quantified as the grams of free water in the waste simulant per } \\
& \text { gram of dry blend solids. } \mathrm{MR}=0.4 \text { was coded as } 0 \text {, and } \mathrm{MR}=0.6 \text { was } \\
& \text { coded as } 1 \text {. } \\
& \beta_{0}, \ldots, \beta_{7}=\text { model coefficients to be estimated from test data using least squares } \\
& \text { regression } \\
& \varepsilon=\text { random error from testing and measuring property } y \text { for a given test. }
\end{aligned}
$$

To use ordinary least squares (OLS) regression to fit the model coefficients to experimental data obtained from a test matrix, the random errors must be independently and identically distributed according to a normal distribution. One aspect of this assumption is that the random errors must have constant variance over all test combinations in the test matrix. Often when these assumptions are not satisfied for a given property, they will be satisfied for a mathematical transformation (e.g., logarithm) of the property. Typically, a commonly used transformation of the property has a subject-matter basis as well as the statistical basis. The assumption of equal variance was assessed as part of data analyses performed on the data from the test matrix, the results of which are discussed in Section 8.0.

Although the simulant, fly ash (FA), and blast furnace slag (BFS) test parameters are categorical, numeric coding for their settings was used to enable specifying a numeric model form in Equation (A-1). However, with this numeric coding convention, the FA and BFS parameters can only take the values of 0 and 1 ; intermediate values are not appropriate. The waste concentration (WC) and mix ratio (MR) test parameters are numeric, and conceptually could take a value anywhere in the selected testing range of each parameter. However, for the screening test matrix, it was decided that WC and MR would only take values equal to their lower and upper bounds. Those values were not decided upon at the time that the test matrix was constructed, so the 0 and 1 coded values of WC and MR (along with FA and BFS) were used to develop the test matrix.

Because the Simulant test parameter is categorical with four possible simulants, choices had to be made to enable numeric coding of the four simulants. The coding of the chosen Simulant test parameter involves comparing (via differencing) each of the SST Blend, High $\mathrm{Al}$, and $\mathrm{High} \mathrm{SO}_{4}$ simulants to the Average simulant. Obviously, other comparisons could be made and may be of interest. However, this set of comparisons was chosen because it was believed that there would not be much difference in property values for the Average and SST Blend simulants, and so comparing those two simulants was of interest. It was then natural to also compare the High $\mathrm{Al}$ and High $\mathrm{SO}_{4}$ simulants to the Average simulant.

With all of the test parameters (and simulant comparisons) coded 0 and 1 as discussed, note that the OLS estimate of the $\beta_{0}$ coefficient is the model-predicted property value when all parameters and simulant comparisons are set to their 0 coded values. That corresponds to the Average simulant, 5.0 Na molarity, southeast (SE; low-Ca) FA, northwest (NW) BFS, and MR $=0.4$. The OLS estimates of $\beta_{1}, \beta_{2}$, and $\beta_{3}$ are predictions of the increase in the property value when changing from the Average Simulant to the SST Blend, High Al, and High $\mathrm{SO}_{4}$ simulants, 
respectively. The OLS estimates of $\beta_{4}, \beta_{5}, \beta_{6}$, and $\beta_{7}$ are predictions of the increase in the property value when changing the $\mathrm{WC}, \mathrm{FA}, \mathrm{BFS}$, and MR parameters, respectively, from their 0 to 1 coded values.

Block 1 of the test matrix was designed to include 12 distinct tests and 2 replicates, for a total of 14 tests. These numbers of tests and replicates provided a minimal basis for 1) fitting the model (A.1) to property data from the tests, 2) assessing the testing and measurement uncertainty in the property values, and 3) assessing the lack-of-fit (LOF) when fitting the model in Equation (A-1) to experimental data.

The Design-Expert software (Stat-Ease 2010) was used to first select the 12 distinct tests for Block 1 using the D-optimality criterion based on the model in Equation (A-1). The DesignExpert's default set of 128 candidate points was too large because of the special nature of coding the four simulants as three comparisons. Hence, a set of 64 candidate points was generated and supplied to Design-Expert to use in selecting the 12 test conditions. The number of candidate points results from $(4$ simulants $) \times(2 \mathrm{WC}$ values $) \times(2 \mathrm{FA}$ values $) \times(2 \mathrm{BFS}$ values $) \times(2 \mathrm{MR}$ values $)=64$ combinations. After selecting the 12 distinct tests for Block 1 of the test matrix, a separate run was made in Design-Expert to select 2 of the 12 design points as replicates, again using D-optimality as the OED criterion based on the model in Equation (A-1). The resulting 12 tests plus 2 replicates are listed as Tests 1 through 14 in Table 2-1 of Section 2.0 in the main body of this report.

\section{A.3 Screening Test Matrix, Block 2}

Block 2 of the test matrix was developed using OED methodology to augment the Block 1 test matrix with additional tests to support the assessment of whether selected pairs of parameters have significant two-parameter interactive effects on Cast Stone properties. A two-parameter interaction occurs when the effect of one parameter on a property depends of the value of a second parameter.

As guidance for developing the test matrix, it was thought that the Average and SST Blend simulants would have similar effects on the Cast Stone properties, because each simulant was an estimate of the average LAW composition. Hence, it was thought that interactions of other parameters with the difference in the effects of the SST Blend and Average simulants would not be significant. Those interactions are the first three listed in the left column of Table A-1. Further, it was believed that there would not be much difference in the effects of the two sources of BFS on Cast Stone properties. Hence, it was believed that interactions of other parameters with BFS would not be significant. Those interactions are the final six interactions listed in the left column of Table A-1. 
Table A-1. Two-Parameter Interactions Thought Not to Have Significant Effects and the Remaining Two-Parameter Interactions Planned for in Constructing Block 2 of the Test Matrix

\begin{tabular}{|c|c|}
\hline $\begin{array}{c}\text { Two-Parameter Interactions Thought Not to } \\
\text { Have Significant Effects }\end{array}$ & $\begin{array}{c}\text { Remaining Two-Parameter Interactions } \\
\text { Planned for in the Test Matrix }\end{array}$ \\
\hline (SST Blend vs. Average)*Waste Concentration & (High Al vs. Average)*Waste Concentration \\
\hline (SST Blend vs. Average)*Fly Ash & ${\text { (High } \mathrm{SO}_{4} \text { vS. Average) }}^{*}$ Waste Concentration \\
\hline (SST Blend vs. Average)*Mix Ratio & (High Al vs. Average)*Fly Ash \\
\hline BFS*(High Al vs. Average) & (High $\mathrm{SO}_{4}$ vs. Average)*Fly Ash \\
\hline $\mathrm{BFS}^{*}\left(\right.$ High $\mathrm{SO}_{4}$ vs. Average) & (High Al vs. Average)*Mix Ratio \\
\hline BFS*(SST Blend vs. Average) & (High $\mathrm{SO}_{4}$ vs. Average)*Mix Ratio \\
\hline BFS*Waste Concentration & Fly Ash*Waste Concentration \\
\hline BFS*Fly Ash & Waste Concentration*Mix Ratio \\
\hline BFS*Mix Ratio & Fly Ash*Mix Ratio \\
\hline
\end{tabular}

The two-parameter interactions remaining (nine of them) are listed in the right column of Table A-1. The model listed in Equation (A-1) was expanded to include terms for these nine interactions:

$$
\begin{aligned}
& y=\beta_{0}+\beta_{1}\left(S_{\text {SSTBlend }-A v g}+\beta_{2} S_{\text {HighAl-Avg }}+\beta_{3} S_{\text {HighSO } 4-A v g}\right. \\
& +\beta_{4} W C+\beta_{5} F A+\beta_{6} B F S+\beta_{7} M R+\beta_{8}\left(S_{\text {HighAl-Avg }}\right) *(W C) \\
& +\beta_{9}\left(S_{\text {HighSO } 4-A v g}\right) *(W C)+\beta_{10}\left(S_{\text {HighAl-Avg }}\right)^{*}(F A) \\
& +\beta_{11}\left(S_{\text {HighSO4-Avg }}\right)^{*}(F A)+\beta_{12}\left(S_{\text {HighAl-Avg }}\right)^{*}(M R) \\
& +\beta_{13}\left(S_{\text {HighSO4-Avg }}\right) *(M R)+\beta_{14}(F A) *(W C)+\beta_{15}(W C)^{*}(M R) \\
& +\beta_{16}(F A)^{*}(M R)+\beta_{17} \text { Block }+\varepsilon
\end{aligned}
$$

where $\beta_{8}$ to $\beta_{16}$ are model coefficients of the interaction terms, $\beta_{17}$ is the model coefficient of the "block effect" term, and all other notation is the same as defined for Equation (A-1).

Block 2 of the test matrix was designed to contain 10 distinct test combinations and two replicates, so that together the whole test matrix (Blocks 1 and 2) contained 22 distinct test combinations and 4 replicates for a total of 26 tests. Design-Expert (Stat-Ease 2010) was used to select the 10 additional distinct test combinations to augment the 14 tests in Block 1, based on D-optimality and the model in Equation (A-2). The 10 additional test combinations were selected from the subset of the 64 candidate points discussed previously that were not selected for Block 1. Finally, Design-Expert was used to select the two replicates for Block 2 from among the 10 distinct test combinations chosen for Block 2. The resulting $10+2=12$ tests in Block 2 of the test matrix are listed as Tests 15-26 in Table 2-1 of Section 2.0. 
PNNL-22747

SRNL-STI-2013-00465

Appendix B. Dry Blend Materials Characterization 
Appendix B provides additional information about the characteristics of the individual blast furnace slag (BFS), fly ash (FA), and ordinary portland cement (OPC) dry blend components used in preparing the Cast Stone specimens used in these screening tests. This appendix also describes the chemical analysis methods used to characterize the waste simulants, dry materials, Cast Stone specimens, and EPA Draft Method 1315 leach tests.

\section{B.1 Blast Furnace Slag Properties}

Figure B-1 shows scanning electron microscopy (SEM) micrographs of the slags used in this study. The delay in onset of the reaction of slags with gypsum added is demonstrated in the isothermal calorimeter data shown in Figure B-2. For the SE slag, the onset of the heat generation peak is consistent with previously reported results (Harbour et al. 2007). Calorimeter data in Figure B-3 show that the total heat generated by the NW slag exceeds that of the SE slag after 80 hours. For the SE slag, the total heat generated is comparable with previously reported results over a similar time period (Harbour et al. 2007). Figure B-4 and Figure B-5 show the volumetric particle size distribution and thermal gravimetric analyses of the two slags. The surface areas of the NW and SE slags are 3.03 and $2.87 \mathrm{~m}^{2} / \mathrm{g}$ as measured by Brunauer-EmmettTeller (BET) analysis (Brunauer et al. 1938). The true particle density and the aerated and tap densities for the slags are listed in Table B-1 (see Section B.10 of the methods used). The table includes the calculated Hausner ratio, the tap density divided by the aerated density. The Hausner ratio is related to flowability. A Hausner ratio $<1.46$ is considered poor to very poor (Amidon et al. 2009). 

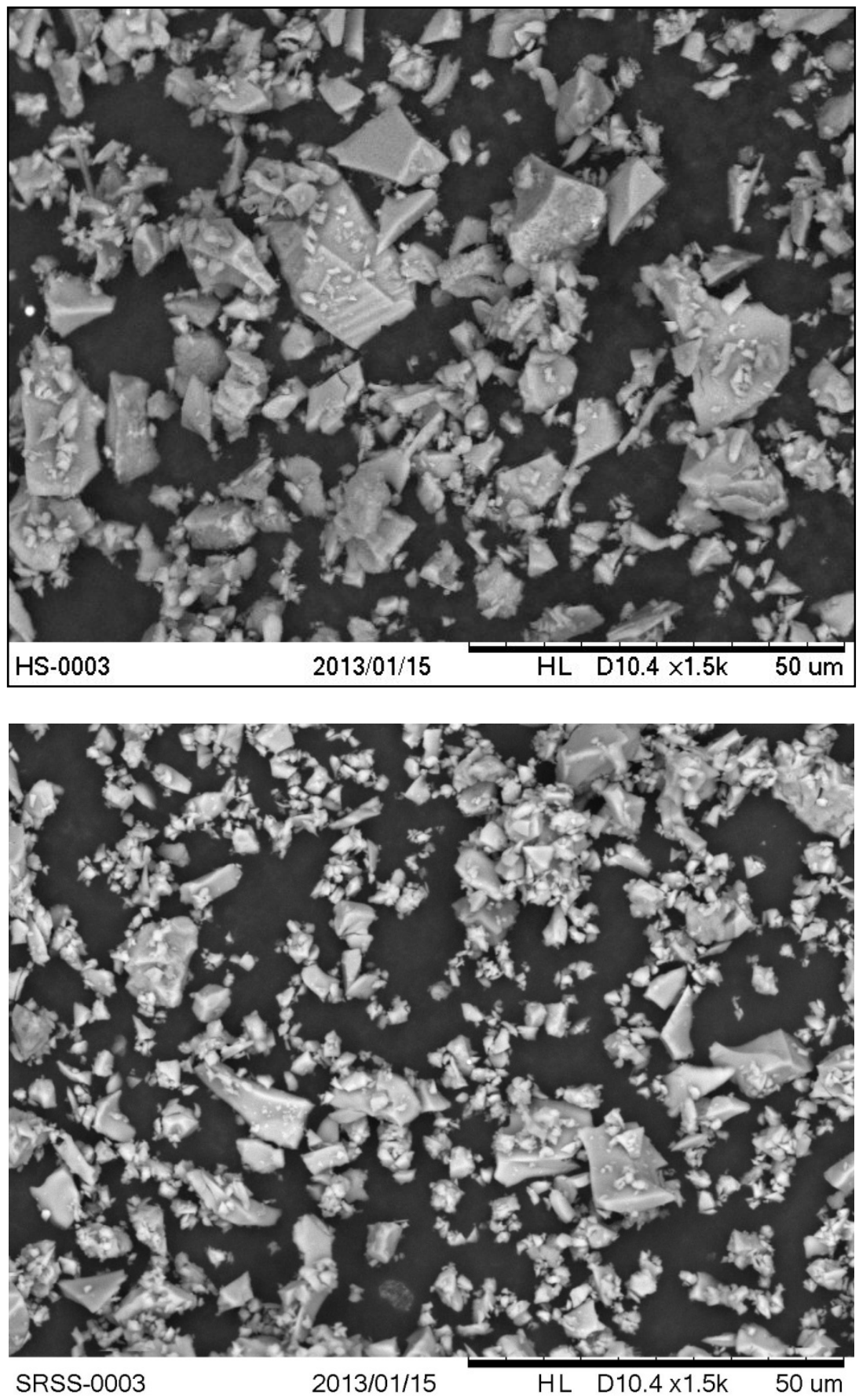

Figure B-1. Micrographs (1500x) of the Northwest (top) and Southeast (bottom) Blast Furnace Slags 


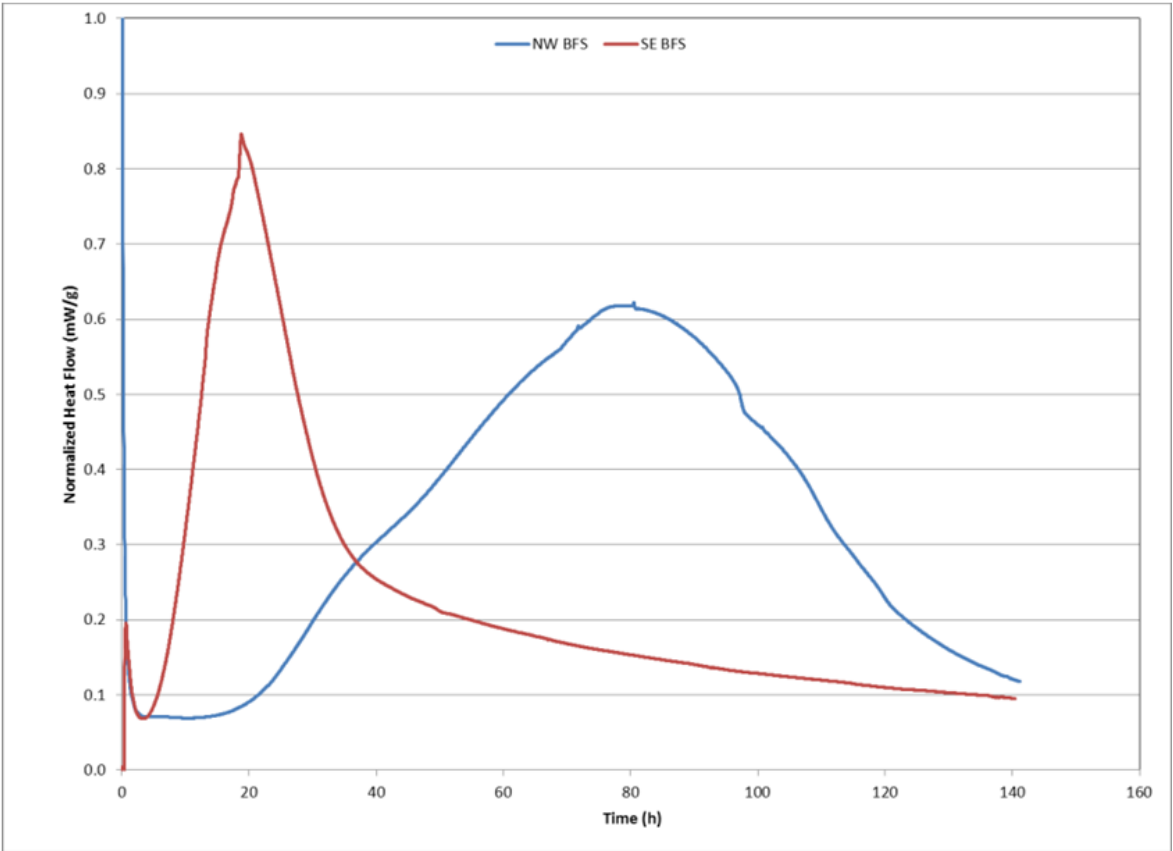

Figure B-2. Normalized Heat Flow Blast Furnace Slags (BFSs) Mixed with Water (1:0.4 BFS:Water)

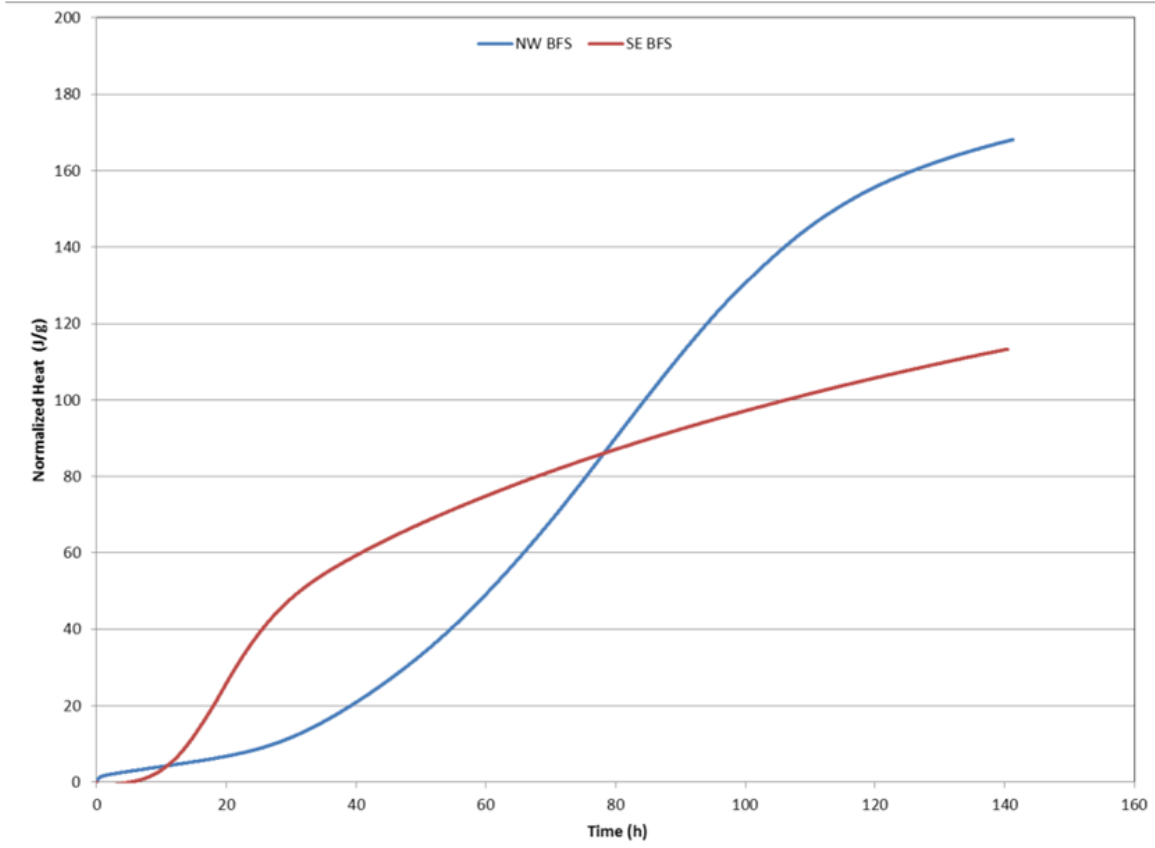

Figure B-3. Normalized Total Heat Generated by Blast Furnace Slags with Water (1:0.4 BFS:Water) 


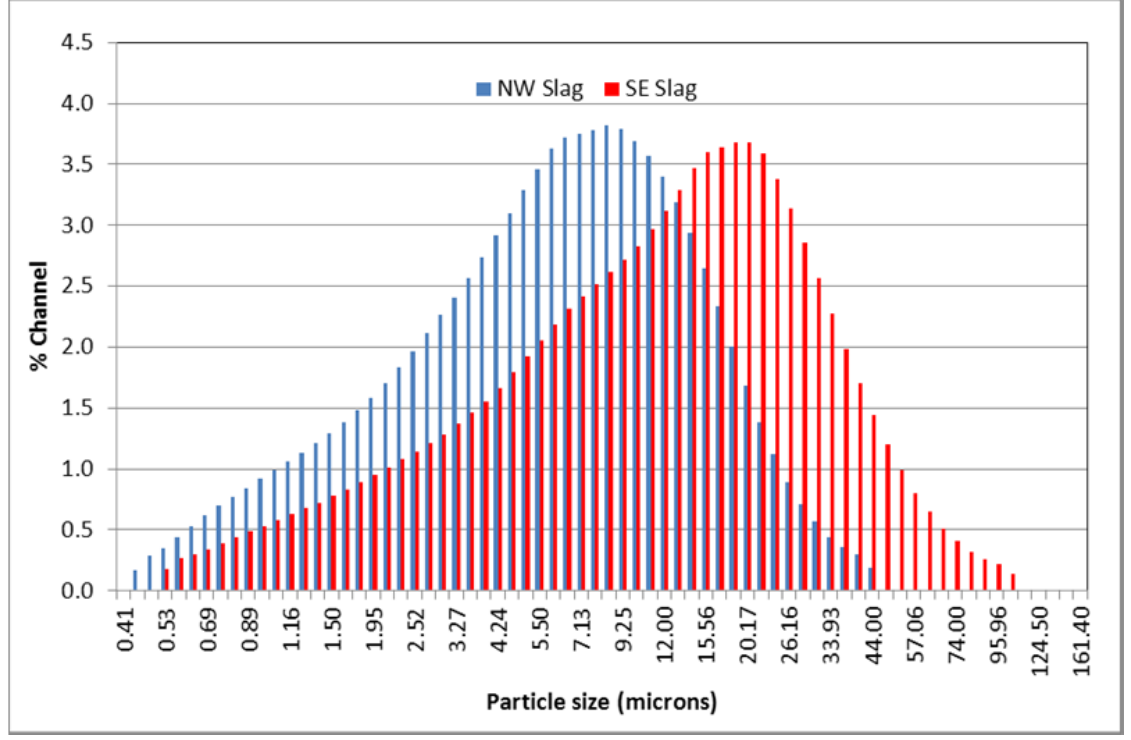

Figure B-4. Volumetric Particle Size Distribution of Blast Furnace Slags

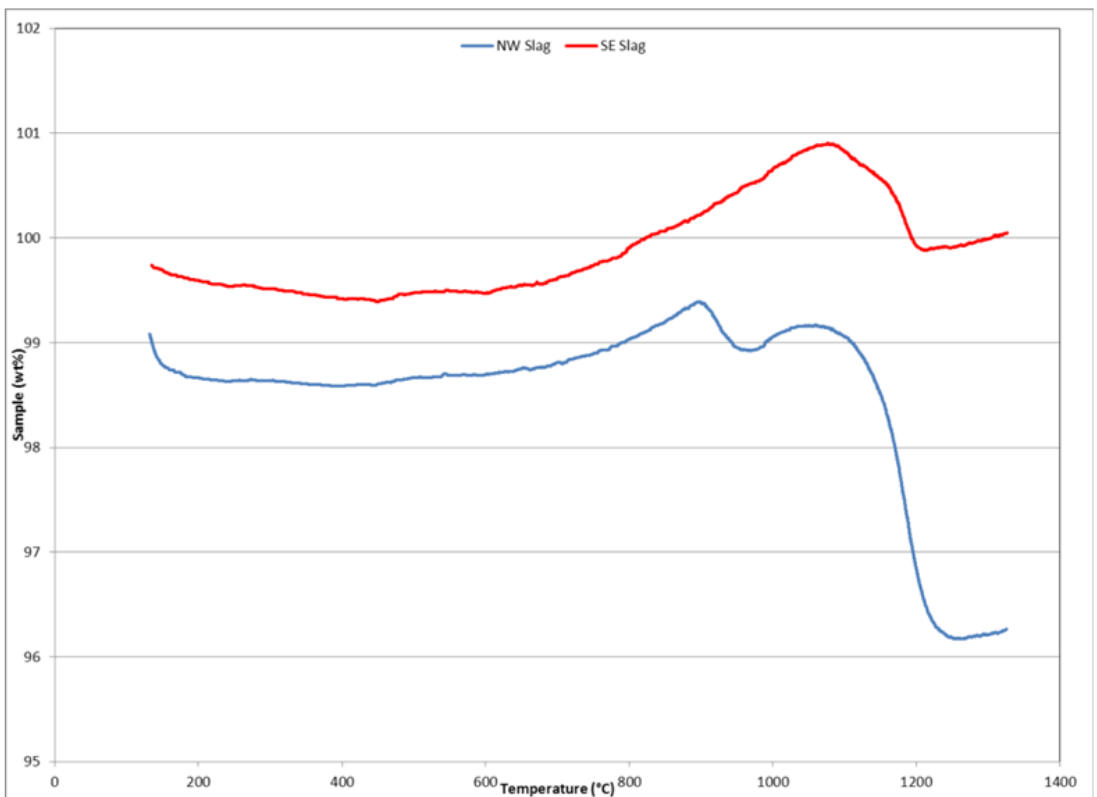

Figure B-5. Thermal Gravimetric Analysis of the Blast Furnace Slags

Table B-1. Density and Hausner Ratio of Blast Furnace Slags

\begin{tabular}{|c|c|c|c|c|}
\hline Slag Source & $\begin{array}{c}\text { True Density } \\
(\mathbf{g} / \mathbf{m l})\end{array}$ & $\begin{array}{c}\text { Aerated Density } \\
(\mathbf{g} / \mathbf{m l})\end{array}$ & $\begin{array}{c}\text { Tap Density } \\
(\mathbf{g} / \mathbf{m l})\end{array}$ & Hausner Ratio \\
\hline Northwest & 2.881 & 0.78 & 1.12 & 1.44 \\
\hline Southeast & 2.907 & 0.82 & 1.37 & 1.68 \\
\hline
\end{tabular}




\section{B.2 Fly Ash Properties}

Figure B-6 shows SEM micrographs of the FAs used in this study. Figure B-7 and Figure B-8 show that in water, only the NW sourced fly ash produced any reaction. The minimal pozzolanic activity in the SE sourced fly ash has also been observed with salt solutions (Harbour et al. 2007). Figure B-9 and Figure B-10 show the volumetric particle size distribution and thermal gravimetric analyses of the two FAs. The surface areas of the NW and SE fly ashes are 0.79 and $0.87 \mathrm{~m}^{2} / \mathrm{g}$ as measured by BET analysis. The true density and the aerated and tap densities for the slags are listed in Table B-2.
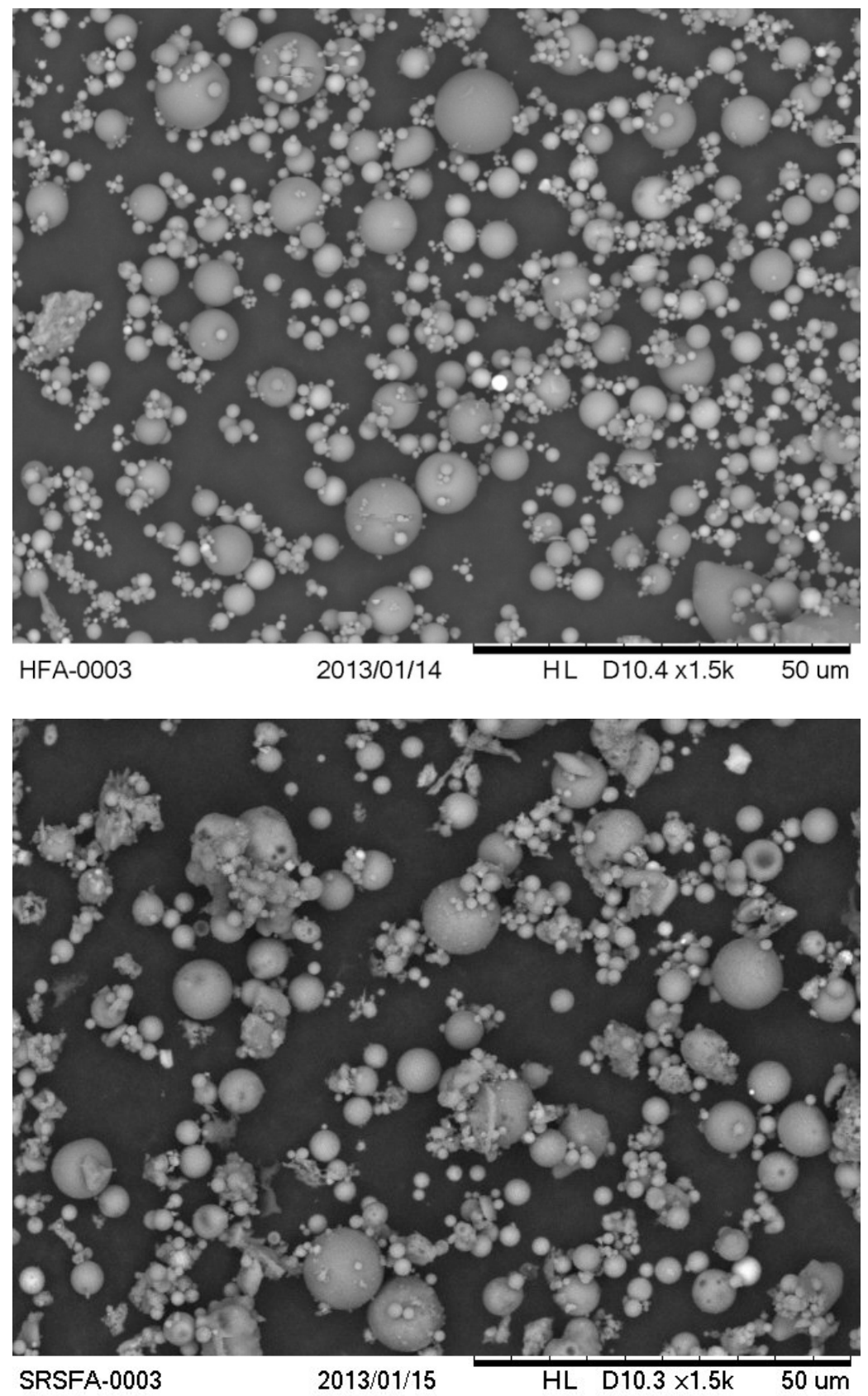

Figure B-6. Micrographs (1500x) Northwest (top) and Southeast (bottom) Fly Ashes 


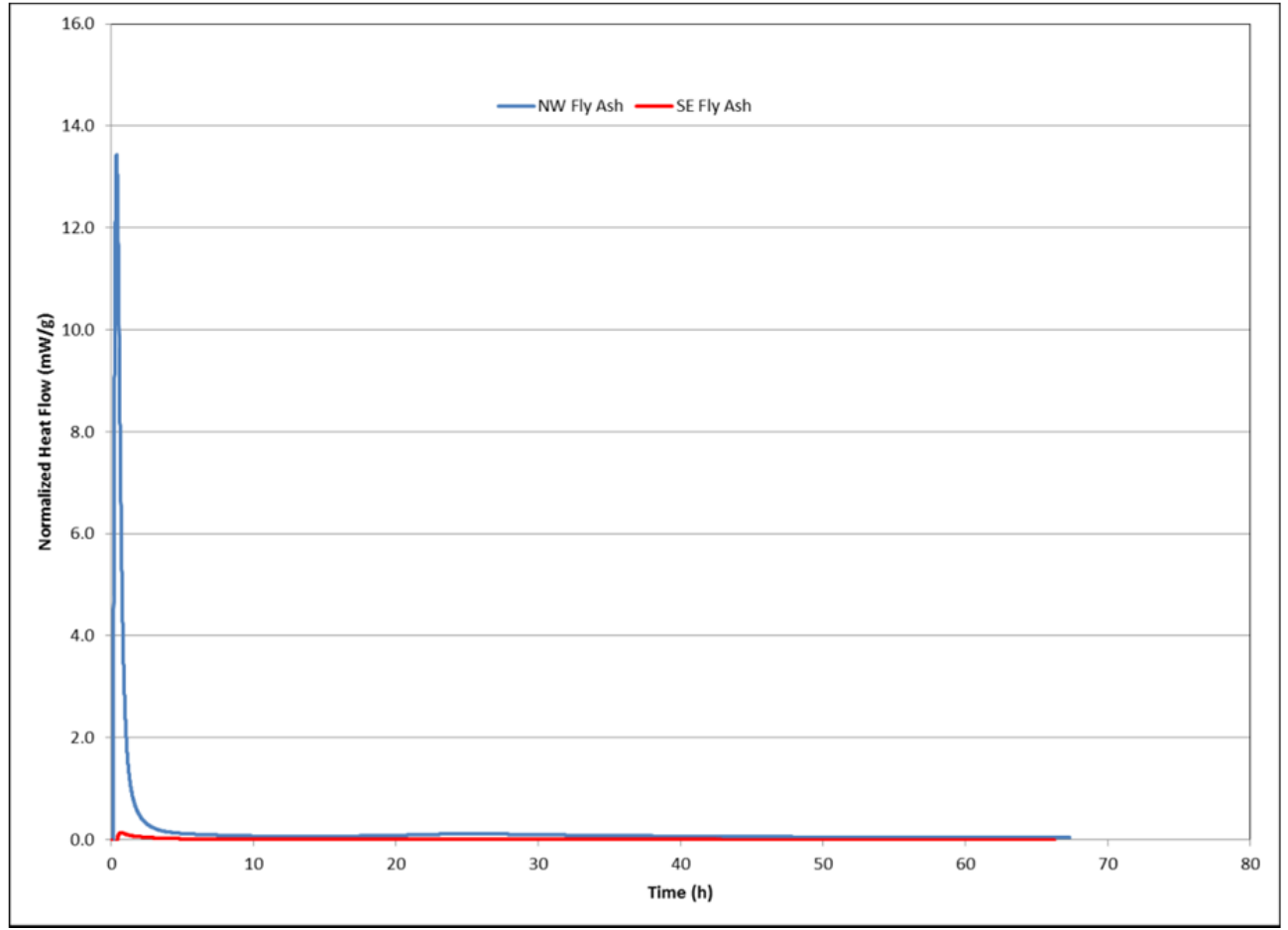

Figure B-7. Normalized Heat Flow of Fly Ashes Mixed with Water (1:0.4 FA:Water)

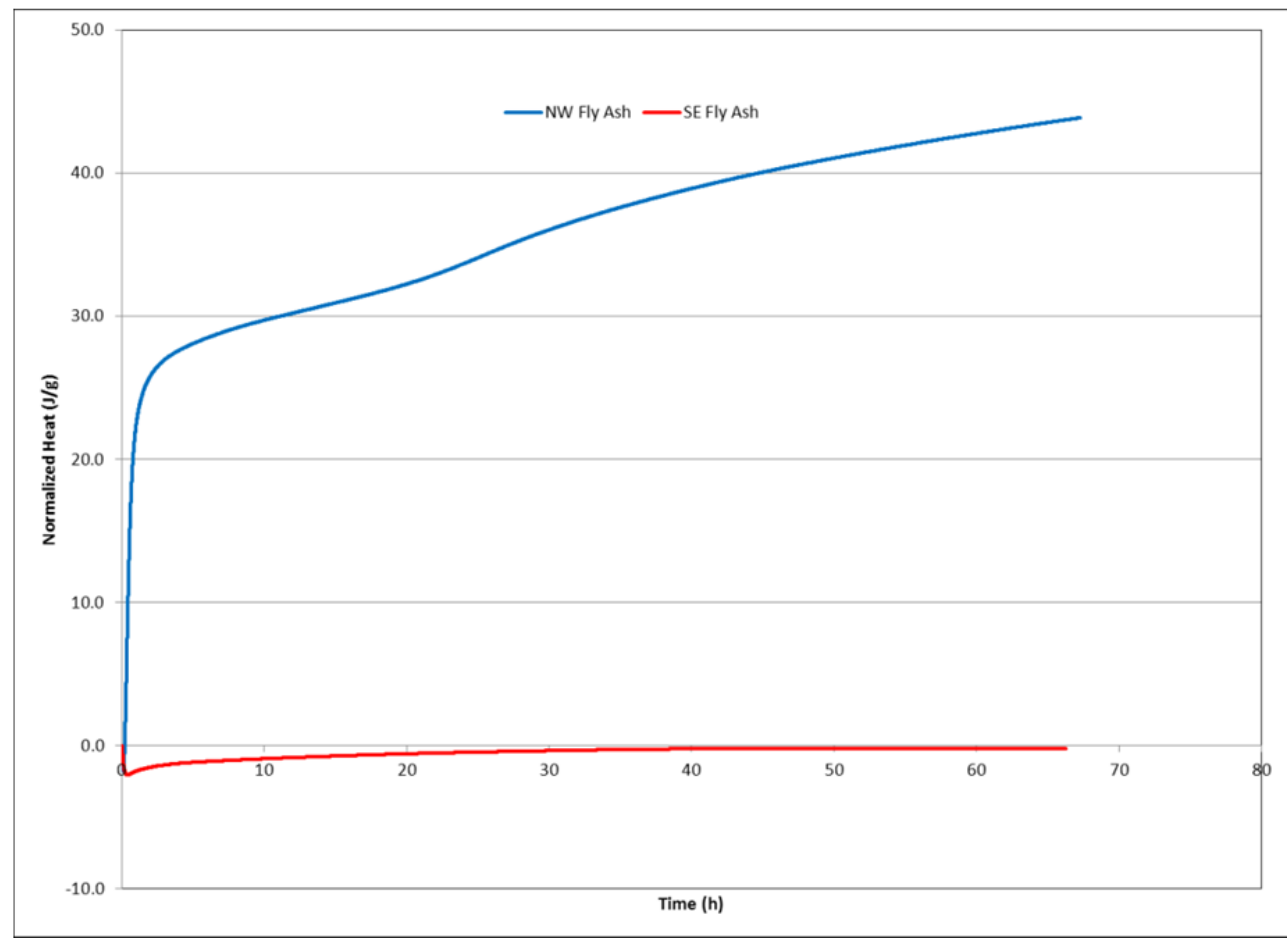

Figure B-8. Normalized Total Heat Generated by Fly Ashes with Water (1:0.4 FA:Water) 


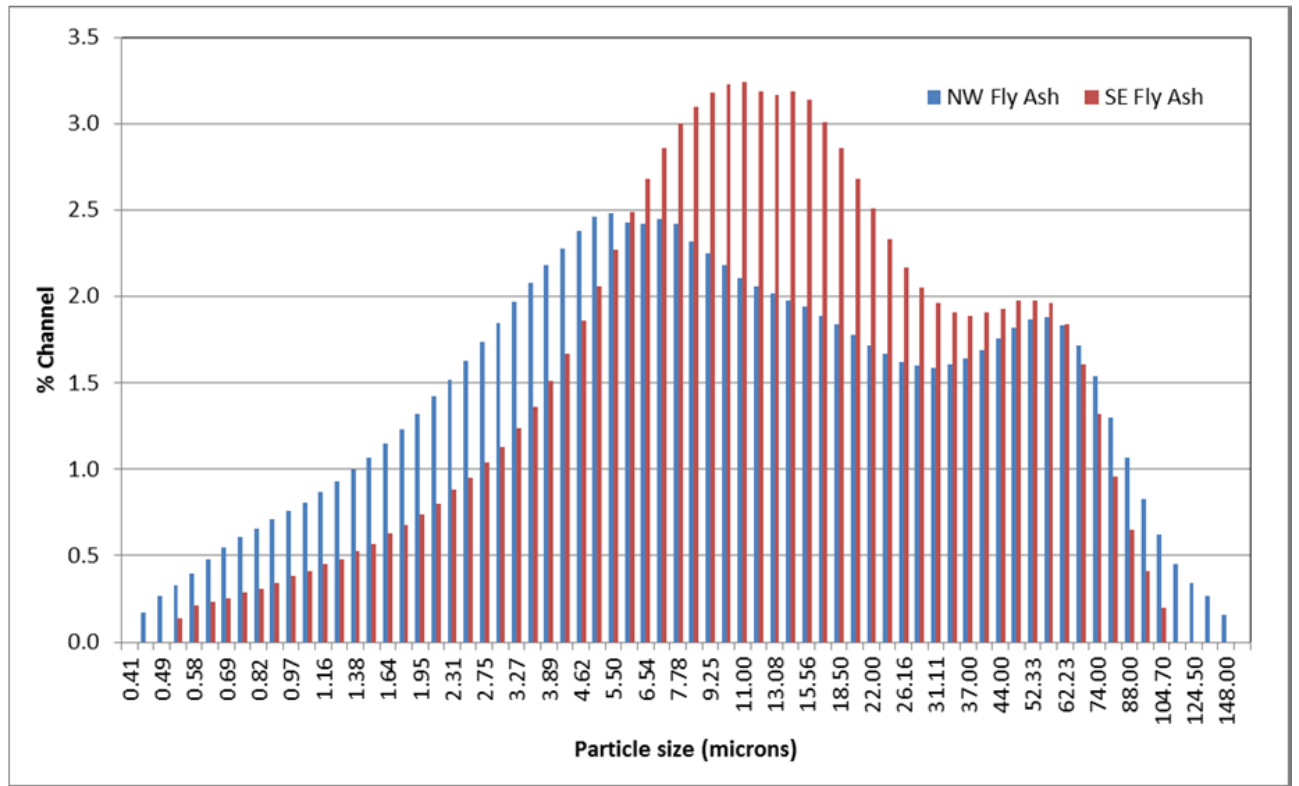

Figure B-9. Volumetric Particle Size Distribution of Fly Ashes

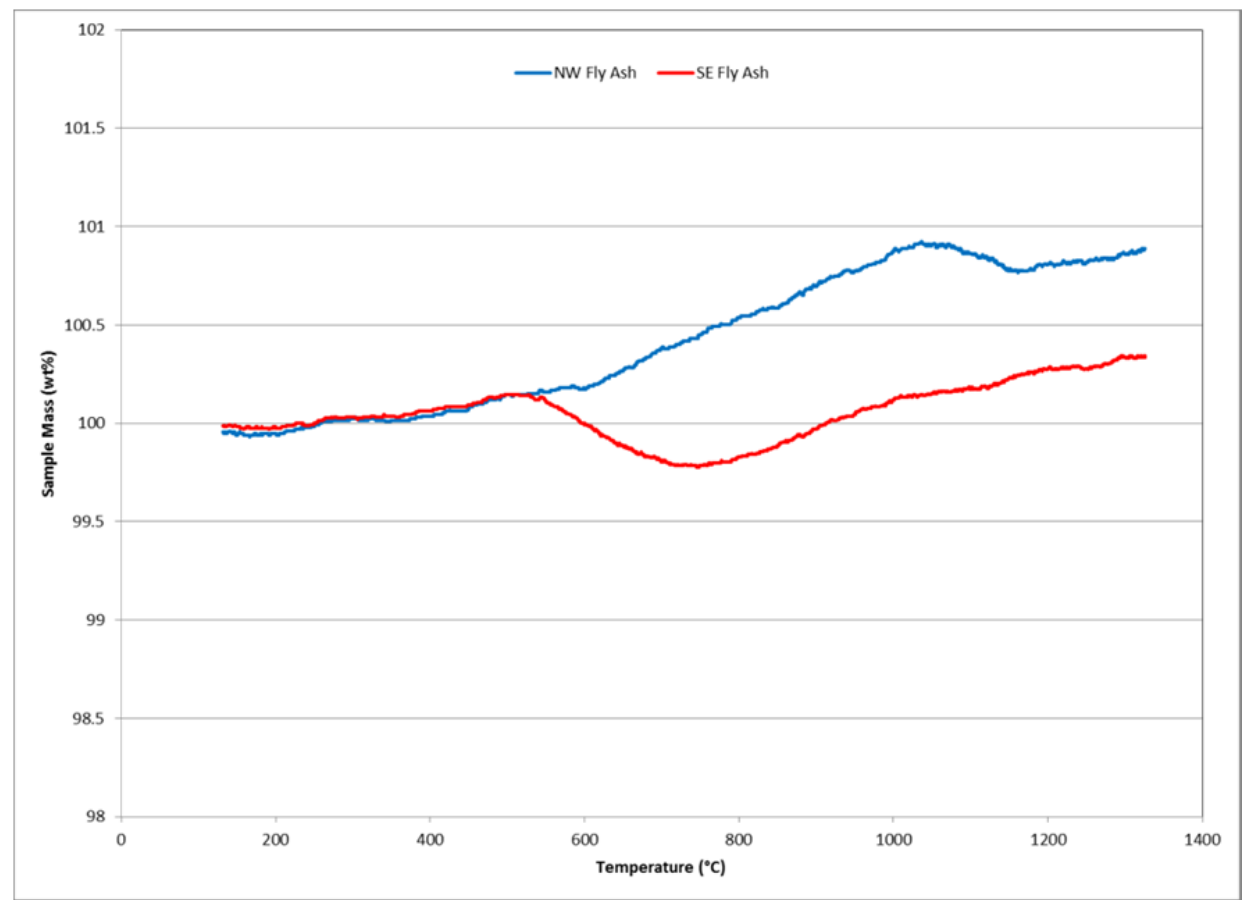

Figure B-10. Thermal Gravimetric Analysis of the Fly Ashes

Table B-2. Density and Hausner Ratio of Fly Ashes

\begin{tabular}{|c|c|c|c|c|}
\hline Fly Ash Source & $\begin{array}{c}\text { True Density } \\
(\mathbf{g} / \mathbf{m l})\end{array}$ & $\begin{array}{c}\text { Aerated Density } \\
(\mathbf{g} / \mathbf{m l})\end{array}$ & $\begin{array}{c}\text { Tap Density } \\
(\mathbf{g} / \mathbf{m l})\end{array}$ & Hausner Ratio \\
\hline Northwest & 2.588 & 0.98 & 1.59 & 1.63 \\
\hline Southeast & 2.432 & 0.74 & 1.29 & 1.75 \\
\hline
\end{tabular}




\section{B.3 Ordinary Portland Cement Properties}

Figure B-11 is an SEM micrograph of the NW sourced ordinary portland cement (OPC). The normalized heat flow and total heat of a 0.4 water-to-cement mix is shown in Figure B-12. The values are expected for mixes of this ratio with OPC. Figure B-13 and Figure B-14 show the volumetric particle size distribution and thermal gravimetric analyses of the OPC. The surface area of the cement as measured by BET is $1.57 \mathrm{~m}^{2} / \mathrm{g}$. The true density and the aerated and tap densities for the cement are listed in Table B-3.

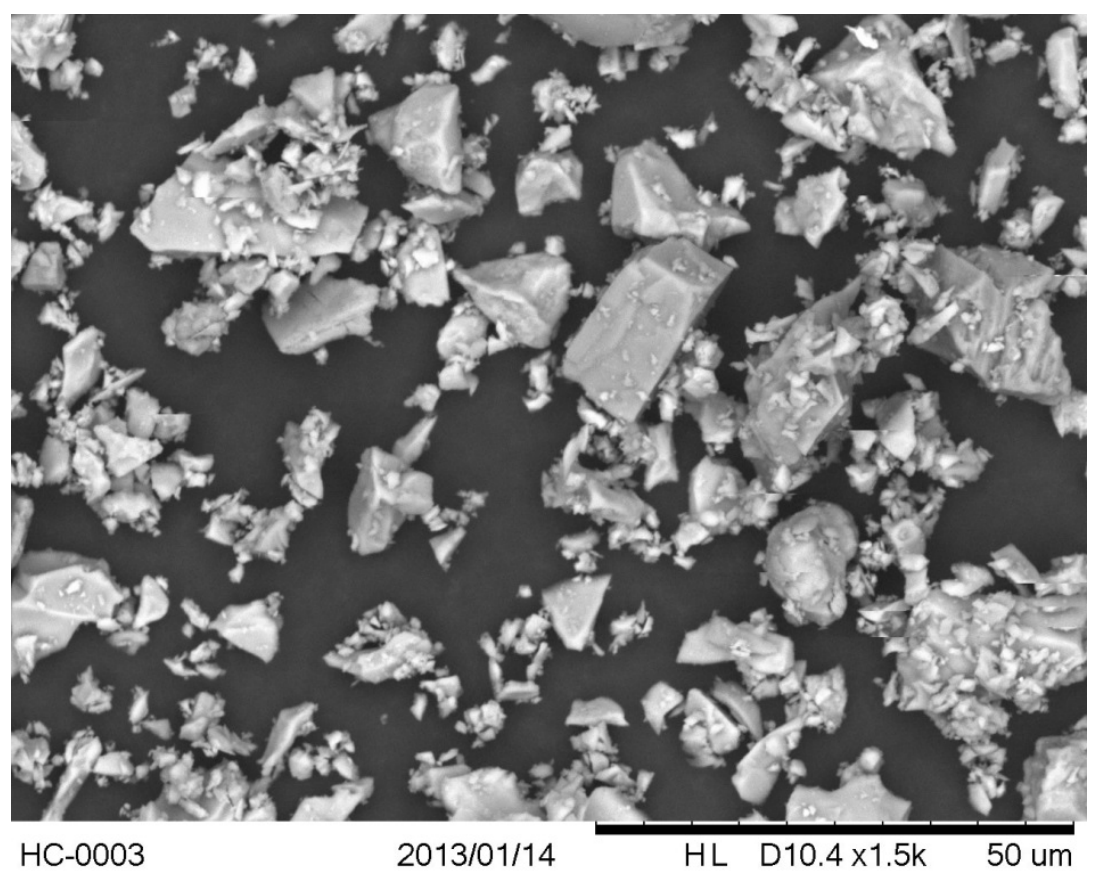

Figure B-11. Micrograph of Ordinary Portland Cement (1500x) 


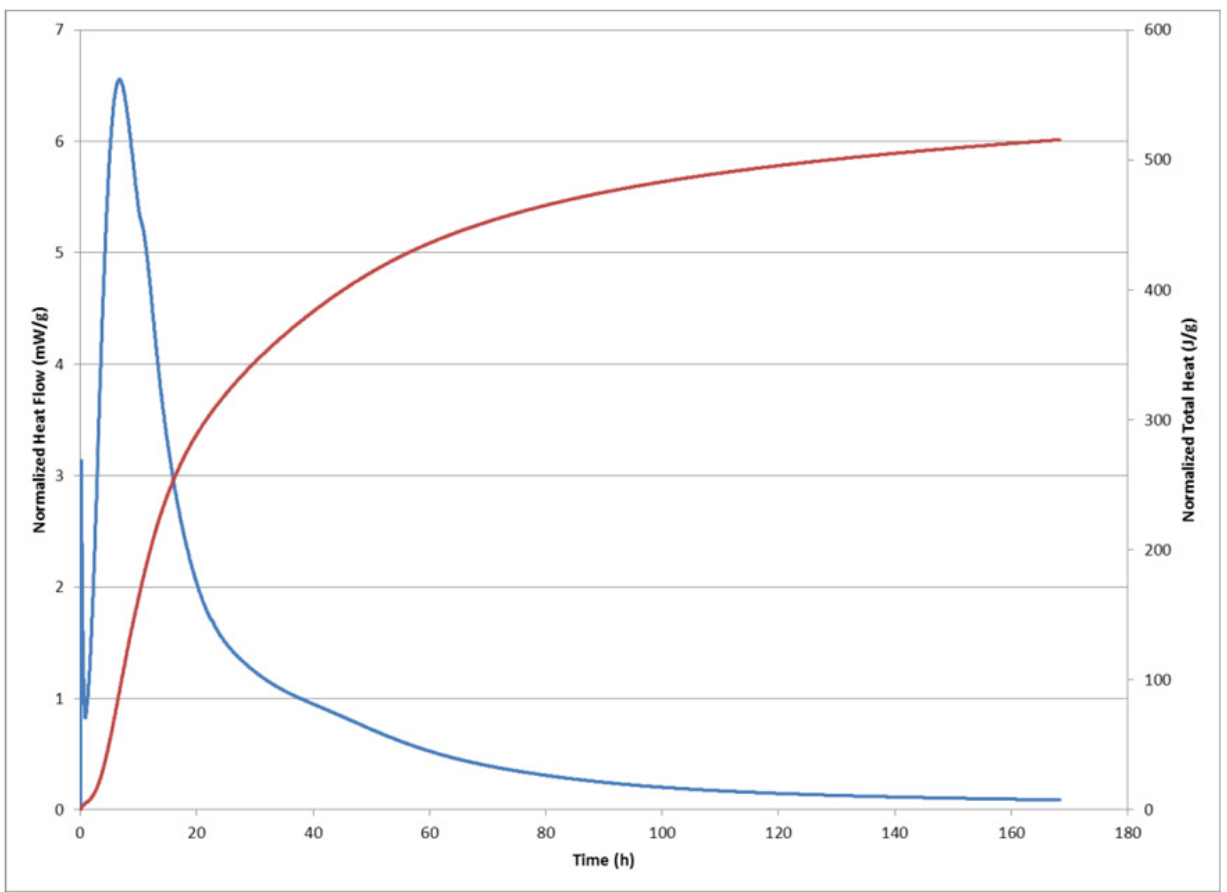

Figure B-12. Normalized Heat Flow and Total Heat from Ordinary Portland Cement with Water (1:0.4 OPC:Water)

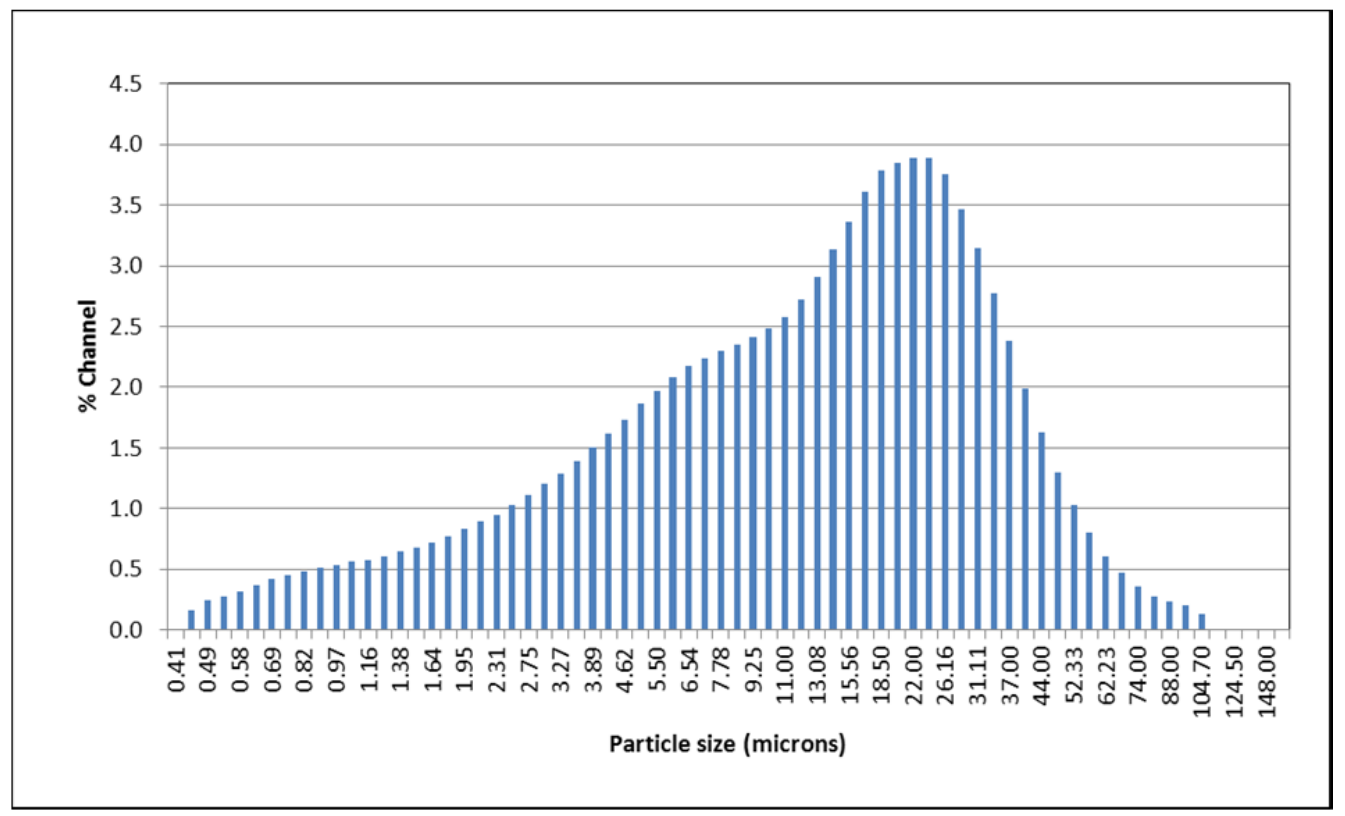

Figure B-13. Volumetric Particle Size Distribution of Ordinary Portland Cement 


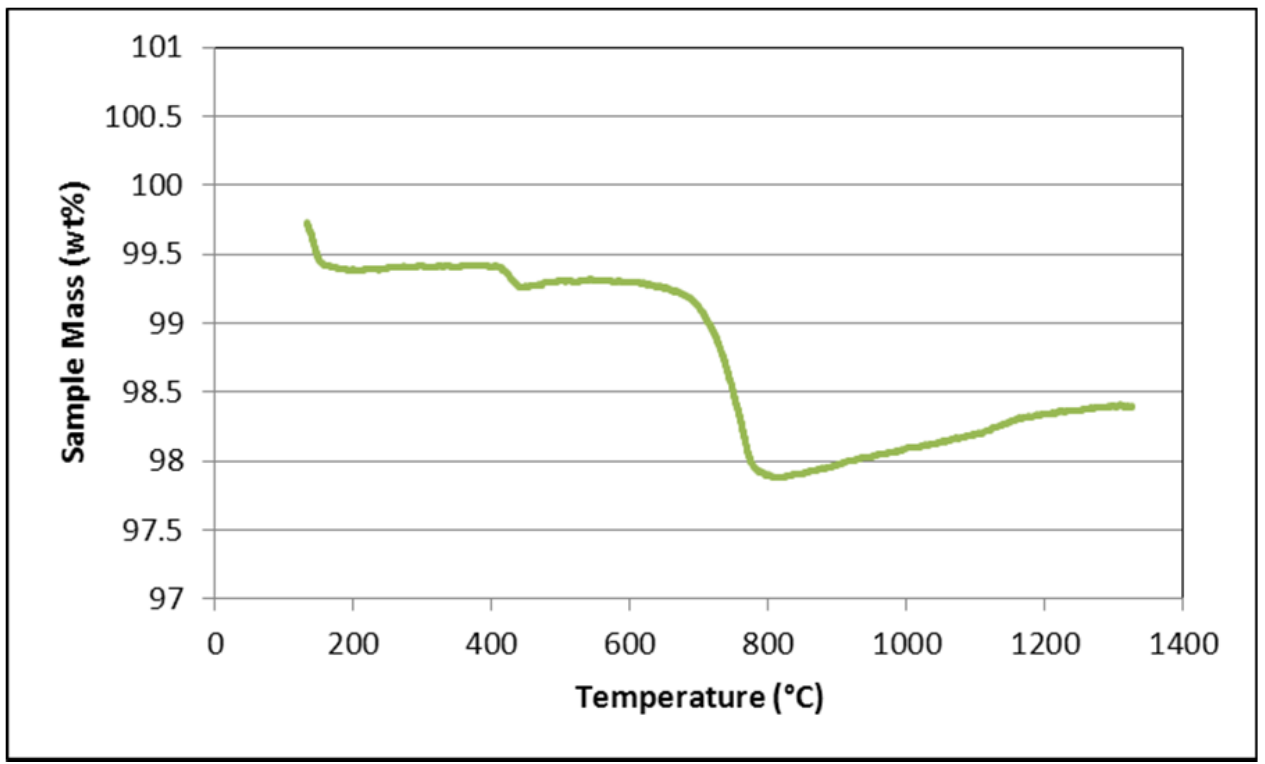

Figure B-14. Thermal Gravimetric Analysis of the Cement

Table B-3. Density and Hausner Ratio of Ordinary Portland Cement

\begin{tabular}{|c|c|c|c|c|}
\hline Cement Source & $\begin{array}{c}\text { True Density } \\
(\mathbf{g} / \mathbf{m l})\end{array}$ & $\begin{array}{c}\text { Aerated Density } \\
(\mathbf{g} / \mathbf{m l})\end{array}$ & $\begin{array}{c}\text { Tap Density } \\
(\mathbf{g} / \mathbf{m l})\end{array}$ & Hausner Ratio \\
\hline Northwest & 3.204 & 1.00 & 1.56 & 1.56 \\
\hline
\end{tabular}

\section{B.4 Final Dry Blend Mix Properties}

Figure B-15 shows the volumetric particle size distributions of the four dry blends calculated from the measured particle size distribution of the individual components and the dry blend ratio. Table B-4 is the calculated density, measured aerated and tap densities, and calculated Hausner ratio of the dry blends. The flowability of a powder with a Hausner ratio $>1.60$ is considered very, very poor (Amidon et al. 2009). 


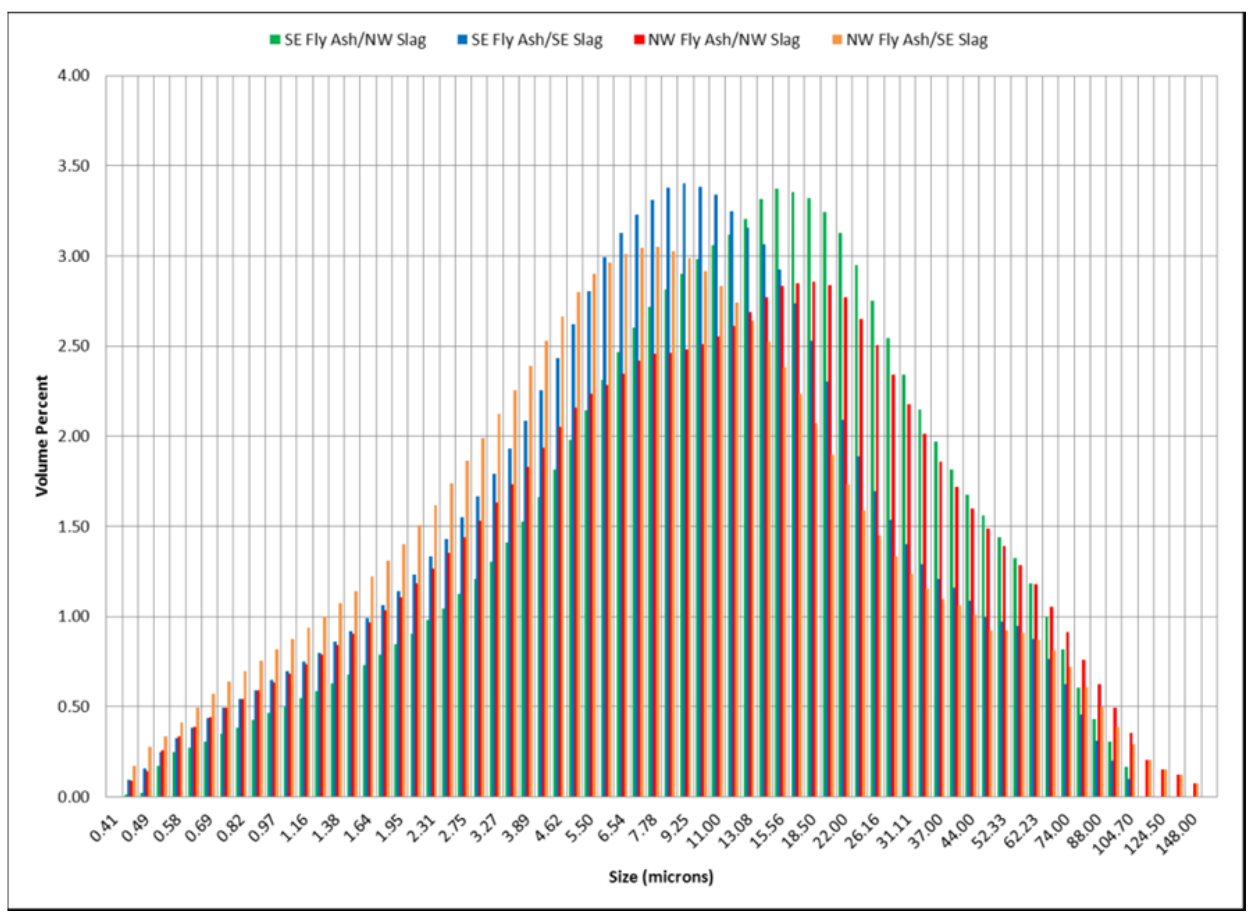

Figure B-15. Calculated Particle Size Distribution of the Dry Blends

Table B-4. Density and Hausner Ratio of Dry Blends

\begin{tabular}{|c|c|c|c|c|c|}
\hline \multicolumn{2}{|c|}{ Source } & \multirow{2}{*}{$\begin{array}{c}\text { True Density } \\
(\mathrm{g} / \mathrm{ml})^{(\mathrm{a})}\end{array}$} & \multirow{2}{*}{$\begin{array}{c}\text { Aerated Density } \\
(\mathrm{g} / \mathrm{ml})\end{array}$} & \multirow{2}{*}{$\begin{array}{l}\text { Tap Density } \\
\text { (g/ml) }\end{array}$} & \multirow{2}{*}{$\begin{array}{l}\text { Hausner Ratio } \\
\text { (unitless) }\end{array}$} \\
\hline Fly Ash & Slag & & & & \\
\hline Southeast & Northwest & 2.6802 & 0.80 & 1.35 & 1.68 \\
\hline Southeast & Southeast & 2.6907 & 0.72 & 1.19 & 1.65 \\
\hline Northwest & Northwest & 2.7628 & 0.88 & 1.44 & 1.63 \\
\hline Northwest & Southeast & 2.7740 & 0.74 & 1.36 & 1.61 \\
\hline
\end{tabular}

\section{B.5 Chemical Analysis Methods}

This section describes the analytical methods used to characterize the chemical compositions of the waste simulants, dry blend components, Cast Stone specimens, and leachates from the EPA Draft Method 1315 (2012) leach tests.

\section{B.5.1 Sample Preparation- Microwave Digestion}

The three dry materials used to make Cast Stone were individually chemically digested at PNNL to determine their elemental composition. Microwave-assisted strong acid digestions were conducted using a combination of $16 \mathrm{M} \mathrm{HNO}_{3}(\sim 17 \mathrm{wt} \%), 12 \mathrm{M} \mathrm{HCl}(7 \mathrm{wt} \%), 32 \mathrm{M} \mathrm{HF}$ (3.3 wt\%), 0.5 grams of $\mathrm{H}_{3} \mathrm{BO}_{3}(1.5 \mathrm{wt} \%$ ), and deionized water (DIW; $71.2 \mathrm{wt} \%$ ). The dry materials were first pulverized to powders and digested following the PNNL-AGG-MARS-001 ${ }^{1}$

\footnotetext{
${ }^{1}$ Lindberg MJ. 2011. "Operation of the MARS 5 Microwave Accelerated Reaction System." AGG-MARS-001
} (Rev. 3), unpublished PNNL Technical Procedure, Pacific Northwest National Laboratory, Richland, Washington. 
method, which was modified from EPA Draft Method 3052 (EPA 1996). The dry materials solid-acid mixture ratio $(0.1 \mathrm{~g} / 35 \mathrm{~mL})$ was typically reacted for 1 hour at $90 \pm 5^{\circ} \mathrm{C}$. Upon complete dissolution of the sample, the resulting solution was centrifuged, filtered through a $0.45-\mu \mathrm{m}$ membrane, and analyzed for trace metals using inductively coupled plasma-mass spectroscopy (ICP-MS) and major cations using inductively coupled plasma-optical emission spectroscopy (ICP-OES). The results of the elemental composition measurements were converted to elemental oxide composition to estimate the mass balance of each solid.

\section{B.5.2 Sample Preparation, Cations- Lithium Tetraborate Fusion}

The dry materials used to make Cast Stone were chemically digested to determine the elemental composition. The powdered samples were prepared following the Savannah River National Laboratory (SRNL) L29, ITS-0070 method (SRNL 2010). Samples were pulverized using a Wig $\mathrm{L}$ Bug grinding mill with agate grinding media. The samples were ground to a fine powder to increase the surface area of the sample that comes in contact with the flux material. The $\mathrm{Li}_{2} \mathrm{~B}_{4} \mathrm{O}_{7}$ flux is prepared in $50-\mathrm{ml}$ platinum crucibles by adding $0.1 \mathrm{~g}$ of sample to the crucible and $0.5 \mathrm{~g}$ of $\mathrm{Li}_{2} \mathrm{~B}_{4} \mathrm{O}_{7}$. The sample is mixed and another $0.5 \mathrm{~g}$ of sample is added on top of the mixed sample. The crucible is placed in a furnace at $1000^{\circ} \mathrm{C}$ for 30 minutes and then taken out to cool. A stir bar is added to the crucible after cooling and $20 \mathrm{ml}$ of $4 \%$ nitric acid and $2 \mathrm{ml}$ of concentrated $\mathrm{HCl}$ are added to the crucible. The sample is placed on a heater/stir plate set at $90^{\circ} \mathrm{C}$. After the sample has dissolved, the contents are poured into a 100-ml volumetric flask and the volume is brought to $100 \mathrm{ml}$ with DIW.

\section{B.5.3 Sample Preparation, Anions- Potassium Hydroxide Fusion}

For anion analyses, a 1-g sample of the pulverized sample is added to a $50-\mathrm{ml}$ platinum crucible. Three grams of $\mathrm{KOH}$ are added to the crucible. The crucible is then placed in a heating block set at $360^{\circ} \mathrm{C}$. The heating block is placed on a gyratory shaker set at $125 \mathrm{rpm}$. The flux is heated and shaken for at least 1 hour or until the sample solidifies. The crucible is then removed, allowed to cool and a stir bar is added. Ten milliliters of DIW are added to the crucible and the sample is stirred for 30 minutes at $90^{\circ} \mathrm{C}$. The sample digestion is then transferred to a $50-\mathrm{ml}$ volumetric flask and brought to volume with DIW.

\section{B.5.4 Percent Solids}

The percent solids of dry blend materials and cured Cast Stone was determined gravimetrically by drying a $10 \mathrm{-g}$ aliquot of the material in an oven at $105^{\circ} \mathrm{C}$. The sample is dried to a constant weight and the percent solid is calculated by the mass change before and after drying.

\section{B.5.5 Major Cation Analysis}

At Pacific Northwest National Laboratory (PNNL), major cation analysis (including Al, Si, Ca, $\mathrm{Mg}, \mathrm{Na}, \mathrm{K}, \mathrm{Fe}$, and $\mathrm{Mn}$ ) for both solids digestates and solution leachates were performed using a Perkin Elmer OPTIMA 3300 DV (Waltham, MA) inductively coupled plasma-atomic emission spectrometer (ICP-AES or ICP-OES) using procedure PNNL-AGG-ICP-AES, Determination of Element by ICP-AES, ${ }^{1}$ which is similar to Test Methods for Evaluating Solid Wastes: Physical/Chemical Methods SW-846 6010C (EPA 2007a). High-purity calibration standards

\footnotetext{
${ }^{1}$ Baum SR. 2008. "Inductively Coupled Plasma - Optical Emission Spectrometry (ICP-OES) Analysis." PNNL-AGG-ICP-AES (Rev. 2), unpublished PNNL Technical Procedure, Pacific Northwest National Laboratory, Richland, Washington.
} 
were used to generate calibration curves and verify continuing calibration during the analytical run. A serial dilution was made of select samples to investigate and correct for matrix interferences.

At SRNL, elements were analyzed using Agilent's Varian 730-ES® Inductively Coupled PlasmaAtomic Emission Spectrometer (ICP-AES). The instrument is calibrated using matrix matched standards at 1,5 and $10 \mathrm{ppm}$. A glass cyclonic spray chamber and a glass Meinhard $\mathrm{C} 3{ }^{\circledR}$ concentric nebulizer are used. Gas flow rates consist of a plasma gas at $16.5 \mathrm{~L} / \mathrm{min}$, auxiliary gas at $1.5 \mathrm{~L} / \mathrm{min}$, and the nebulizer gas at $1.2 \mathrm{~L} / \mathrm{min}$. The radio frequency generator is set at $1.2 \mathrm{~kW}$. The sample digestion is diluted by $10 \mathrm{X}$ in a $\mathrm{Li}_{2} \mathrm{~B}_{4} \mathrm{O}_{7}$ matrix blank for elements greater than $1 \mathrm{wt} \%$ and the sample digestion is also run straight for elements that are less than $1 \mathrm{wt} \%$. Elemental concentrations are reported as a wt $\%$ element and also $w t \%$ elemental oxide.

\section{B.6 Anion Analysis}

Anions are run on a Dionex ICS-5000 capillary ion chromatography (IC) system at both national laboratories. A gradient run using $0.2 \mathrm{mM}$ to $35 \mathrm{mM}$ of $\mathrm{KOH}$ is used. The anions run on the $\mathrm{KOH}$ digestion are nitrite, nitrate, fluoride, chloride, and oxalate. The instrument is calibrated using 1,5 and $10 \mathrm{ppm}$ of each anion in water. The flux is filtered and a $100 \mathrm{X}$ dilution from the filtrate in water is made to run through the instrument for analyses.

\section{B.7 Trace Metals Analysis}

Trace metals for both solids digestates and solution leachates were measured at PNNL using a Perkin Elmer ELAN DRC II (Waltham, MA) inductively coupled plasma-mass spectrometer (ICP-MS) following procedure PNNL-AGG-415, "Inductively Coupled Plasma Mass Spectrophotometry (ICP-MS) Analysis,"1 which is similar to Test Methods for Evaluating Solid Wastes: Physical/Chemical Methods (SW-846 6020A; EPA 2007b). High-purity calibration standards were used to generate calibration curves and verify continuing calibration during the analytical run. A serial dilution was made of select samples to investigate and correct for matrix interferences. Typical instrument detection limits for trace metals using this ICP-MS are in the parts per trillion range.

\section{B.8 Uranium, Technetium, and Iodine Analysis}

Uranium, Tc, and iodine in the Cast Stone (after microwave digestion for $\mathrm{U}$ and $\mathrm{Tc}$ and fusion for iodine) and EPA Draft Method 1315 leachates were also measured at PNNL using a Perkin Elmer ELAN DRC II (Waltham, MA) ICP-MS following procedure PNNL-AGG-415, "Inductively Coupled Plasma Mass Spectrophotometry (ICP-MS) Analysis,"1 which is similar to Test Methods for Evaluating Solid Wastes: Physical/Chemical Methods (SW-846 6020A; EPA 2007b).

\section{B.9 Total Carbon Analysis}

The total carbon content of the dry materials used to make the dry blend was determined at PNNL directly using a Shimadzu Carbon analyzer Model TOC-V CSN with a SSM-5000A following procedure AGG-TOC-001 Operating of Carbon Analyzer ${ }^{2}$ (TOC-V + SSM-5000A + ASI (Shimadzu)), which is similar to ASTM Method E1915-01 Standard Test Methods for Analysis of

\footnotetext{
${ }^{1}$ Clayton E. 2008. "Inductively Coupled Plasma Mass Spectrometric (ICP-MS) Analysis.” PNNL-AGG-415 (Rev. 2), unpublished PNNL Technical Procedure, Pacific Northwest National Laboratory, Richland, Washington.

${ }^{2}$ Kutnyakov IK. 2004. "Operating of Carbon Analyzer (TOC-V + SSM-500A +ASI (Shimadzu))." AGG-TOC-001 (Rev. 0), unpublished PNNL Technical Procedure, Pacific Northwest National Laboratory, Richland, Washington.
} 
Metal Bearing Ores and Related Materials by Combustion Infrared Absorption Spectrometry (ASTM E1915 2001). The sample is combusted at $900^{\circ} \mathrm{C}$ with an oxidative catalyst. The carbon is converted to $\mathrm{CO}_{2}$ and measured using a non-dispersive infrared gas analyzer.

\section{B.10 Powder X-ray Diffraction}

At PNNL, X-ray diffraction was used to characterize a portion of the dry material. X-ray diffractograms were collected using a Rigaku Ultima IV X-ray diffractometer with $\mathrm{Cu}-\mathrm{Ka}$ radiation X-ray tube and a graphite monochromator. Data were collected in the $2 \Theta$ range: $2-65^{\circ}$ with a scanning step size of $0.05^{\circ} 2 \Theta$ and a 4-second dwell time. The data were analyzed with the computer program JADE (MDI, Livermore, CA combined with the Joint Committee on Powder Diffraction Standards, International Center for Diffraction Data (ICDD) Newtown Square, PA database).

At SRNL, samples were ground in an agate mortar and pestle to reduce the particle size and to homogenize the samples. The ground powder was placed on a glass slide. A few drops of a 10\% Amyl Acetate/Collodion solution was added to the ground powder to fix the powder to the glass slide.

At SRNL, X-ray diffraction data were collected on a Bruker D8 X-ray diffractometer by step scanning over the $2 \Theta$ ranges of $5-70^{\circ}$ with a step size of $0.02^{\circ}$ and a dwell time of 1 second. All the instrument parameters are listed in the Table B-5 below. Search-match identification of all the phases was performed using Jade software (Version 9.0) from Materials Data Inc. combined with the ICDD's PDF-4 database.

Table B-5. Instrument Parameters

\begin{tabular}{||l|l||}
\hline Radiation Source & $\mathrm{CuK \alpha}$ X-ray \\
\hline Source Power & $45 \mathrm{kV}, 40 \mathrm{~mA}$ \\
\hline Wavelength & $1.5405982 \AA$ \\
\hline Goniometer & Bruker D8 \\
\hline Divergence Slit & $1^{\circ}$ \\
\hline Divergence Soller Slit & None \\
\hline Divergence Antiscatter & $1^{\circ}$ \\
\hline Specimen Rotation & No \\
\hline Diffracted Beam Antiscatter & $1^{\circ}$ \\
\hline Diffracted Beam Soller Slit & $2^{\circ}$ \\
\hline Secondary Monochromator & Curved pyrolytic graphite \\
\hline Receiving Slit & $0.15^{\circ}$ \\
\hline Detector & NaI Scintillation \\
\hline $2 \theta$ Range & $5^{\circ}-70^{\circ}$ \\
\hline Step Interval & $0.02^{\circ}(2 \Theta)$ \\
\hline Fixed Counting Time & $1 \mathrm{~s} /$ step \\
\hline
\end{tabular}

\section{B.11 Surface Area}

The BET method of surface area measurement is based on the phenomenon of physical adsorption. At liquid nitrogen temperatures, nitrogen gas will adsorb to the surface of a solid due to physical forces of attraction between the adsorbent (solid) and the adsorbate (gas). These forces, which are essentially electrostatic in nature, are often called Van der Waals forces. The 
quantity, or number of moles, of gas adsorbed at some equilibrium point is a function of the equilibrium vapor pressure of nitrogen in the system. The so-called BET method (1938) quantifies the amount of gas adsorbed at various equilibrium pressures in terms of the deposition of a monomolecular layer of gas followed by successive additional layers as the equilibrium pressure is progressively increased upwards to saturation - approximately 760 torr for nitrogen at liquid nitrogen temperature. Adsorption isotherms are measured as the quantity (moles) of gas adsorbed versus relative pressure, defined as the equilibrium pressure divided by the saturated vapor pressure of nitrogen.

During a surface area measurement, the sample is heated under vacuum to remove volatiles, usually water, from the material. The sample tube containing the sample is then pumped to high vacuum and the free volume of the sample/sample tube system is measured with helium. The sample is again evacuated to high vacuum and the saturated vapor pressure of nitrogen is measured in a separate tube before the adsorption measurement begins.

An adsorption isotherm is measured as follows. Nitrogen gas is dosed into the initially evacuated sample tube in measured quantities. At equilibrium, the amount adsorbed is simply the total quantity of gas that has been dosed into the system minus the quantity remaining in the free volume. This process is repeated for a number of equilibrium points from about 0.05 relative pressure up to 0.3 . The data are plotted according to the BET equation, and $1 /($ slope + intercept) gives the number of moles of gas in a monolayer. The total surface area is then calculated using 16.2 Angstroms squared as the area occupied by one nitrogen molecule, and the specific surface area in meters squared per gram $\left(\mathrm{m}^{2} / \mathrm{g}\right)$ is obtained by dividing the total area by the sample mass.

\section{B.12 Particle Size Distribution}

The Microtrac X-100 particle size analyzer uses a wet sample delivery controller (recirculator) to disperse the sample uniformly in a fluid and deliver the sample to the analyzer. This wet sample delivery controller in its basic form consists of a reservoir where the sample is introduced, a fluid pump, a valve to the drain system, and the necessary tubing connections to the analyzer. The flow through the analyzer sample cell is always from the bottom to the top. A laser beam is projected through a transparent quartz cell containing a stream of moving particles suspended in DIW. Light from the laser strikes the particles and is scattered through various angles. The scattering angles and intensities of the scattered light are measured by two photodiode arrays producing electronic signals proportional to the measured light flux. The Microtrac proprietary mathematical software processes the signals to obtain a particle size distribution. Upon completion of the analysis, the Microtrac generates a report containing the tabular data, a histogram plot of the data, and various instrument parameters.

\section{B.13 Particle Density}

The density of the dry blend particles was measured using a Quantachrome Multipycnometer (SRNL Manual L29, ITS-0168). The density is determined by measuring the pressure difference when a known quantity of helium under pressure is allowed to flow from a known volume into a sample cell of known volume to which the solid or powdered material has been added. The density is then calculated by dividing the mass of the sample analyzed by the measured volume.

\section{B.14 Fill and Tap Density}

A Quantachrome Autotap was used to measure the tap density of dry blend components. Samples were placed in 250-ml graduated cylinders and mounted on a universal tap platform. After noting the initial volume and weight of the material, the sample was tapped 300 times. When 
the tapping was completed the powder volume was read. Automatic rotation of cylinders during tapping promoted a flat powder interface.

\section{B.15 Simultaneous Thermal Analysis}

A Netzsch STA 409 Luxx, which couples differential scanning calorimetry (DSC) with thermal gravimetric analysis (TGA), was used at SRNL for determining the thermal response of the dry blend components. After loading the sample, the chamber was purged with nitrogen at $60 \mathrm{ml} / \mathrm{min}$ prior to heating. Samples were heated at $5^{\circ} \mathrm{C} / \mathrm{min}$ up to $650^{\circ} \mathrm{C}$ in a flowing nitrogen atmosphere of $60 \mathrm{ml} / \mathrm{min}$. 
PNNL-22747

SRNL-STI-2013-00465

Appendix C. Cast Stone Processing Properties Data 
This appendix contains data related to Cast Stone flow properties (flow diameter), gel time, slurry/paste rheology properties (yield stress and plastic viscosity), heat-of-hydration properties (heat generation at 300 hours, time to peak heat generation, and heat generation at peak), and bleed water measurements. All of these property measurements were made at Savannah River National Laboratory (SRNL) using samples of the Cast Stone mixes prepared by SRNL. However, 12 of the original 26 mixes in Table 2-1 were mistakenly made with the wrong source of blast furnace slag (BFS), as shown in Table 6-1. Additional samples of the 12 originally intended mixes (i.e., with the intended sources of BFS) were made by SRNL and all processing properties were measured for these 12 mixes. Hence, for all processing properties, there were 38 Cast Stone formulations prepared and property values measured. Table C- 1 lists the parameter combinations for the 38 Cast Stone mixes. Table C-2 shows these mixes in a matrix display. 
Table C-1. Test Matrix Used by SRNL for Cast Stone Processing and Curing Properties

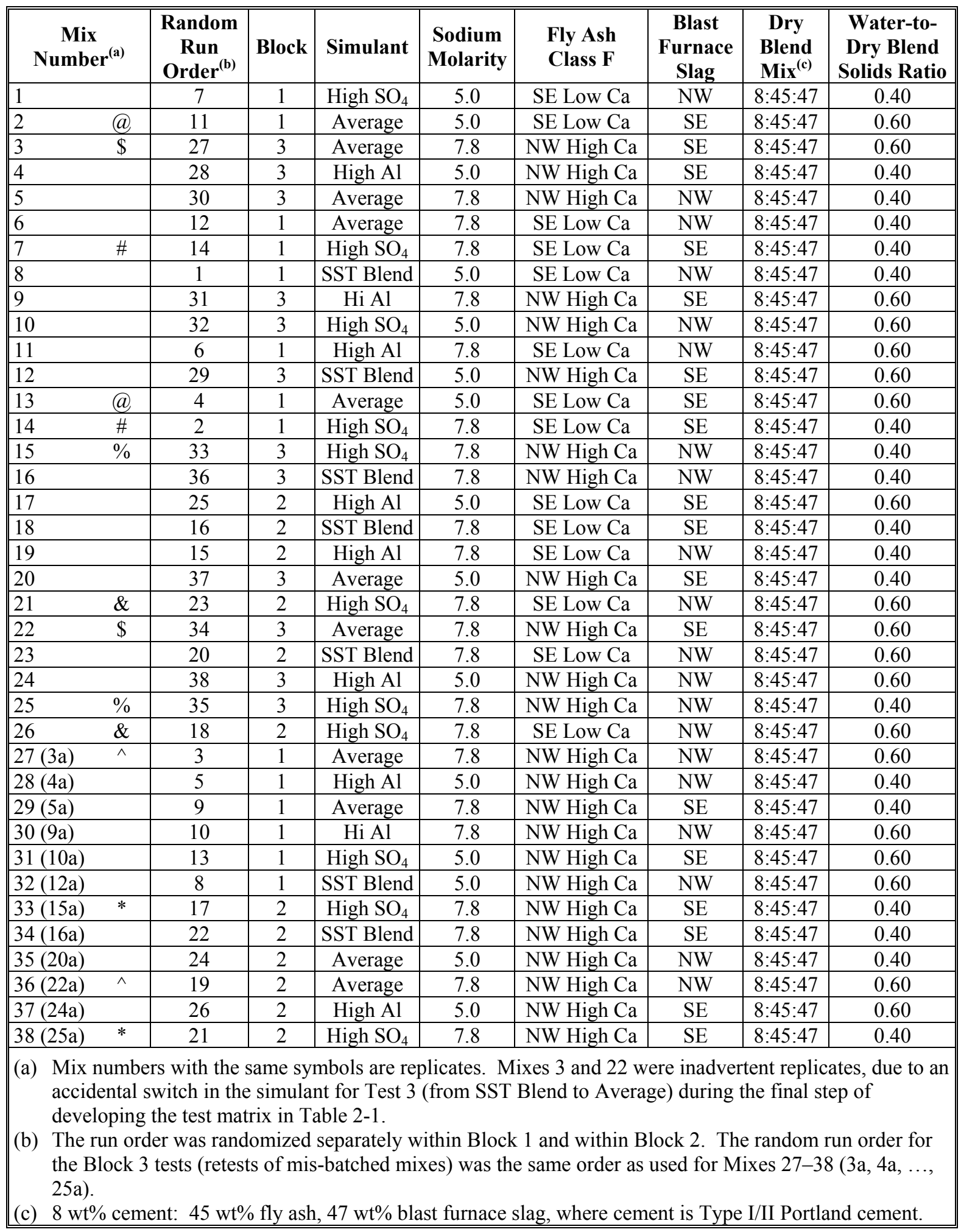


Table C-2. Test Matrix for Cast Stone Processing Properties of 38 Cast Stone Mixes

\begin{tabular}{|c|c|c|c|c|c|c|c|c|}
\hline & \multicolumn{8}{|c|}{ Fly Ash Source/Blast Furnace Slag Source (Northwest or Southeast USA) } \\
\hline Waste Composition & $\mathbf{N W / N W}$ & NW/SE & SE/NW & SE/SE & $\mathbf{N W / N W}$ & NW/SE & SE/NW & SE/SE \\
\hline Average $5 \mathrm{M}$ & 35 (20a) & 20 & & & & & & $\begin{array}{c}13 \\
2\end{array}$ \\
\hline $\mathrm{High} \mathrm{SO}_{4} 5 \mathrm{M}$ & & & 1 & & 10 & 31 (10a) & & \\
\hline High Al 5M & $28(4 a)$ & 4 & & & 24 & 37 (24a) & & 17 \\
\hline SST Blend $5 \mathrm{M}$ & & & 8 & & 32 (12a) & 12 & & \\
\hline Average $7.8 \mathrm{M}$ & 5 & $29(5 a)$ & 6 & & $\begin{array}{c}27(3 a) \\
36(22 a)\end{array}$ & $\begin{array}{c}3 \\
22 \\
\end{array}$ & & \\
\hline High $\mathrm{SO}_{4} 7.8 \mathrm{M}$ & $\begin{array}{l}15 \\
25 \\
\end{array}$ & $\begin{array}{l}33 \text { (15a) } \\
38 \text { (25a) }\end{array}$ & & $\begin{array}{c}14 \\
7 \\
\end{array}$ & & & $\begin{array}{l}26 \\
21 \\
\end{array}$ & \\
\hline High Al 7.8M & & & 19 & & 30 (9a) & 9 & 11 & \\
\hline SST Blend 7.8M & 16 & 34 (16a) & & 18 & & & 23 & \\
\hline Mix Ratio (w/dry mix) & 0.4 & 0.4 & 0.4 & 0.4 & 0.6 & 0.6 & 0.6 & 0.6 \\
\hline
\end{tabular}

Original Mix No.

Mix No. (intended Mix)

Test Combination

Replicate 
C.1 Average Flow Diameters

Table C-3 lists the average flow diameters for the 38 Cast Stone mixes.

Table C-3. Average Flow Diameter of 38 Cast Stone Mixes

\begin{tabular}{|c|c|c|c|c|}
\hline \multicolumn{2}{|c|}{ Mix Number ${ }^{(a)}$} & \multirow{2}{*}{$\begin{array}{c}\begin{array}{c}\text { Random Run } \\
\text { Number }\end{array} \\
7\end{array}$} & \multirow{2}{*}{$\begin{array}{c}\begin{array}{c}\text { Average Flow Diameter } \\
(\mathbf{m m})^{(\mathbf{b})}\end{array} \\
93.5 \\
\end{array}$} & \multirow{2}{*}{$\begin{array}{c}\begin{array}{c}\text { Water-to-Dry-Blend } \\
\text { Ratio }\end{array} \\
0.40\end{array}$} \\
\hline 1 & & & & \\
\hline 2 & (a) & 11 & 228.1 & 0.60 \\
\hline 3 & $\$$ & 27 & 260.7 & 0.60 \\
\hline 4 & & 28 & 131.8 & 0.40 \\
\hline 5 & & 30 & 125.1 & 0.40 \\
\hline 6 & & 12 & 119.6 & 0.40 \\
\hline 7 & \# & 14 & 138.9 & 0.40 \\
\hline 8 & & 1 & 108.0 & 0.40 \\
\hline 9 & & 31 & 255.5 & 0.60 \\
\hline 10 & & 32 & 238.0 & 0.60 \\
\hline 11 & & 6 & 230.8 & 0.60 \\
\hline 12 & & 29 & 298.3 & 0.60 \\
\hline 13 & (a) & 4 & 203.5 & 0.60 \\
\hline 14 & $\#$ & 2 & 139.9 & 0.40 \\
\hline 15 & $\%$ & 33 & 160.4 & 0.40 \\
\hline 16 & & 36 & 156.5 & 0.40 \\
\hline 17 & & 25 & 248.6 & 0.60 \\
\hline 18 & & 16 & 127.3 & 0.40 \\
\hline 19 & & 15 & 137.7 & 0.40 \\
\hline 20 & & 37 & 121.2 & 0.40 \\
\hline 21 & $\&$ & 23 & 240.4 & 0.60 \\
\hline 22 & $\$$ & 34 & 255.5 & 0.60 \\
\hline 23 & & 20 & 193.3 & 0.60 \\
\hline 24 & & 38 & 245.2 & 0.60 \\
\hline 25 & $\%$ & 35 & 158.6 & 0.40 \\
\hline 26 & $\&$ & 18 & 232.8 & 0.60 \\
\hline $27(3 a)$ & $\wedge$ & 3 & 234.0 & 0.60 \\
\hline $28(4 a)$ & & 5 & 109.0 & 0.40 \\
\hline $29(5 a)$ & & 9 & 158.7 & 0.40 \\
\hline $30(9 a)$ & & 10 & 248.9 & 0.60 \\
\hline $31(10 a)$ & & 13 & 229.4 & 0.60 \\
\hline $32(12 a)$ & & 8 & 242.0 & 0.60 \\
\hline $33(15 a)$ & $*$ & 17 & 163.7 & 0.40 \\
\hline $34(16 a)$ & & 22 & 140.6 & 0.40 \\
\hline 35 (20a) & & 24 & 111.5 & 0.40 \\
\hline $36(22 a)$ & $\wedge$ & 19 & 203.4 & 0.60 \\
\hline $37(24 a)$ & & 26 & 234.0 & 0.60 \\
\hline $38(25 a)$ & $*$ & 21 & 165.0 & 0.40 \\
\hline $\begin{array}{l}\text { (a) Test nur } \\
\text { (b) Values }\end{array}$ & s wi & same symbols a & $\begin{array}{l}\text { plicates. } \\
\text { mal places shown. }\end{array}$ & \\
\hline
\end{tabular}


C.2 Gel Times

Table C-4 lists the measured gel times for the 38 Cast Stone mixes.

Table C-4. Gel Times and Water-to-Dry-Blend Ratios for 38 Cast Stone Mixes

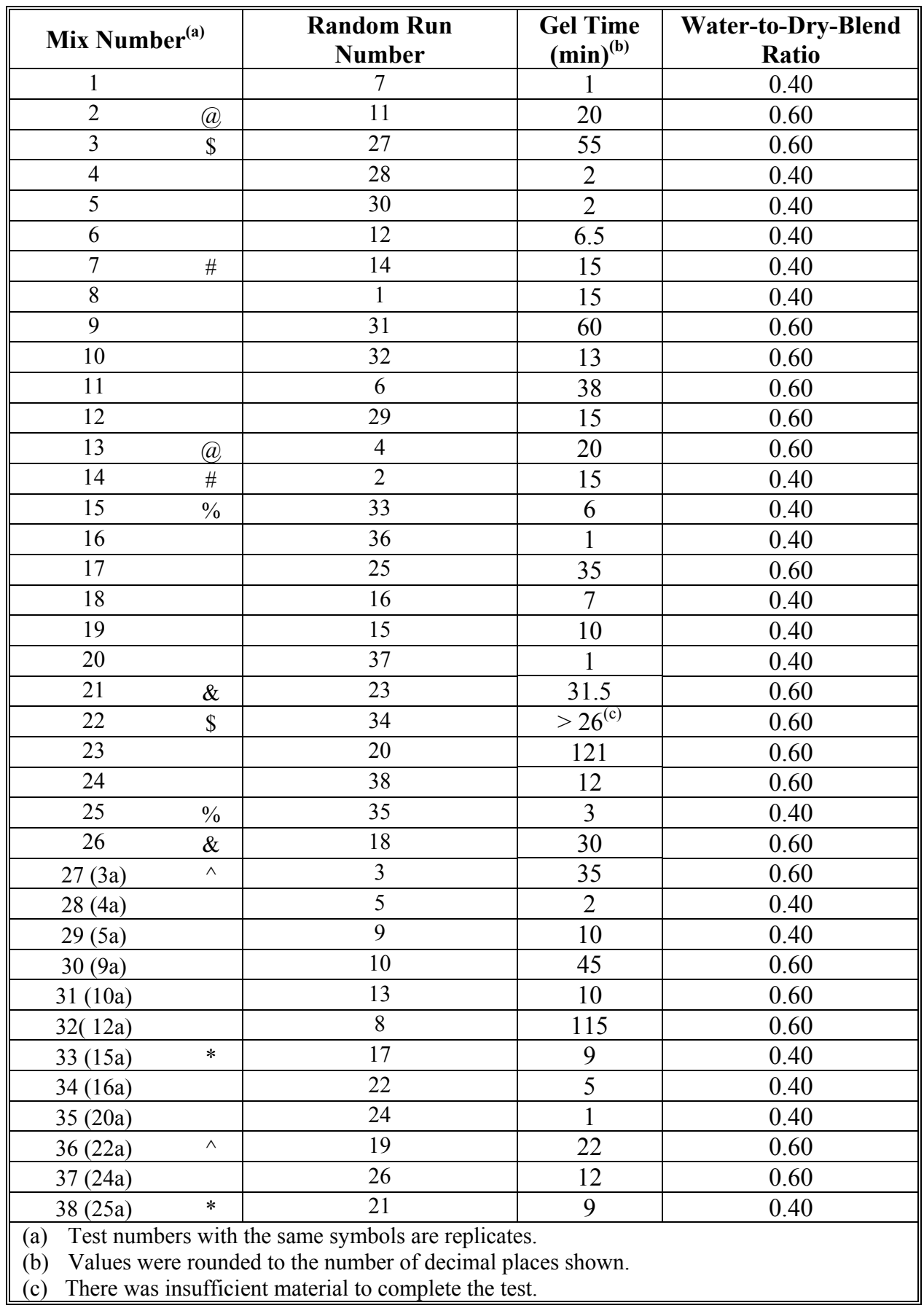




\section{C.3 Set or Hardening Time}

Figure C-1 displays plots of the ultrasonic pulse velocity (UPV) measurements described in Section 6.3. Also on the plots are the Vicat results when it was noted that the sonic velocity was increasing. The two points plotted show the penetration of the needle fully extending to $35 \mathrm{~mm}$ and then not penetrating, indicating "set." See Section 6.3 for further discussion of these data and how they were generated. 

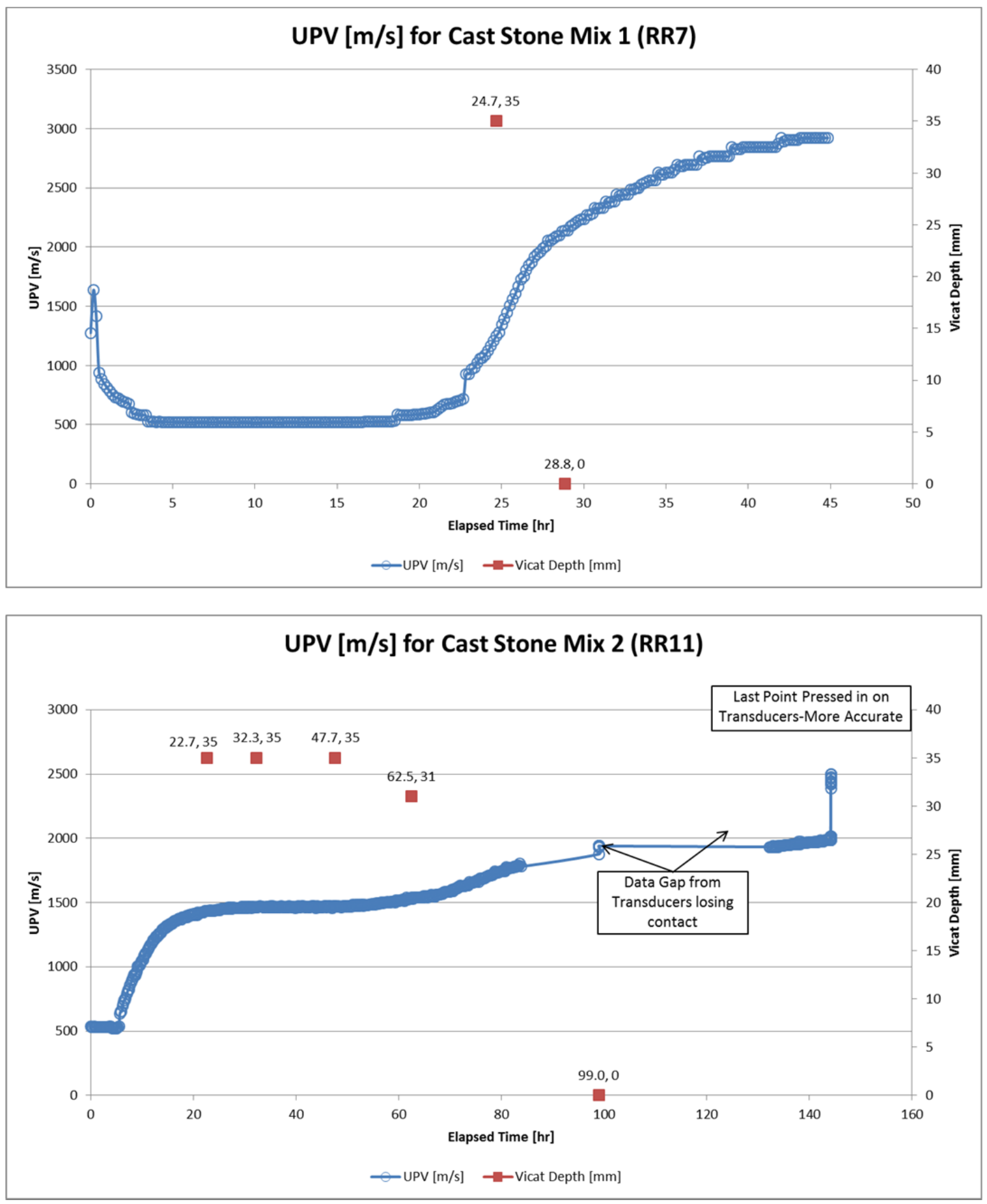

Figure C-1. UPV Data for Cast Stone Mixes to Estimate Set Time 

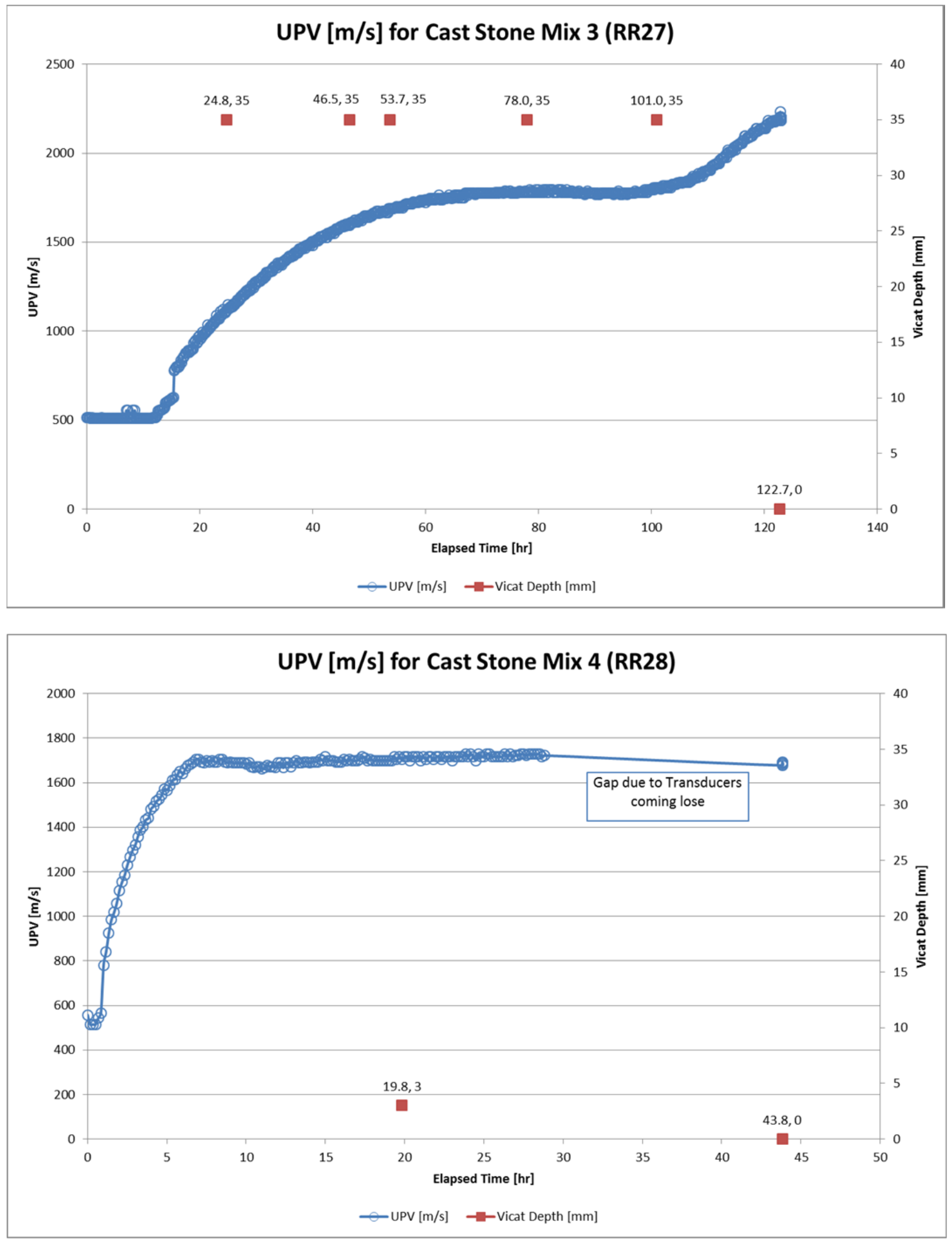

Figure C-1. UPV Data for Cast Stone Mixes to Estimate Set Time (contd) 

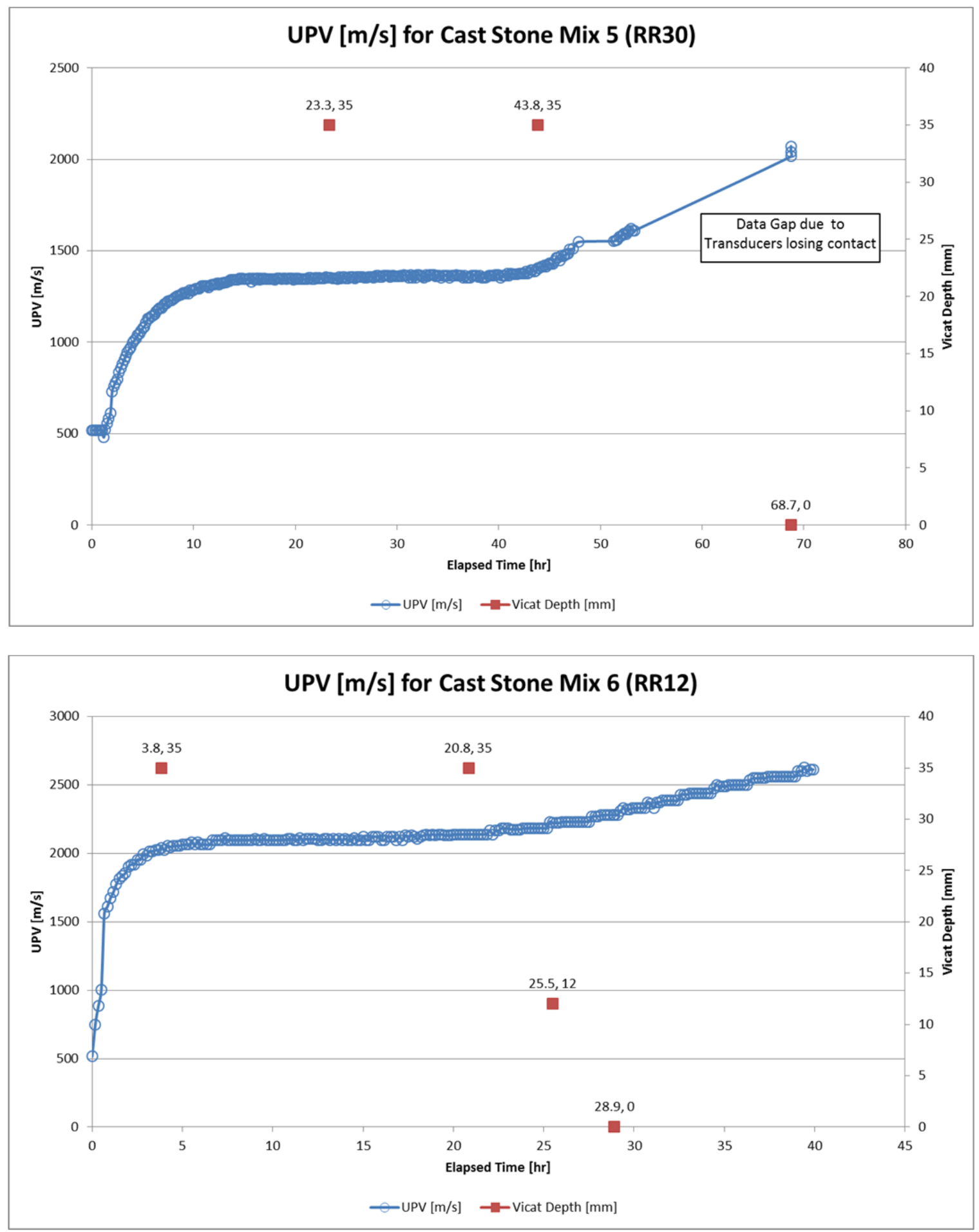

Figure C-1. UPV Data for Cast Stone Mixes to Estimate Set Time (contd) 

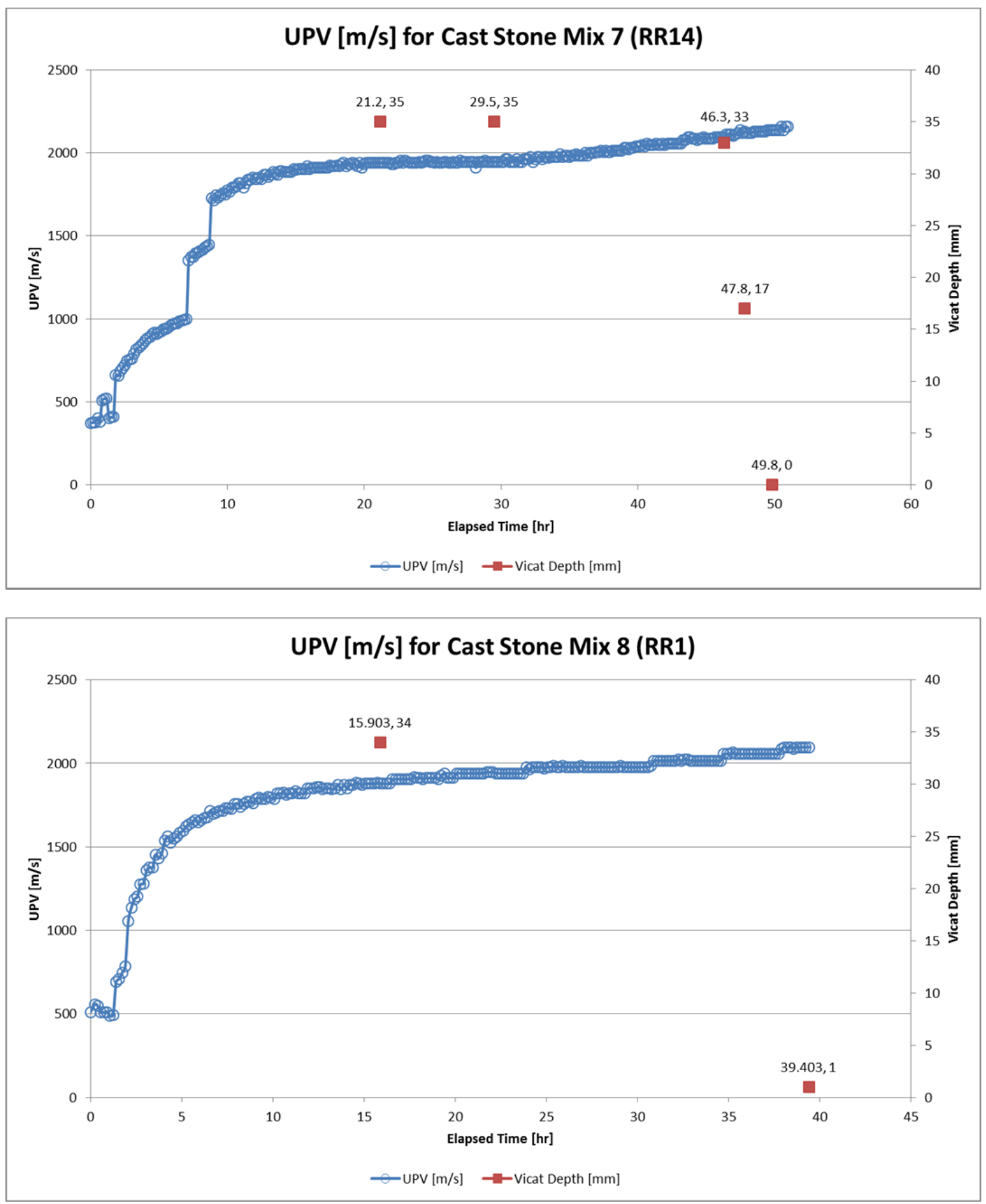

Figure C-1. UPV Data for Cast Stone Mixes to Estimate Set Time (contd) 

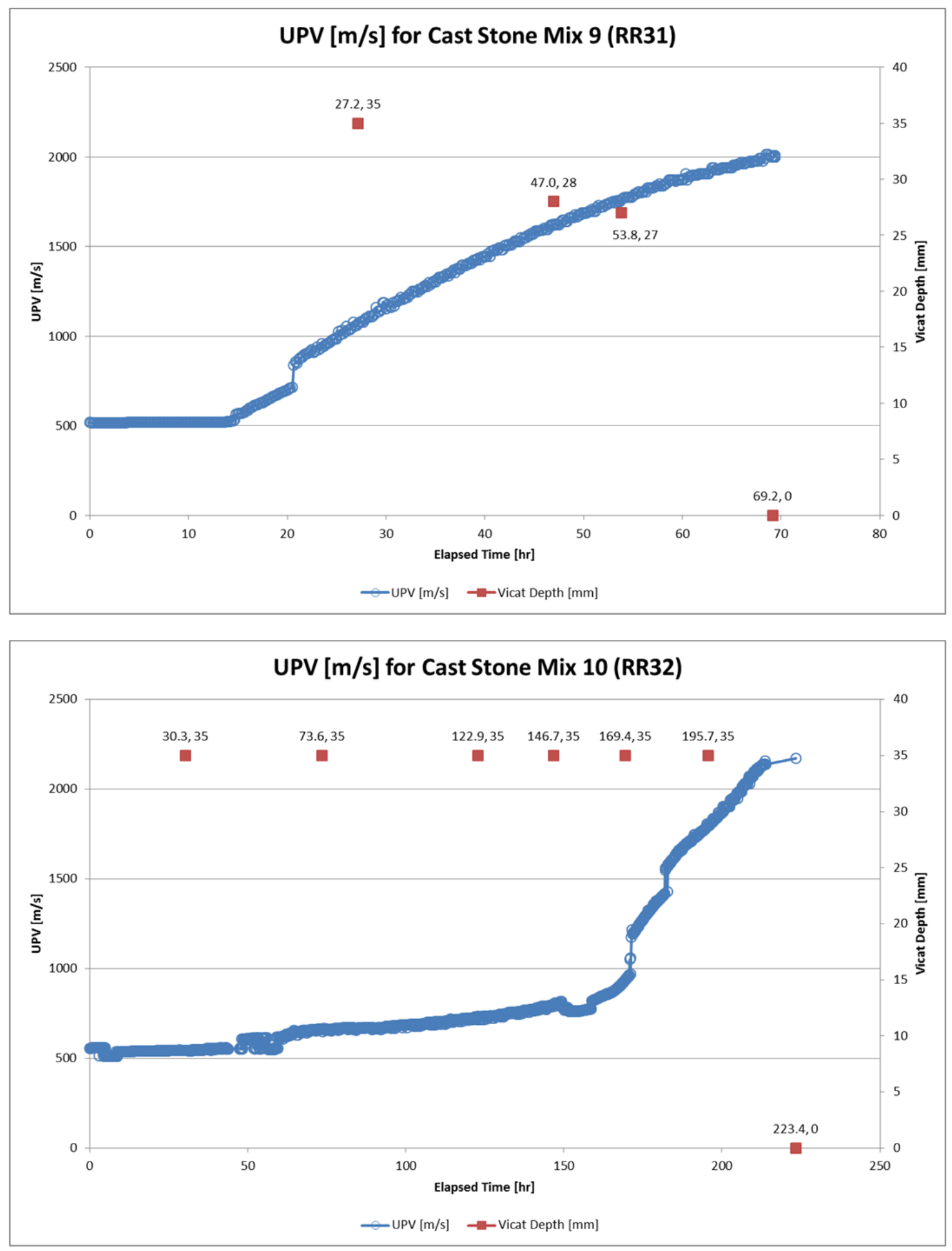

Figure C-1. UPV Data for Cast Stone Mixes to Estimate Set Time (contd) 

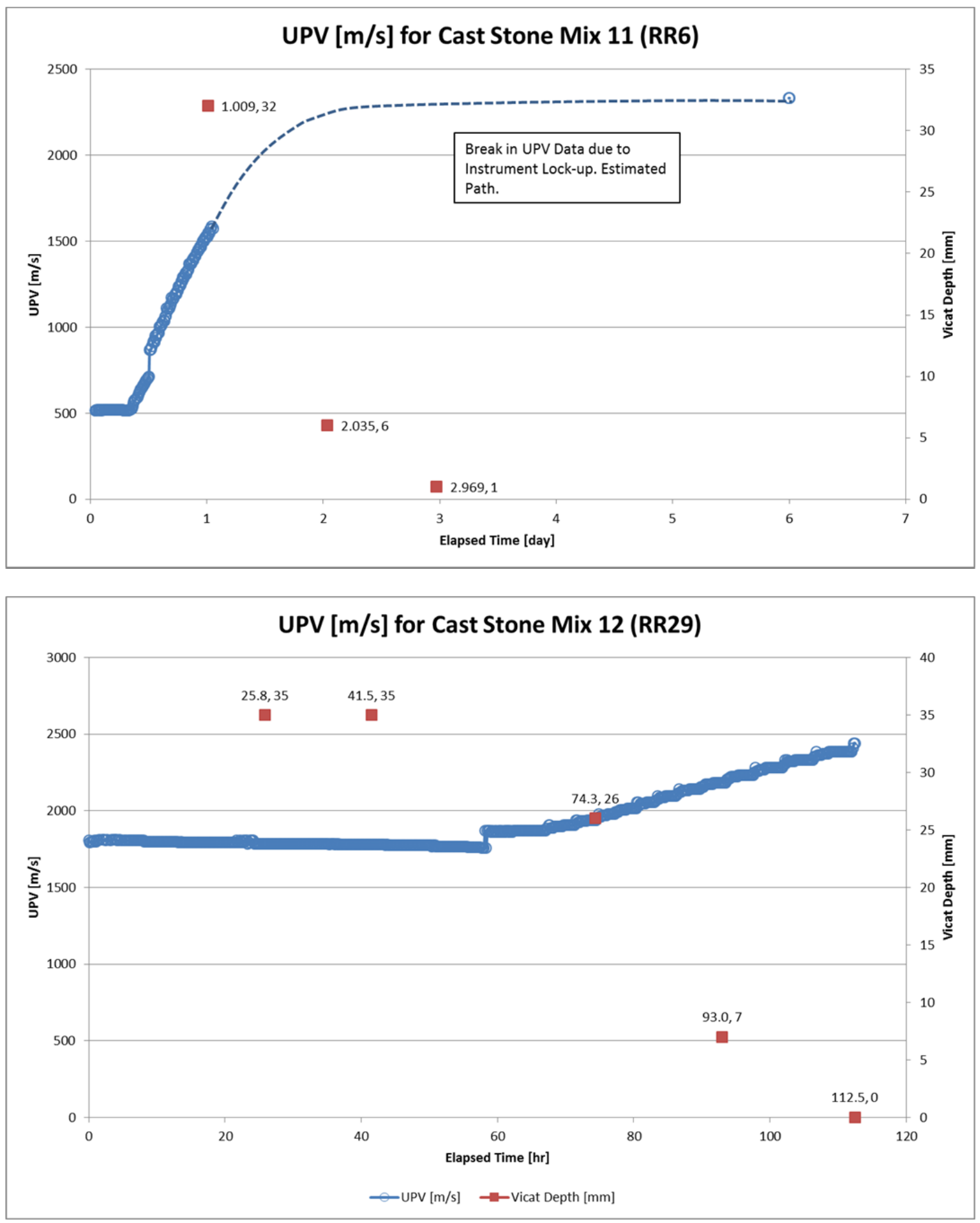

Figure C-1. UPV Data for Cast Stone Mixes to Estimate Set Time (contd) 

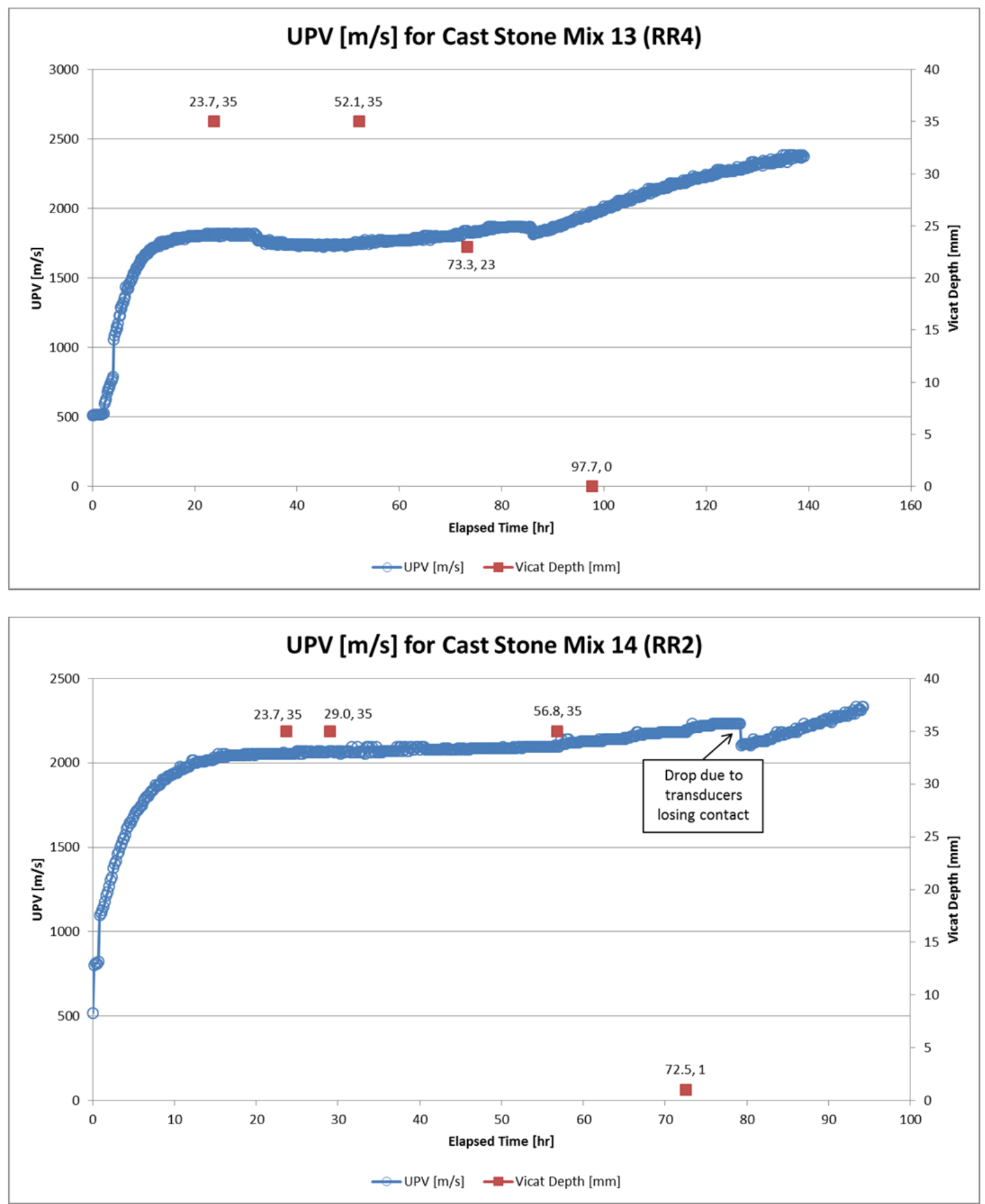

Figure C-1. UPV Data for Cast Stone Mixes to Estimate Set Time (contd) 

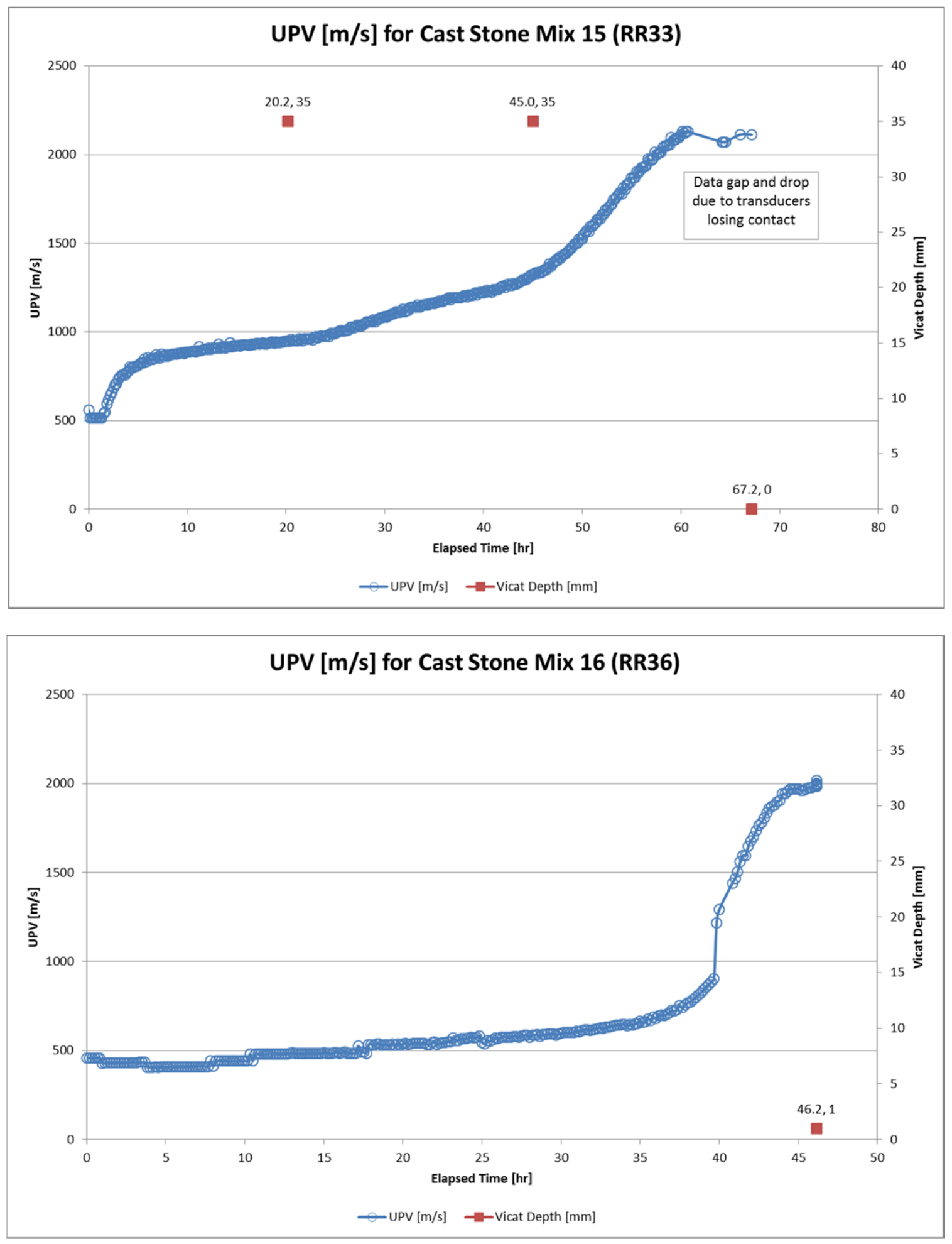

Figure C-1. UPV Data for Cast Stone Mixes to Estimate Set Time (contd) 

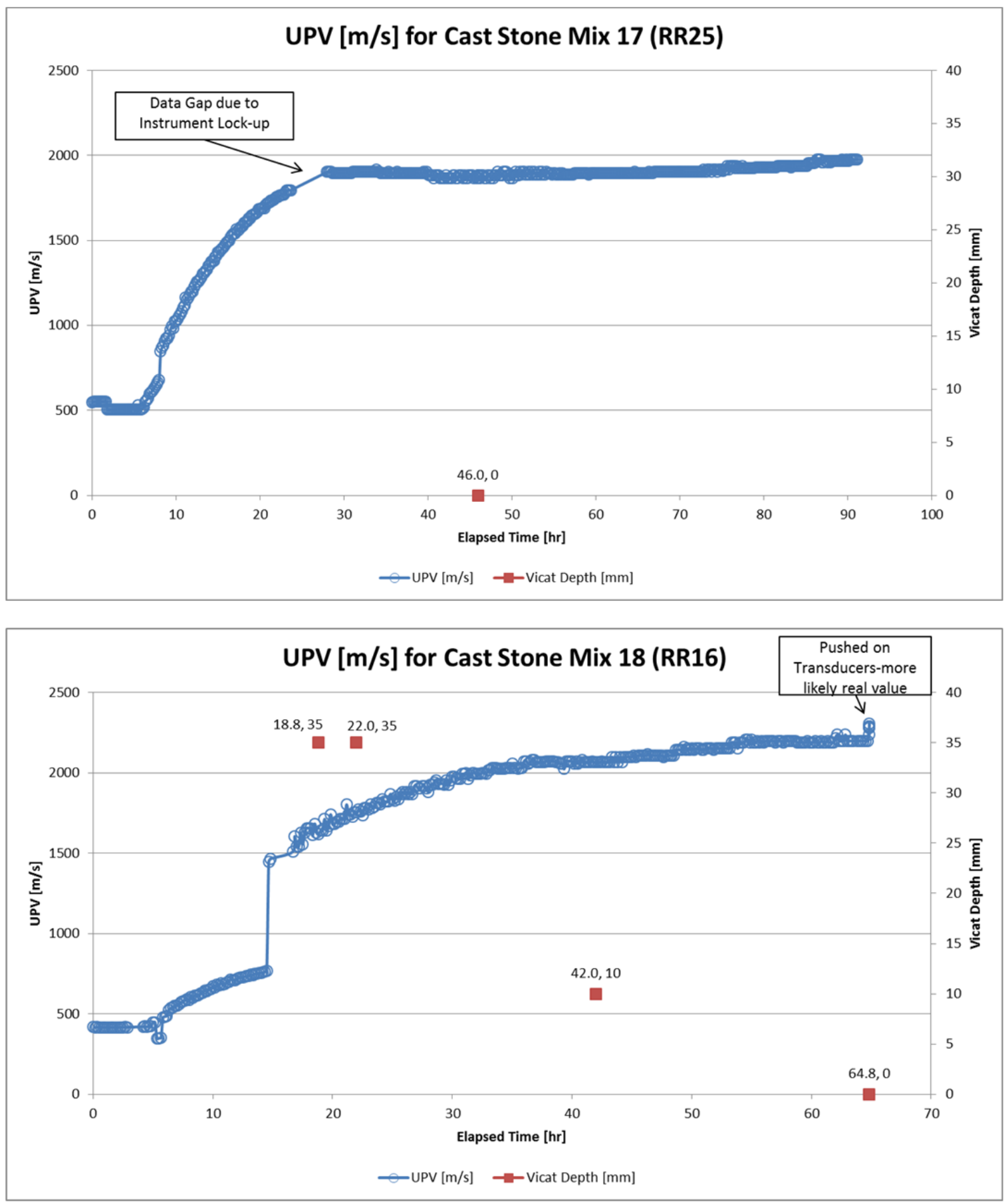

Figure C-1. UPV Data for Cast Stone Mixes to Estimate Set Time (contd) 

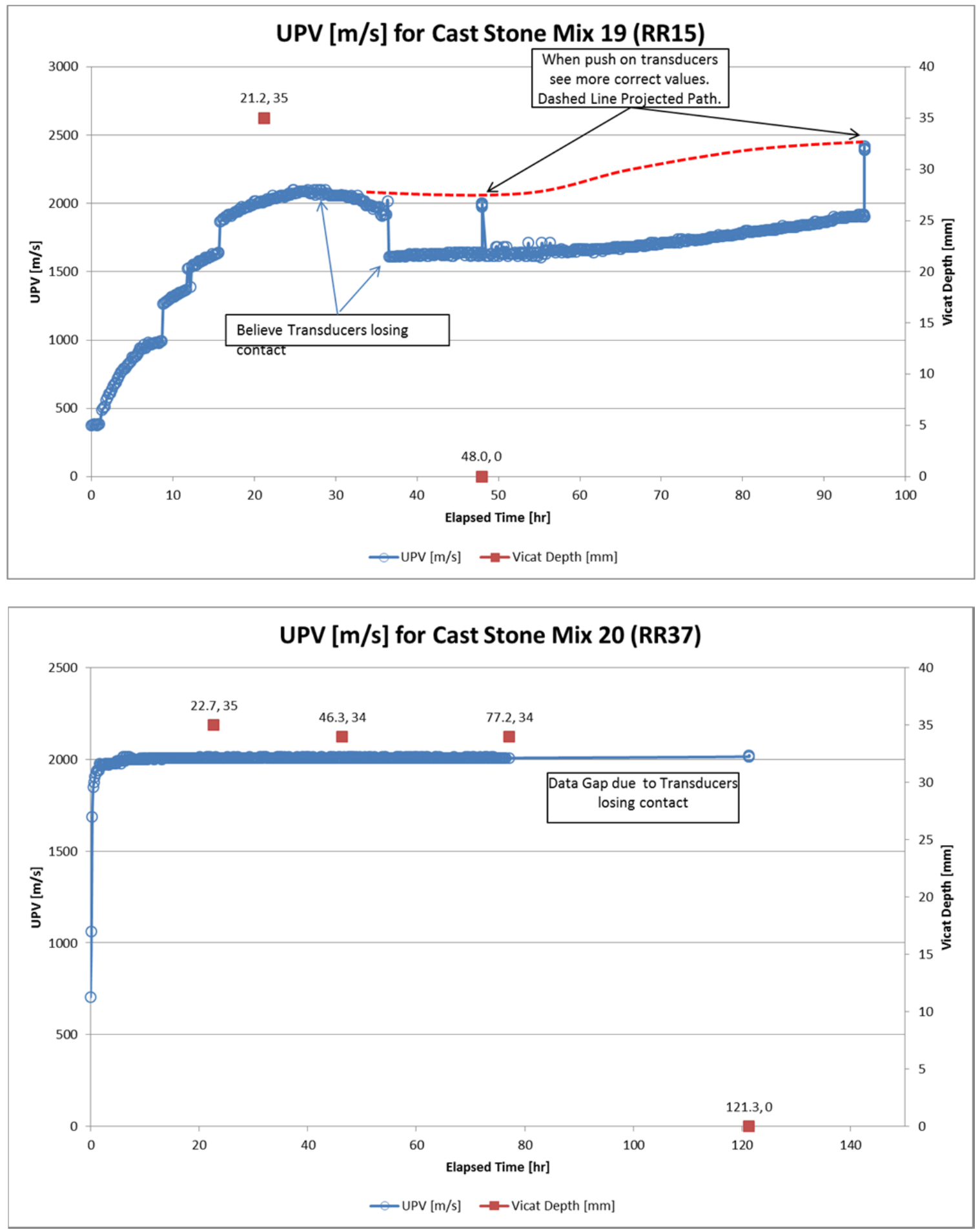

Figure C-1. UPV Data for Cast Stone Mixes to Estimate Set Time (contd) 
PNNL-22747

SRNL-STI-2013-00465
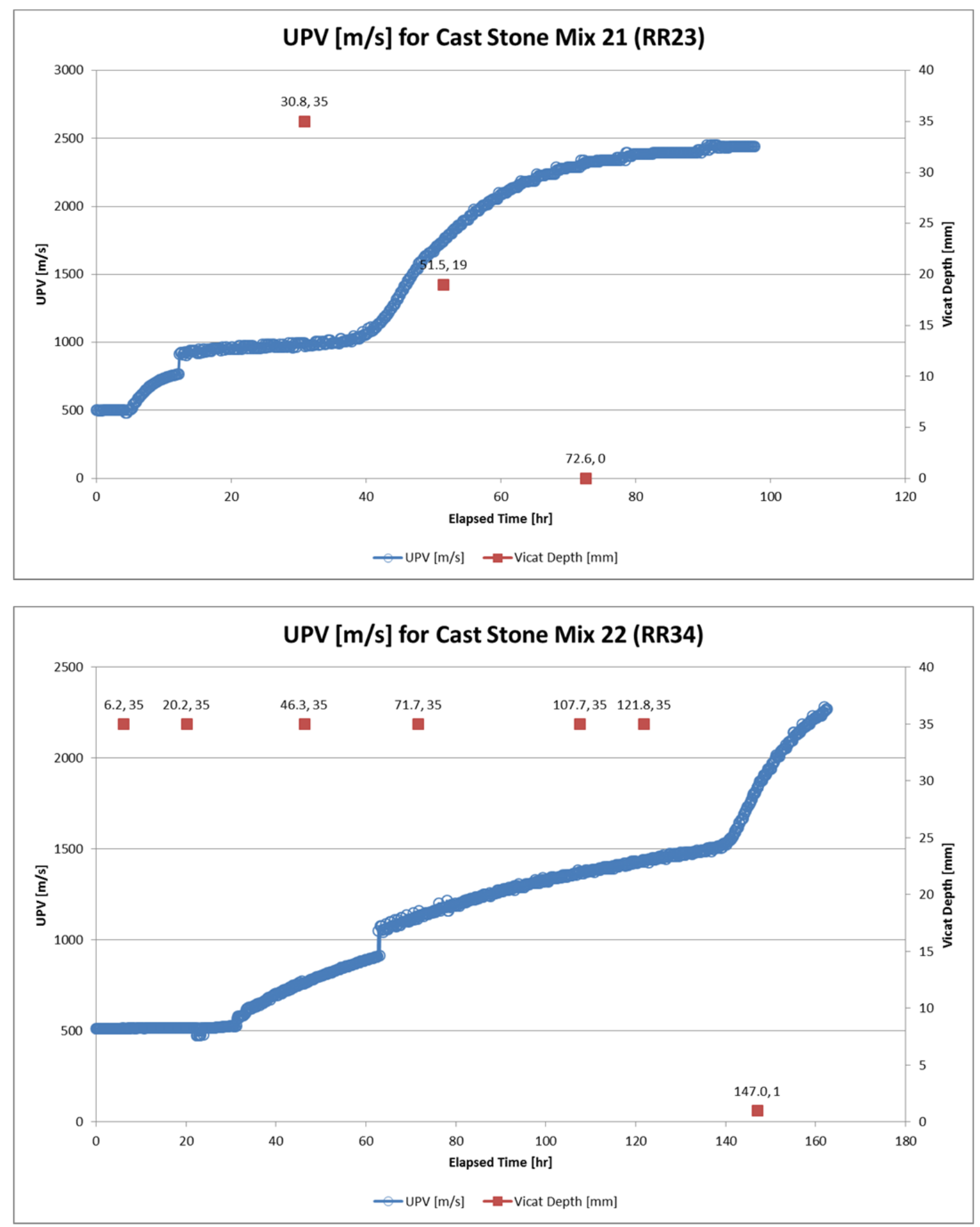

Figure C-1. UPV Data for Cast Stone Mixes to Estimate Set Time (contd)

Page C-18 of $\mathbf{3 1 5}$ 

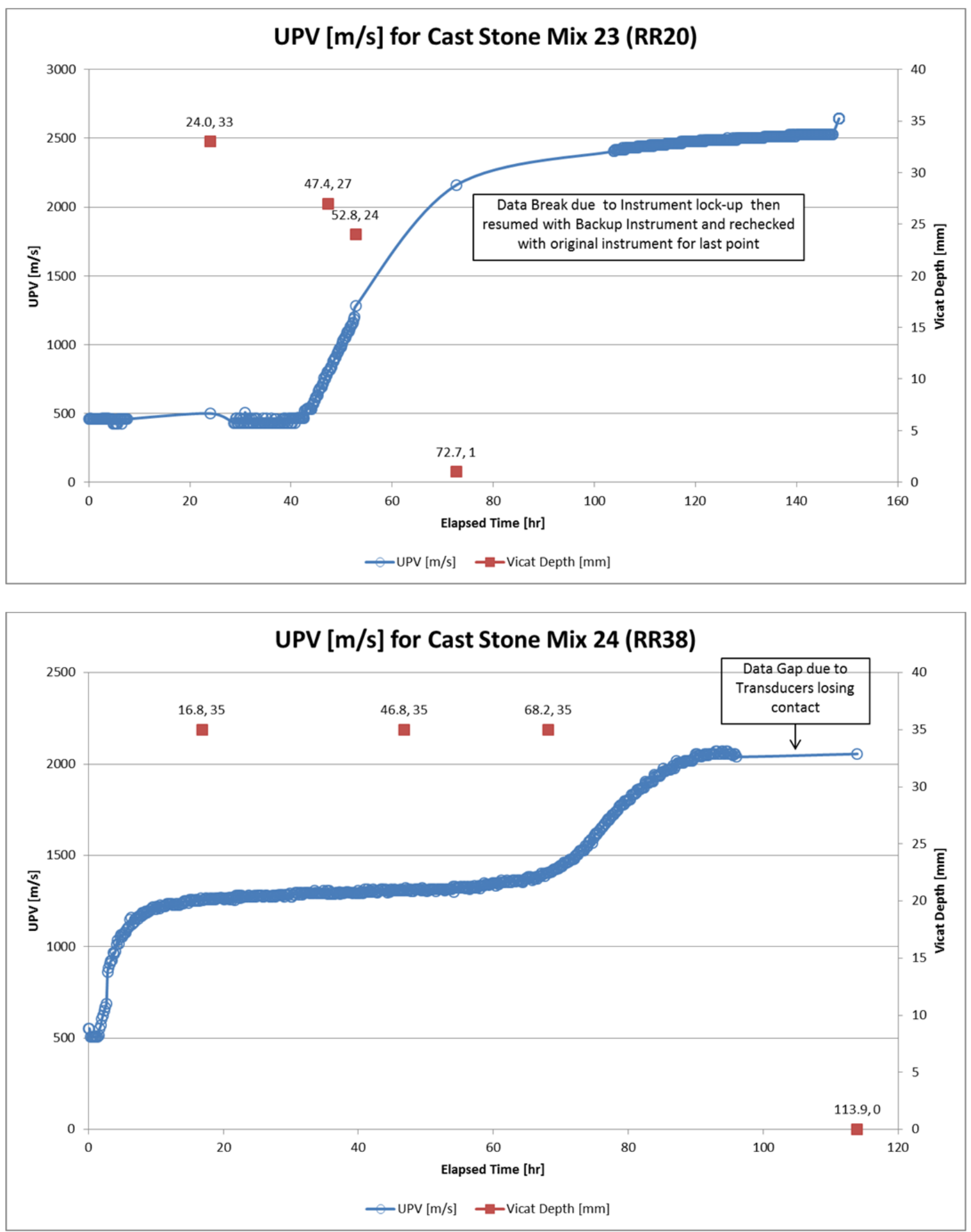

Figure C-1. UPV Data for Cast Stone Mixes to Estimate Set Time (contd) 

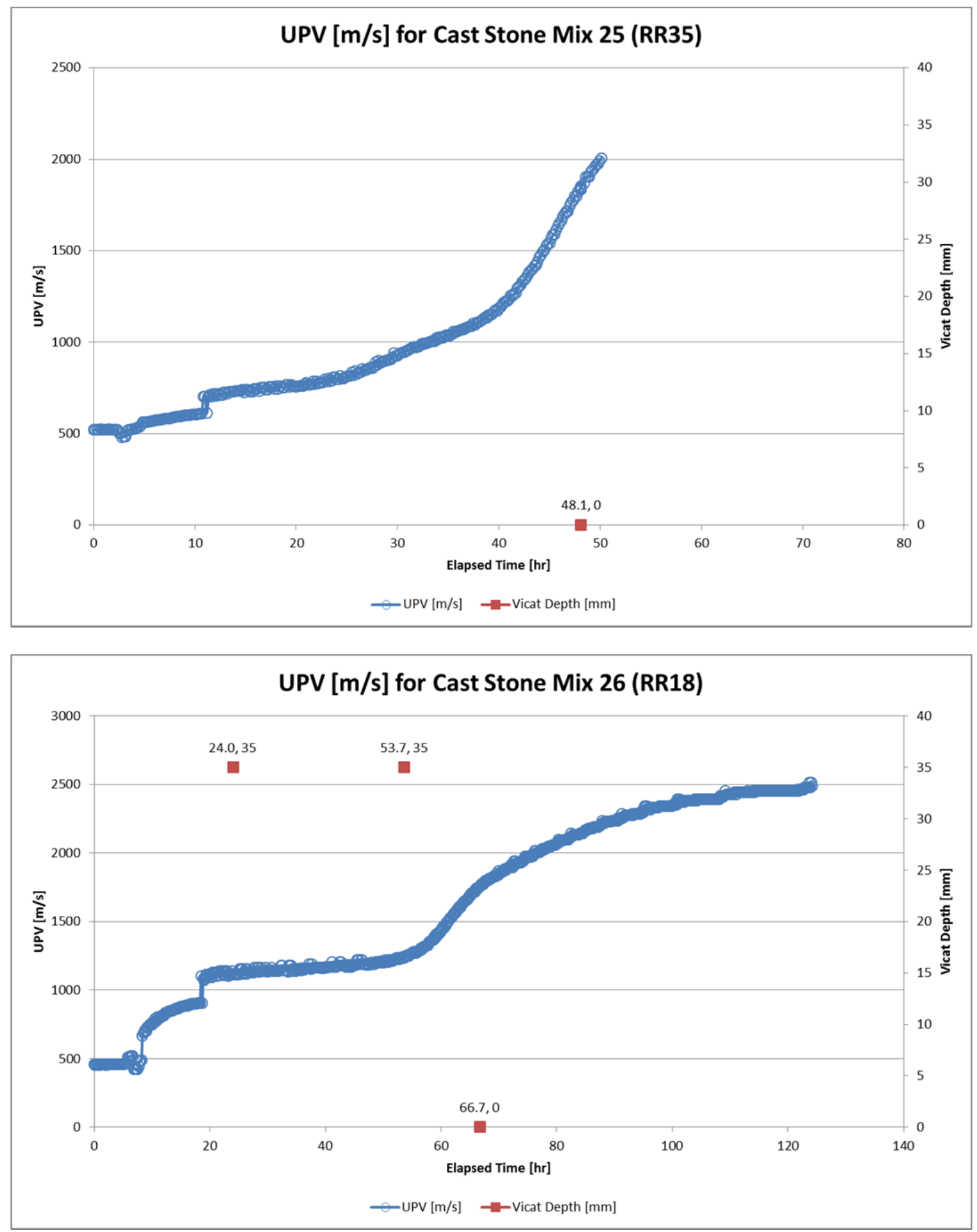

Figure C-1. UPV Data for Cast Stone Mixes to Estimate Set Time (contd) 
PNNL-22747

SRNL-STI-2013-00465
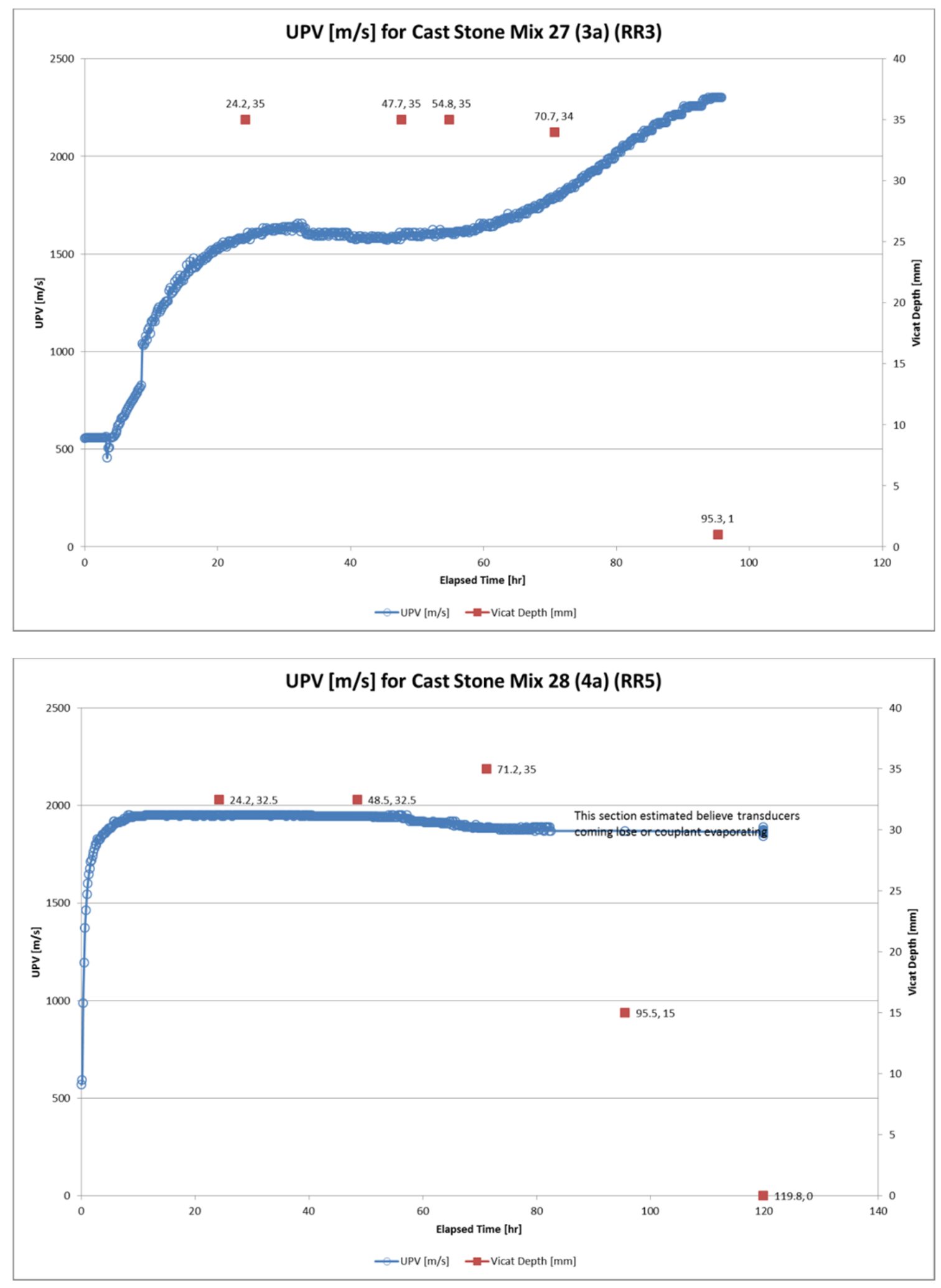

Figure C-1. UPV Data for Cast Stone Mixes to Estimate Set Time (contd)

Page C-21 of 315 

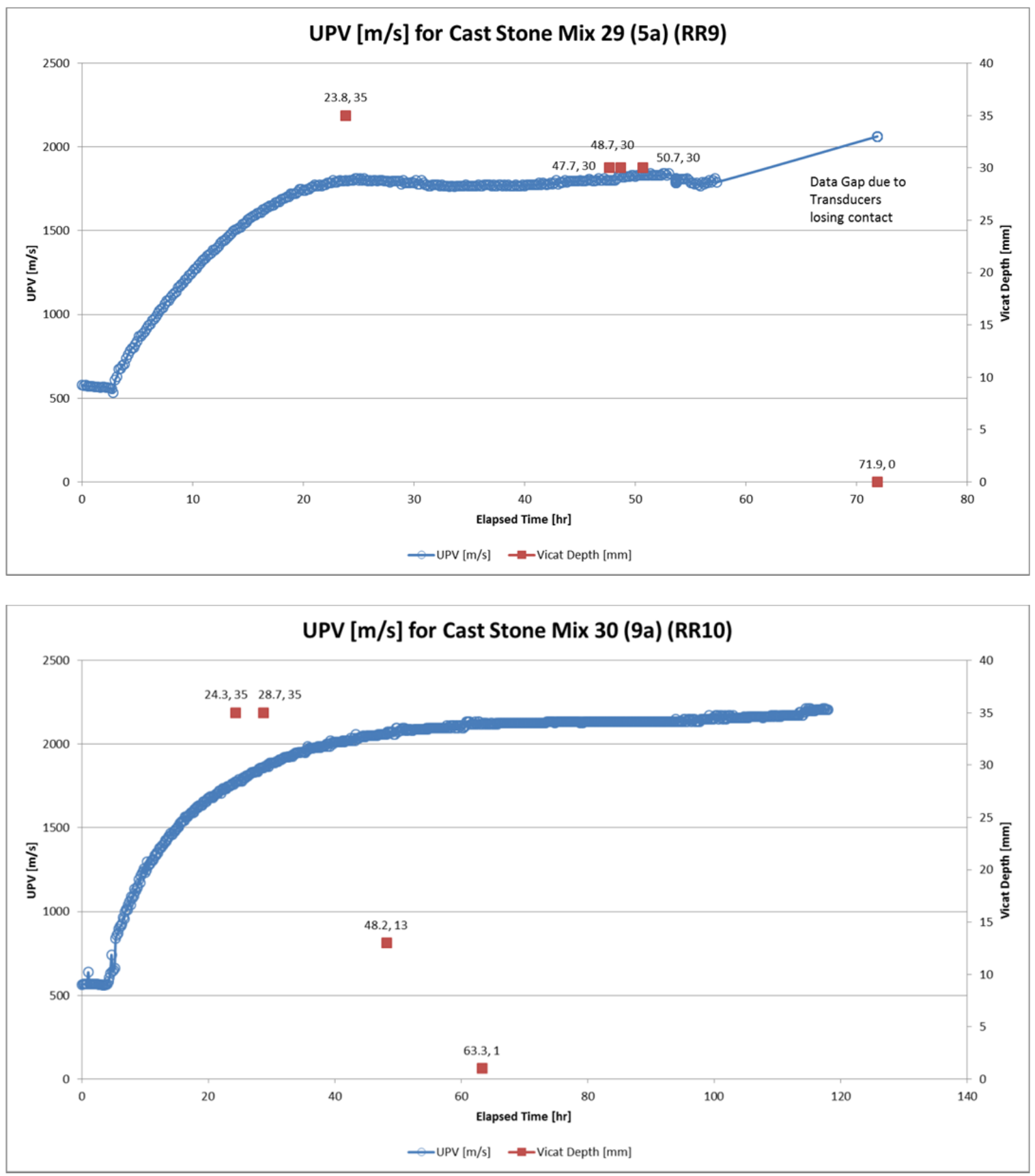

Figure C-1. UPV Data for Cast Stone Mixes to Estimate Set Time (contd) 

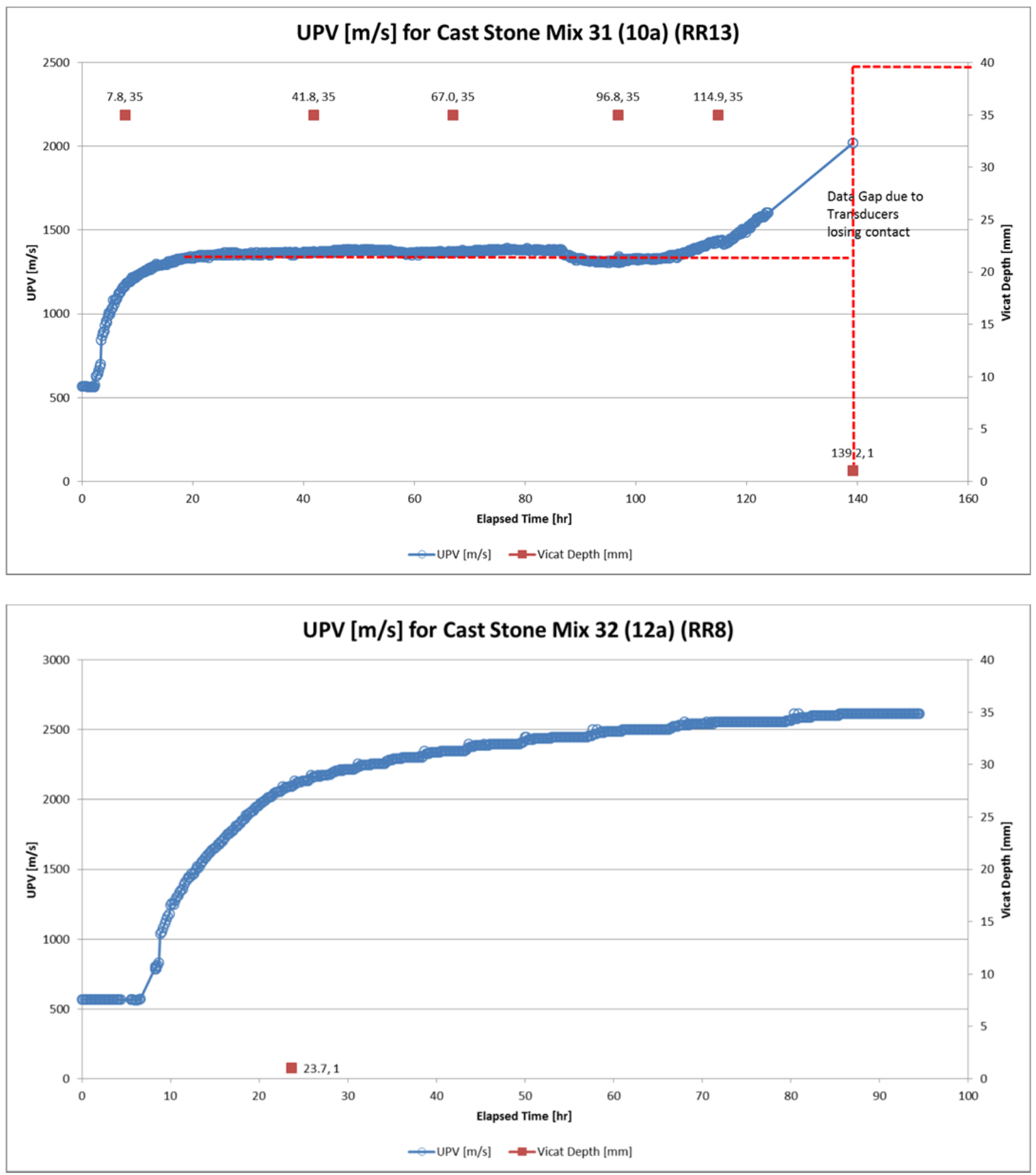

Figure C-1. UPV Data for Cast Stone Mixes to Estimate Set Time (contd) 

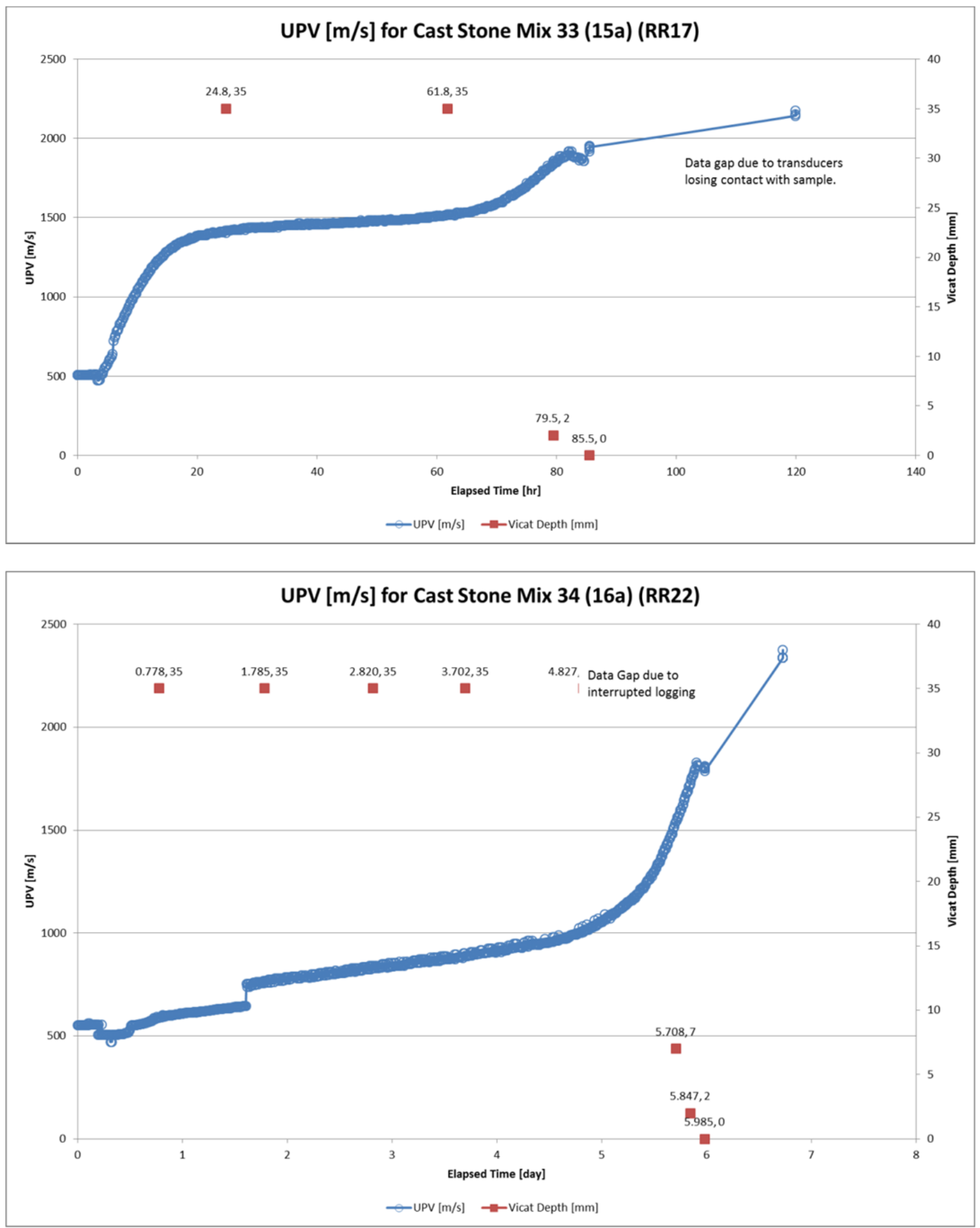

Figure C-1. UPV Data for Cast Stone Mixes to Estimate Set Time (contd) 

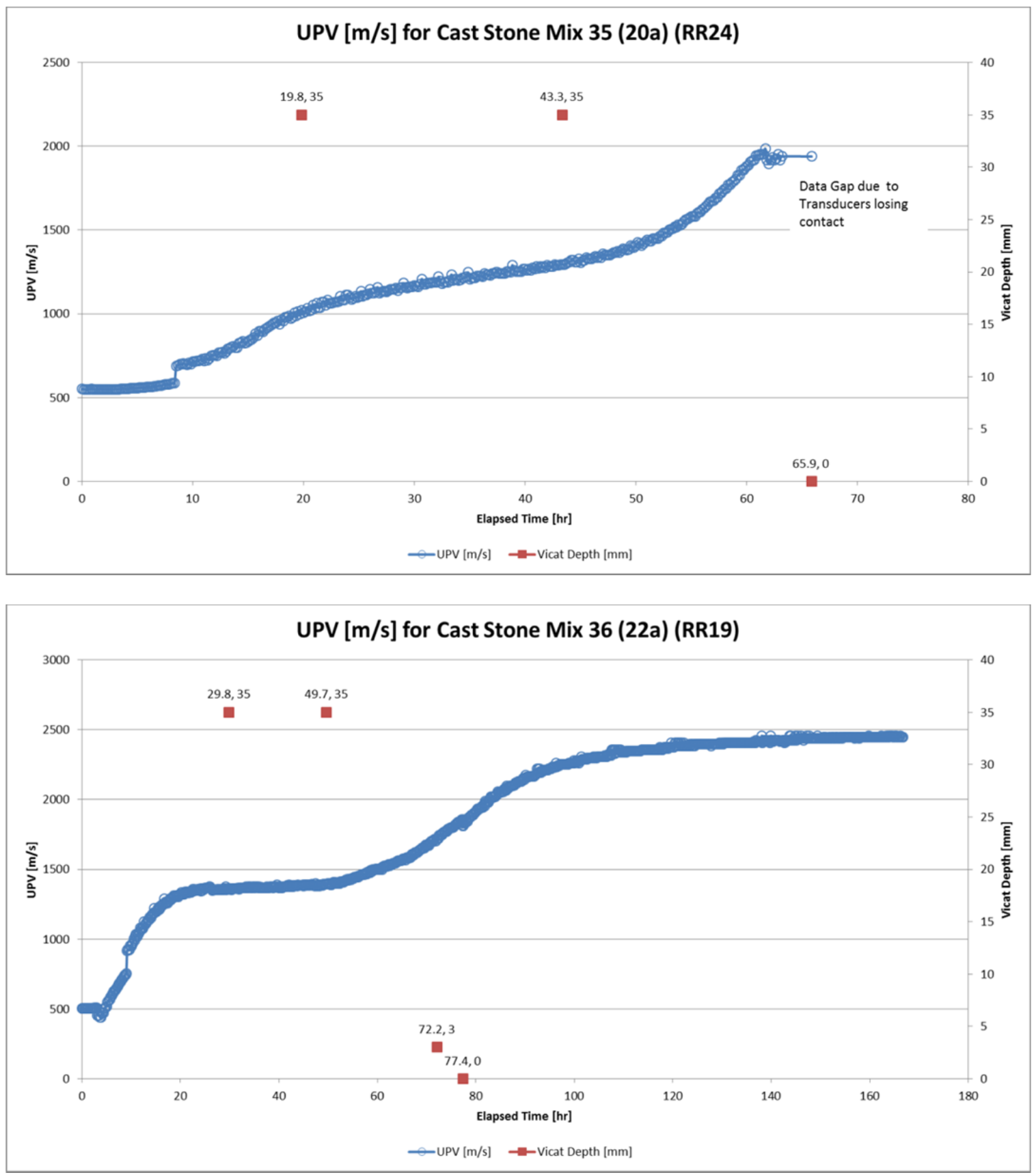

Figure C-1. UPV Data for Cast Stone Mixes to Estimate Set Time (contd) 

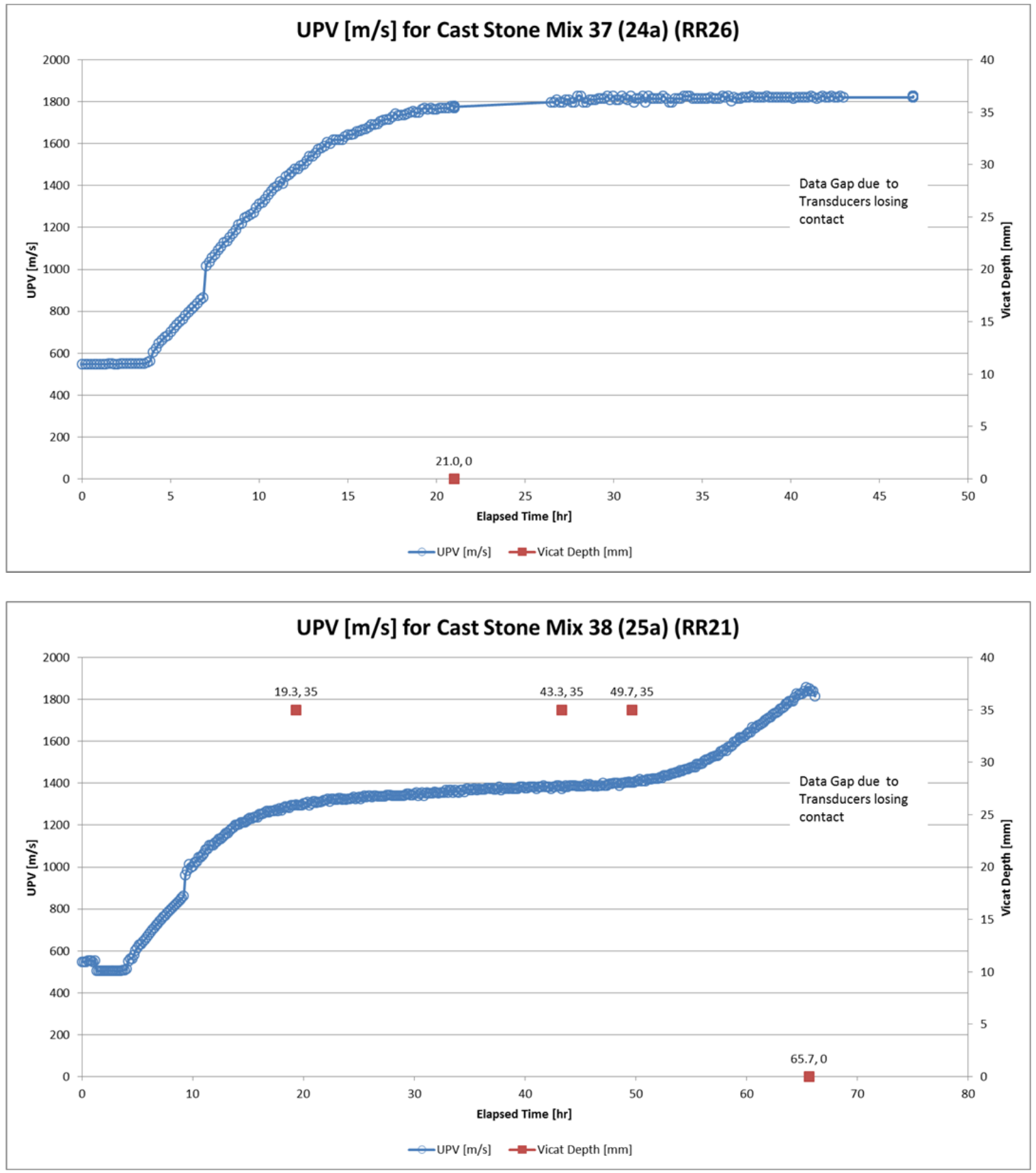

Figure C-1. UPV Data for Cast Stone Mixes to Estimate Set Time (contd) 


\section{C.4 Slurry Rheology Properties}

Table C-5 contains the measured values for two flow properties: yield stress (Pa) and plastic viscosity $(\mathrm{cP})$. These properties were measured on only one sample per Cast Stone mix, so there are no repeat results with which to calculate means and standard deviations (SDs). The calculated Bingham plastic viscosities and yield stress values over the linear range, including the linear regression $\mathrm{R}^{2}$ values are shown in Table C-6. Table C-7 shows the Bingham plastic viscosities and yield stress values for the replicate pairs for tests, including averages, SDs, and percent relative standard deviation. The results are similar between the replicate pairs, with \%RSD being less than $10 \%$ (Table C-7).

\section{C.5 Heat Generation}

Table C-8 contains the measured values for three heat generation properties of Cast Stone: heat generation (energy per gram) at 300 hours $(\mathrm{J} / \mathrm{g})$, time to peak energy (hr) (referred to time to peak heat generation in main text), and energy per gram at peak $(\mathrm{mW} / \mathrm{g})($ referred to heat generation at peak in main text). These properties were measured on only one sample per Cast Stone mix, so there are no repeat results with which to calculate means and SDs. See Section 6.5 for further discussion of how these property data were obtained. 
Table C-5. Slurry Rheological Properties for 38 Cast Stone Mixes

\begin{tabular}{|c|c|c|c|c|}
\hline \multicolumn{2}{|c|}{$\begin{array}{c}\text { Mix/ } \\
\text { Number }^{(a)}\end{array}$} & $\begin{array}{c}\text { Random } \\
\text { Run Order }\end{array}$ & $\begin{array}{c}\text { Yield Stress }^{(\mathbf{b})} \\
\text { (Pa) }\end{array}$ & $\begin{array}{c}\text { Plastic Viscosity } \\
\text { (cP) }\end{array}$ \\
\hline \multicolumn{2}{|c|}{1} & 7 & (c) & (c) \\
\hline \multicolumn{2}{|r|}{ a } & 11 & 9.0 & 86 \\
\hline \multicolumn{2}{|l|}{3} & 27 & 3.1 & 80 \\
\hline \multicolumn{2}{|l|}{4} & 28 & 48.2 & 329 \\
\hline \multicolumn{2}{|l|}{5} & 30 & 67.3 & 421 \\
\hline \multicolumn{2}{|l|}{6} & 12 & 58.7 & 580 \\
\hline 7 & $\#$ & 14 & 38.1 & 558 \\
\hline \multicolumn{2}{|l|}{8} & 1 & 39.6 & 520 \\
\hline \multicolumn{2}{|l|}{9} & 31 & 2.1 & 82 \\
\hline \multicolumn{2}{|l|}{10} & 32 & 6.8 & 93 \\
\hline \multicolumn{2}{|l|}{11} & 6 & 3.0 & 92 \\
\hline \multicolumn{2}{|l|}{12} & 29 & 3.1 & 54 \\
\hline \multicolumn{2}{|l|}{13} & 4 & 9.1 & 92 \\
\hline \multicolumn{2}{|l|}{14} & 2 & 36.7 & 602 \\
\hline \multicolumn{2}{|l|}{15} & 33 & 36.5 & 278 \\
\hline \multicolumn{2}{|l|}{16} & 36 & 31.1 & 296 \\
\hline \multicolumn{2}{|l|}{17} & 25 & 5.9 & 67 \\
\hline \multicolumn{2}{|l|}{18} & 16 & 43.7 & 518 \\
\hline \multicolumn{2}{|l|}{19} & 15 & 31.9 & 521 \\
\hline \multicolumn{2}{|l|}{20} & 37 & 71.9 & 322 \\
\hline \multicolumn{2}{|l|}{21} & 23 & 4.7 & 93 \\
\hline \multicolumn{2}{|l|}{22} & 34 & 3.5 & 91 \\
\hline \multicolumn{2}{|l|}{23} & 20 & 7.9 & 165 \\
\hline \multicolumn{2}{|l|}{24} & 38 & 5.8 & 98 \\
\hline \multicolumn{2}{|l|}{25} & 35 & 37.9 & 287 \\
\hline \multicolumn{2}{|l|}{26} & 18 & 4.8 & 91 \\
\hline \multicolumn{2}{|l|}{$27(3 a)$} & 3 & 4.2 & 88 \\
\hline $28(4 a)$ & & 5 & 64.6 & 267 \\
\hline $29(5 a)$ & & 9 & 23.7 & 240 \\
\hline $30(9 a)$ & & 10 & 2.7 & 72 \\
\hline $31(10 a)$ & & 13 & 10.0 & 68 \\
\hline $32(12 a)$ & & 8 & 3.9 & 71 \\
\hline $33(15 a)$ & $*$ & 17 & 21.9 & 202 \\
\hline $34(16 a)$ & & 22 & 50.6 & 338 \\
\hline $35(20 a)$ & & 24 & 92.4 & 275 \\
\hline $36(22 a)$ & $\wedge$ & 19 & 5.1 & 85 \\
\hline $37(24 a)$ & & 26 & 6.7 & 80 \\
\hline $38(25 a)$ & $*$ & 21 & 28.8 & 236 \\
\hline $\begin{array}{l}\text { (a) Test } \\
\text { (b) Valu } \\
\text { decin } \\
\text { (c) Slurr }\end{array}$ & $\begin{array}{l}\text { umb } \\
\text { we } \\
\text { al pl } \\
\text { was }\end{array}$ & $\begin{array}{l}\text { vith the same } \\
\text { lculated to se } \\
\text { shown for rep } \\
\text { thick to meas }\end{array}$ & $\begin{array}{l}\text { ols are replicates } \\
\text { decimal places b } \\
\mathrm{g} \text { in this table an } \\
\text { eological proper }\end{array}$ & $\begin{array}{l}\text { Inded to the number of } \\
\text { istical data analyses. }\end{array}$ \\
\hline
\end{tabular}


Table C-6. Bingham Plastic Results

\begin{tabular}{|c|c|c|c|c|c|c|c|c|}
\hline \multirow[b]{2}{*}{$\begin{array}{c}\text { Mix } \\
\text { Number }\end{array}$} & \multirow{2}{*}{$\begin{array}{l}\text { Water- } \\
\text { to-Dry } \\
\text { Blend } \\
\text { Ratio }\end{array}$} & \multicolumn{3}{|c|}{ Up Curve } & \multicolumn{3}{|c|}{ Down Curve } & \multirow{2}{*}{$\begin{array}{c}\text { Fitted } \\
\text { Range } \\
\left(s^{-1}\right)\end{array}$} \\
\hline & & $\begin{array}{c}\text { Plastic } \\
\text { Viscosity } \\
\text { (cP) }\end{array}$ & $\begin{array}{c}\text { Yield } \\
\text { Stress } \\
(\mathrm{Pa})\end{array}$ & $\mathbf{R}^{2}$ & $\begin{array}{l}\text { Plastic } \\
\text { Viscosity } \\
\text { (cP) }\end{array}$ & $\begin{array}{c}\text { Yield } \\
\text { Stress } \\
(\mathrm{Pa})\end{array}$ & $\mathbf{R}^{2}$ & \\
\hline 1 & 0.4 & 285 & 64.3 & 0.9947 & (a) & (a) & (a) & $25-300$ \\
\hline 2 & 0.6 & 90.2 & 7.7 & 0.9976 & 86.0 & 9.0 & 0.9965 & $10-300$ \\
\hline 3 & 0.6 & 90.2 & 4.6 & 0.9978 & 88.1 & 4.2 & 0.9994 & $10-300$ \\
\hline 4 & 0.4 & 285 & 64.3 & 0.9947 & 267 & 64.6 & 0.9996 & $25-300$ \\
\hline 5 & 0.4 & 433 & 67.2 & 0.9968 & 421 & 67.3 & 0.9994 & $10-300$ \\
\hline 6 & 0.4 & 597 & 57.6 & 0.9994 & 580 & 58.7 & 0.9999 & $25-300$ \\
\hline 7 & 0.4 & 571 & 33.9 & 0.9994 & 558 & 38.1 & 0.9992 & $10-300$ \\
\hline 8 & 0.4 & 469 & 61.1 & 0.9953 & 520 & 39.6 & 0.9991 & $25-300$ \\
\hline 9 & 0.6 & 82.2 & 2.7 & 0.9998 & 82.0 & 2.1 & 0.9999 & $10-300$ \\
\hline 10 & 0.6 & 95.3 & 7.3 & 0.9974 & 93.1 & 6.8 & 0.9982 & $10-300$ \\
\hline 11 & 0.6 & 92.7 & 3.3 & 0.9992 & 92.0 & 3.0 & 0.9997 & $10-300$ \\
\hline 12 & 0.6 & 49.3 & 4.0 & 0.9981 & 51.2 & 3.4 & 0.9978 & $10-300$ \\
\hline 13 & 0.6 & 96.2 & 7.8 & 0.9978 & 92.2 & 9.1 & 0.9964 & $10-300$ \\
\hline 14 & 0.4 & 617 & 33.3 & 0.9997 & 602 & 36.7 & 0.9994 & $10-300$ \\
\hline 15 & 0.4 & 275 & 40.3 & 0.9975 & 278 & 36.5 & 0.9998 & $10-300$ \\
\hline 16 & 0.4 & 271 & 37.9 & 0.9938 & 296 & 31.1 & 0.9999 & $10-300$ \\
\hline 17 & 0.6 & 68.3 & 5.1 & 0.9991 & 67.4 & 5.9 & 0.9962 & $10-300$ \\
\hline 18 & 0.4 & 525 & 47.0 & 0.9989 & 518 & 43.7 & 0.9996 & $25-300$ \\
\hline 19 & 0.4 & 522 & 35.9 & 0.9994 & 521 & 31.9 & 0.9999 & $25-300$ \\
\hline 20 & 0.4 & 308 & 79.5 & 0.9957 & 322 & 71.9 & 0.9955 & $10-300$ \\
\hline 21 & 0.6 & 94.1 & 4.7 & 0.9987 & 92.6 & 4.7 & 0.9993 & $10-300$ \\
\hline 22 & 0.6 & 91.6 & 4.1 & 0.9997 & 91.0 & 3.5 & 0.9998 & $10-300$ \\
\hline 23 & 0.6 & 161 & 10.8 & 0.9985 & 165 & 7.9 & 0.9996 & $10-300$ \\
\hline 24 & 0.6 & 99.9 & 6.5 & 0.9982 & 97.8 & 5.8 & 0.9987 & $10-300$ \\
\hline 25 & 0.4 & 273 & 44.8 & 0.9997 & 287 & 37.9 & 0.9998 & $10-300$ \\
\hline 26 & 0.6 & 92.3 & 4.9 & 0.9989 & 90.9 & 4.8 & 0.9993 & $10-300$ \\
\hline
\end{tabular}


Table C-7. Bingham Plastic Results for Replicate Pairs of Tests

\begin{tabular}{|c|c|c|c|c|c|}
\hline \multirow[b]{2}{*}{$\begin{array}{c}\text { Mix } \\
\text { Number }\end{array}$} & \multirow[b]{2}{*}{$\begin{array}{l}\text { Water-to- } \\
\text { Dry Blend } \\
\text { Ratio }\end{array}$} & \multicolumn{2}{|c|}{ Up Curve } & \multicolumn{2}{|c|}{ Down Curve } \\
\hline & & $\begin{array}{c}\text { Plastic } \\
\text { Viscosity } \\
\text { (cP) }\end{array}$ & $\begin{array}{l}\text { Yield Stress } \\
\quad(\mathbf{P a})\end{array}$ & $\begin{array}{c}\text { Plastic } \\
\text { Viscosity } \\
\text { (cP) }\end{array}$ & $\begin{array}{l}\text { Yield Stress } \\
\quad(\mathbf{P a})\end{array}$ \\
\hline 2 & 0.4 & 617 & 33.3 & 602 & 36.7 \\
\hline \multirow[t]{4}{*}{14} & 0.4 & 571 & 33.9 & 558 & 38.1 \\
\hline & Avg. & 594 & 33.6 & 580 & 37.4 \\
\hline & SD & 32 & 0.4 & 31 & 1.0 \\
\hline & $\%$ RSD & 5.4 & 1.3 & 5.4 & 2.7 \\
\hline 3 & 0.6 & 79.7 & 3.6 & 80.0 & 3.1 \\
\hline \multirow[t]{4}{*}{19} & 0.6 & 91.6 & 4.1 & 91.0 & 3.5 \\
\hline & Avg. & 85.7 & 3.9 & 85.5 & 3.3 \\
\hline & SD & 8.4 & 0.3 & 7.8 & 0.3 \\
\hline & $\% \mathrm{RSD}$ & 9.8 & 9.0 & 9.1 & 8.8 \\
\hline 4 & 0.6 & 96.2 & 7.8 & 92.2 & 9.1 \\
\hline \multirow[t]{4}{*}{11} & 0.6 & 90.2 & 7.7 & 86.0 & 9.0 \\
\hline & Avg. & 93.2 & 7.7 & 89.1 & 9.0 \\
\hline & $\mathrm{SD}$ & 4.3 & 0.1 & 4.4 & 0.1 \\
\hline & $\% \mathrm{RSD}$ & 4.6 & 1.1 & 4.9 & 1.2 \\
\hline 17 & 0.4 & 275 & 40.3 & 278 & 36.5 \\
\hline \multirow[t]{4}{*}{21} & 0.4 & 273 & 44.8 & 287 & 37.9 \\
\hline & Avg. & 274 & 42.5 & 282 & 37.2 \\
\hline & SD & 1 & 3.2 & 6 & 1.0 \\
\hline & $\%$ RSD & 0.4 & 7.6 & 2.1 & 2.6 \\
\hline 18 & 0.6 & 92.3 & 4.9 & 90.9 & 4.8 \\
\hline \multirow[t]{4}{*}{23} & 0.6 & 94.1 & 4.7 & 92.6 & 4.7 \\
\hline & Avg. & 93.2 & 4.8 & 91.8 & 4.7 \\
\hline & $\mathrm{SD}$ & 1.3 & 0.1 & 1.2 & 0.1 \\
\hline & $\%$ RSD & 1.4 & 2.1 & 1.3 & 1.8 \\
\hline
\end{tabular}


Table C-8. Cast Stone Heat Generation Properties for 38 Cast Stone Mixes

\begin{tabular}{|c|c|c|c|c|c|}
\hline \multicolumn{2}{|c|}{$\begin{array}{c}\text { Mix/ } \\
\text { Test } \#^{(a)}\end{array}$} & $\begin{array}{l}\text { Random } \\
\text { Run Order }\end{array}$ & $\begin{array}{c}\text { Energy at } \\
300 \mathbf{h r}^{(\mathbf{b})} \\
(\mathrm{J} / \mathrm{g})\end{array}$ & $\begin{array}{c}\text { Time to Peak } \\
\text { Energy } \\
(\mathrm{c}) \\
(\mathrm{hr})\end{array}$ & $\begin{array}{c}\text { Energy at Peak }^{(a)} \\
(\mathrm{mW} / \mathrm{g})\end{array}$ \\
\hline \multicolumn{2}{|l|}{1} & 7 & 230.0 & 27.30 & 4259 \\
\hline a & (a) & 11 & 382.3 & 73.87 & 2157 \\
\hline \multicolumn{2}{|l|}{3} & 27 & 394.0 & 86.23 & 2798 \\
\hline \multicolumn{2}{|l|}{4} & 28 & 328.0 & 96.82 & 2028 \\
\hline \multicolumn{2}{|l|}{5} & 30 & 292.0 & 37.80 & 1502 \\
\hline \multicolumn{2}{|l|}{6} & 12 & 250.3 & 35.12 & 1614 \\
\hline \multicolumn{2}{|l|}{7} & 14 & 334.6 & 47.27 & 2280 \\
\hline \multicolumn{2}{|l|}{8} & 1 & 150.4 & 26.55 & 892 \\
\hline \multicolumn{2}{|l|}{9} & 31 & 434.0 & 96.20 & 2557 \\
\hline \multicolumn{2}{|l|}{10} & 32 & 363.0 & 94.97 & 2939 \\
\hline \multicolumn{2}{|l|}{11} & 6 & 287.6 & 81.75 & 1452 \\
\hline \multicolumn{2}{|l|}{12} & 29 & 405.0 & 56.02 & 1873 \\
\hline \multicolumn{2}{|l|}{13} & 4 & 351.8 & 71.93 & 2152 \\
\hline \multicolumn{2}{|l|}{14} & 2 & 340.9 & 45.92 & 2275 \\
\hline \multicolumn{2}{|l|}{15} & 33 & 314.0 & 43.88 & 1838 \\
\hline \multicolumn{2}{|l|}{16} & 36 & 294.0 & 59.53 & 2280 \\
\hline \multicolumn{2}{|l|}{17} & 25 & 394.0 & 97.20 & 2115 \\
\hline \multicolumn{2}{|l|}{18} & 16 & 306.2 & 35.93 & 1725 \\
\hline \multicolumn{2}{|l|}{19} & 15 & 253.3 & 70.10 & 1106 \\
\hline \multicolumn{2}{|l|}{20} & 37 & 326.0 & 96.35 & 2095 \\
\hline \multicolumn{2}{|l|}{21} & 23 & 271.0 & 51.78 & 1609 \\
\hline \multicolumn{2}{|l|}{22} & 34 & 397.0 & 84.65 & 2806 \\
\hline \multicolumn{2}{|l|}{23} & 20 & 270.0 & 48.02 & 2434 \\
\hline \multicolumn{2}{|l|}{24} & 38 & 371.0 & 91.57 & 2173 \\
\hline \multicolumn{2}{|l|}{25} & 35 & 291.0 & 36.88 & 1972 \\
\hline 26 & $\&$ & 18 & 272.0 & 50.72 & 1675 \\
\hline $27(3 a)$ & $\wedge$ & 3 & 325.2 & 53.48 & 1744 \\
\hline $28(4 a)$ & & 5 & 288.3 & 90.00 & 1635 \\
\hline $29(5 a)$ & & 9 & 330.9 & 60.80 & 2622 \\
\hline $30(9 a)$ & & 10 & 342.3 & 76.32 & 1625 \\
\hline $31(10 a)$ & & 13 & 394.7 & 94.97 & 2589 \\
\hline $32(12 a)$ & & 8 & 316.9 & 15.97 & 3775 \\
\hline 33 (15a) & $*$ & 17 & 318.0 & 52.93 & 2346 \\
\hline 34 (16a) & & 22 & 297.0 & 164.07 & 2200 \\
\hline $35(20 a)$ & & 24 & 272.0 & 93.85 & 923 \\
\hline $36(22 a)$ & $\wedge$ & 19 & 327.0 & 55.70 & 1748 \\
\hline $37(24 a)$ & & 26 & 403.0 & 100.90 & 1877 \\
\hline $38(25 a)$ & $*$ & 21 & 323.0 & 53.25 & 2393 \\
\hline $\begin{array}{ll}\text { (a) } & \text { Test } \\
\text { (b) Valu } \\
\text { (c) Valu } \\
\text { with }\end{array}$ & $\begin{array}{l}\text { Imbe } \\
\text { wer } \\
\text { wer }\end{array}$ & $\begin{array}{l}\text { ith the same s } \\
\text { orted to the } n \\
\text { corded in an } \mathrm{h} \\
\text { al places. }\end{array}$ & $\begin{array}{l}\text { are replicat } \\
\text { of decimal } p \\
\text { ormat, and } v\end{array}$ & $\begin{array}{l}\text { wn and did not ro } \\
\text { erted to values or }\end{array}$ & $\begin{array}{l}\text { ounding. } \\
\text { in decimal format }\end{array}$ \\
\hline
\end{tabular}




\section{C.6 Fresh Densities}

The measured densities of freshly prepared Cast Stone mixes closely approximated the densities calculated using the measured densities of the salt solutions and the dry blend materials using the equation

$$
\frac{1}{\rho}=\sum_{i=1}^{n} \frac{x_{i}}{\rho_{i}}
$$

where

$$
\begin{aligned}
& \rho=\text { density of the mixture, } \mathrm{g} / \mathrm{cm}^{3} \\
& \rho_{\mathrm{i}}=\text { density of each component, } \mathrm{g} / \mathrm{cm}^{3} \\
& \mathrm{x}_{\mathrm{i}}=\text { mass fraction of each component. }
\end{aligned}
$$

Although reactions occur and there are phase changes, the measured density is not significantly different from the density calculated from the mass fraction and density of the individual components. The results are presented in Table C-9. 
Table C-9. Fresh Density Results for 38 Cast Stone Mixes

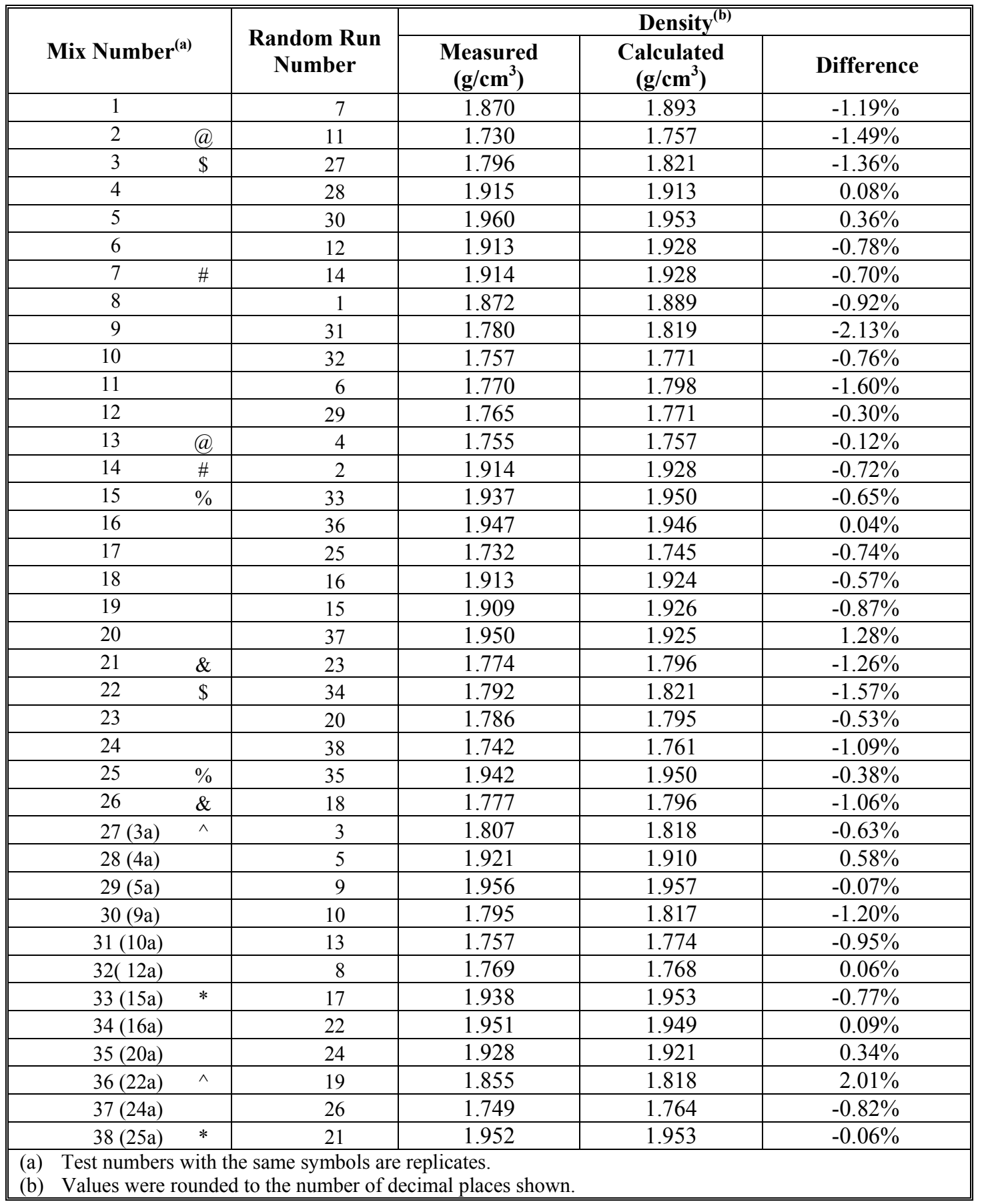

\section{C.7 Free Liquids}

Table C-10 contains the results of free liquids (i.e., bleed water) measurements (vol\%) from duplicate samples after 1 and 3 days. All except three mixes (\# 12, 23, and 32) yielded zero bleed 
water after 3 days. Because nearly all results are zero, the means and SDs of the duplicate results were not calculated. See Section 6.7 for further discussion of these data and how they were generated.

Table C-10. Free Water (vol \%) for 38 Cast Stone Mixes

\begin{tabular}{|c|c|c|c|c|c|c|}
\hline \multirow{2}{*}{\multicolumn{2}{|c|}{ Mix/Test $\#^{(a)}$}} & \multirow{2}{*}{$\begin{array}{l}\text { Random Run } \\
\text { Order }\end{array}$} & \multicolumn{2}{|c|}{ Day $1^{(b)}$} & \multicolumn{2}{|c|}{ Day $3^{(b)}$} \\
\hline & & & Duplicate 1 & Duplicate 2 & Duplicate 1 & Duplicate 2 \\
\hline 1 & & 7 & 0.00 & 0.00 & 0.00 & 0.00 \\
\hline 2 & @ & 11 & 0.00 & 0.00 & 0.00 & 0.00 \\
\hline 3 & $\$$ & 27 & 0.00 & 0.00 & 0.00 & 0.00 \\
\hline 4 & & 28 & 0.00 & 0.00 & 0.00 & 0.00 \\
\hline 5 & & 30 & 0.00 & 0.00 & 0.00 & 0.00 \\
\hline 6 & & 12 & 0.00 & 0.00 & 0.00 & 0.00 \\
\hline 7 & $\#$ & 14 & 0.00 & 0.00 & 0.00 & 0.00 \\
\hline 8 & & 1 & 0.00 & 0.00 & 0.00 & 0.00 \\
\hline 9 & & 31 & 0.45 & 0.40 & 0.00 & 0.00 \\
\hline 10 & & 32 & 0.00 & 0.00 & 0.00 & 0.00 \\
\hline 11 & & 6 & 0.00 & 0.00 & 0.00 & 0.00 \\
\hline 12 & & 29 & 1.09 & 1.11 & 0.00 & 0.00 \\
\hline 13 & $@$ & 4 & 0.00 & 0.00 & 0.00 & 0.00 \\
\hline 14 & $\#$ & 2 & 0.00 & 0.00 & 0.00 & 0.00 \\
\hline 15 & $\%$ & 33 & 0.00 & 0.00 & 0.00 & 0.00 \\
\hline 16 & & 36 & 0.84 & 0.68 & 0.00 & 0.00 \\
\hline 17 & & 25 & 0.52 & 0.45 & 0.28 & 0.21 \\
\hline 18 & & 16 & 0.00 & 0.00 & 0.00 & 0.00 \\
\hline 19 & & 15 & 0.00 & 0.00 & 0.00 & 0.00 \\
\hline 20 & & 37 & 0.00 & 0.00 & 0.00 & 0.00 \\
\hline 21 & $\&$ & 23 & 0.00 & 0.00 & 0.00 & 0.00 \\
\hline 22 & $\$$ & 34 & 0.00 & 0.00 & 0.00 & 0.00 \\
\hline 23 & & 20 & 2.33 & 2.39 & 2.43 & 2.20 \\
\hline 24 & & 38 & 0.00 & 0.00 & 0.00 & 0.00 \\
\hline 25 & $\%$ & 35 & 0.00 & 0.00 & 0.00 & 0.00 \\
\hline 26 & $\&$ & 18 & 0.00 & 0.00 & 0.00 & 0.00 \\
\hline $27(3 a)$ & $\wedge$ & 3 & 0.00 & 0.00 & 0.00 & 0.00 \\
\hline $28(4 a)$ & & 5 & 0.00 & 0.00 & 0.00 & 0.00 \\
\hline $29(5 a)$ & & 9 & 0.00 & 0.00 & 0.00 & 0.00 \\
\hline $30(9 a)$ & & 10 & 0.00 & 0.00 & 0.00 & 0.00 \\
\hline $31(10 a)$ & & 13 & 0.00 & 0.00 & 0.00 & 0.00 \\
\hline $32(12 a)$ & & 8 & 5.84 & 5.91 & 4.47 & 4.46 \\
\hline $33(15 a)$ & $*$ & 17 & 0.00 & 0.00 & 0.00 & 0.00 \\
\hline 34 (16a) & & 22 & 0.00 & 0.00 & 0.00 & 0.00 \\
\hline 35 (20a) & & 24 & 0.00 & 0.00 & 0.00 & 0.00 \\
\hline $36(22 a)$ & $\wedge$ & 19 & 0.00 & 0.00 & 0.00 & 0.00 \\
\hline $37(24 a)$ & & 26 & 0.00 & 0.00 & 0.00 & 0.00 \\
\hline $38(25 a)$ & $*$ & 21 & 0.00 & 0.00 & 0.00 & 0.00 \\
\hline
\end{tabular}


PNNL-22747

SRNL-STI-2013-00465

Appendix D. Cured Cast Stone Properties Data 
This appendix contains data from compressive strength, cured density, and EPA Draft Method 1315 (2012) leach test measurements (effective diffusivity and leachability index) for Cast Stone Mixes 1-26 prepared by PNNL. Compressive strength and cured density results measured by SRNL for a subset of these mixes are also presented.

\section{D.1 Chemical Composition}

Table D-1 lists the chemical compositions of Cast Stone Mixes 1-26 (see Table 2-1) measured at PNNL for the specimens spiked with Tc and U for the EPA Draft Method 1315 leach tests. Note that the mixes are labeled as "tests" in Table D-1. The analytical methods are described in Appendix B.

Table D-1. Total Cation Composition of the Monoliths Used for Leach Tests

\begin{tabular}{|c|c|c|c|c|c|}
\hline \multirow{2}{*}{ Analyte } & \multirow{2}{*}{ Units } & Test 1 & Test 2 & Test 3 & Test 4 \\
\hline & & T1LCS1-5HIS & T2LCS2-5AVG & T3HCS2-7.8AVG & CT4HCS2-5HIA \\
\hline Aluminum & $\mu \mathrm{g} / \mathrm{g}$ & 83900 & 71600 & 54700 & 42500 \\
\hline Antimony & $\mu \mathrm{g} / \mathrm{g}$ & $<22.6$ & $<23.7$ & $<23.7$ & $<21.9$ \\
\hline Arsenic & $\mu \mathrm{g} / \mathrm{g}$ & $<35.2$ & $<36.9$ & $<36.9$ & $<34.1$ \\
\hline Barium & $\mu \mathrm{g} / \mathrm{g}$ & 792 & 712 & 2260 & 1710 \\
\hline Cadmium & $\mu \mathrm{g} / \mathrm{g}$ & $<5.82$ & $<6.09$ & $<6.10$ & $<5.63$ \\
\hline Calcium & $\mu \mathrm{g} / \mathrm{g}$ & 161000 & 128000 & 153000 & 115000 \\
\hline Cesium & $\mu \mathrm{g} / \mathrm{g}$ & 5.23 & 4.68 & 2.24 & 2.64 \\
\hline Chromium & $\mu \mathrm{g} / \mathrm{g}$ & 487 & 626 & 976 & 462 \\
\hline Copper & $\mu \mathrm{g} / \mathrm{g}$ & $<161$ & $<168$ & $<168$ & $<155$ \\
\hline Iron & $\mu \mathrm{g} / \mathrm{g}$ & 25600 & 21800 & 18600 & 13900 \\
\hline Lead & $\mu \mathrm{g} / \mathrm{g}$ & 64.9 & 58.8 & 50.1 & 33.7 \\
\hline Magnesium & $\mu \mathrm{g} / \mathrm{g}$ & 12000 & 29100 & 36200 & 27500 \\
\hline Manganese & $\mu \mathrm{g} / \mathrm{g}$ & 784 & 1360 & 1570 & 1170 \\
\hline Mercury & $\mu \mathrm{g} / \mathrm{g}$ & 11.6 & $<11.2$ & $<11.3$ & $<10.4$ \\
\hline Molybdenum & $\mu \mathrm{g} / \mathrm{g}$ & $<38.7$ & $<40.5$ & $<40.6$ & $<37.4$ \\
\hline Nickel & $\mu \mathrm{g} / \mathrm{g}$ & $<602$ & $<630$ & $<631$ & $<583$ \\
\hline Phosphorus & $\mu \mathrm{g} / \mathrm{g}$ & $<3840$ & $<4020$ & $<4020$ & $<3710$ \\
\hline Potassium & $\mu \mathrm{g} / \mathrm{g}$ & 11500 & $<11600$ & $<11600$ & $<10800$ \\
\hline Selenium & $\mu \mathrm{g} / \mathrm{g}$ & $<68.1$ & $<71.3$ & $<71.4$ & $<65.9$ \\
\hline Silicon & $\mu \mathrm{g} / \mathrm{g}$ & 172000 & 163000 & 169000 & 129000 \\
\hline Silver & $\mu \mathrm{g} / \mathrm{g}$ & 8.19 & 3.69 & $<2.31$ & $<2.13$ \\
\hline Sodium & $\mu \mathrm{g} / \mathrm{g}$ & 48100 & 63700 & 53000 & 86500 \\
\hline Strontium & $\mu \mathrm{g} / \mathrm{g}$ & 855 & 714 & 1330 & 1000 \\
\hline Titanium & $\mu \mathrm{g} / \mathrm{g}$ & 4740 & 4030 & 3060 & 2300 \\
\hline Zinc & $\mu \mathrm{g} / \mathrm{g}$ & $<473$ & $<496$ & $<496$ & $<458$ \\
\hline Zirconium & $\mu \mathrm{g} / \mathrm{g}$ & $<348$ & $<364$ & $<364$ & $<336$ \\
\hline Technetium-99 & $\mu \mathrm{g} / \mathrm{g}$ & 4.53 & 5.93 & 8.01 & 4.35 \\
\hline Iodine 127 & $\mu \mathrm{g} / \mathrm{g}$ & 149 & 76 & 119 & 79.7 \\
\hline Uranium 238 & $\mu \mathrm{g} / \mathrm{g}$ & 62.8 & 45.6 & 105 & 60.7 \\
\hline$\%$ Dry Solids & $\mathrm{wt} \%$ & 78.4 & 73.2 & 75.0 & 80.9 \\
\hline
\end{tabular}


Table D-1. Total Composition of the Monoliths Used for Leach Tests (contd)

\begin{tabular}{||l|c|c|c|c|c||}
\hline \multirow{2}{*}{ Analyte } & \multirow{2}{*}{ Units } & Test 5 & Test 6 & Test 7 & Test 8 \\
\cline { 3 - 6 } & & T5HCS1-7.8AVG & T6LCS1-7.8AVG & T7LCS2-7.8HIS & T8LCS1-5RAS \\
\hline Aluminum & $\mu \mathrm{g} / \mathrm{g}$ & 53600 & 72700 & 63400 & 73800 \\
\hline Antimony & $\mu \mathrm{g} / \mathrm{g}$ & $<21.8$ & $<22.1$ & $<21.2$ & $<22.5$ \\
\hline Arsenic & $\mu \mathrm{g} / \mathrm{g}$ & $<34.0$ & $<34.4$ & $<33.0$ & $<35.1$ \\
\hline Barium & $\mu \mathrm{g} / \mathrm{g}$ & 2020 & 644 & 636 & 721 \\
\hline Cadmium & $\mu \mathrm{g} / \mathrm{g}$ & $<5.62$ & $<5.68$ & 5.5 & $<5.79$ \\
\hline Calcium & $\mu \mathrm{g} / \mathrm{g}$ & 153000 & 132000 & 116000 & 148000 \\
\hline Cesium & $\mu \mathrm{g} / \mathrm{g}$ & 2.66 & 4.94 & 4.68 & 5.27 \\
\hline Chromium & $\mu \mathrm{g} / \mathrm{g}$ & 689 & 618 & 574 & 246 \\
\hline Copper & $\mu \mathrm{g} / \mathrm{g}$ & $<155$ & $<157$ & $<150$ & $<160$ \\
\hline Iron & $\mu \mathrm{g} / \mathrm{g}$ & 17400 & 21300 & 19600 & 22600 \\
\hline Lead & $\mu \mathrm{g} / \mathrm{g}$ & 50.3 & 73.1 & 62.5 & 59.9 \\
\hline Magnesium & $\mu \mathrm{g} / \mathrm{g}$ & 15700 & 10100 & 26300 & 10900 \\
\hline Manganese & $\mu \mathrm{g} / \mathrm{g}$ & 777 & 649 & 1240 & 707 \\
\hline Mercury & $\mu \mathrm{g} / \mathrm{g}$ & $<10.4$ & $<10.5$ & $<10.1$ & $<10.7$ \\
\hline Molybdenum & $\mu \mathrm{g} / \mathrm{g}$ & $<37.4$ & $<37.8$ & $<36.3$ & $<38.5$ \\
\hline Nickel & $\mu \mathrm{g} / \mathrm{g}$ & $<581$ & $<588$ & $<564$ & $<599$ \\
\hline Phosphorus & $\mu \mathrm{g} / \mathrm{g}$ & $<3710$ & $<3750$ & $<3600$ & $<3820$ \\
\hline Potassium & $\mu \mathrm{g} / \mathrm{g}$ & $<10700$ & $<10900$ & $<10400$ & $<11100$ \\
\hline Selenium & $\mu \mathrm{g} / \mathrm{g}$ & $<65.8$ & $<66.5$ & $<63.8$ & $<67.8$ \\
\hline Silicon & $\mu \mathrm{g} / \mathrm{g}$ & 137000 & 141000 & 154000 & 156000 \\
\hline Silver & $\mu \mathrm{g} / \mathrm{g}$ & $<2.13$ & $<2.15$ & $<2.07$ & $<2.19$ \\
\hline Sodium & $\mu \mathrm{g} / \mathrm{g}$ & 72100 & 63600 & 58700 & 43100 \\
\hline Strontium & $\mu \mathrm{g} / \mathrm{g}$ & 1250 & 698 & 645 & 779 \\
\hline Titanium & $\mu \mathrm{g} / \mathrm{g}$ & 2960 & 3980 & 3660 & 4290 \\
\hline Zinc & $\mu \mathrm{g} / \mathrm{g}$ & $<457$ & $<462$ & $<444$ & $<471$ \\
\hline Zirconium & $\mu \mathrm{g} / \mathrm{g}$ & $<336$ & $<340$ & $<326$ & $<346$ \\
\hline & & & & & \\
\hline Technetium-99 & $\mu \mathrm{g} / \mathrm{g}$ & 6.64 & 6.55 & 7.17 & 4.26 \\
\hline Iodine 127 & $\mu \mathrm{g} / \mathrm{g}$ & 137 & 56.6 & 48 & 31.5 \\
\hline Uranium 238 & $\mu \mathrm{g} / \mathrm{g}$ & 100 & 122 & 130 & 87.9 \\
\hline \% Dry Solids & $\mathrm{w} \mathrm{g} \%$ & 79.8 & 78.8 & 82.5 & 78.8 \\
\hline \hline
\end{tabular}


Table D-1. Total Composition of the Monoliths Used for Leach Tests (contd)

\begin{tabular}{|c|c|c|c|c|c|}
\hline \multirow{2}{*}{ Analyte } & \multirow{2}{*}{ Units } & Test 9 & Test 10 & Test 11 & Test 12 \\
\hline & & T9HCS2-7.8HIA & T10HCS1-5HIS & T11LCS1-7.8HIA & T12HCS2-5RAS \\
\hline Aluminum & $\mu \mathrm{g} / \mathrm{g}$ & 47900 & 54400 & 70400 & 45300 \\
\hline Antimony & $\mu g / g$ & $<24.0$ & $<24.7$ & $<24.8$ & $<23.0$ \\
\hline Arsenic & $\mu \mathrm{g} / \mathrm{g}$ & $<37.4$ & $<38.5$ & $<38.6$ & $<35.8$ \\
\hline Barium & $\mu \mathrm{g} / \mathrm{g}$ & 1750 & 2130 & 590 & 2130 \\
\hline Cadmium & $\mu \mathrm{g} / \mathrm{g}$ & 12.7 & 9.61 & 11.7 & $<5.91$ \\
\hline Calcium & $\mu \mathrm{g} / \mathrm{g}$ & 119000 & 161000 & 120000 & 146000 \\
\hline Cesium & $\mu \mathrm{g} / \mathrm{g}$ & 2.22 & 2.75 & 4.37 & 2.41 \\
\hline Chromium & $\mu \mathrm{g} / \mathrm{g}$ & 833 & 592 & 752 & 289 \\
\hline Copper & $\mu \mathrm{g} / \mathrm{g}$ & $<171$ & $<176$ & $<176$ & $<163$ \\
\hline Iron & $\mu \mathrm{g} / \mathrm{g}$ & 13900 & 17800 & 18400 & 16600 \\
\hline Lead & $\mu \mathrm{g} / \mathrm{g}$ & 52.7 & 49.1 & 78.2 & 36.8 \\
\hline Magnesium & $\mu \mathrm{g} / \mathrm{g}$ & 27500 & 16300 & 8860 & 32600 \\
\hline Manganese & $\mu \mathrm{g} / \mathrm{g}$ & 1150 & 807 & 560 & 1350 \\
\hline Mercury & $\mu \mathrm{g} / \mathrm{g}$ & $<11.4$ & $<11.7$ & $<11.8$ & $<10.9$ \\
\hline Molybdenum & $\mu \mathrm{g} / \mathrm{g}$ & $<41.1$ & $<42.3$ & $<42.5$ & $<39.3$ \\
\hline Nickel & $\mu \mathrm{g} / \mathrm{g}$ & $<639$ & $<658$ & $<661$ & $<611$ \\
\hline Phosphorus & $\mu \mathrm{g} / \mathrm{g}$ & $<4080$ & $<4200$ & $<4210$ & $<3900$ \\
\hline Potassium & $\mu \mathrm{g} / \mathrm{g}$ & $<11800$ & $<12200$ & $<12200$ & $<11300$ \\
\hline Selenium & $\mu \mathrm{g} / \mathrm{g}$ & $<72.3$ & $<74.5$ & $<74.7$ & $<69.1$ \\
\hline Silicon & $\mu \mathrm{g} / \mathrm{g}$ & 129000 & 142000 & 127000 & 152000 \\
\hline Silver & $\mu \mathrm{g} / \mathrm{g}$ & $<2.34$ & $<2.41$ & $<2.42$ & $<2.24$ \\
\hline Sodium & $\mu \mathrm{g} / \mathrm{g}$ & 95600 & 66100 & 89600 & 71000 \\
\hline Strontium & $\mu \mathrm{g} / \mathrm{g}$ & 1030 & 1310 & 632 & 1220 \\
\hline Titanium & $\mu \mathrm{g} / \mathrm{g}$ & 2320 & 3050 & 3500 & 2730 \\
\hline Zinc & $\mu \mathrm{g} / \mathrm{g}$ & $<503$ & $<518$ & $<519$ & $<481$ \\
\hline Zirconium & $\mu \mathrm{g} / \mathrm{g}$ & $<369$ & $<380$ & $<382$ & $<353$ \\
\hline Technetium-99 & $\mu \mathrm{g} / \mathrm{g}$ & 9.26 & 6 & 9.16 & 5.96 \\
\hline Iodine 127 & $\mu \mathrm{g} / \mathrm{g}$ & 62.1 & 36.6 & 78.5 & 47.5 \\
\hline Uranium 238 & $\mu \mathrm{g} / \mathrm{g}$ & 113 & 86.4 & 128 & 64.9 \\
\hline \% Dry Solids & $\mathrm{wt} \%$ & 75.8 & 72.4 & 74.2 & 74.0 \\
\hline
\end{tabular}


PNNL-22747

SRNL-STI-2013-00465

Table D-1. Total Composition of the Monoliths Used for Leach Tests (contd)

\begin{tabular}{|c|c|c|c|c|c|}
\hline \multirow{2}{*}{ Analyte } & \multirow{2}{*}{ Units } & Test 13 & Test 14 & Test 15 & Test 16 \\
\hline & & T13LCS2-5AVG & T14LCS2-7.8HIS & T15HCS1-7.8HIS & T16HCS1-7.8RAS \\
\hline Aluminum & $\mu g / g$ & 68500 & 68600 & 57500 & 53600 \\
\hline Antimony & $\mu \mathrm{g} / \mathrm{g}$ & $<24.7$ & $<22.3$ & $<22.7$ & $<22.2$ \\
\hline Arsenic & $\mu \mathrm{g} / \mathrm{g}$ & $<38.5$ & $<34.8$ & $<35.4$ & $<34.5$ \\
\hline Barium & $\mu \mathrm{g} / \mathrm{g}$ & 715 & 675 & 2180 & 2110 \\
\hline Cadmium & $\mu \mathrm{g} / \mathrm{g}$ & $<6.35$ & $<5.74$ & $<5.84$ & $<5.70$ \\
\hline Calcium & $\mu \mathrm{g} / \mathrm{g}$ & 130000 & 124000 & 167000 & 163000 \\
\hline Cesium & $\mu \mathrm{g} / \mathrm{g}$ & 4.74 & 4.75 & 2.69 & 2.64 \\
\hline Chromium & $\mu \mathrm{g} / \mathrm{g}$ & 541 & 576 & 620 & 346 \\
\hline Copper & $\mu \mathrm{g} / \mathrm{g}$ & $<175$ & $<158$ & $<161$ & $<157$ \\
\hline Iron & $\mu \mathrm{g} / \mathrm{g}$ & 21300 & 21200 & 18700 & 18300 \\
\hline Lead & $\mu \mathrm{g} / \mathrm{g}$ & 56.3 & 64.2 & 50.2 & 44.4 \\
\hline Magnesium & $\mu \mathrm{g} / \mathrm{g}$ & 27700 & 28000 & 16900 & 16600 \\
\hline Manganese & $\mu \mathrm{g} / \mathrm{g}$ & 1300 & 1320 & 820 & 797 \\
\hline Mercury & $\mu \mathrm{g} / \mathrm{g}$ & $<11.7$ & $<10.6$ & $<10.8$ & $<10.5$ \\
\hline Molybdenum & $\mu \mathrm{g} / \mathrm{g}$ & $<42.2$ & $<38.2$ & $<38.9$ & $<37.9$ \\
\hline Nickel & $\mu \mathrm{g} / \mathrm{g}$ & $<657$ & $<594$ & $<605$ & $<590$ \\
\hline Phosphorus & $\mu \mathrm{g} / \mathrm{g}$ & $<4190$ & $<3790$ & $<3850$ & $<3760$ \\
\hline Potassium & $\mu \mathrm{g} / \mathrm{g}$ & $<12100$ & $<11000$ & $<11200$ & $<10900$ \\
\hline Selenium & $\mu \mathrm{g} / \mathrm{g}$ & $<74.3$ & $<67.2$ & $<68.4$ & $<66.8$ \\
\hline Silicon & $\mu \mathrm{g} / \mathrm{g}$ & 164000 & 164000 & 145000 & 142000 \\
\hline Silver & $\mu \mathrm{g} / \mathrm{g}$ & $<2.41$ & $<2.18$ & $<2.21$ & $<2.16$ \\
\hline Sodium & $\mu \mathrm{g} / \mathrm{g}$ & 64500 & 67400 & 78800 & 80000 \\
\hline Strontium & $\mu \mathrm{g} / \mathrm{g}$ & 684 & 655 & 1300 & 1270 \\
\hline Titanium & $\mu \mathrm{g} / \mathrm{g}$ & 3870 & 3890 & 3180 & 3120 \\
\hline Zinc & $\mu \mathrm{g} / \mathrm{g}$ & $<517$ & $<467$ & $<476$ & $<464$ \\
\hline Zirconium & $\mu \mathrm{g} / \mathrm{g}$ & $<380$ & $<343$ & $<349$ & $<341$ \\
\hline Technetium-99 & $\mu \mathrm{g} / \mathrm{g}$ & 6.44 & 7.1 & 7.11 & 7.49 \\
\hline Iodine 127 & $\mu \mathrm{g} / \mathrm{g}$ & 49.4 & 56 & 44.3 & 58.1 \\
\hline Uranium 238 & $\mu \mathrm{g} / \mathrm{g}$ & 79.6 & 137 & 110 & 108 \\
\hline \% Dry Solids & $\mathrm{wt} \%$ & 73.1 & 81.1 & 80.0 & 81.0 \\
\hline
\end{tabular}


PNNL-22747

SRNL-STI-2013-00465

Table D-1. Total Composition of the Monoliths Used for Leach Tests (contd)

\begin{tabular}{|c|c|c|c|c|c|}
\hline \multirow{2}{*}{ Analyte } & \multirow{2}{*}{ Units } & Test 17 & Test 18 & Test 19 & Test 20 \\
\hline & & T17LCS2-5HIA & T18LCS2-7.8RAS & T19-LCS1-7.8 HIA & T20HCS2-5AVG \\
\hline Aluminum & $\mu \mathrm{g} / \mathrm{g}$ & 72200 & 68600 & 81300 & 52800 \\
\hline Antimony & $\mu \mathrm{g} / \mathrm{g}$ & $<24.1$ & $<22.0$ & $<22.8$ & $<22.9$ \\
\hline Arsenic & $\mu \mathrm{g} / \mathrm{g}$ & $<37.6$ & $<34.3$ & $<35.5$ & $<35.7$ \\
\hline Barium & $\mu \mathrm{g} / \mathrm{g}$ & 677 & 675 & 713 & 2280 \\
\hline Cadmium & $\mu \mathrm{g} / \mathrm{g}$ & $<6.20$ & $<5.67$ & 10.7 & $<5.89$ \\
\hline Calcium & $\mu \mathrm{g} / \mathrm{g}$ & 127000 & 123000 & 147000 & 156000 \\
\hline Cesium & $\mu \mathrm{g} / \mathrm{g}$ & 4.56 & 4.52 & 4.73 & 2.74 \\
\hline Chromium & $\mu \mathrm{g} / \mathrm{g}$ & 514 & 336 & 518 & 408 \\
\hline Copper & $\mu \mathrm{g} / \mathrm{g}$ & $<171$ & $<156$ & $<162$ & $<163$ \\
\hline Iron & $\mu \mathrm{g} / \mathrm{g}$ & 20900 & 21600 & 22600 & 18600 \\
\hline Lead & $\mu \mathrm{g} / \mathrm{g}$ & 59.7 & 60.3 & 70.5 & 28.8 \\
\hline Magnesium & $\mu \mathrm{g} / \mathrm{g}$ & 28200 & 29200 & 10500 & 36600 \\
\hline Manganese & $\mu \mathrm{g} / \mathrm{g}$ & 1290 & 1360 & 675 & 1570 \\
\hline Mercury & $\mu \mathrm{g} / \mathrm{g}$ & $<11.5$ & $<10.5$ & $<10.8$ & $<10.9$ \\
\hline Molybdenum & $\mu \mathrm{g} / \mathrm{g}$ & $<41.3$ & $<37.7$ & $<39.0$ & $<39.2$ \\
\hline Nickel & $\mu \mathrm{g} / \mathrm{g}$ & $<642$ & $<586$ & $<607$ & $<610$ \\
\hline Phosphorus & $\mu \mathrm{g} / \mathrm{g}$ & $<4090$ & $<3740$ & $<3870$ & $<3890$ \\
\hline Potassium & $\mu \mathrm{g} / \mathrm{g}$ & 13000 & $<10800$ & 13200 & $<11300$ \\
\hline Selenium & $\mu \mathrm{g} / \mathrm{g}$ & $<72.6$ & $<66.3$ & $<68.7$ & $<69.0$ \\
\hline Silicon & $\mu \mathrm{g} / \mathrm{g}$ & 160000 & 171000 & 151000 & 167000 \\
\hline Silver & $\mu \mathrm{g} / \mathrm{g}$ & $<2.35$ & $<2.15$ & $<2.22$ & $<2.23$ \\
\hline Sodium & $\mu \mathrm{g} / \mathrm{g}$ & 63800 & 70100 & 75200 & 54300 \\
\hline Strontium & $\mu \mathrm{g} / \mathrm{g}$ & 674 & 654 & 745 & 1300 \\
\hline Titanium & $\mu \mathrm{g} / \mathrm{g}$ & 3850 & 4030 & 4210 & 3080 \\
\hline Zinc & $\mu \mathrm{g} / \mathrm{g}$ & $<505$ & $<461$ & $<478$ & $<479$ \\
\hline Zirconium & $\mu \mathrm{g} / \mathrm{g}$ & $<371$ & $<339$ & $<351$ & $<352$ \\
\hline Technetium-99 & $\mu \mathrm{g} / \mathrm{g}$ & 6.41 & 7.26 & 6.78 & 4.51 \\
\hline Iodine 127 & $\mu \mathrm{g} / \mathrm{g}$ & 50.6 & 57.7 & 55.2 & 24.8 \\
\hline Uranium 238 & $\mu \mathrm{g} / \mathrm{g}$ & 106 & 128 & 127 & 71.4 \\
\hline \% Dry Solids & $\mathrm{wt} \%$ & 72.9 & 80.8 & 80.2 & 80.2 \\
\hline
\end{tabular}


Table D-1. Total Composition of the Monoliths Used for Leach Tests (contd)

\begin{tabular}{|c|c|c|c|c|c|}
\hline \multirow{2}{*}{ Analyte } & \multirow{2}{*}{ Units } & Test 21 & Test 22 & Test 23 & Test 24 \\
\hline & & T21LCS1-7.8HIS & T22HCS2-7.8AVG & T23LCS1-7.8RAS & T24HCS1-5HIA \\
\hline Aluminum & $\mu \mathrm{g} / \mathrm{g}$ & 73300 & 49100 & 67700 & 63500 \\
\hline Antimony & $\mu \mathrm{g} / \mathrm{g}$ & $<24.4$ & $<23.4$ & $<24.6$ & $<25.2$ \\
\hline Arsenic & $\mu \mathrm{g} / \mathrm{g}$ & $<38.0$ & $<36.4$ & $<38.3$ & $<39.2$ \\
\hline Barium & $\mu \mathrm{g} / \mathrm{g}$ & 637 & 1920 & 575 & 2240 \\
\hline Cadmium & $\mu \mathrm{g} / \mathrm{g}$ & $<6.28$ & $<6.02$ & $<6.32$ & $<6.48$ \\
\hline Calcium & $\mu \mathrm{g} / \mathrm{g}$ & 131000 & 131000 & 115000 & 164000 \\
\hline Cesium & $\mu \mathrm{g} / \mathrm{g}$ & 4.5 & 2.32 & 4.34 & 2.69 \\
\hline Chromium & $\mu \mathrm{g} / \mathrm{g}$ & 756 & 828 & 409 & 534 \\
\hline Copper & $\mu \mathrm{g} / \mathrm{g}$ & $<173$ & $<166$ & $<174$ & $<179$ \\
\hline Iron & $\mu \mathrm{g} / \mathrm{g}$ & 21300 & 15800 & 19800 & 20200 \\
\hline Lead & $\mu \mathrm{g} / \mathrm{g}$ & 79.6 & 52.7 & 76.9 & 45.8 \\
\hline Magnesium & $\mu \mathrm{g} / \mathrm{g}$ & 10000 & 31500 & 9570 & 18600 \\
\hline Manganese & $\mu \mathrm{g} / \mathrm{g}$ & 640 & 1340 & 465 & 777 \\
\hline Mercury & $\mu \mathrm{g} / \mathrm{g}$ & $<11.6$ & $<11.1$ & $<11.7$ & $<12.0$ \\
\hline Molybdenum & $\mu \mathrm{g} / \mathrm{g}$ & $<41.8$ & $<40.0$ & $<42.0$ & $<43.1$ \\
\hline Nickel & $\mu \mathrm{g} / \mathrm{g}$ & $<650$ & $<623$ & $<654$ & $<671$ \\
\hline Phosphorus & $\mu \mathrm{g} / \mathrm{g}$ & $<4140$ & $<3970$ & $<4170$ & $<4270$ \\
\hline Potassium & $\mu \mathrm{g} / \mathrm{g}$ & $<12000$ & $<11500$ & $<12100$ & $<12400$ \\
\hline Selenium & $\mu \mathrm{g} / \mathrm{g}$ & $<73.6$ & $<70.5$ & $<74.0$ & $<75.9$ \\
\hline Silicon & $\mu \mathrm{g} / \mathrm{g}$ & 144000 & 142000 & 133000 & 157000 \\
\hline Silver & $\mu \mathrm{g} / \mathrm{g}$ & $<2.38$ & $<2.28$ & $<2.39$ & $<2.45$ \\
\hline Sodium & $\mu \mathrm{g} / \mathrm{g}$ & 93200 & 101000 & 86000 & 76700 \\
\hline Strontium & $\mu \mathrm{g} / \mathrm{g}$ & 661 & 1090 & 577 & 1280 \\
\hline Titanium & $\mu \mathrm{g} / \mathrm{g}$ & 3990 & 2620 & 3690 & 3380 \\
\hline Zinc & $\mu \mathrm{g} / \mathrm{g}$ & $<511$ & $<490$ & $<514$ & $<527$ \\
\hline Zirconium & $\mu \mathrm{g} / \mathrm{g}$ & $<376$ & $<360$ & $<378$ & $<387$ \\
\hline Technetium-99 & $\mu \mathrm{g} / \mathrm{g}$ & 9.68 & 9.7 & 9.9 & 6.67 \\
\hline Iodine 127 & $\mu \mathrm{g} / \mathrm{g}$ & 87.3 & 84.5 & 92.3 & 51.2 \\
\hline Uranium 238 & $\mu \mathrm{g} / \mathrm{g}$ & 194 & 1050 & 193 & 101 \\
\hline \% Dry Solids & $\mathrm{wt} \%$ & 73.6 & 74.2 & 74.0 & 72.5 \\
\hline
\end{tabular}


PNNL-22747

SRNL-STI-2013-00465

Table D-1. Total Composition of the Monoliths Used for Leach Tests (contd)

\begin{tabular}{|c|c|c|c|}
\hline \multirow{2}{*}{ Analyte } & \multirow{2}{*}{ Units } & Test 25 & Test 26 \\
\hline & & T25HCS1-7.8HIS & T26LCS1-7.8HIS \\
\hline Aluminum & $\mu \mathrm{g} / \mathrm{g}$ & 55600 & 55400 \\
\hline Antimony & $\mu \mathrm{g} / \mathrm{g}$ & $<22.9$ & $<24.6$ \\
\hline Arsenic & $\mu \mathrm{g} / \mathrm{g}$ & $<35.7$ & $<38.3$ \\
\hline Barium & $\mu \mathrm{g} / \mathrm{g}$ & 1890 & 1950 \\
\hline Cadmium & $\mu \mathrm{g} / \mathrm{g}$ & $<5.89$ & $<6.33$ \\
\hline Calcium & $\mu \mathrm{g} / \mathrm{g}$ & 137000 & 143000 \\
\hline Cesium & $\mu \mathrm{g} / \mathrm{g}$ & 2.71 & 2.45 \\
\hline Chromium & $\mu \mathrm{g} / \mathrm{g}$ & 578 & 807 \\
\hline Copper & $\mu \mathrm{g} / \mathrm{g}$ & $<163$ & $<175$ \\
\hline Iron & $\mu \mathrm{g} / \mathrm{g}$ & 16600 & 17000 \\
\hline Lead & $\mu \mathrm{g} / \mathrm{g}$ & 50 & 59.6 \\
\hline Magnesium & $\mu \mathrm{g} / \mathrm{g}$ & 15100 & 15600 \\
\hline Manganese & $\mu \mathrm{g} / \mathrm{g}$ & 613 & 636 \\
\hline Mercury & $\mu \mathrm{g} / \mathrm{g}$ & $<10.9$ & $<11.7$ \\
\hline Molybdenum & $\mu \mathrm{g} / \mathrm{g}$ & $<39.2$ & $<42.1$ \\
\hline Nickel & $\mu \mathrm{g} / \mathrm{g}$ & $<610$ & $<655$ \\
\hline Phosphorus & $\mu \mathrm{g} / \mathrm{g}$ & $<3880$ & $<4180$ \\
\hline Potassium & $\mu \mathrm{g} / \mathrm{g}$ & $<11300$ & $<12100$ \\
\hline Selenium & $\mu \mathrm{g} / \mathrm{g}$ & $<68.9$ & $<74.1$ \\
\hline Silicon & $\mu \mathrm{g} / \mathrm{g}$ & 128000 & 132000 \\
\hline Silver & $\mu \mathrm{g} / \mathrm{g}$ & $<2.23$ & $<2.40$ \\
\hline Sodium & $\mu \mathrm{g} / \mathrm{g}$ & 60200 & 96100 \\
\hline Strontium & $\mu \mathrm{g} / \mathrm{g}$ & 1070 & 1110 \\
\hline Titanium & $\mu \mathrm{g} / \mathrm{g}$ & 2750 & 2820 \\
\hline Zinc & $\mu \mathrm{g} / \mathrm{g}$ & $<479$ & $<515$ \\
\hline Zirconium & $\mu \mathrm{g} / \mathrm{g}$ & $<352$ & $<378$ \\
\hline Technetium-99 & $\mu \mathrm{g} / \mathrm{g}$ & 7 & 9.69 \\
\hline Iodine 127 & $\mu \mathrm{g} / \mathrm{g}$ & 60.6 & 77.9 \\
\hline Uranium 238 & $\mu \mathrm{g} / \mathrm{g}$ & 134 & 86.5 \\
\hline \% Dry Solids & $\mathrm{wt} \%$ & 80.5 & 74.3 \\
\hline
\end{tabular}




\section{D.2 Compressive Strength}

Compressive strength measurements for three cylindrical samples (referred to as repeats) of each of the Cast Stone mixes are presented in Table D-2 for the PNNL results and Table D-3 for the SRNL results. SRNL did not re-batch and test the 12 mixes that were mis-batched, so there are no SRNL data for those mixes (nor any PNNL data for the mixes mis-batched by SRNL). The tables also show the means and standard deviations (SDs) for the three repeat results. The "Repeat SDs" represent the variation in making three cylindrical samples from each mix and measuring compressive strength. The results are presented in units of pounds per square inch (psi) and megapascals (MPa). The mean values in psi units from the PNNL data (Table D-2) were used as the compressive strength response values for plots and statistical analyses of the data from the 26 mixes. Note that only the PNNL compressive strength data were statistically analyzed. 
PNNL-22747

SRNL-STI-2013-00465

Table D-2. PNNL Compressive Strength Results for 26 Cast Stone Mixes

\begin{tabular}{|c|c|c|c|c|c|c|c|c|c|c|c|}
\hline \multirow{3}{*}{$\begin{array}{c}\text { Test/Mix } \\
\#^{(a)}\end{array}$} & \multirow{3}{*}{$\begin{array}{c}\text { Random } \\
\text { Run } \\
\text { Order }\end{array}$} & \multicolumn{5}{|c|}{ Compressive Strength (psi) ${ }^{(\mathbf{b})}$} & \multicolumn{5}{|c|}{ Compressive Strength (MPa) } \\
\hline & & \multicolumn{3}{|c|}{ Repeats } & \multicolumn{2}{|c|}{ Summary } & \multicolumn{3}{|c|}{ Repeats } & \multicolumn{2}{|c|}{ Summary } \\
\hline & & 1 & 2 & 3 & Mean & SD & 1 & 2 & 3 & Mean & SD \\
\hline 1 & 7 & 4633 & 4424 & 4173 & 4410 & 230.3 & 31.94 & 30.50 & 28.77 & 30.40 & 1.587 \\
\hline $2 @$ & 11 & 4809 & 4844 & 4823 & 4825 & 17.6 & 33.16 & 33.40 & 33.25 & 33.27 & 0.121 \\
\hline $3 \$$ & 3 & 2522 & 2550 & 2428 & 2500 & 63.9 & 17.39 & 17.58 & 16.74 & 17.24 & 0.440 \\
\hline 4 & 5 & 8988 & 7237 & 7878 & 8034 & 885.9 & 61.97 & 49.90 & 54.32 & 55.40 & 6.107 \\
\hline 5 & 9 & 5123 & 4991 & 5153 & 5089 & 86.2 & 35.32 & 34.41 & 35.53 & 35.09 & 0.595 \\
\hline 6 & 12 & 3198 & 2937 & 3244 & 3126 & 165.6 & 22.05 & 20.25 & 22.37 & 21.56 & 1.143 \\
\hline $7 \#$ & 14 & 6931 & 6537 & 5865 & 6444 & 539.0 & 47.79 & 45.07 & 40.44 & 44.43 & 3.716 \\
\hline 8 & 1 & 1768 & 1774 & 1716 & 1753 & 31.9 & 12.19 & 12.23 & 11.83 & 12.08 & 0.220 \\
\hline 9 & 10 & 1955 & 1926 & 1404 & 1762 & 310.1 & 13.48 & 13.28 & 9.68 & 12.15 & 2.139 \\
\hline 10 & 13 & 3472 & 2608 & 1787 & 2622 & 842.6 & 23.94 & 17.98 & 12.32 & 18.08 & 5.811 \\
\hline 11 & 6 & 847 & 875 & 848 & 857 & 15.9 & 5.84 & 6.03 & 5.85 & 5.91 & 0.107 \\
\hline 12 & 8 & 6247 & 6467 & 6527 & 6414 & 147.4 & 43.07 & 44.59 & 45.00 & 44.22 & 1.017 \\
\hline $13 @$ & 4 & 4840 & 4872 & 4809 & 4840 & 31.5 & 33.37 & 33.59 & 33.16 & 33.37 & 0.215 \\
\hline $14 \mathrm{H}$ & 2 & 6696 & 6454 & 6856 & 6669 & 202.4 & 46.17 & 44.50 & 47.27 & 45.98 & 1.395 \\
\hline $15 \%$ & 17 & 4543 & 4570 & 5819 & 4977 & 729.0 & 31.32 & 31.51 & 40.12 & 34.32 & 5.027 \\
\hline 16 & 22 & 5324 & 6039 & 6454 & 5939 & 571.6 & 36.71 & 41.64 & 44.50 & 40.95 & 3.941 \\
\hline 17 & 25 & 3681 & 4209 & 4099 & 3996 & 278.6 & 25.38 & 29.02 & 28.26 & 27.55 & 1.920 \\
\hline 18 & 16 & 7227 & 7298 & 7388 & 7304 & 80.7 & 49.83 & 50.32 & 50.94 & 50.36 & 0.556 \\
\hline 19 & 15 & 2995 & 2554 & 2996 & 2848 & 254.9 & 20.65 & 17.61 & 20.66 & 19.64 & 1.758 \\
\hline 20 & 24 & 7778 & 7929 & 7361 & 7689 & 294.2 & 53.63 & 54.67 & 50.75 & 53.02 & 2.031 \\
\hline $21 \&$ & 23 & 1411 & 1336 & 1329 & 1359 & 45.5 & 9.73 & 9.21 & 9.16 & 9.37 & 0.316 \\
\hline $22 \$$ & 19 & 2316 & 2287 & 2587 & 2397 & 165.5 & 15.97 & 15.77 & 17.84 & 16.53 & 1.142 \\
\hline 23 & 20 & 1578 & 1546 & 1803 & 1642 & 140.1 & 10.88 & 10.66 & 12.43 & 11.32 & 0.965 \\
\hline 24 & 26 & 3588 & 3292 & 3610 & 3497 & 177.6 & 24.74 & 22.70 & 24.89 & 24.11 & 1.223 \\
\hline $25 \%$ & 21 & 6032 & 6295 & 6209 & 6179 & 134.1 & 41.59 & 43.40 & 42.81 & 42.60 & 0.923 \\
\hline $26 \&$ & 18 & 922 & 980 & 940 & 947 & 29.7 & 6.36 & 6.76 & 6.48 & 6.53 & 0.205 \\
\hline \multicolumn{12}{|c|}{$\begin{array}{l}\text { (a) Test numbers with the same symbols are replicates. } \\
\text { (b) The repeat values were rounded to zero decimal places before calculating the mean and SD. After the mean } \\
\text { and SD were calculated, they were rounded to zero and one decimal places, respectively. } \\
\text { (c) The repeat values were rounded to two decimal places before calculating the mean and SD. After the mean } \\
\text { and SD were calculated, they were rounded to two and three decimal places, respectively. }\end{array}$} \\
\hline
\end{tabular}


PNNL-22747

SRNL-STI-2013-00465

Table D-3. SRNL Compressive Strength Results for 26 Cast Stone Mixes

\begin{tabular}{|c|c|c|c|c|c|c|c|c|c|c|c|}
\hline \multirow{3}{*}{\begin{tabular}{||c}
$\#^{(a)}$ \\
Test/Mix
\end{tabular}} & \multirow{3}{*}{$\begin{array}{c}\text { Random } \\
\text { Run } \\
\text { Order } \\
\end{array}$} & \multicolumn{5}{|c|}{ "Compressive Strength (psi) ${ }^{(\mathbf{b})}$} & \multicolumn{5}{|c|}{ "Compressive Strength (MPa) ${ }^{(\mathrm{c})}$} \\
\hline & & \multicolumn{3}{|c|}{ Repeats } & \multicolumn{2}{|c|}{ Summary } & \multicolumn{3}{|c|}{ Repeats } & \multicolumn{2}{|c|}{ Summary } \\
\hline & & 1 & 2 & 3 & Mean & SD & 1 & 2 & 3 & Mean & SD \\
\hline 1 & 7 & 3591 & 2940 & 3007 & 3179 & 358.1 & 24.76 & 20.27 & 20.73 & 21.92 & 2.470 \\
\hline a, & 11 & 4623 & 4737 & 4302 & 4554 & 225.6 & 31.87 & 32.66 & 29.66 & 31.40 & 1.555 \\
\hline 3 & $-(\mathrm{e})$ & - & - & - & - & - & - & - & - & - & - \\
\hline 4 & - & - & - & - & - & - & - & - & - & - & - \\
\hline 5 & - & - & - & - & - & - & - & - & - & - & - \\
\hline 6 & 12 & 2871 & 2925 & 2834 & 2877 & 45.8 & 19.79 & 20.17 & 19.54 & 19.83 & 0.317 \\
\hline 7 & 14 & 5575 & 5845 & 5594 & 5671 & 150.7 & 38.44 & 40.30 & 38.57 & 39.10 & 1.038 \\
\hline 8 & 1 & 1661 & 1660 & 1654 & 1658 & 3.8 & 11.45 & 11.45 & 11.40 & 11.43 & 0.029 \\
\hline 9 & - & - & - & - & - & - & - & - & - & - & - \\
\hline 10 & - & - & - & - & - & - & - & - & - & - & - \\
\hline 11 & 6 & 1065 & 1078 & 1070 & 1071 & 6.6 & 7.34 & 7.43 & 7.38 & 7.38 & 0.045 \\
\hline 12 & - & & & & & & & & & & \\
\hline 13 & 4 & 4671 & 4970 & 4555 & 4732 & 214.1 & 32.21 & 34.27 & 31.41 & 32.63 & 1.476 \\
\hline 14 & 2 & 5584 & 5557 & 5516 & 5552 & 34.2 & 38.50 & 38.31 & 38.03 & 38.28 & 0.236 \\
\hline 15 & - & - & - & - & - & - & - & - & - & - & - \\
\hline 16 & - & - & - & - & - & - & - & - & - & - & - \\
\hline 17 & 25 & 5131 & 4594 & 5050 & 4925 & 289.5 & 35.38 & 31.67 & 34.82 & 33.96 & 2.000 \\
\hline 18 & 16 & 6282 & 5930 & 6081 & 6098 & 176.6 & 43.31 & 40.89 & 41.93 & 42.04 & 1.214 \\
\hline 19 & 15 & 3164 & 3123 & 3106 & 3131 & 29.8 & 21.82 & 21.53 & 21.42 & 21.59 & 0.207 \\
\hline 20 & - & - & - & - & - & - & - & - & - & - & - \\
\hline 21 & 23 & 1011 & 1218 & 1057 & 1095 & 108.7 & 6.97 & 8.40 & 7.29 & 7.55 & 0.750 \\
\hline 22 & - & - & - & - & - & - & - & - & - & - & - \\
\hline 23 & 20 & $190^{(\mathrm{d})}$ & 1683 & 1360 & 1522 & 228.4 & $1.31^{(\mathrm{d})}$ & 11.60 & 9.38 & 10.49 & 1.570 \\
\hline 24 & - & - & - & - & - & - & - & - & - & - & - \\
\hline 25 & - & - & - & - & - & - & - & - & - & - & - \\
\hline 26 & 18 & 1166 & 1168 & 1137 & 1157 & 17.3 & 8.04 & 8.05 & 7.84 & 7.98 & 0.118 \\
\hline $27(3 a)$ & 3 & 1329 & 1363 & 1380 & 1357 & 26.0 & 9.16 & 9.40 & 9.51 & 9.36 & 0.179 \\
\hline $28(4 a)$ & 5 & 7683 & 7575 & 7807 & 7688 & 116.1 & 52.97 & 52.23 & 53.83 & 53.01 & 0.801 \\
\hline $29(5 a)$ & 9 & 5074 & 5281 & 5124 & 5160 & 108.0 & 34.98 & 36.41 & 35.33 & 35.57 & 0.745 \\
\hline $30(9 a)$ & 10 & 1332 & 1355 & 1385 & 1357 & 26.6 & 9.18 & 9.34 & 9.55 & 9.36 & 0.186 \\
\hline $31(10 a)$ & 13 & 4381 & 4585 & 4713 & 4560 & 167.4 & 30.21 & 31.61 & 32.49 & 31.44 & 1.150 \\
\hline $32(12 a)$ & 8 & 4189 & 4348 & 3930 & 4156 & 211.0 & 28.88 & 29.98 & 27.10 & 28.65 & 1.453 \\
\hline $33(15 a)$ & 17 & 5023 & 4839 & 4338 & 4733 & 354.5 & 34.63 & 33.36 & 29.91 & 32.63 & 2.442 \\
\hline 34 (16a) & 22 & 7263 & 7238 & 6809 & 7103 & 255.2 & 50.08 & 49.90 & 46.95 & 48.98 & 1.757 \\
\hline $35(20 a)$ & 24 & 6928 & 6116 & 6836 & 6627 & 444.6 & 47.77 & 42.17 & 47.13 & 45.69 & 3.065 \\
\hline $36(22 a)$ & 19 & 1382 & 1381 & 1366 & 1376 & 9.0 & 9.53 & 9.52 & 9.42 & 9.49 & 0.061 \\
\hline $37(24 a)$ & 26 & 5018 & 5085 & 5307 & 5137 & 151.3 & 34.60 & 35.06 & 36.59 & 35.42 & 1.042 \\
\hline $38(25 a) *$ & 21 & 5134 & 4798 & 5088 & 5007 & 182.2 & 35.40 & 33.08 & 35.08 & 34.52 & 1.257 \\
\hline \multicolumn{12}{|c|}{$\begin{array}{l}\text { (a) Test numbers with the same symbols are replicates. } \\
\text { (b) The repeat values were rounded to zero decimal places before calculating the Mean and SD. After the mean } \\
\text { and SD were calculated, they were rounded to zero and one decimal places, respectively. } \\
\text { (c) The repeat values were rounded to one decimal place before calculating the mean and SD. After the mean } \\
\text { and SD were calculated, they were rounded to one and two decimal places, respectively. } \\
\text { (d) This value was judged to be an outlier and was not used to calculate the mean and SD. } \\
\text { (e) A dash (-) denotes mixes that were not re-made and tested after originally being mis-batched. }\end{array}$} \\
\hline
\end{tabular}




\section{D.3 Density, Surface Area, and Volume of PNNL Cast Stone Specimens}

Table D-4 lists the cured monolith density, surface area, and volume of each of the six cylinders prepared from Cast Stone Mixes 1-26 made at PNNL. The average of three diameter measurements and the average of three overall length measurements were used to determine the volume of each monolith. Each monolith was weighed to determine its mass. The mass of the monolith was divided by the calculated volume resulting in the cured density. Cylinder surface areas and volumes were calculated from the average measured monolith dimensions. 
Table D-4. Cast Stone Monolith Density, Surface Area, and Volume

\begin{tabular}{|c|c|c|c|c|c|c|c|}
\hline Mix \#1 Sample Name & $\begin{array}{l}\text { Cast Stone } \\
\text { Cylinder } \\
\text { Density } \\
\text { (g/cc) }\end{array}$ & $\begin{array}{c}\text { Cast Stone } \\
\text { Cylinder } \\
\text { Surface Area } \\
\left(\mathrm{cm}^{2}\right)\end{array}$ & $\begin{array}{l}\text { Cast Stone } \\
\text { Cylinder } \\
\text { Volume } \\
\text { (cc) }\end{array}$ & Mix \#2 Sample Name & $\begin{array}{l}\text { Cast Stone } \\
\text { Cylinder } \\
\text { Density } \\
(\mathrm{g} / \mathrm{cc})\end{array}$ & $\begin{array}{c}\text { Cast Stone } \\
\text { Cylinder } \\
\text { Surface Area } \\
\left(\mathrm{cm}^{2}\right)\end{array}$ & $\begin{array}{l}\text { Cast Stone } \\
\text { Cylinder } \\
\text { Volume } \\
\text { (cc) }\end{array}$ \\
\hline CS-T1LCS1-5HIS-1 & 1.87 & 196 & 195 & CS-T2LCS2-5AVG-1 & 1.74 & 193 & 190 \\
\hline CS-T1LCS1-5HIS-2 & 1.86 & 197 & 196 & CS-T2LCS2-5AVG-2 & 1.72 & 196 & 194 \\
\hline CS-T1LCS1-5HIS-3 & 1.87 & 194 & 192 & CS-T2LCS2-5AVG-3 & 1.71 & 196 & 195 \\
\hline CS-T1LCS1-5HIS-4 & 1.89 & 196 & 193 & CS-T2LCS2-5AVG-4 & 1.72 & 196 & 194 \\
\hline CS-T1LCS1-5HIS-5 & 1.87 & 197 & 195 & CS-T2LCS2-5AVG-5 & 1.74 & 194 & 191 \\
\hline CS-T1LCS1-5HIS-6 & 1.85 & 197 & 197 & CS-T2LCS2-5AVG-6 & 1.73 & 196 & 193 \\
\hline Mix \#3 Sample Name & & & & Mix \#4 Sample Name & & & \\
\hline CS-T3HCS2-7.8AVG-1 & 1.77 & 196 & 195 & CS-T4HCS2-5HIA-1 & 1.94 & 196 & 193 \\
\hline CS-T3HCS2-7.8AVG-2 & 1.78 & 196 & 194 & CS-T4HCS2-5HIA-2 & 1.94 & 195 & 192 \\
\hline CS-T3HCS2-7.8AVG-3 & 1.76 & 196 & 194 & CS-T4HCS2-5HIA-3 & 1.92 & 196 & 194 \\
\hline CS-T3HCS2-7.8AVG-4 & 1.76 & 197 & 196 & CS-T4HCS2-5HIA-4 & 1.94 & 197 & 194 \\
\hline CS-T3HCS2-7.8AVG-5 & 1.77 & 195 & 193 & CS-T4HCS2-5HIA-5 & 1.94 & 195 & 193 \\
\hline CS-T3HCS2-7.8AVG-6 & 1.76 & 197 & 197 & CS-T4HCS2-5HIA-6 & 1.97 & 193 & 189 \\
\hline Mix \#5 Sample Name & & & & Mix \#6 Sample Name & & & \\
\hline CS-T5HCS1-7.8AVG-1 & 1.98 & 194 & 191 & CS-T6LCS1-7.8AVG-1 & 1.92 & 196 & 193 \\
\hline CS-T5HCS1-7.8AVG-2 & 1.95 & 197 & 195 & CS-T6LCS1-7.8AVG-2 & 1.90 & 195 & 193 \\
\hline CS-T5HCS1-7.8AVG-3 & 1.95 & 196 & 194 & CS-T6LCS1-7.8AVG-3 & 1.91 & 197 & 196 \\
\hline CS-T5HCS1-7.8AVG-4 & 1.95 & 197 & 195 & CS-T6LCS1-7.8AVG-4 & 1.92 & 194 & 192 \\
\hline CS-T5HCS1-7.8AVG-5 & 1.96 & 193 & 190 & CS-T6LCS1-7.8AVG-5 & 1.90 & 196 & 194 \\
\hline CS-T5HCS1-7.8AVG-6 & 1.96 & 196 & 194 & CS-T6LCS1-7.8AVG-6 & 1.90 & 195 & 193 \\
\hline Mix \#7 Sample Name & & & & Mix \#8 Sample Name & & & \\
\hline CS-T7LCS2-7.8HIS-1 & 1.95 & 195 & 193 & CS-T8LCS1-5RAS-1 & 1.89 & 194 & 192 \\
\hline CS-T7LCS2-7.8HIS-2 & 1.94 & 195 & 193 & CS-T8LCS1-5RAS-2 & 1.89 & 194 & 192 \\
\hline CS-T7LCS2-7.8HIS-3 & 1.96 & 195 & 193 & CS-T8LCS1-5RAS-3 & 1.88 & 195 & 193 \\
\hline CS-T7LCS2-7.8HIS-4 & 1.94 & 195 & 193 & CS-T8LCS1-5RAS-4 & 1.87 & 196 & 195 \\
\hline CS-T7LCS2-7.8HIS-5 & 1.92 & 198 & 197 & CS-T8LCS1-5RAS-5 & 1.89 & 194 & 191 \\
\hline CS-T7LCS2-7.8HIS-6 & 1.94 & 196 & 194 & CS-T8LCS1-5RAS-7 & 1.86 & 196 & 195 \\
\hline
\end{tabular}


Table D-4. Cast Stone Monolith Density, Surface Area, and Volume (contd)

\begin{tabular}{|c|c|c|c|c|c|c|c|}
\hline Mix \#9 Sample Name & $\begin{array}{c}\text { Cast Stone } \\
\text { Cylinder } \\
\text { Density } \\
(\mathrm{g} / \mathrm{cc}) \\
\end{array}$ & $\begin{array}{c}\text { Cast Stone } \\
\text { Cylinder } \\
\text { Surface Area } \\
\left(\mathrm{cm}^{2}\right) \\
\end{array}$ & $\begin{array}{c}\text { Cast Stone } \\
\text { Cylinder } \\
\text { Volume } \\
\text { (cc) } \\
\end{array}$ & Mix \#10 Sample Name & $\begin{array}{c}\text { Cast Stone } \\
\text { Cylinder } \\
\text { Density } \\
(\mathrm{g} / \mathrm{cc}) \\
\end{array}$ & $\begin{array}{c}\text { Cast Stone } \\
\text { Cylinder } \\
\text { Surface Area } \\
\left(\mathrm{cm}^{2}\right) \\
\end{array}$ & $\begin{array}{c}\text { Cast Stone } \\
\text { Cylinder } \\
\text { Volume } \\
\text { (cc) } \\
\end{array}$ \\
\hline CS-T9HCS2-7.8HIA-1 & 1.79 & 195 & 193 & CS-T10HCS1-5HIS-1 & 1.79 & 193 & 190 \\
\hline CS-T9HCS2-7.8HIA-2 & 1.78 & 196 & 195 & CS-T10HCS1-5HIS-2 & 1.78 & 195 & 193 \\
\hline CS-T9HCS2-7.8HIA-3 & 1.80 & 195 & 192 & CS-T10HCS1-5HIS-3 & 1.77 & 193 & 191 \\
\hline CS-T9HCS2-7.8HIA-4 & 1.78 & 196 & 194 & CS-T10HCS1-5HIS-4 & 1.80 & 192 & 188 \\
\hline CS-T9HCS2-7.8HIA-5 & 1.82 & 196 & 193 & CS-T10HCS1-5HIS-5 & 1.81 & 191 & 187 \\
\hline CS-T9HCS2-7.8HIA-6 & 1.80 & 195 & 192 & CS-T10HCS1-5HIS-6 & 1.78 & 194 & 192 \\
\hline Mix \#11 Sample Name & & & & Mix \#12 Sample Name & & & \\
\hline CS-T11LCS1-7.8HIA-1 & 1.75 & 196 & 194 & CS-T12HCS2-5RAS-1 & 1.82 & 190 & 186 \\
\hline CS-T11LCS1-7.8HIA-2 & 1.77 & 195 & 192 & CS-T12HCS2-5RAS-2 & 1.81 & 192 & 189 \\
\hline CS-T11LCS1-7.8HIA-3 & 1.78 & 195 & 192 & CS-T12HCS2-5RAS-3 & 1.79 & 194 & 191 \\
\hline CS-T11LCS1-7.8HIA-4 & 1.74 & 197 & 196 & CS-T12HCS2-5RAS-4 & 1.80 & 194 & 192 \\
\hline CS-T11LCS1-7.8HIA-5 & 1.75 & 195 & 193 & CS-T12HCS2-5RAS-5 & 1.78 & 196 & 195 \\
\hline CS-T11LCS1-7.8HIA-6 & 1.76 & 195 & 193 & CS-T12HCS2-5RAS-6 & 1.80 & 193 & 190 \\
\hline Mix \#13 Sample Name & & & & Mix \#14 Sample Name & & & \\
\hline CS-T13LCS2-5AVG-1 & 1.68 & 197 & 195 & CS-T14LCS2-7.8HIS-1 & 1.92 & 194 & 192 \\
\hline CS-T13LCS2-5AVG-2 & 1.71 & 196 & 195 & CS-T14LCS2-7.8HIS-2 & 1.94 & 194 & 191 \\
\hline CS-T13LCS2-5AVG-3 & 1.71 & 196 & 194 & CS-T14LCS2-7.8HIS-3 & 1.91 & 197 & 195 \\
\hline CS-T13LCS2-5AVG-4 & 1.71 & 196 & 194 & CS-T14LCS2-7.8HIS-4 & 1.93 & 194 & 191 \\
\hline CS-T13LCS2-5AVG-5 & 1.73 & 194 & 192 & CS-T14LCS2-7.8HIS-5 & 1.93 & 194 & 191 \\
\hline CS-T13LCS2-5AVG-6 & 1.71 & 196 & 194 & CS-T14LCS2-7.8HIS-6 & 1.90 & 198 & 197 \\
\hline Mix \#15 Sample Name & & & & Mix \#16 Sample Name & & & \\
\hline CS-T15HCS1-7.8HIS-1 & 1.95 & 195 & 193 & CS-T16HCS1-7.8RAS-1 & 1.97 & 194 & 192 \\
\hline CS-T15HCS1-7.8HIS-2 & 1.97 & 194 & 191 & CS-T16HCS1-7.8RAS-2 & 1.97 & 195 & 193 \\
\hline CS-T15HCS1-7.8HIS-3 & 1.96 & 195 & 193 & CS-T16HCS1-7.8RAS-3 & 1.98 & 194 & 191 \\
\hline CS-T15HCS1-7.8HIS-4 & 1.95 & 196 & 194 & CS-T16HCS1-7.8RAS-4 & 1.97 & 194 & 192 \\
\hline CS-T15HCS1-7.8HIS-5 & 1.94 & 196 & 194 & CS-T16HCS1-7.8RAS-5 & 1.98 & 193 & 190 \\
\hline CS-T15HCS1-7.8HIS-6 & 1.92 & 198 & 197 & CS-T16HCS1-7.8RAS-6 & 2.04 & 191 & 186 \\
\hline
\end{tabular}


Table D-4. Cast Stone Monolith Density, Surface Area, and Volume (contd)

\begin{tabular}{|c|c|c|c|c|c|c|c|}
\hline Mix \#17 Sample Name & $\begin{array}{l}\text { Cast Stone } \\
\text { Cylinder } \\
\text { Density } \\
(\mathrm{g} / \mathrm{cc}) \\
\end{array}$ & $\begin{array}{c}\text { Cast Stone } \\
\text { Cylinder } \\
\text { Surface Area } \\
\left(\mathrm{cm}^{2}\right) \\
\end{array}$ & $\begin{array}{c}\text { Cast Stone } \\
\text { Cylinder } \\
\text { Volume } \\
(\mathrm{cc}) \\
\end{array}$ & Mix \#18 Sample Name & $\begin{array}{c}\text { Cast Stone } \\
\text { Cylinder } \\
\text { Density } \\
(\mathrm{g} / \mathrm{cc}) \\
\end{array}$ & $\begin{array}{c}\text { Cast Stone } \\
\text { Cylinder } \\
\text { Surface Area } \\
\left(\mathrm{cm}^{2}\right) \\
\end{array}$ & $\begin{array}{c}\text { Cast Stone } \\
\text { Cylinder } \\
\text { Volume } \\
\text { (cc) }\end{array}$ \\
\hline CS-T17LCS2-5HIA-1 & 1.71 & 196 & 195 & CS-T18LCS2-7.8RAS-1 & 1.90 & 196 & 195 \\
\hline CS-T17LCS2-5HIA-2 & 1.73 & 194 & 192 & CS-T18LCS2-7.8RAS-2 & 1.90 & 195 & 193 \\
\hline CS-T17LCS2-5HIA-3 & 1.74 & 195 & 193 & CS-T18LCS2-7.8RAS-3 & 1.93 & 194 & 192 \\
\hline CS-T17LCS2-5HIA-4 & 1.74 & 193 & 191 & CS-T18LCS2-7.8RAS-4 & 1.92 & 194 & 192 \\
\hline CS-T17LCS2-5HIA-5 & 1.76 & 193 & 190 & CS-T18LCS2-7.8RAS-5 & 1.90 & 197 & 195 \\
\hline CS-T17LCS2-5HIA-6 & 1.74 & 194 & 191 & CS-T18LCS2-7.8RAS-6 & 1.92 & 196 & 194 \\
\hline Mix \#19 Sample Name & & & & Mix \#20 Sample Name & & & \\
\hline CS-T19LCS1-7.8HIA-1 & 1.91 & 195 & 193 & CS-T20HCS2-5AVG-1 & 1.96 & 193 & 190 \\
\hline CS-T19LCS1-7.8HIA-2 & 1.91 & 196 & 194 & CS-T20HCS2-5AVG-2 & 1.95 & 194 & 191 \\
\hline CS-T19LCS1-7.8HIA-3 & 1.91 & 196 & 194 & CS-T20HCS2-5AVG-3 & 1.92 & 196 & 195 \\
\hline CS-T19LCS1-7.8HIA-4 & 1.92 & 197 & 195 & CS-T20HCS2-5AVG-4 & 1.93 & 196 & 194 \\
\hline CS-T19LCS1-7.8HIA-5 & 1.93 & 193 & 190 & CS-T20HCS2-5AVG-5 & 1.95 & 194 & 191 \\
\hline CS-T19LCS1-7.8HIA-6 & 1.91 & 195 & 192 & CS-T20HCS2-5AVG-6 & 1.95 & 199 & 197 \\
\hline Mix \#21 Sample Name & & & & Mix \#22 Sample Name & & & \\
\hline CS-T21LCS1-7.8HIS-2 & 1.77 & 195 & 193 & CS-T22HCS2-7.8AVG-2 & 1.77 & 197 & 195 \\
\hline CS-T21LCS1-7.8HIS-3 & 1.79 & 194 & 191 & CS-T22HCS2-7.8AVG-3 & 1.79 & 195 & 193 \\
\hline CS-T21LCS1-7.8HIS-4 & 1.77 & 196 & 194 & CS-T22HCS2-7.8AVG-4 & 1.77 & 197 & 195 \\
\hline CS-T21LCS1-7.8HIS-5 & 1.77 & 196 & 194 & CS-T22HCS2-7.8AVG-5 & 1.79 & 195 & 193 \\
\hline CS-T21LCS1-7.8HIS-6 & 1.79 & 194 & 192 & CS-T22HCS2-7.8AVG-6 & 1.78 & 196 & 195 \\
\hline Mix \#23 Sample Name & & & & Mix \#24 Sample Name & & & \\
\hline CS-T23LCS1-7.8RAS-1 & 1.81 & 192 & 189 & CS-T24HCS1-5HIA-1 & 1.79 & 194 & 192 \\
\hline CS-T23LCS1-7.8RAS-2 & 1.79 & 194 & 192 & CS-T24HCS1-5HIA-2 & 1.76 & 196 & 195 \\
\hline CS-T23LCS1-7.8RAS-3 & 1.79 & 195 & 193 & CS-T24HCS1-5HIA-3 & 1.74 & 198 & 198 \\
\hline CS-T23LCS1-7.8RAS-4 & 1.81 & 193 & 190 & CS-T24HCS1-5HIA-4 & 1.77 & 195 & 193 \\
\hline CS-T23LCS1-7.8RAS-5 & 1.81 & 194 & 192 & CS-T24HCS1-5HIA-5 & 1.79 & 194 & 192 \\
\hline CS-T23LCS1-7.8RAS-6 & 1.79 & 194 & 192 & CS-T24HCS1-5HIA-6 & 1.78 & 195 & 193 \\
\hline
\end{tabular}


Table D-4. Cast Stone Monolith Density, Surface Area, and Volume (contd)

\begin{tabular}{|c|c|c|c|c|c|c|c|}
\hline Mix \#25 Sample Name & $\begin{array}{c}\text { Cast Stone } \\
\text { Cylinder } \\
\text { Density } \\
\text { (g/cc) } \\
\end{array}$ & $\begin{array}{c}\text { Cast Stone } \\
\text { Cylinder } \\
\text { Surface Area } \\
\left(\mathrm{cm}^{2}\right) \\
\end{array}$ & $\begin{array}{c}\text { Cast Stone } \\
\text { Cylinder } \\
\text { Volume } \\
\text { (cc) } \\
\end{array}$ & Mix \#26 Sample Name & $\begin{array}{c}\text { Cast Stone } \\
\text { Cylinder } \\
\text { Density } \\
(\mathrm{g} / \mathrm{cc}) \\
\end{array}$ & $\begin{array}{c}\text { Cast Stone } \\
\text { Cylinder } \\
\text { Surface Area } \\
\left(\mathrm{cm}^{2}\right) \\
\end{array}$ & $\begin{array}{c}\text { Cast Stone } \\
\text { Cylinder } \\
\text { Volume } \\
\text { (cc) } \\
\end{array}$ \\
\hline CS-T25HCS1-7.8HIS-1 & 1.91 & 198 & 197 & CS-T26LCS1-7.8HIS-1 & 1.79 & 195 & 193 \\
\hline CS-T25HCS1-7.8HIS-2 & 1.94 & 198 & 196 & CS-T26LCS1-7.8HIS-2 & 1.76 & 197 & 196 \\
\hline CS-T25HCS1-7.8HIS-3 & 1.95 & 196 & 194 & CS-T26LCS1-7.8HIS-3 & 1.79 & 195 & 193 \\
\hline CS-T25HCS1-7.8HIS-4 & 1.98 & 196 & 193 & CS-T26LCS1-7.8HIS-4 & 1.78 & 197 & 196 \\
\hline CS-T25HCS1-7.8HIS-5 & 1.97 & 194 & 191 & CS-T26LCS1-7.8HIS-5 & 1.79 & 196 & 194 \\
\hline CS-T25HCS1-7.8HIS-6 & 1.95 & 196 & 194 & CS-T26LCS1-7.8HIS-6 & 1.78 & 196 & 194 \\
\hline
\end{tabular}


Table D-5 lists the cured density values for triplicate samples prepared from 26 Cast Stone mixes at SRNL. SRNL did not re-batch and test the 12 mixes that were mis-batched, so there are no data for those mixes. Table D-5 also shows the means and SDs for cured- density measurements made using the pycnometer method on three "repeat" monoliths made from each mix. The "Repeat SDs" represent the variation in preparing three samples from each mix and measuring the cured density for each sample. 
Table D-5. Cast Stone Cured Densities $\left(\mathrm{g} / \mathrm{cm}^{3}\right)$ Measured by Pycnometer at SRNL

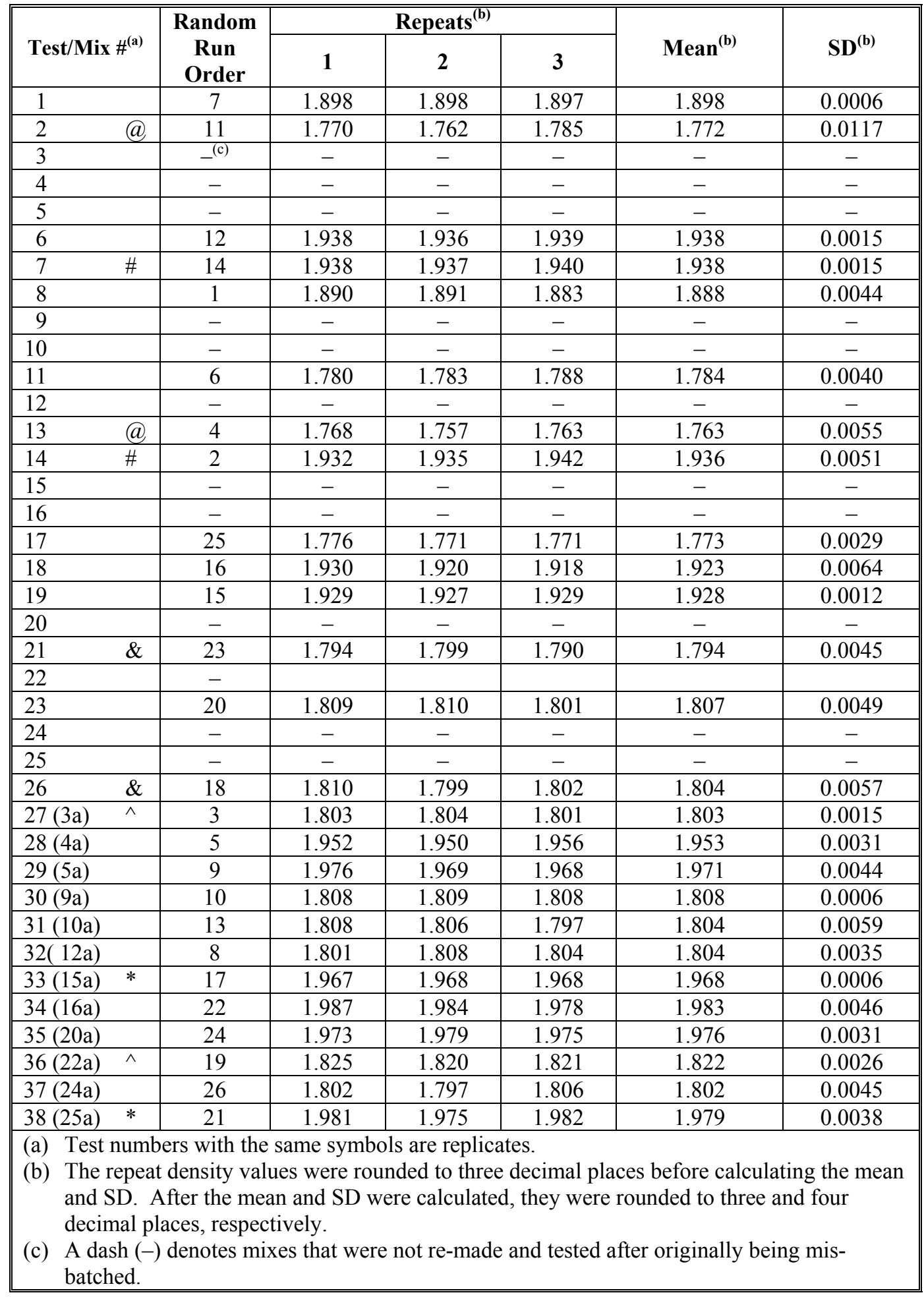




\section{D.4 Porosity}

Table D-6 lists the porosity values for triplicate samples prepared from 26 Cast Stone mixes made at SRNL. SRNL did not re-batch and test the 12 mixes that were mis-batched, so there are no data for those mixes. Table D-6 also shows the means and SDs for the three results per mix. The "Repeat SDs" represent the variation in preparing three samples from each mix and measuring the porosity of each sample.

The porosity was determined by the mass loss upon heating samples to $105^{\circ} \mathrm{C}$ in a laboratory oven. The samples were measured repeatedly until the mass change on consecutive days was $<5 \%$. The Cast Stone pieces that were used to measure the porosity were taken from the Cast Stone specimens by breaking the cylinders and removing pieces from the center region. The total porosity is defined here as the percentage of total volume occupied by the pore solution for the saturated case. It is assumed that the density of the pore solution is equivalent to the density of the salt solution from which the sample was prepared. The porosity is then calculated by dividing the volume of the pore solution by the overall volume of the Cast Stone. The volume of the pore solution is determined by assuming the mass loss is due entirely to water and dividing by the density of water and the volume fraction of water in the original salt solution. 
Table D-6. Cast Stone Porosities (\%) Measured at SRNL

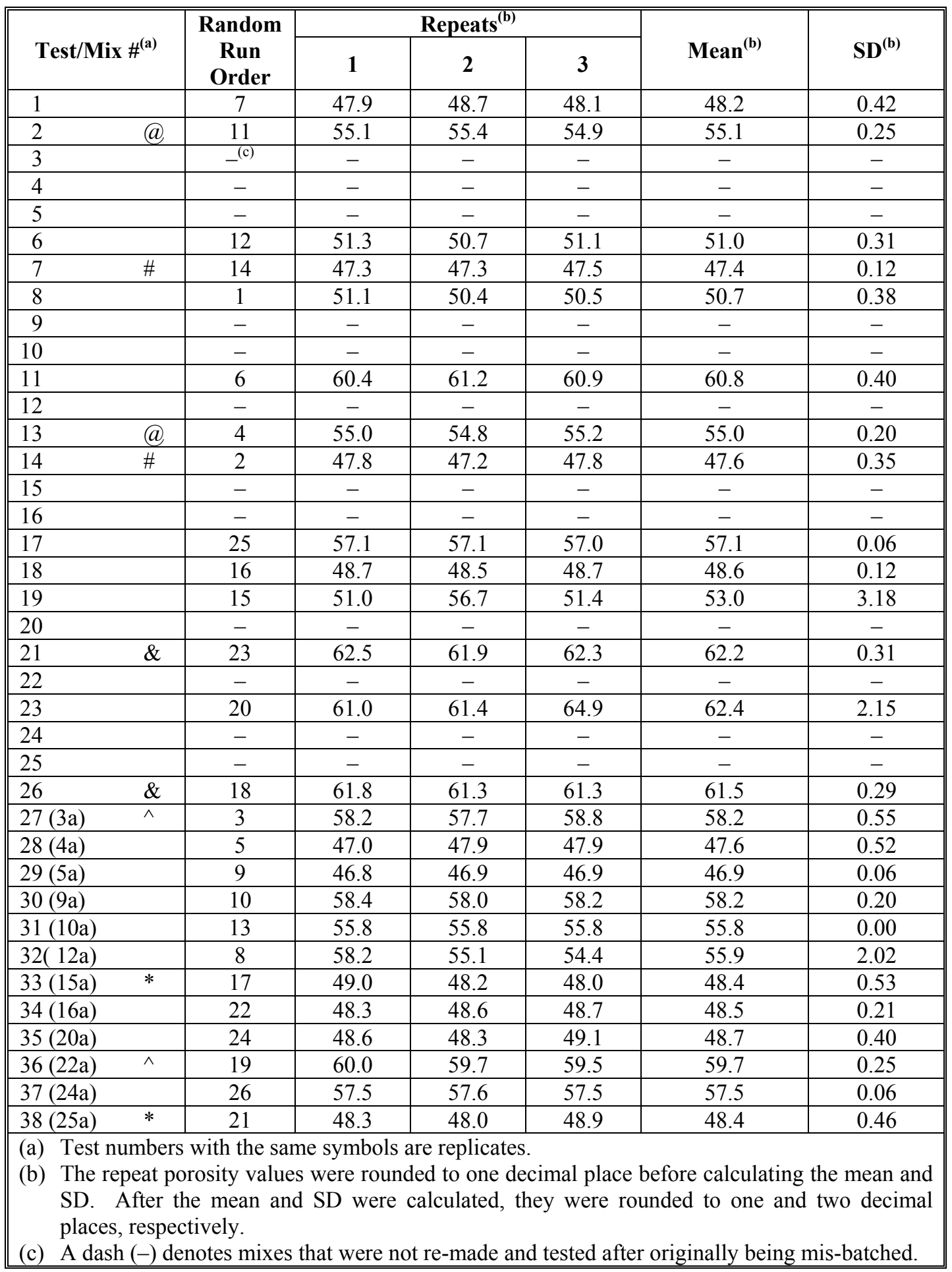


PNNL-22747

SRNL-STI-2013-00465

\section{D.5 EPA Draft Method 1315 Leach Test Results}

Table D-7 through Table D-13 provide the measured effective diffusivities of $\mathrm{Na}$, nitrate $\left(\mathrm{NO}_{3}\right)$, nitrite $\left(\mathrm{NO}_{2}\right), \mathrm{I}, \mathrm{Tc}, \mathrm{Cr}$, and $\mathrm{U}$ based on performing EPA Draft Method 1315 on duplicate (i.e., replicate) samples from each of the 26 Cast Stone mixes prepared at PNNL (Mixes 1-26). The leach tests were conducted for a total of 91 days and leachate exchanges occurred at $0.08,1,2,7$, $14,28,42,49,63,77$, and 91 cumulative days. The 77- and 91-day intervals provide longer-term data beyond the 63 days in EPA Draft Method 1315, but they were not included in the statistical analyses for the screening tests. The results are provided for both monoliths of each of the 26 mixes.

For purposes of statistical analyses, the average diffusivity values were calculated for the total durations of 28, 42, 49, and 63 days for each of the two duplicate leach tests for each of the 26 Cast Stone mixes. Also, leachability index (LI) values were calculated using these averages, according to the formula

$$
L I=-\log _{10}\left(\frac{\text { Diff }_{28}+\text { Diff }_{42}+\text { Diff }_{49}+\text { Diff }_{63}}{4}\right)
$$

for each of the duplicate samples for each of the 26 Cast Stone mixes. Table D-14 and Table D-15 present the average effective diffusivity and LI values for $\mathrm{Na}, \mathrm{NO}_{3}, \mathrm{NO}_{2}, \mathrm{I}, \mathrm{Tc}, \mathrm{Cr}$, and $U$ for each of the duplicate leach tests for the 26 Cast Stone samples. Also included are the mean and SD values for the duplicate (repeat) values. The mean values of LI (for the 28-, 42-, 49-, and 63-day periods, and for the duplicate samples) were chosen for statistical analyses because LI values satisfy the "constant variance" assumption of ordinary least squares fitting methods used in the statistical analyses better than the diffusivity values. 
Table D-7. Sodium Effective Diffusion Coefficients

\begin{tabular}{|c|c|c|c|c|c|c|c|c|c|c|c|}
\hline \multirow{3}{*}{$\begin{array}{c}\text { Interval } \\
\text { (days) }\end{array}$} & \multirow{3}{*}{$\begin{array}{c}\text { Total } \\
\text { Duration } \\
\text { (days) }\end{array}$} & \multicolumn{10}{|c|}{ Sodium Effective Diffusion Coefficient $\left(\mathrm{cm}^{2} / \mathrm{s}\right)$} \\
\hline & & \multicolumn{10}{|c|}{ Mix Number and Duplicate (Repeat) } \\
\hline & & 1a & 1b & $\mathbf{2 a}$ & 2b & 3a & $\mathbf{3 b}$ & $4 \mathbf{a}$ & $4 \mathbf{b}$ & $5 \mathbf{a}$ & $\mathbf{5 b}$ \\
\hline 0.08 & 0.08 & $1.53 \mathrm{E}-09$ & $1.83 \mathrm{E}-07$ & $3.84 \mathrm{E}-07$ & $3.81 \mathrm{E}-07$ & $3.45 \mathrm{E}-07$ & $1.19 \mathrm{E}-07$ & $7.57 \mathrm{E}-07$ & $6.66 \mathrm{E}-08$ & 8.69E-08 & $1.82 \mathrm{E}-07$ \\
\hline 0.92 & 1 & $2.26 \mathrm{E}-08$ & $1.58 \mathrm{E}-08$ & 7.63E-08 & 8.97E-08 & $9.86 \mathrm{E}-08$ & $9.11 \mathrm{E}-08$ & $1.69 \mathrm{E}-08$ & 3.04E-08 & $3.60 \mathrm{E}-08$ & $3.54 \mathrm{E}-08$ \\
\hline 1 & 2 & 4.32E-09 & 4.16E-09 & $3.22 \mathrm{E}-08$ & 3.09E-08 & $2.85 \mathrm{E}-08$ & $2.91 \mathrm{E}-08$ & $1.86 \mathrm{E}-08$ & $1.66 \mathrm{E}-08$ & $3.16 \mathrm{E}-08$ & $2.96 \mathrm{E}-08$ \\
\hline 5 & 7 & $1.97 \mathrm{E}-09$ & $2.17 \mathrm{E}-09$ & $2.01 \mathrm{E}-08$ & $1.99 \mathrm{E}-08$ & $1.37 \mathrm{E}-08$ & $1.74 \mathrm{E}-08$ & $5.17 \mathrm{E}-08$ & $2.80 \mathrm{E}-08$ & $1.17 \mathrm{E}-08$ & $2.18 \mathrm{E}-08$ \\
\hline 7 & 14 & $1.97 \mathrm{E}-09$ & $1.61 \mathrm{E}-09$ & $1.36 \mathrm{E}-08$ & $1.27 \mathrm{E}-08$ & $9.96 \mathrm{E}-09$ & $1.01 \mathrm{E}-08$ & $1.52 \mathrm{E}-08$ & $1.23 \mathrm{E}-08$ & $1.37 \mathrm{E}-08$ & $1.30 \mathrm{E}-08$ \\
\hline 14 & 28 & $1.42 \mathrm{E}-09$ & $1.51 \mathrm{E}-09$ & 8.60E-09 & $8.43 \mathrm{E}-09$ & 7.01E-09 & $6.63 \mathrm{E}-09$ & $2.31 \mathrm{E}-08$ & $9.71 \mathrm{E}-09$ & 3.99E-09 & $9.95 \mathrm{E}-09$ \\
\hline 14 & 42 & $1.22 \mathrm{E}-09$ & $1.21 \mathrm{E}-09$ & $5.72 \mathrm{E}-09$ & 1.39E-08 & $2.40 \mathrm{E}-09$ & $5.46 \mathrm{E}-09$ & $7.66 \mathrm{E}-09$ & 7.09E-09 & $6.16 \mathrm{E}-09$ & $6.49 \mathrm{E}-09$ \\
\hline 7 & 49 & $1.16 \mathrm{E}-09$ & $1.11 \mathrm{E}-09$ & $6.01 \mathrm{E}-09$ & $5.46 \mathrm{E}-09$ & 5.33E-09 & $5.22 \mathrm{E}-09$ & $5.72 \mathrm{E}-09$ & 7.95E-09 & $5.16 \mathrm{E}-09$ & $4.87 \mathrm{E}-09$ \\
\hline 14 & 63 & $1.00 \mathrm{E}-09$ & $1.06 \mathrm{E}-09$ & $3.67 \mathrm{E}-09$ & $3.55 \mathrm{E}-09$ & $3.96 \mathrm{E}-09$ & $3.95 \mathrm{E}-09$ & 6.19E-09 & 5.92E-09 & 3.79E-09 & 4.11E-09 \\
\hline 14 & 77 & $1.09 \mathrm{E}-09$ & $1.02 \mathrm{E}-09$ & $2.15 \mathrm{E}-09$ & $3.09 \mathrm{E}-09$ & $3.81 \mathrm{E}-09$ & $2.73 \mathrm{E}-09$ & $4.34 \mathrm{E}-09$ & $4.51 \mathrm{E}-09$ & $3.40 \mathrm{E}-09$ & $2.07 \mathrm{E}-09$ \\
\hline 14 & 91 & $9.22 \mathrm{E}-10$ & $9.61 \mathrm{E}-10$ & $2.51 \mathrm{E}-09$ & $1.67 \mathrm{E}-09$ & $3.50 \mathrm{E}-09$ & 3.04E-09 & $4.28 \mathrm{E}-09$ & 4.69E-09 & $1.86 \mathrm{E}-09$ & $2.36 \mathrm{E}-09$ \\
\hline
\end{tabular}

\begin{tabular}{|c|c|c|c|c|c|c|c|c|c|c|c|}
\hline \multirow{3}{*}{$\begin{array}{c}\text { Interval } \\
\text { (days) }\end{array}$} & \multirow{3}{*}{$\begin{array}{c}\text { Total } \\
\text { Duration } \\
\text { (days) }\end{array}$} & \multicolumn{10}{|c|}{ "Sodium Effective Diffusion Coefficient $\left(\mathrm{cm}^{2} / \mathrm{s}\right)$} \\
\hline & & \multicolumn{10}{|c|}{ Mix Number and Duplicate (Repeat) } \\
\hline & & $\mathbf{6 a}$ & $\mathbf{6 b}$ & $7 \mathbf{a}$ & $7 \mathbf{b}$ & $\mathbf{8 a}$ & $\mathbf{8 b}$ & $9 \mathbf{a}$ & $9 \mathbf{b}$ & $10 \mathbf{a}$ & $10 \mathrm{~b}$ \\
\hline 0.08 & 0.08 & $3.04 \mathrm{E}-07$ & $2.84 \mathrm{E}-07$ & $2.05 \mathrm{E}-08$ & $6.16 \mathrm{E}-08$ & $1.21 \mathrm{E}-07$ & $6.20 \mathrm{E}-08$ & $5.23 \mathrm{E}-08$ & $3.51 \mathrm{E}-07$ & $4.01 \mathrm{E}-07$ & $2.52 \mathrm{E}-07$ \\
\hline 0.92 & 1 & $5.58 \mathrm{E}-08$ & $5.43 \mathrm{E}-08$ & $2.22 \mathrm{E}-08$ & $2.05 \mathrm{E}-08$ & $1.17 \mathrm{E}-08$ & $1.44 \mathrm{E}-08$ & $3.55 \mathrm{E}-08$ & $3.54 \mathrm{E}-08$ & $3.69 \mathrm{E}-08$ & $4.18 \mathrm{E}-08$ \\
\hline 1 & 2 & 4.13E-08 & 4.08E-08 & $1.87 \mathrm{E}-08$ & $1.96 \mathrm{E}-08$ & $6.03 \mathrm{E}-09$ & $6.30 \mathrm{E}-09$ & $2.66 \mathrm{E}-08$ & $2.39 \mathrm{E}-08$ & $3.00 \mathrm{E}-08$ & $3.64 \mathrm{E}-08$ \\
\hline 5 & 7 & $1.73 \mathrm{E}-08$ & $2.60 \mathrm{E}-08$ & $1.00 \mathrm{E}-08$ & $1.07 \mathrm{E}-08$ & $4.22 \mathrm{E}-09$ & $3.85 \mathrm{E}-09$ & $1.33 \mathrm{E}-08$ & $1.11 \mathrm{E}-08$ & $1.71 \mathrm{E}-08$ & $2.18 \mathrm{E}-08$ \\
\hline 7 & 14 & $1.39 \mathrm{E}-08$ & $1.43 \mathrm{E}-08$ & $8.66 \mathrm{E}-09$ & $8.32 \mathrm{E}-09$ & $3.91 \mathrm{E}-09$ & $3.55 \mathrm{E}-09$ & $6.04 \mathrm{E}-09$ & $7.81 \mathrm{E}-09$ & $2.53 \mathrm{E}-08$ & $1.69 \mathrm{E}-08$ \\
\hline 14 & 28 & $1.00 \mathrm{E}-08$ & $1.07 \mathrm{E}-08$ & $4.93 \mathrm{E}-09$ & $6.07 \mathrm{E}-09$ & $2.80 \mathrm{E}-09$ & $2.79 \mathrm{E}-09$ & $5.85 \mathrm{E}-09$ & $5.73 \mathrm{E}-09$ & $1.02 \mathrm{E}-08$ & $1.07 \mathrm{E}-08$ \\
\hline 14 & 42 & 6.81E-09 & $6.62 \mathrm{E}-09$ & $3.38 \mathrm{E}-09$ & $3.74 \mathrm{E}-09$ & $2.53 \mathrm{E}-09$ & $2.26 \mathrm{E}-09$ & $4.55 \mathrm{E}-09$ & $4.59 \mathrm{E}-09$ & $7.56 \mathrm{E}-09$ & $7.56 \mathrm{E}-09$ \\
\hline 7 & 49 & $4.93 \mathrm{E}-09$ & $5.70 \mathrm{E}-09$ & $2.77 \mathrm{E}-09$ & $3.13 \mathrm{E}-09$ & $2.35 \mathrm{E}-09$ & $2.33 \mathrm{E}-09$ & $4.44 \mathrm{E}-09$ & $4.43 \mathrm{E}-09$ & $6.44 \mathrm{E}-09$ & $6.98 \mathrm{E}-09$ \\
\hline 14 & 63 & $3.50 \mathrm{E}-09$ & $3.63 \mathrm{E}-09$ & $1.97 \mathrm{E}-09$ & $2.14 \mathrm{E}-09$ & $2.11 \mathrm{E}-09$ & $2.05 \mathrm{E}-09$ & $3.76 \mathrm{E}-09$ & $3.71 \mathrm{E}-09$ & $5.35 \mathrm{E}-09$ & $5.42 \mathrm{E}-09$ \\
\hline 14 & 77 & $1.42 \mathrm{E}-09$ & 1.99E-09 & $9.43 \mathrm{E}-10$ & $1.23 \mathrm{E}-09$ & $1.65 \mathrm{E}-09$ & $1.95 \mathrm{E}-09$ & $2.52 \mathrm{E}-09$ & $1.84 \mathrm{E}-09$ & $4.07 \mathrm{E}-09$ & $3.70 \mathrm{E}-09$ \\
\hline 14 & 91 & $1.15 \mathrm{E}-09$ & $1.70 \mathrm{E}-09$ & $1.08 \mathrm{E}-09$ & $1.44 \mathrm{E}-09$ & $1.06 \mathrm{E}-09$ & $1.38 \mathrm{E}-09$ & $2.50 \mathrm{E}-09$ & $2.81 \mathrm{E}-09$ & $3.32 \mathrm{E}-09$ & $3.37 \mathrm{E}-09$ \\
\hline
\end{tabular}


Table D-7. Sodium Effective Diffusion Coefficients (contd)

\begin{tabular}{|c|c|c|c|c|c|c|c|c|c|c|c|}
\hline \multirow{3}{*}{$\begin{array}{c}\text { Interval } \\
\text { (days) }\end{array}$} & \multirow{3}{*}{$\begin{array}{c}\text { Total } \\
\text { Duration } \\
\text { (days) }\end{array}$} & \multicolumn{10}{|c|}{ Sodium Effective Diffusion Coefficient $\left(\mathrm{cm}^{2} / \mathrm{s}\right)$} \\
\hline & & \multicolumn{10}{|c|}{ Mix Number and Duplicate (Repeat) } \\
\hline & & 11a & 11b & $12 \mathbf{a}$ & $12 \mathrm{~b}$ & $13 \mathbf{a}$ & $13 \mathbf{b}$ & $14 a$ & $14 \mathrm{~b}$ & $15 \mathbf{a}$ & $\mathbf{1 5 b}$ \\
\hline 0.08 & 0.08 & $7.50 \mathrm{E}-07$ & $1.73 \mathrm{E}-07$ & $5.50 \mathrm{E}-08$ & $2.55 \mathrm{E}-08$ & 7.17E-08 & $2.57 \mathrm{E}-07$ & $1.10 \mathrm{E}-07$ & $3.12 \mathrm{E}-07$ & $3.97 \mathrm{E}-08$ & $3.81 \mathrm{E}-08$ \\
\hline 0.92 & 1 & 4.91E-08 & 4.87E-08 & $7.87 \mathrm{E}-09$ & $8.15 \mathrm{E}-09$ & 4.02E-08 & $3.62 \mathrm{E}-08$ & $2.80 \mathrm{E}-08$ & $2.92 \mathrm{E}-08$ & $3.38 \mathrm{E}-08$ & $3.01 \mathrm{E}-08$ \\
\hline 1 & 2 & $3.36 \mathrm{E}-08$ & 3.49E-08 & $6.30 \mathrm{E}-09$ & 6.81E-09 & $3.28 \mathrm{E}-08$ & $3.14 \mathrm{E}-08$ & $2.38 \mathrm{E}-08$ & $2.65 \mathrm{E}-08$ & $2.83 \mathrm{E}-08$ & $2.70 \mathrm{E}-08$ \\
\hline 5 & 7 & $1.88 \mathrm{E}-08$ & $1.84 \mathrm{E}-08$ & $5.46 \mathrm{E}-09$ & $4.56 \mathrm{E}-09$ & $2.04 \mathrm{E}-08$ & $1.89 \mathrm{E}-08$ & $1.34 \mathrm{E}-08$ & $1.49 \mathrm{E}-08$ & $1.40 \mathrm{E}-08$ & $1.54 \mathrm{E}-08$ \\
\hline 7 & 14 & $1.10 \mathrm{E}-08$ & $1.26 \mathrm{E}-08$ & $4.38 \mathrm{E}-09$ & $4.86 \mathrm{E}-09$ & $1.37 \mathrm{E}-08$ & $1.27 \mathrm{E}-08$ & $8.89 \mathrm{E}-09$ & $1.00 \mathrm{E}-08$ & $1.24 \mathrm{E}-08$ & $1.33 \mathrm{E}-08$ \\
\hline 14 & 28 & $8.05 \mathrm{E}-09$ & $7.20 \mathrm{E}-09$ & $4.08 \mathrm{E}-09$ & $3.73 \mathrm{E}-09$ & $8.86 \mathrm{E}-09$ & 8.81E-09 & $5.65 \mathrm{E}-09$ & $6.00 \mathrm{E}-09$ & $9.50 \mathrm{E}-09$ & $9.10 \mathrm{E}-09$ \\
\hline 14 & 42 & $6.35 \mathrm{E}-09$ & $6.53 \mathrm{E}-09$ & $4.21 \mathrm{E}-09$ & $4.15 \mathrm{E}-09$ & 7.04E-09 & $6.25 \mathrm{E}-09$ & $4.82 \mathrm{E}-09$ & $4.64 \mathrm{E}-09$ & $8.22 \mathrm{E}-09$ & $7.20 \mathrm{E}-09$ \\
\hline 7 & 49 & $5.55 \mathrm{E}-09$ & $5.92 \mathrm{E}-09$ & $4.02 \mathrm{E}-09$ & $4.04 \mathrm{E}-09$ & $6.18 \mathrm{E}-09$ & $6.10 \mathrm{E}-09$ & $4.06 \mathrm{E}-09$ & $4.31 \mathrm{E}-09$ & $7.45 \mathrm{E}-09$ & $6.14 \mathrm{E}-09$ \\
\hline 14 & 63 & $4.43 \mathrm{E}-09$ & $5.29 \mathrm{E}-09$ & $4.09 \mathrm{E}-09$ & $3.77 \mathrm{E}-09$ & $4.16 \mathrm{E}-09$ & $4.13 \mathrm{E}-09$ & $3.04 \mathrm{E}-09$ & $3.06 \mathrm{E}-09$ & $5.88 \mathrm{E}-09$ & $5.18 \mathrm{E}-09$ \\
\hline 14 & 77 & $2.26 \mathrm{E}-09$ & $3.43 \mathrm{E}-09$ & $3.31 \mathrm{E}-09$ & $4.08 \mathrm{E}-09$ & $3.59 \mathrm{E}-09$ & $3.09 \mathrm{E}-09$ & $2.42 \mathrm{E}-09$ & $2.17 \mathrm{E}-09$ & $3.07 \mathrm{E}-09$ & $3.90 \mathrm{E}-09$ \\
\hline 14 & 91 & $1.64 \mathrm{E}-09$ & $2.31 \mathrm{E}-09$ & $3.57 \mathrm{E}-09$ & $2.23 \mathrm{E}-09$ & $2.90 \mathrm{E}-09$ & $2.38 \mathrm{E}-09$ & $1.55 \mathrm{E}-09$ & $1.56 \mathrm{E}-09$ & $3.03 \mathrm{E}-09$ & $2.16 \mathrm{E}-09$ \\
\hline
\end{tabular}

\begin{tabular}{|c|c|c|c|c|c|c|c|c|c|c|c|}
\hline \multirow{3}{*}{$\begin{array}{c}\text { Interval } \\
\text { (days) }\end{array}$} & \multirow{3}{*}{$\begin{array}{c}\text { Total } \\
\text { Duration } \\
\text { (days) }\end{array}$} & \multicolumn{10}{|c|}{ Sodium Effective Diffusion Coefficient $\left(\mathrm{cm}^{2} / \mathrm{s}\right)$} \\
\hline & & \multicolumn{10}{|c|}{ Mix Number and Duplicate (Repeat) } \\
\hline & & 16a & $16 \mathrm{~b}$ & $17 \mathbf{a}$ & $17 \mathbf{b}$ & $18 a$ & $18 b$ & $19 a$ & 19b & $20 a$ & $20 b$ \\
\hline 0.08 & 0.08 & $4.39 \mathrm{E}-08$ & $2.62 \mathrm{E}-08$ & $7.81 \mathrm{E}-08$ & $4.89 \mathrm{E}-08$ & $2.37 \mathrm{E}-08$ & $2.20 \mathrm{E}-08$ & $5.85 \mathrm{E}-08$ & $5.69 \mathrm{E}-08$ & $3.14 \mathrm{E}-08$ & $3.07 \mathrm{E}-08$ \\
\hline 0.92 & 1 & $2.44 \mathrm{E}-08$ & $2.37 \mathrm{E}-08$ & 3.81E-08 & $3.96 \mathrm{E}-08$ & $9.93 \mathrm{E}-09$ & $1.04 \mathrm{E}-08$ & $3.43 \mathrm{E}-08$ & $3.42 \mathrm{E}-08$ & $1.65 \mathrm{E}-08$ & $1.87 \mathrm{E}-08$ \\
\hline 1 & 2 & $1.98 \mathrm{E}-08$ & $1.97 \mathrm{E}-08$ & $3.78 \mathrm{E}-08$ & $3.42 \mathrm{E}-08$ & $9.23 \mathrm{E}-09$ & $9.36 \mathrm{E}-09$ & $2.57 \mathrm{E}-08$ & $2.48 \mathrm{E}-08$ & $1.54 \mathrm{E}-08$ & $1.96 \mathrm{E}-08$ \\
\hline 5 & 7 & $1.10 \mathrm{E}-08$ & $1.01 \mathrm{E}-08$ & $1.76 \mathrm{E}-08$ & $1.67 \mathrm{E}-08$ & $4.65 \mathrm{E}-09$ & $4.36 \mathrm{E}-09$ & $1.16 \mathrm{E}-08$ & $1.09 \mathrm{E}-08$ & $1.93 \mathrm{E}-08$ & $1.57 \mathrm{E}-08$ \\
\hline 7 & 14 & $1.15 \mathrm{E}-08$ & $1.21 \mathrm{E}-08$ & $1.29 \mathrm{E}-08$ & $1.69 \mathrm{E}-08$ & $5.18 \mathrm{E}-09$ & $4.88 \mathrm{E}-09$ & $9.25 \mathrm{E}-09$ & $1.02 \mathrm{E}-08$ & $2.51 \mathrm{E}-08$ & $1.25 \mathrm{E}-08$ \\
\hline 14 & 28 & 8.36E-09 & 8.94E-09 & 9.47E-09 & $9.14 \mathrm{E}-09$ & 3.04E-09 & $3.22 \mathrm{E}-09$ & $6.09 \mathrm{E}-09$ & $5.18 \mathrm{E}-09$ & $1.18 \mathrm{E}-08$ & $6.55 \mathrm{E}-09$ \\
\hline 14 & 42 & $7.00 \mathrm{E}-09$ & $7.63 \mathrm{E}-09$ & $6.61 \mathrm{E}-09$ & $6.98 \mathrm{E}-09$ & $2.80 \mathrm{E}-09$ & $2.89 \mathrm{E}-09$ & $3.68 \mathrm{E}-09$ & $3.64 \mathrm{E}-09$ & $9.35 \mathrm{E}-09$ & $6.76 \mathrm{E}-09$ \\
\hline 7 & 49 & $6.49 \mathrm{E}-09$ & $6.69 \mathrm{E}-09$ & 5.92E-09 & $6.30 \mathrm{E}-09$ & $2.76 \mathrm{E}-09$ & $2.85 \mathrm{E}-09$ & $2.54 \mathrm{E}-09$ & $2.78 \mathrm{E}-09$ & $9.38 \mathrm{E}-09$ & $6.38 \mathrm{E}-09$ \\
\hline 14 & 63 & $5.75 \mathrm{E}-09$ & 5.91E-09 & $4.60 \mathrm{E}-09$ & $4.33 \mathrm{E}-09$ & $2.70 \mathrm{E}-09$ & $2.46 \mathrm{E}-09$ & $1.71 \mathrm{E}-09$ & $2.01 \mathrm{E}-09$ & $7.50 \mathrm{E}-09$ & $6.51 \mathrm{E}-09$ \\
\hline 14 & 77 & $2.31 \mathrm{E}-09$ & $3.40 \mathrm{E}-09$ & $3.53 \mathrm{E}-09$ & 3.44E-09 & $1.75 \mathrm{E}-09$ & $2.12 \mathrm{E}-09$ & $1.01 \mathrm{E}-09$ & $1.11 \mathrm{E}-09$ & $3.72 \mathrm{E}-09$ & $5.16 \mathrm{E}-09$ \\
\hline 14 & 91 & $3.45 \mathrm{E}-09$ & $3.45 \mathrm{E}-09$ & $2.92 \mathrm{E}-09$ & $2.65 \mathrm{E}-09$ & $1.82 \mathrm{E}-09$ & $2.26 \mathrm{E}-09$ & $8.68 \mathrm{E}-10$ & $9.77 \mathrm{E}-10$ & $4.03 \mathrm{E}-09$ & $5.03 \mathrm{E}-09$ \\
\hline
\end{tabular}


Table D-7. Sodium Effective Diffusion Coefficients (contd)

\begin{tabular}{|c|c|c|c|c|c|c|c||}
\hline \multirow{2}{*}{$\begin{array}{c}\text { Interval } \\
\text { (days) }\end{array}$} & \multirow{2}{*}{$\begin{array}{c}\text { Total } \\
\text { Duration } \\
\text { (days) }\end{array}$} & \multicolumn{6}{|c||}{ Sodium Effective Diffusion Coefficient $\left(\mathbf{c m}^{2} / \mathbf{s}\right)$} \\
\cline { 3 - 8 } & \multicolumn{5}{|c|}{ Mix Number and Duplicate (Repeat) } \\
\hline 0.08 & 0.08 & $1.50 \mathrm{E}-07$ & $1.44 \mathrm{E}-07$ & $5.69 \mathrm{E}-08$ & $6.27 \mathrm{E}-08$ & $9.95 \mathrm{E}-08$ & $1.07 \mathrm{E}-07$ \\
\hline 0.92 & 1 & $9.58 \mathrm{E}-08$ & $9.94 \mathrm{E}-08$ & $3.55 \mathrm{E}-08$ & $3.30 \mathrm{E}-08$ & $1.01 \mathrm{E}-07$ & $1.02 \mathrm{E}-07$ \\
\hline 1 & 2 & $7.57 \mathrm{E}-08$ & $8.11 \mathrm{E}-08$ & $2.71 \mathrm{E}-08$ & $2.59 \mathrm{E}-08$ & $1.02 \mathrm{E}-07$ & $1.11 \mathrm{E}-07$ \\
\hline 5 & 7 & $3.51 \mathrm{E}-08$ & $3.79 \mathrm{E}-08$ & $1.14 \mathrm{E}-08$ & $1.19 \mathrm{E}-08$ & $5.96 \mathrm{E}-08$ & $7.56 \mathrm{E}-08$ \\
\hline 7 & 14 & $3.10 \mathrm{E}-08$ & $3.22 \mathrm{E}-08$ & $9.27 \mathrm{E}-09$ & $8.16 \mathrm{E}-09$ & $5.07 \mathrm{E}-08$ & $5.46 \mathrm{E}-08$ \\
\hline 14 & 28 & $1.53 \mathrm{E}-08$ & $1.47 \mathrm{E}-08$ & $5.49 \mathrm{E}-09$ & $5.77 \mathrm{E}-09$ & $3.38 \mathrm{E}-08$ & $3.40 \mathrm{E}-08$ \\
\hline 14 & 42 & $1.13 \mathrm{E}-08$ & $1.10 \mathrm{E}-08$ & $5.17 \mathrm{E}-09$ & $4.93 \mathrm{E}-09$ & $2.42 \mathrm{E}-08$ & $2.87 \mathrm{E}-08$ \\
\hline 7 & 49 & $9.14 \mathrm{E}-09$ & $9.31 \mathrm{E}-09$ & $4.61 \mathrm{E}-09$ & $4.76 \mathrm{E}-09$ & $2.30 \mathrm{E}-08$ & $2.56 \mathrm{E}-08$ \\
\hline 14 & 63 & $6.46 \mathrm{E}-09$ & $6.65 \mathrm{E}-09$ & $3.92 \mathrm{E}-09$ & $4.09 \mathrm{E}-09$ & $1.72 \mathrm{E}-08$ & $2.02 \mathrm{E}-08$ \\
\hline 14 & 77 & $2.81 \mathrm{E}-09$ & $2.87 \mathrm{E}-09$ & $2.91 \mathrm{E}-09$ & $1.94 \mathrm{E}-09$ & $8.71 \mathrm{E}-09$ & $1.01 \mathrm{E}-08$ \\
\hline 14 & 91 & $2.70 \mathrm{E}-09$ & $2.66 \mathrm{E}-09$ & $3.82 \mathrm{E}-09$ & $1.94 \mathrm{E}-09$ & $6.16 \mathrm{E}-09$ & $6.26 \mathrm{E}-09$ \\
\hline
\end{tabular}

\begin{tabular}{|c|c|c|c|c|c|c|c|}
\hline \multirow{3}{*}{$\begin{array}{c}\text { Interval } \\
\text { (days) }\end{array}$} & \multirow{3}{*}{$\begin{array}{c}\text { Total } \\
\text { Duration } \\
\text { (days) }\end{array}$} & \multicolumn{6}{|c|}{ Sodium Effective Diffusion Coefficient $\left(\mathrm{cm}^{2} / \mathrm{s}\right)$} \\
\hline & & \multicolumn{6}{|c|}{ Mix Number and Duplicate (Repeat) } \\
\hline & & $24 a$ & 24b & $25 \mathbf{a}$ & $25 \mathbf{b}$ & $26 a$ & 26b \\
\hline 0.08 & 0.08 & $1.01 \mathrm{E}-07$ & $1.04 \mathrm{E}-07$ & $5.21 \mathrm{E}-08$ & $5.06 \mathrm{E}-08$ & $1.39 \mathrm{E}-07$ & $1.38 \mathrm{E}-07$ \\
\hline 0.92 & 1 & $6.05 \mathrm{E}-08$ & $5.91 \mathrm{E}-08$ & $3.36 \mathrm{E}-08$ & $3.47 \mathrm{E}-08$ & $6.28 \mathrm{E}-08$ & $6.37 \mathrm{E}-08$ \\
\hline 1 & 2 & 4.92E-08 & 4.84E-08 & $2.85 \mathrm{E}-08$ & $2.86 \mathrm{E}-08$ & 4.83E-08 & 4.92E-08 \\
\hline 5 & 7 & $2.48 \mathrm{E}-08$ & $2.52 \mathrm{E}-08$ & $1.90 \mathrm{E}-08$ & $1.90 \mathrm{E}-08$ & $2.42 \mathrm{E}-08$ & $2.59 \mathrm{E}-08$ \\
\hline 7 & 14 & $1.73 \mathrm{E}-08$ & $1.95 \mathrm{E}-08$ & $1.15 \mathrm{E}-08$ & $1.01 \mathrm{E}-08$ & $1.42 \mathrm{E}-08$ & $1.23 \mathrm{E}-08$ \\
\hline 14 & 28 & $1.42 \mathrm{E}-08$ & $1.31 \mathrm{E}-08$ & $1.00 \mathrm{E}-08$ & $8.64 \mathrm{E}-09$ & $1.10 \mathrm{E}-08$ & $1.19 \mathrm{E}-08$ \\
\hline 14 & 42 & $9.16 \mathrm{E}-09$ & $9.78 \mathrm{E}-09$ & $7.32 \mathrm{E}-09$ & $7.55 \mathrm{E}-09$ & 8.98E-09 & $8.81 \mathrm{E}-09$ \\
\hline 7 & 49 & $8.58 \mathrm{E}-09$ & $8.71 \mathrm{E}-09$ & $5.90 \mathrm{E}-09$ & $6.12 \mathrm{E}-09$ & $6.84 \mathrm{E}-09$ & $7.02 \mathrm{E}-09$ \\
\hline 14 & 63 & $7.86 \mathrm{E}-09$ & 7.09E-09 & $4.75 \mathrm{E}-09$ & $4.60 \mathrm{E}-09$ & $5.07 \mathrm{E}-09$ & $5.00 \mathrm{E}-09$ \\
\hline 14 & 77 & $3.69 \mathrm{E}-09$ & $5.04 \mathrm{E}-09$ & $3.66 \mathrm{E}-09$ & $3.11 \mathrm{E}-09$ & $2.71 \mathrm{E}-09$ & $1.58 \mathrm{E}-09$ \\
\hline 14 & 91 & $3.44 \mathrm{E}-09$ & $4.68 \mathrm{E}-09$ & $2.93 \mathrm{E}-09$ & $2.67 \mathrm{E}-09$ & $2.74 \mathrm{E}-09$ & $2.99 \mathrm{E}-09$ \\
\hline
\end{tabular}


Table D-8. Nitrate Effective Diffusion Coefficients

\begin{tabular}{|c|c|c|c|c|c|c|c|c|c|c|c|}
\hline \multirow{3}{*}{$\begin{array}{c}\text { Interval } \\
\text { (days) }\end{array}$} & \multirow{3}{*}{$\begin{array}{c}\text { Total } \\
\text { Duration } \\
\text { (days) }\end{array}$} & \multicolumn{10}{|c|}{ Nitrate Effective Diffusion Coefficient $\left(\mathrm{cm}^{2} / \mathrm{s}\right)$} \\
\hline & & \multicolumn{10}{|c|}{ Mix Number and Duplicate (Repeat) } \\
\hline & & $1 \mathbf{a}$ & $\mathbf{1 b}$ & $\mathbf{2 a}$ & 2b & $\mathbf{3 a}$ & $\mathbf{3 b}$ & $4 \mathbf{a}$ & $\mathbf{4 b}$ & $\mathbf{5 a}$ & $\mathbf{5 b}$ \\
\hline 0.08 & 0.08 & 4.73E-08 & 9.87E-08 & 4.41E-07 & 7.64E-07 & $3.41 \mathrm{E}-07$ & 7.12E-09 & $1.83 \mathrm{E}-07$ & $1.95 \mathrm{E}-07$ & $4.06 \mathrm{E}-07$ & $3.95 \mathrm{E}-07$ \\
\hline 0.92 & 1 & $2.33 \mathrm{E}-08$ & $1.70 \mathrm{E}-08$ & $1.03 \mathrm{E}-07$ & $1.16 \mathrm{E}-07$ & $9.85 \mathrm{E}-08$ & $1.11 \mathrm{E}-07$ & $1.66 \mathrm{E}-08$ & $4.16 \mathrm{E}-08$ & 4.13E-08 & 4.47E-08 \\
\hline 1 & 2 & $3.83 \mathrm{E}-09$ & $3.28 \mathrm{E}-09$ & $4.21 \mathrm{E}-08$ & 4.09E-08 & $2.76 \mathrm{E}-08$ & $2.82 \mathrm{E}-08$ & $1.83 \mathrm{E}-08$ & $1.49 \mathrm{E}-08$ & 3.39E-08 & $3.56 \mathrm{E}-08$ \\
\hline 5 & 7 & $2.62 \mathrm{E}-09$ & $2.47 \mathrm{E}-09$ & $3.17 \mathrm{E}-08$ & $2.84 \mathrm{E}-08$ & $1.89 \mathrm{E}-08$ & $1.67 \mathrm{E}-08$ & $3.95 \mathrm{E}-08$ & $4.37 \mathrm{E}-08$ & $2.95 \mathrm{E}-08$ & $3.07 \mathrm{E}-08$ \\
\hline 7 & 14 & $1.53 \mathrm{E}-09$ & $1.41 \mathrm{E}-09$ & $1.90 \mathrm{E}-08$ & $1.80 \mathrm{E}-08$ & $9.65 \mathrm{E}-09$ & 8.81E-09 & $1.47 \mathrm{E}-08$ & $1.43 \mathrm{E}-08$ & $1.74 \mathrm{E}-08$ & $1.72 \mathrm{E}-08$ \\
\hline 14 & 28 & $1.19 \mathrm{E}-09$ & $1.08 \mathrm{E}-09$ & $1.08 \mathrm{E}-08$ & $1.07 \mathrm{E}-08$ & $5.58 \mathrm{E}-09$ & $5.64 \mathrm{E}-09$ & $7.78 \mathrm{E}-09$ & $7.53 \mathrm{E}-09$ & $1.17 \mathrm{E}-08$ & $1.15 \mathrm{E}-08$ \\
\hline 14 & 42 & $6.07 \mathrm{E}-10$ & $8.23 \mathrm{E}-10$ & $5.21 \mathrm{E}-09$ & 5.85E-09 & 4.24E-09 & 4.64E-09 & $5.59 \mathrm{E}-09$ & $4.62 \mathrm{E}-09$ & $5.17 \mathrm{E}-09$ & $5.14 \mathrm{E}-09$ \\
\hline 7 & 49 & $7.97 \mathrm{E}-10$ & $8.49 \mathrm{E}-10$ & $5.80 \mathrm{E}-09$ & 5.49E-09 & 4.34E-09 & 4.12E-09 & $4.50 \mathrm{E}-09$ & $5.36 \mathrm{E}-09$ & 4.81E-09 & $5.24 \mathrm{E}-09$ \\
\hline 14 & 63 & $7.93 \mathrm{E}-10$ & $8.30 \mathrm{E}-10$ & $4.81 \mathrm{E}-09$ & 4.59E-09 & $4.12 \mathrm{E}-09$ & $4.12 \mathrm{E}-09$ & $4.51 \mathrm{E}-09$ & $4.33 \mathrm{E}-09$ & $3.78 \mathrm{E}-09$ & $4.16 \mathrm{E}-09$ \\
\hline 14 & 77 & $7.79 \mathrm{E}-10$ & $8.00 \mathrm{E}-10$ & $2.60 \mathrm{E}-09$ & $3.51 \mathrm{E}-09$ & $3.60 \mathrm{E}-09$ & 2.39E-09 & $2.71 \mathrm{E}-09$ & 3.08E-09 & $2.59 \mathrm{E}-09$ & $1.52 \mathrm{E}-09$ \\
\hline 14 & 91 & $7.54 \mathrm{E}-10$ & $8.04 \mathrm{E}-10$ & $3.07 \mathrm{E}-09$ & $1.98 \mathrm{E}-09$ & $3.37 \mathrm{E}-09$ & $2.90 \mathrm{E}-09$ & $3.19 \mathrm{E}-09$ & $3.63 \mathrm{E}-09$ & $1.46 \mathrm{E}-09$ & $2.10 \mathrm{E}-09$ \\
\hline
\end{tabular}

\begin{tabular}{|c|c|c|c|c|c|c|c|c|c|c|c|}
\hline \multirow{3}{*}{$\begin{array}{c}\text { Interval } \\
\text { (days) }\end{array}$} & \multirow{3}{*}{$\begin{array}{c}\text { Total } \\
\text { Duration } \\
\text { (days) }\end{array}$} & \multicolumn{10}{|c|}{ Nitrate Effective Diffusion Coefficient $\left(\mathrm{cm}^{2} / \mathrm{s}\right)$} \\
\hline & & \multicolumn{10}{|c|}{ Mix Number and Duplicate (Repeat) } \\
\hline & & $\mathbf{6 a}$ & $\mathbf{6 b}$ & $7 \mathbf{a}$ & $7 \mathbf{b}$ & $\mathbf{8 a}$ & $\mathbf{8 b}$ & $9 a$ & $9 \mathbf{b}$ & $10 \mathbf{a}$ & 10b \\
\hline 0.08 & 0.08 & $9.11 \mathrm{E}-07$ & $1.15 \mathrm{E}-06$ & 4.18E-07 & $1.31 \mathrm{E}-07$ & $5.02 \mathrm{E}-07$ & 7.07E-07 & $2.06 \mathrm{E}-07$ & $2.52 \mathrm{E}-07$ & 4.46E-07 & $2.06 \mathrm{E}-07$ \\
\hline 0.92 & 1 & $8.02 \mathrm{E}-08$ & $8.43 \mathrm{E}-08$ & $3.46 \mathrm{E}-08$ & $3.45 \mathrm{E}-08$ & $1.28 \mathrm{E}-08$ & $1.51 \mathrm{E}-08$ & $3.55 \mathrm{E}-08$ & $3.40 \mathrm{E}-08$ & $4.01 \mathrm{E}-08$ & 4.84E-08 \\
\hline 1 & 2 & $5.80 \mathrm{E}-08$ & 5.97E-08 & $2.97 \mathrm{E}-08$ & $2.85 \mathrm{E}-08$ & $6.23 \mathrm{E}-09$ & $6.78 \mathrm{E}-09$ & $2.21 \mathrm{E}-08$ & $2.30 \mathrm{E}-08$ & $3.25 \mathrm{E}-08$ & $3.85 \mathrm{E}-08$ \\
\hline 5 & 7 & $4.65 \mathrm{E}-08$ & 4.49E-08 & $1.94 \mathrm{E}-08$ & $2.09 \mathrm{E}-08$ & $5.98 \mathrm{E}-09$ & $5.28 \mathrm{E}-09$ & $1.31 \mathrm{E}-08$ & $1.27 \mathrm{E}-08$ & $2.54 \mathrm{E}-08$ & $2.96 \mathrm{E}-08$ \\
\hline 7 & 14 & $2.60 \mathrm{E}-08$ & $2.64 \mathrm{E}-08$ & $1.18 \mathrm{E}-08$ & $1.20 \mathrm{E}-08$ & $4.31 \mathrm{E}-09$ & $4.07 \mathrm{E}-09$ & $6.95 \mathrm{E}-09$ & $7.11 \mathrm{E}-09$ & $1.47 \mathrm{E}-08$ & $1.60 \mathrm{E}-08$ \\
\hline 14 & 28 & $1.61 \mathrm{E}-08$ & $1.72 \mathrm{E}-08$ & $8.08 \mathrm{E}-09$ & $1.01 \mathrm{E}-08$ & $3.35 \mathrm{E}-09$ & $3.23 \mathrm{E}-09$ & $5.42 \mathrm{E}-09$ & 5.29E-09 & 9.80E-09 & $9.35 \mathrm{E}-09$ \\
\hline 14 & 42 & $7.80 \mathrm{E}-09$ & $9.43 \mathrm{E}-09$ & $3.22 \mathrm{E}-09$ & $4.06 \mathrm{E}-09$ & $2.27 \mathrm{E}-09$ & $1.78 \mathrm{E}-09$ & $2.73 \mathrm{E}-09$ & $3.40 \mathrm{E}-09$ & $5.20 \mathrm{E}-09$ & 5.82E-09 \\
\hline 7 & 49 & $9.30 \mathrm{E}-09$ & 8.09E-09 & $3.23 \mathrm{E}-09$ & 4.10E-09 & $2.85 \mathrm{E}-09$ & $2.36 \mathrm{E}-09$ & $4.41 \mathrm{E}-09$ & $3.48 \mathrm{E}-09$ & $5.60 \mathrm{E}-09$ & $4.60 \mathrm{E}-09$ \\
\hline 14 & 63 & $4.96 \mathrm{E}-09$ & $5.48 \mathrm{E}-09$ & $2.37 \mathrm{E}-09$ & $2.66 \mathrm{E}-09$ & $2.53 \mathrm{E}-09$ & $2.41 \mathrm{E}-09$ & $3.94 \mathrm{E}-09$ & $4.10 \mathrm{E}-09$ & $4.28 \mathrm{E}-09$ & 4.04E-09 \\
\hline 14 & 77 & $1.65 \mathrm{E}-09$ & $2.47 \mathrm{E}-09$ & $9.46 \mathrm{E}-10$ & $1.26 \mathrm{E}-09$ & $1.87 \mathrm{E}-09$ & $2.16 \mathrm{E}-09$ & $2.42 \mathrm{E}-09$ & $1.73 \mathrm{E}-09$ & $2.66 \mathrm{E}-09$ & $2.35 \mathrm{E}-09$ \\
\hline 14 & 91 & $1.45 \mathrm{E}-09$ & $2.16 \mathrm{E}-09$ & $1.14 \mathrm{E}-09$ & $1.85 \mathrm{E}-09$ & $1.19 \mathrm{E}-09$ & $1.59 \mathrm{E}-09$ & $3.41 \mathrm{E}-09$ & $3.24 \mathrm{E}-09$ & $2.62 \mathrm{E}-09$ & $2.86 \mathrm{E}-09$ \\
\hline
\end{tabular}


Table D-8. Nitrate Effective Diffusion Coefficients (contd)

\begin{tabular}{|c|c|c|c|c|c|c|c|c|c|c|c|}
\hline \multirow{3}{*}{$\begin{array}{c}\text { Interval } \\
\text { (days) }\end{array}$} & \multirow{3}{*}{$\begin{array}{c}\text { Total } \\
\text { Duration } \\
\text { (days) }\end{array}$} & \multicolumn{10}{|c|}{ Nitrate Effective Diffusion Coefficient $\left(\mathrm{cm}^{2} / \mathrm{s}\right)$} \\
\hline & & \multicolumn{10}{|c|}{ Mix Number and Duplicate (Repeat) } \\
\hline & & $11 \mathbf{a}$ & $11 \mathrm{~b}$ & $12 \mathbf{a}$ & $\mathbf{1 2 b}$ & $13 \mathbf{a}$ & $13 \mathbf{b}$ & $14 \mathbf{a}$ & $14 \mathrm{~b}$ & $15 \mathbf{a}$ & $15 \mathrm{~b}$ \\
\hline 0.08 & 0.08 & $1.98 \mathrm{E}-07$ & $4.51 \mathrm{E}-07$ & $1.45 \mathrm{E}-07$ & $1.44 \mathrm{E}-07$ & $3.15 \mathrm{E}-07$ & $4.43 \mathrm{E}-07$ & $4.71 \mathrm{E}-07$ & $4.18 \mathrm{E}-07$ & 5.33E-08 & $4.24 \mathrm{E}-08$ \\
\hline 0.92 & 1 & $5.34 \mathrm{E}-08$ & $5.48 \mathrm{E}-08$ & 8.70E-09 & $7.75 \mathrm{E}-09$ & $5.97 \mathrm{E}-08$ & $5.58 \mathrm{E}-08$ & $4.43 \mathrm{E}-08$ & $4.81 \mathrm{E}-08$ & $4.11 \mathrm{E}-08$ & $3.76 \mathrm{E}-08$ \\
\hline 1 & 2 & $3.56 \mathrm{E}-08$ & $3.64 \mathrm{E}-08$ & $6.22 \mathrm{E}-09$ & $6.20 \mathrm{E}-09$ & $4.25 \mathrm{E}-08$ & $4.31 \mathrm{E}-08$ & $3.82 \mathrm{E}-08$ & $4.17 \mathrm{E}-08$ & $3.10 \mathrm{E}-08$ & $3.05 \mathrm{E}-08$ \\
\hline 5 & 7 & $2.15 \mathrm{E}-08$ & $2.43 \mathrm{E}-08$ & $7.51 \mathrm{E}-09$ & 5.91E-09 & $3.53 \mathrm{E}-08$ & $3.36 \mathrm{E}-08$ & $3.02 \mathrm{E}-08$ & $3.19 \mathrm{E}-08$ & $2.27 \mathrm{E}-08$ & $2.23 \mathrm{E}-08$ \\
\hline 7 & 14 & $1.20 \mathrm{E}-08$ & $1.11 \mathrm{E}-08$ & 4.79E-09 & $5.41 \mathrm{E}-09$ & $2.18 \mathrm{E}-08$ & $2.21 \mathrm{E}-08$ & $1.64 \mathrm{E}-08$ & $1.86 \mathrm{E}-08$ & $1.61 \mathrm{E}-08$ & $1.63 \mathrm{E}-08$ \\
\hline 14 & 28 & $9.76 \mathrm{E}-09$ & $1.02 \mathrm{E}-08$ & $4.16 \mathrm{E}-09$ & $4.46 \mathrm{E}-09$ & $1.42 \mathrm{E}-08$ & $1.37 \mathrm{E}-08$ & $9.71 \mathrm{E}-09$ & $1.01 \mathrm{E}-08$ & $1.08 \mathrm{E}-08$ & $1.06 \mathrm{E}-08$ \\
\hline 14 & 42 & $7.98 \mathrm{E}-09$ & $7.40 \mathrm{E}-09$ & $3.48 \mathrm{E}-09$ & $3.35 \mathrm{E}-09$ & $8.74 \mathrm{E}-09$ & $6.65 \mathrm{E}-09$ & $5.05 \mathrm{E}-09$ & $4.29 \mathrm{E}-09$ & $4.20 \mathrm{E}-09$ & $5.15 \mathrm{E}-09$ \\
\hline 7 & 49 & $8.06 \mathrm{E}-09$ & $9.15 \mathrm{E}-09$ & $4.13 \mathrm{E}-09$ & $4.32 \mathrm{E}-09$ & $8.11 \mathrm{E}-09$ & $7.26 \mathrm{E}-09$ & $6.60 \mathrm{E}-09$ & $6.26 \mathrm{E}-09$ & $8.27 \mathrm{E}-09$ & $6.45 \mathrm{E}-09$ \\
\hline 14 & 63 & $7.48 \mathrm{E}-09$ & 8.79E-09 & $4.05 \mathrm{E}-09$ & $3.58 \mathrm{E}-09$ & $5.73 \mathrm{E}-09$ & $5.69 \mathrm{E}-09$ & $3.93 \mathrm{E}-09$ & $4.07 \mathrm{E}-09$ & 5.83E-09 & 4.71E-09 \\
\hline 14 & 77 & $3.57 \mathrm{E}-09$ & $4.97 \mathrm{E}-09$ & $2.92 \mathrm{E}-09$ & $3.64 \mathrm{E}-09$ & $4.18 \mathrm{E}-09$ & $3.31 \mathrm{E}-09$ & $2.77 \mathrm{E}-09$ & $2.41 \mathrm{E}-09$ & $3.03 \mathrm{E}-09$ & $3.90 \mathrm{E}-09$ \\
\hline 14 & 91 & $2.69 \mathrm{E}-09$ & $4.02 \mathrm{E}-09$ & $3.91 \mathrm{E}-09$ & $2.20 \mathrm{E}-09$ & $3.87 \mathrm{E}-09$ & $3.21 \mathrm{E}-09$ & $1.94 \mathrm{E}-09$ & $1.89 \mathrm{E}-09$ & $2.53 \mathrm{E}-09$ & $1.98 \mathrm{E}-09$ \\
\hline
\end{tabular}

\begin{tabular}{|c|c|c|c|c|c|c|c|c|c|c|c|}
\hline \multirow{3}{*}{$\begin{array}{c}\text { Interval } \\
\text { (days) }\end{array}$} & \multirow{3}{*}{$\begin{array}{c}\text { Total } \\
\text { Duration } \\
\text { (days) }\end{array}$} & \multicolumn{10}{|c|}{ Nitrate Effective Diffusion Coefficient $\left(\mathrm{cm}^{2} / \mathrm{s}\right)$} \\
\hline & & \multicolumn{10}{|c|}{ Mix Number and Duplicate (Repeat) } \\
\hline & & $16 \mathbf{a}$ & $16 \mathrm{~b}$ & $17 \mathbf{a}$ & $\mathbf{1 7 b}$ & $18 \mathbf{a}$ & $18 \mathrm{~b}$ & $19 a$ & 19b & 20a & $20 b$ \\
\hline 0.08 & 0.08 & $5.60 \mathrm{E}-08$ & 5.08E-08 & $7.20 \mathrm{E}-08$ & $6.84 \mathrm{E}-08$ & $3.33 \mathrm{E}-08$ & $3.46 \mathrm{E}-08$ & $8.30 \mathrm{E}-08$ & $8.00 \mathrm{E}-08$ & $3.86 \mathrm{E}-08$ & $3.45 \mathrm{E}-08$ \\
\hline 0.92 & 1 & $3.16 \mathrm{E}-08$ & $3.13 \mathrm{E}-08$ & $5.93 \mathrm{E}-08$ & $5.90 \mathrm{E}-08$ & $1.50 \mathrm{E}-08$ & $1.51 \mathrm{E}-08$ & $5.07 \mathrm{E}-08$ & $5.17 \mathrm{E}-08$ & $1.54 \mathrm{E}-08$ & $2.01 \mathrm{E}-08$ \\
\hline 1 & 2 & $2.69 \mathrm{E}-08$ & $2.75 \mathrm{E}-08$ & $5.22 \mathrm{E}-08$ & $4.78 \mathrm{E}-08$ & $1.23 \mathrm{E}-08$ & $1.25 \mathrm{E}-08$ & $3.71 \mathrm{E}-08$ & $3.54 \mathrm{E}-08$ & $1.25 \mathrm{E}-08$ & $2.15 \mathrm{E}-08$ \\
\hline 5 & 7 & $1.67 \mathrm{E}-08$ & $1.63 \mathrm{E}-08$ & $2.95 \mathrm{E}-08$ & $2.92 \mathrm{E}-08$ & 7.84E-09 & $7.75 \mathrm{E}-09$ & $1.94 \mathrm{E}-08$ & $2.10 \mathrm{E}-08$ & $2.73 \mathrm{E}-08$ & $2.46 \mathrm{E}-08$ \\
\hline 7 & 14 & $1.38 \mathrm{E}-08$ & $1.53 \mathrm{E}-08$ & $1.84 \mathrm{E}-08$ & $1.92 \mathrm{E}-08$ & $5.50 \mathrm{E}-09$ & $5.39 \mathrm{E}-09$ & $1.20 \mathrm{E}-08$ & $1.42 \mathrm{E}-08$ & $2.68 \mathrm{E}-08$ & $1.18 \mathrm{E}-08$ \\
\hline 14 & 28 & $1.03 \mathrm{E}-08$ & $1.20 \mathrm{E}-08$ & $1.15 \mathrm{E}-08$ & $1.21 \mathrm{E}-08$ & $3.89 \mathrm{E}-09$ & $4.00 \mathrm{E}-09$ & $8.90 \mathrm{E}-09$ & $8.47 \mathrm{E}-09$ & $1.00 \mathrm{E}-08$ & $6.59 \mathrm{E}-09$ \\
\hline 14 & 42 & $6.49 \mathrm{E}-09$ & $6.38 \mathrm{E}-09$ & $5.57 \mathrm{E}-09$ & $7.08 \mathrm{E}-09$ & $2.47 \mathrm{E}-09$ & $3.04 \mathrm{E}-09$ & $4.37 \mathrm{E}-09$ & $3.76 \mathrm{E}-09$ & $5.69 \mathrm{E}-09$ & $4.57 \mathrm{E}-09$ \\
\hline 7 & 49 & $8.14 \mathrm{E}-09$ & $7.95 \mathrm{E}-09$ & $6.86 \mathrm{E}-09$ & $7.07 \mathrm{E}-09$ & $3.44 \mathrm{E}-09$ & $3.44 \mathrm{E}-09$ & $3.60 \mathrm{E}-09$ & $4.08 \mathrm{E}-09$ & $6.47 \mathrm{E}-09$ & 4.84E-09 \\
\hline 14 & 63 & $6.62 \mathrm{E}-09$ & $6.70 \mathrm{E}-09$ & $5.72 \mathrm{E}-09$ & $5.79 \mathrm{E}-09$ & $3.16 \mathrm{E}-09$ & $3.08 \mathrm{E}-09$ & $2.34 \mathrm{E}-09$ & $2.75 \mathrm{E}-09$ & $5.58 \mathrm{E}-09$ & $4.71 \mathrm{E}-09$ \\
\hline 14 & 77 & $2.78 \mathrm{E}-09$ & $4.21 \mathrm{E}-09$ & $4.82 \mathrm{E}-09$ & $4.93 \mathrm{E}-09$ & $2.42 \mathrm{E}-09$ & $2.86 \mathrm{E}-09$ & $1.38 \mathrm{E}-09$ & $1.54 \mathrm{E}-09$ & $2.92 \mathrm{E}-09$ & $4.02 \mathrm{E}-09$ \\
\hline 14 & 91 & $4.02 \mathrm{E}-09$ & $3.77 \mathrm{E}-09$ & $3.83 \mathrm{E}-09$ & $3.48 \mathrm{E}-09$ & $2.23 \mathrm{E}-09$ & $2.80 \mathrm{E}-09$ & $1.00 \mathrm{E}-09$ & $1.14 \mathrm{E}-09$ & $2.73 \mathrm{E}-09$ & $3.67 \mathrm{E}-09$ \\
\hline
\end{tabular}


Table D-8. Nitrate Effective Diffusion Coefficients (contd)

\begin{tabular}{|c|c|c|c|c|c|c|c||}
\hline \hline \multirow{3}{*}{$\begin{array}{c}\text { Interval } \\
\text { (days) }\end{array}$} & \multirow{2}{*}{$\begin{array}{c}\text { Total } \\
\text { Duration } \\
\text { (days) }\end{array}$} & \multicolumn{6}{|c||}{ Nitrate Effective Diffusion Coefficient (cm $\mathbf{2} / \mathbf{s})$} \\
\cline { 3 - 8 } & & $\mathbf{2 1 a}$ & $\mathbf{2 1 b}$ & $\mathbf{2 2 a}$ & $\mathbf{2 2 b}$ & $\mathbf{2 3 a}$ & $\mathbf{2 3 b}$ \\
\hline 0.08 & 0.08 & $2.06 \mathrm{E}-07$ & $2.01 \mathrm{E}-07$ & $6.67 \mathrm{E}-08$ & $7.24 \mathrm{E}-08$ & $1.48 \mathrm{E}-07$ & $1.48 \mathrm{E}-07$ \\
\hline 0.92 & 1 & $1.31 \mathrm{E}-07$ & $1.28 \mathrm{E}-07$ & $4.70 \mathrm{E}-08$ & $4.19 \mathrm{E}-08$ & $1.69 \mathrm{E}-07$ & $1.74 \mathrm{E}-07$ \\
\hline 1 & 2 & $1.06 \mathrm{E}-07$ & $1.06 \mathrm{E}-07$ & $2.83 \mathrm{E}-08$ & $2.77 \mathrm{E}-08$ & $1.67 \mathrm{E}-07$ & $1.77 \mathrm{E}-07$ \\
\hline 5 & 7 & $6.62 \mathrm{E}-08$ & $6.10 \mathrm{E}-08$ & $1.40 \mathrm{E}-08$ & $1.32 \mathrm{E}-08$ & $1.15 \mathrm{E}-07$ & $1.36 \mathrm{E}-07$ \\
\hline 7 & 14 & $4.41 \mathrm{E}-08$ & $3.79 \mathrm{E}-08$ & $8.10 \mathrm{E}-09$ & $7.99 \mathrm{E}-09$ & $7.37 \mathrm{E}-08$ & $8.89 \mathrm{E}-08$ \\
\hline 14 & 28 & $2.42 \mathrm{E}-08$ & $2.31 \mathrm{E}-08$ & $5.36 \mathrm{E}-09$ & $5.33 \mathrm{E}-09$ & $4.86 \mathrm{E}-08$ & $5.75 \mathrm{E}-08$ \\
\hline 14 & 42 & $1.47 \mathrm{E}-08$ & $1.20 \mathrm{E}-08$ & $4.58 \mathrm{E}-09$ & $3.18 \mathrm{E}-09$ & $4.12 \mathrm{E}-08$ & $3.66 \mathrm{E}-08$ \\
\hline 7 & 49 & $1.37 \mathrm{E}-08$ & $1.37 \mathrm{E}-08$ & $3.84 \mathrm{E}-09$ & $4.38 \mathrm{E}-09$ & $2.86 \mathrm{E}-08$ & $3.37 \mathrm{E}-08$ \\
\hline 14 & 63 & $9.83 \mathrm{E}-09$ & $9.97 \mathrm{E}-09$ & $3.77 \mathrm{E}-09$ & $4.06 \mathrm{E}-09$ & $2.29 \mathrm{E}-08$ & $2.84 \mathrm{E}-08$ \\
\hline 14 & 77 & $4.28 \mathrm{E}-09$ & $4.36 \mathrm{E}-09$ & $3.11 \mathrm{E}-09$ & $1.76 \mathrm{E}-09$ & $1.21 \mathrm{E}-08$ & $1.35 \mathrm{E}-08$ \\
\hline 14 & 91 & $3.63 \mathrm{E}-09$ & $3.44 \mathrm{E}-09$ & $3.51 \mathrm{E}-09$ & $1.74 \mathrm{E}-09$ & $7.59 \mathrm{E}-09$ & $7.62 \mathrm{E}-09$ \\
\hline \hline
\end{tabular}

\begin{tabular}{|c|c|c|c|c|c|c|c|}
\hline \multirow{3}{*}{$\begin{array}{c}\text { Interval } \\
\text { (days) }\end{array}$} & \multirow{3}{*}{$\begin{array}{c}\text { Total } \\
\text { Duration } \\
\text { (days) }\end{array}$} & \multicolumn{6}{|c|}{ Nitrate Effective Diffusion Coefficient $\left(\mathrm{cm}^{2} / \mathrm{s}\right)$} \\
\hline & & \multicolumn{6}{|c|}{ Mix Number and Duplicate (Repeat) } \\
\hline & & 24a & 24b & $25 a$ & $25 b$ & $26 a$ & $26 \mathbf{b}$ \\
\hline 0.08 & 0.08 & $1.15 \mathrm{E}-07$ & $1.30 \mathrm{E}-07$ & $6.84 \mathrm{E}-08$ & $6.53 \mathrm{E}-08$ & $1.50 \mathrm{E}-07$ & $1.54 \mathrm{E}-07$ \\
\hline 0.92 & 1 & $6.92 \mathrm{E}-08$ & $7.12 \mathrm{E}-08$ & $4.36 \mathrm{E}-08$ & 4.30E-08 & $7.13 \mathrm{E}-08$ & $6.89 \mathrm{E}-08$ \\
\hline 1 & 2 & $6.03 \mathrm{E}-08$ & $5.00 \mathrm{E}-08$ & $3.49 \mathrm{E}-08$ & $3.31 \mathrm{E}-08$ & 4.73E-08 & $4.80 \mathrm{E}-08$ \\
\hline 5 & 7 & 3.38E-08 & $3.52 \mathrm{E}-08$ & $2.03 \mathrm{E}-08$ & $2.08 \mathrm{E}-08$ & $2.56 \mathrm{E}-08$ & $2.61 \mathrm{E}-08$ \\
\hline 7 & 14 & $1.78 \mathrm{E}-08$ & $2.21 \mathrm{E}-08$ & $1.29 \mathrm{E}-08$ & $9.35 \mathrm{E}-09$ & $1.09 \mathrm{E}-08$ & $1.24 \mathrm{E}-08$ \\
\hline 14 & 28 & $1.47 \mathrm{E}-08$ & $1.37 \mathrm{E}-08$ & $1.12 \mathrm{E}-08$ & $1.04 \mathrm{E}-08$ & $1.21 \mathrm{E}-08$ & $1.21 \mathrm{E}-08$ \\
\hline 14 & 42 & $7.25 \mathrm{E}-09$ & $9.24 \mathrm{E}-09$ & 7.36E-09 & $6.21 \mathrm{E}-09$ & 7.87E-09 & $6.73 \mathrm{E}-09$ \\
\hline 7 & 49 & $8.69 \mathrm{E}-09$ & $8.61 \mathrm{E}-09$ & $5.56 \mathrm{E}-09$ & $5.70 \mathrm{E}-09$ & $7.06 \mathrm{E}-09$ & $6.71 \mathrm{E}-09$ \\
\hline 14 & 63 & $7.68 \mathrm{E}-09$ & 7.22E-09 & 4.73E-09 & 4.71E-09 & $5.07 \mathrm{E}-09$ & $5.25 \mathrm{E}-09$ \\
\hline 14 & 77 & 3.99E-09 & 5.47E-09 & $3.25 \mathrm{E}-09$ & $3.48 \mathrm{E}-09$ & $1.61 \mathrm{E}-09$ & $3.05 \mathrm{E}-09$ \\
\hline 14 & 91 & $3.04 \mathrm{E}-09$ & $4.67 \mathrm{E}-09$ & $2.81 \mathrm{E}-09$ & $2.44 \mathrm{E}-09$ & $2.48 \mathrm{E}-09$ & $2.91 \mathrm{E}-09$ \\
\hline
\end{tabular}


Table D-9. Nitrite Effective Diffusion Coefficients

\begin{tabular}{|c|c|c|c|c|c|c|c|c|c|c|c|}
\hline \multirow{3}{*}{$\begin{array}{c}\text { Interval } \\
\text { (days) }\end{array}$} & \multirow{3}{*}{$\begin{array}{c}\text { Total } \\
\text { Duration } \\
\text { (days) }\end{array}$} & \multicolumn{10}{|c|}{ Nitrite Effective Diffusion Coefficient $\left(\mathrm{cm}^{2} / \mathrm{s}\right)$} \\
\hline & & \multicolumn{10}{|c|}{ Mix Number and Duplicate (Repeat) } \\
\hline & & 1a & $1 \mathbf{b}$ & $\mathbf{2 a}$ & $2 \mathbf{b}$ & $\mathbf{3 a}$ & $\mathbf{3 b}$ & $4 a$ & $4 \mathbf{b}$ & $\mathbf{5 a}$ & $5 \mathbf{b}$ \\
\hline 0.08 & 0.08 & $5.31 \mathrm{E}-08$ & $8.63 \mathrm{E}-08$ & $2.65 \mathrm{E}-07$ & $8.01 \mathrm{E}-07$ & $3.70 \mathrm{E}-07$ & 5.93E-09 & $9.52 \mathrm{E}-08$ & $1.01 \mathrm{E}-07$ & $4.06 \mathrm{E}-07$ & $3.91 \mathrm{E}-07$ \\
\hline 0.92 & 1 & $2.09 \mathrm{E}-08$ & $1.55 \mathrm{E}-08$ & $7.98 \mathrm{E}-08$ & $9.17 \mathrm{E}-08$ & $8.18 \mathrm{E}-08$ & $9.12 \mathrm{E}-08$ & $1.42 \mathrm{E}-08$ & $3.45 \mathrm{E}-08$ & $3.42 \mathrm{E}-08$ & $3.68 \mathrm{E}-08$ \\
\hline 1 & 2 & 4.16E-09 & 3.59E-09 & $4.26 \mathrm{E}-08$ & $4.14 \mathrm{E}-08$ & $3.10 \mathrm{E}-08$ & $3.15 \mathrm{E}-08$ & $1.97 \mathrm{E}-08$ & $1.63 \mathrm{E}-08$ & $3.52 \mathrm{E}-08$ & $3.70 \mathrm{E}-08$ \\
\hline 5 & 7 & $3.17 \mathrm{E}-09$ & $2.97 \mathrm{E}-09$ & $3.35 \mathrm{E}-08$ & $2.95 \mathrm{E}-08$ & $2.05 \mathrm{E}-08$ & $1.84 \mathrm{E}-08$ & 4.10E-08 & $4.40 \mathrm{E}-08$ & $2.89 \mathrm{E}-08$ & $2.99 \mathrm{E}-08$ \\
\hline 7 & 14 & $1.61 \mathrm{E}-09$ & $1.52 \mathrm{E}-09$ & $1.86 \mathrm{E}-08$ & $1.74 \mathrm{E}-08$ & $1.01 \mathrm{E}-08$ & $8.83 \mathrm{E}-09$ & $1.41 \mathrm{E}-08$ & $1.38 \mathrm{E}-08$ & $1.49 \mathrm{E}-08$ & $1.52 \mathrm{E}-08$ \\
\hline 14 & 28 & $1.50 \mathrm{E}-09$ & $1.33 \mathrm{E}-09$ & $1.44 \mathrm{E}-08$ & $1.34 \mathrm{E}-08$ & $7.52 \mathrm{E}-09$ & $7.15 \mathrm{E}-09$ & $9.23 \mathrm{E}-09$ & $8.64 \mathrm{E}-09$ & $1.13 \mathrm{E}-08$ & $1.09 \mathrm{E}-08$ \\
\hline 14 & 42 & $7.41 \mathrm{E}-10$ & $9.77 \mathrm{E}-10$ & $5.55 \mathrm{E}-09$ & $6.37 \mathrm{E}-09$ & $4.95 \mathrm{E}-09$ & $5.30 \mathrm{E}-09$ & $6.71 \mathrm{E}-09$ & $5.37 \mathrm{E}-09$ & $5.26 \mathrm{E}-09$ & $5.11 \mathrm{E}-09$ \\
\hline 7 & 49 & $8.75 \mathrm{E}-10$ & $9.37 \mathrm{E}-10$ & $5.45 \mathrm{E}-09$ & $5.11 \mathrm{E}-09$ & $4.54 \mathrm{E}-09$ & $4.37 \mathrm{E}-09$ & $4.68 \mathrm{E}-09$ & 5.59E-09 & 4.63E-09 & $5.08 \mathrm{E}-09$ \\
\hline 14 & 63 & $8.67 \mathrm{E}-10$ & $9.16 \mathrm{E}-10$ & $4.99 \mathrm{E}-09$ & $4.65 \mathrm{E}-09$ & $4.93 \mathrm{E}-09$ & $4.73 \mathrm{E}-09$ & $4.78 \mathrm{E}-09$ & $4.48 \mathrm{E}-09$ & $3.57 \mathrm{E}-09$ & 3.92E-09 \\
\hline 14 & 77 & $9.02 \mathrm{E}-10$ & $8.45 \mathrm{E}-10$ & $2.52 \mathrm{E}-09$ & $3.31 \mathrm{E}-09$ & $4.27 \mathrm{E}-09$ & $2.80 \mathrm{E}-09$ & $2.90 \mathrm{E}-09$ & $3.00 \mathrm{E}-09$ & $2.47 \mathrm{E}-09$ & 1.39E-09 \\
\hline 14 & 91 & $8.95 \mathrm{E}-10$ & $9.34 \mathrm{E}-10$ & $3.12 \mathrm{E}-09$ & $2.10 \mathrm{E}-09$ & 4.69E-09 & $3.95 \mathrm{E}-09$ & $3.68 \mathrm{E}-09$ & $4.16 \mathrm{E}-09$ & $1.57 \mathrm{E}-09$ & $2.23 \mathrm{E}-09$ \\
\hline
\end{tabular}

\begin{tabular}{|c|c|c|c|c|c|c|c|c|c|c|c|}
\hline \multirow{3}{*}{$\begin{array}{c}\text { Interval } \\
\text { (days) }\end{array}$} & \multirow{3}{*}{$\begin{array}{c}\text { Total } \\
\text { Duration } \\
\text { (days) }\end{array}$} & \multicolumn{10}{|c|}{ Nitrite Effective Diffusion Coefficient $\left(\mathrm{cm}^{2} / \mathrm{s}\right)$} \\
\hline & & \multicolumn{10}{|c|}{ Mix Number and Duplicate (Repeat) } \\
\hline & & $\mathbf{6 a}$ & $\mathbf{6 b}$ & $7 \mathbf{a}$ & $7 \mathbf{b}$ & $\mathbf{8 a}$ & $\mathbf{8 b}$ & $9 a$ & 9b & $10 \mathbf{a}$ & $10 \mathrm{~b}$ \\
\hline 0.08 & 0.08 & $8.91 \mathrm{E}-07$ & $1.06 \mathrm{E}-06$ & $2.11 \mathrm{E}-07$ & 8.54E-08 & $2.70 \mathrm{E}-07$ & $3.90 \mathrm{E}-07$ & $2.45 \mathrm{E}-07$ & $2.92 \mathrm{E}-07$ & $2.22 \mathrm{E}-07$ & $1.18 \mathrm{E}-07$ \\
\hline 0.92 & 1 & $6.55 \mathrm{E}-08$ & $6.83 \mathrm{E}-08$ & $3.22 \mathrm{E}-08$ & $3.19 \mathrm{E}-08$ & $1.06 \mathrm{E}-08$ & $1.22 \mathrm{E}-08$ & $3.31 \mathrm{E}-08$ & $3.18 \mathrm{E}-08$ & $3.48 \mathrm{E}-08$ & 4.17E-08 \\
\hline 1 & 2 & $6.34 \mathrm{E}-08$ & $6.50 \mathrm{E}-08$ & $3.49 \mathrm{E}-08$ & $3.42 \mathrm{E}-08$ & $6.29 \mathrm{E}-09$ & $6.65 \mathrm{E}-09$ & $2.80 \mathrm{E}-08$ & $2.86 \mathrm{E}-08$ & $3.51 \mathrm{E}-08$ & $4.18 \mathrm{E}-08$ \\
\hline 5 & 7 & $4.67 \mathrm{E}-08$ & $4.47 \mathrm{E}-08$ & $2.10 \mathrm{E}-08$ & $2.37 \mathrm{E}-08$ & $6.37 \mathrm{E}-09$ & $5.64 \mathrm{E}-09$ & $1.61 \mathrm{E}-08$ & $1.55 \mathrm{E}-08$ & $2.60 \mathrm{E}-08$ & $3.12 \mathrm{E}-08$ \\
\hline 7 & 14 & $2.29 \mathrm{E}-08$ & $2.40 \mathrm{E}-08$ & $1.18 \mathrm{E}-08$ & $1.18 \mathrm{E}-08$ & $3.93 \mathrm{E}-09$ & $3.79 \mathrm{E}-09$ & $7.67 \mathrm{E}-09$ & $7.74 \mathrm{E}-09$ & $1.31 \mathrm{E}-08$ & $1.39 \mathrm{E}-08$ \\
\hline 14 & 28 & $1.62 \mathrm{E}-08$ & $1.67 \mathrm{E}-08$ & $7.88 \mathrm{E}-09$ & $9.45 \mathrm{E}-09$ & $3.02 \mathrm{E}-09$ & $2.92 \mathrm{E}-09$ & $6.30 \mathrm{E}-09$ & $5.93 \mathrm{E}-09$ & $8.41 \mathrm{E}-09$ & $8.10 \mathrm{E}-09$ \\
\hline 14 & 42 & $8.20 \mathrm{E}-09$ & $9.92 \mathrm{E}-09$ & $3.36 \mathrm{E}-09$ & $4.30 \mathrm{E}-09$ & $2.27 \mathrm{E}-09$ & $1.73 \mathrm{E}-09$ & 3.69E-09 & $4.43 \mathrm{E}-09$ & $5.11 \mathrm{E}-09$ & $5.80 \mathrm{E}-09$ \\
\hline 7 & 49 & $9.24 \mathrm{E}-09$ & $8.30 \mathrm{E}-09$ & $3.30 \mathrm{E}-09$ & $4.15 \mathrm{E}-09$ & $2.74 \mathrm{E}-09$ & $2.35 \mathrm{E}-09$ & $5.88 \mathrm{E}-09$ & $4.53 \mathrm{E}-09$ & $5.30 \mathrm{E}-09$ & 4.44E-09 \\
\hline 14 & 63 & 4.99E-09 & $5.37 \mathrm{E}-09$ & $2.34 \mathrm{E}-09$ & $2.66 \mathrm{E}-09$ & $2.30 \mathrm{E}-09$ & $2.16 \mathrm{E}-09$ & $4.86 \mathrm{E}-09$ & $4.88 \mathrm{E}-09$ & $3.85 \mathrm{E}-09$ & $3.45 \mathrm{E}-09$ \\
\hline 14 & 77 & $1.59 \mathrm{E}-09$ & $2.44 \mathrm{E}-09$ & $9.12 \mathrm{E}-10$ & $1.22 \mathrm{E}-09$ & $1.73 \mathrm{E}-09$ & $2.04 \mathrm{E}-09$ & 3.19E-09 & $2.30 \mathrm{E}-09$ & $2.54 \mathrm{E}-09$ & $2.15 \mathrm{E}-09$ \\
\hline 14 & 91 & $1.55 \mathrm{E}-09$ & $2.35 \mathrm{E}-09$ & $1.20 \mathrm{E}-09$ & $1.96 \mathrm{E}-09$ & $1.16 \mathrm{E}-09$ & $1.54 \mathrm{E}-09$ & $4.63 \mathrm{E}-09$ & $4.99 \mathrm{E}-09$ & $2.48 \mathrm{E}-09$ & $2.71 \mathrm{E}-09$ \\
\hline
\end{tabular}


Table D-9. Nitrite Effective Diffusion Coefficients (contd)

\begin{tabular}{|c|c|c|c|c|c|c|c|c|c|c|c|}
\hline \multirow{3}{*}{$\begin{array}{c}\text { Interval } \\
\text { (days) }\end{array}$} & \multirow{3}{*}{$\begin{array}{c}\text { Total } \\
\text { Duration } \\
\text { (days) }\end{array}$} & \multicolumn{10}{|c|}{ Nitrite Effective Diffusion Coefficient $\left(\mathrm{cm}^{2} / \mathrm{s}\right)$} \\
\hline & & \multicolumn{10}{|c|}{ Mix Number and Duplicate (Repeat) } \\
\hline & & $11 \mathbf{a}$ & $11 \mathrm{~b}$ & $12 \mathbf{a}$ & $12 \mathbf{b}$ & $13 \mathbf{a}$ & $13 \mathbf{b}$ & $14 a$ & $14 \mathrm{~b}$ & $15 \mathbf{a}$ & $15 b$ \\
\hline 0.08 & 0.08 & $2.13 \mathrm{E}-07$ & $4.46 \mathrm{E}-07$ & $9.15 \mathrm{E}-08$ & $8.75 \mathrm{E}-08$ & $1.52 \mathrm{E}-07$ & $2.11 \mathrm{E}-07$ & $2.26 \mathrm{E}-07$ & $2.21 \mathrm{E}-07$ & $6.00 \mathrm{E}-08$ & $4.76 \mathrm{E}-08$ \\
\hline 0.92 & 1 & $4.76 \mathrm{E}-08$ & 4.83E-08 & $8.12 \mathrm{E}-09$ & $7.20 \mathrm{E}-09$ & $4.85 \mathrm{E}-08$ & $4.54 \mathrm{E}-08$ & 4.17E-08 & 4.44E-08 & $4.56 \mathrm{E}-08$ & $4.22 \mathrm{E}-08$ \\
\hline 1 & 2 & $4.36 \mathrm{E}-08$ & 4.47E-08 & $6.66 \mathrm{E}-09$ & $6.67 \mathrm{E}-09$ & $4.36 \mathrm{E}-08$ & $4.42 \mathrm{E}-08$ & $4.51 \mathrm{E}-08$ & $4.88 \mathrm{E}-08$ & $3.58 \mathrm{E}-08$ & $3.61 \mathrm{E}-08$ \\
\hline 5 & 7 & $2.44 \mathrm{E}-08$ & $2.66 \mathrm{E}-08$ & 7.92E-09 & $6.23 \mathrm{E}-09$ & $3.45 \mathrm{E}-08$ & $3.27 \mathrm{E}-08$ & $3.37 \mathrm{E}-08$ & $3.55 \mathrm{E}-08$ & $2.06 \mathrm{E}-08$ & $2.02 \mathrm{E}-08$ \\
\hline 7 & 14 & $1.25 \mathrm{E}-08$ & $1.15 \mathrm{E}-08$ & 4.24E-09 & $4.76 \mathrm{E}-09$ & $1.85 \mathrm{E}-08$ & $1.83 \mathrm{E}-08$ & $1.55 \mathrm{E}-08$ & $1.66 \mathrm{E}-08$ & $2.02 \mathrm{E}-08$ & $1.88 \mathrm{E}-08$ \\
\hline 14 & 28 & 9.93E-09 & $1.02 \mathrm{E}-08$ & 3.48E-09 & $3.71 \mathrm{E}-09$ & $1.13 \mathrm{E}-08$ & $1.08 \mathrm{E}-08$ & 8.60E-09 & $9.01 \mathrm{E}-09$ & $1.22 \mathrm{E}-08$ & $1.03 \mathrm{E}-08$ \\
\hline 14 & 42 & $9.33 \mathrm{E}-09$ & 8.81E-09 & $3.41 \mathrm{E}-09$ & $3.26 \mathrm{E}-09$ & $7.92 \mathrm{E}-09$ & $6.19 \mathrm{E}-09$ & $5.21 \mathrm{E}-09$ & $4.43 \mathrm{E}-09$ & 4.79E-09 & $5.73 \mathrm{E}-09$ \\
\hline 7 & 49 & $1.01 \mathrm{E}-08$ & $1.16 \mathrm{E}-08$ & 4.07E-09 & $4.23 \mathrm{E}-09$ & $7.57 \mathrm{E}-09$ & $6.74 \mathrm{E}-09$ & $6.66 \mathrm{E}-09$ & $6.36 \mathrm{E}-09$ & 7.69E-09 & 6.04E-09 \\
\hline 14 & 63 & $8.17 \mathrm{E}-09$ & $9.58 \mathrm{E}-09$ & $3.57 \mathrm{E}-09$ & $3.15 \mathrm{E}-09$ & 4.72E-09 & $4.48 \mathrm{E}-09$ & $3.45 \mathrm{E}-09$ & 3.69E-09 & $5.96 \mathrm{E}-09$ & $4.66 \mathrm{E}-09$ \\
\hline 14 & 77 & $4.31 \mathrm{E}-09$ & $6.05 \mathrm{E}-09$ & $2.54 \mathrm{E}-09$ & $3.36 \mathrm{E}-09$ & $3.52 \mathrm{E}-09$ & $2.78 \mathrm{E}-09$ & $2.61 \mathrm{E}-09$ & $2.23 \mathrm{E}-09$ & $3.29 \mathrm{E}-09$ & $4.18 \mathrm{E}-09$ \\
\hline 14 & 91 & $3.77 \mathrm{E}-09$ & 5.41E-09 & $3.60 \mathrm{E}-09$ & $1.95 \mathrm{E}-09$ & $3.31 \mathrm{E}-09$ & $2.84 \mathrm{E}-09$ & $1.81 \mathrm{E}-09$ & $1.80 \mathrm{E}-09$ & $3.00 \mathrm{E}-09$ & $2.31 \mathrm{E}-09$ \\
\hline
\end{tabular}

\begin{tabular}{|c|c|c|c|c|c|c|c|c|c|c|c|}
\hline \multirow{3}{*}{$\begin{array}{c}\text { Interval } \\
\text { (days) }\end{array}$} & \multirow{3}{*}{$\begin{array}{c}\text { Total } \\
\text { Duration } \\
\text { (days) }\end{array}$} & \multicolumn{10}{|c|}{ Nitrite Effective Diffusion Coefficient $\left(\mathrm{cm}^{2} / \mathrm{s}\right)$} \\
\hline & & \multicolumn{10}{|c|}{ Mix Number and Duplicate (Repeat) } \\
\hline & & $16 \mathbf{a}$ & $16 \mathrm{~b}$ & $17 \mathbf{a}$ & $\mathbf{1 7 b}$ & $18 \mathbf{a}$ & $18 \mathrm{~b}$ & $19 a$ & 19b & 20a & $20 b$ \\
\hline 0.08 & 0.08 & $6.15 \mathrm{E}-08$ & $5.66 \mathrm{E}-08$ & $7.60 \mathrm{E}-08$ & $7.00 \mathrm{E}-08$ & $3.69 \mathrm{E}-08$ & $3.78 \mathrm{E}-08$ & $1.06 \mathrm{E}-07$ & $1.02 \mathrm{E}-07$ & $3.82 \mathrm{E}-08$ & $3.32 \mathrm{E}-08$ \\
\hline 0.92 & 1 & $3.45 \mathrm{E}-08$ & $3.46 \mathrm{E}-08$ & $6.27 \mathrm{E}-08$ & $6.24 \mathrm{E}-08$ & $1.63 \mathrm{E}-08$ & $1.64 \mathrm{E}-08$ & $6.11 \mathrm{E}-08$ & $6.31 \mathrm{E}-08$ & $1.72 \mathrm{E}-08$ & $2.25 \mathrm{E}-08$ \\
\hline 1 & 2 & $3.10 \mathrm{E}-08$ & $3.05 \mathrm{E}-08$ & $5.80 \mathrm{E}-08$ & $5.23 \mathrm{E}-08$ & $1.32 \mathrm{E}-08$ & $1.37 \mathrm{E}-08$ & $4.91 \mathrm{E}-08$ & $4.74 \mathrm{E}-08$ & $1.44 \mathrm{E}-08$ & $2.50 \mathrm{E}-08$ \\
\hline 5 & 7 & $1.53 \mathrm{E}-08$ & $1.46 \mathrm{E}-08$ & $2.54 \mathrm{E}-08$ & $2.54 \mathrm{E}-08$ & $6.97 \mathrm{E}-09$ & $6.92 \mathrm{E}-09$ & $1.98 \mathrm{E}-08$ & $2.12 \mathrm{E}-08$ & $2.52 \mathrm{E}-08$ & $2.28 \mathrm{E}-08$ \\
\hline 7 & 14 & $1.49 \mathrm{E}-08$ & $1.61 \mathrm{E}-08$ & $2.19 \mathrm{E}-08$ & $2.10 \mathrm{E}-08$ & $5.26 \mathrm{E}-09$ & $5.01 \mathrm{E}-09$ & $1.49 \mathrm{E}-08$ & $1.64 \mathrm{E}-08$ & $2.61 \mathrm{E}-08$ & 1.19E-08 \\
\hline 14 & 28 & $9.47 \mathrm{E}-09$ & $1.07 \mathrm{E}-08$ & $1.10 \mathrm{E}-08$ & $1.07 \mathrm{E}-08$ & $3.07 \mathrm{E}-09$ & $3.23 \mathrm{E}-09$ & 8.89E-09 & $8.27 \mathrm{E}-09$ & $8.50 \mathrm{E}-09$ & $5.64 \mathrm{E}-09$ \\
\hline 14 & 42 & $6.27 \mathrm{E}-09$ & $6.60 \mathrm{E}-09$ & $6.09 \mathrm{E}-09$ & $7.54 \mathrm{E}-09$ & $2.34 \mathrm{E}-09$ & $2.93 \mathrm{E}-09$ & $5.63 \mathrm{E}-09$ & $4.63 \mathrm{E}-09$ & $5.71 \mathrm{E}-09$ & $4.86 \mathrm{E}-09$ \\
\hline 7 & 49 & $7.28 \mathrm{E}-09$ & $6.98 \mathrm{E}-09$ & $6.46 \mathrm{E}-09$ & $6.44 \mathrm{E}-09$ & $3.16 \mathrm{E}-09$ & $3.15 \mathrm{E}-09$ & $4.10 \mathrm{E}-09$ & $4.63 \mathrm{E}-09$ & $6.45 \mathrm{E}-09$ & 4.91E-09 \\
\hline 14 & 63 & $6.01 \mathrm{E}-09$ & $5.91 \mathrm{E}-09$ & $5.53 \mathrm{E}-09$ & $5.22 \mathrm{E}-09$ & $2.80 \mathrm{E}-09$ & $2.80 \mathrm{E}-09$ & $2.73 \mathrm{E}-09$ & $3.25 \mathrm{E}-09$ & $5.30 \mathrm{E}-09$ & $4.55 \mathrm{E}-09$ \\
\hline 14 & 77 & $2.74 \mathrm{E}-09$ & $4.05 \mathrm{E}-09$ & $5.05 \mathrm{E}-09$ & 4.91E-09 & $2.34 \mathrm{E}-09$ & $2.85 \mathrm{E}-09$ & $1.73 \mathrm{E}-09$ & $1.95 \mathrm{E}-09$ & $2.85 \mathrm{E}-09$ & $3.88 \mathrm{E}-09$ \\
\hline 14 & 91 & $3.90 \mathrm{E}-09$ & $3.96 \mathrm{E}-09$ & $4.45 \mathrm{E}-09$ & $3.78 \mathrm{E}-09$ & $2.21 \mathrm{E}-09$ & $2.71 \mathrm{E}-09$ & $1.42 \mathrm{E}-09$ & $1.57 \mathrm{E}-09$ & $2.51 \mathrm{E}-09$ & $3.62 \mathrm{E}-09$ \\
\hline
\end{tabular}


Table D-9. Nitrite Effective Diffusion Coefficients (contd)

\begin{tabular}{|c|c|c|c|c|c|c|c||}
\hline \multirow{2}{*}{$\begin{array}{c}\text { Interval } \\
\text { (days) }\end{array}$} & \multirow{2}{*}{$\begin{array}{c}\text { Total } \\
\text { Duration } \\
\text { (days) }\end{array}$} & \multicolumn{6}{|c||}{ Nitrite Effective Diffusion Coefficient $\left(\mathbf{c m}^{\mathbf{2}} / \mathbf{s}\right)$} \\
\cline { 3 - 8 } & \multicolumn{5}{|c|}{ Mix Number and Duplicate (Repeat) } \\
\hline 0.08 & 0.08 & $2.18 \mathrm{E}-07$ & $2.16 \mathrm{E}-07$ & $7.53 \mathrm{E}-08$ & $8.24 \mathrm{E}-08$ & $1.55 \mathrm{E}-07$ & $1.56 \mathrm{E}-07$ \\
\hline 0.92 & 1 & $1.41 \mathrm{E}-07$ & $1.40 \mathrm{E}-07$ & $5.14 \mathrm{E}-08$ & $4.65 \mathrm{E}-08$ & $1.53 \mathrm{E}-07$ & $1.66 \mathrm{E}-07$ \\
\hline 1 & 2 & $1.27 \mathrm{E}-07$ & $1.19 \mathrm{E}-07$ & $3.38 \mathrm{E}-08$ & $3.30 \mathrm{E}-08$ & $1.74 \mathrm{E}-07$ & $1.87 \mathrm{E}-07$ \\
\hline 5 & 7 & $5.64 \mathrm{E}-08$ & $5.10 \mathrm{E}-08$ & $1.35 \mathrm{E}-08$ & $1.29 \mathrm{E}-08$ & $8.58 \mathrm{E}-08$ & $9.79 \mathrm{E}-08$ \\
\hline 7 & 14 & $4.35 \mathrm{E}-08$ & $3.73 \mathrm{E}-08$ & $8.03 \mathrm{E}-09$ & $8.01 \mathrm{E}-09$ & $6.11 \mathrm{E}-08$ & $7.51 \mathrm{E}-08$ \\
\hline 14 & 28 & $2.01 \mathrm{E}-08$ & $1.90 \mathrm{E}-08$ & $4.49 \mathrm{E}-09$ & $4.57 \mathrm{E}-09$ & $3.23 \mathrm{E}-08$ & $3.65 \mathrm{E}-08$ \\
\hline 14 & 42 & $1.55 \mathrm{E}-08$ & $1.25 \mathrm{E}-08$ & $4.76 \mathrm{E}-09$ & $3.40 \mathrm{E}-09$ & $2.66 \mathrm{E}-08$ & $2.88 \mathrm{E}-08$ \\
\hline 7 & 49 & $1.23 \mathrm{E}-08$ & $1.28 \mathrm{E}-08$ & $3.86 \mathrm{E}-09$ & $4.35 \mathrm{E}-09$ & $2.27 \mathrm{E}-08$ & $2.62 \mathrm{E}-08$ \\
\hline 14 & 63 & $8.80 \mathrm{E}-09$ & $9.35 \mathrm{E}-09$ & $3.70 \mathrm{E}-09$ & $3.99 \mathrm{E}-09$ & $1.73 \mathrm{E}-08$ & $2.06 \mathrm{E}-08$ \\
\hline 14 & 77 & $4.40 \mathrm{E}-09$ & $4.42 \mathrm{E}-09$ & $3.32 \mathrm{E}-09$ & $1.88 \mathrm{E}-09$ & $1.03 \mathrm{E}-08$ & $1.05 \mathrm{E}-08$ \\
\hline 14 & 91 & $3.79 \mathrm{E}-09$ & $3.58 \mathrm{E}-09$ & $3.76 \mathrm{E}-09$ & $1.87 \mathrm{E}-09$ & $6.57 \mathrm{E}-09$ & $6.15 \mathrm{E}-09$ \\
\hline
\end{tabular}

\begin{tabular}{|c|c|c|c|c|c|c|c||}
\hline \multirow{2}{*}{$\begin{array}{c}\text { Interval } \\
\text { (days) }\end{array}$} & \multirow{2}{*}{$\begin{array}{c}\text { Total } \\
\text { Duration } \\
\text { (days) }\end{array}$} & \multicolumn{6}{|c||}{ Nitrite Effective Diffusion Coefficient $\left(\mathbf{c m}^{2} / \mathbf{s}\right)$} \\
\cline { 3 - 8 } & & $\mathbf{2 4 a}$ & $\mathbf{2 4 b}$ & $\mathbf{2 5 a}$ & $\mathbf{2 5 b}$ & $\mathbf{2 6 a}$ & $\mathbf{2 6 b}$ \\
\hline 0.08 & 0.08 & $1.17 \mathrm{E}-07$ & $1.30 \mathrm{E}-07$ & $7.25 \mathrm{E}-08$ & $7.10 \mathrm{E}-08$ & $1.58 \mathrm{E}-07$ & $1.66 \mathrm{E}-07$ \\
\hline 0.92 & 1 & $6.68 \mathrm{E}-08$ & $6.94 \mathrm{E}-08$ & $4.46 \mathrm{E}-08$ & $4.51 \mathrm{E}-08$ & $7.69 \mathrm{E}-08$ & $7.64 \mathrm{E}-08$ \\
\hline 1 & 2 & $6.56 \mathrm{E}-08$ & $5.53 \mathrm{E}-08$ & $3.81 \mathrm{E}-08$ & $3.70 \mathrm{E}-08$ & $5.60 \mathrm{E}-08$ & $5.63 \mathrm{E}-08$ \\
\hline 5 & 7 & $2.75 \mathrm{E}-08$ & $2.90 \mathrm{E}-08$ & $1.74 \mathrm{E}-08$ & $1.79 \mathrm{E}-08$ & $2.38 \mathrm{E}-08$ & $2.43 \mathrm{E}-08$ \\
\hline 7 & 14 & $1.58 \mathrm{E}-08$ & $1.90 \mathrm{E}-08$ & $1.12 \mathrm{E}-08$ & $8.39 \mathrm{E}-09$ & $1.10 \mathrm{E}-08$ & $1.26 \mathrm{E}-08$ \\
\hline 14 & 28 & $1.07 \mathrm{E}-08$ & $1.01 \mathrm{E}-08$ & $8.10 \mathrm{E}-09$ & $7.60 \mathrm{E}-09$ & $9.72 \mathrm{E}-09$ & $9.65 \mathrm{E}-09$ \\
\hline 14 & 42 & $6.77 \mathrm{E}-09$ & $8.33 \mathrm{E}-09$ & $6.58 \mathrm{E}-09$ & $5.67 \mathrm{E}-09$ & $7.59 \mathrm{E}-09$ & $6.66 \mathrm{E}-09$ \\
\hline 7 & 49 & $7.76 \mathrm{E}-09$ & $7.40 \mathrm{E}-09$ & $5.04 \mathrm{E}-09$ & $5.24 \mathrm{E}-09$ & $6.81 \mathrm{E}-09$ & $6.50 \mathrm{E}-09$ \\
\hline 14 & 63 & $6.55 \mathrm{E}-09$ & $6.26 \mathrm{E}-09$ & $4.04 \mathrm{E}-09$ & $4.12 \mathrm{E}-09$ & $4.71 \mathrm{E}-09$ & $5.06 \mathrm{E}-09$ \\
\hline 14 & 77 & $3.63 \mathrm{E}-09$ & $5.08 \mathrm{E}-09$ & $3.00 \mathrm{E}-09$ & $3.21 \mathrm{E}-09$ & $1.66 \mathrm{E}-09$ & $3.16 \mathrm{E}-09$ \\
\hline 14 & 91 & $2.97 \mathrm{E}-09$ & $4.56 \mathrm{E}-09$ & $2.47 \mathrm{E}-09$ & $2.20 \mathrm{E}-09$ & $2.47 \mathrm{E}-09$ & $2.75 \mathrm{E}-09$ \\
\hline
\end{tabular}


Table D-10. Iodine Effective Diffusion Coefficients

\begin{tabular}{|c|c|c|c|c|c|c|c|c|c|c|c|}
\hline \multirow{3}{*}{$\begin{array}{c}\text { Interval } \\
\text { (days) }\end{array}$} & \multirow{3}{*}{$\begin{array}{c}\text { Total } \\
\text { Duration } \\
\text { (days) }\end{array}$} & \multicolumn{10}{|c|}{ Iodine Effective Diffusion Coefficient $\left(\mathrm{cm}^{2} / \mathrm{s}\right)$} \\
\hline & & \multicolumn{10}{|c|}{ Mix Number and Duplicate (Repeat) } \\
\hline & & $1 \mathbf{a}$ & $\mathbf{1 b}$ & $\mathbf{2 a}$ & 2b & $\mathbf{3 a}$ & $\mathbf{3 b}$ & $\mathbf{4 a}$ & $4 \mathbf{b}$ & $\mathbf{5 a}$ & $\mathbf{5 b}$ \\
\hline 0.08 & 0.08 & 1.19E-09 & 5.41E-08 & $1.83 \mathrm{E}-07$ & $5.25 \mathrm{E}-07$ & $3.53 \mathrm{E}-07$ & $6.48 \mathrm{E}-07$ & $8.16 \mathrm{E}-08$ & $1.43 \mathrm{E}-07$ & $3.28 \mathrm{E}-07$ & $4.25 \mathrm{E}-07$ \\
\hline 0.92 & 1 & $1.71 \mathrm{E}-08$ & $1.71 \mathrm{E}-08$ & $1.05 \mathrm{E}-07$ & $1.25 \mathrm{E}-07$ & $1.33 \mathrm{E}-07$ & $1.36 \mathrm{E}-07$ & $1.27 \mathrm{E}-08$ & $2.27 \mathrm{E}-08$ & $3.77 \mathrm{E}-08$ & $3.91 \mathrm{E}-08$ \\
\hline 1 & 2 & $3.15 \mathrm{E}-09$ & $2.82 \mathrm{E}-09$ & 3.99E-08 & $3.91 \mathrm{E}-08$ & $3.39 \mathrm{E}-08$ & $3.32 \mathrm{E}-08$ & $1.31 \mathrm{E}-08$ & $1.14 \mathrm{E}-08$ & $3.45 \mathrm{E}-08$ & $3.43 \mathrm{E}-08$ \\
\hline 5 & 7 & $1.67 \mathrm{E}-09$ & $1.63 \mathrm{E}-09$ & $2.50 \mathrm{E}-08$ & $2.42 \mathrm{E}-08$ & $1.76 \mathrm{E}-08$ & $1.71 \mathrm{E}-08$ & $2.41 \mathrm{E}-08$ & $2.45 \mathrm{E}-08$ & $2.33 \mathrm{E}-08$ & $2.32 \mathrm{E}-08$ \\
\hline 7 & 14 & $1.05 \mathrm{E}-09$ & $1.03 \mathrm{E}-09$ & $1.64 \mathrm{E}-08$ & $1.57 \mathrm{E}-08$ & $9.73 \mathrm{E}-09$ & 8.68E-09 & $9.18 \mathrm{E}-09$ & $8.85 \mathrm{E}-09$ & $1.44 \mathrm{E}-08$ & $1.45 \mathrm{E}-08$ \\
\hline 14 & 28 & $8.53 \mathrm{E}-10$ & $8.51 \mathrm{E}-10$ & $1.09 \mathrm{E}-08$ & $1.05 \mathrm{E}-08$ & $6.32 \mathrm{E}-09$ & $6.06 \mathrm{E}-09$ & $5.38 \mathrm{E}-09$ & $5.37 \mathrm{E}-09$ & $9.32 \mathrm{E}-09$ & $9.48 \mathrm{E}-09$ \\
\hline 14 & 42 & $7.01 \mathrm{E}-10$ & $7.04 \mathrm{E}-10$ & 7.17E-09 & $6.97 \mathrm{E}-09$ & 4.72E-09 & $5.51 \mathrm{E}-09$ & $4.01 \mathrm{E}-09$ & $3.70 \mathrm{E}-09$ & 5.23E-09 & $5.31 \mathrm{E}-09$ \\
\hline 7 & 49 & $6.18 \mathrm{E}-10$ & $6.04 \mathrm{E}-10$ & 5.79E-09 & $5.40 \mathrm{E}-09$ & $4.54 \mathrm{E}-09$ & $4.46 \mathrm{E}-09$ & $3.02 \mathrm{E}-09$ & $3.44 \mathrm{E}-09$ & $3.55 \mathrm{E}-09$ & $3.70 \mathrm{E}-09$ \\
\hline 14 & 63 & $6.00 \mathrm{E}-10$ & $6.09 \mathrm{E}-10$ & $4.76 \mathrm{E}-09$ & 4.72E-09 & $4.18 \mathrm{E}-09$ & $4.08 \mathrm{E}-09$ & $3.19 \mathrm{E}-09$ & $3.29 \mathrm{E}-09$ & $2.77 \mathrm{E}-09$ & $2.94 \mathrm{E}-09$ \\
\hline 14 & 77 & $5.88 \mathrm{E}-10$ & $6.01 \mathrm{E}-10$ & $2.61 \mathrm{E}-09$ & $3.54 \mathrm{E}-09$ & 3.59E-09 & $2.34 \mathrm{E}-09$ & $2.06 \mathrm{E}-09$ & 2.32E-09 & $1.74 \mathrm{E}-09$ & $1.07 \mathrm{E}-09$ \\
\hline 14 & 91 & $5.70 \mathrm{E}-10$ & $6.02 \mathrm{E}-10$ & $2.97 \mathrm{E}-09$ & $1.85 \mathrm{E}-09$ & $3.17 \mathrm{E}-09$ & $2.69 \mathrm{E}-09$ & $2.34 \mathrm{E}-09$ & $2.70 \mathrm{E}-09$ & $9.51 \mathrm{E}-10$ & $1.32 \mathrm{E}-09$ \\
\hline
\end{tabular}

\begin{tabular}{|c|c|c|c|c|c|c|c|c|c|c|c|}
\hline \multirow{3}{*}{$\begin{array}{c}\text { Interval } \\
\text { (days) }\end{array}$} & \multirow{3}{*}{$\begin{array}{c}\text { Total } \\
\text { Duration } \\
\text { (days) }\end{array}$} & \multicolumn{10}{|c|}{ Iodine Effective Diffusion Coefficient $\left(\mathrm{cm}^{2} / \mathrm{s}\right)$} \\
\hline & & \multicolumn{10}{|c|}{ Mix Number and Duplicate (Repeat) } \\
\hline & & $\mathbf{6 a}$ & $\mathbf{6 b}$ & $7 \mathbf{a}$ & $7 \mathbf{b}$ & $\mathbf{8 a}$ & $\mathbf{8 b}$ & $9 a$ & $9 \mathbf{b}$ & $10 \mathbf{a}$ & $10 \mathrm{~b}$ \\
\hline 0.08 & 0.08 & $8.06 \mathrm{E}-07$ & 5.82E-07 & $6.90 \mathrm{E}-09$ & $1.60 \mathrm{E}-07$ & $1.07 \mathrm{E}-07$ & $6.37 \mathrm{E}-08$ & $5.66 \mathrm{E}-07$ & 4.46E-07 & $3.04 \mathrm{E}-07$ & $1.60 \mathrm{E}-07$ \\
\hline 0.92 & 1 & $9.52 \mathrm{E}-08$ & 9.67E-08 & $3.77 \mathrm{E}-08$ & $3.68 \mathrm{E}-08$ & $1.17 \mathrm{E}-08$ & $1.29 \mathrm{E}-08$ & $4.78 \mathrm{E}-08$ & 4.77E-08 & $2.83 \mathrm{E}-08$ & $3.32 \mathrm{E}-08$ \\
\hline 1 & 2 & 7.19E-08 & 7.27E-08 & $3.21 \mathrm{E}-08$ & $2.99 \mathrm{E}-08$ & $6.18 \mathrm{E}-09$ & $6.14 \mathrm{E}-09$ & $3.03 \mathrm{E}-08$ & $2.84 \mathrm{E}-08$ & $2.29 \mathrm{E}-08$ & $2.80 \mathrm{E}-08$ \\
\hline 5 & 7 & 4.60E-08 & $4.55 \mathrm{E}-08$ & $1.90 \mathrm{E}-08$ & $1.91 \mathrm{E}-08$ & 4.74E-09 & 4.34E-09 & $1.45 \mathrm{E}-08$ & $1.40 \mathrm{E}-08$ & $1.65 \mathrm{E}-08$ & $1.94 \mathrm{E}-08$ \\
\hline 7 & 14 & $2.68 \mathrm{E}-08$ & $2.82 \mathrm{E}-08$ & $1.12 \mathrm{E}-08$ & $1.12 \mathrm{E}-08$ & $3.79 \mathrm{E}-09$ & $3.54 \mathrm{E}-09$ & $8.01 \mathrm{E}-09$ & $8.20 \mathrm{E}-09$ & $1.06 \mathrm{E}-08$ & $1.18 \mathrm{E}-08$ \\
\hline 14 & 28 & $1.75 \mathrm{E}-08$ & $1.78 \mathrm{E}-08$ & 7.09E-09 & $8.36 \mathrm{E}-09$ & $3.19 \mathrm{E}-09$ & $3.03 \mathrm{E}-09$ & $6.41 \mathrm{E}-09$ & $6.05 \mathrm{E}-09$ & $6.66 \mathrm{E}-09$ & $6.93 \mathrm{E}-09$ \\
\hline 14 & 42 & $1.05 \mathrm{E}-08$ & $1.07 \mathrm{E}-08$ & $3.93 \mathrm{E}-09$ & $4.53 \mathrm{E}-09$ & $2.68 \mathrm{E}-09$ & $2.44 \mathrm{E}-09$ & $5.08 \mathrm{E}-09$ & 5.01E-09 & 4.47E-09 & 4.49E-09 \\
\hline 7 & 49 & $6.99 \mathrm{E}-09$ & $7.52 \mathrm{E}-09$ & $2.68 \mathrm{E}-09$ & $2.97 \mathrm{E}-09$ & $2.42 \mathrm{E}-09$ & $2.27 \mathrm{E}-09$ & $4.70 \mathrm{E}-09$ & $4.91 \mathrm{E}-09$ & $3.58 \mathrm{E}-09$ & $3.42 \mathrm{E}-09$ \\
\hline 14 & 63 & 4.74E-09 & $5.29 \mathrm{E}-09$ & $2.02 \mathrm{E}-09$ & $2.37 \mathrm{E}-09$ & $2.22 \mathrm{E}-09$ & $2.13 \mathrm{E}-09$ & $4.62 \mathrm{E}-09$ & $4.75 \mathrm{E}-09$ & $3.08 \mathrm{E}-09$ & $2.78 \mathrm{E}-09$ \\
\hline 14 & 77 & $1.46 \mathrm{E}-09$ & 2.29E-09 & $8.01 \mathrm{E}-10$ & $1.05 \mathrm{E}-09$ & $1.68 \mathrm{E}-09$ & $1.82 \mathrm{E}-09$ & $2.77 \mathrm{E}-09$ & $2.00 \mathrm{E}-09$ & $1.93 \mathrm{E}-09$ & $1.60 \mathrm{E}-09$ \\
\hline 14 & 91 & $1.14 \mathrm{E}-09$ & $1.74 \mathrm{E}-09$ & $9.78 \mathrm{E}-10$ & $1.47 \mathrm{E}-09$ & $1.07 \mathrm{E}-09$ & $1.40 \mathrm{E}-09$ & $3.22 \mathrm{E}-09$ & $3.70 \mathrm{E}-09$ & $1.91 \mathrm{E}-09$ & $1.92 \mathrm{E}-09$ \\
\hline
\end{tabular}


Table D-10. Iodine Effective Diffusion Coefficients (contd)

\begin{tabular}{|c|c|c|c|c|c|c|c|c|c|c|c|}
\hline \multirow{3}{*}{$\begin{array}{c}\text { Interval } \\
\text { (days) }\end{array}$} & \multirow{3}{*}{$\begin{array}{c}\text { Total } \\
\text { Duration } \\
\text { (days) }\end{array}$} & \multicolumn{10}{|c|}{ Iodine Effective Diffusion Coefficient $\left(\mathrm{cm}^{2} / \mathrm{s}\right)$} \\
\hline & & \multicolumn{10}{|c|}{ Mix Number and Duplicate (Repeat) } \\
\hline & & $11 \mathbf{a}$ & $11 \mathrm{~b}$ & $12 \mathbf{a}$ & 12b & $13 \mathbf{a}$ & $13 b$ & $14 a$ & $14 \mathrm{~b}$ & $15 \mathbf{a}$ & 15b \\
\hline 0.08 & 0.08 & $2.77 \mathrm{E}-07$ & 4.74E-07 & $1.17 \mathrm{E}-08$ & $3.67 \mathrm{E}-08$ & $1.79 \mathrm{E}-07$ & $3.77 \mathrm{E}-07$ & $3.40 \mathrm{E}-07$ & $2.80 \mathrm{E}-07$ & $3.15 \mathrm{E}-08$ & 2.89E-08 \\
\hline 0.92 & 1 & 7.79E-08 & $7.97 \mathrm{E}-08$ & $6.32 \mathrm{E}-09$ & $6.32 \mathrm{E}-09$ & 5.82E-08 & $5.44 \mathrm{E}-08$ & $5.45 \mathrm{E}-08$ & $5.85 \mathrm{E}-08$ & $2.83 \mathrm{E}-08$ & $2.58 \mathrm{E}-08$ \\
\hline 1 & 2 & $5.25 \mathrm{E}-08$ & $5.17 \mathrm{E}-08$ & $4.66 \mathrm{E}-09$ & 4.79E-09 & $4.12 \mathrm{E}-08$ & $4.01 \mathrm{E}-08$ & 4.29E-08 & $4.50 \mathrm{E}-08$ & $2.44 \mathrm{E}-08$ & $2.33 \mathrm{E}-08$ \\
\hline 5 & 7 & $2.93 \mathrm{E}-08$ & $2.94 \mathrm{E}-08$ & $4.90 \mathrm{E}-09$ & $4.04 \mathrm{E}-09$ & $2.91 \mathrm{E}-08$ & $2.74 \mathrm{E}-08$ & $2.77 \mathrm{E}-08$ & $2.98 \mathrm{E}-08$ & $1.87 \mathrm{E}-08$ & $1.87 \mathrm{E}-08$ \\
\hline 7 & 14 & $1.63 \mathrm{E}-08$ & $1.60 \mathrm{E}-08$ & $3.50 \mathrm{E}-09$ & $3.84 \mathrm{E}-09$ & $2.01 \mathrm{E}-08$ & $1.95 \mathrm{E}-08$ & $1.64 \mathrm{E}-08$ & $1.84 \mathrm{E}-08$ & $1.35 \mathrm{E}-08$ & $1.30 \mathrm{E}-08$ \\
\hline 14 & 28 & $1.33 \mathrm{E}-08$ & $1.32 \mathrm{E}-08$ & $2.77 \mathrm{E}-09$ & $3.12 \mathrm{E}-09$ & $1.30 \mathrm{E}-08$ & $1.24 \mathrm{E}-08$ & $8.85 \mathrm{E}-09$ & $9.05 \mathrm{E}-09$ & 8.83E-09 & $8.26 \mathrm{E}-09$ \\
\hline 14 & 42 & $1.24 \mathrm{E}-08$ & $1.29 \mathrm{E}-08$ & $2.77 \mathrm{E}-09$ & $2.74 \mathrm{E}-09$ & $9.18 \mathrm{E}-09$ & $8.54 \mathrm{E}-09$ & $6.13 \mathrm{E}-09$ & 5.94E-09 & $6.13 \mathrm{E}-09$ & $5.52 \mathrm{E}-09$ \\
\hline 7 & 49 & $1.11 \mathrm{E}-08$ & $1.24 \mathrm{E}-08$ & $2.53 \mathrm{E}-09$ & $2.56 \mathrm{E}-09$ & $6.94 \mathrm{E}-09$ & $6.54 \mathrm{E}-09$ & $4.43 \mathrm{E}-09$ & $4.56 \mathrm{E}-09$ & $5.22 \mathrm{E}-09$ & $4.16 \mathrm{E}-09$ \\
\hline 14 & 63 & $9.97 \mathrm{E}-09$ & $1.19 \mathrm{E}-08$ & $2.72 \mathrm{E}-09$ & $2.54 \mathrm{E}-09$ & $5.75 \mathrm{E}-09$ & $5.50 \mathrm{E}-09$ & $3.24 \mathrm{E}-09$ & $3.40 \mathrm{E}-09$ & 4.03E-09 & $3.20 \mathrm{E}-09$ \\
\hline 14 & 77 & $4.74 \mathrm{E}-09$ & $6.64 \mathrm{E}-09$ & $2.03 \mathrm{E}-09$ & $2.64 \mathrm{E}-09$ & $4.04 \mathrm{E}-09$ & $3.30 \mathrm{E}-09$ & $2.25 \mathrm{E}-09$ & $2.01 \mathrm{E}-09$ & $2.04 \mathrm{E}-09$ & $2.52 \mathrm{E}-09$ \\
\hline 14 & 91 & $3.74 \mathrm{E}-09$ & $5.43 \mathrm{E}-09$ & $2.68 \mathrm{E}-09$ & $1.62 \mathrm{E}-09$ & $3.86 \mathrm{E}-09$ & $3.12 \mathrm{E}-09$ & $1.66 \mathrm{E}-09$ & $1.63 \mathrm{E}-09$ & $1.85 \mathrm{E}-09$ & $1.37 \mathrm{E}-09$ \\
\hline
\end{tabular}

\begin{tabular}{|c|c|c|c|c|c|c|c|c|c|c|c|}
\hline \multirow{3}{*}{$\begin{array}{c}\text { Interval } \\
\text { (days) }\end{array}$} & \multirow{3}{*}{$\begin{array}{c}\text { Total } \\
\text { Duration } \\
\text { (days) }\end{array}$} & \multicolumn{10}{|c|}{ Iodine Effective Diffusion Coefficient $\left(\mathrm{cm}^{2} / \mathrm{s}\right)$} \\
\hline & & \multicolumn{10}{|c|}{ Mix Number and Duplicate (Repeat) } \\
\hline & & $16 \mathbf{a}$ & $16 \mathrm{~b}$ & $17 \mathbf{a}$ & $17 \mathbf{b}$ & $18 \mathbf{a}$ & $18 \mathrm{~b}$ & $19 \mathrm{a}$ & 19b & $\mathbf{2 0 a}$ & 20b \\
\hline 0.08 & 0.08 & $4.53 \mathrm{E}-08$ & $4.17 \mathrm{E}-08$ & 5.89E-08 & 5.74E-08 & $2.94 \mathrm{E}-08$ & 2.97E-08 & $9.25 \mathrm{E}-08$ & $8.69 \mathrm{E}-08$ & $2.59 \mathrm{E}-08$ & $2.19 \mathrm{E}-08$ \\
\hline 0.92 & 1 & $2.65 \mathrm{E}-08$ & $2.56 \mathrm{E}-08$ & $5.10 \mathrm{E}-08$ & $5.10 \mathrm{E}-08$ & $1.37 \mathrm{E}-08$ & $1.41 \mathrm{E}-08$ & $6.22 \mathrm{E}-08$ & $6.32 \mathrm{E}-08$ & $1.03 \mathrm{E}-08$ & $1.29 \mathrm{E}-08$ \\
\hline 1 & 2 & $2.23 \mathrm{E}-08$ & $2.25 \mathrm{E}-08$ & 4.77E-08 & $4.52 \mathrm{E}-08$ & $1.14 \mathrm{E}-08$ & $1.08 \mathrm{E}-08$ & $4.73 \mathrm{E}-08$ & $4.74 \mathrm{E}-08$ & 8.14E-09 & $1.25 \mathrm{E}-08$ \\
\hline 5 & 7 & $1.66 \mathrm{E}-08$ & $1.50 \mathrm{E}-08$ & $2.74 \mathrm{E}-08$ & $2.88 \mathrm{E}-08$ & 7.24E-09 & 7.27E-09 & $2.62 \mathrm{E}-08$ & $2.81 \mathrm{E}-08$ & $1.73 \mathrm{E}-08$ & $1.40 \mathrm{E}-08$ \\
\hline 7 & 14 & $1.35 \mathrm{E}-08$ & $1.50 \mathrm{E}-08$ & $1.79 \mathrm{E}-08$ & $1.87 \mathrm{E}-08$ & $5.37 \mathrm{E}-09$ & $5.35 \mathrm{E}-09$ & $1.64 \mathrm{E}-08$ & $1.79 \mathrm{E}-08$ & $1.60 \mathrm{E}-08$ & $6.93 \mathrm{E}-09$ \\
\hline 14 & 28 & $9.98 \mathrm{E}-09$ & $1.09 \mathrm{E}-08$ & $1.11 \mathrm{E}-08$ & $1.16 \mathrm{E}-08$ & $3.73 \mathrm{E}-09$ & $3.85 \mathrm{E}-09$ & $1.04 \mathrm{E}-08$ & $9.85 \mathrm{E}-09$ & $6.37 \mathrm{E}-09$ & $3.93 \mathrm{E}-09$ \\
\hline 14 & 42 & $7.93 \mathrm{E}-09$ & $8.70 \mathrm{E}-09$ & $7.72 \mathrm{E}-09$ & $7.76 \mathrm{E}-09$ & $3.04 \mathrm{E}-09$ & $3.28 \mathrm{E}-09$ & 5.92E-09 & $5.62 \mathrm{E}-09$ & $4.38 \mathrm{E}-09$ & $3.15 \mathrm{E}-09$ \\
\hline 7 & 49 & 6.64E-09 & $6.88 \mathrm{E}-09$ & 5.83E-09 & $6.14 \mathrm{E}-09$ & $2.72 \mathrm{E}-09$ & $2.87 \mathrm{E}-09$ & $3.28 \mathrm{E}-09$ & $3.81 \mathrm{E}-09$ & $3.71 \mathrm{E}-09$ & $2.67 \mathrm{E}-09$ \\
\hline 14 & 63 & 5.98E-09 & $6.13 \mathrm{E}-09$ & $5.20 \mathrm{E}-09$ & $5.32 \mathrm{E}-09$ & 2.79E-09 & $2.85 \mathrm{E}-09$ & $2.19 \mathrm{E}-09$ & $2.67 \mathrm{E}-09$ & $3.54 \mathrm{E}-09$ & $2.71 \mathrm{E}-09$ \\
\hline 14 & 77 & $2.41 \mathrm{E}-09$ & $3.67 \mathrm{E}-09$ & 4.44E-09 & $4.52 \mathrm{E}-09$ & $2.20 \mathrm{E}-09$ & $2.60 \mathrm{E}-09$ & $1.21 \mathrm{E}-09$ & $1.35 \mathrm{E}-09$ & $1.92 \mathrm{E}-09$ & $2.58 \mathrm{E}-09$ \\
\hline 14 & 91 & 3.64E-09 & $3.33 \mathrm{E}-09$ & $3.63 \mathrm{E}-09$ & $3.35 \mathrm{E}-09$ & $2.08 \mathrm{E}-09$ & 2.64E-09 & $8.84 \mathrm{E}-10$ & $9.86 \mathrm{E}-10$ & $1.88 \mathrm{E}-09$ & $2.41 \mathrm{E}-09$ \\
\hline
\end{tabular}


Table D-10. Iodine Effective Diffusion Coefficients (contd)

\begin{tabular}{|c|c|c|c|c|c|c|c||}
\hline \multirow{2}{*}{$\begin{array}{c}\text { Interval } \\
\text { (days) }\end{array}$} & \multirow{2}{*}{$\begin{array}{c}\text { Total } \\
\text { Duration } \\
\text { (days) }\end{array}$} & \multicolumn{6}{|c||}{ Iodine Effective Diffusion Coefficient $\left(\mathbf{c m}^{\mathbf{2}} / \mathbf{s}\right)$} \\
\cline { 3 - 8 } & \multicolumn{5}{|c|}{ Mix Number and Duplicate (Repeat) } \\
\hline 0.08 & 0.08 & $1.69 \mathrm{E}-07$ & $1.80 \mathrm{E}-07$ & $5.79 \mathrm{E}-08$ & $6.40 \mathrm{E}-08$ & $1.42 \mathrm{E}-07$ & $1.45 \mathrm{E}-07$ \\
\hline 0.92 & 1 & $1.55 \mathrm{E}-07$ & $1.51 \mathrm{E}-07$ & $5.16 \mathrm{E}-08$ & $4.42 \mathrm{E}-08$ & $1.72 \mathrm{E}-07$ & $1.79 \mathrm{E}-07$ \\
\hline 1 & 2 & $1.18 \mathrm{E}-07$ & $1.19 \mathrm{E}-07$ & $2.88 \mathrm{E}-08$ & $2.69 \mathrm{E}-08$ & $1.72 \mathrm{E}-07$ & $1.91 \mathrm{E}-07$ \\
\hline 5 & 7 & $7.55 \mathrm{E}-08$ & $7.27 \mathrm{E}-08$ & $1.44 \mathrm{E}-08$ & $1.39 \mathrm{E}-08$ & $1.16 \mathrm{E}-07$ & $1.41 \mathrm{E}-07$ \\
\hline 7 & 14 & $5.16 \mathrm{E}-08$ & $4.92 \mathrm{E}-08$ & $8.49 \mathrm{E}-09$ & $8.38 \mathrm{E}-09$ & $7.92 \mathrm{E}-08$ & $9.82 \mathrm{E}-08$ \\
\hline 14 & 28 & $2.82 \mathrm{E}-08$ & $2.79 \mathrm{E}-08$ & $5.78 \mathrm{E}-09$ & $5.53 \mathrm{E}-09$ & $4.87 \mathrm{E}-08$ & $5.94 \mathrm{E}-08$ \\
\hline 14 & 42 & $1.73 \mathrm{E}-08$ & $1.75 \mathrm{E}-08$ & $4.56 \mathrm{E}-09$ & $4.40 \mathrm{E}-09$ & $3.20 \mathrm{E}-08$ & $3.84 \mathrm{E}-08$ \\
\hline 7 & 49 & $1.25 \mathrm{E}-08$ & $1.28 \mathrm{E}-08$ & $3.79 \mathrm{E}-09$ & $3.99 \mathrm{E}-09$ & $2.65 \mathrm{E}-08$ & $2.97 \mathrm{E}-08$ \\
\hline 14 & 63 & $9.08 \mathrm{E}-09$ & $9.11 \mathrm{E}-09$ & $3.61 \mathrm{E}-09$ & $3.71 \mathrm{E}-09$ & $2.00 \mathrm{E}-08$ & $2.41 \mathrm{E}-08$ \\
\hline 14 & 77 & $4.09 \mathrm{E}-09$ & $3.97 \mathrm{E}-09$ & $3.07 \mathrm{E}-09$ & $1.68 \mathrm{E}-09$ & $1.17 \mathrm{E}-08$ & $1.18 \mathrm{E}-08$ \\
\hline 14 & 91 & $3.40 \mathrm{E}-09$ & $3.23 \mathrm{E}-09$ & $3.28 \mathrm{E}-09$ & $1.69 \mathrm{E}-09$ & $6.98 \mathrm{E}-09$ & $5.81 \mathrm{E}-09$ \\
\hline
\end{tabular}

\begin{tabular}{|c|c|c|c|c|c|c|c||}
\hline \multirow{2}{*}{$\begin{array}{c}\text { Interval } \\
\text { (days) }\end{array}$} & \multirow{2}{*}{$\begin{array}{c}\text { Total } \\
\text { Duration } \\
\text { (days) }\end{array}$} & \multicolumn{6}{|c||}{ Iodine Effective Diffusion Coefficient $\left(\mathbf{c m}^{2} / \mathbf{s}\right)$} \\
\cline { 3 - 8 } & & $\mathbf{2 4 a}$ & $\mathbf{2 4 b}$ & $\mathbf{2 5 a}$ & $\mathbf{2 5 b}$ & $\mathbf{2 6 a}$ & $\mathbf{2 6 b}$ \\
\hline 0.08 & 0.08 & $8.45 \mathrm{E}-08$ & $8.69 \mathrm{E}-08$ & $4.33 \mathrm{E}-08$ & $4.16 \mathrm{E}-08$ & $1.22 \mathrm{E}-07$ & $1.21 \mathrm{E}-07$ \\
\hline 0.92 & 1 & $5.67 \mathrm{E}-08$ & $5.70 \mathrm{E}-08$ & $3.16 \mathrm{E}-08$ & $3.24 \mathrm{E}-08$ & $6.60 \mathrm{E}-08$ & $6.69 \mathrm{E}-08$ \\
\hline 1 & 2 & $4.72 \mathrm{E}-08$ & $4.52 \mathrm{E}-08$ & $2.59 \mathrm{E}-08$ & $2.55 \mathrm{E}-08$ & $4.64 \mathrm{E}-08$ & $4.72 \mathrm{E}-08$ \\
\hline 5 & 7 & $2.94 \mathrm{E}-08$ & $3.03 \mathrm{E}-08$ & $1.81 \mathrm{E}-08$ & $1.72 \mathrm{E}-08$ & $2.62 \mathrm{E}-08$ & $2.72 \mathrm{E}-08$ \\
\hline 7 & 14 & $1.63 \mathrm{E}-08$ & $1.99 \mathrm{E}-08$ & $9.22 \mathrm{E}-09$ & $9.11 \mathrm{E}-09$ & $1.14 \mathrm{E}-08$ & $1.14 \mathrm{E}-08$ \\
\hline 14 & 28 & $1.27 \mathrm{E}-08$ & $1.25 \mathrm{E}-08$ & $8.52 \mathrm{E}-09$ & $7.66 \mathrm{E}-09$ & $1.17 \mathrm{E}-08$ & $1.21 \mathrm{E}-08$ \\
\hline 14 & 42 & $8.37 \mathrm{E}-09$ & $8.17 \mathrm{E}-09$ & $4.96 \mathrm{E}-09$ & $4.94 \mathrm{E}-09$ & $7.94 \mathrm{E}-09$ & $7.65 \mathrm{E}-09$ \\
\hline 7 & 49 & $6.22 \mathrm{E}-09$ & $6.22 \mathrm{E}-09$ & $3.42 \mathrm{E}-09$ & $3.59 \mathrm{E}-09$ & $5.46 \mathrm{E}-09$ & $5.43 \mathrm{E}-09$ \\
\hline 14 & 63 & $5.71 \mathrm{E}-09$ & $5.41 \mathrm{E}-09$ & $2.93 \mathrm{E}-09$ & $2.93 \mathrm{E}-09$ & $3.98 \mathrm{E}-09$ & $4.14 \mathrm{E}-09$ \\
\hline 14 & 77 & $3.26 \mathrm{E}-09$ & $4.21 \mathrm{E}-09$ & $2.04 \mathrm{E}-09$ & $2.16 \mathrm{E}-09$ & $1.31 \mathrm{E}-09$ & $2.47 \mathrm{E}-09$ \\
\hline 14 & 91 & $2.47 \mathrm{E}-09$ & $3.50 \mathrm{E}-09$ & $1.73 \mathrm{E}-09$ & $1.52 \mathrm{E}-09$ & $1.92 \mathrm{E}-09$ & $2.29 \mathrm{E}-09$ \\
\hline
\end{tabular}


Table D-11. Technetium Effective Diffusion Coefficients

\begin{tabular}{|c|c|c|c|c|c|c|c|c|c|c|c|}
\hline \multirow{3}{*}{$\begin{array}{c}\text { Interval } \\
\text { (days) }\end{array}$} & \multirow{3}{*}{$\begin{array}{c}\text { Total } \\
\text { Duration } \\
\text { (days) }\end{array}$} & \multicolumn{10}{|c|}{ Technetium Effective Diffusion Coefficient $\left(\mathrm{cm}^{2} / \mathrm{s}\right)$} \\
\hline & & \multicolumn{10}{|c|}{ Mix Number and Duplicate (Repeat) } \\
\hline & & $1 a$ & $\mathbf{1 b}$ & $\mathbf{2 a}$ & $\mathbf{2 b}$ & $\mathbf{3 a}$ & $\mathbf{3 b}$ & $4 \mathbf{a}$ & $\mathbf{4 b}$ & $5 \mathbf{5 a}$ & $\mathbf{5 b}$ \\
\hline 0.08 & 0.08 & $3.67 \mathrm{E}-11$ & $6.45 \mathrm{E}-09$ & $2.60 \mathrm{E}-09$ & $2.76 \mathrm{E}-09$ & $2.08 \mathrm{E}-09$ & $6.86 \mathrm{E}-10$ & $3.75 \mathrm{E}-13$ & $2.68 \mathrm{E}-12$ & 5.24E-11 & $5.69 \mathrm{E}-11$ \\
\hline 0.92 & 1 & $5.25 \mathrm{E}-10$ & $4.28 \mathrm{E}-10$ & $4.06 \mathrm{E}-10$ & $5.75 \mathrm{E}-10$ & $4.04 \mathrm{E}-10$ & $4.04 \mathrm{E}-10$ & $2.91 \mathrm{E}-12$ & $5.77 \mathrm{E}-12$ & $1.08 \mathrm{E}-11$ & $4.58 \mathrm{E}-11$ \\
\hline 1 & 2 & $1.39 \mathrm{E}-10$ & $1.26 \mathrm{E}-10$ & $9.22 \mathrm{E}-11$ & $1.18 \mathrm{E}-10$ & $8.18 \mathrm{E}-12$ & $7.54 \mathrm{E}-12$ & $9.30 \mathrm{E}-12$ & $9.99 \mathrm{E}-12$ & $2.37 \mathrm{E}-11$ & $7.44 \mathrm{E}-11$ \\
\hline 5 & 7 & $1.12 \mathrm{E}-10$ & $1.05 \mathrm{E}-10$ & 4.79E-11 & $5.02 \mathrm{E}-11$ & $1.26 \mathrm{E}-11$ & $1.33 \mathrm{E}-11$ & $1.47 \mathrm{E}-11$ & $1.62 \mathrm{E}-11$ & $2.76 \mathrm{E}-11$ & $5.51 \mathrm{E}-11$ \\
\hline 7 & 14 & $7.50 \mathrm{E}-11$ & $7.22 \mathrm{E}-11$ & $5.37 \mathrm{E}-11$ & $4.67 \mathrm{E}-11$ & $2.51 \mathrm{E}-11$ & $2.88 \mathrm{E}-11$ & $2.05 \mathrm{E}-11$ & $1.73 \mathrm{E}-11$ & $5.34 \mathrm{E}-11$ & $6.58 \mathrm{E}-11$ \\
\hline 14 & 28 & $5.19 \mathrm{E}-11$ & $5.03 \mathrm{E}-11$ & $7.06 \mathrm{E}-11$ & $5.56 \mathrm{E}-11$ & $3.13 \mathrm{E}-11$ & $3.02 \mathrm{E}-11$ & $1.92 \mathrm{E}-11$ & $2.51 \mathrm{E}-11$ & $5.00 \mathrm{E}-11$ & $5.57 \mathrm{E}-11$ \\
\hline 14 & 42 & $4.22 \mathrm{E}-11$ & $3.97 \mathrm{E}-11$ & $7.23 \mathrm{E}-11$ & $5.89 \mathrm{E}-11$ & $3.41 \mathrm{E}-11$ & $3.49 \mathrm{E}-11$ & $2.28 \mathrm{E}-11$ & $2.57 \mathrm{E}-11$ & $8.41 \mathrm{E}-11$ & $7.96 \mathrm{E}-11$ \\
\hline 7 & 49 & $4.43 \mathrm{E}-11$ & $4.15 \mathrm{E}-11$ & $6.59 \mathrm{E}-11$ & $5.13 \mathrm{E}-11$ & $3.61 \mathrm{E}-11$ & $3.82 \mathrm{E}-11$ & $2.90 \mathrm{E}-11$ & $3.65 \mathrm{E}-11$ & $8.58 \mathrm{E}-11$ & $8.77 \mathrm{E}-11$ \\
\hline 14 & 63 & $5.14 \mathrm{E}-11$ & $5.07 \mathrm{E}-11$ & $5.86 \mathrm{E}-11$ & $4.56 \mathrm{E}-11$ & $3.71 \mathrm{E}-11$ & $3.56 \mathrm{E}-11$ & $3.05 \mathrm{E}-11$ & $3.72 \mathrm{E}-11$ & $6.44 \mathrm{E}-11$ & $6.44 \mathrm{E}-11$ \\
\hline 14 & 77 & $4.89 \mathrm{E}-11$ & $4.87 \mathrm{E}-11$ & 3.32E-11 & $3.60 \mathrm{E}-11$ & $3.29 \mathrm{E}-11$ & $2.13 \mathrm{E}-11$ & $2.28 \mathrm{E}-11$ & $2.93 \mathrm{E}-11$ & $3.73 \mathrm{E}-11$ & $2.18 \mathrm{E}-11$ \\
\hline 14 & 91 & $4.39 \mathrm{E}-11$ & $4.56 \mathrm{E}-11$ & $3.89 \mathrm{E}-11$ & $1.90 \mathrm{E}-11$ & $3.01 \mathrm{E}-11$ & $2.46 \mathrm{E}-11$ & $2.66 \mathrm{E}-11$ & $3.92 \mathrm{E}-11$ & $2.16 \mathrm{E}-11$ & $2.73 \mathrm{E}-11$ \\
\hline
\end{tabular}

\begin{tabular}{|c|c|c|c|c|c|c|c|c|c|c|c|}
\hline \multirow{3}{*}{$\begin{array}{c}\text { Interval } \\
\text { (days) }\end{array}$} & \multirow{3}{*}{$\begin{array}{c}\text { Total } \\
\text { Duration } \\
\text { (days) }\end{array}$} & \multicolumn{10}{|c|}{ Technetium Effective Diffusion Coefficient $\left(\mathrm{cm}^{2} / \mathrm{s}\right)$} \\
\hline & & \multicolumn{10}{|c|}{ Mix Number and Duplicate (Repeat) } \\
\hline & & $\mathbf{6 a}$ & 6b & $7 \mathbf{a}$ & $7 \mathbf{b}$ & $\mathbf{8 a}$ & $8 \mathbf{b}$ & $9 a$ & $9 \mathbf{b}$ & $10 \mathbf{a}$ & 10b \\
\hline 0.08 & 0.08 & $2.44 \mathrm{E}-09$ & $3.30 \mathrm{E}-09$ & $1.09 \mathrm{E}-12$ & $8.96 \mathrm{E}-12$ & 2.19E-09 & $1.25 \mathrm{E}-09$ & 8.99E-12 & $1.96 \mathrm{E}-10$ & 7.07E-09 & $6.91 \mathrm{E}-09$ \\
\hline 0.92 & 1 & $5.49 \mathrm{E}-11$ & $3.22 \mathrm{E}-11$ & $1.03 \mathrm{E}-11$ & $1.06 \mathrm{E}-11$ & $2.28 \mathrm{E}-10$ & $3.95 \mathrm{E}-10$ & $2.40 \mathrm{E}-11$ & $3.76 \mathrm{E}-11$ & $1.11 \mathrm{E}-09$ & $2.01 \mathrm{E}-09$ \\
\hline 1 & 2 & $7.61 \mathrm{E}-12$ & $5.60 \mathrm{E}-12$ & $9.74 \mathrm{E}-12$ & $1.25 \mathrm{E}-11$ & $2.51 \mathrm{E}-10$ & $5.10 \mathrm{E}-10$ & $5.74 \mathrm{E}-11$ & $5.58 \mathrm{E}-11$ & 5.99E-10 & $1.03 \mathrm{E}-09$ \\
\hline 5 & 7 & $7.09 \mathrm{E}-12$ & $6.36 \mathrm{E}-12$ & $7.97 \mathrm{E}-12$ & $1.22 \mathrm{E}-11$ & $2.89 \mathrm{E}-10$ & $4.43 \mathrm{E}-10$ & $3.74 \mathrm{E}-11$ & $3.73 \mathrm{E}-11$ & $3.03 \mathrm{E}-10$ & $4.57 \mathrm{E}-10$ \\
\hline 7 & 14 & $1.80 \mathrm{E}-11$ & $1.80 \mathrm{E}-11$ & $7.91 \mathrm{E}-12$ & $1.09 \mathrm{E}-11$ & $2.75 \mathrm{E}-10$ & $3.15 \mathrm{E}-10$ & $4.73 \mathrm{E}-11$ & $4.21 \mathrm{E}-11$ & $1.99 \mathrm{E}-10$ & $2.42 \mathrm{E}-10$ \\
\hline 14 & 28 & $4.22 \mathrm{E}-11$ & $4.08 \mathrm{E}-11$ & $8.74 \mathrm{E}-12$ & $9.66 \mathrm{E}-12$ & $2.22 \mathrm{E}-10$ & $2.23 \mathrm{E}-10$ & $2.98 \mathrm{E}-11$ & $3.03 \mathrm{E}-11$ & $1.40 \mathrm{E}-10$ & $1.49 \mathrm{E}-10$ \\
\hline 14 & 42 & $1.26 \mathrm{E}-10$ & $1.24 \mathrm{E}-10$ & $9.22 \mathrm{E}-12$ & $8.75 \mathrm{E}-12$ & $2.21 \mathrm{E}-10$ & $2.03 \mathrm{E}-10$ & $3.92 \mathrm{E}-11$ & $3.79 \mathrm{E}-11$ & $1.13 \mathrm{E}-10$ & $1.19 \mathrm{E}-10$ \\
\hline 7 & 49 & $2.52 \mathrm{E}-10$ & $2.35 \mathrm{E}-10$ & $9.51 \mathrm{E}-12$ & $1.01 \mathrm{E}-11$ & $2.20 \mathrm{E}-10$ & $2.08 \mathrm{E}-10$ & $4.16 \mathrm{E}-11$ & $3.84 \mathrm{E}-11$ & $1.16 \mathrm{E}-10$ & $1.16 \mathrm{E}-10$ \\
\hline 14 & 63 & $1.96 \mathrm{E}-10$ & $2.01 \mathrm{E}-10$ & $8.40 \mathrm{E}-12$ & $8.17 \mathrm{E}-12$ & $2.26 \mathrm{E}-10$ & $2.03 \mathrm{E}-10$ & $3.20 \mathrm{E}-11$ & $2.86 \mathrm{E}-11$ & $1.15 \mathrm{E}-10$ & $1.11 \mathrm{E}-10$ \\
\hline 14 & 77 & $8.05 \mathrm{E}-11$ & $1.07 \mathrm{E}-10$ & $3.58 \mathrm{E}-12$ & $4.90 \mathrm{E}-12$ & $1.62 \mathrm{E}-10$ & $1.75 \mathrm{E}-10$ & $1.88 \mathrm{E}-11$ & $1.29 \mathrm{E}-11$ & $8.20 \mathrm{E}-11$ & $7.17 \mathrm{E}-11$ \\
\hline 14 & 91 & $8.11 \mathrm{E}-11$ & $1.20 \mathrm{E}-10$ & $5.85 \mathrm{E}-12$ & $7.67 \mathrm{E}-12$ & $8.25 \mathrm{E}-11$ & $1.18 \mathrm{E}-10$ & $2.14 \mathrm{E}-11$ & $2.40 \mathrm{E}-11$ & $8.35 \mathrm{E}-11$ & $8.80 \mathrm{E}-11$ \\
\hline
\end{tabular}


Table D-11. Technetium Effective Diffusion Coefficients (contd)

\begin{tabular}{|c|c|c|c|c|c|c|c|c|c|c|c|}
\hline \multirow{3}{*}{$\begin{array}{c}\text { Interval } \\
\text { (days) }\end{array}$} & \multirow{3}{*}{$\begin{array}{c}\text { Total } \\
\text { Duration } \\
\text { (days) }\end{array}$} & \multicolumn{10}{|c|}{ "Technetium Effective Diffusion Coefficient $\left(\mathrm{cm}^{2} / \mathrm{s}\right)$} \\
\hline & & \multicolumn{10}{|c|}{ Mix Number and Duplicate (Repeat) } \\
\hline & & $11 \mathbf{a}$ & $11 \mathrm{~b}$ & $12 \mathbf{a}$ & $\mathbf{1 2 b}$ & $13 \mathbf{a}$ & $13 \mathbf{b}$ & $14 \mathbf{a}$ & $14 \mathrm{~b}$ & $15 \mathbf{a}$ & $15 \mathbf{b}$ \\
\hline 0.08 & 0.08 & $5.09 \mathrm{E}-10$ & $6.94 \mathrm{E}-11$ & $1.16 \mathrm{E}-10$ & $6.57 \mathrm{E}-11$ & $7.59 \mathrm{E}-11$ & $3.00 \mathrm{E}-10$ & $4.64 \mathrm{E}-11$ & $1.07 \mathrm{E}-10$ & $2.30 \mathrm{E}-09$ & $1.45 \mathrm{E}-09$ \\
\hline 0.92 & 1 & $3.75 \mathrm{E}-11$ & $2.59 \mathrm{E}-11$ & $4.13 \mathrm{E}-11$ & $6.35 \mathrm{E}-11$ & $7.16 \mathrm{E}-11$ & $5.37 \mathrm{E}-11$ & $1.87 \mathrm{E}-11$ & $1.65 \mathrm{E}-11$ & $9.35 \mathrm{E}-10$ & $5.62 \mathrm{E}-10$ \\
\hline 1 & 2 & $4.43 \mathrm{E}-11$ & $3.62 \mathrm{E}-11$ & $4.47 \mathrm{E}-11$ & $6.11 \mathrm{E}-11$ & $2.20 \mathrm{E}-11$ & $2.62 \mathrm{E}-11$ & $1.94 \mathrm{E}-11$ & $1.80 \mathrm{E}-11$ & $3.02 \mathrm{E}-10$ & $2.20 \mathrm{E}-10$ \\
\hline 5 & 7 & $1.90 \mathrm{E}-11$ & $1.75 \mathrm{E}-11$ & $4.56 \mathrm{E}-11$ & $5.31 \mathrm{E}-11$ & $2.26 \mathrm{E}-11$ & $2.89 \mathrm{E}-11$ & $1.32 \mathrm{E}-11$ & $1.47 \mathrm{E}-11$ & $1.78 \mathrm{E}-10$ & $1.86 \mathrm{E}-10$ \\
\hline 7 & 14 & $2.96 \mathrm{E}-11$ & $4.02 \mathrm{E}-11$ & $3.79 \mathrm{E}-11$ & $4.53 \mathrm{E}-11$ & $5.13 \mathrm{E}-11$ & $5.34 \mathrm{E}-11$ & $9.07 \mathrm{E}-12$ & $1.24 \mathrm{E}-11$ & $1.25 \mathrm{E}-10$ & $1.33 \mathrm{E}-10$ \\
\hline 14 & 28 & $5.01 \mathrm{E}-11$ & $4.41 \mathrm{E}-11$ & $3.91 \mathrm{E}-11$ & $4.19 \mathrm{E}-11$ & $7.94 \mathrm{E}-11$ & $6.46 \mathrm{E}-11$ & $7.03 \mathrm{E}-12$ & $1.12 \mathrm{E}-11$ & $5.98 \mathrm{E}-11$ & $6.16 \mathrm{E}-11$ \\
\hline 14 & 42 & $8.84 \mathrm{E}-11$ & $1.08 \mathrm{E}-10$ & $4.10 \mathrm{E}-11$ & $4.05 \mathrm{E}-11$ & $9.71 \mathrm{E}-11$ & $7.90 \mathrm{E}-11$ & $8.44 \mathrm{E}-12$ & $1.13 \mathrm{E}-11$ & $4.27 \mathrm{E}-11$ & $4.80 \mathrm{E}-11$ \\
\hline 7 & 49 & $1.84 \mathrm{E}-10$ & $1.81 \mathrm{E}-10$ & $4.13 \mathrm{E}-11$ & $4.44 \mathrm{E}-11$ & $9.73 \mathrm{E}-11$ & $8.59 \mathrm{E}-11$ & $9.40 \mathrm{E}-12$ & $1.17 \mathrm{E}-11$ & $4.37 \mathrm{E}-11$ & $4.55 \mathrm{E}-11$ \\
\hline 14 & 63 & $1.97 \mathrm{E}-10$ & $1.88 \mathrm{E}-10$ & $4.46 \mathrm{E}-11$ & $4.33 \mathrm{E}-11$ & $8.46 \mathrm{E}-11$ & $7.42 \mathrm{E}-11$ & $7.54 \mathrm{E}-12$ & $1.02 \mathrm{E}-11$ & $3.43 \mathrm{E}-11$ & $3.36 \mathrm{E}-11$ \\
\hline 14 & 77 & $8.95 \mathrm{E}-11$ & $1.11 \mathrm{E}-10$ & $3.36 \mathrm{E}-11$ & $4.51 \mathrm{E}-11$ & $6.10 \mathrm{E}-11$ & $5.11 \mathrm{E}-11$ & $7.28 \mathrm{E}-12$ & $7.33 \mathrm{E}-12$ & $1.73 \mathrm{E}-11$ & $2.86 \mathrm{E}-11$ \\
\hline 14 & 91 & $7.67 \mathrm{E}-11$ & $1.11 \mathrm{E}-10$ & $3.81 \mathrm{E}-11$ & $2.24 \mathrm{E}-11$ & $5.73 \mathrm{E}-11$ & $5.01 \mathrm{E}-11$ & $5.35 \mathrm{E}-12$ & $5.78 \mathrm{E}-12$ & $1.81 \mathrm{E}-11$ & $1.34 \mathrm{E}-11$ \\
\hline
\end{tabular}

\begin{tabular}{|c|c|c|c|c|c|c|c|c|c|c|c|}
\hline \multirow{3}{*}{$\begin{array}{c}\text { Interval } \\
\text { (days) }\end{array}$} & \multirow{3}{*}{$\begin{array}{c}\text { Total } \\
\text { Duration } \\
\text { (days) }\end{array}$} & \multicolumn{10}{|c|}{ Technetium Effective Diffusion Coefficient $\left(\mathrm{cm}^{2} / \mathrm{s}\right)$} \\
\hline & & \multicolumn{10}{|c|}{ Mix Number and Duplicate (Repeat) } \\
\hline & & $16 \mathbf{a}$ & $16 \mathrm{~b}$ & $17 \mathbf{a}$ & $17 \mathbf{b}$ & $18 \mathbf{a}$ & $18 \mathrm{~b}$ & $19 \mathbf{a}$ & 19b & $\mathbf{2 0 a}$ & $20 b$ \\
\hline 0.08 & 0.08 & $2.03 \mathrm{E}-10$ & $3.03 \mathrm{E}-10$ & $3.52 \mathrm{E}-10$ & $3.48 \mathrm{E}-10$ & $5.87 \mathrm{E}-11$ & $5.19 \mathrm{E}-11$ & $1.80 \mathrm{E}-11$ & $1.25 \mathrm{E}-11$ & $1.31 \mathrm{E}-11$ & $7.21 \mathrm{E}-13$ \\
\hline 0.92 & 1 & $1.76 \mathrm{E}-10$ & $2.95 \mathrm{E}-10$ & $6.97 \mathrm{E}-11$ & $6.94 \mathrm{E}-11$ & $3.06 \mathrm{E}-11$ & $1.44 \mathrm{E}-11$ & $2.48 \mathrm{E}-12$ & $2.06 \mathrm{E}-12$ & $2.93 \mathrm{E}-11$ & $3.27 \mathrm{E}-12$ \\
\hline 1 & 2 & $1.44 \mathrm{E}-10$ & $2.18 \mathrm{E}-10$ & $1.32 \mathrm{E}-10$ & $1.09 \mathrm{E}-10$ & $3.32 \mathrm{E}-11$ & $1.57 \mathrm{E}-11$ & $1.57 \mathrm{E}-12$ & $1.67 \mathrm{E}-12$ & $3.19 \mathrm{E}-11$ & $8.34 \mathrm{E}-12$ \\
\hline 5 & 7 & $1.47 \mathrm{E}-10$ & $1.68 \mathrm{E}-10$ & $1.47 \mathrm{E}-10$ & $1.74 \mathrm{E}-10$ & $2.42 \mathrm{E}-11$ & $1.35 \mathrm{E}-11$ & $1.72 \mathrm{E}-12$ & $2.11 \mathrm{E}-12$ & $4.17 \mathrm{E}-11$ & $2.46 \mathrm{E}-11$ \\
\hline 7 & 14 & $1.67 \mathrm{E}-10$ & $1.78 \mathrm{E}-10$ & $1.89 \mathrm{E}-10$ & $1.72 \mathrm{E}-10$ & $7.64 \mathrm{E}-12$ & $6.15 \mathrm{E}-12$ & $3.83 \mathrm{E}-12$ & $4.54 \mathrm{E}-12$ & $4.73 \mathrm{E}-11$ & $3.43 \mathrm{E}-11$ \\
\hline 14 & 28 & $1.37 \mathrm{E}-10$ & $1.37 \mathrm{E}-10$ & $1.53 \mathrm{E}-10$ & $1.36 \mathrm{E}-10$ & $4.42 \mathrm{E}-12$ & $4.44 \mathrm{E}-12$ & $1.08 \mathrm{E}-11$ & $1.18 \mathrm{E}-11$ & $3.68 \mathrm{E}-11$ & $3.03 \mathrm{E}-11$ \\
\hline 14 & 42 & $1.50 \mathrm{E}-10$ & $1.62 \mathrm{E}-10$ & $1.89 \mathrm{E}-10$ & $1.88 \mathrm{E}-10$ & $4.80 \mathrm{E}-12$ & $5.33 \mathrm{E}-12$ & $3.82 \mathrm{E}-11$ & $3.30 \mathrm{E}-11$ & $4.42 \mathrm{E}-11$ & $3.73 \mathrm{E}-11$ \\
\hline 7 & 49 & $1.74 \mathrm{E}-10$ & $1.84 \mathrm{E}-10$ & $2.20 \mathrm{E}-10$ & $2.02 \mathrm{E}-10$ & $6.19 \mathrm{E}-12$ & $6.56 \mathrm{E}-12$ & $6.64 \mathrm{E}-11$ & $6.44 \mathrm{E}-11$ & $4.80 \mathrm{E}-11$ & $3.74 \mathrm{E}-11$ \\
\hline 14 & 63 & $1.54 \mathrm{E}-10$ & $1.60 \mathrm{E}-10$ & $1.61 \mathrm{E}-10$ & $1.59 \mathrm{E}-10$ & $6.88 \mathrm{E}-12$ & $6.75 \mathrm{E}-12$ & $7.26 \mathrm{E}-11$ & $6.81 \mathrm{E}-11$ & $3.60 \mathrm{E}-11$ & $3.22 \mathrm{E}-11$ \\
\hline 14 & 77 & $6.39 \mathrm{E}-11$ & $1.08 \mathrm{E}-10$ & $1.52 \mathrm{E}-10$ & $1.45 \mathrm{E}-10$ & $6.18 \mathrm{E}-12$ & $7.15 \mathrm{E}-12$ & $4.88 \mathrm{E}-11$ & $4.94 \mathrm{E}-11$ & $2.43 \mathrm{E}-11$ & $2.71 \mathrm{E}-11$ \\
\hline 14 & 91 & $1.07 \mathrm{E}-10$ & $1.02 \mathrm{E}-10$ & $1.29 \mathrm{E}-10$ & $1.13 \mathrm{E}-10$ & $5.42 \mathrm{E}-12$ & $8.14 \mathrm{E}-12$ & $3.87 \mathrm{E}-11$ & $4.10 \mathrm{E}-11$ & $1.96 \mathrm{E}-11$ & $2.60 \mathrm{E}-11$ \\
\hline
\end{tabular}


Table D-11. Technetium Effective Diffusion Coefficients (contd)

\begin{tabular}{|c|c|c|c|c|c|c|c||}
\hline \multirow{2}{*}{$\begin{array}{c}\text { Interval } \\
\text { (days) }\end{array}$} & \multirow{2}{*}{$\begin{array}{c}\text { Total } \\
\text { Duration } \\
\text { (days) }\end{array}$} & \multicolumn{6}{|c|}{ Technetium Effective Diffusion Coefficient $\left(\mathbf{c m}^{\mathbf{2}} / \mathbf{s}\right.$ ) } \\
\cline { 3 - 8 } & $\mathbf{2 1 a}$ & $\mathbf{2 1 b}$ & $\mathbf{2 2 a}$ & $\mathbf{2 2 b}$ & $\mathbf{2 3 a}$ & $\mathbf{2 3 b}$ \\
\hline 0.08 & 0.08 & $1.02 \mathrm{E}-08$ & $3.05 \mathrm{E}-09$ & $2.90 \mathrm{E}-09$ & $2.37 \mathrm{E}-09$ & $1.72 \mathrm{E}-09$ & $4.67 \mathrm{E}-09$ \\
\hline 0.92 & 1 & $8.06 \mathrm{E}-09$ & $9.79 \mathrm{E}-10$ & $1.30 \mathrm{E}-09$ & $4.32 \mathrm{E}-10$ & $1.30 \mathrm{E}-09$ & $3.88 \mathrm{E}-09$ \\
\hline 1 & 2 & $5.32 \mathrm{E}-10$ & $1.19 \mathrm{E}-10$ & $1.28 \mathrm{E}-10$ & $1.49 \mathrm{E}-11$ & $4.84 \mathrm{E}-10$ & $1.17 \mathrm{E}-09$ \\
\hline 5 & 7 & $1.73 \mathrm{E}-11$ & $1.44 \mathrm{E}-11$ & $2.91 \mathrm{E}-11$ & $9.59 \mathrm{E}-12$ & $3.78 \mathrm{E}-10$ & $4.58 \mathrm{E}-10$ \\
\hline 7 & 14 & $2.18 \mathrm{E}-11$ & $1.41 \mathrm{E}-11$ & $1.43 \mathrm{E}-11$ & $1.29 \mathrm{E}-11$ & $7.21 \mathrm{E}-10$ & $4.05 \mathrm{E}-10$ \\
\hline 14 & 28 & $2.69 \mathrm{E}-11$ & $1.97 \mathrm{E}-11$ & $1.37 \mathrm{E}-11$ & $1.68 \mathrm{E}-11$ & $6.63 \mathrm{E}-10$ & $4.29 \mathrm{E}-10$ \\
\hline 14 & 42 & $5.02 \mathrm{E}-11$ & $4.61 \mathrm{E}-11$ & $2.01 \mathrm{E}-11$ & $2.62 \mathrm{E}-11$ & $1.11 \mathrm{E}-09$ & $6.90 \mathrm{E}-10$ \\
\hline 7 & 49 & $1.02 \mathrm{E}-10$ & $1.61 \mathrm{E}-10$ & $2.60 \mathrm{E}-11$ & $3.49 \mathrm{E}-11$ & $1.91 \mathrm{E}-09$ & $1.19 \mathrm{E}-09$ \\
\hline 14 & 63 & $1.20 \mathrm{E}-10$ & $2.27 \mathrm{E}-10$ & $2.72 \mathrm{E}-11$ & $3.36 \mathrm{E}-11$ & $1.24 \mathrm{E}-09$ & $8.68 \mathrm{E}-10$ \\
\hline 14 & 77 & $9.19 \mathrm{E}-11$ & $2.26 \mathrm{E}-10$ & $2.47 \mathrm{E}-11$ & $1.64 \mathrm{E}-11$ & $7.59 \mathrm{E}-10$ & $6.01 \mathrm{E}-10$ \\
\hline 14 & 91 & $1.73 \mathrm{E}-10$ & $3.52 \mathrm{E}-10$ & $2.90 \mathrm{E}-11$ & $1.43 \mathrm{E}-11$ & $4.12 \mathrm{E}-10$ & $3.98 \mathrm{E}-10$ \\
\hline
\end{tabular}

\begin{tabular}{|c|c|c|c|c|c|c|c||}
\hline \multirow{2}{*}{$\begin{array}{c}\text { Interval } \\
\text { (days) }\end{array}$} & \multirow{2}{*}{$\begin{array}{c}\text { Total } \\
\text { Duration } \\
\text { (days) }\end{array}$} & \multicolumn{6}{|c||}{ Technetium Effective Diffusion Coefficient $\left(\mathbf{c m}^{2} / \mathbf{s}\right)$} \\
\cline { 3 - 8 } & $\mathbf{2 4 a}$ & $\mathbf{2 4 b}$ & $\mathbf{2 5 a}$ & $\mathbf{2 5 b}$ & $\mathbf{2 6 a}$ & $\mathbf{2 6 b}$ \\
\hline 0.08 & 0.08 & $1.80 \mathrm{E}-09$ & $1.21 \mathrm{E}-09$ & $3.77 \mathrm{E}-09$ & $4.57 \mathrm{E}-09$ & $1.37 \mathrm{E}-09$ & $1.48 \mathrm{E}-09$ \\
\hline 0.92 & 1 & $6.65 \mathrm{E}-10$ & $3.64 \mathrm{E}-10$ & $1.32 \mathrm{E}-09$ & $1.75 \mathrm{E}-09$ & $9.27 \mathrm{E}-11$ & $6.80 \mathrm{E}-11$ \\
\hline 1 & 2 & $1.84 \mathrm{E}-10$ & $6.91 \mathrm{E}-11$ & $2.94 \mathrm{E}-10$ & $5.17 \mathrm{E}-10$ & $7.72 \mathrm{E}-12$ & $5.86 \mathrm{E}-12$ \\
\hline 5 & 7 & $1.06 \mathrm{E}-10$ & $3.99 \mathrm{E}-11$ & $9.28 \mathrm{E}-11$ & $1.78 \mathrm{E}-10$ & $8.60 \mathrm{E}-12$ & $8.44 \mathrm{E}-12$ \\
\hline 7 & 14 & $5.71 \mathrm{E}-11$ & $4.25 \mathrm{E}-11$ & $3.76 \mathrm{E}-11$ & $3.44 \mathrm{E}-11$ & $2.01 \mathrm{E}-11$ & $1.32 \mathrm{E}-11$ \\
\hline 14 & 28 & $5.80 \mathrm{E}-11$ & $5.37 \mathrm{E}-11$ & $3.39 \mathrm{E}-11$ & $2.51 \mathrm{E}-11$ & $4.20 \mathrm{E}-11$ & $3.41 \mathrm{E}-11$ \\
\hline 14 & 42 & $6.43 \mathrm{E}-11$ & $6.44 \mathrm{E}-11$ & $3.56 \mathrm{E}-11$ & $2.48 \mathrm{E}-11$ & $1.45 \mathrm{E}-10$ & $1.51 \mathrm{E}-10$ \\
\hline 7 & 49 & $7.19 \mathrm{E}-11$ & $6.96 \mathrm{E}-11$ & $3.64 \mathrm{E}-11$ & $2.56 \mathrm{E}-11$ & $2.96 \mathrm{E}-10$ & $2.51 \mathrm{E}-10$ \\
\hline 14 & 63 & $7.28 \mathrm{E}-11$ & $6.88 \mathrm{E}-11$ & $2.88 \mathrm{E}-11$ & $2.05 \mathrm{E}-11$ & $2.20 \mathrm{E}-10$ & $1.89 \mathrm{E}-10$ \\
\hline 14 & 77 & $4.81 \mathrm{E}-11$ & $6.29 \mathrm{E}-11$ & $1.69 \mathrm{E}-10$ & $2.10 \mathrm{E}-11$ & $1.26 \mathrm{E}-11$ & $6.09 \mathrm{E}-11$ \\
\hline 14 & 91 & $4.45 \mathrm{E}-11$ & $6.57 \mathrm{E}-11$ & $1.65 \mathrm{E}-11$ & $1.16 \mathrm{E}-11$ & $1.02 \mathrm{E}-10$ & $1.49 \mathrm{E}-10$ \\
\hline
\end{tabular}


Table D-12. Chromium Effective Diffusion Coefficients

\begin{tabular}{|c|c|c|c|c|c|c|c|c|c|c|c|}
\hline \multirow{3}{*}{$\begin{array}{c}\text { Interval } \\
\text { (days) }\end{array}$} & \multirow{3}{*}{$\begin{array}{c}\text { Total } \\
\text { Duration } \\
\text { (days) }\end{array}$} & \multicolumn{10}{|c|}{ "Chromium Effective Diffusion Coefficient $\left(\mathrm{cm}^{2} / \mathrm{s}\right)$} \\
\hline & & \multicolumn{10}{|c|}{ Mix Number and Duplicate (Repeat) } \\
\hline & & $1 \mathbf{a}$ & $\mathbf{1 b}$ & $\mathbf{2 a}$ & $\mathbf{2 b}$ & $3 \mathbf{a}$ & $\mathbf{3 b}$ & $4 \mathbf{a}$ & $4 \mathrm{~b}$ & $5 \mathbf{a}$ & $\mathbf{5 b}$ \\
\hline 0.08 & 0.08 & $6.59 \mathrm{E}-12$ & $1.47 \mathrm{E}-09$ & $1.14 \mathrm{E}-11$ & $1.16 \mathrm{E}-11$ & $2.30 \mathrm{E}-12$ & $6.63 \mathrm{E}-13$ & $1.10 \mathrm{E}-13$ & $4.58 \mathrm{E}-13$ & $1.79 \mathrm{E}-12$ & $2.92 \mathrm{E}-12$ \\
\hline 0.92 & 1 & $3.76 \mathrm{E}-11$ & $2.74 \mathrm{E}-11$ & $2.25 \mathrm{E}-12$ & $2.57 \mathrm{E}-12$ & $3.10 \mathrm{E}-12$ & $2.91 \mathrm{E}-12$ & $8.12 \mathrm{E}-14$ & $1.66 \mathrm{E}-13$ & $1.90 \mathrm{E}-13$ & $2.02 \mathrm{E}-12$ \\
\hline 1 & 2 & $9.19 \mathrm{E}-12$ & $7.82 \mathrm{E}-12$ & $1.05 \mathrm{E}-12$ & $1.09 \mathrm{E}-12$ & $8.56 \mathrm{E}-13$ & $9.59 \mathrm{E}-13$ & $1.42 \mathrm{E}-13$ & $1.42 \mathrm{E}-13$ & $2.17 \mathrm{E}-13$ & $2.62 \mathrm{E}-12$ \\
\hline 5 & 7 & $3.01 \mathrm{E}-12$ & $2.60 \mathrm{E}-12$ & $4.43 \mathrm{E}-13$ & $4.42 \mathrm{E}-13$ & $2.74 \mathrm{E}-13$ & $3.12 \mathrm{E}-13$ & $9.58 \mathrm{E}-14$ & $9.96 \mathrm{E}-14$ & $5.77 \mathrm{E}-14$ & $5.59 \mathrm{E}-13$ \\
\hline 7 & 14 & $6.76 \mathrm{E}-13$ & 5.99E-13 & $1.96 \mathrm{E}-13$ & $1.92 \mathrm{E}-13$ & $2.20 \mathrm{E}-13$ & $2.44 \mathrm{E}-13$ & $7.27 \mathrm{E}-14$ & $6.20 \mathrm{E}-14$ & $4.93 \mathrm{E}-14$ & $1.14 \mathrm{E}-13$ \\
\hline 14 & 28 & $2.80 \mathrm{E}-13$ & $2.42 \mathrm{E}-13$ & $1.15 \mathrm{E}-13$ & $1.14 \mathrm{E}-13$ & $1.68 \mathrm{E}-13$ & $1.66 \mathrm{E}-13$ & $6.12 \mathrm{E}-14$ & $6.52 \mathrm{E}-14$ & $4.37 \mathrm{E}-14$ & $6.32 \mathrm{E}-14$ \\
\hline 14 & 42 & $1.53 \mathrm{E}-13$ & $1.37 \mathrm{E}-13$ & $7.04 \mathrm{E}-14$ & $7.12 \mathrm{E}-14$ & $1.57 \mathrm{E}-13$ & $1.50 \mathrm{E}-13$ & $4.33 \mathrm{E}-14$ & $4.86 \mathrm{E}-14$ & $5.77 \mathrm{E}-14$ & $6.11 \mathrm{E}-14$ \\
\hline 7 & 49 & $1.91 \mathrm{E}-13$ & $1.65 \mathrm{E}-13$ & $8.38 \mathrm{E}-14$ & $7.31 \mathrm{E}-14$ & $2.31 \mathrm{E}-13$ & $2.15 \mathrm{E}-13$ & $6.64 \mathrm{E}-14$ & $7.51 \mathrm{E}-14$ & $1.16 \mathrm{E}-13$ & $1.19 \mathrm{E}-13$ \\
\hline 14 & 63 & $1.64 \mathrm{E}-13$ & $1.64 \mathrm{E}-13$ & $6.32 \mathrm{E}-14$ & $6.73 \mathrm{E}-14$ & $1.09 \mathrm{E}-13$ & $1.16 \mathrm{E}-13$ & $6.87 \mathrm{E}-14$ & $7.44 \mathrm{E}-14$ & $9.14 \mathrm{E}-14$ & $8.97 \mathrm{E}-14$ \\
\hline 14 & 77 & $1.66 \mathrm{E}-13$ & $1.74 \mathrm{E}-13$ & $4.59 \mathrm{E}-14$ & $5.62 \mathrm{E}-14$ & $1.16 \mathrm{E}-13$ & $8.57 \mathrm{E}-14$ & $5.26 \mathrm{E}-14$ & $5.68 \mathrm{E}-14$ & $8.16 \mathrm{E}-14$ & $4.35 \mathrm{E}-14$ \\
\hline 14 & 91 & $1.79 \mathrm{E}-13$ & $1.68 \mathrm{E}-13$ & $5.02 \mathrm{E}-14$ & $3.05 \mathrm{E}-14$ & $1.06 \mathrm{E}-13$ & $9.14 \mathrm{E}-14$ & $5.85 \mathrm{E}-14$ & $6.27 \mathrm{E}-14$ & $6.16 \mathrm{E}-14$ & $7.96 \mathrm{E}-14$ \\
\hline
\end{tabular}

\begin{tabular}{|c|c|c|c|c|c|c|c|c|c|c|c|}
\hline \multirow{3}{*}{$\begin{array}{c}\text { Interval } \\
\text { (days) }\end{array}$} & \multirow{3}{*}{$\begin{array}{c}\text { Total } \\
\text { Duration } \\
\text { (days) }\end{array}$} & \multicolumn{10}{|c|}{ Chromium Effective Diffusion Coefficient $\left(\mathrm{cm}^{2} / \mathrm{s}\right)$} \\
\hline & & \multicolumn{10}{|c|}{ Mix Number and Duplicate (Repeat) } \\
\hline & & 6a & 6b & $7 \mathbf{a}$ & $7 \mathbf{b}$ & $\mathbf{8 a}$ & $\mathbf{8 b}$ & 9a & 9b & $10 \mathbf{a}$ & 10b \\
\hline 0.08 & 0.08 & $5.72 \mathrm{E}-13$ & $2.44 \mathrm{E}-13$ & $<3.82 \mathrm{E}-14$ & $<4.00 \mathrm{E}-14$ & $7.57 \mathrm{E}-10$ & $2.36 \mathrm{E}-10$ & $2.14 \mathrm{E}-13$ & $1.42 \mathrm{E}-11$ & $4.31 \mathrm{E}-11$ & $4.56 \mathrm{E}-11$ \\
\hline 0.92 & 1 & $9.85 \mathrm{E}-14$ & $6.92 \mathrm{E}-14$ & $2.81 \mathrm{E}-14$ & $3.19 \mathrm{E}-14$ & $2.83 \mathrm{E}-11$ & 4.44E-11 & $7.08 \mathrm{E}-13$ & $1.78 \mathrm{E}-12$ & $6.77 \mathrm{E}-12$ & $1.23 \mathrm{E}-11$ \\
\hline 1 & 2 & $8.63 \mathrm{E}-14$ & $7.43 \mathrm{E}-14$ & $2.29 \mathrm{E}-14$ & $3.13 \mathrm{E}-14$ & $5.22 \mathrm{E}-12$ & $1.23 \mathrm{E}-11$ & $1.06 \mathrm{E}-12$ & $1.87 \mathrm{E}-12$ & $5.69 \mathrm{E}-12$ & $1.26 \mathrm{E}-11$ \\
\hline 5 & 7 & $4.87 \mathrm{E}-14$ & $4.78 \mathrm{E}-14$ & $1.11 \mathrm{E}-14$ & $1.61 \mathrm{E}-14$ & $1.17 \mathrm{E}-12$ & $1.33 \mathrm{E}-12$ & $4.57 \mathrm{E}-13$ & $7.04 \mathrm{E}-13$ & $1.96 \mathrm{E}-12$ & $4.71 \mathrm{E}-12$ \\
\hline 7 & 14 & $6.39 \mathrm{E}-14$ & $6.03 \mathrm{E}-14$ & $7.17 \mathrm{E}-15$ & $6.74 \mathrm{E}-15$ & $7.84 \mathrm{E}-13$ & $9.84 \mathrm{E}-13$ & $3.27 \mathrm{E}-13$ & $4.27 \mathrm{E}-13$ & $8.34 \mathrm{E}-13$ & $2.19 \mathrm{E}-12$ \\
\hline 14 & 28 & $8.39 \mathrm{E}-14$ & $7.83 \mathrm{E}-14$ & $6.36 \mathrm{E}-15$ & $6.49 \mathrm{E}-15$ & $6.52 \mathrm{E}-13$ & $8.23 \mathrm{E}-13$ & $1.67 \mathrm{E}-13$ & $2.16 \mathrm{E}-13$ & $5.08 \mathrm{E}-13$ & $1.42 \mathrm{E}-12$ \\
\hline 14 & 42 & $1.15 \mathrm{E}-13$ & $1.01 \mathrm{E}-13$ & $5.32 \mathrm{E}-15$ & $5.54 \mathrm{E}-15$ & $5.55 \mathrm{E}-13$ & $6.25 \mathrm{E}-13$ & $1.30 \mathrm{E}-13$ & $1.72 \mathrm{E}-13$ & $2.97 \mathrm{E}-13$ & $9.18 \mathrm{E}-13$ \\
\hline 7 & 49 & $2.73 \mathrm{E}-13$ & $1.83 \mathrm{E}-13$ & $1.00 \mathrm{E}-14$ & $1.14 \mathrm{E}-14$ & 7.39E-13 & $8.51 \mathrm{E}-13$ & $1.72 \mathrm{E}-13$ & $2.00 \mathrm{E}-13$ & $3.38 \mathrm{E}-13$ & $9.56 \mathrm{E}-13$ \\
\hline 14 & 63 & $1.92 \mathrm{E}-13$ & $1.96 \mathrm{E}-13$ & $1.01 \mathrm{E}-14$ & $1.11 \mathrm{E}-14$ & $6.90 \mathrm{E}-13$ & $7.82 \mathrm{E}-13$ & $9.97 \mathrm{E}-14$ & $1.20 \mathrm{E}-13$ & $3.21 \mathrm{E}-13$ & $8.31 \mathrm{E}-13$ \\
\hline 14 & 77 & $8.48 \mathrm{E}-14$ & $1.28 \mathrm{E}-13$ & $6.13 \mathrm{E}-15$ & $8.29 \mathrm{E}-15$ & $5.73 \mathrm{E}-13$ & $6.43 \mathrm{E}-13$ & $5.58 \mathrm{E}-14$ & $4.62 \mathrm{E}-14$ & $2.30 \mathrm{E}-13$ & $5.08 \mathrm{E}-13$ \\
\hline 14 & 91 & $1.11 \mathrm{E}-13$ & $1.56 \mathrm{E}-13$ & $7.93 \mathrm{E}-15$ & $1.13 \mathrm{E}-14$ & $2.96 \mathrm{E}-13$ & $5.14 \mathrm{E}-13$ & $6.05 \mathrm{E}-14$ & $8.33 \mathrm{E}-14$ & $2.18 \mathrm{E}-13$ & $5.69 \mathrm{E}-13$ \\
\hline
\end{tabular}


Table D-12. Chromium Effective Diffusion Coefficients (contd)

\begin{tabular}{|c|c|c|c|c|c|c|c|c|c|c|c|}
\hline \multirow{3}{*}{$\begin{array}{c}\text { Interval } \\
\text { (days) }\end{array}$} & \multirow{3}{*}{$\begin{array}{c}\text { Total } \\
\text { Duration } \\
\text { (days) }\end{array}$} & \multicolumn{10}{|c|}{ Chromium Effective Diffusion Coefficient $\left(\mathrm{cm}^{2} / \mathrm{s}\right)$} \\
\hline & & \multicolumn{10}{|c|}{ Mix Number and Duplicate (Repeat) } \\
\hline & & $11 \mathbf{a}$ & 11b & $12 \mathbf{a}$ & 12b & $13 a$ & 13b & $14 a$ & $14 b$ & $15 \mathbf{a}$ & 15b \\
\hline 0.08 & 0.08 & $1.42 \mathrm{E}-11$ & $1.84 \mathrm{E}-13$ & $1.70 \mathrm{E}-12$ & $8.95 \mathrm{E}-13$ & $8.13 \mathrm{E}-13$ & $1.38 \mathrm{E}-12$ & $1.12 \mathrm{E}-13$ & $2.37 \mathrm{E}-13$ & $4.49 \mathrm{E}-12$ & $3.60 \mathrm{E}-12$ \\
\hline 0.92 & 1 & $6.89 \mathrm{E}-13$ & $9.16 \mathrm{E}-14$ & $1.05 \mathrm{E}-13$ & $1.13 \mathrm{E}-13$ & $5.99 \mathrm{E}-13$ & $3.11 \mathrm{E}-13$ & $6.68 \mathrm{E}-14$ & $4.76 \mathrm{E}-14$ & $3.70 \mathrm{E}-12$ & $3.04 \mathrm{E}-12$ \\
\hline 1 & 2 & $4.87 \mathrm{E}-13$ & $1.34 \mathrm{E}-13$ & $1.90 \mathrm{E}-13$ & $1.67 \mathrm{E}-13$ & $5.14 \mathrm{E}-13$ & $2.48 \mathrm{E}-13$ & $4.62 \mathrm{E}-14$ & $3.30 \mathrm{E}-14$ & $5.23 \mathrm{E}-12$ & $4.17 \mathrm{E}-12$ \\
\hline 5 & 7 & $1.56 \mathrm{E}-13$ & $9.75 \mathrm{E}-14$ & $1.44 \mathrm{E}-13$ & $1.75 \mathrm{E}-13$ & $2.04 \mathrm{E}-13$ & $1.20 \mathrm{E}-13$ & $1.87 \mathrm{E}-14$ & $9.79 \mathrm{E}-15$ & $5.01 \mathrm{E}-12$ & $4.15 \mathrm{E}-12$ \\
\hline 7 & 14 & $8.85 \mathrm{E}-14$ & $1.01 \mathrm{E}-13$ & $1.15 \mathrm{E}-13$ & $2.63 \mathrm{E}-13$ & $1.00 \mathrm{E}-13$ & $7.64 \mathrm{E}-14$ & $9.73 \mathrm{E}-15$ & $9.00 \mathrm{E}-15$ & $3.03 \mathrm{E}-12$ & $2.48 \mathrm{E}-12$ \\
\hline 14 & 28 & $1.08 \mathrm{E}-13$ & $1.02 \mathrm{E}-13$ & $1.09 \mathrm{E}-13$ & $1.18 \mathrm{E}-13$ & $6.77 \mathrm{E}-14$ & $5.51 \mathrm{E}-14$ & $8.49 \mathrm{E}-15$ & $8.72 \mathrm{E}-15$ & $9.09 \mathrm{E}-13$ & $6.84 \mathrm{E}-13$ \\
\hline 14 & 42 & $1.07 \mathrm{E}-13$ & $1.08 \mathrm{E}-13$ & $1.10 \mathrm{E}-13$ & $1.13 \mathrm{E}-13$ & $4.82 \mathrm{E}-14$ & $3.91 \mathrm{E}-14$ & $6.88 \mathrm{E}-15$ & $7.55 \mathrm{E}-15$ & $2.24 \mathrm{E}-13$ & $1.59 \mathrm{E}-13$ \\
\hline 7 & 49 & $1.89 \mathrm{E}-13$ & $1.80 \mathrm{E}-13$ & $2.14 \mathrm{E}-13$ & $5.54 \mathrm{E}-13$ & $5.38 \mathrm{E}-14$ & $6.54 \mathrm{E}-14$ & $1.20 \mathrm{E}-14$ & $1.11 \mathrm{E}-14$ & $1.93 \mathrm{E}-13$ & $1.53 \mathrm{E}-13$ \\
\hline 14 & 63 & $1.39 \mathrm{E}-13$ & $1.41 \mathrm{E}-13$ & $2.21 \mathrm{E}-13$ & $1.77 \mathrm{E}-13$ & $5.61 \mathrm{E}-14$ & $5.54 \mathrm{E}-14$ & $1.27 \mathrm{E}-14$ & $1.18 \mathrm{E}-14$ & $1.10 \mathrm{E}-13$ & $8.98 \mathrm{E}-14$ \\
\hline 14 & 77 & $6.03 \mathrm{E}-14$ & $7.88 \mathrm{E}-14$ & $1.28 \mathrm{E}-13$ & $1.70 \mathrm{E}-13$ & $5.24 \mathrm{E}-14$ & $4.53 \mathrm{E}-14$ & $1.57 \mathrm{E}-14$ & $1.23 \mathrm{E}-14$ & $1.17 \mathrm{E}-13$ & $1.04 \mathrm{E}-13$ \\
\hline 14 & 91 & $5.29 \mathrm{E}-14$ & $7.67 \mathrm{E}-14$ & $1.58 \mathrm{E}-13$ & $8.14 \mathrm{E}-14$ & $5.16 \mathrm{E}-14$ & $3.99 \mathrm{E}-14$ & $1.02 \mathrm{E}-14$ & $1.05 \mathrm{E}-14$ & $7.13 \mathrm{E}-14$ & $4.62 \mathrm{E}-14$ \\
\hline
\end{tabular}

\begin{tabular}{|c|c|c|c|c|c|c|c|c|c|c|c|}
\hline \multirow{3}{*}{$\begin{array}{c}\text { Interval } \\
\text { (days) }\end{array}$} & \multirow{3}{*}{$\begin{array}{c}\text { Total } \\
\text { Duration } \\
\text { (days) }\end{array}$} & \multicolumn{10}{|c|}{ "Chromium Effective Diffusion Coefficient $\left(\mathrm{cm}^{2} / \mathrm{s}\right)$} \\
\hline & & \multicolumn{10}{|c|}{ Mix Number and Duplicate (Repeat) } \\
\hline & & $16 \mathbf{a}$ & $16 \mathrm{~b}$ & $17 \mathbf{a}$ & $\mathbf{1 7 b}$ & $18 \mathbf{a}$ & $18 b$ & $19 a$ & 19b & 20a & $20 b$ \\
\hline 0.08 & 0.08 & $1.06 \mathrm{E}-10$ & $7.71 \mathrm{E}-11$ & $1.06 \mathrm{E}-13$ & $3.03 \mathrm{E}-13$ & $<1.20 \mathrm{E}-13$ & $<1.17 \mathrm{E}-13$ & $3.79 \mathrm{E}-14$ & $<3.37 \mathrm{E}-14$ & $3.76 \mathrm{E}-12$ & $4.34 \mathrm{E}-13$ \\
\hline 0.92 & 1 & $1.81 \mathrm{E}-11$ & $1.48 \mathrm{E}-11$ & $9.96 \mathrm{E}-14$ & $1.16 \mathrm{E}-13$ & $<1.98 \mathrm{E}-14$ & $<1.93 \mathrm{E}-14$ & $4.22 \mathrm{E}-14$ & $2.97 \mathrm{E}-14$ & $1.54 \mathrm{E}-12$ & $3.66 \mathrm{E}-13$ \\
\hline 1 & 2 & $2.72 \mathrm{E}-12$ & $2.89 \mathrm{E}-12$ & $1.33 \mathrm{E}-13$ & $1.29 \mathrm{E}-13$ & $<5.83 \mathrm{E}-14$ & $<5.68 \mathrm{E}-14$ & $3.79 \mathrm{E}-14$ & $2.83 \mathrm{E}-14$ & $9.00 \mathrm{E}-13$ & $2.72 \mathrm{E}-13$ \\
\hline 5 & 7 & $8.91 \mathrm{E}-13$ & $1.03 \mathrm{E}-12$ & $1.53 \mathrm{E}-13$ & $1.71 \mathrm{E}-13$ & $2.21 \mathrm{E}-14$ & $2.08 \mathrm{E}-14$ & $2.83 \mathrm{E}-14$ & $2.93 \mathrm{E}-14$ & $3.35 \mathrm{E}-13$ & $1.52 \mathrm{E}-13$ \\
\hline 7 & 14 & $4.24 \mathrm{E}-13$ & $5.80 \mathrm{E}-13$ & $1.87 \mathrm{E}-13$ & $1.76 \mathrm{E}-13$ & $1.28 \mathrm{E}-14$ & $1.28 \mathrm{E}-14$ & $3.55 \mathrm{E}-14$ & $3.65 \mathrm{E}-14$ & $1.69 \mathrm{E}-13$ & $1.12 \mathrm{E}-13$ \\
\hline 14 & 28 & $2.73 \mathrm{E}-13$ & $3.27 \mathrm{E}-13$ & $1.85 \mathrm{E}-13$ & $1.74 \mathrm{E}-13$ & $1.56 \mathrm{E}-14$ & $1.87 \mathrm{E}-14$ & $4.99 \mathrm{E}-14$ & $5.07 \mathrm{E}-14$ & $1.07 \mathrm{E}-13$ & $8.59 \mathrm{E}-14$ \\
\hline 14 & 42 & $1.94 \mathrm{E}-13$ & $2.12 \mathrm{E}-13$ & $1.59 \mathrm{E}-13$ & $1.47 \mathrm{E}-13$ & $8.25 \mathrm{E}-15$ & $8.43 \mathrm{E}-15$ & $4.82 \mathrm{E}-14$ & $5.01 \mathrm{E}-14$ & $7.18 \mathrm{E}-14$ & $6.15 \mathrm{E}-14$ \\
\hline 7 & 49 & $2.80 \mathrm{E}-13$ & $2.95 \mathrm{E}-13$ & $2.07 \mathrm{E}-13$ & $1.75 \mathrm{E}-13$ & $<3.72 \mathrm{E}-14$ & $<3.62 \mathrm{E}-14$ & $6.95 \mathrm{E}-14$ & $8.20 \mathrm{E}-14$ & $8.99 \mathrm{E}-14$ & $8.25 \mathrm{E}-14$ \\
\hline 14 & 63 & $1.88 \mathrm{E}-13$ & $1.93 \mathrm{E}-13$ & $1.52 \mathrm{E}-13$ & $1.25 \mathrm{E}-13$ & $<1.14 \mathrm{E}-14$ & $<1.11 \mathrm{E}-14$ & $5.55 \mathrm{E}-14$ & $5.99 \mathrm{E}-14$ & $5.11 \mathrm{E}-14$ & $5.56 \mathrm{E}-14$ \\
\hline 14 & 77 & $1.40 \mathrm{E}-13$ & $2.08 \mathrm{E}-13$ & $2.00 \mathrm{E}-13$ & $1.83 \mathrm{E}-13$ & $2.85 \mathrm{E}-14$ & $3.18 \mathrm{E}-14$ & $7.70 \mathrm{E}-14$ & $8.27 \mathrm{E}-14$ & $7.54 \mathrm{E}-14$ & $9.02 \mathrm{E}-14$ \\
\hline 14 & 91 & $1.89 \mathrm{E}-13$ & $1.77 \mathrm{E}-13$ & $1.87 \mathrm{E}-13$ & $1.47 \mathrm{E}-13$ & $2.14 \mathrm{E}-14$ & $2.58 \mathrm{E}-14$ & $6.92 \mathrm{E}-14$ & $7.86 \mathrm{E}-14$ & $4.54 \mathrm{E}-14$ & $7.53 \mathrm{E}-14$ \\
\hline
\end{tabular}


Table D-12. Chromium Effective Diffusion Coefficients (contd)

\begin{tabular}{|c|c|c|c|c|c|c|c||}
\hline \multirow{2}{*}{$\begin{array}{c}\text { Interval } \\
\text { (days) }\end{array}$} & \multirow{2}{*}{$\begin{array}{c}\text { Total } \\
\text { Duration } \\
\text { (days) }\end{array}$} & \multicolumn{6}{|c||}{ Chromium Effective Diffusion Coefficient $\left(\mathbf{c m}^{\mathbf{2}} / \mathbf{s}\right)$} \\
\cline { 3 - 8 } & $\mathbf{2 1 a}$ & $\mathbf{2 1 b}$ & $\mathbf{2 2 a}$ & $\mathbf{2 2 b}$ & $\mathbf{2 3 a}$ & $\mathbf{2 3 b}$ \\
\hline 0.08 & 0.08 & $3.60 \mathrm{E}-13$ & $6.47 \mathrm{E}-13$ & $8.69 \mathrm{E}-12$ & $2.47 \mathrm{E}-12$ & $5.78 \mathrm{E}-13$ & $1.48 \mathrm{E}-13$ \\
\hline 0.92 & 1 & $2.87 \mathrm{E}-13$ & $3.38 \mathrm{E}-13$ & $5.03 \mathrm{E}-12$ & $1.68 \mathrm{E}-12$ & $2.51 \mathrm{E}-13$ & $1.99 \mathrm{E}-13$ \\
\hline 1 & 2 & $1.17 \mathrm{E}-13$ & $1.35 \mathrm{E}-13$ & $3.38 \mathrm{E}-12$ & $1.30 \mathrm{E}-12$ & $6.04 \mathrm{E}-13$ & $2.71 \mathrm{E}-13$ \\
\hline 5 & 7 & $4.89 \mathrm{E}-14$ & $4.60 \mathrm{E}-14$ & $1.15 \mathrm{E}-12$ & $5.89 \mathrm{E}-13$ & $6.17 \mathrm{E}-13$ & $3.84 \mathrm{E}-13$ \\
\hline 7 & 14 & $5.52 \mathrm{E}-14$ & $5.67 \mathrm{E}-14$ & $4.37 \mathrm{E}-13$ & $3.42 \mathrm{E}-13$ & $9.03 \mathrm{E}-13$ & $5.85 \mathrm{E}-13$ \\
\hline 14 & 28 & $6.98 \mathrm{E}-14$ & $8.15 \mathrm{E}-14$ & $2.21 \mathrm{E}-13$ & $1.94 \mathrm{E}-13$ & $9.15 \mathrm{E}-13$ & $6.96 \mathrm{E}-13$ \\
\hline 14 & 42 & $1.03 \mathrm{E}-13$ & $1.09 \mathrm{E}-13$ & $1.93 \mathrm{E}-13$ & $1.62 \mathrm{E}-13$ & $1.01 \mathrm{E}-12$ & $8.70 \mathrm{E}-13$ \\
\hline 7 & 49 & $1.99 \mathrm{E}-13$ & $2.14 \mathrm{E}-13$ & $2.51 \mathrm{E}-13$ & $2.16 \mathrm{E}-13$ & $1.79 \mathrm{E}-12$ & $1.55 \mathrm{E}-12$ \\
\hline 14 & 63 & $2.09 \mathrm{E}-13$ & $2.23 \mathrm{E}-13$ & $1.08 \mathrm{E}-13$ & $8.87 \mathrm{E}-14$ & $1.24 \mathrm{E}-12$ & $1.19 \mathrm{E}-12$ \\
\hline 14 & 77 & $1.72 \mathrm{E}-13$ & $1.91 \mathrm{E}-13$ & $1.41 \mathrm{E}-13$ & $6.91 \mathrm{E}-14$ & $9.21 \mathrm{E}-13$ & $9.47 \mathrm{E}-13$ \\
\hline 14 & 91 & $2.39 \mathrm{E}-13$ & $2.35 \mathrm{E}-13$ & $1.26 \mathrm{E}-13$ & $4.48 \mathrm{E}-14$ & $5.10 \mathrm{E}-13$ & $5.82 \mathrm{E}-13$ \\
\hline
\end{tabular}

\begin{tabular}{|c|c|c|c|c|c|c|c||}
\hline \multirow{2}{*}{$\begin{array}{c}\text { Interval } \\
\text { (days) }\end{array}$} & \multirow{2}{*}{$\begin{array}{c}\text { Total } \\
\text { Duration } \\
\text { (days) }\end{array}$} & \multicolumn{6}{|c||}{ Chromium Effective Diffusion Coefficient (cm $\mathbf{2} / \mathbf{s})$} \\
\cline { 3 - 8 } & $\mathbf{6 4}$ & $\mathbf{2 4 a}$ & $\mathbf{2 4 b}$ & $\mathbf{2 5 a}$ & $\mathbf{2 5 b}$ & $\mathbf{2 6 a}$ & $\mathbf{2 6 b}$ \\
\hline 0.08 & 0.08 & $3.19 \mathrm{E}-12$ & $1.35 \mathrm{E}-12$ & $1.00 \mathrm{E}-11$ & $1.34 \mathrm{E}-11$ & $2.24 \mathrm{E}-12$ & $2.55 \mathrm{E}-12$ \\
\hline 0.92 & 1 & $2.46 \mathrm{E}-12$ & $9.52 \mathrm{E}-13$ & $5.50 \mathrm{E}-12$ & $8.39 \mathrm{E}-12$ & $6.27 \mathrm{E}-13$ & $5.91 \mathrm{E}-13$ \\
\hline 1 & 2 & $1.95 \mathrm{E}-12$ & $6.93 \mathrm{E}-13$ & $6.43 \mathrm{E}-12$ & $9.43 \mathrm{E}-12$ & $2.91 \mathrm{E}-13$ & $2.73 \mathrm{E}-13$ \\
\hline 5 & 7 & $7.03 \mathrm{E}-13$ & $2.48 \mathrm{E}-13$ & $4.86 \mathrm{E}-12$ & $8.27 \mathrm{E}-12$ & $6.85 \mathrm{E}-14$ & $6.40 \mathrm{E}-14$ \\
\hline 7 & 14 & $2.67 \mathrm{E}-13$ & $1.24 \mathrm{E}-13$ & $1.99 \mathrm{E}-12$ & $3.08 \mathrm{E}-12$ & $5.61 \mathrm{E}-14$ & $4.21 \mathrm{E}-14$ \\
\hline 14 & 28 & $1.73 \mathrm{E}-13$ & $8.27 \mathrm{E}-14$ & $7.98 \mathrm{E}-13$ & $1.30 \mathrm{E}-12$ & $6.22 \mathrm{E}-14$ & $5.66 \mathrm{E}-14$ \\
\hline 14 & 42 & $8.95 \mathrm{E}-14$ & $5.65 \mathrm{E}-14$ & $2.14 \mathrm{E}-13$ & $2.70 \mathrm{E}-13$ & $7.22 \mathrm{E}-14$ & $7.28 \mathrm{E}-14$ \\
\hline 7 & 49 & $1.19 \mathrm{E}-13$ & $8.98 \mathrm{E}-14$ & $1.87 \mathrm{E}-13$ & $1.95 \mathrm{E}-13$ & $1.80 \mathrm{E}-13$ & $1.72 \mathrm{E}-13$ \\
\hline 14 & 63 & $8.37 \mathrm{E}-14$ & $6.13 \mathrm{E}-14$ & $1.28 \mathrm{E}-13$ & $1.20 \mathrm{E}-13$ & $9.97 \mathrm{E}-14$ & $9.58 \mathrm{E}-14$ \\
\hline 14 & 77 & $9.01 \mathrm{E}-14$ & $1.08 \mathrm{E}-13$ & $1.45 \mathrm{E}-13$ & $1.21 \mathrm{E}-13$ & $8.93 \mathrm{E}-14$ & $5.80 \mathrm{E}-14$ \\
\hline 14 & 91 & $7.32 \mathrm{E}-14$ & $9.99 \mathrm{E}-14$ & $9.63 \mathrm{E}-14$ & $7.87 \mathrm{E}-14$ & $9.64 \mathrm{E}-14$ & $1.37 \mathrm{E}-13$ \\
\hline
\end{tabular}


Table D-13. Uranium Effective Diffusion Coefficients

\begin{tabular}{|c|c|c|c|c|c|c|c|c|c|c|c|}
\hline \multirow{3}{*}{$\begin{array}{c}\text { Interval } \\
\text { (days) }\end{array}$} & \multirow{3}{*}{$\begin{array}{c}\text { Total } \\
\text { Duration } \\
\text { (days) }\end{array}$} & \multicolumn{10}{|c|}{ Uranium Effective Diffusion Coefficient $\left(\mathrm{cm}^{2} / \mathrm{s}\right)$} \\
\hline & & \multicolumn{10}{|c|}{ Mix Number and Duplicate (Repeat) } \\
\hline & & 1a & $\mathbf{1 b}$ & $\mathbf{2 a}$ & 2b & $3 \mathbf{a}$ & $\mathbf{3 b}$ & $4 a$ & $4 \mathbf{b}$ & $\mathbf{5 a}$ & $\mathbf{5 b}$ \\
\hline 0.08 & 0.08 & $3.02 \mathrm{E}-15$ & $6.93 \mathrm{E}-13$ & $5.96 \mathrm{E}-15$ & $6.62 \mathrm{E}-15$ & $2.76 \mathrm{E}-15$ & 9.99E-16 & $4.66 \mathrm{E}-16$ & $5.20 \mathrm{E}-15$ & $1.05 \mathrm{E}-14$ & $2.46 \mathrm{E}-15$ \\
\hline 0.92 & 1 & $4.98 \mathrm{E}-16$ & 4.99E-16 & $2.81 \mathrm{E}-16$ & $2.92 \mathrm{E}-16$ & $6.22 \mathrm{E}-17$ & $6.58 \mathrm{E}-17$ & $1.92 \mathrm{E}-16$ & $1.15 \mathrm{E}-16$ & $4.68 \mathrm{E}-17$ & $9.08 \mathrm{E}-17$ \\
\hline 1 & 2 & $2.33 \mathrm{E}-14$ & $2.68 \mathrm{E}-16$ & $3.47 \mathrm{E}-16$ & $1.96 \mathrm{E}-16$ & $<5.79 \mathrm{E}-17$ & $<5.96 \mathrm{E}-17$ & $1.93 \mathrm{E}-16$ & $<1.95 \mathrm{E}-16$ & $1.06 \mathrm{E}-16$ & $7.25 \mathrm{E}-17$ \\
\hline 5 & 7 & $8.67 \mathrm{E}-17$ & $8.16 \mathrm{E}-17$ & $1.03 \mathrm{E}-16$ & $9.04 \mathrm{E}-17$ & $5.62 \mathrm{E}-16$ & $<1.51 \mathrm{E}-17$ & $2.21 \mathrm{E}-16$ & $2.23 \mathrm{E}-15$ & $7.72 \mathrm{E}-17$ & $4.94 \mathrm{E}-17$ \\
\hline 7 & 14 & $9.84 \mathrm{E}-17$ & $1.48 \mathrm{E}-16$ & $1.11 \mathrm{E}-16$ & $9.98 \mathrm{E}-17$ & $<1.88 \mathrm{E}-17$ & $<1.94 \mathrm{E}-17$ & $1.05 \mathrm{E}-16$ & $<6.32 \mathrm{E}-17$ & $<2.35 \mathrm{E}-17$ & $<2.35 \mathrm{E}-17$ \\
\hline 14 & 28 & $9.72 \mathrm{E}-17$ & $1.12 \mathrm{E}-16$ & 7.64E-17 & $6.51 \mathrm{E}-17$ & $<9.30 \mathrm{E}-18$ & $<9.57 \mathrm{E}-18$ & $<3.10 \mathrm{E}-17$ & $<3.13 \mathrm{E}-17$ & $<1.16 \mathrm{E}-17$ & $<1.16 \mathrm{E}-17$ \\
\hline 14 & 42 & $1.86 \mathrm{E}-16$ & $1.97 \mathrm{E}-16$ & $6.04 \mathrm{E}-17$ & $5.58 \mathrm{E}-17$ & $<1.58 \mathrm{E}-17$ & $<1.62 \mathrm{E}-17$ & $<5.24 \mathrm{E}-17$ & $<5.30 \mathrm{E}-17$ & $<1.97 \mathrm{E}-17$ & $<1.97 \mathrm{E}-17$ \\
\hline 7 & 49 & $5.59 \mathrm{E}-16$ & $6.66 \mathrm{E}-16$ & $<2.16 \mathrm{E}-16$ & $<2.11 \mathrm{E}-16$ & $<8.26 \mathrm{E}-17$ & $<8.50 \mathrm{E}-17$ & $<2.74 \mathrm{E}-16$ & $<2.78 \mathrm{E}-16$ & $<1.03 \mathrm{E}-16$ & $<1.03 \mathrm{E}-16$ \\
\hline 14 & 63 & $3.15 \mathrm{E}-16$ & $3.37 \mathrm{E}-16$ & $<6.65 \mathrm{E}-17$ & $<6.52 \mathrm{E}-17$ & $<2.55 \mathrm{E}-17$ & $<2.62 \mathrm{E}-17$ & $<8.47 \mathrm{E}-17$ & $<8.56 \mathrm{E}-17$ & $<3.19 \mathrm{E}-17$ & $<3.19 \mathrm{E}-17$ \\
\hline 14 & 77 & $3.84 \mathrm{E}-16$ & 4.39E-16 & $<8.31 \mathrm{E}-17$ & $<8.14 \mathrm{E}-17$ & $<3.18 \mathrm{E}-17$ & $<3.25 \mathrm{E}-17$ & $<1.06 \mathrm{E}-16$ & $<1.07 \mathrm{E}-16$ & $<3.98 \mathrm{E}-17$ & $<3.97 \mathrm{E}-17$ \\
\hline 14 & 91 & $5.22 \mathrm{E}-16$ & $5.06 \mathrm{E}-16$ & $<9.89 \mathrm{E}-17$ & $<9.69 \mathrm{E}-17$ & $<3.79 \mathrm{E}-17$ & $<3.90 \mathrm{E}-17$ & $<1.26 \mathrm{E}-16$ & $<1.27 \mathrm{E}-16$ & $<4.74 \mathrm{E}-17$ & $<4.67 \mathrm{E}-17$ \\
\hline
\end{tabular}

\begin{tabular}{|c|c|c|c|c|c|c|c|c|c|c|c|}
\hline \multirow{3}{*}{$\begin{array}{c}\text { Interval } \\
\text { (days) }\end{array}$} & \multirow{3}{*}{$\begin{array}{c}\text { Total } \\
\text { Duration } \\
\text { (days) }\end{array}$} & \multicolumn{10}{|c|}{ Uranium Effective Diffusion Coefficient $\left(\mathrm{cm}^{2} / \mathrm{s}\right)$} \\
\hline & & \multicolumn{10}{|c|}{ Mix Number and Duplicate (Repeat) } \\
\hline & & $\mathbf{6 a}$ & $\mathbf{6 b}$ & $7 \mathbf{a}$ & $7 \mathbf{b}$ & $\mathbf{8 a}$ & $8 b$ & $9 a$ & $9 \mathbf{b}$ & $10 a$ & $\mathbf{1 0 b}$ \\
\hline 0.08 & 0.08 & $6.72 \mathrm{E}-15$ & $2.93 \mathrm{E}-15$ & $<1.52 \mathrm{E}-16$ & $5.67 \mathrm{E}-16$ & $6.00 \mathrm{E}-13$ & $6.20 \mathrm{E}-14$ & $<1.15 \mathrm{E}-16$ & $5.33 \mathrm{E}-16$ & $5.82 \mathrm{E}-14$ & $3.49 \mathrm{E}-13$ \\
\hline 0.92 & 1 & $1.40 \mathrm{E}-16$ & $1.04 \mathrm{E}-16$ & $4.43 \mathrm{E}-17$ & $3.88 \mathrm{E}-17$ & $1.63 \mathrm{E}-15$ & $2.05 \mathrm{E}-15$ & $<1.89 \mathrm{E}-17$ & $<1.87 \mathrm{E}-17$ & $4.16 \mathrm{E}-16$ & $4.16 \mathrm{E}-16$ \\
\hline 1 & 2 & $<7.81 \mathrm{E}-17$ & $<7.94 \mathrm{E}-17$ & $<7.38 \mathrm{E}-17$ & $4.71 \mathrm{E}-14$ & $1.25 \mathrm{E}-15$ & $1.32 \mathrm{E}-15$ & $<5.58 \mathrm{E}-17$ & $<5.50 \mathrm{E}-17$ & $2.25 \mathrm{E}-16$ & $1.38 \mathrm{E}-13$ \\
\hline 5 & 7 & $3.04 \mathrm{E}-17$ & $6.43 \mathrm{E}-14$ & $7.02 \mathrm{E}-16$ & $2.73 \mathrm{E}-17$ & $2.04 \mathrm{E}-16$ & $2.26 \mathrm{E}-16$ & $<1.41 \mathrm{E}-17$ & $1.72 \mathrm{E}-17$ & $8.01 \mathrm{E}-17$ & $8.95 \mathrm{E}-17$ \\
\hline 7 & 14 & $3.93 \mathrm{E}-17$ & $2.94 \mathrm{E}-17$ & $<2.40 \mathrm{E}-17$ & $<2.52 \mathrm{E}-17$ & $2.80 \mathrm{E}-16$ & $2.73 \mathrm{E}-16$ & $<1.82 \mathrm{E}-17$ & $<1.79 \mathrm{E}-17$ & $6.03 \mathrm{E}-17$ & $8.30 \mathrm{E}-17$ \\
\hline 14 & 28 & $1.52 \mathrm{E}-17$ & $1.55 \mathrm{E}-17$ & $1.42 \mathrm{E}-17$ & $1.28 \mathrm{E}-17$ & $1.83 \mathrm{E}-16$ & $1.89 \mathrm{E}-16$ & $<8.96 \mathrm{E}-18$ & $<8.83 \mathrm{E}-18$ & $4.68 \mathrm{E}-17$ & $4.79 \mathrm{E}-17$ \\
\hline 14 & 42 & $<2.13 \mathrm{E}-17$ & $<2.17 \mathrm{E}-17$ & $<2.01 \mathrm{E}-17$ & $<2.11 \mathrm{E}-17$ & $2.32 \mathrm{E}-16$ & $2.14 \mathrm{E}-16$ & $<1.52 \mathrm{E}-17$ & $<1.50 \mathrm{E}-17$ & $<3.70 \mathrm{E}-17$ & $5.53 \mathrm{E}-17$ \\
\hline 7 & 49 & $2.17 \mathrm{E}-16$ & $<1.13 \mathrm{E}-16$ & $<1.05 \mathrm{E}-16$ & $<1.10 \mathrm{E}-16$ & $1.03 \mathrm{E}-15$ & $9.41 \mathrm{E}-16$ & $<7.96 \mathrm{E}-17$ & $<7.85 \mathrm{E}-17$ & $<1.94 \mathrm{E}-16$ & $<1.96 \mathrm{E}-16$ \\
\hline 14 & 63 & $<3.44 \mathrm{E}-17$ & $<3.49 \mathrm{E}-17$ & $<3.25 \mathrm{E}-17$ & $<3.40 \mathrm{E}-17$ & $6.00 \mathrm{E}-16$ & $4.68 \mathrm{E}-16$ & $<2.46 \mathrm{E}-17$ & $<2.42 \mathrm{E}-17$ & $<5.97 \mathrm{E}-17$ & $<6.06 \mathrm{E}-17$ \\
\hline 14 & 77 & $<4.29 \mathrm{E}-17$ & $<4.36 \mathrm{E}-17$ & $<4.05 \mathrm{E}-17$ & $<4.25 \mathrm{E}-17$ & $5.84 \mathrm{E}-16$ & $7.19 \mathrm{E}-16$ & $<3.06 \mathrm{E}-17$ & $<3.02 \mathrm{E}-17$ & $<7.45 \mathrm{E}-17$ & $<7.56 \mathrm{E}-17$ \\
\hline 14 & 91 & $<5.12 \mathrm{E}-17$ & $<5.20 \mathrm{E}-17$ & $<4.84 \mathrm{E}-17$ & $<5.07 \mathrm{E}-17$ & $3.37 \mathrm{E}-16$ & $8.98 \mathrm{E}-16$ & $<3.66 \mathrm{E}-17$ & $<3.61 \mathrm{E}-17$ & $<8.89 \mathrm{E}-17$ & $<9.02 \mathrm{E}-17$ \\
\hline
\end{tabular}


Table D-13. Uranium Effective Diffusion Coefficients (contd)

\begin{tabular}{|c|c|c|c|c|c|c|c|c|c|c|c|}
\hline \multirow{3}{*}{$\begin{array}{c}\text { Interval } \\
\text { (days) }\end{array}$} & \multirow{3}{*}{$\begin{array}{c}\text { Total } \\
\text { Duration } \\
\text { (days) }\end{array}$} & \multicolumn{10}{|c|}{ "Uranium Effective Diffusion Coefficient $\left(\mathrm{cm}^{2} / \mathrm{s}\right)$} \\
\hline & & \multicolumn{10}{|c|}{ Mix Number and Duplicate (Repeat) } \\
\hline & & $11 \mathbf{a}$ & $11 \mathbf{b}$ & $12 \mathbf{a}$ & $12 b$ & $13 \mathbf{a}$ & $13 \mathbf{b}$ & $14 a$ & $14 b$ & $15 \mathbf{a}$ & $15 \mathbf{b}$ \\
\hline 0.08 & 0.08 & $6.40 \mathrm{E}-15$ & $1.56 \mathrm{E}-15$ & $5.76 \mathrm{E}-15$ & $3.63 \mathrm{E}-15$ & $1.07 \mathrm{E}-15$ & $4.61 \mathrm{E}-15$ & $8.72 \mathrm{E}-16$ & $3.47 \mathrm{E}-15$ & $5.89 \mathrm{E}-16$ & $5.87 \mathrm{E}-16$ \\
\hline 0.92 & 1 & $2.46 \mathrm{E}-17$ & $2.72 \mathrm{E}-17$ & $<4.57 \mathrm{E}-17$ & $<4.63 \mathrm{E}-17$ & $2.34 \mathrm{E}-16$ & $2.91 \mathrm{E}-16$ & $2.82 \mathrm{E}-17$ & $3.52 \mathrm{E}-17$ & $5.56 \mathrm{E}-17$ & $5.29 \mathrm{E}-17$ \\
\hline 1 & 2 & $<6.05 \mathrm{E}-17$ & $<5.96 \mathrm{E}-17$ & $<1.35 \mathrm{E}-16$ & $<1.37 \mathrm{E}-16$ & $2.08 \mathrm{E}-16$ & $2.37 \mathrm{E}-16$ & $<7.37 \mathrm{E}-17$ & $<7.58 \mathrm{E}-17$ & $<7.47 \mathrm{E}-17$ & $<7.42 \mathrm{E}-17$ \\
\hline 5 & 7 & $<1.53 \mathrm{E}-17$ & $<1.51 \mathrm{E}-17$ & $<3.41 \mathrm{E}-17$ & $<3.45 \mathrm{E}-17$ & $1.36 \mathrm{E}-16$ & $1.28 \mathrm{E}-16$ & $<1.87 \mathrm{E}-17$ & $<1.92 \mathrm{E}-17$ & $<1.90 \mathrm{E}-17$ & $<1.90 \mathrm{E}-17$ \\
\hline 7 & 14 & $<1.98 \mathrm{E}-17$ & $<1.95 \mathrm{E}-17$ & $<4.41 \mathrm{E}-17$ & $8.94 \mathrm{E}-17$ & $1.09 \mathrm{E}-16$ & $1.10 \mathrm{E}-16$ & $2.57 \mathrm{E}-17$ & $<2.47 \mathrm{E}-17$ & $<2.40 \mathrm{E}-17$ & $<2.39 \mathrm{E}-17$ \\
\hline 14 & 28 & $<9.70 \mathrm{E}-18$ & $<9.55 \mathrm{E}-18$ & $<2.16 \mathrm{E}-17$ & $<2.19 \mathrm{E}-17$ & 7.14E-17 & $6.65 \mathrm{E}-17$ & $1.43 \mathrm{E}-17$ & $<1.22 \mathrm{E}-17$ & $<1.20 \mathrm{E}-17$ & $<1.20 \mathrm{E}-17$ \\
\hline 14 & 42 & $<1.65 \mathrm{E}-17$ & $<1.62 \mathrm{E}-17$ & $<3.67 \mathrm{E}-17$ & $4.46 \mathrm{E}-17$ & $4.93 \mathrm{E}-17$ & $5.02 \mathrm{E}-17$ & $2.33 \mathrm{E}-17$ & $<2.07 \mathrm{E}-17$ & $<2.04 \mathrm{E}-17$ & $<2.03 \mathrm{E}-17$ \\
\hline 7 & 49 & $<8.63 \mathrm{E}-17$ & $<8.50 \mathrm{E}-17$ & $<1.92 \mathrm{E}-16$ & $1.09 \mathrm{E}-15$ & $<2.22 \mathrm{E}-16$ & $<2.23 \mathrm{E}-16$ & $<1.05 \mathrm{E}-16$ & $<1.08 \mathrm{E}-16$ & $1.08 \mathrm{E}-16$ & $<1.07 \mathrm{E}-16$ \\
\hline 14 & 63 & $<2.66 \mathrm{E}-17$ & $<2.62 \mathrm{E}-17$ & $<5.92 \mathrm{E}-17$ & $6.27 \mathrm{E}-17$ & $<6.83 \mathrm{E}-17$ & $<6.87 \mathrm{E}-17$ & $<3.24 \mathrm{E}-17$ & $<3.33 \mathrm{E}-17$ & $8.09 \mathrm{E}-17$ & $<3.27 \mathrm{E}-17$ \\
\hline 14 & 77 & $<3.32 \mathrm{E}-17$ & $<3.27 \mathrm{E}-17$ & $<7.39 \mathrm{E}-17$ & $9.60 \mathrm{E}-17$ & $<8.52 \mathrm{E}-17$ & $<8.56 \mathrm{E}-17$ & $<4.04 \mathrm{E}-17$ & $<4.16 \mathrm{E}-17$ & $7.06 \mathrm{E}-17$ & $<4.09 \mathrm{E}-17$ \\
\hline 14 & 91 & $<3.97 \mathrm{E}-17$ & $<3.91 \mathrm{E}-17$ & $<8.84 \mathrm{E}-17$ & $<8.96 \mathrm{E}-17$ & $<1.02 \mathrm{E}-16$ & $<1.02 \mathrm{E}-16$ & $<4.84 \mathrm{E}-17$ & $<4.97 \mathrm{E}-17$ & $6.73 \mathrm{E}-17$ & $<4.90 \mathrm{E}-17$ \\
\hline
\end{tabular}

\begin{tabular}{|c|c|c|c|c|c|c|c|c|c|c|c|}
\hline \multirow{3}{*}{$\begin{array}{c}\text { Interval } \\
\text { (days) }\end{array}$} & \multirow{3}{*}{$\begin{array}{c}\text { Total } \\
\text { Duration } \\
\text { (days) }\end{array}$} & \multicolumn{10}{|c|}{ Uranium Effective Diffusion Coefficient $\left(\mathrm{cm}^{2} / \mathrm{s}\right)$} \\
\hline & & \multicolumn{10}{|c|}{ Mix Number and Duplicate (Repeat) } \\
\hline & & 16a & $16 \mathbf{b}$ & $17 \mathbf{a}$ & $17 \mathbf{b}$ & $18 \mathbf{a}$ & $18 \mathrm{~b}$ & $19 a$ & 19b & $\mathbf{2 0 a}$ & $20 b$ \\
\hline 0.08 & 0.08 & $7.80 \mathrm{E}-15$ & $4.92 \mathrm{E}-15$ & $7.06 \mathrm{E}-16$ & $6.02 \mathrm{E}-16$ & $6.54 \mathrm{E}-16$ & $5.27 \mathrm{E}-16$ & $3.66 \mathrm{E}-16$ & $3.26 \mathrm{E}-16$ & $<3.45 \mathrm{E}-16$ & $<3.37 \mathrm{E}-16$ \\
\hline 0.92 & 1 & $5.23 \mathrm{E}-16$ & $5.12 \mathrm{E}-16$ & $1.44 \mathrm{E}-16$ & $1.33 \mathrm{E}-16$ & 9.37E-17 & $8.95 \mathrm{E}-17$ & $5.84 \mathrm{E}-17$ & $4.62 \mathrm{E}-17$ & $3.31 \mathrm{E}-16$ & $7.66 \mathrm{E}-17$ \\
\hline 1 & 2 & $3.43 \mathrm{E}-16$ & $2.37 \mathrm{E}-16$ & $1.45 \mathrm{E}-16$ & $<1.38 \mathrm{E}-16$ & $1.43 \mathrm{E}-16$ & $1.21 \mathrm{E}-16$ & $<7.87 \mathrm{E}-17$ & $<7.83 \mathrm{E}-17$ & $8.07 \mathrm{E}-16$ & $3.60 \mathrm{E}-16$ \\
\hline 5 & 7 & $6.77 \mathrm{E}-17$ & $6.84 \mathrm{E}-17$ & $7.10 \mathrm{E}-17$ & $1.03 \mathrm{E}-16$ & $3.88 \mathrm{E}-17$ & $2.90 \mathrm{E}-17$ & $<2.01 \mathrm{E}-17$ & $<2.00 \mathrm{E}-17$ & $1.05 \mathrm{E}-15$ & $1.80 \mathrm{E}-16$ \\
\hline 7 & 14 & $9.93 \mathrm{E}-17$ & $7.97 \mathrm{E}-17$ & $1.33 \mathrm{E}-16$ & $1.02 \mathrm{E}-16$ & $8.02 \mathrm{E}-17$ & $7.81 \mathrm{E}-17$ & $<2.53 \mathrm{E}-17$ & $<2.52 \mathrm{E}-17$ & $<5.38 \mathrm{E}-17$ & $<5.25 \mathrm{E}-17$ \\
\hline 14 & 28 & $3.91 \mathrm{E}-17$ & $1.21 \mathrm{E}-16$ & $5.00 \mathrm{E}-17$ & $5.06 \mathrm{E}-17$ & 7.32E-17 & $1.27 \mathrm{E}-16$ & $<1.27 \mathrm{E}-17$ & $<1.19 \mathrm{E}-17$ & $<2.69 \mathrm{E}-17$ & $<2.63 \mathrm{E}-17$ \\
\hline 14 & 42 & $6.08 \mathrm{E}-17$ & $7.49 \mathrm{E}-17$ & $<3.89 \mathrm{E}-17$ & $<3.79 \mathrm{E}-17$ & $1.28 \mathrm{E}-16$ & $1.60 \mathrm{E}-16$ & $<2.16 \mathrm{E}-17$ & $<2.15 \mathrm{E}-17$ & $<4.58 \mathrm{E}-17$ & $<4.47 \mathrm{E}-17$ \\
\hline 7 & 49 & $1.71 \mathrm{E}-16$ & $2.81 \mathrm{E}-16$ & $<2.04 \mathrm{E}-16$ & $<1.98 \mathrm{E}-16$ & $2.34 \mathrm{E}-16$ & $6.38 \mathrm{E}-16$ & $<1.13 \mathrm{E}-16$ & $<1.12 \mathrm{E}-16$ & $<2.40 \mathrm{E}-16$ & $<2.34 \mathrm{E}-16$ \\
\hline 14 & 63 & $1.10 \mathrm{E}-16$ & $1.36 \mathrm{E}-16$ & $<6.26 \mathrm{E}-17$ & $<6.09 \mathrm{E}-17$ & $1.75 \mathrm{E}-16$ & $4.48 \mathrm{E}-16$ & $<3.47 \mathrm{E}-17$ & $<3.46 \mathrm{E}-17$ & $<7.36 \mathrm{E}-17$ & $<7.20 \mathrm{E}-17$ \\
\hline 14 & 77 & $9.64 \mathrm{E}-17$ & $1.74 \mathrm{E}-16$ & $<7.83 \mathrm{E}-17$ & $<7.62 \mathrm{E}-17$ & $2.05 \mathrm{E}-16$ & $8.84 \mathrm{E}-16$ & $<4.34 \mathrm{E}-17$ & $<4.32 \mathrm{E}-17$ & $<9.21 \mathrm{E}-17$ & $<9.00 \mathrm{E}-17$ \\
\hline 14 & 91 & $1.77 \mathrm{E}-16$ & $1.81 \mathrm{E}-16$ & $<9.37 \mathrm{E}-17$ & $<9.12 \mathrm{E}-17$ & $2.25 \mathrm{E}-16$ & $6.47 \mathrm{E}-16$ & $<5.20 \mathrm{E}-17$ & $<5.17 \mathrm{E}-17$ & $<1.10 \mathrm{E}-16$ & $6.22 \mathrm{E}-16$ \\
\hline
\end{tabular}


Table D-13. Uranium Effective Diffusion Coefficients (contd)

\begin{tabular}{|c|c|c|c|c|c|c|c|}
\hline \multirow{3}{*}{$\begin{array}{c}\text { Interval } \\
\text { (days) }\end{array}$} & \multirow{3}{*}{$\begin{array}{c}\text { Total } \\
\text { Duration } \\
\text { (days) }\end{array}$} & \multicolumn{6}{|c|}{ Uranium Effective Diffusion Coefficient $\left(\mathrm{cm}^{2} / \mathrm{s}\right)$} \\
\hline & & \multicolumn{6}{|c|}{ Mix Number and Duplicate (Repeat) } \\
\hline & & $21 \mathbf{a}$ & 21b & $22 \mathbf{a}$ & $22 b$ & $23 a$ & 23b \\
\hline 0.08 & 0.08 & $2.41 \mathrm{E}-15$ & $1.32 \mathrm{E}-15$ & $1.67 \mathrm{E}-16$ & $1.40 \mathrm{E}-16$ & $2.73 \mathrm{E}-15$ & $3.57 \mathrm{E}-15$ \\
\hline 0.92 & 1 & $1.94 \mathrm{E}-16$ & $1.72 \mathrm{E}-16$ & $2.72 \mathrm{E}-17$ & $<1.96 \mathrm{E}-17$ & $2.66 \mathrm{E}-16$ & $7.47 \mathrm{E}-16$ \\
\hline 1 & 2 & $1.01 \mathrm{E}-16$ & $7.51 \mathrm{E}-17$ & $<5.67 \mathrm{E}-17$ & $<5.77 \mathrm{E}-17$ & $3.63 \mathrm{E}-16$ & $6.59 \mathrm{E}-16$ \\
\hline 5 & 7 & $3.70 \mathrm{E}-17$ & $3.36 \mathrm{E}-17$ & $<1.44 \mathrm{E}-17$ & $1.19 \mathrm{E}-16$ & $1.42 \mathrm{E}-16$ & $2.31 \mathrm{E}-16$ \\
\hline 7 & 14 & $5.43 \mathrm{E}-17$ & $4.85 \mathrm{E}-17$ & $<1.81 \mathrm{E}-17$ & $3.90 \mathrm{E}-17$ & $2.55 \mathrm{E}-16$ & $3.69 \mathrm{E}-16$ \\
\hline 14 & 28 & $3.79 \mathrm{E}-17$ & $3.36 \mathrm{E}-17$ & $<9.12 \mathrm{E}-18$ & $<9.29 \mathrm{E}-18$ & $2.18 \mathrm{E}-16$ & $2.62 \mathrm{E}-16$ \\
\hline 14 & 42 & $2.39 \mathrm{E}-17$ & $3.19 \mathrm{E}-17$ & $<1.55 \mathrm{E}-17$ & $<1.57 \mathrm{E}-17$ & $2.20 \mathrm{E}-16$ & $3.39 \mathrm{E}-16$ \\
\hline 7 & 49 & $<8.40 \mathrm{E}-17$ & $<8.47 \mathrm{E}-17$ & $<8.12 \mathrm{E}-17$ & $<8.28 \mathrm{E}-17$ & $6.15 \mathrm{E}-16$ & $1.90 \mathrm{E}-15$ \\
\hline 14 & 63 & $<2.58 \mathrm{E}-17$ & $2.99 \mathrm{E}-17$ & $<2.49 \mathrm{E}-17$ & $<2.54 \mathrm{E}-17$ & $2.12 \mathrm{E}-16$ & $4.83 \mathrm{E}-16$ \\
\hline 14 & 77 & $<3.22 \mathrm{E}-17$ & $<3.25 \mathrm{E}-17$ & $<3.11 \mathrm{E}-17$ & $<3.17 \mathrm{E}-17$ & $1.82 \mathrm{E}-16$ & $2.64 \mathrm{E}-16$ \\
\hline 14 & 91 & $<3.86 \mathrm{E}-17$ & $<3.89 \mathrm{E}-17$ & $<3.73 \mathrm{E}-17$ & $<3.80 \mathrm{E}-17$ & $8.98 \mathrm{E}-17$ & $2.91 \mathrm{E}-16$ \\
\hline
\end{tabular}

\begin{tabular}{|c|c|c|c|c|c|c|c||}
\hline \multirow{2}{*}{$\begin{array}{c}\text { Interval } \\
\text { (days) }\end{array}$} & \multirow{2}{*}{$\begin{array}{c}\text { Total } \\
\text { Duration } \\
\text { (days) }\end{array}$} & \multicolumn{6}{|c||}{ Uranium Effective Diffusion Coefficient $\left(\mathbf{c m}^{2} / \mathbf{s}\right)$} \\
\cline { 3 - 8 } & $\mathbf{2 4 a}$ & $\mathbf{2 4 b}$ & $\mathbf{2 5 a}$ & $\mathbf{2 5 b}$ & $\mathbf{2 6 a}$ & $\mathbf{2 6 b}$ \\
\hline 0.08 & 0.08 & $1.84 \mathrm{E}-15$ & $2.41 \mathrm{E}-15$ & $9.83 \mathrm{E}-16$ & $1.04 \mathrm{E}-15$ & $9.47 \mathrm{E}-16$ & $1.23 \mathrm{E}-15$ \\
\hline 0.92 & 1 & $1.58 \mathrm{E}-16$ & $1.80 \mathrm{E}-16$ & $6.21 \mathrm{E}-17$ & $6.94 \mathrm{E}-17$ & $4.90 \mathrm{E}-17$ & $4.08 \mathrm{E}-17$ \\
\hline 1 & 2 & $<1.39 \mathrm{E}-16$ & $<1.43 \mathrm{E}-16$ & $<7.47 \mathrm{E}-17$ & $<7.55 \mathrm{E}-17$ & $7.27 \mathrm{E}-17$ & $<5.78 \mathrm{E}-17$ \\
\hline 5 & 7 & $3.79 \mathrm{E}-17$ & $<3.65 \mathrm{E}-17$ & $<1.90 \mathrm{E}-17$ & $<1.93 \mathrm{E}-17$ & $<1.48 \mathrm{E}-17$ & $<1.47 \mathrm{E}-17$ \\
\hline 7 & 14 & $<4.45 \mathrm{E}-17$ & $<4.58 \mathrm{E}-17$ & $<2.39 \mathrm{E}-17$ & $2.54 \mathrm{E}-17$ & $<1.86 \mathrm{E}-17$ & $<1.85 \mathrm{E}-17$ \\
\hline 14 & 28 & $<2.53 \mathrm{E}-17$ & $<2.71 \mathrm{E}-17$ & $<1.20 \mathrm{E}-17$ & $1.63 \mathrm{E}-17$ & $<9.36 \mathrm{E}-18$ & $<9.29 \mathrm{E}-18$ \\
\hline 14 & 42 & $<3.79 \mathrm{E}-17$ & $<3.90 \mathrm{E}-17$ & $<2.04 \mathrm{E}-17$ & $<2.06 \mathrm{E}-17$ & $<1.59 \mathrm{E}-17$ & $<1.58 \mathrm{E}-17$ \\
\hline 7 & 49 & $<1.99 \mathrm{E}-16$ & $<2.05 \mathrm{E}-16$ & $<1.07 \mathrm{E}-16$ & $<1.08 \mathrm{E}-16$ & $<8.34 \mathrm{E}-17$ & $<8.28 \mathrm{E}-17$ \\
\hline 14 & 63 & $<6.11 \mathrm{E}-17$ & $<6.29 \mathrm{E}-17$ & $<3.29 \mathrm{E}-17$ & $<3.32 \mathrm{E}-17$ & $<2.56 \mathrm{E}-17$ & $<2.54 \mathrm{E}-17$ \\
\hline 14 & 77 & $<7.64 \mathrm{E}-17$ & $<7.86 \mathrm{E}-17$ & $<4.10 \mathrm{E}-17$ & $<4.15 \mathrm{E}-17$ & $<3.20 \mathrm{E}-17$ & $<3.17 \mathrm{E}-17$ \\
\hline 14 & 91 & $<9.16 \mathrm{E}-17$ & $<9.43 \mathrm{E}-17$ & $<4.92 \mathrm{E}-17$ & $<4.98 \mathrm{E}-17$ & $<3.83 \mathrm{E}-17$ & $<3.81 \mathrm{E}-17$ \\
\hline
\end{tabular}


Table D-14. Duplicate Values, Means, and Standard Deviations of Effective Diffusion Coefficients from EPA Draft Method 1315 Leach Tests Averaged Over the 28-, 42-, 49-, and 63-Day Results ${ }^{(a)}$

\begin{tabular}{|c|c|c|c|c|c|c|c|c|c|c|c|c|c|}
\hline \multirow{2}{*}{$\begin{array}{c}\text { Test/ } \\
\text { Mix } \\
\#^{(\mathbf{b})}\end{array}$} & \multirow{2}{*}{$\begin{array}{c}\text { Random } \\
\text { Run } \\
\text { Order }\end{array}$} & \multicolumn{4}{|c|}{ Na Effective Diffusion Coefficient $\left(\mathrm{cm}^{2} / \mathrm{s}\right)$} & \multicolumn{4}{|c|}{$\mathrm{NO}_{3}$ Effective Diffusion Coefficient $\left(\mathrm{cm}^{2} / \mathrm{s}\right)$} & \multicolumn{4}{|c|}{$\mathrm{NO}_{2}$ Effective Diffusion Coefficient $\left(\mathrm{cm}^{2} / \mathrm{s}\right)$} \\
\hline & & $\begin{array}{c}\text { Duplicate } \\
\# 1\end{array}$ & $\begin{array}{c}\text { Duplicate } \\
\# 2\end{array}$ & Mean & $\mathbf{S D}^{(\mathbf{c})}$ & $\begin{array}{c}\text { Duplicate } \\
\# 1\end{array}$ & $\begin{array}{c}\text { Duplicate } \\
\# 2\end{array}$ & Mean & $\mathbf{S D}^{(\mathbf{c})}$ & $\begin{array}{c}\text { Duplicate } \\
\# 1\end{array}$ & $\begin{array}{c}\text { Duplicate } \\
\# 2\end{array}$ & Mean & $\mathbf{S D}^{(\mathrm{c})}$ \\
\hline 1 & 7 & $1.20 \mathrm{E}-09$ & $1.22 \mathrm{E}-09$ & $1.21 \mathrm{E}-09$ & $1.41 \mathrm{E}-11$ & $8.46 \mathrm{E}-10$ & $8.94 \mathrm{E}-10$ & $8.70 \mathrm{E}-10$ & $3.39 \mathrm{E}-11$ & $9.96 \mathrm{E}-10$ & $1.04 \mathrm{E}-09$ & $1.02 \mathrm{E}-09$ & $3.11 \mathrm{E}-11$ \\
\hline $2 @$ & 11 & $6.00 \mathrm{E}-09$ & 7.84E-09 & $6.92 \mathrm{E}-09$ & $1.30 \mathrm{E}-09$ & $6.66 \mathrm{E}-09$ & $6.65 \mathrm{E}-09$ & $6.65 \mathrm{E}-09$ & $7.07 \mathrm{E}-12$ & 7.61E-09 & 7.38E-09 & $7.50 \mathrm{E}-09$ & $1.63 \mathrm{E}-10$ \\
\hline $3 \$$ & 3 & $4.67 \mathrm{E}-09$ & 5.32E-09 & 4.99E-09 & $4.60 \mathrm{E}-10$ & $4.57 \mathrm{E}-09$ & $4.63 \mathrm{E}-09$ & $4.60 \mathrm{E}-09$ & $4.24 \mathrm{E}-11$ & $5.48 \mathrm{E}-09$ & $5.39 \mathrm{E}-09$ & $5.44 \mathrm{E}-09$ & $6.36 \mathrm{E}-11$ \\
\hline 4 & 5 & $1.07 \mathrm{E}-08$ & 7.67E-09 & $9.18 \mathrm{E}-09$ & $2.14 \mathrm{E}-09$ & $5.59 \mathrm{E}-09$ & $5.46 \mathrm{E}-09$ & $5.52 \mathrm{E}-09$ & $9.19 \mathrm{E}-11$ & $6.35 \mathrm{E}-09$ & $6.02 \mathrm{E}-09$ & $6.19 \mathrm{E}-09$ & $2.33 \mathrm{E}-10$ \\
\hline 5 & 9 & 4.77E-09 & $6.35 \mathrm{E}-09$ & 5.56E-09 & $1.12 \mathrm{E}-09$ & $6.37 \mathrm{E}-09$ & $6.52 \mathrm{E}-09$ & $6.45 \mathrm{E}-09$ & $1.06 \mathrm{E}-10$ & $6.20 \mathrm{E}-09$ & 6.24E-09 & $6.22 \mathrm{E}-09$ & $2.83 \mathrm{E}-11$ \\
\hline 6 & 12 & $6.32 \mathrm{E}-09$ & $6.67 \mathrm{E}-09$ & 6.49E-09 & $2.47 \mathrm{E}-10$ & $9.53 \mathrm{E}-09$ & $1.00 \mathrm{E}-08$ & $9.77 \mathrm{E}-09$ & $3.32 \mathrm{E}-10$ & $9.66 \mathrm{E}-09$ & $1.01 \mathrm{E}-08$ & $9.88 \mathrm{E}-09$ & $3.11 \mathrm{E}-10$ \\
\hline $7 \#$ & 14 & $3.26 \mathrm{E}-09$ & $3.77 \mathrm{E}-09$ & $3.52 \mathrm{E}-09$ & $3.61 \mathrm{E}-10$ & $4.23 \mathrm{E}-09$ & $5.22 \mathrm{E}-09$ & 4.72E-09 & $7.00 \mathrm{E}-10$ & $4.22 \mathrm{E}-09$ & $5.14 \mathrm{E}-09$ & $4.68 \mathrm{E}-09$ & $6.51 \mathrm{E}-10$ \\
\hline 8 & 1 & $2.45 \mathrm{E}-09$ & $2.36 \mathrm{E}-09$ & $2.40 \mathrm{E}-09$ & $6.36 \mathrm{E}-11$ & $2.75 \mathrm{E}-09$ & $2.45 \mathrm{E}-09$ & $2.60 \mathrm{E}-09$ & $2.12 \mathrm{E}-10$ & $2.58 \mathrm{E}-09$ & $2.29 \mathrm{E}-09$ & $2.44 \mathrm{E}-09$ & $2.05 \mathrm{E}-10$ \\
\hline 9 & 10 & $4.65 \mathrm{E}-09$ & 4.61E-09 & 4.63E-09 & $2.83 \mathrm{E}-11$ & $4.12 \mathrm{E}-09$ & $4.07 \mathrm{E}-09$ & 4.09E-09 & $3.54 \mathrm{E}-11$ & $5.18 \mathrm{E}-09$ & 4.94E-09 & $5.06 \mathrm{E}-09$ & $1.70 \mathrm{E}-10$ \\
\hline 10 & 13 & 7.39E-09 & 7.66E-09 & $7.52 \mathrm{E}-09$ & $1.91 \mathrm{E}-10$ & $6.22 \mathrm{E}-09$ & $5.95 \mathrm{E}-09$ & $6.08 \mathrm{E}-09$ & $1.91 \mathrm{E}-10$ & $5.67 \mathrm{E}-09$ & $5.45 \mathrm{E}-09$ & $5.56 \mathrm{E}-09$ & $1.56 \mathrm{E}-10$ \\
\hline 11 & 6 & $6.10 \mathrm{E}-09$ & $6.23 \mathrm{E}-09$ & 6.17E-09 & $9.19 \mathrm{E}-11$ & 8.32E-09 & 8.87E-09 & 8.59E-09 & 3.89E-10 & $9.37 \mathrm{E}-09$ & $1.00 \mathrm{E}-08$ & 9.69E-09 & $4.45 \mathrm{E}-10$ \\
\hline 12 & 8 & 4.10E-09 & 3.92E-09 & 4.01E-09 & $1.27 \mathrm{E}-10$ & $3.95 \mathrm{E}-09$ & $3.93 \mathrm{E}-09$ & 3.94E-09 & $1.41 \mathrm{E}-11$ & 3.63E-09 & 3.59E-09 & $3.61 \mathrm{E}-09$ & $2.83 \mathrm{E}-11$ \\
\hline $13 @$ & 4 & $6.56 \mathrm{E}-09$ & $6.32 \mathrm{E}-09$ & 6.44E-09 & $1.70 \mathrm{E}-10$ & $9.19 \mathrm{E}-09$ & $8.31 \mathrm{E}-09$ & $8.75 \mathrm{E}-09$ & $6.22 \mathrm{E}-10$ & $7.87 \mathrm{E}-09$ & $7.07 \mathrm{E}-09$ & $7.47 \mathrm{E}-09$ & $5.66 \mathrm{E}-10$ \\
\hline 14 \# & 2 & 4.39E-09 & & 4.44E-09 & & $6.32 \mathrm{E}-09$ & & & & 5.98E-09 & & 5.93E-09 & \\
\hline $15 \%$ & 17 & $7.76 \mathrm{E}-09$ & $6.90 \mathrm{E}-09$ & 7.33E-09 & $6.08 \mathrm{E}-10$ & $7.28 \mathrm{E}-09$ & $6.74 \mathrm{E}-09$ & 7.01E-09 & $3.82 \mathrm{E}-10$ & $7.66 \mathrm{E}-09$ & $6.68 \mathrm{E}-09$ & 7.17E-09 & $6.93 \mathrm{E}-10$ \\
\hline 16 & 22 & $6.90 \mathrm{E}-09$ & 7.29E-09 & $7.10 \mathrm{E}-09$ & $2.76 \mathrm{E}-10$ & 7.89E-09 & $8.26 \mathrm{E}-09$ & $8.07 \mathrm{E}-09$ & $2.62 \mathrm{E}-10$ & $7.26 \mathrm{E}-09$ & 7.53E-09 & 7.40E-09 & $1.91 \mathrm{E}-10$ \\
\hline 17 & 25 & $6.65 \mathrm{E}-09$ & $6.69 \mathrm{E}-09$ & $6.67 \mathrm{E}-09$ & $2.83 \mathrm{E}-11$ & $7.41 \mathrm{E}-09$ & 8.01E-09 & $7.71 \mathrm{E}-09$ & $4.24 \mathrm{E}-10$ & $7.26 \mathrm{E}-09$ & $7.47 \mathrm{E}-09$ & 7.37E-09 & $1.48 \mathrm{E}-10$ \\
\hline 18 & 16 & 2.82E-09 & $2.86 \mathrm{E}-09$ & 2.84E-09 & $2.83 \mathrm{E}-11$ & $3.24 \mathrm{E}-09$ & 3.39E-09 & 3.32E-09 & $1.06 \mathrm{E}-10$ & 2.84E-09 & 3.03E-09 & 2.94E-09 & $1.34 \mathrm{E}-10$ \\
\hline 19 & 15 & $3.51 \mathrm{E}-09$ & $3.40 \mathrm{E}-09$ & $3.46 \mathrm{E}-09$ & $7.78 \mathrm{E}-11$ & $4.80 \mathrm{E}-09$ & 4.77E-09 & $4.78 \mathrm{E}-09$ & $2.12 \mathrm{E}-11$ & 5.34E-09 & 5.19E-09 & $5.26 \mathrm{E}-09$ & $1.06 \mathrm{E}-10$ \\
\hline 20 & 24 & $9.51 \mathrm{E}-09$ & $6.55 \mathrm{E}-09$ & 8.03E-09 & $2.09 \mathrm{E}-09$ & $6.95 \mathrm{E}-09$ & $5.18 \mathrm{E}-09$ & $6.07 \mathrm{E}-09$ & $1.25 \mathrm{E}-09$ & 6.49E-09 & 4.99E-09 & 5.74E-09 & $1.06 \mathrm{E}-09$ \\
\hline $21 \&$ & 23 & $1.05 \mathrm{E}-08$ & 1.04E-08 & $1.05 \mathrm{E}-08$ & $7.07 \mathrm{E}-11$ & $1.56 \mathrm{E}-08$ & $1.47 \mathrm{E}-08$ & $1.52 \mathrm{E}-08$ & $6.36 \mathrm{E}-10$ & $1.42 \mathrm{E}-08$ & $1.34 \mathrm{E}-08$ & $1.38 \mathrm{E}-08$ & $5.66 \mathrm{E}-10$ \\
\hline $22 \$$ & 19 & 4.80E-09 & 4.89E-09 & 4.84E-09 & $6.36 \mathrm{E}-11$ & 4.39E-09 & 4.24E-09 & $4.32 \mathrm{E}-09$ & $1.06 \mathrm{E}-10$ & 4.20E-09 & $4.08 \mathrm{E}-09$ & 4.14E-09 & $8.49 \mathrm{E}-11$ \\
\hline 23 & 20 & $2.45 \mathrm{E}-08$ & 2.71E-08 & $2.58 \mathrm{E}-08$ & $1.84 \mathrm{E}-09$ & 3.53E-08 & 3.91E-08 & 3.72E-08 & 2.69E-09 & $2.47 \mathrm{E}-08$ & $2.80 \mathrm{E}-08$ & 2.64E-08 & $2.33 \mathrm{E}-09$ \\
\hline 24 & 26 & 9.96E-09 & $9.68 \mathrm{E}-09$ & 9.82E-09 & $1.98 \mathrm{E}-10$ & $9.59 \mathrm{E}-09$ & $9.70 \mathrm{E}-09$ & $9.64 \mathrm{E}-09$ & $7.78 \mathrm{E}-11$ & 7.94E-09 & $8.03 \mathrm{E}-09$ & 7.99E-09 & $6.36 \mathrm{E}-11$ \\
\hline $25 \%$ & 21 & $7.00 \mathrm{E}-09$ & $6.73 \mathrm{E}-09$ & $6.86 \mathrm{E}-09$ & $1.91 \mathrm{E}-10$ & $7.22 \mathrm{E}-09$ & $6.76 \mathrm{E}-09$ & $6.99 \mathrm{E}-09$ & $3.25 \mathrm{E}-10$ & $5.94 \mathrm{E}-09$ & $5.66 \mathrm{E}-09$ & $5.80 \mathrm{E}-09$ & $1.98 \mathrm{E}-10$ \\
\hline $26 \&$ & 18 & 7.97E-09 & $8.18 \mathrm{E}-09$ & $8.07 \mathrm{E}-09$ & $1.48 \mathrm{E}-10$ & 8.02E-09 & 7.69E-09 & 7.85E-09 & $2.33 \mathrm{E}-10$ & 7.21E-09 & 6.97E-09 & 7.09E-09 & $1.70 \mathrm{E}-10$ \\
\hline \multicolumn{14}{|c|}{$\begin{array}{l}\text { (a) The duplicate diffusion coefficients for each test were rounded to two decimal places in scientific notation before calculating the mean and SD. After the } \\
\text { mean and SD were calculated, they were rounded to two decimal places in scientific notation. }\end{array}$} \\
\hline
\end{tabular}


Table D-14. Duplicate Values, Means, and Standard Deviations of Effective Diffusion Coefficients from EPA Draft Method 1315 Leach Tests Averaged Over the 28-, 42-, 49-, and 63-Day Results (contd) ${ }^{\text {(a) }}$

\begin{tabular}{|c|c|c|c|c|c|c|c|c|c|c|c|c|c|}
\hline \multirow{2}{*}{$\begin{array}{c}\text { Test/ } \\
\text { Mix } \\
\#^{(\mathbf{b})}\end{array}$} & \multirow{2}{*}{$\begin{array}{c}\text { Random } \\
\text { Run } \\
\text { Order }\end{array}$} & \multicolumn{4}{|c|}{ I Effective Diffusion Coefficient $\left(\mathrm{cm}^{2} / \mathrm{s}\right)$} & \multicolumn{4}{|c|}{ Tc Effective Diffusion Coefficient $\left(\mathrm{cm}^{2} / \mathrm{s}\right)$} & \multicolumn{4}{|c|}{ Cr Effective Diffusion Coefficient $\left(\mathrm{cm}^{2} / \mathrm{s}\right)$} \\
\hline & & $\begin{array}{c}\text { Duplicate } \\
\# 1\end{array}$ & \begin{tabular}{|c|} 
Duplicate \\
$\# 2$
\end{tabular} & Mean & $\mathbf{S D}^{(\mathbf{c})}$ & $\begin{array}{c}\text { Duplicate } \\
\# 1\end{array}$ & \begin{tabular}{|c|} 
Duplicate \\
$\# 2$
\end{tabular} & Mean & $\mathbf{S D}^{(\mathrm{c})}$ & $\begin{array}{c}\text { Duplicate } \\
\# 1\end{array}$ & $\begin{array}{c}\text { Duplicate } \\
\# 2\end{array}$ & Mean & $\mathbf{S D}^{(\mathbf{c})}$ \\
\hline 1 & 7 & $6.93 \mathrm{E}-10$ & $6.92 \mathrm{E}-10$ & $6.93 \mathrm{E}-10$ & 7.07E-13 & 4.75E-11 & $4.55 \mathrm{E}-11$ & $4.65 \mathrm{E}-11$ & $1.41 \mathrm{E}-12$ & $1.97 \mathrm{E}-13$ & $1.77 \mathrm{E}-13$ & $1.87 \mathrm{E}-13$ & $1.41 \mathrm{E}-14$ \\
\hline $2 @$ & 11 & 7.14E-09 & 6.89E-09 & 7.02E-09 & $1.77 \mathrm{E}-10$ & $6.69 \mathrm{E}-11$ & $5.29 \mathrm{E}-11$ & 5.99E-11 & $9.90 \mathrm{E}-12$ & $8.30 \mathrm{E}-14$ & $8.14 \mathrm{E}-14$ & $8.22 \mathrm{E}-14$ & $1.13 \mathrm{E}-15$ \\
\hline $3 \$$ & 3 & 4.94E-09 & 5.03E-09 & 4.98E-09 & $6.36 \mathrm{E}-11$ & $3.46 \mathrm{E}-11$ & $3.47 \mathrm{E}-11$ & $3.47 \mathrm{E}-11$ & $7.07 \mathrm{E}-14$ & $1.66 \mathrm{E}-13$ & $1.62 \mathrm{E}-13$ & $1.64 \mathrm{E}-13$ & $2.83 \mathrm{E}-15$ \\
\hline 4 & 5 & $3.90 \mathrm{E}-09$ & $3.95 \mathrm{E}-09$ & $3.93 \mathrm{E}-09$ & $3.54 \mathrm{E}-11$ & $2.54 \mathrm{E}-11$ & $3.11 \mathrm{E}-11$ & $2.82 \mathrm{E}-11$ & $4.03 \mathrm{E}-12$ & $5.99 \mathrm{E}-14$ & $6.58 \mathrm{E}-14$ & $6.29 \mathrm{E}-14$ & $4.17 \mathrm{E}-15$ \\
\hline 5 & 9 & $5.22 \mathrm{E}-09$ & $5.36 \mathrm{E}-09$ & $5.29 \mathrm{E}-09$ & $9.90 \mathrm{E}-11$ & $7.11 \mathrm{E}-11$ & $7.18 \mathrm{E}-11$ & $7.14 \mathrm{E}-11$ & $4.95 \mathrm{E}-13$ & $7.73 \mathrm{E}-14$ & $8.33 \mathrm{E}-14$ & $8.03 \mathrm{E}-14$ & $4.24 \mathrm{E}-15$ \\
\hline 6 & 12 & 9.94E-09 & $1.03 \mathrm{E}-08$ & $1.01 \mathrm{E}-08$ & $2.55 \mathrm{E}-10$ & $1.54 \mathrm{E}-10$ & $1.50 \mathrm{E}-10$ & $1.52 \mathrm{E}-10$ & $2.83 \mathrm{E}-12$ & $1.66 \mathrm{E}-13$ & $1.40 \mathrm{E}-13$ & & $1.84 \mathrm{E}-14$ \\
\hline $7 \#$ & 14 & 3.93E-09 & $4.56 \mathrm{E}-09$ & $4.25 \mathrm{E}-09$ & $4.45 \mathrm{E}-10$ & $8.97 \mathrm{E}-12$ & $9.16 \mathrm{E}-12$ & $9.06 \mathrm{E}-12$ & $1.34 \mathrm{E}-13$ & $7.95 \mathrm{E}-15$ & $8.62 \mathrm{E}-15$ & $8.28 \mathrm{E}-15$ & $4.74 \mathrm{E}-16$ \\
\hline 8 & 1 & $2.63 \mathrm{E}-09$ & $2.47 \mathrm{E}-09$ & $2.55 \mathrm{E}-09$ & $1.13 \mathrm{E}-10$ & $2.22 \mathrm{E}-10$ & $2.09 \mathrm{E}-10$ & $2.16 \mathrm{E}-10$ & $9.19 \mathrm{E}-12$ & $6.59 \mathrm{E}-13$ & $7.70 \mathrm{E}-13$ & $7.15 \mathrm{E}-13$ & $7.85 \mathrm{E}-14$ \\
\hline 9 & 10 & $5.20 \mathrm{E}-09$ & $5.18 \mathrm{E}-09$ & $5.19 \mathrm{E}-09$ & $1.41 \mathrm{E}-11$ & $3.56 \mathrm{E}-11$ & $3.38 \mathrm{E}-11$ & & $1.27 \mathrm{E}-12$ & $1.42 \mathrm{E}-13$ & $1.77 \mathrm{E}-13$ & & $2.47 \mathrm{E}-14$ \\
\hline 10 & 13 & $4.45 \mathrm{E}-09$ & $4.41 \mathrm{E}-09$ & $4.43 \mathrm{E}-09$ & $2.83 \mathrm{E}-11$ & $1.21 \mathrm{E}-10$ & $1.24 \mathrm{E}-10$ & $1.22 \mathrm{E}-10$ & $2.12 \mathrm{E}-12$ & $3.66 \mathrm{E}-13$ & $1.03 \mathrm{E}-12$ & $6.98 \mathrm{E}-13$ & $4.70 \mathrm{E}-13$ \\
\hline 11 & 6 & $1.17 \mathrm{E}-08$ & $1.26 \mathrm{E}-08$ & $1.22 \mathrm{E}-08$ & $6.36 \mathrm{E}-10$ & $1.30 \mathrm{E}-10$ & $1.30 \mathrm{E}-10$ & & $0.00 \mathrm{E}+00$ & $1.36 \mathrm{E}-13$ & $1.33 \mathrm{E}-13$ & & $2.12 \mathrm{E}-15$ \\
\hline 12 & 8 & 2.70E-09 & 2.74E-09 & 2.72E-09 & $2.83 \mathrm{E}-11$ & $4.15 \mathrm{E}-11$ & $4.25 \mathrm{E}-11$ & $4.20 \mathrm{E}-11$ & $7.07 \mathrm{E}-13$ & $1.64 \mathrm{E}-13$ & $2.41 \mathrm{E}-13$ & $2.03 \mathrm{E}-13$ & $5.44 \mathrm{E}-14$ \\
\hline $13 @$ & 4 & 8.72E-09 & 8.24E-09 & 8.48E-09 & $3.39 \mathrm{E}-10$ & $8.96 \mathrm{E}-11$ & $7.59 \mathrm{E}-11$ & $8.27 \mathrm{E}-11$ & $9.69 \mathrm{E}-12$ & $5.64 \mathrm{E}-14$ & $5.37 \mathrm{E}-14$ & $5.51 \mathrm{E}-14$ & $1.91 \mathrm{E}-15$ \\
\hline $14 \#$ & 2 & $5.66 \mathrm{E}-09$ & $5.74 \mathrm{E}-09$ & $5.70 \mathrm{E}-09$ & $5.66 \mathrm{E}-11$ & $8.11 \mathrm{E}-12$ & $1.11 \mathrm{E}-11$ & $9.61 \mathrm{E}-12$ & $2.11 \mathrm{E}-12$ & $1.00 \mathrm{E}-14$ & $9.79 \mathrm{E}-15$ & $9.90 \mathrm{E}-15$ & $1.48 \mathrm{E}-16$ \\
\hline $15 \%$ & 17 & $6.05 \mathrm{E}-09$ & 5.29E-09 & $5.67 \mathrm{E}-09$ & $5.37 \mathrm{E}-10$ & $4.51 \mathrm{E}-11$ & $4.72 \mathrm{E}-11$ & $4.62 \mathrm{E}-11$ & $1.48 \mathrm{E}-12$ & $3.59 \mathrm{E}-13$ & $2.72 \mathrm{E}-13$ & $3.16 \mathrm{E}-13$ & $6.15 \mathrm{E}-14$ \\
\hline 16 & 22 & 7.63E-09 & $8.15 \mathrm{E}-09$ & 7.89E-09 & $3.68 \mathrm{E}-10$ & $1.54 \mathrm{E}-10$ & $1.61 \mathrm{E}-10$ & $1.58 \mathrm{E}-10$ & $4.95 \mathrm{E}-12$ & $2.34 \mathrm{E}-13$ & $2.57 \mathrm{E}-13$ & $2.46 \mathrm{E}-13$ & $1.63 \mathrm{E}-14$ \\
\hline 17 & 25 & $7.46 \mathrm{E}-09$ & 7.71E-09 & 7.58E-09 & $1.77 \mathrm{E}-10$ & $1.81 \mathrm{E}-10$ & $1.71 \mathrm{E}-10$ & $1.76 \mathrm{E}-10$ & $7.07 \mathrm{E}-12$ & $1.76 \mathrm{E}-13$ & $1.55 \mathrm{E}-13$ & $1.66 \mathrm{E}-13$ & $1.48 \mathrm{E}-14$ \\
\hline 18 & 16 & $3.07 \mathrm{E}-09$ & $3.21 \mathrm{E}-09$ & $3.14 \mathrm{E}-09$ & $9.90 \mathrm{E}-11$ & $5.57 \mathrm{E}-12$ & $5.77 \mathrm{E}-12$ & $5.67 \mathrm{E}-12$ & $1.41 \mathrm{E}-13$ & $1.81 \mathrm{E}-14$ & $1.86 \mathrm{E}-14$ & $1.83 \mathrm{E}-14$ & $3.54 \mathrm{E}-16$ \\
\hline 19 & 15 & $5.45 \mathrm{E}-09$ & $5.49 \mathrm{E}-09$ & $5.47 \mathrm{E}-09$ & $2.83 \mathrm{E}-11$ & $4.70 \mathrm{E}-11$ & $4.43 \mathrm{E}-11$ & $4.56 \mathrm{E}-11$ & $1.91 \mathrm{E}-12$ & $5.58 \mathrm{E}-14$ & $6.07 \mathrm{E}-14$ & $5.83 \mathrm{E}-14$ & $3.46 \mathrm{E}-15$ \\
\hline 20 & 24 & 4.50E-09 & $3.12 \mathrm{E}-09$ & 3.81E-09 & $9.76 \mathrm{E}-10$ & $4.12 \mathrm{E}-11$ & $3.43 \mathrm{E}-11$ & $3.77 \mathrm{E}-11$ & $4.88 \mathrm{E}-12$ & $8.00 \mathrm{E}-14$ & $7.14 \mathrm{E}-14$ & $7.57 \mathrm{E}-14$ & $6.08 \mathrm{E}-15$ \\
\hline $21 \&$ & 23 & $1.68 \mathrm{E}-08$ & $1.68 \mathrm{E}-08$ & $1.68 \mathrm{E}-08$ & $0.00 \mathrm{E}+00$ & $7.48 \mathrm{E}-11$ & $1.14 \mathrm{E}-10$ & $9.44 \mathrm{E}-11$ & $2.77 \mathrm{E}-11$ & $1.45 \mathrm{E}-13$ & $1.57 \mathrm{E}-13$ & $1.51 \mathrm{E}-13$ & $8.49 \mathrm{E}-15$ \\
\hline $22 \$$ & 19 & $4.43 \mathrm{E}-09$ & 4.41E-09 & $4.42 \mathrm{E}-09$ & $1.41 \mathrm{E}-11$ & $2.18 \mathrm{E}-11$ & $2.79 \mathrm{E}-11$ & $2.48 \mathrm{E}-11$ & $4.31 \mathrm{E}-12$ & $1.93 \mathrm{E}-13$ & $1.65 \mathrm{E}-13$ & $1.79 \mathrm{E}-13$ & $1.98 \mathrm{E}-14$ \\
\hline 23 & 20 & $3.18 \mathrm{E}-08$ & $3.79 \mathrm{E}-08$ & $3.48 \mathrm{E}-08$ & $4.31 \mathrm{E}-09$ & $1.23 \mathrm{E}-09$ & $7.94 \mathrm{E}-10$ & $1.01 \mathrm{E}-09$ & $3.08 \mathrm{E}-10$ & $1.24 \mathrm{E}-12$ & $1.08 \mathrm{E}-12$ & $1.16 \mathrm{E}-12$ & $1.13 \mathrm{E}-13$ \\
\hline 24 & 26 & $8.24 \mathrm{E}-09$ & 8.07E-09 & $8.15 \mathrm{E}-09$ & $1.20 \mathrm{E}-10$ & $6.68 \mathrm{E}-11$ & $6.41 \mathrm{E}-11$ & $6.55 \mathrm{E}-11$ & $1.91 \mathrm{E}-12$ & $1.16 \mathrm{E}-13$ & $7.26 \mathrm{E}-14$ & $9.43 \mathrm{E}-14$ & $3.07 \mathrm{E}-14$ \\
\hline $25 \%$ & 21 & $4.96 \mathrm{E}-09$ & 4.78E-09 & $4.87 \mathrm{E}-09$ & $1.27 \mathrm{E}-10$ & $3.37 \mathrm{E}-11$ & $2.40 \mathrm{E}-11$ & $2.88 \mathrm{E}-11$ & $6.86 \mathrm{E}-12$ & $3.32 \mathrm{E}-13$ & $4.71 \mathrm{E}-13$ & $4.02 \mathrm{E}-13$ & $9.83 \mathrm{E}-14$ \\
\hline $26 \&$ & 18 & 7.27E-09 & 7.32E-09 & $7.30 \mathrm{E}-09$ & $3.54 \mathrm{E}-11$ & $1.76 \mathrm{E}-10$ & $1.56 \mathrm{E}-10$ & $1.66 \mathrm{E}-10$ & $1.41 \mathrm{E}-11$ & $1.04 \mathrm{E}-13$ & $9.92 \mathrm{E}-14$ & $1.02 \mathrm{E}-13$ & $3.39 \mathrm{E}-15$ \\
\hline \multicolumn{14}{|c|}{$\begin{array}{l}\text { (a) The duplicate diffusion coefficients for each test were rounded to two decimal places in scientific notation before calculating the mean and SD. After the } \\
\text { mean and SD were calculated, they were rounded to two decimal places in scientific notation. } \\
\text { (b) Test numbers with the same symbols are replicates. } \\
\text { (c) The SD of duplicate results represents the variation in results of making duplicate samples from each test/mix, then testing them and averaging results over } \\
\text { the } 28-, 42-, 49-\text {, and } 63 \text {-day periods. This "Duplicate or Repeat SD" is distinct from "Replicate SD," which takes into account variations in making the } \\
\text { mixes and testing with different beginning dates over the period of the screening matrix testing. See Section } 8.5 \text { for discussion of replicate variation. }\end{array}$} \\
\hline
\end{tabular}


Table D-14. Duplicate Values, Means, and Standard Deviations of Effective Diffusion Coefficients from EPA Draft Method 1315 Leach Tests Averaged Over the 28-, 42-, 49-, and 63-Day Results (contd) ${ }^{\text {(a) }}$

\begin{tabular}{|c|c|c|c|c|c|}
\hline \multirow[b]{2}{*}{ Test/Mix $\#^{(\mathbf{b})}$} & \multirow{2}{*}{$\begin{array}{c}\text { Random Run } \\
\text { Order }\end{array}$} & \multicolumn{4}{|c|}{ U Effective Diffusion Coefficient $\left(\mathrm{cm}^{2} / \mathrm{s}\right)$} \\
\hline & & Duplicate \#1 & Duplicate \#2 & Mean & $\mathbf{S D}^{(\mathbf{c})}$ \\
\hline 1 & 7 & $2.90 \mathrm{E}-16$ & $3.28 \mathrm{E}-16$ & $3.09 \mathrm{E}-16$ & $2.69 \mathrm{E}-17$ \\
\hline $2 @$ & 11 & $1.05 \mathrm{E}-16$ & 9.93E-17 & $1.02 \mathrm{E}-16$ & $4.03 \mathrm{E}-18$ \\
\hline $3 \$$ & 3 & $3.33 \mathrm{E}-17$ & $3.43 \mathrm{E}-17$ & $3.38 \mathrm{E}-17$ & $7.07 \mathrm{E}-19$ \\
\hline 4 & 5 & $1.11 \mathrm{E}-16$ & $1.12 \mathrm{E}-16$ & $1.11 \mathrm{E}-16$ & 7.07E-19 \\
\hline 5 & 9 & $4.16 \mathrm{E}-17$ & $4.17 \mathrm{E}-17$ & $4.16 \mathrm{E}-17$ & $7.07 \mathrm{E}-20$ \\
\hline 6 & 12 & $7.20 \mathrm{E}-17$ & $4.64 \mathrm{E}-17$ & $5.92 \mathrm{E}-17$ & $1.81 \mathrm{E}-17$ \\
\hline $7 \#$ & 14 & $4.30 \mathrm{E}-17$ & $4.46 \mathrm{E}-17$ & $4.38 \mathrm{E}-17$ & $1.13 \mathrm{E}-18$ \\
\hline 8 & 1 & $5.10 \mathrm{E}-16$ & $4.53 \mathrm{E}-16$ & $4.82 \mathrm{E}-16$ & $4.03 \mathrm{E}-17$ \\
\hline 9 & 10 & $3.21 \mathrm{E}-17$ & $3.16 \mathrm{E}-17$ & $3.19 \mathrm{E}-17$ & $3.54 \mathrm{E}-19$ \\
\hline 10 & 13 & $8.43 \mathrm{E}-17$ & $9.00 \mathrm{E}-17$ & $8.71 \mathrm{E}-17$ & $4.03 \mathrm{E}-18$ \\
\hline 11 & 6 & $3.48 \mathrm{E}-17$ & $3.42 \mathrm{E}-17$ & $3.45 \mathrm{E}-17$ & 4.24E-19 \\
\hline 12 & 8 & $7.75 \mathrm{E}-17$ & $3.05 \mathrm{E}-16$ & $1.91 \mathrm{E}-16$ & $1.61 \mathrm{E}-16$ \\
\hline $13 @$ & 4 & $1.03 \mathrm{E}-16$ & $1.02 \mathrm{E}-16$ & $1.03 \mathrm{E}-16$ & $7.07 \mathrm{E}-19$ \\
\hline $14 \#$ & 2 & $4.38 \mathrm{E}-17$ & $4.36 \mathrm{E}-17$ & $4.37 \mathrm{E}-17$ & $1.41 \mathrm{E}-19$ \\
\hline $15 \%$ & 17 & $5.52 \mathrm{E}-17$ & $4.29 \mathrm{E}-17$ & $4.91 \mathrm{E}-17$ & $8.70 \mathrm{E}-18$ \\
\hline 16 & 22 & $9.52 \mathrm{E}-17$ & $1.53 \mathrm{E}-16$ & $1.24 \mathrm{E}-16$ & $4.09 \mathrm{E}-17$ \\
\hline 17 & 25 & $8.88 \mathrm{E}-17$ & $8.69 \mathrm{E}-17$ & 8.79E-17 & $1.34 \mathrm{E}-18$ \\
\hline 18 & 16 & $1.53 \mathrm{E}-16$ & $3.43 \mathrm{E}-16$ & $2.48 \mathrm{E}-16$ & $1.34 \mathrm{E}-16$ \\
\hline 19 & 15 & $4.55 \mathrm{E}-17$ & $4.51 \mathrm{E}-17$ & $4.53 \mathrm{E}-17$ & $2.83 \mathrm{E}-19$ \\
\hline 20 & 24 & $9.65 \mathrm{E}-17$ & $9.43 \mathrm{E}-17$ & $9.54 \mathrm{E}-17$ & $1.56 \mathrm{E}-18$ \\
\hline $21 \&$ & 23 & $4.29 \mathrm{E}-17$ & $4.50 \mathrm{E}-17$ & 4.39E-17 & $1.48 \mathrm{E}-18$ \\
\hline $22 \$$ & 19 & $3.27 \mathrm{E}-17$ & $3.33 \mathrm{E}-17$ & $3.30 \mathrm{E}-17$ & $4.24 \mathrm{E}-19$ \\
\hline 23 & 20 & $3.16 \mathrm{E}-16$ & $7.46 \mathrm{E}-16$ & 5.31E-16 & $3.04 \mathrm{E}-16$ \\
\hline 24 & 26 & $8.09 \mathrm{E}-17$ & $8.36 \mathrm{E}-17$ & $8.23 \mathrm{E}-17$ & $1.91 \mathrm{E}-18$ \\
\hline $25 \%$ & 21 & $4.31 \mathrm{E}-17$ & $4.46 \mathrm{E}-17$ & $4.39 \mathrm{E}-17$ & $1.06 \mathrm{E}-18$ \\
\hline $26 \&$ & 18 & $3.35 \mathrm{E}-17$ & 3.33E-17 & 3.34E-17 & $1.41 \mathrm{E}-19$ \\
\hline
\end{tabular}

(a) The duplicate diffusion coefficients for each test were rounded to two decimal places in scientific notation before calculating the mean and SD. After the mean and SD were calculated, they were rounded to two decimal places in scientific notation.

(b) Test numbers with the same symbols are replicates.

(c) The SD of duplicate results represents the variation in results of making duplicate samples from each test/mix, then testing them and averaging results over the 28-, 42-, 49-, and 63-day periods. This "Duplicate or Repeat SD" is distinct from "Replicate SD," which takes into account variations in making the mixes and testing with different beginning dates over the period of the screening matrix testing. See Section 8.5 for discussion of replicate variation. 
Table D-15. Duplicate Values, Means, and Standard Deviations of Leachability Index Values from EPA Draft Method 1315 Leach Tests Averaged Over the 28-, 42-, 49-, and 63-Day Results ${ }^{(a)}$

\begin{tabular}{|c|c|c|c|c|c|c|c|c|c|c|c|c|c|}
\hline \multirow{2}{*}{$\begin{array}{l}\text { Test/ } \\
\text { Mix } \\
\#^{(\mathbf{b})} \\
\end{array}$} & \multirow{2}{*}{$\begin{array}{c}\text { Random } \\
\text { Run } \\
\text { Order }\end{array}$} & \multicolumn{4}{|c|}{ Na Leachability Index $\left(-\log _{10}\left(\mathrm{~cm}^{2} / \mathrm{s}\right)\right)$} & \multicolumn{4}{|c|}{$\mathrm{NO}_{3}$ Leachability Index $\left(-\log _{10}\left(\mathrm{~cm}^{2} / \mathrm{s}\right)\right)$} & \multicolumn{4}{|c|}{$\mathrm{NO}_{2}$ Leachability Index $\left(-\log _{10}\left(\mathrm{~cm}^{2} / \mathrm{s}\right)\right)$} \\
\hline & & $\begin{array}{c}\text { Duplicate } \\
\# 1\end{array}$ & $\begin{array}{c}\text { Duplicate } \\
\# 2\end{array}$ & Mean & $\mathbf{S D}^{(\mathrm{c})}$ & $\begin{array}{c}\text { Duplicate } \\
\# 1\end{array}$ & $\begin{array}{c}\text { Duplicate } \\
\# 2\end{array}$ & Mean & $\mathbf{S D}^{(\mathbf{c})}$ & $\begin{array}{c}\text { Duplicate } \\
\# 1\end{array}$ & $\begin{array}{c}\text { Duplicate } \\
\# 2\end{array}$ & Mean & $\mathbf{S D}^{(\mathbf{c})}$ \\
\hline 1 & 7 & 8.92 & 8.92 & 8.92 & 0.000 & 9.09 & 9.05 & 9.07 & 0.028 & 9.02 & 8.99 & 9.00 & 0.021 \\
\hline $2 @$ & 11 & 8.24 & 8.16 & 8.20 & 0.057 & 8.20 & 8.20 & 8.20 & 0.000 & 8.17 & 8.17 & 8.17 & 0.000 \\
\hline $3 \$$ & 3 & 8.36 & 8.28 & 8.32 & 0.057 & 8.34 & 8.34 & 8.34 & 0.000 & 8.27 & 8.28 & 8.27 & 0.007 \\
\hline 4 & 5 & 8.05 & 8.12 & 8.09 & 0.049 & 8.26 & 8.27 & 8.27 & 0.007 & 8.21 & 8.23 & 8.22 & 0.014 \\
\hline 5 & 9 & 8.33 & 8.22 & 8.28 & 0.078 & 8.24 & 8.22 & 8.23 & 0.014 & 8.25 & 8.24 & 8.25 & 0.007 \\
\hline 6 & 12 & 8.23 & 8.21 & 8.22 & 0.014 & 8.06 & 8.04 & 8.05 & 0.014 & 8.05 & 8.03 & 8.04 & 0.014 \\
\hline $7 \#$ & 14 & 8.51 & 8.45 & 8.48 & 0.042 & 8.43 & 8.34 & 8.38 & 0.064 & 8.42 & 8.34 & 8.38 & 0.057 \\
\hline 8 & 1 & 8.61 & 8.63 & 8.62 & 0.014 & 8.56 & 8.62 & 8.59 & 0.042 & 8.59 & 8.65 & 8.62 & 0.042 \\
\hline 9 & 10 & 8.34 & 8.34 & 8.34 & 0.000 & 8.40 & 8.40 & 8.40 & 0.000 & 8.29 & 8.31 & 8.30 & 0.014 \\
\hline 10 & 13 & 8.14 & 8.13 & 8.14 & 0.007 & 8.23 & 8.25 & 8.24 & 0.014 & 8.26 & 8.29 & 8.27 & 0.021 \\
\hline 11 & 6 & 8.23 & 8.21 & 8.22 & 0.014 & 8.08 & 8.05 & 8.07 & 0.021 & 8.03 & 8.00 & 8.02 & 0.021 \\
\hline 12 & 8 & 8.39 & 8.41 & 8.40 & 0.014 & 8.40 & 8.41 & 8.41 & 0.007 & 8.44 & 8.45 & 8.45 & 0.007 \\
\hline $13 @$ & 4 & 8.20 & 8.21 & 8.21 & 0.007 & 8.06 & 8.11 & 8.09 & 0.035 & 8.12 & 8.17 & 8.14 & 0.035 \\
\hline $14 \#$ & 2 & 8.37 & 8.36 & 8.36 & 0.007 & 8.22 & 8.24 & 8.23 & 0.014 & 8.25 & 8.26 & 8.25 & 0.007 \\
\hline $15 \%$ & 17 & 8.12 & 8.17 & 8.14 & 0.035 & 8.17 & 8.19 & 8.18 & 0.014 & 8.14 & 8.20 & 8.17 & 0.042 \\
\hline 16 & 22 & 8.17 & 8.14 & 8.16 & 0.021 & 8.11 & 8.10 & 8.11 & 0.007 & 8.15 & 8.13 & 8.14 & 0.014 \\
\hline 17 & 25 & 8.19 & 8.19 & 8.19 & 0.000 & 8.15 & 8.11 & 8.13 & 0.028 & 8.16 & 8.14 & 8.15 & 0.014 \\
\hline 18 & 16 & 8.55 & 8.55 & 8.55 & 0.000 & 8.50 & 8.47 & 8.48 & 0.021 & 8.55 & 8.52 & 8.54 & 0.021 \\
\hline 19 & 15 & 8.50 & 8.49 & 8.50 & 0.007 & 8.37 & 8.36 & 8.36 & 0.007 & 8.31 & 8.31 & 8.31 & 0.000 \\
\hline 20 & 24 & 8.03 & 8.18 & 8.11 & 0.106 & 8.17 & 8.29 & 8.23 & 0.085 & 8.19 & 8.30 & 8.25 & 0.078 \\
\hline $21 \&$ & 23 & 8.00 & 8.00 & 8.00 & 0.000 & 7.83 & 7.86 & 7.85 & 0.021 & 7.87 & 7.89 & 7.88 & 0.014 \\
\hline $22 \$$ & 19 & 8.32 & 8.31 & 8.32 & 0.007 & 8.36 & 8.38 & 8.37 & 0.014 & 8.38 & 8.39 & 8.39 & 0.007 \\
\hline 23 & 20 & 7.62 & 7.57 & 7.60 & 0.035 & 7.47 & 7.42 & 7.45 & 0.035 & 7.62 & 7.56 & 7.59 & 0.042 \\
\hline 24 & 26 & 8.01 & 8.03 & 8.02 & 0.014 & 8.04 & 8.03 & 8.04 & 0.007 & 8.11 & 8.10 & 8.11 & 0.007 \\
\hline $25 \%$ & 21 & 8.17 & 8.18 & 8.18 & 0.007 & 8.17 & 8.19 & 8.18 & 0.014 & 8.24 & 8.26 & 8.25 & 0.014 \\
\hline $26 \&$ & 18 & 8.12 & 8.11 & 8.11 & 0.007 & 8.12 & 8.14 & 8.13 & 0.014 & 8.16 & 8.17 & 8.16 & 0.007 \\
\hline
\end{tabular}

(a) The duplicate LI values were calculated by converting the effective diffusion coefficients for 28-, 42-, 49-, and 63-day periods to LI values. Then the LI values were averaged over those four periods and the averages were rounded to two decimal places. Finally, the mean and SD were calculated from the rounded values, and the means and SDs themselves were rounded to two and three decimal places, respectively.

(b) Test numbers with the same symbols are replicates.

(c) The SD of duplicate results represents the variation in results of making duplicate samples from each test/mix, then testing them and averaging results over the 28-, 42-, 49-, and 63-day periods. This "Duplicate or Repeat SD" is distinct from "Replicate SD," which takes into account variations in making the mixes and testing with different beginning dates over the period of the screening matrix testing. See Section 8.5 for discussion of replicate variation. 
Table D-15. Duplicate Values, Means, and Standard Deviations of Leachability Index Values from EPA Draft Method 1315 Leach Tests Averaged Over the 28-, 42-, 49-, and 63-Day Results (contd) ${ }^{(a)}$

\begin{tabular}{|c|c|c|c|c|c|c|c|c|c|c|c|c|c|}
\hline \multirow{2}{*}{$\begin{array}{l}\text { Test/ } \\
\text { Mix } \\
\#^{(\mathbf{b})}\end{array}$} & \multirow{2}{*}{$\begin{array}{c}\text { Random } \\
\text { Run } \\
\text { Order }\end{array}$} & \multicolumn{4}{|c|}{ I Leachability Index $\left(-\log _{10}\left(\mathrm{~cm}^{2} / \mathrm{s}\right)\right)$} & \multicolumn{4}{|c|}{ Tc Leachability Index $\left(-\log _{10}\left(\mathrm{~cm}^{2} / \mathrm{s}\right)\right)$} & \multicolumn{4}{|c|}{ Cr Leachability Index $\left(-\log _{10}\left(\mathrm{~cm}^{2} / \mathrm{s}\right)\right)$} \\
\hline & & $\begin{array}{c}\text { Duplicate } \\
\# 1 \\
\end{array}$ & $\begin{array}{c}\text { Duplicate } \\
\# 2 \\
\end{array}$ & Mean & $\mathbf{S D}^{(\mathbf{c})}$ & $\begin{array}{c}\text { Duplicate } \\
\# 1 \\
\end{array}$ & $\begin{array}{c}\text { Duplicate } \\
\# 2 \\
\end{array}$ & Mean & $\mathbf{S D}^{(\mathbf{c})}$ & $\begin{array}{c}\text { Duplicate } \\
\# 1 \\
\end{array}$ & $\begin{array}{c}\text { Duplicate } \\
\# 2 \\
\end{array}$ & Mean & $\mathbf{S D}^{(\mathbf{c})}$ \\
\hline 1 & 7 & 9.16 & 9.16 & 9.16 & 0.000 & 10.33 & 10.34 & 10.34 & 0.007 & 12.72 & 12.76 & 12.74 & 0.028 \\
\hline $2 @$ & 11 & 8.17 & 8.18 & 8.18 & 0.007 & 10.18 & 10.28 & 10.23 & 0.071 & 13.09 & 13.10 & 13.09 & 0.007 \\
\hline $3 \$$ & 3 & 8.31 & 8.30 & 8.30 & 0.007 & 10.46 & 10.46 & 10.46 & 0.000 & 12.79 & 12.80 & 12.80 & 0.007 \\
\hline 4 & 5 & 8.42 & 8.41 & 8.41 & 0.007 & 10.60 & 10.51 & 10.56 & 0.064 & 13.23 & 13.19 & 13.21 & 0.028 \\
\hline 5 & 9 & 8.33 & 8.32 & 8.32 & 0.007 & 10.16 & 10.15 & 10.16 & 0.007 & 13.14 & 13.10 & 13.12 & 0.028 \\
\hline 6 & 12 & 8.05 & 8.03 & 8.04 & 0.014 & 9.90 & 9.91 & 9.91 & 0.007 & 12.82 & 12.89 & 12.86 & 0.049 \\
\hline $7 \#$ & 14 & 8.46 & 8.39 & 8.43 & 0.049 & 11.05 & 11.04 & 11.05 & 0.007 & 14.12 & 14.09 & 14.11 & 0.021 \\
\hline 8 & 1 & 8.58 & 8.61 & 8.59 & 0.021 & 9.65 & 9.68 & 9.66 & 0.021 & 12.18 & 12.12 & 12.15 & 0.042 \\
\hline 9 & 10 & 8.29 & 8.29 & 8.29 & 0.000 & 10.45 & 10.47 & 10.46 & 0.014 & 12.86 & 12.76 & 12.81 & 0.071 \\
\hline 10 & 13 & 8.37 & 8.38 & 8.38 & 0.007 & 9.92 & 9.91 & 9.91 & 0.007 & 12.45 & 12.00 & 12.23 & 0.318 \\
\hline 11 & 6 & 7.93 & 7.90 & 7.92 & 0.021 & 9.95 & 9.95 & 9.95 & 0.000 & 12.88 & 12.89 & 12.89 & 0.007 \\
\hline 12 & 8 & 8.57 & 8.56 & 8.57 & 0.007 & 10.38 & 10.37 & 10.38 & 0.007 & 12.81 & 12.72 & 12.77 & 0.064 \\
\hline $13 @$ & 4 & 8.08 & 8.10 & 8.09 & 0.014 & 10.05 & 10.12 & 10.09 & 0.049 & 13.25 & 13.28 & 13.27 & 0.021 \\
\hline $14 \#$ & 2 & 8.28 & 8.27 & 8.27 & 0.007 & 11.09 & 10.96 & 11.03 & 0.092 & 14.01 & 14.02 & 14.02 & 0.007 \\
\hline $15 \%$ & 17 & 8.24 & 8.30 & 8.27 & 0.042 & 10.35 & 10.34 & 10.34 & 0.007 & 12.59 & 12.71 & 12.65 & 0.085 \\
\hline 16 & 22 & 8.13 & 8.10 & 8.12 & 0.021 & 9.82 & 9.80 & 9.81 & 0.014 & 12.64 & 12.60 & 12.62 & 0.028 \\
\hline 18 & 16 & 8.52 & 8.50 & 8.51 & 0.014 & 11.26 & 11.24 & 11.25 & 0.014 & 13.82 & 13.80 & 13.81 & 0.014 \\
\hline 19 & 15 & 8.34 & 8.31 & 8.32 & 0.021 & 10.43 & 10.44 & 10.43 & 0.007 & 13.26 & 13.23 & 13.25 & 0.021 \\
\hline 20 & 24 & 8.36 & 8.51 & 8.43 & 0.106 & 10.39 & 10.47 & 10.43 & 0.057 & 13.11 & 13.15 & 13.13 & 0.028 \\
\hline $21 \&$ & 23 & 7.81 & 7.81 & 7.81 & 0.000 & 10.20 & 10.12 & 10.16 & 0.057 & 12.88 & 12.84 & 12.86 & 0.028 \\
\hline $22 \$$ & 19 & 8.36 & 8.36 & 8.36 & 0.000 & 10.68 & 10.57 & 10.63 & 0.078 & 12.73 & 12.80 & 12.77 & 0.049 \\
\hline 23 & 20 & 7.52 & 7.45 & 7.48 & 0.049 & 8.94 & 9.13 & 9.04 & 0.134 & 11.92 & 11.99 & 11.96 & 0.049 \\
\hline 24 & 26 & 8.11 & 8.12 & 8.11 & 0.007 & 10.18 & 10.20 & 10.19 & 0.014 & 12.95 & 13.15 & 13.05 & 0.141 \\
\hline $25 \%$ & 21 & 8.34 & 8.35 & 8.34 & 0.007 & 10.47 & 10.62 & 10.55 & 0.106 & 12.60 & 12.52 & 12.56 & 0.057 \\
\hline $26 \&$ & 18 & 8.17 & 8.17 & 8.17 & 0.000 & 9.85 & 9.90 & 9.88 & 0.035 & 13.02 & 13.04 & 13.03 & 0.014 \\
\hline
\end{tabular}

(a) The duplicate LI values were calculated by converting the effective diffusion coefficients for $28-, 42-, 49-$, and 63-day periods to LI values. Then the LI values were averaged over those four periods and the averages were rounded to two decimal places. Finally, the mean and SD were calculated from the rounded values, and the means and SDs themselves were rounded to two and three decimal places, respectively.

(b) Test numbers with the same symbols are replicates.

(c) The SD of duplicate results represents the variation in results of making duplicate samples from each test/mix, then testing them and averaging results over the 2842-, 49-, and 63-day periods. This "Duplicate or Repeat SD" is distinct from "Replicate SD," which takes into account variations in making the mixes and testing with different beginning dates over the period of the screening matrix testing. See Section 8.5 for discussion of replicate variation. 
Table D-15. Duplicate Values, Means, and Standard Deviations of Leachability Index Values from EPA Draft Method 1315 Leach Tests Averaged Over the 28-, 42-, 49-, and 63-Day Results (contd) ${ }^{(a)}$

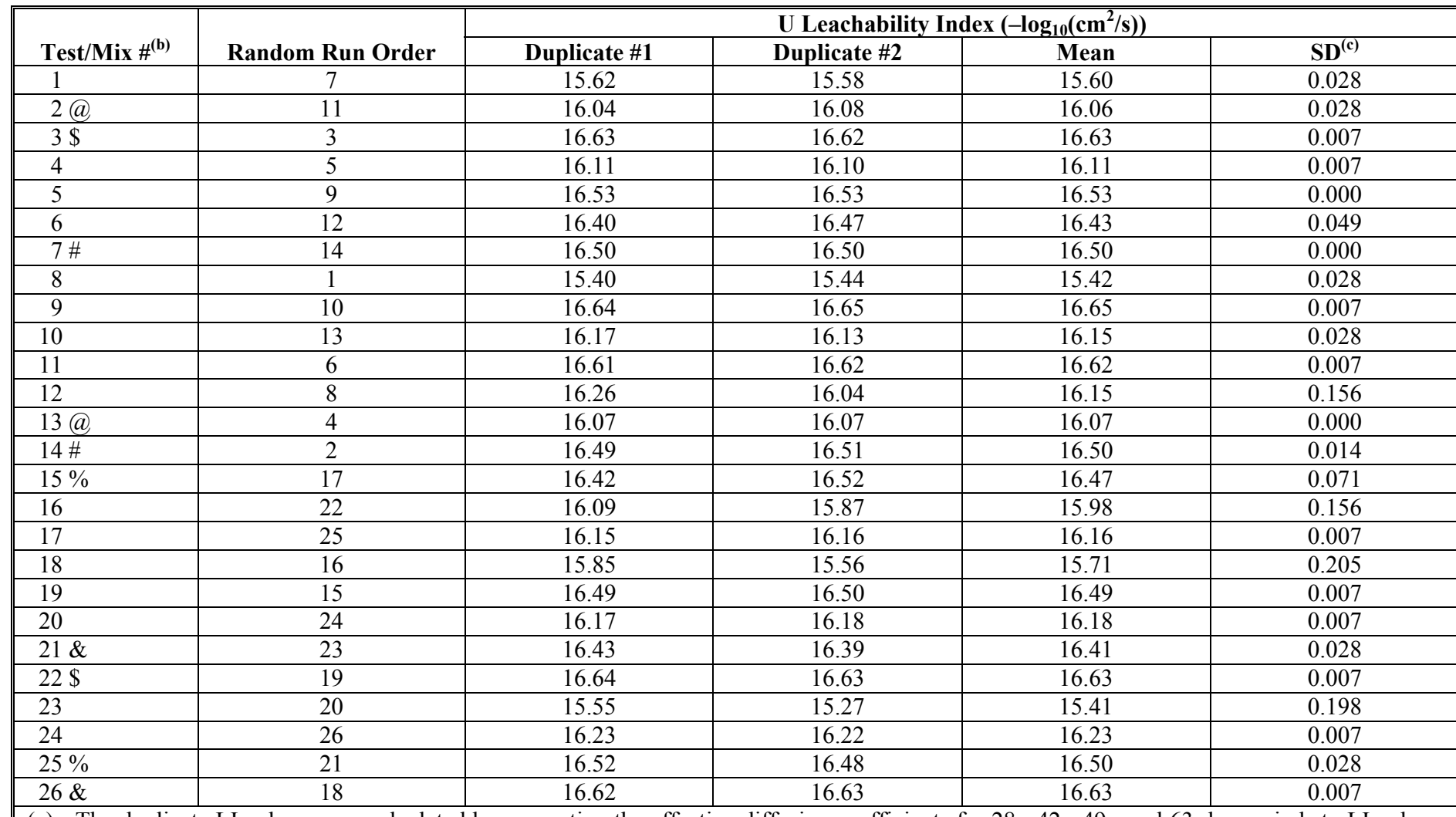

(a) The duplicate LI values were calculated by converting the effective diffusion coefficients for 28-, 42-, 49-, and 63-day periods to LI values. Then the LI values were averaged over those four periods and the averages rounded to two decimal places. Finally, the mean and SD were calculated from the rounded values, and the means and SDs themselves were rounded to two and three decimal places, respectively.

(b) Test numbers with the same symbols are replicates.

(c) The SD of duplicate results represents the variation in results of making duplicate samples from each test/mix, then testing them and averaging results over the 28-, 42-, 49-, and 63-day periods. This "Duplicate or Repeat SD" is distinct from "Replicate SD," which takes into account variations in making the mixes and testing with different beginning dates over the period of the screening matrix testing. See Section 8.5 for discussion of replicate variation. 
PNNL-22747

SRNL-STI-2013-00465

Appendix E. Data-Interaction Plots for Selected Cast Stone Properties 
This appendix contains graphical displays referred to as data-interaction plots for Cast Stone properties that are statistically analyzed in Section 8.0. The properties tested by SRNL (Plastic Viscosity, Heat Generation at 300 Hours, and Time to Peak Heat Generation,) have data for 38 mixes, because 12 of the original 26 mixes (Mixes 1-26) were mis-batched and tested, (denoted Mixes 27-38) and then subsequently those 12 mixes were correctly batched and tested. The remaining properties that are statistically analyzed in Section 8.0 (compressive strength; EPA 1315 leachability indices for $\mathrm{Na}, \mathrm{NO}_{3}, \mathrm{I}, \mathrm{Tc}$, and $\mathrm{Cr}$ ) were batched and tested by PNNL, so there are only data for the original 26 mixes (Mixes 1-26). Hence, the data-interaction plots are based on different numbers of test results depending on the property.

The data-interaction plots have a specific Cast Stone property on the y-axis, one of the test parameters on the x-axis (Parameter A), and another of the test parameters (Parameter B) whose values are represented by different plotting symbols and line segments. The property values for the mixes are plotted using different plotting symbols and colors. Also plotted is a line segment for each value of Parameter B, where the values at the endpoints of the line segment are the means of all property values having the possible values of Parameter A.

For each property two groups of plots are presented. The first group of plots is for pairs of test parameters for which interactions were accounted for in designing the screening test matrix. This group of plots includes the following pairs of components:

- Na Molarity and Simulant

- Fly Ash and Simulant

- Mix Ratio and Simulant

- Na Molarity and Fly Ash

- Na Molarity and Mix Ratio

- Mix Ratio and Fly Ash.

In this group of plots, the line segments are shown as solid lines.

The second group of plots is for pairs of test parameters for which interactions were assumed to be non-significant in designing the screening test matrix. This group of plots includes the following pairs of components:

- blast furnace slag and fly ash

- Na molarity and blast furnace slag

- fly ash and blast furnace slag

- mix ratio and blast furnace slag.

In this group of plots, the line segments are shown as dashed lines as a reminder that twoparameter interactions with BFS were originally assumed to be non-significant when developing the test matrix for Mixes 1-26. However, because the 12 mixes mis-batched by SRNL involved switching the BFS sources (NW and SE), and those 12 mixes were subsequently correctly batched and tested, the data for the SRNL properties noted above contain additional information regarding the individual and two-parameter interaction effects of BFS.

The primary purpose of a data-interaction plot is to graphically assess whether Parameters A and $B$ have a significant interactive effect on a property. A significant interaction occurs when the effect of one parameter on the property depends significantly on the value of the second 
parameter. Graphically, a significant interaction exists when the line segments in a plot are significantly non-parallel. When subjectively judging whether line segments are significantly non-parallel the following four things are considered:

- The spread of the endpoints of the line segments must be considered relative to the spread of the data points. If the spread of the endpoints is small relative to the spread of the data points, that means that test parameters other than Parameters $\mathrm{A}$ and $\mathrm{B}$ in a plot account for substantial variation in the data. In such cases, the potential interactive effect of Parameters A and B may be small compared to the effects of other parameters, and hence less likely to be significant. On the other hand, if the spread of the endpoints of line segments accounts for a substantial fraction of the spread of data points, that means Parameters A and/or B have substantive effects, and hence are more likely to interact.

- Outlying data points may substantively affect the mean property values at the endpoints of the line segments, and hence may be the cause of what appears to be a significant interactive effect of Parameters A and B on the property.

- The screening test matrix was designed based on the assumptions that certain individual parameter effects and two-parameter interactions were not significant (see Appendix A). This results in aliasing of parameter effects and interactions (i.e., some interactions are strongly correlated with other interactions and/or individual parameter effects).

- Mixes 1-26 in the planned test matrix are not "balanced" in that each value of each test parameter does not appear an equal number of times in the test matrix. It was not possible to generate a balanced design given the restrictions on the number of tests that could be performed, and the assumptions about non-significant effects of some individual and twoparameter interaction effects. Mixes 1-38 for the SRNL properties are also not balanced. The consequence of unbalanced data is that when averaging over subsets of data to form the endpoints of the lines in the plots, there can be unequal effects of other parameters than the two parameters whose interaction is being assessed with a given plot. Thus, the parallelism or non-parallelism of lines in a given data-interaction plot can be affected by the lack of balance. The statistical analyses of the data in Section 8.0 account for the structure of the data, and hence may result in conclusions that may appear to differ, in some cases, from what is shown in the data-interaction plots in this appendix.

The following sections present the data-interaction plots for the properties of mixes in the screening test matrix that are statistically analyzed in Section 8.0. Note that the figures in this appendix are provided "For Information Only" (for the reason in the last bullet above), and hence the PNNL quality assurance procedures were not applied for these figures. Similar figures that are based on the models fit as part of statistical data analyses are presented in Section 8.0, and the required QA procedures were completed for those figures.

\section{E.1 Plastic Viscosity}

Figure E-1 to Figure E-10 display the data-interaction plots for the plastic viscosity of Cast Stone Mixes 1 through 38. The data in these plots are from Table C-5 in Appendix C. 
PNNL-22747

SRNL-STI-2013-00465

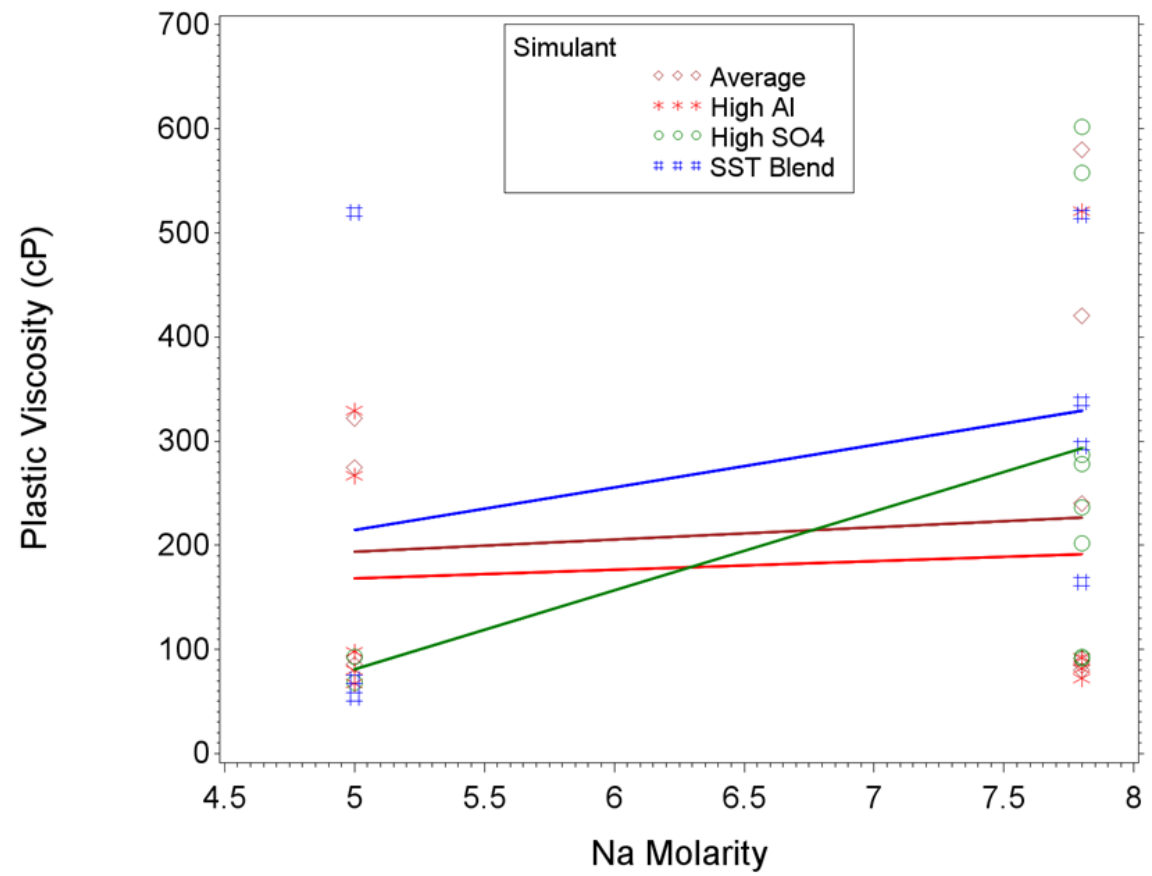

Figure E-1. Data-Interaction Plot for the Effects of Na Molarity and Simulant on Plastic Viscosity

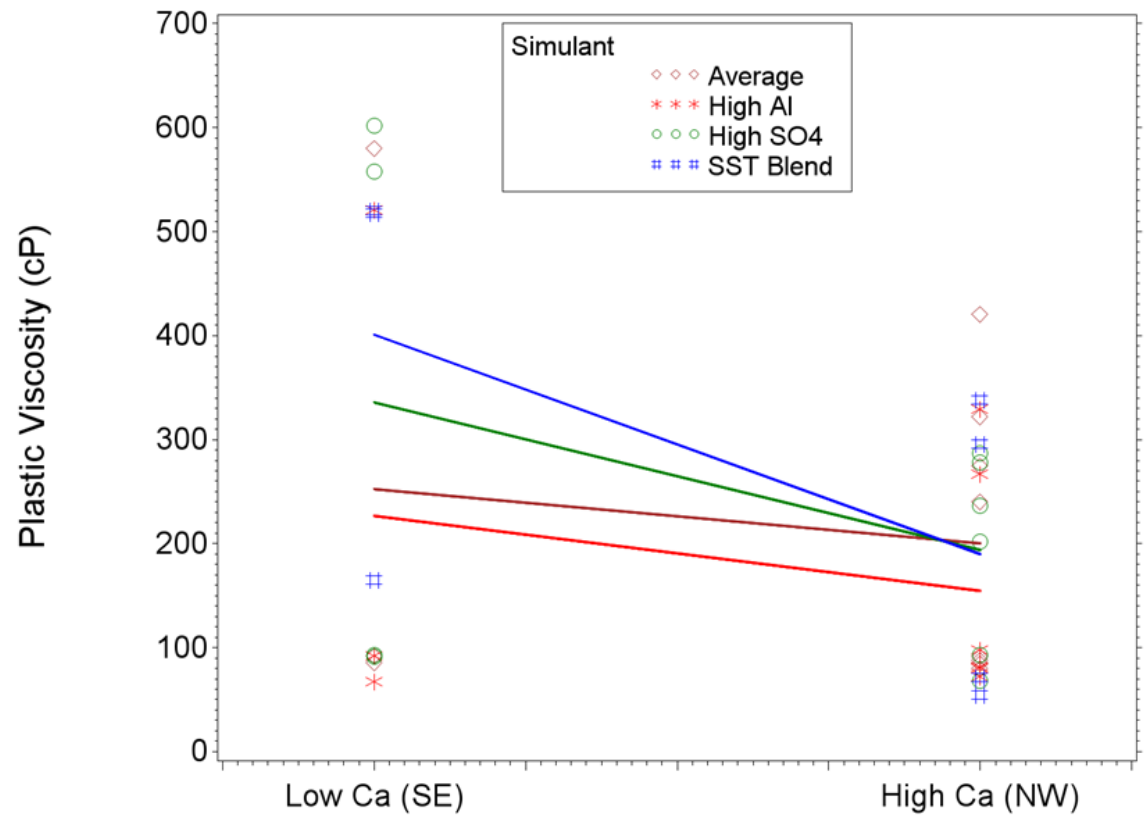

Fly Ash

Figure E-2. Data-Interaction Plot for the Effects of Fly Ash and Simulant on Plastic Viscosity 


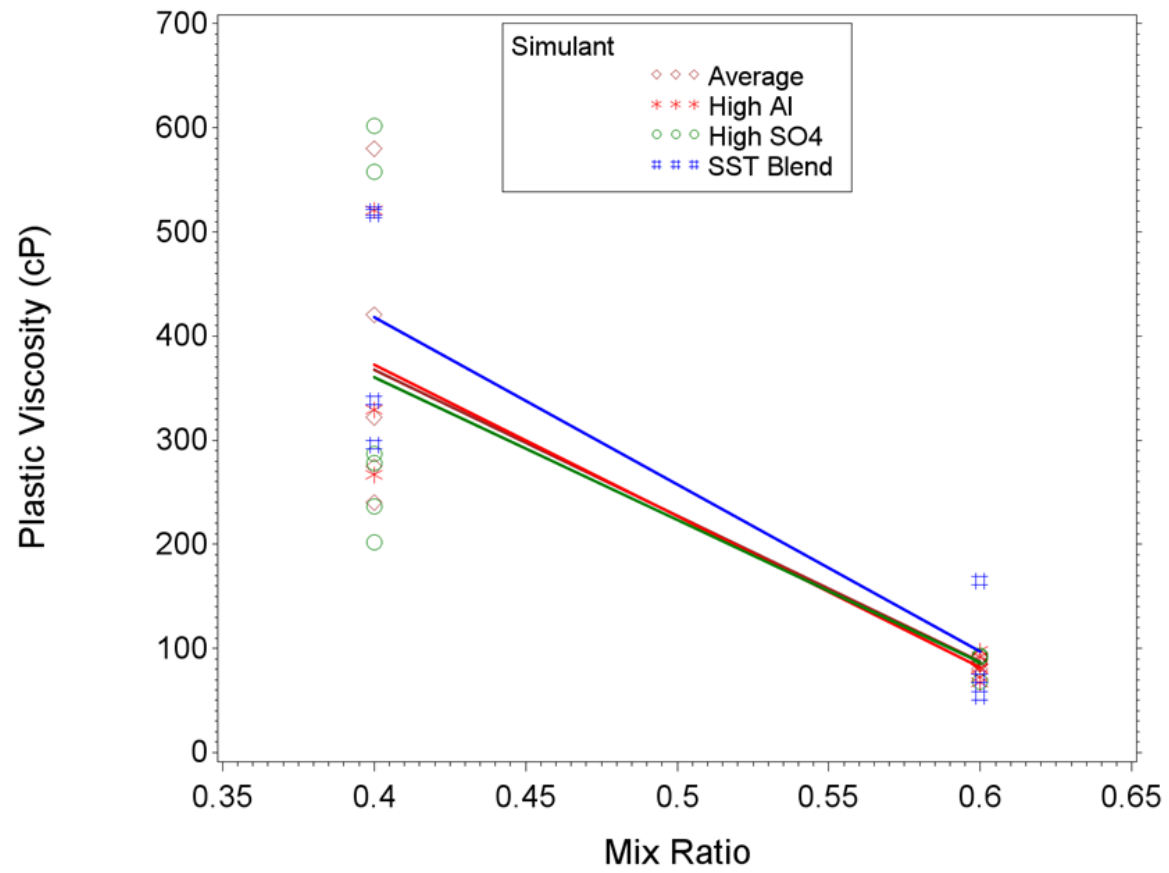

Figure E-3. Data-Interaction Plot for the Effects of Mix Ratio and Simulant on Plastic Viscosity

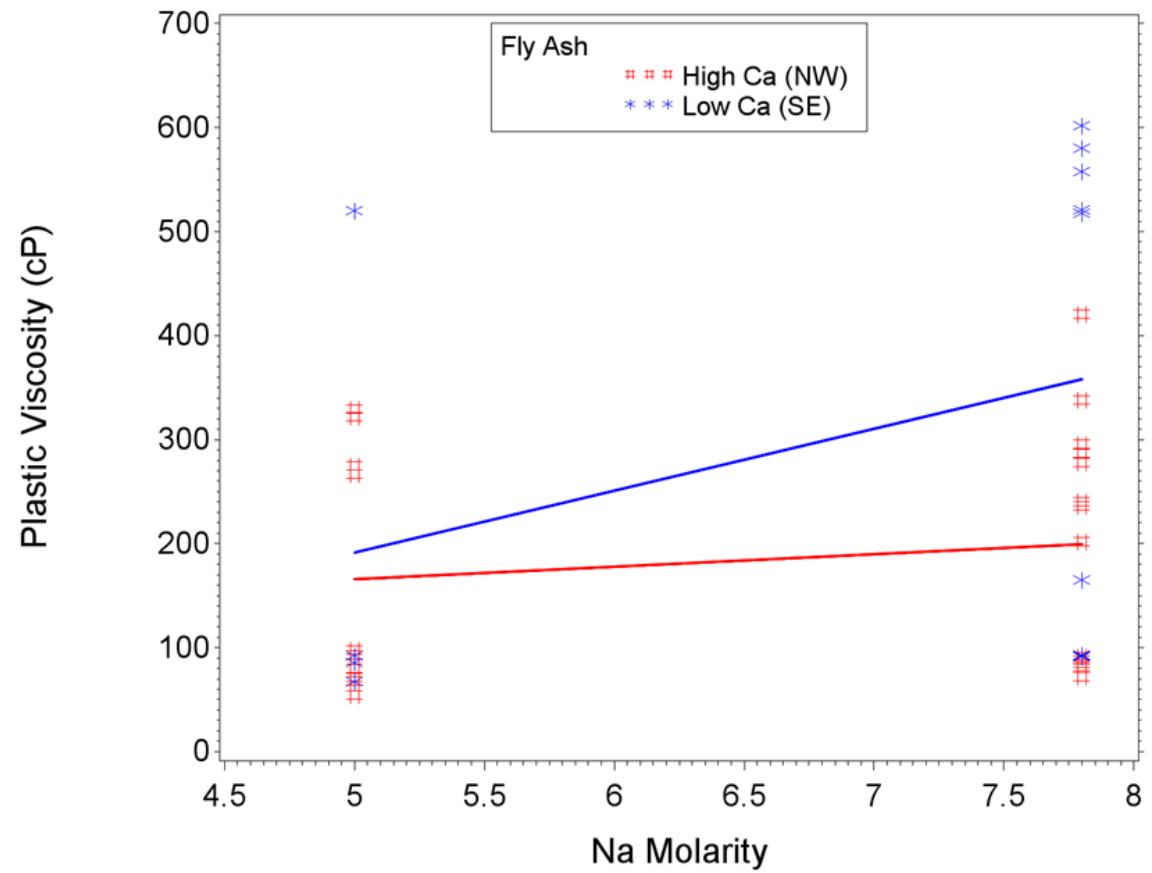

Figure E-4. Data-Interaction Plot for the Effects of Na Molarity and Fly Ash on Plastic Viscosity 


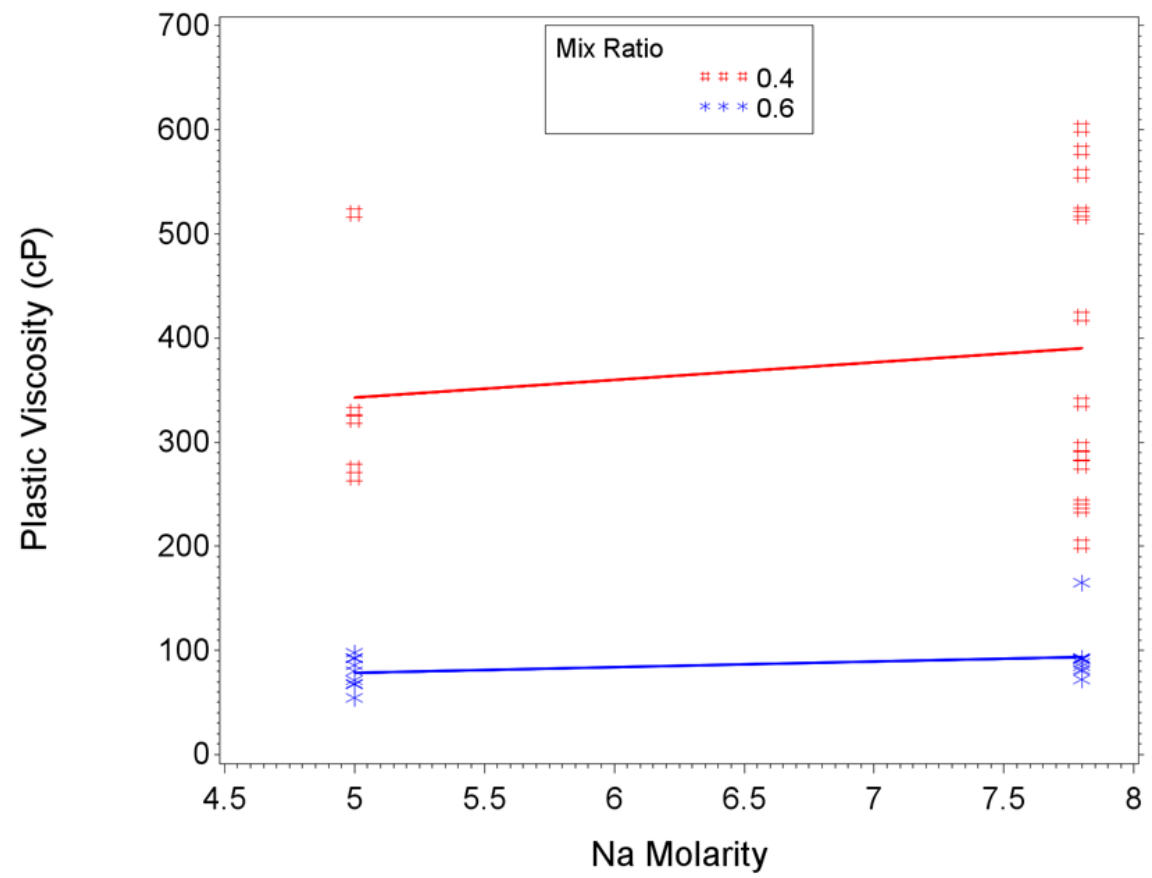

Figure E-5. Data-Interaction Plot for the Effects of Na Molarity and Mix Ratio on Plastic Viscosity

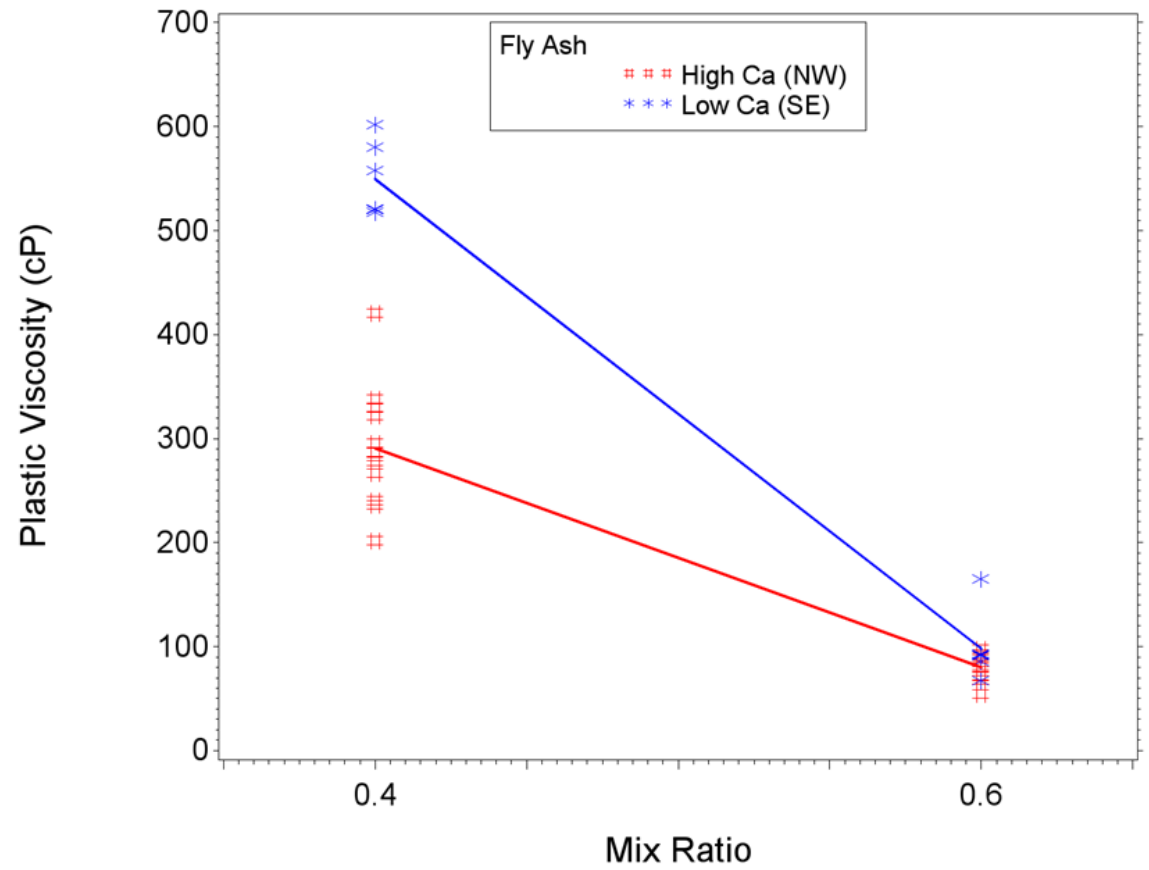

Figure E-6. Data-Interaction Plot for the Effects of Mix Ratio and Fly Ash on Plastic Viscosity 
PNNL-22747

SRNL-STI-2013-00465

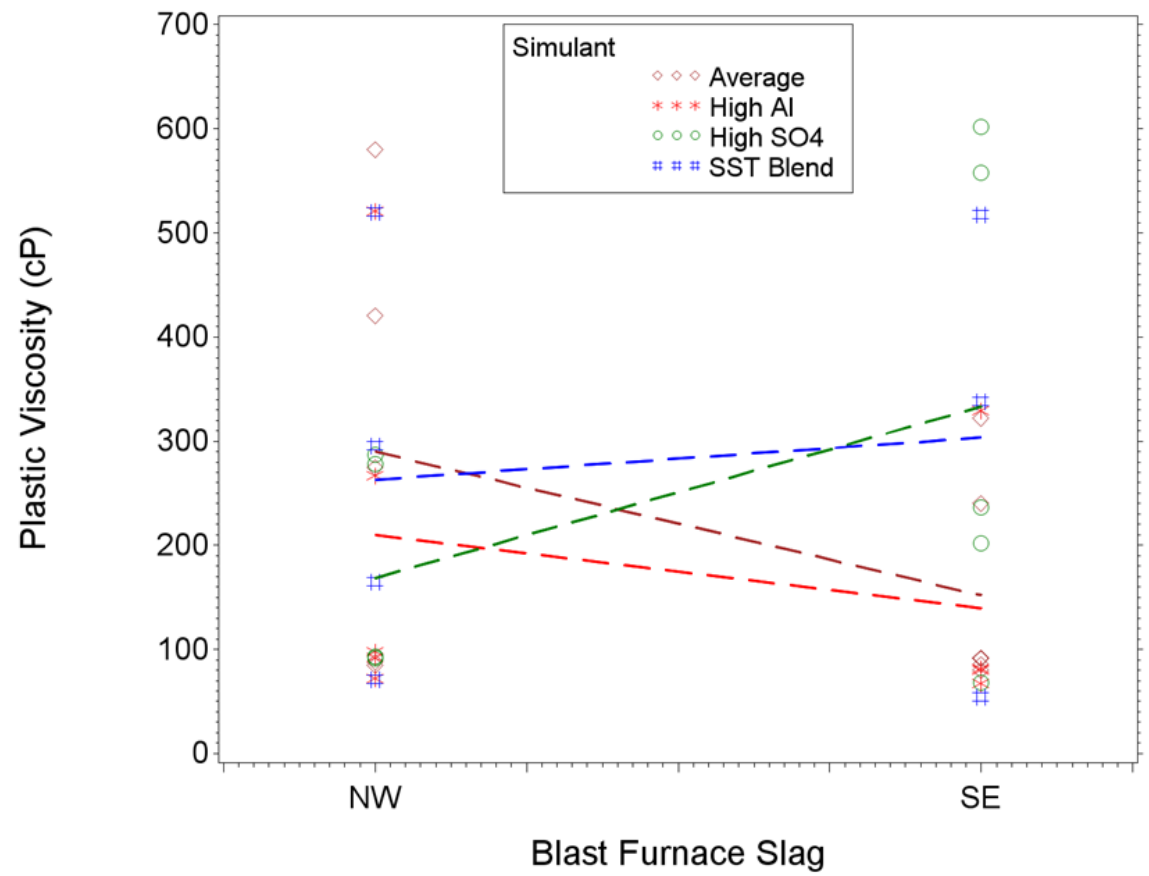

Figure E-7. Data-Interaction Plot for the Effects of Blast Furnace Slag and Simulant on Plastic Viscosity

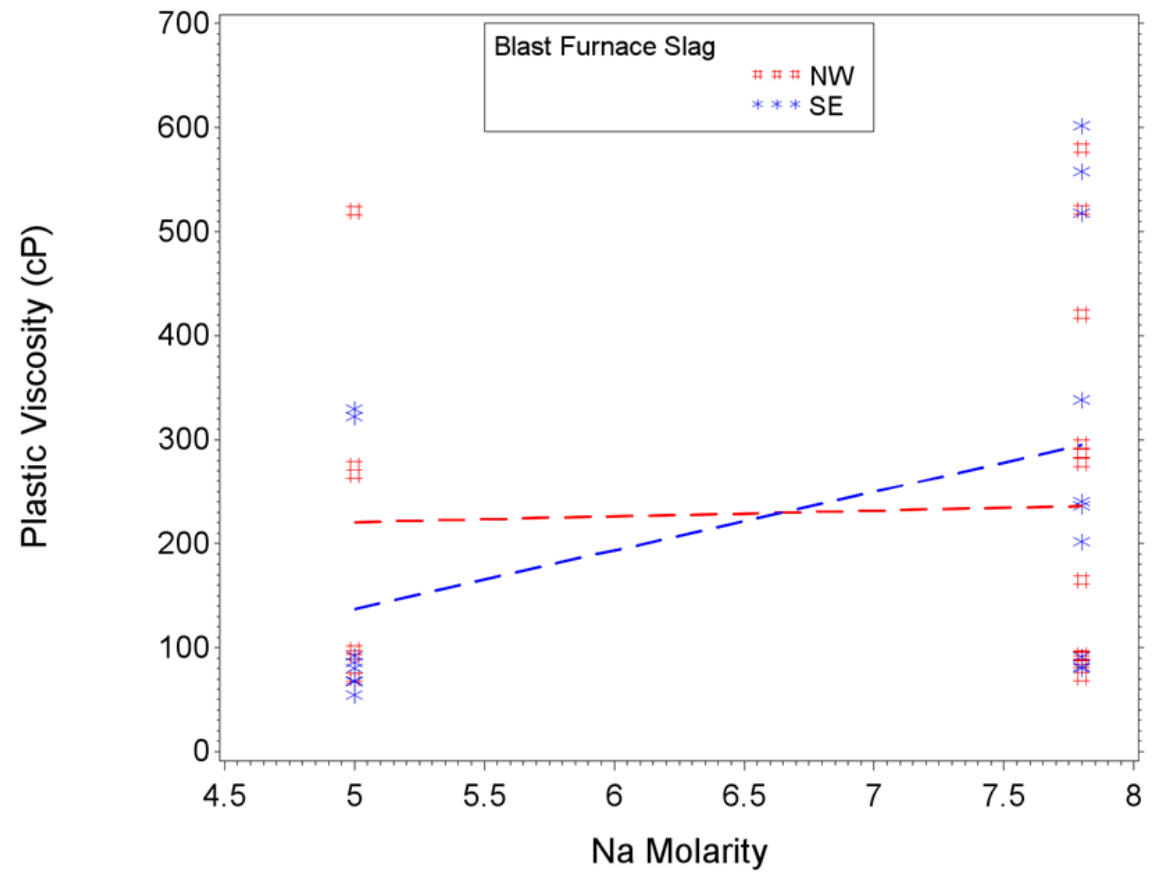

Figure E-8. Data-Interaction Plot for the Effects of Na Molarity and Blast Furnace Slag on Plastic Viscosity 


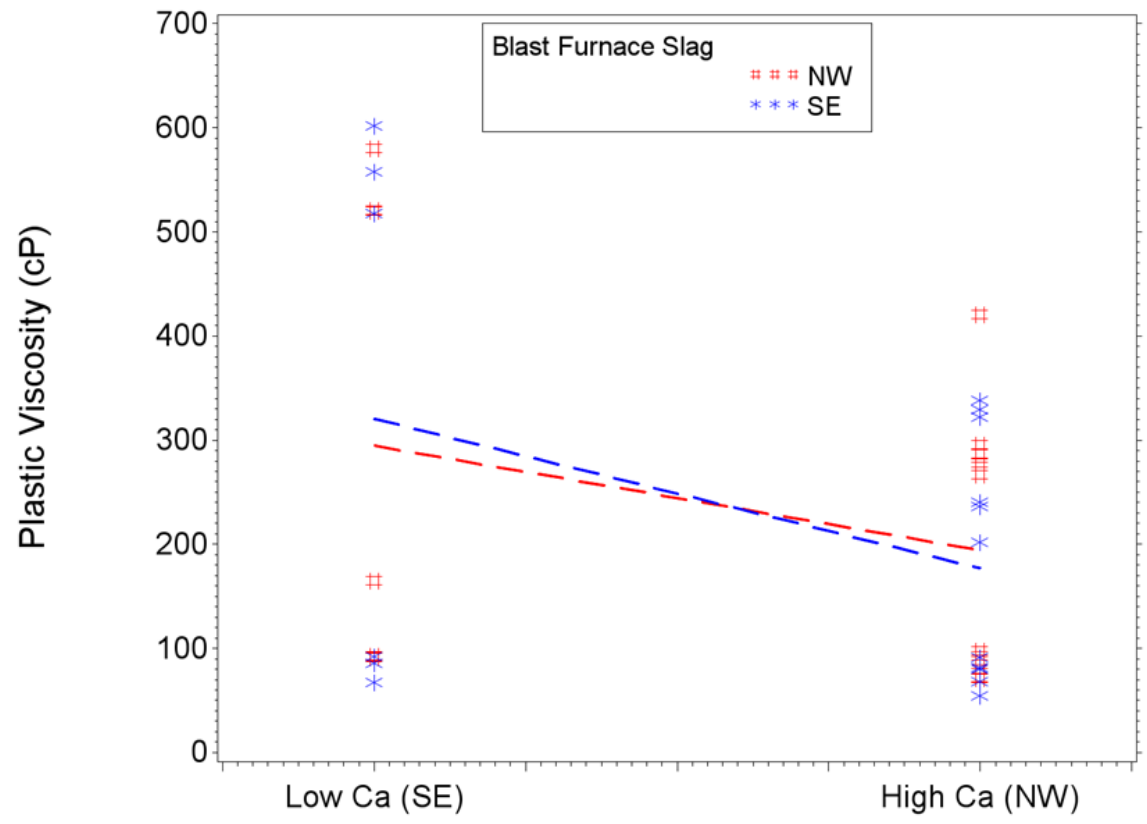

Fly Ash

Figure E-9. Data-Interaction Plot for the Effects of Fly Ash and Blast Furnace Slag on Plastic Viscosity

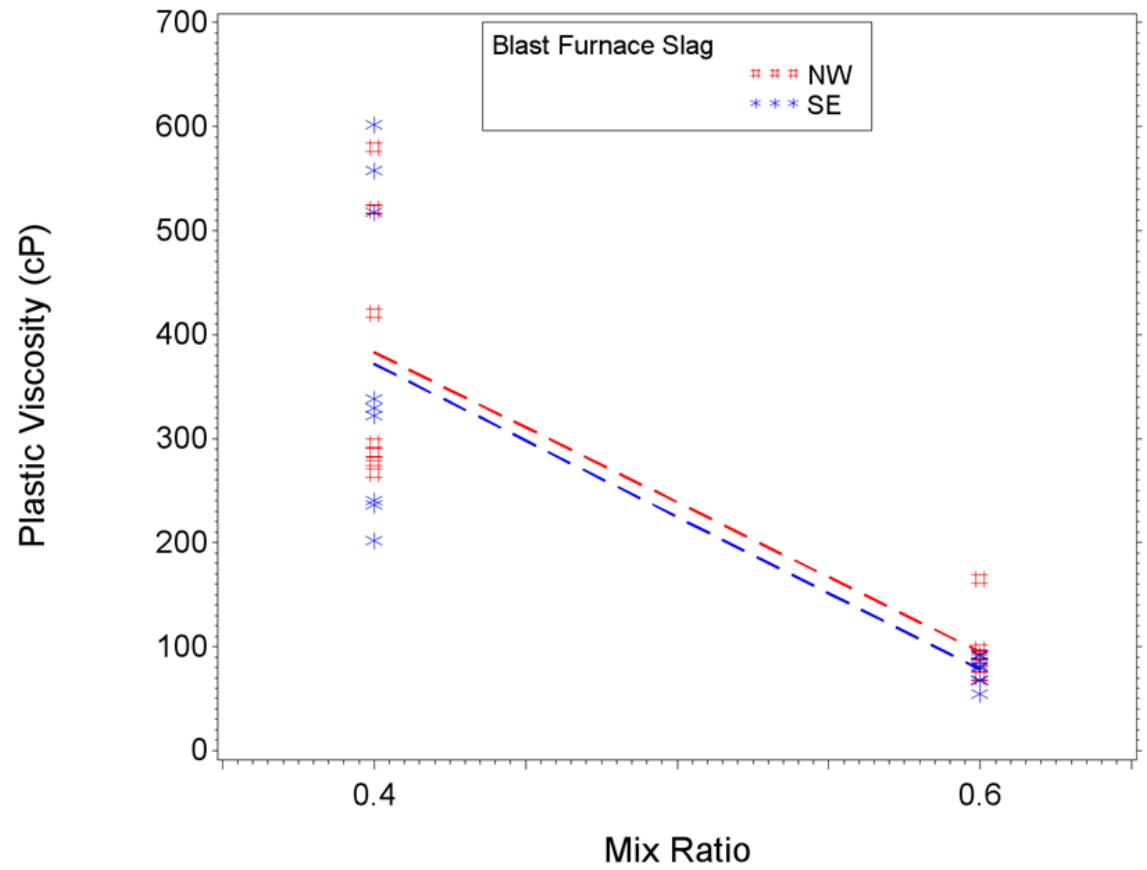

Figure E-10. Data-Interaction Plot for the Effects of Mix Ratio and Blast Furnace Slag on Plastic Viscosity 


\section{E.2 Heat Generation}

This section presents data-interaction plots for two heat-generation properties (Heat Generation at 300 Hours and Time to Peak Heat Generation) of Cast Stone Mixes 1-38. The numerical values (data) in these plots are from Table C-8 in Appendix C.

\section{E.2.1 Heat Generation at 300 Hours}

Figure E-11 through Figure E-20 display the data-interaction plots for Heat Generation at 300 Hours using the data from Cast Stone Mixes 1-38. 
PNNL-22747

SRNL-STI-2013-00465

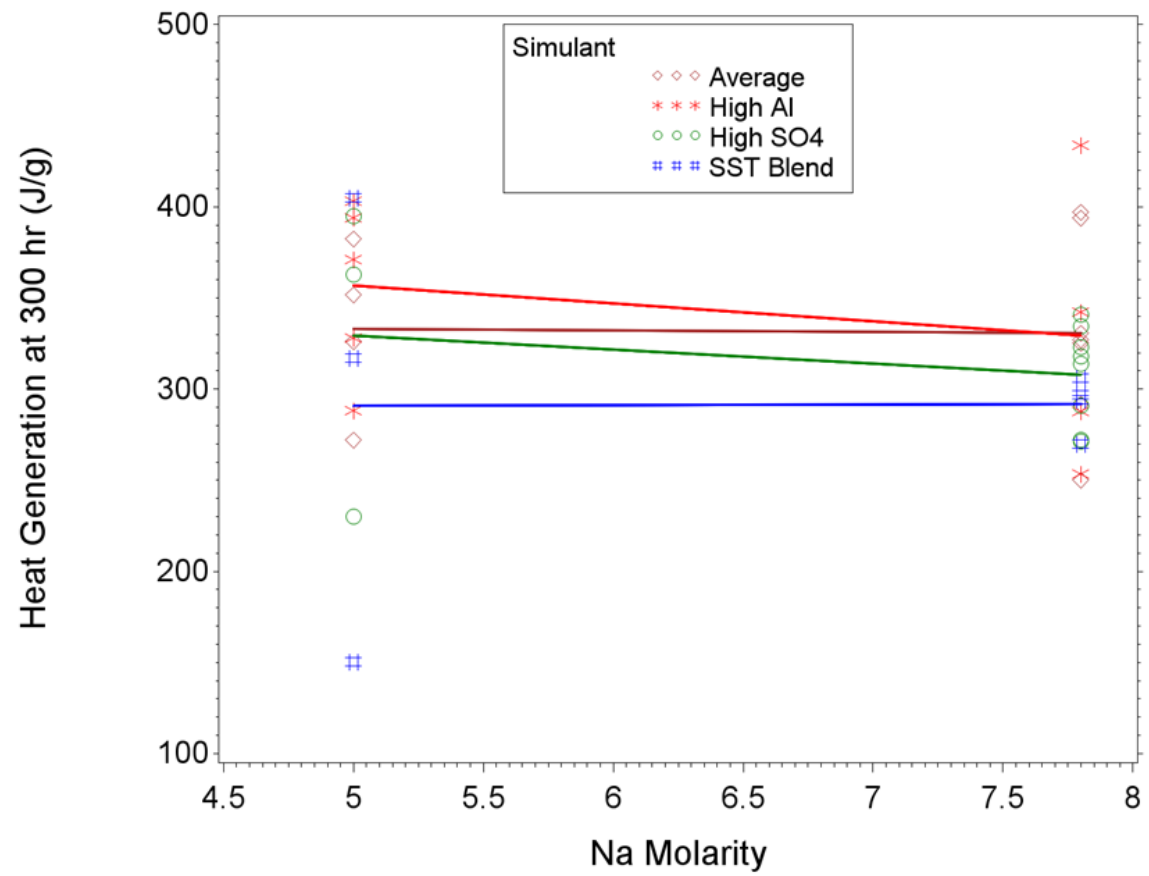

Figure E-11. Data-Interaction Plot for the Effects of Na Molarity and Simulant on Heat Generation at 300 Hours

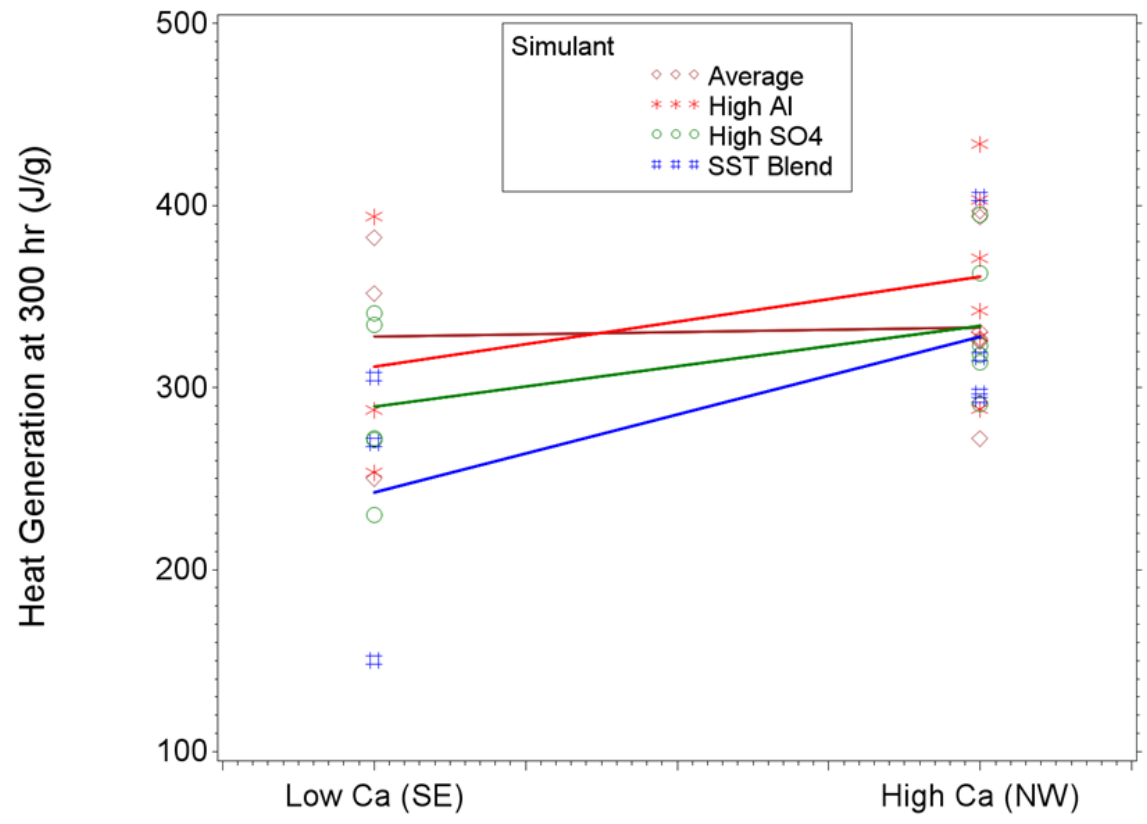

Fly Ash

Figure E-12. Data-Interaction Plot for the Effects of Fly Ash and Simulant on Heat Generation at 300 Hours 
PNNL-22747

SRNL-STI-2013-00465

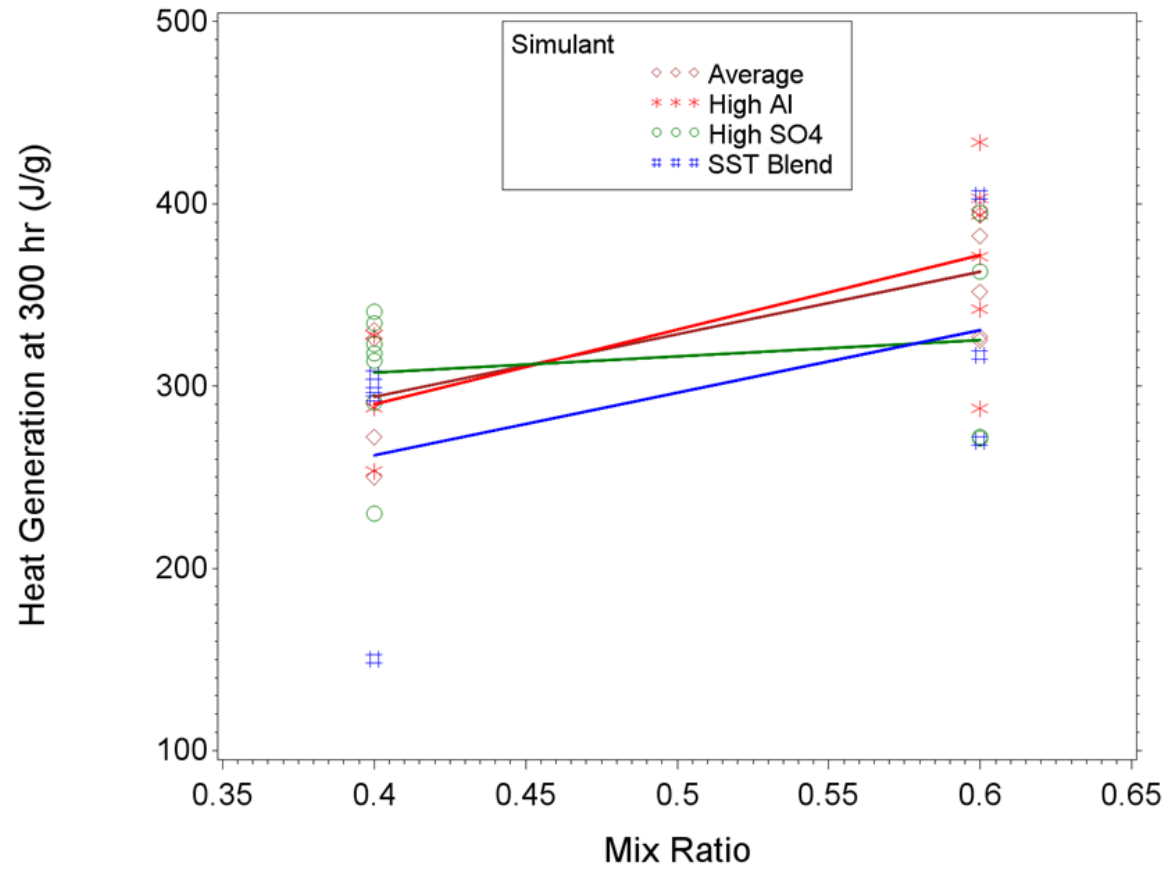

Figure E-13. Data-Interaction Plot for the Effects of Mix Ratio and Simulant on Heat Generation at 300 Hours

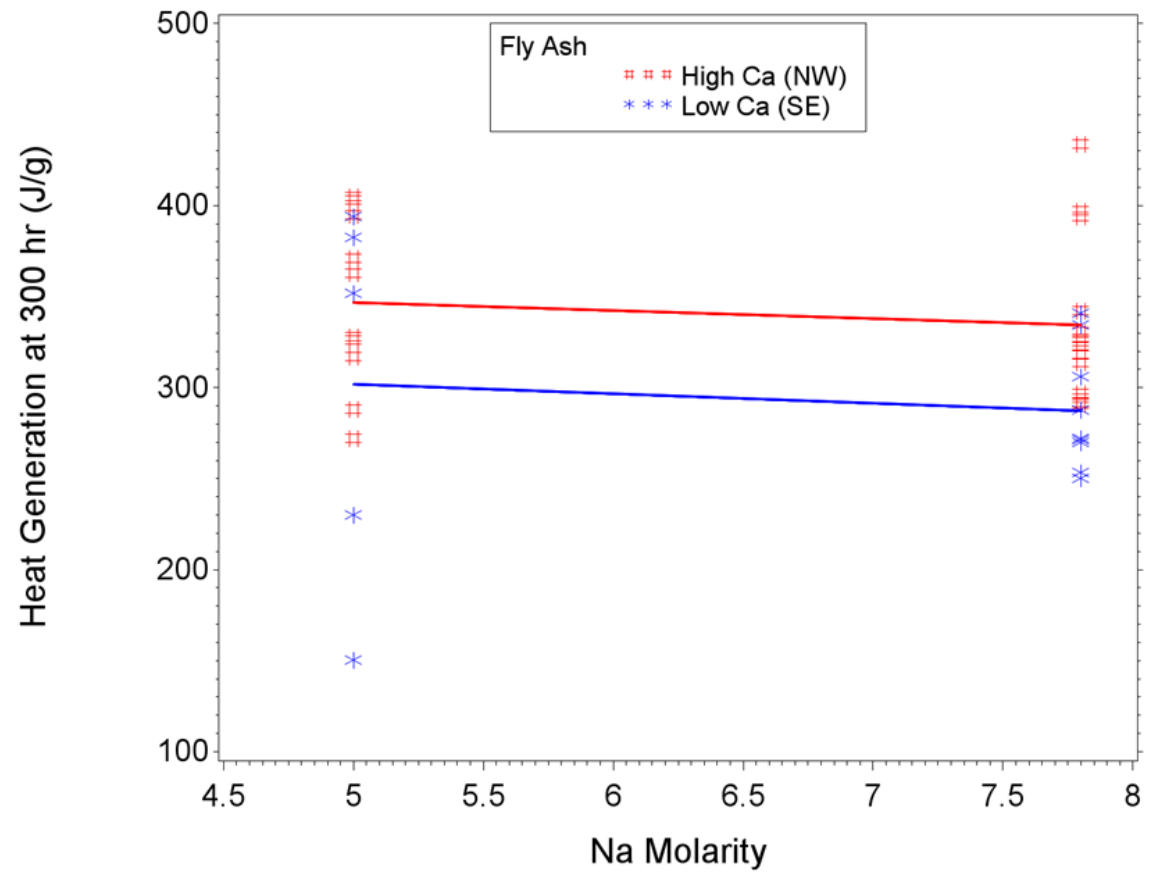

Figure E-14. Data-Interaction Plot for the Effects of Na Molarity and Fly Ash on Heat Generation at 300 Hours 


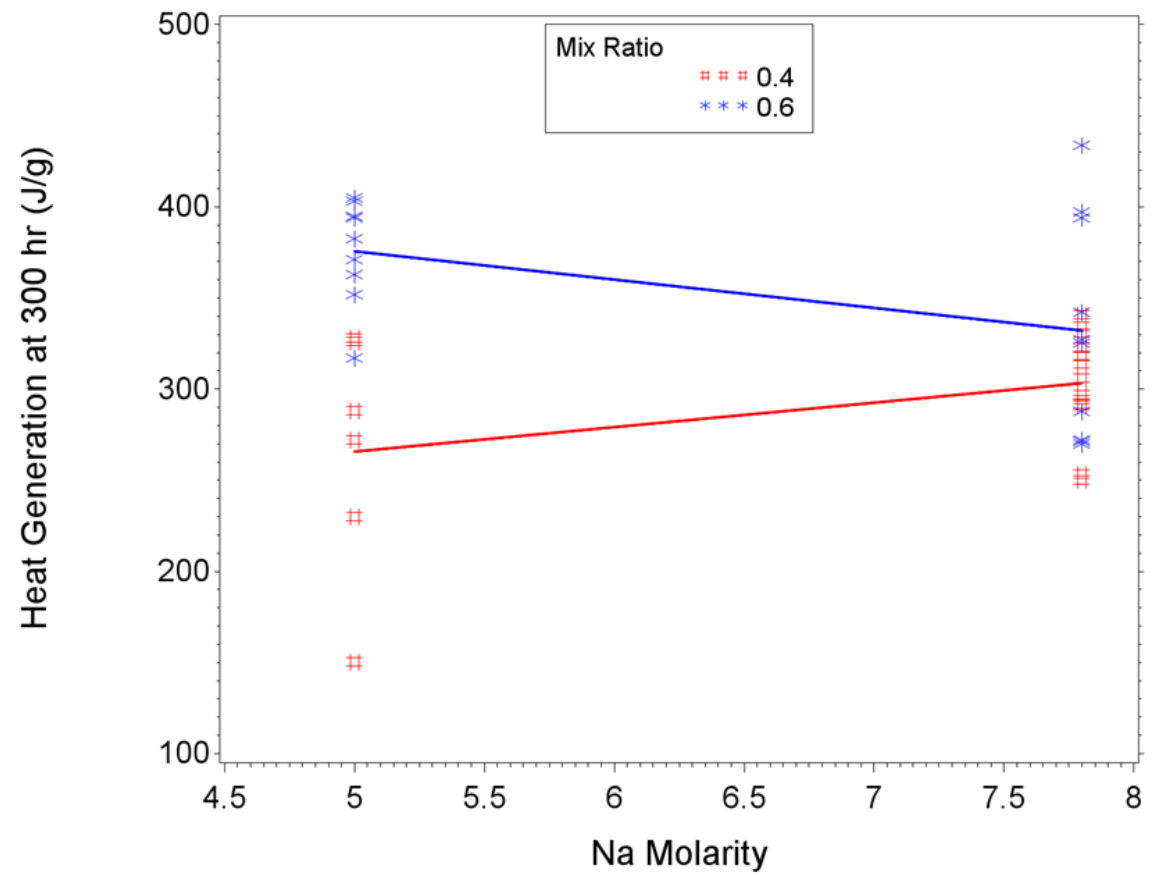

Figure E-15. Data-Interaction Plot for the Effects of Na Molarity and Mix Ratio on Heat Generation at 300 Hours

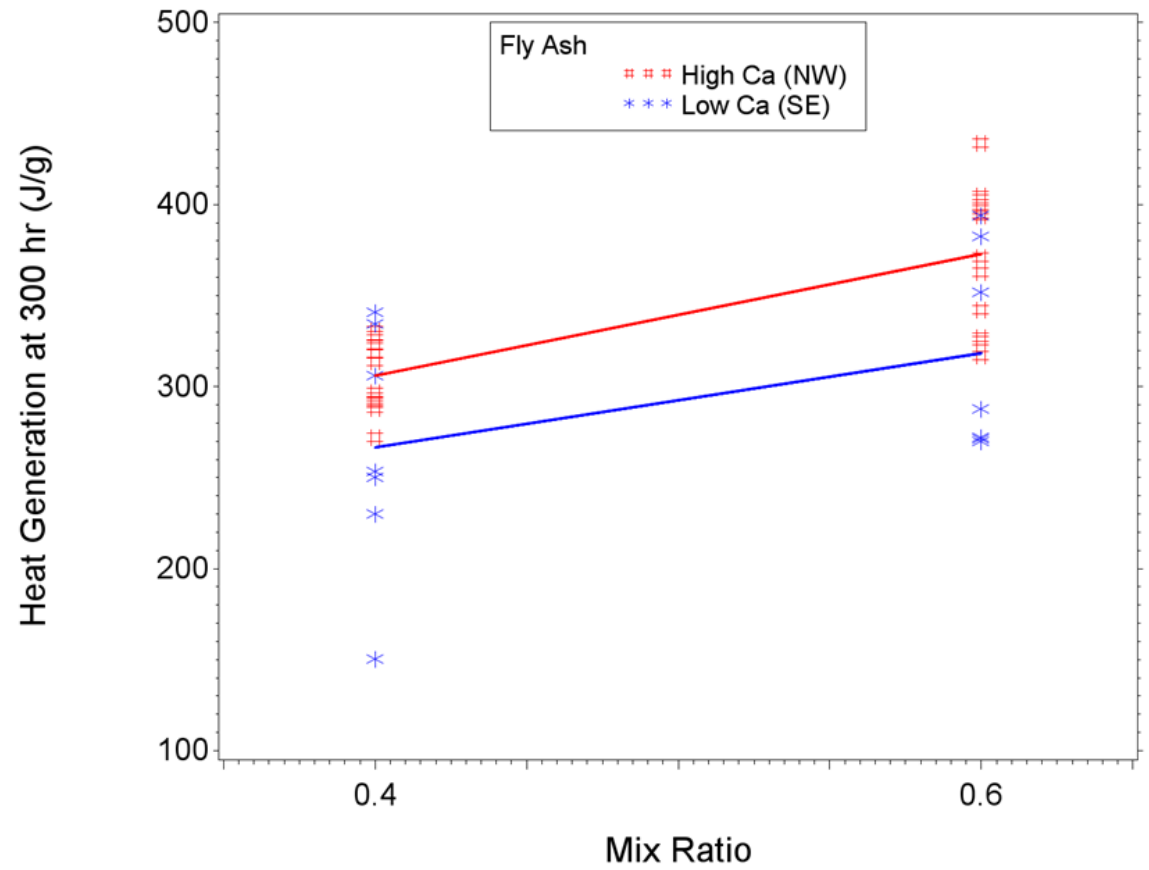

Figure E-16. Data-Interaction Plot for the Effects of Mix Ratio and Fly Ash on Heat Generation at 300 Hours 
PNNL-22747

SRNL-STI-2013-00465

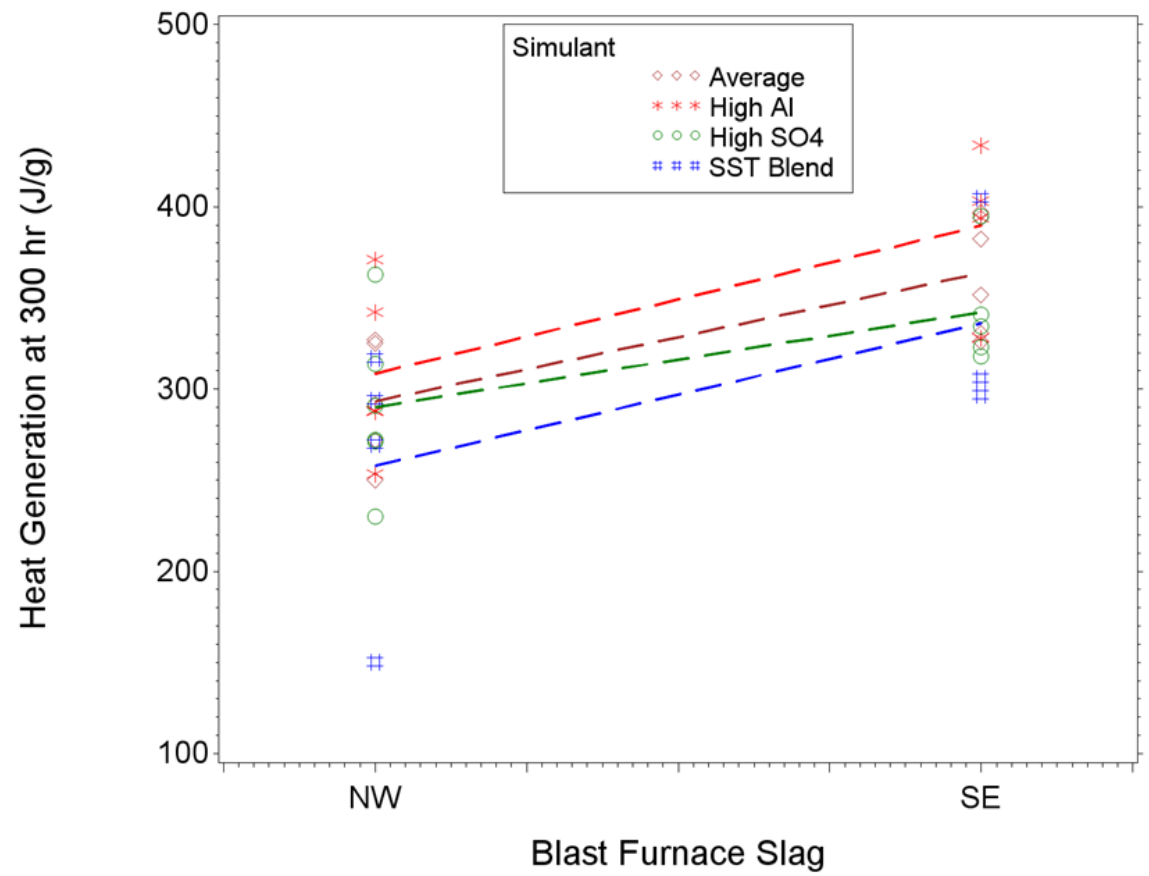

Figure E-17. Data-Interaction Plot for the Effects of Blast Furnace Slag and Simulant on Heat Generation at 300 Hours

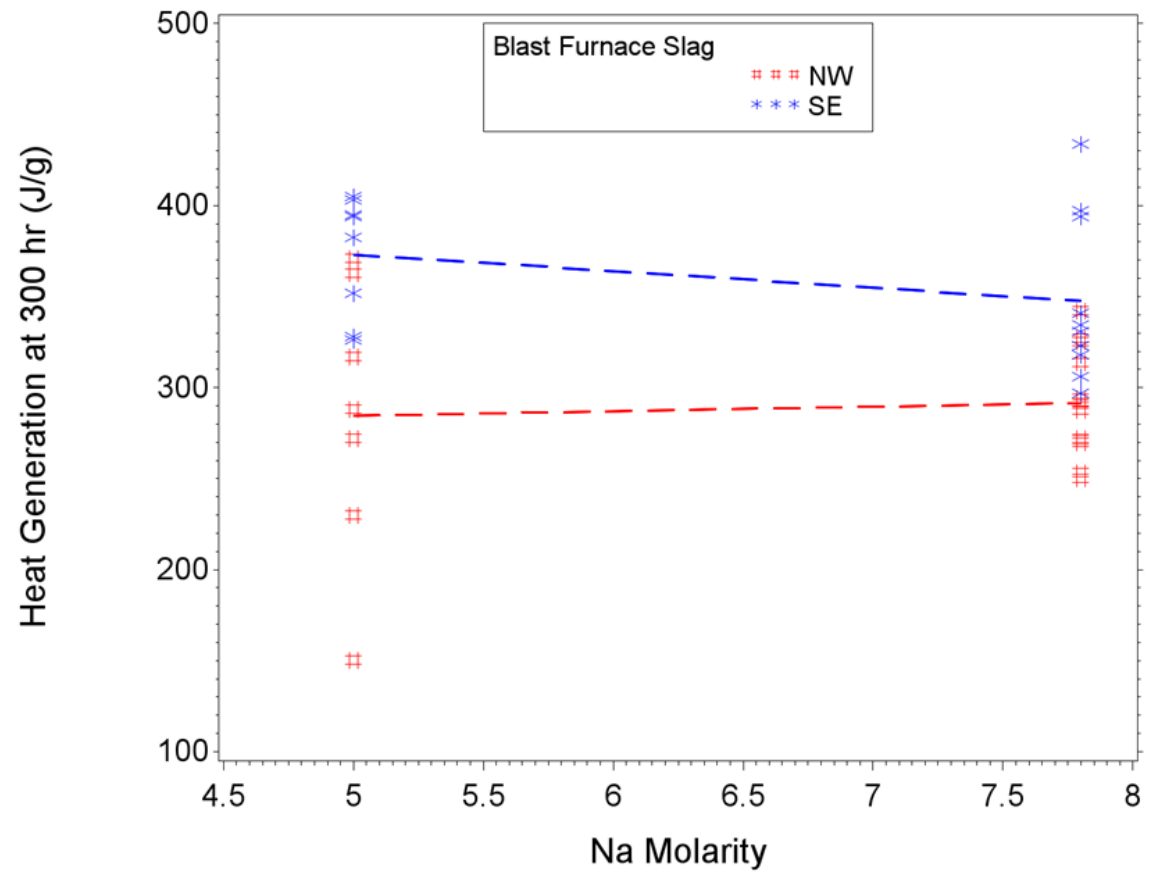

Figure E-18. Data-Interaction Plot for the Effects of Na Molarity and Blast Furnace Slag on Heat Generation at 300 Hours 


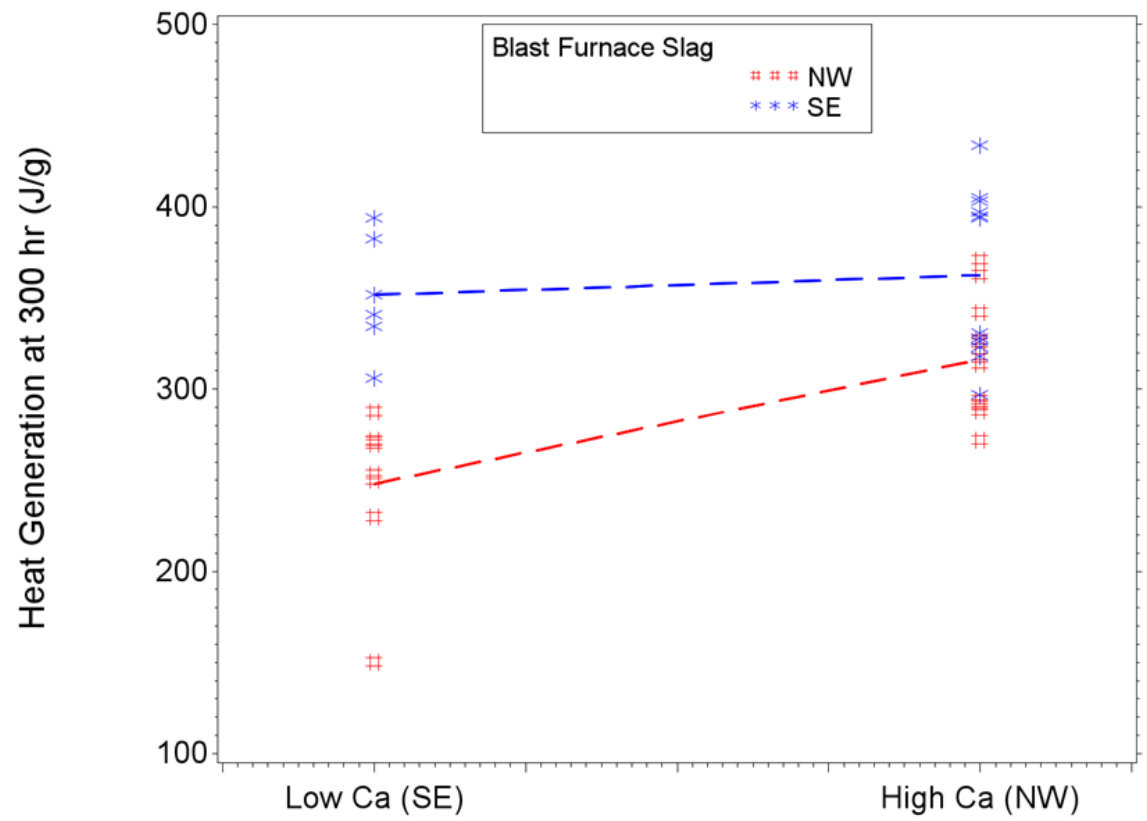

Fly Ash

Figure E-19. Data-Interaction Plot for the Effects of Fly Ash and Blast Furnace Slag on Heat Generation at 300 Hours

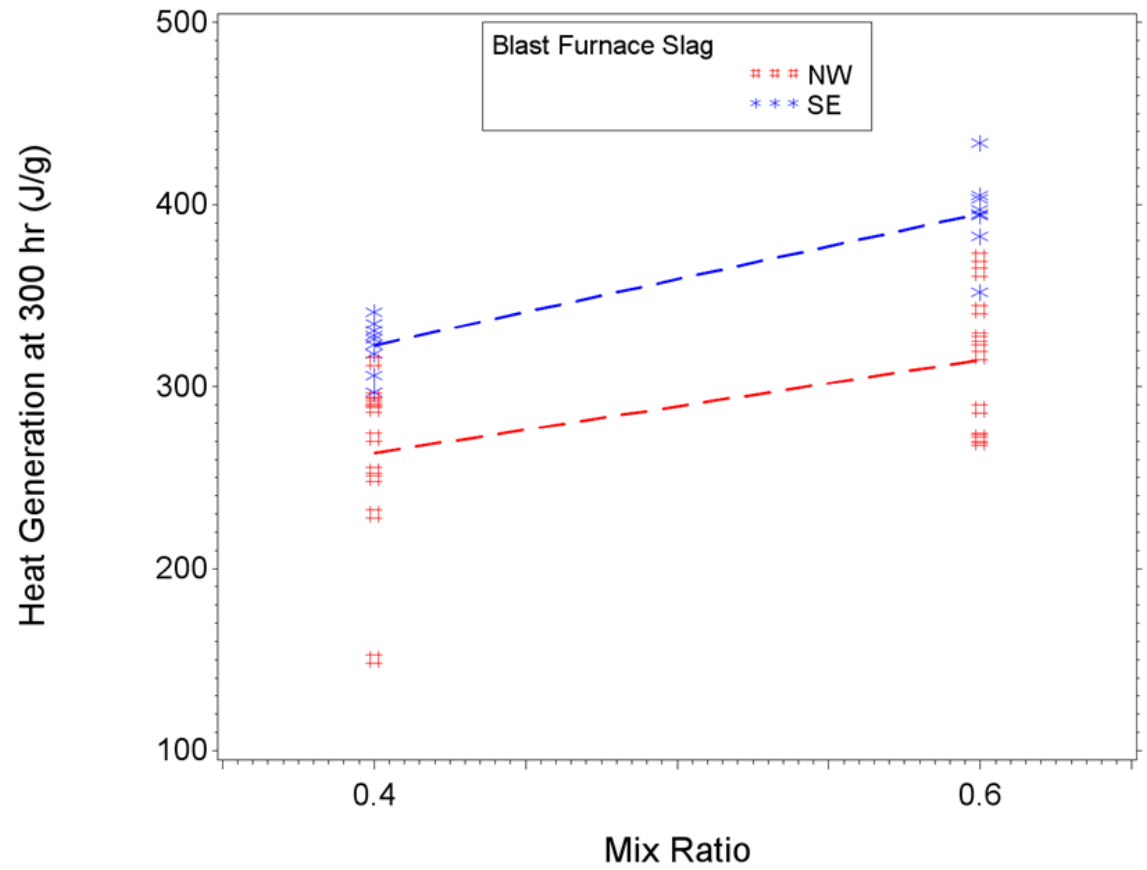

Figure E-20. Data-Interaction Plot for the Effects of Mix Ratio and Blast Furnace Slag on Heat Generation at 300 Hours 
PNNL-22747

SRNL-STI-2013-00465

\section{E.2.2 Heat Generation, Time to Peak Heat Generation}

Figure E-21 through Figure E-30 display the data-interaction plots for Time to Peak Heat Generation using the data from Cast Stone Mixes 1-38. 


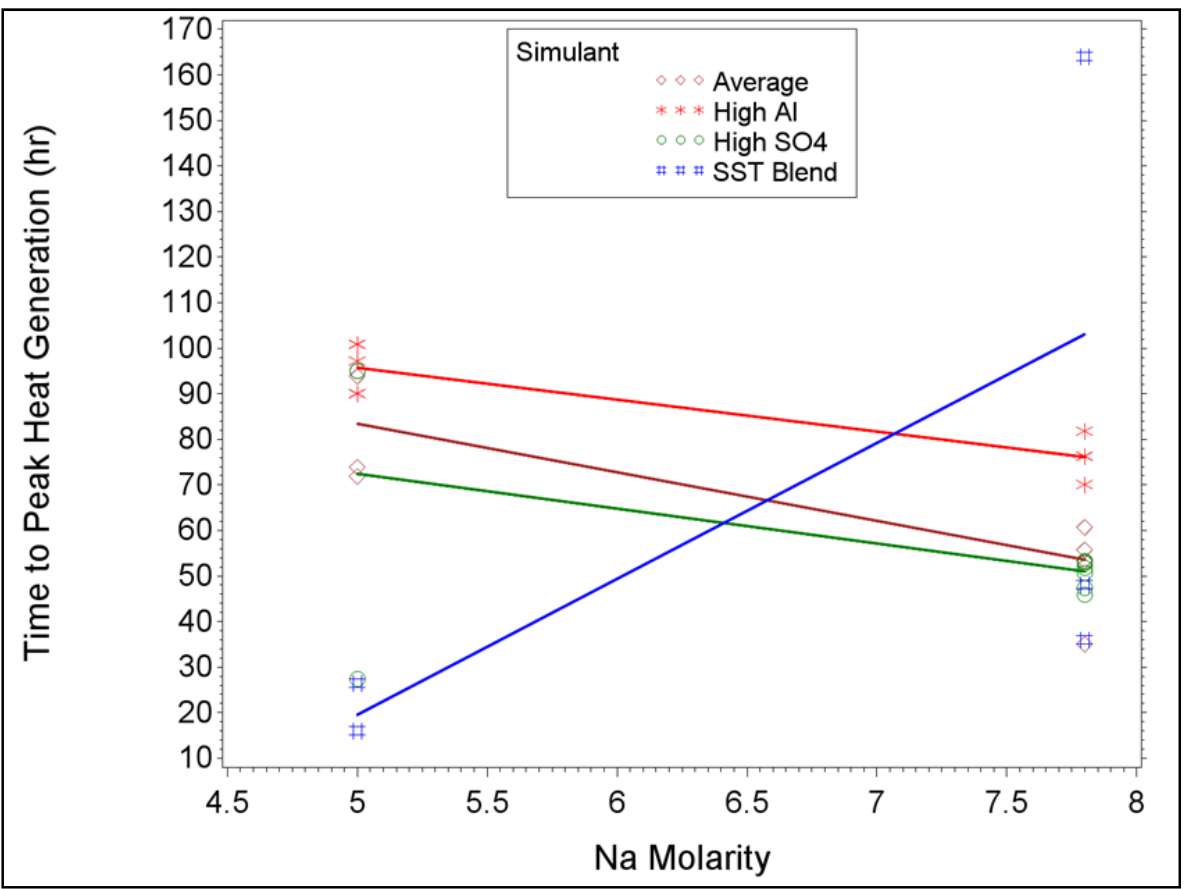

Figure E-21. Data-Interaction Plot for the Effects of Na Molarity and Simulant on Time to Peak Heat Generation

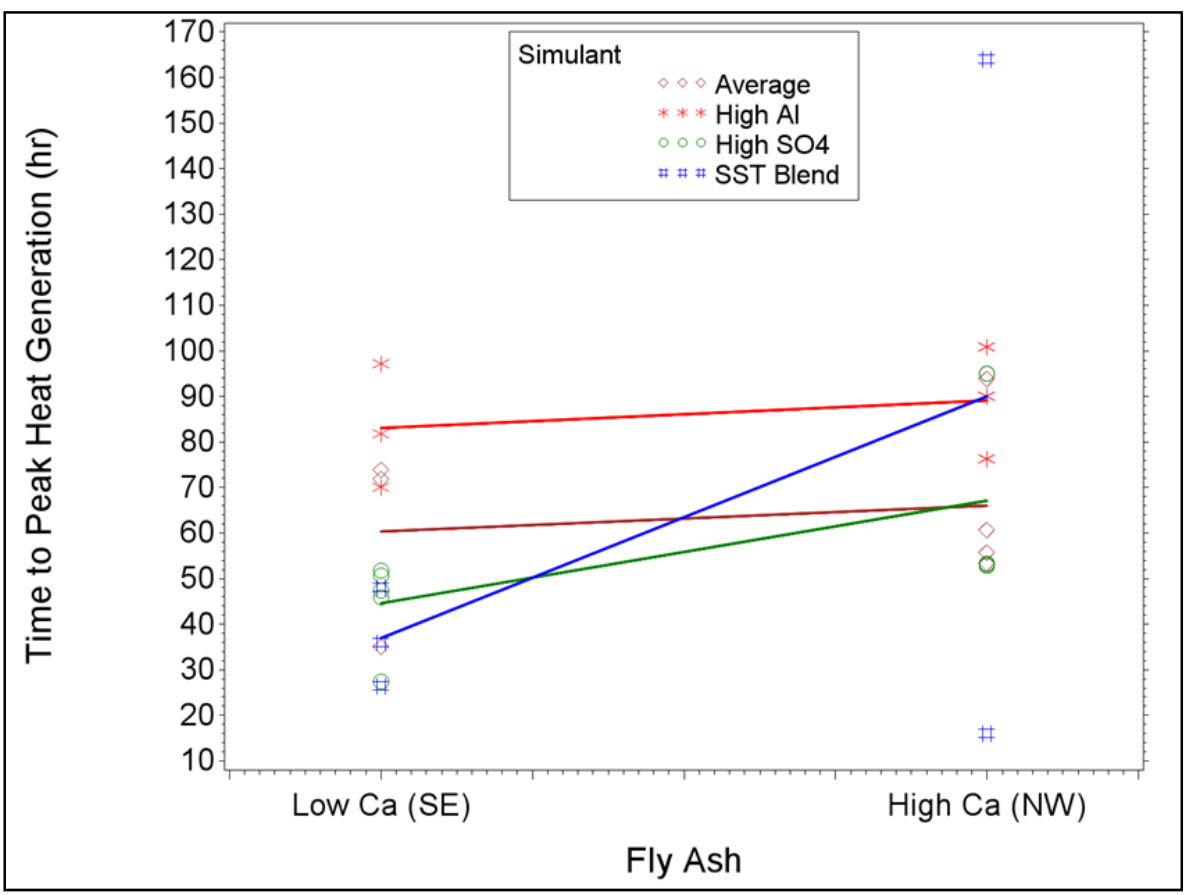

Figure E-22. Data-Interaction Plot for the Effects of Fly Ash and Simulant on Time to Peak Heat Generation 


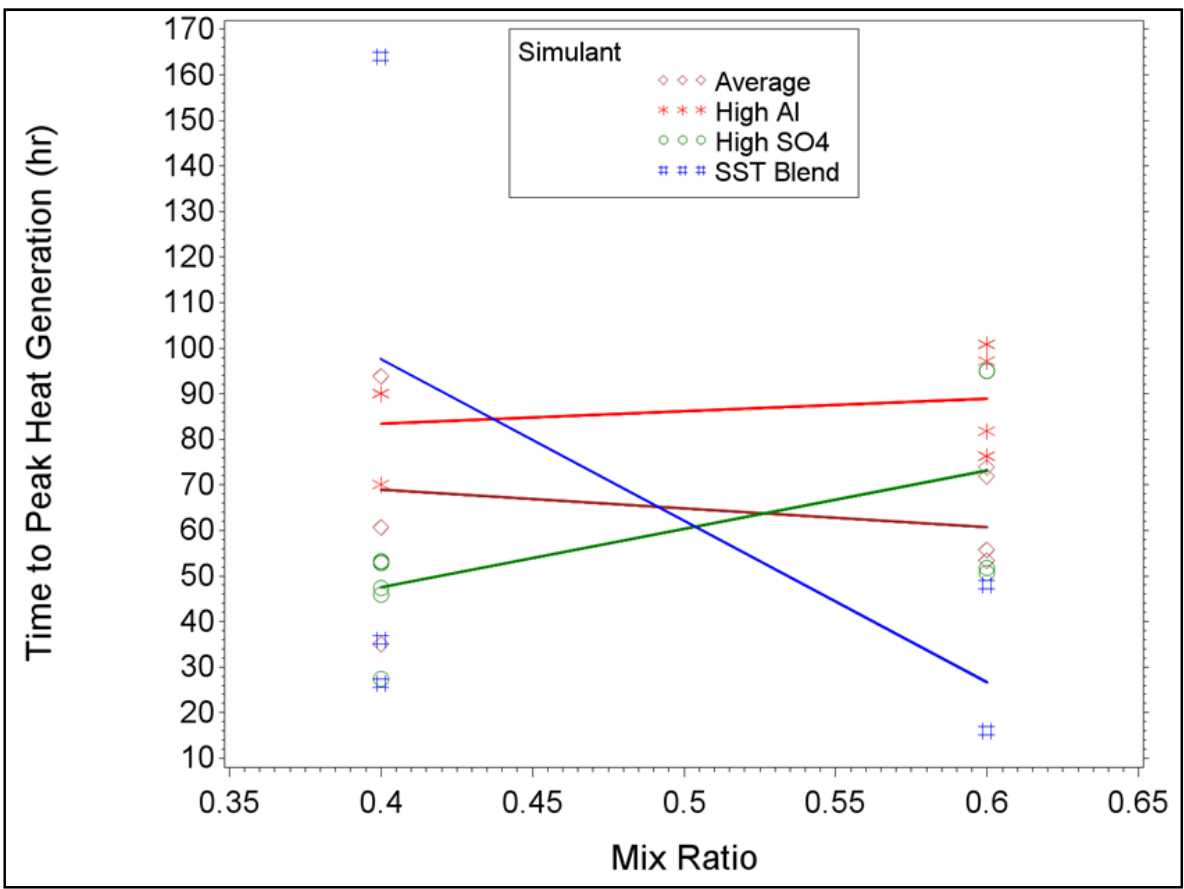

Figure E-23. Data-Interaction Plot for the Effects of Mix Ratio and Simulant on Time to Peak Heat Generation

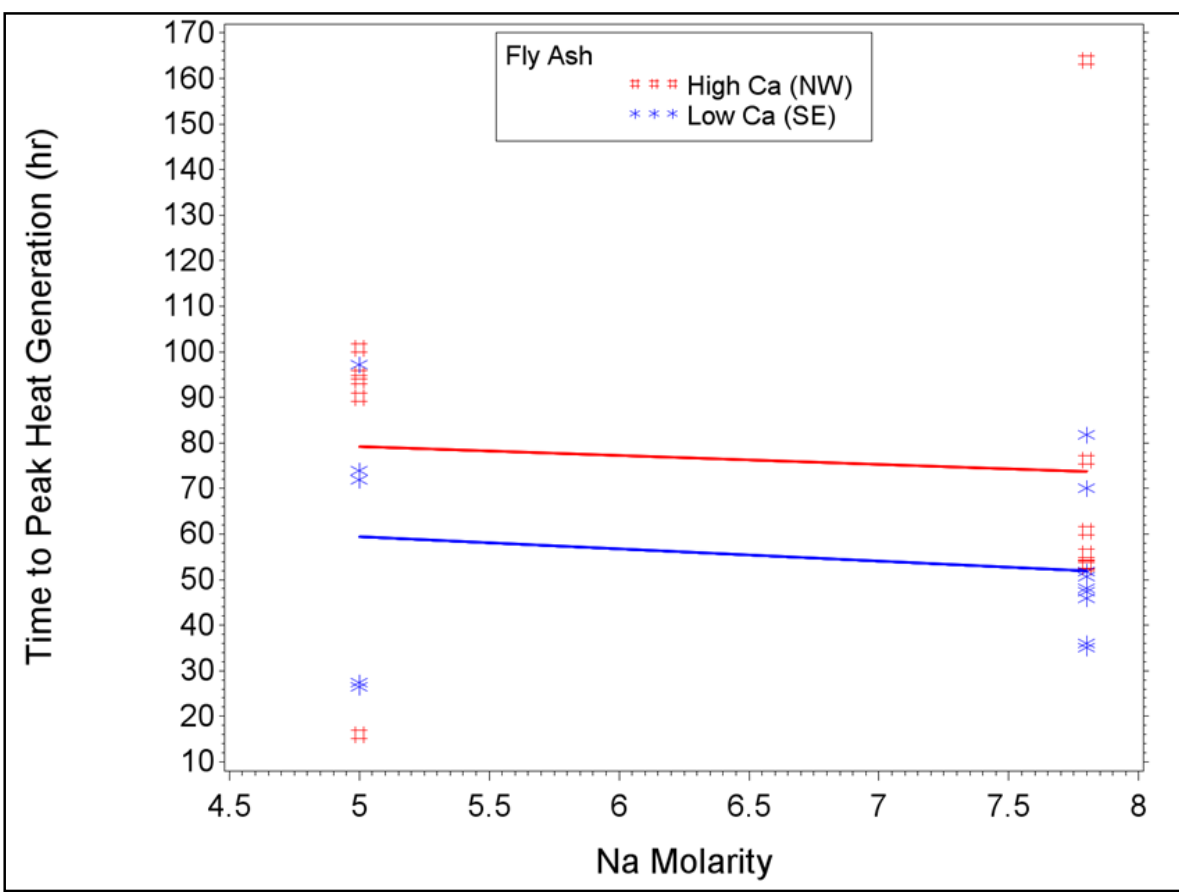

Figure E-24. Data-Interaction Plot for the Effects of Na Molarity and Fly Ash on Time to Peak Heat Generation 


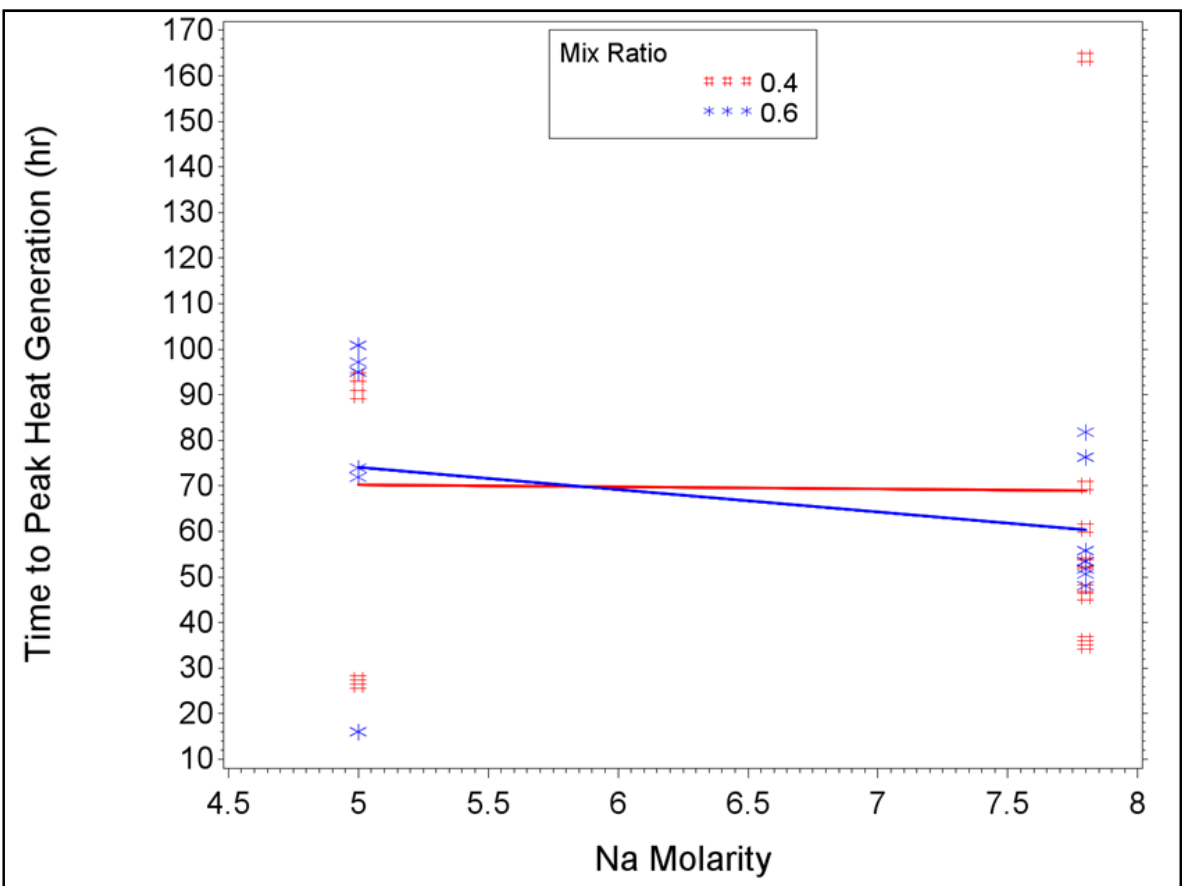

Figure E-25. Data-Interaction Plot for the Effects of Na Molarity and Mix Ratio on Time to Peak Heat Generation

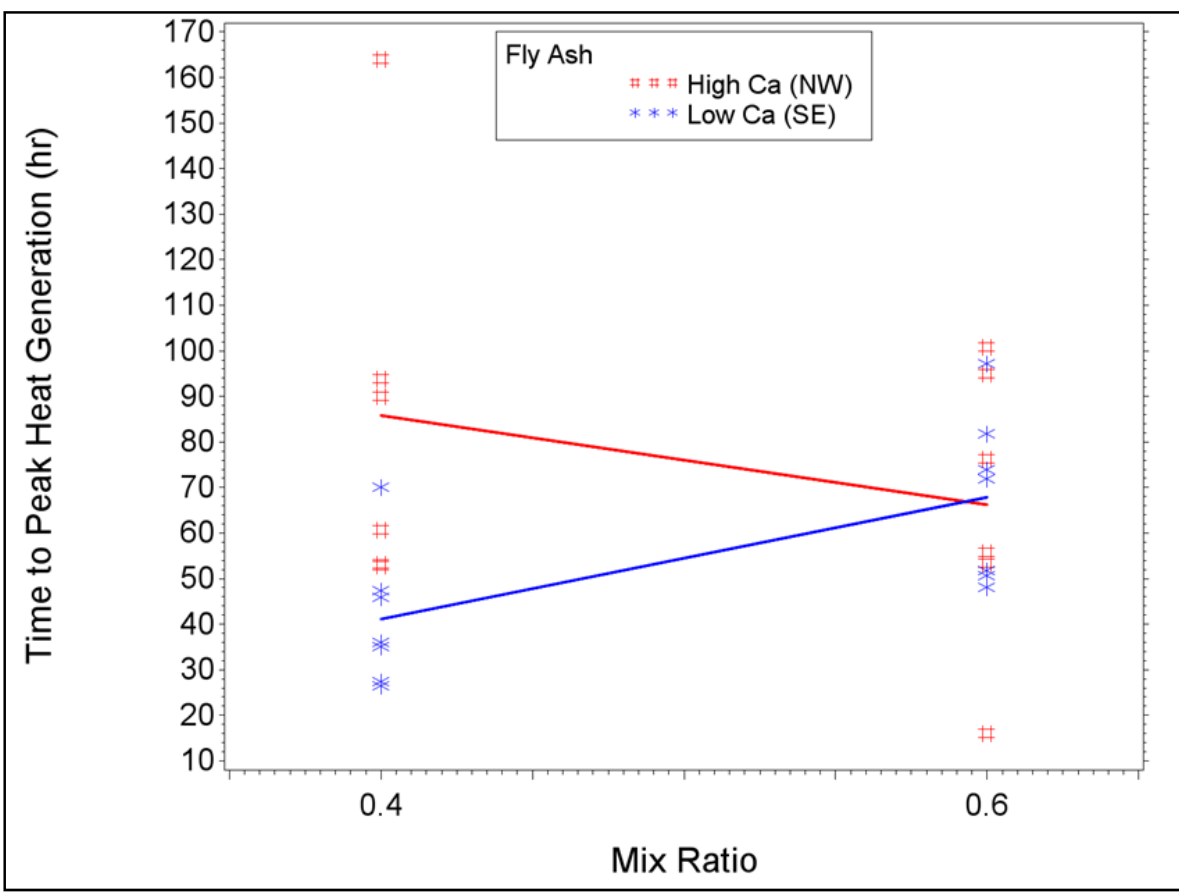

Figure E-26. Data-Interaction Plot for the Effects of Mix Ratio and Fly Ash on Time to Peak Heat Generation 


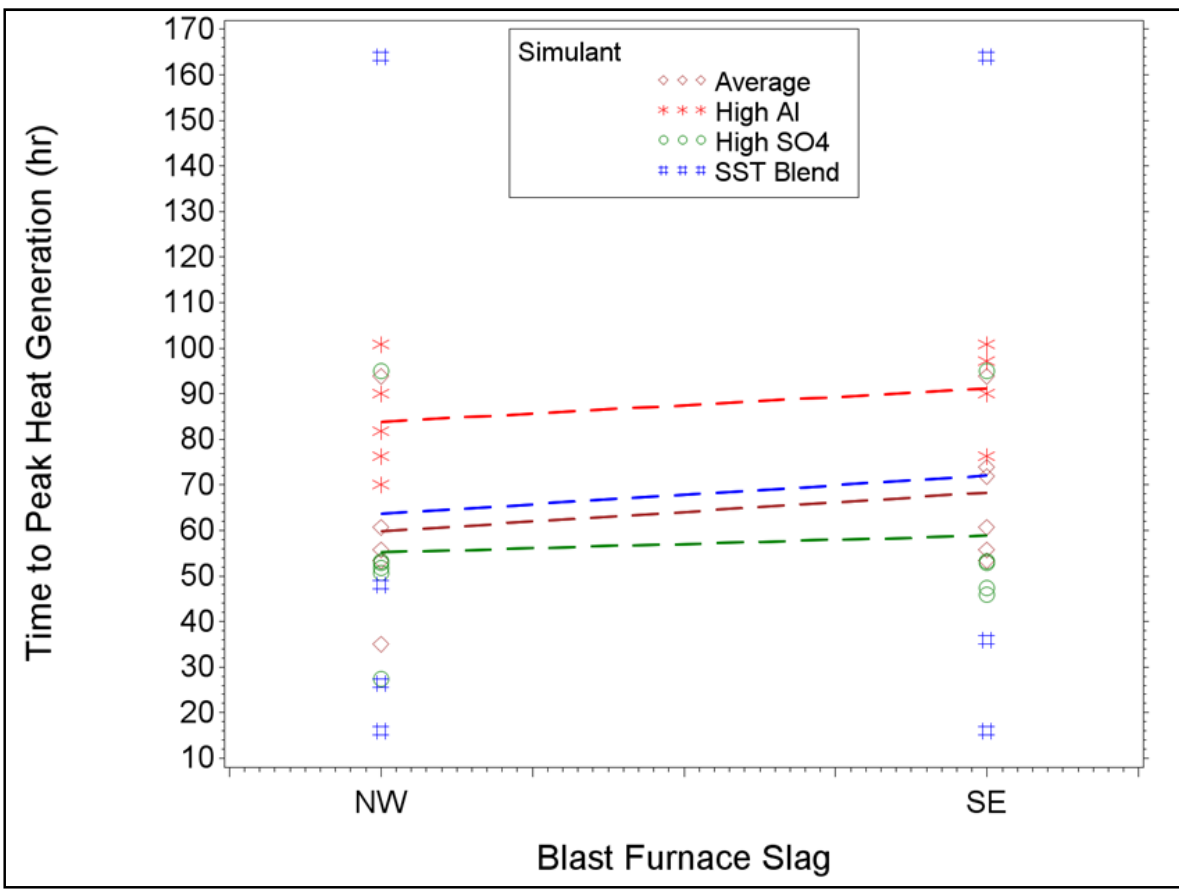

Figure E-27. Data-Interaction Plot for the Effects of Blast Furnace Slag and Simulant on Time to Peak Heat Generation

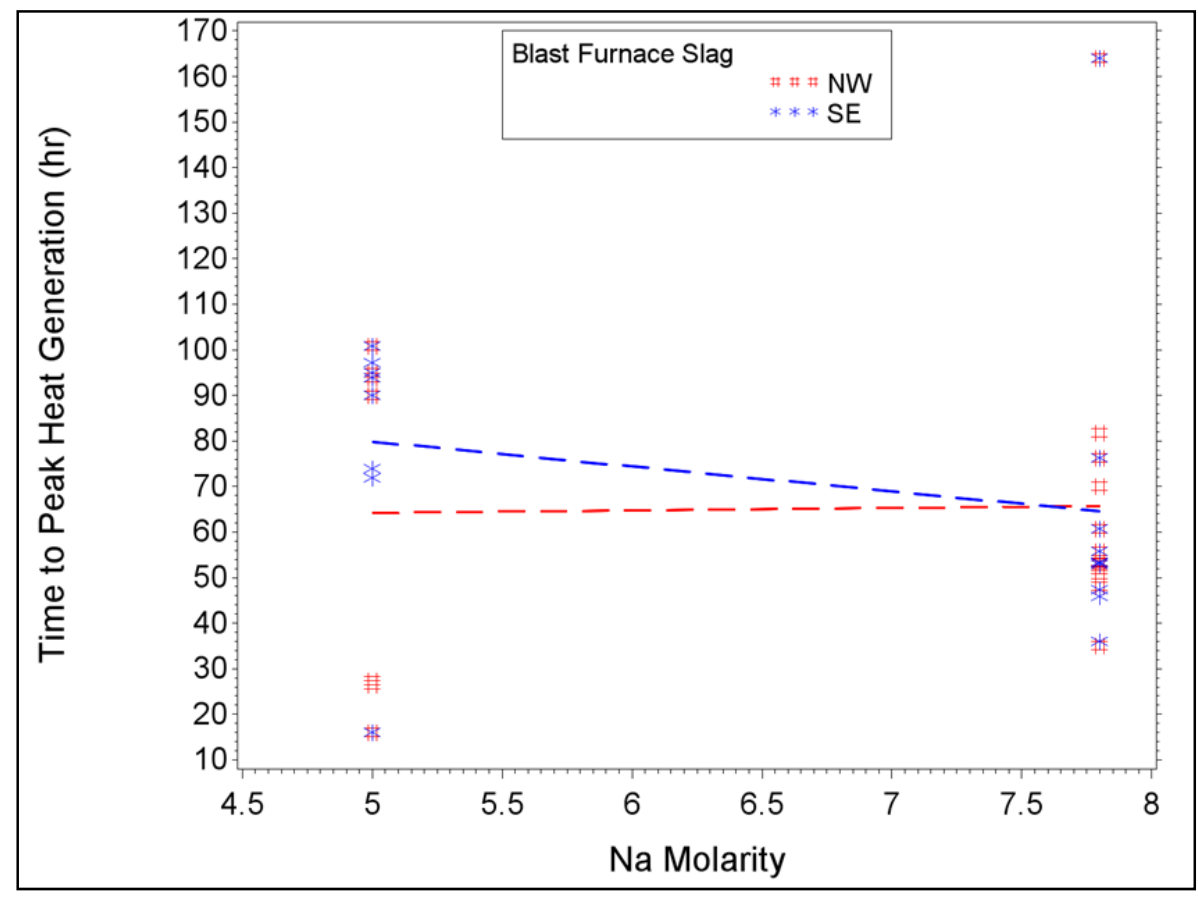

Figure E-28. Data-Interaction Plot for the Effects of Na Molarity and Blast Furnace Slag on Time to Peak Heat Generation 


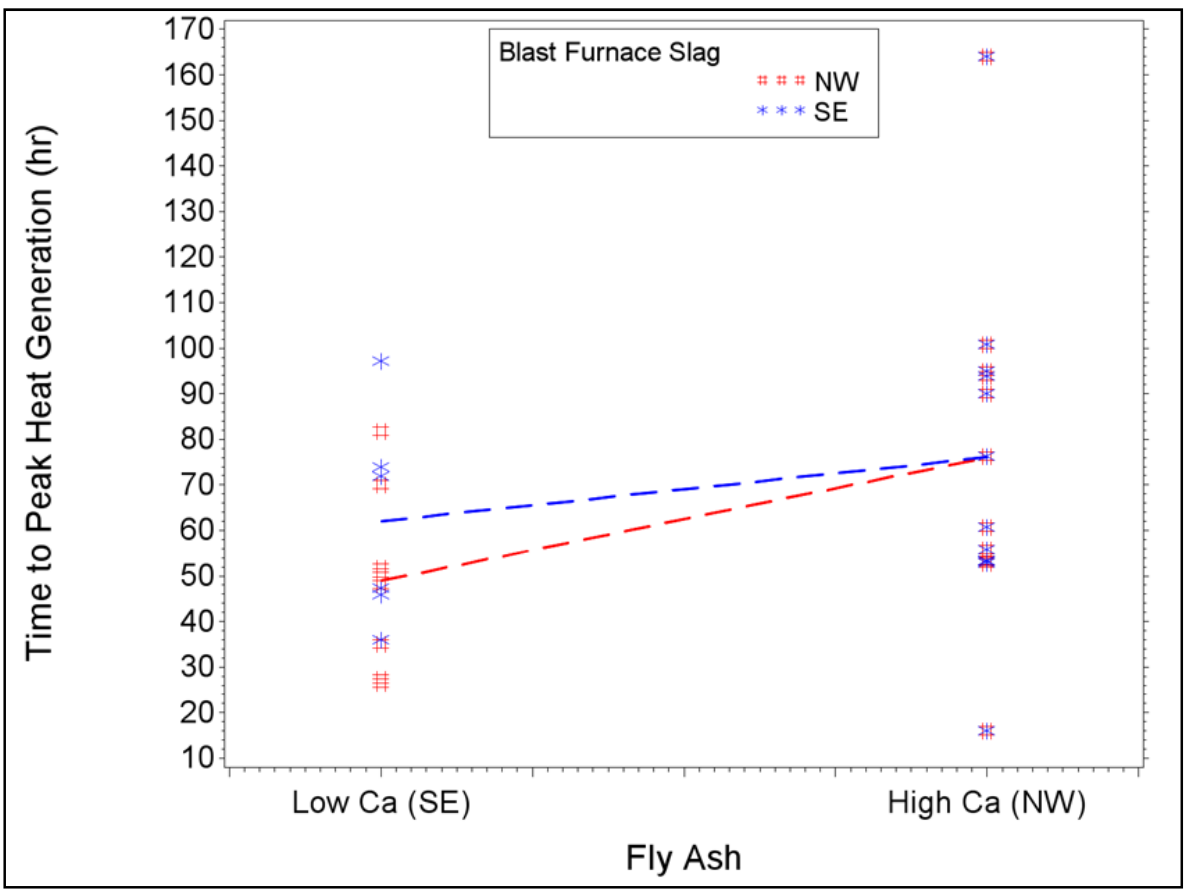

Figure E-29. Data-Interaction Plot for the Effects of Fly Ash and Blast Furnace Slag on Time to Peak Heat Generation

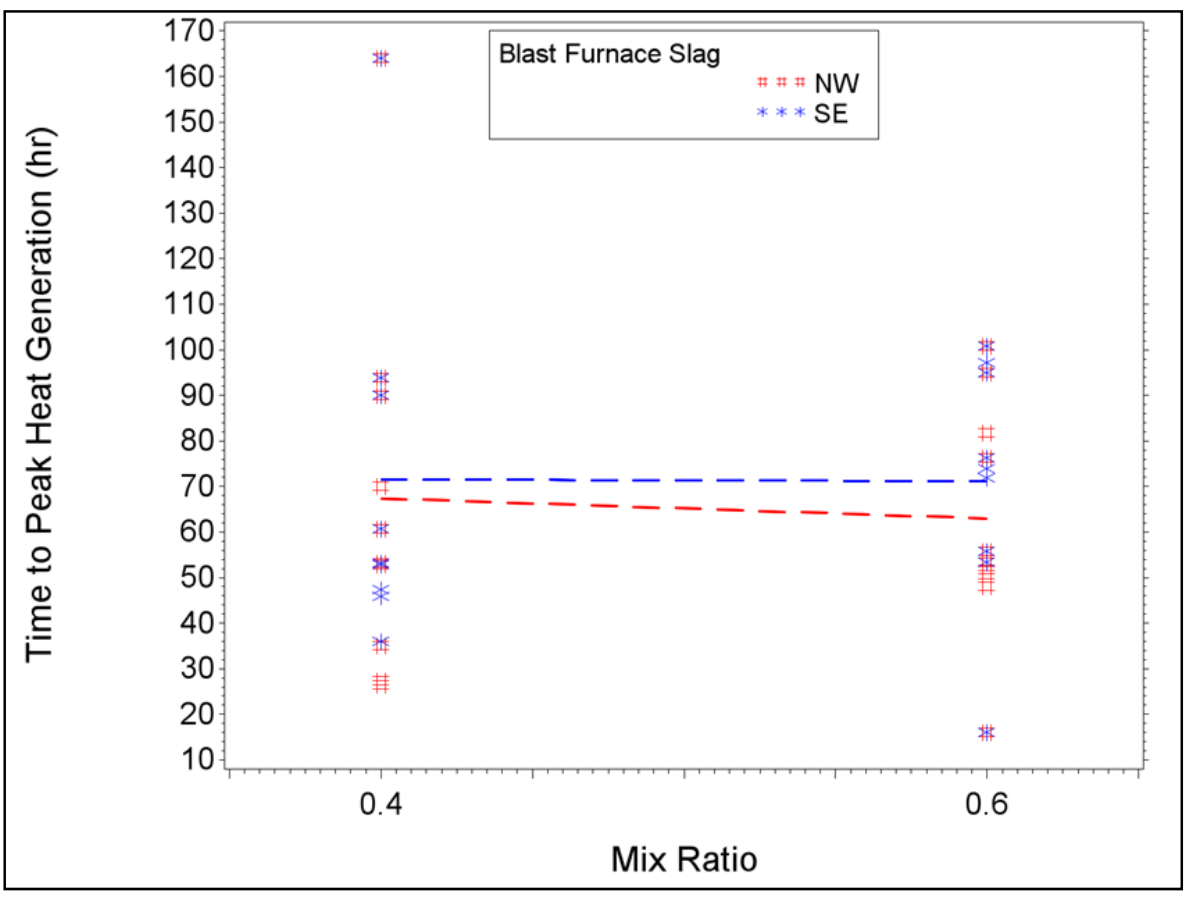

Figure E-30. Data-Interaction Plot for the Effects of Mix Ratio and Blast Furnace Slag on Time to Peak Heat Generation 


\section{E.3 Compressive Strength}

This section presents data-interaction plots of the compressive strength data from for the 26 Cast Stone mixes (1-26) in the screening text matrix. Cylindrical samples of the 26 mixes were made and tested for compressive strength at PNNL. The PNNL data in these plots are from the "Mean" column in Table D-2 in Appendix D.

Figure E-31 through Figure E-40 display the data-interaction plots using the Compressive Strength data measured at PNNL. 
PNNL-22747

SRNL-STI-2013-00465

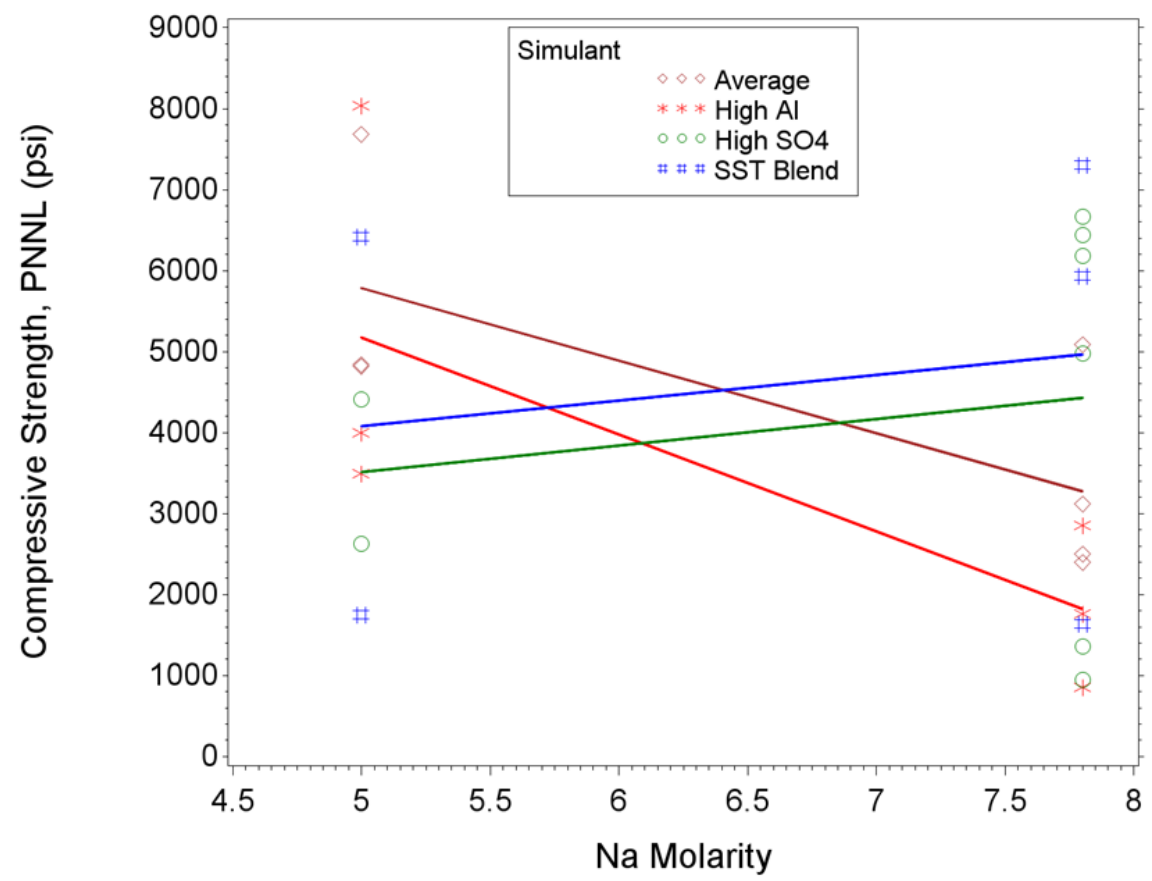

Figure E-31. Data-Interaction Plot for the Effects of Na Molarity and Simulant on Compressive Strength Tested at PNNL

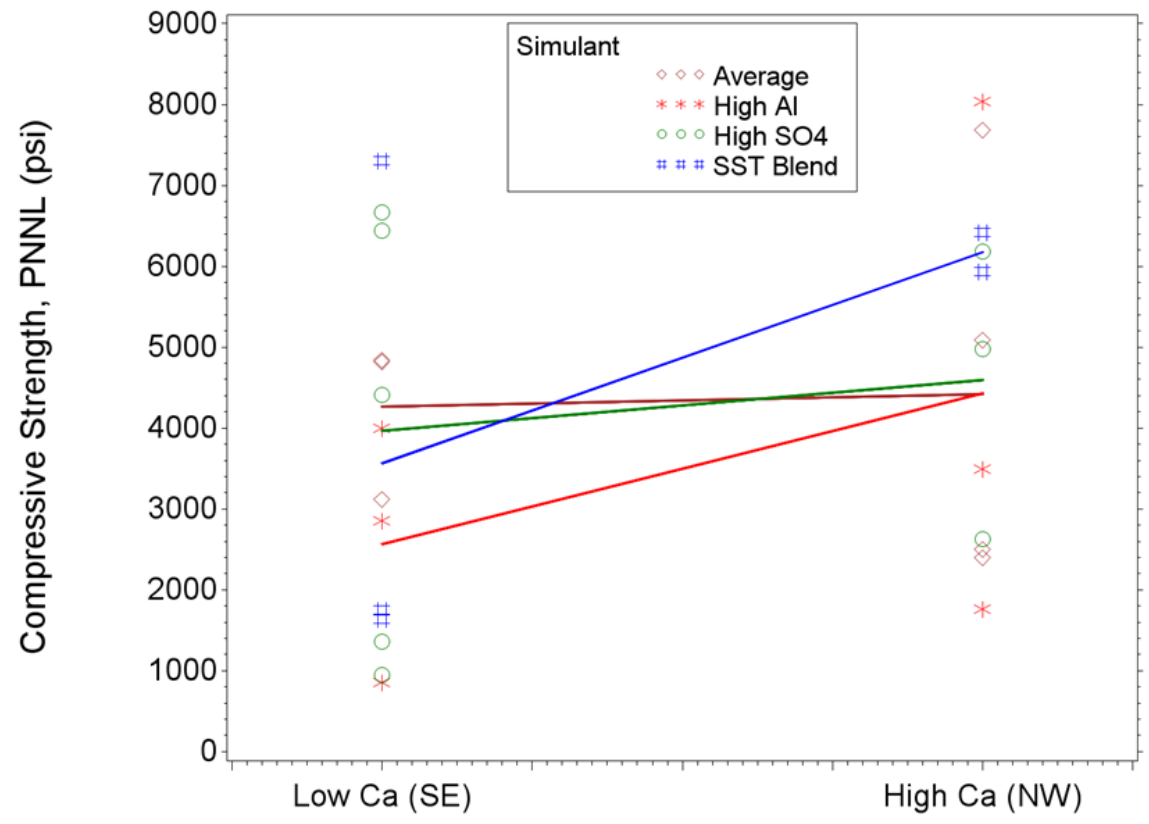

Fly Ash

Figure E-32. Data-Interaction Plot for the Effects of Fly Ash and Simulant on Compressive Strength Tested at PNNL 


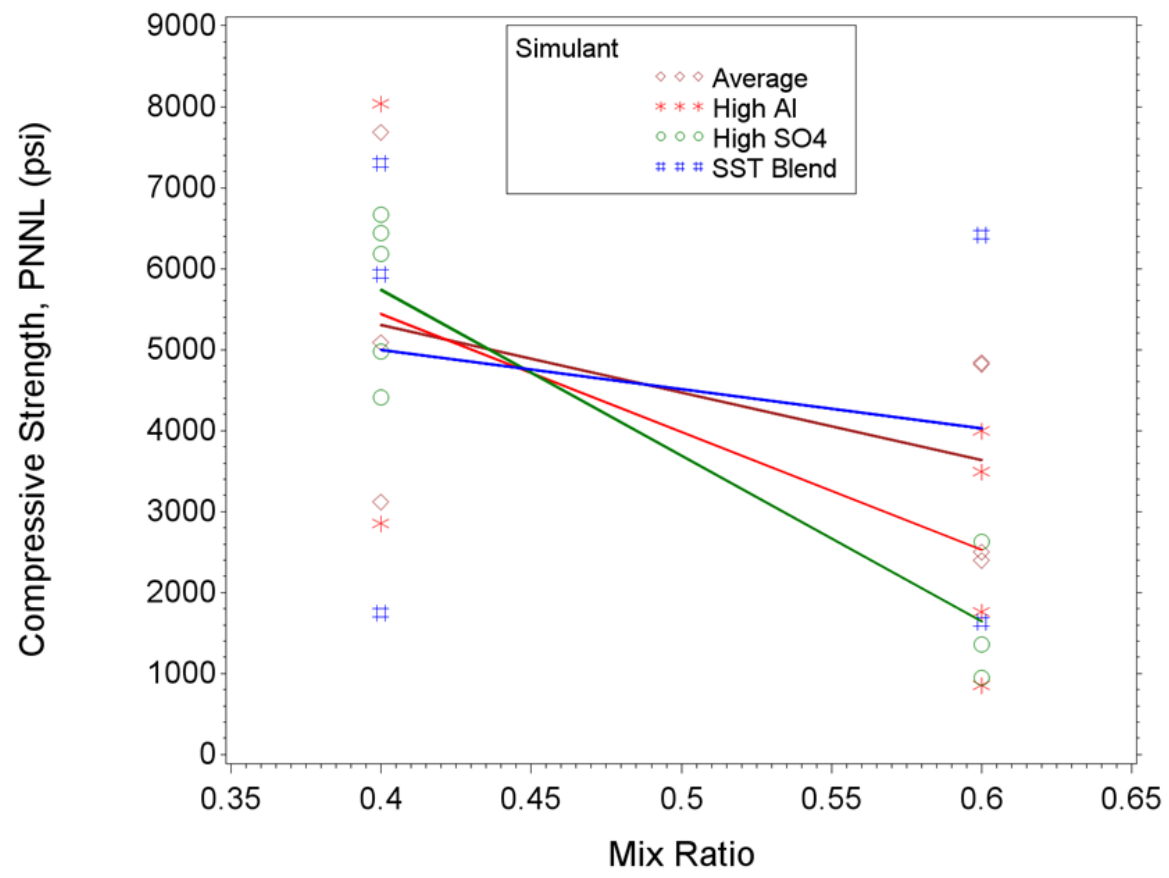

Figure E-33. Data-Interaction Plot for the Effects of Mix Ratio and Simulant on Compressive Strength Tested at PNNL

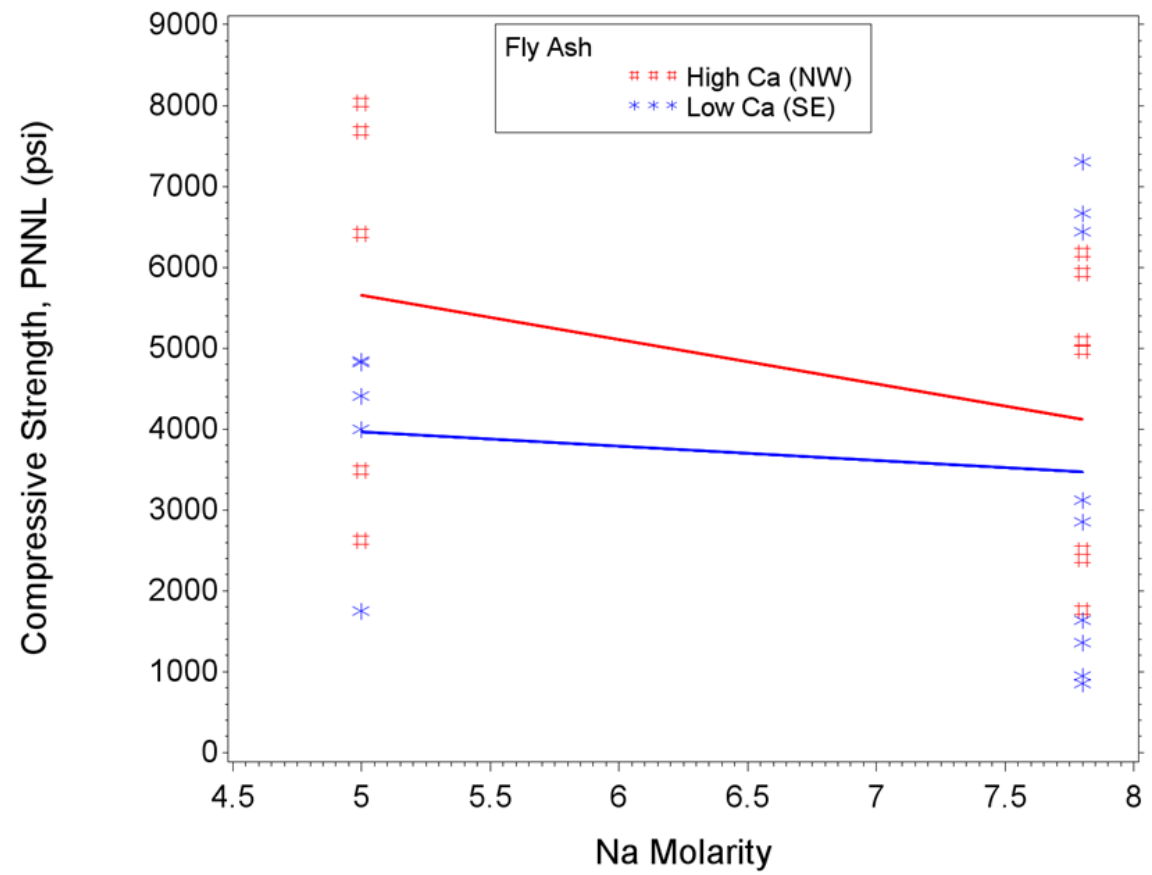

Figure E-34. Data-Interaction Plot for the Effects of Na Molarity and Fly Ash on Compressive Strength Tested at PNNL 


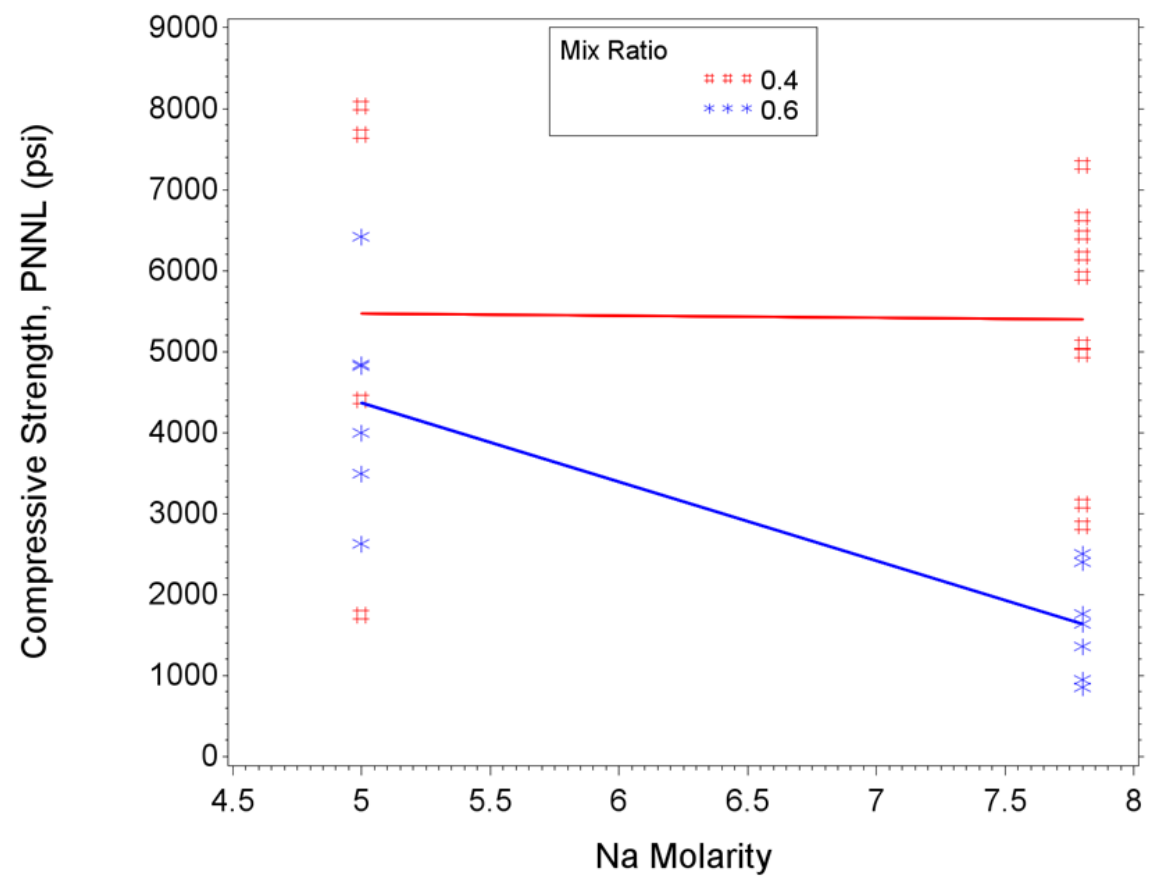

Figure E-35. Data-Interaction Plot for the Effects of Na Molarity and Mix Ratio on Compressive Strength Tested at PNNL

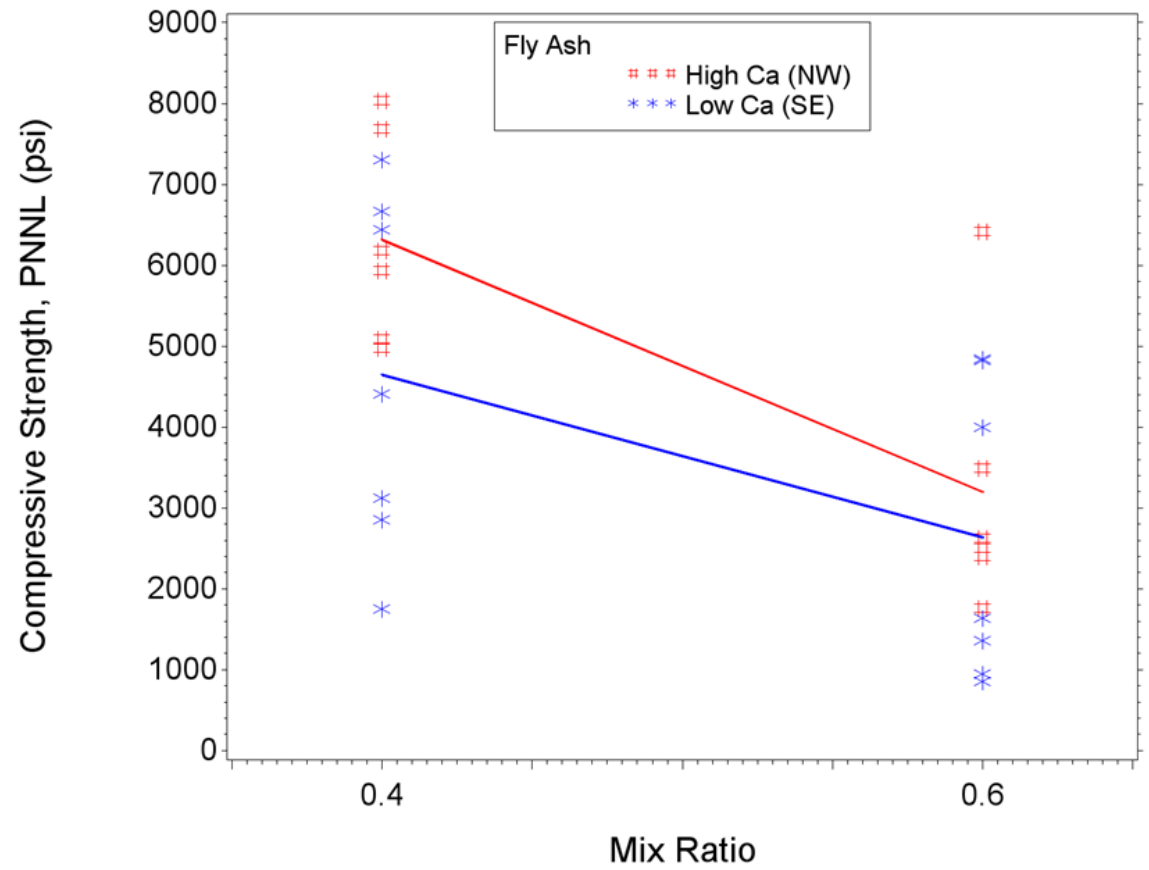

Figure E-36. Data-Interaction Plot for the Effects of Mix Ratio and Fly Ash on Compressive Strength Tested at PNNL 
PNNL-22747

SRNL-STI-2013-00465

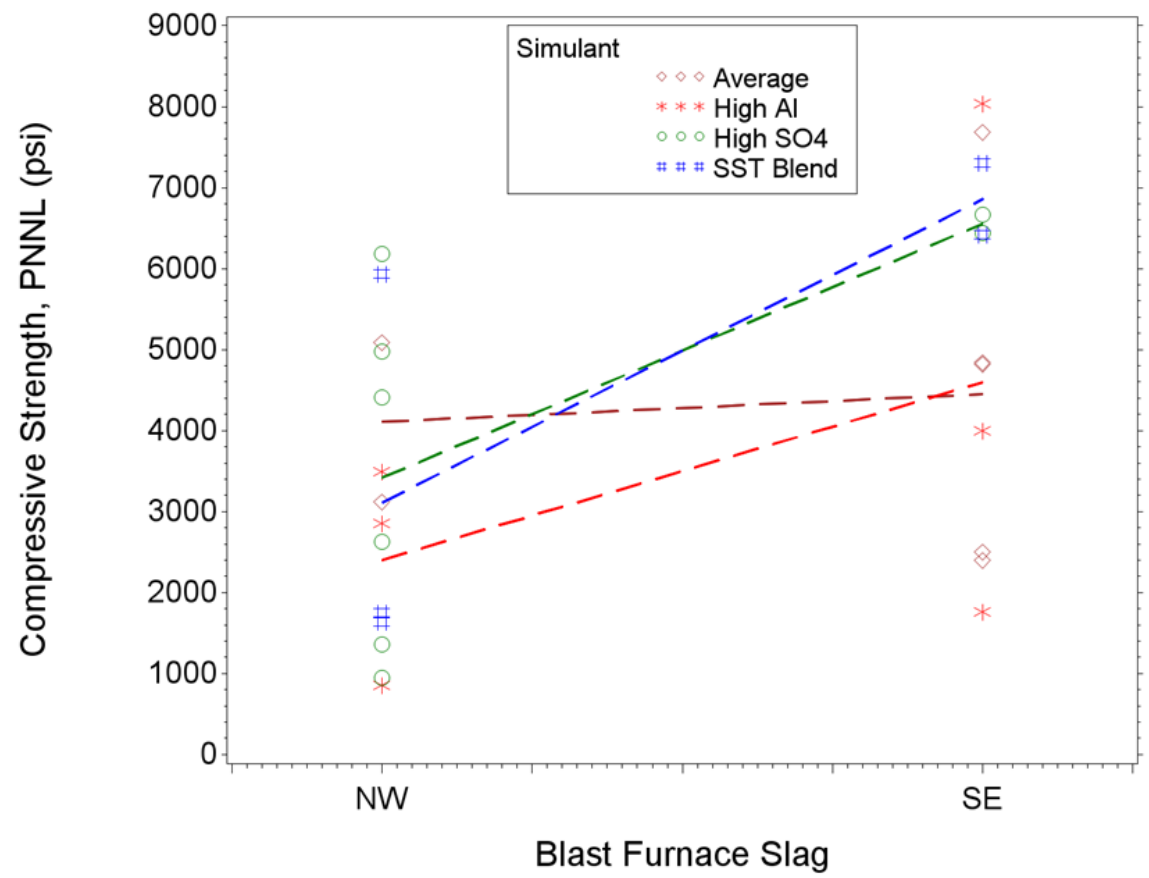

Figure E-37. Data-Interaction Plot for the Effects of Blast Furnace Slag and Simulant on Compressive Strength Tested at PNNL

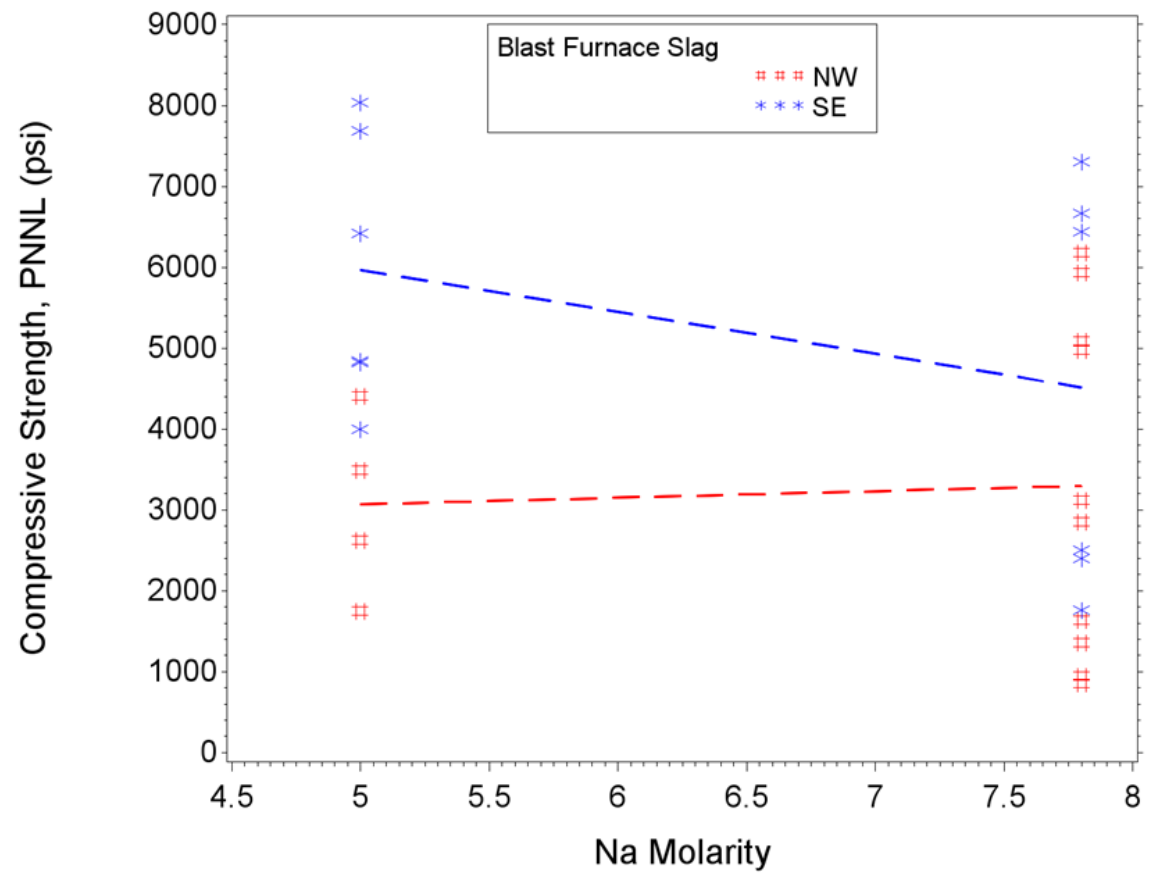

Figure E-38. Data-Interaction Plot for the Effects of Na Molarity and Blast Furnace Slag on Compressive Strength Tested at PNNL 


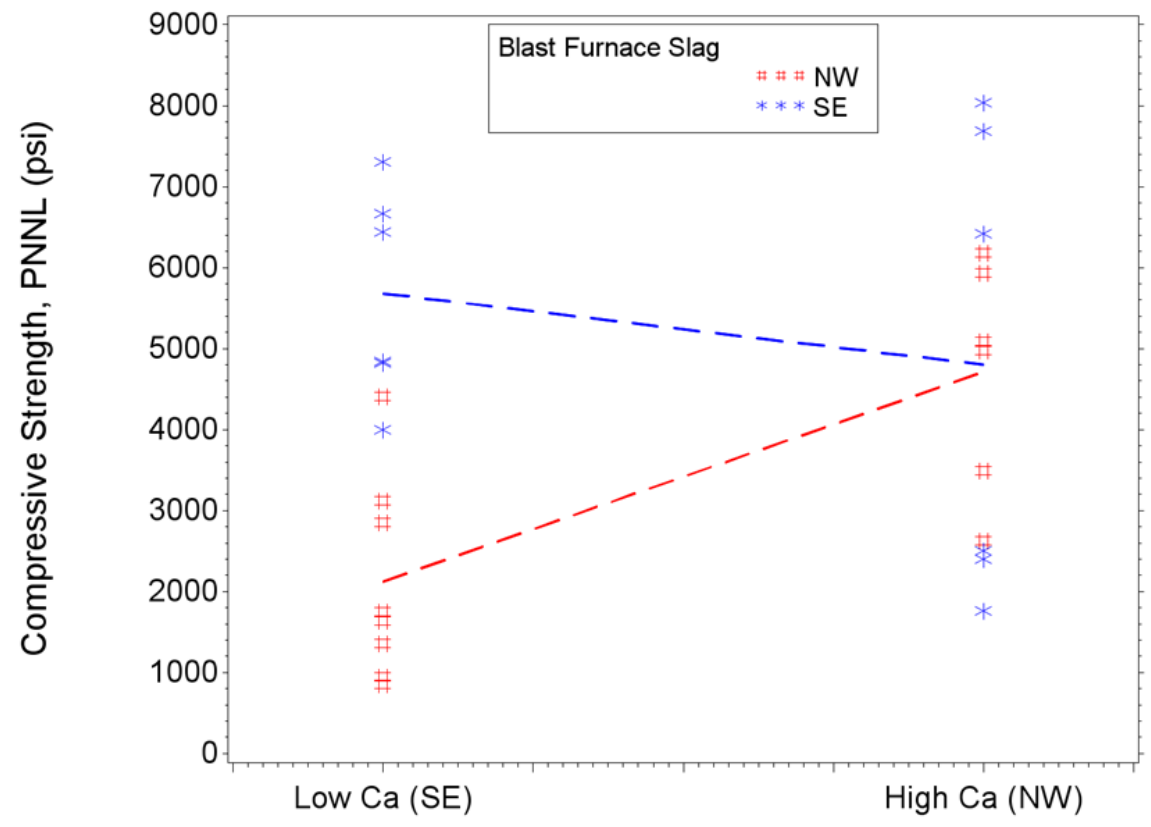

Fly Ash

Figure E-39. Data-Interaction Plot for the Effects of Fly Ash and Blast Furnace Slag on Compressive Strength Tested at PNNL

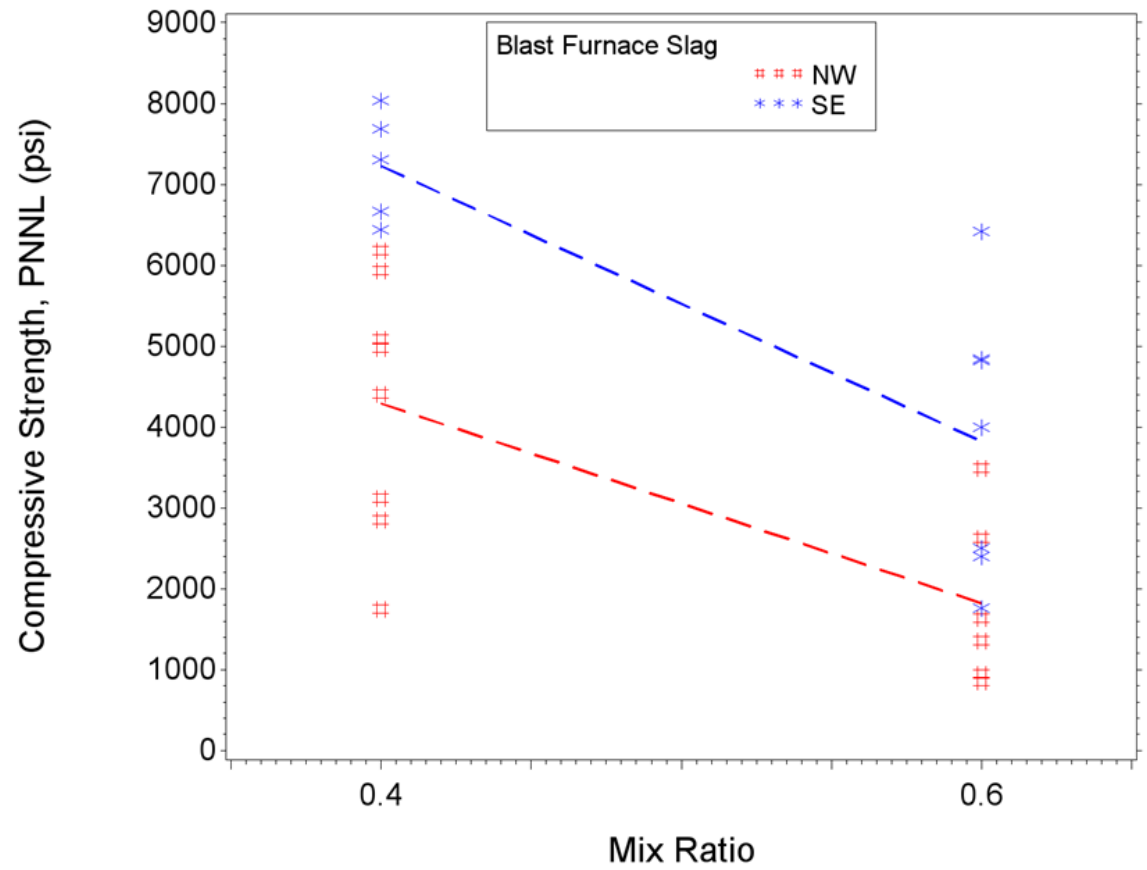

Figure E-40. Data-Interaction Plot for the Effects of Mix Ratio and Blast Furnace Slag on Compressive Strength Tested at PNNL 


\section{E.4 Leachability Index, EPA Draft Method 1315 Leach Test}

This section presents data-interaction plots for averaged leachability indices (LIs) over the cumulative leach times of 28 to 63 cumulative days of $\mathrm{Na}, \mathrm{NO}_{3}, \mathrm{I}, \mathrm{Tc}$, and $\mathrm{Cr}$. Plots are not included for $\mathrm{NO}_{2}$ because the nitrate and nitrite data are very strongly correlated (see Figure 8-3). Leachability indices were calculated from effective diffusivities using Equation (7-2). The averaged LIs were determined using Equation (D-1). The data plotted in the figures are listed in the "Mean" column for each of the leachates in Table D-15 in Appendix D.

\section{E.4.1 Sodium Leachability Index}

Figure E-41 through Figure E-50 display the data-interaction plots for Na LI of the 26 Cast Stone mixes in the screening text matrix. 


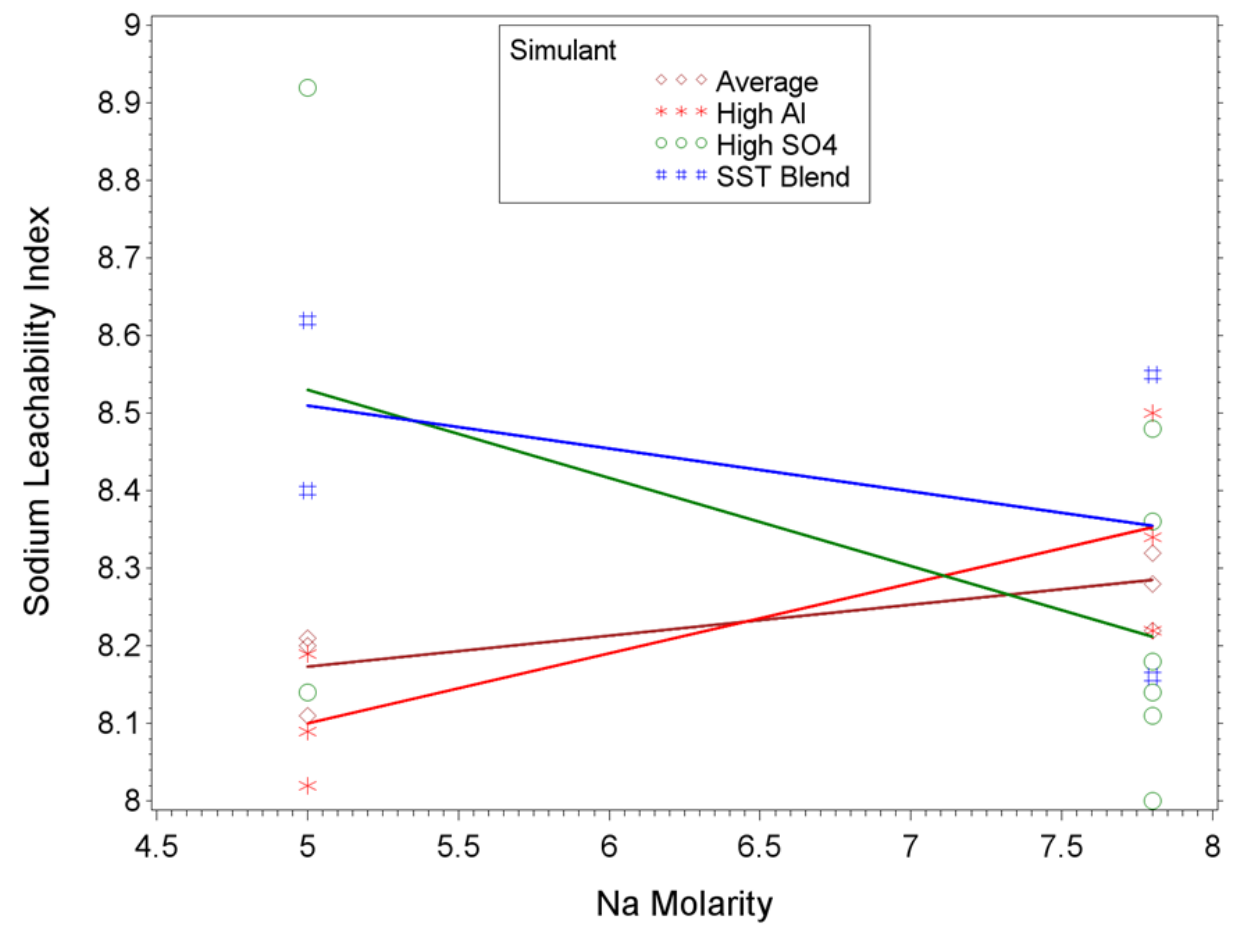

Figure E-41. Data-Interaction Plot for the Effects of Na Molarity and Simulant on Sodium Leachability Index

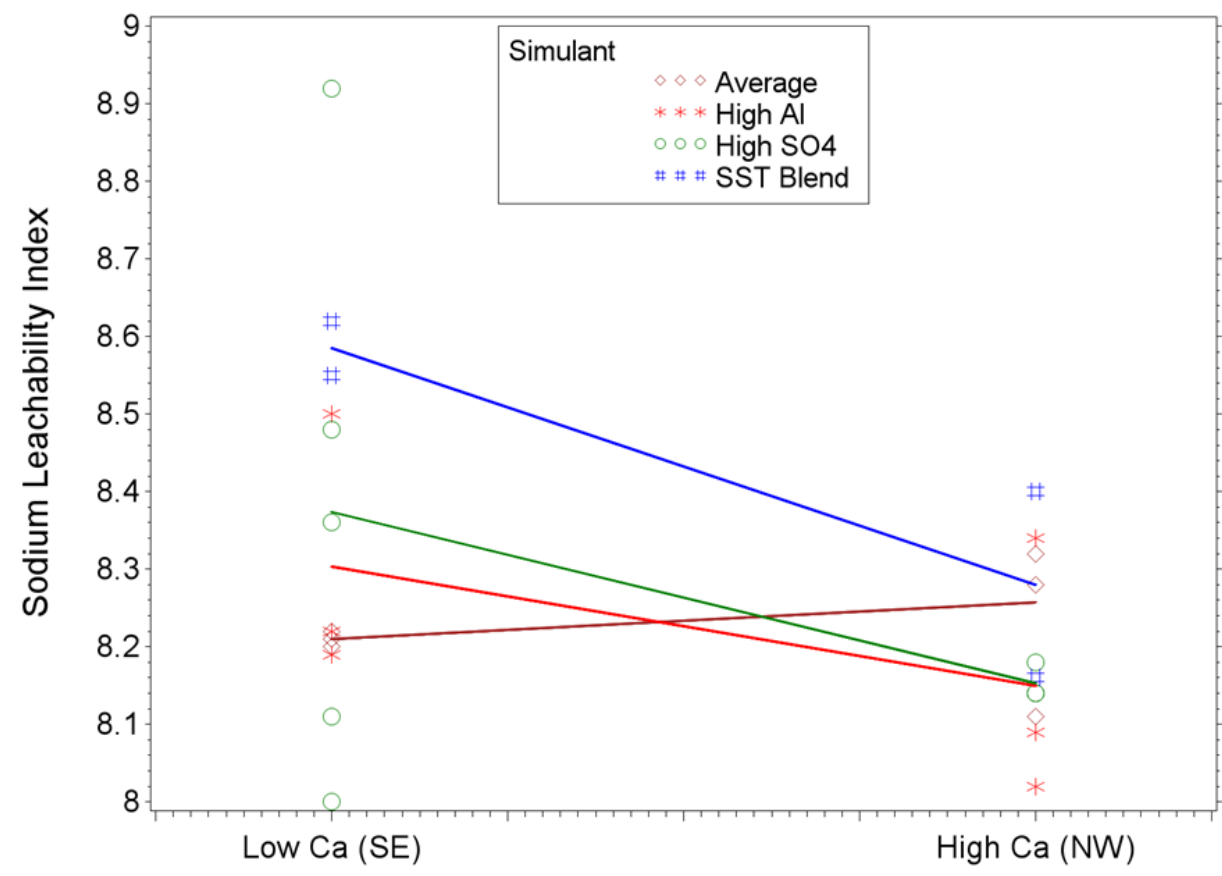

Fly Ash

Figure E-42. Data-Interaction Plot for the Effects of Fly Ash and Simulant on Sodium Leachability Index 


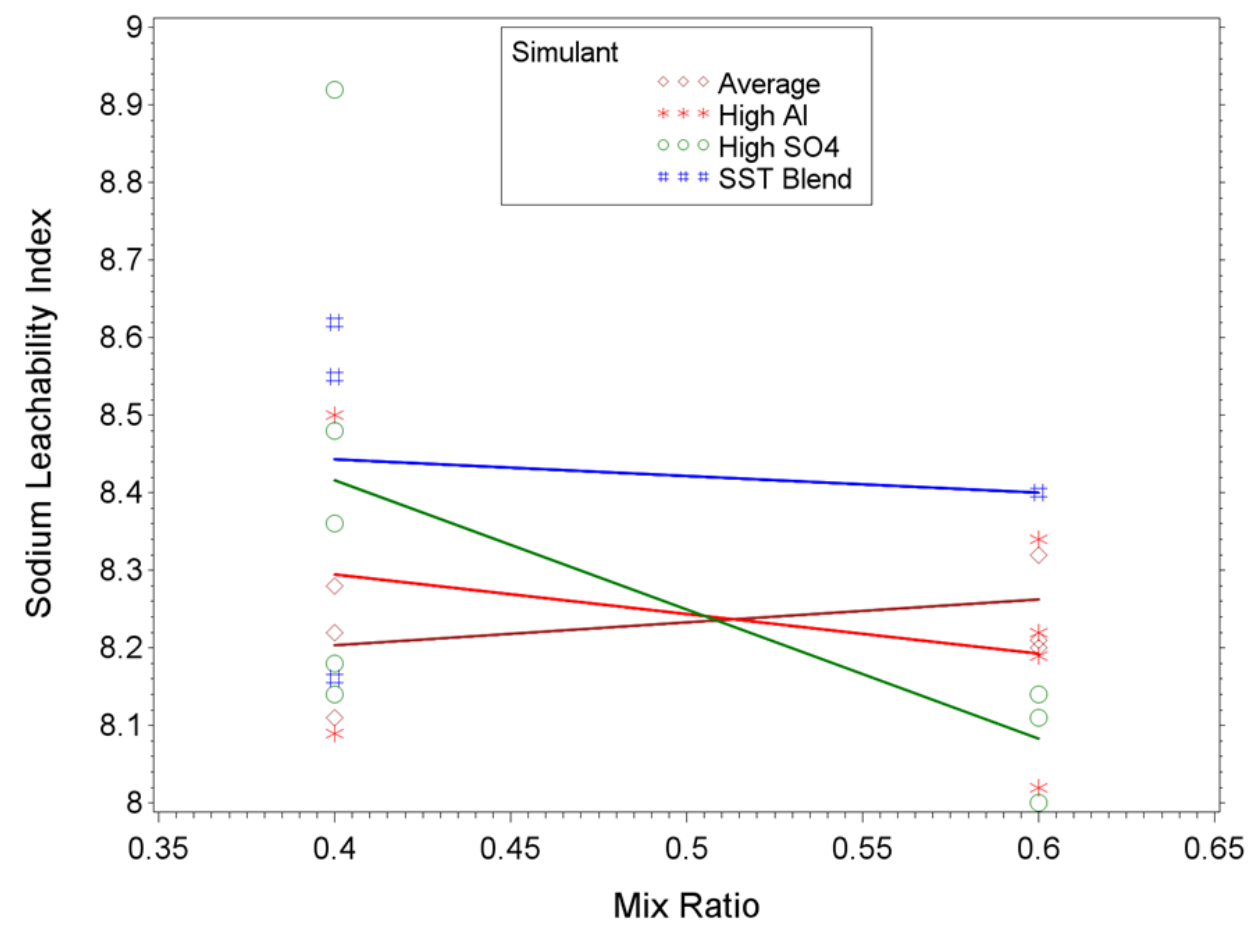

Figure E-43. Data-Interaction Plot for the Effects of Mix Ratio and Simulant on Sodium Leachability Index

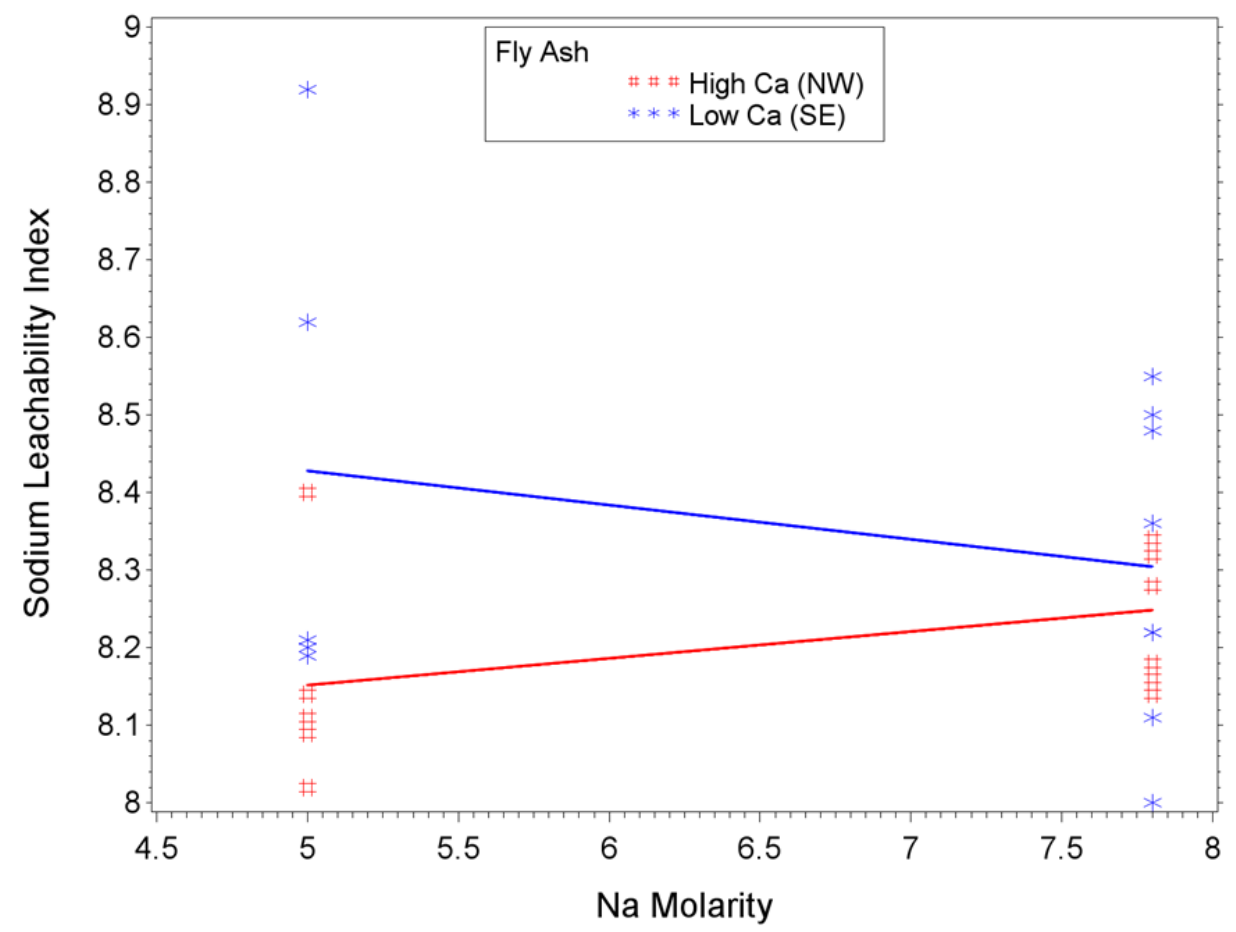

Figure E-44. Data-Interaction Plot for the Effects of Na Molarity and Fly Ash on Sodium Leachability Index 


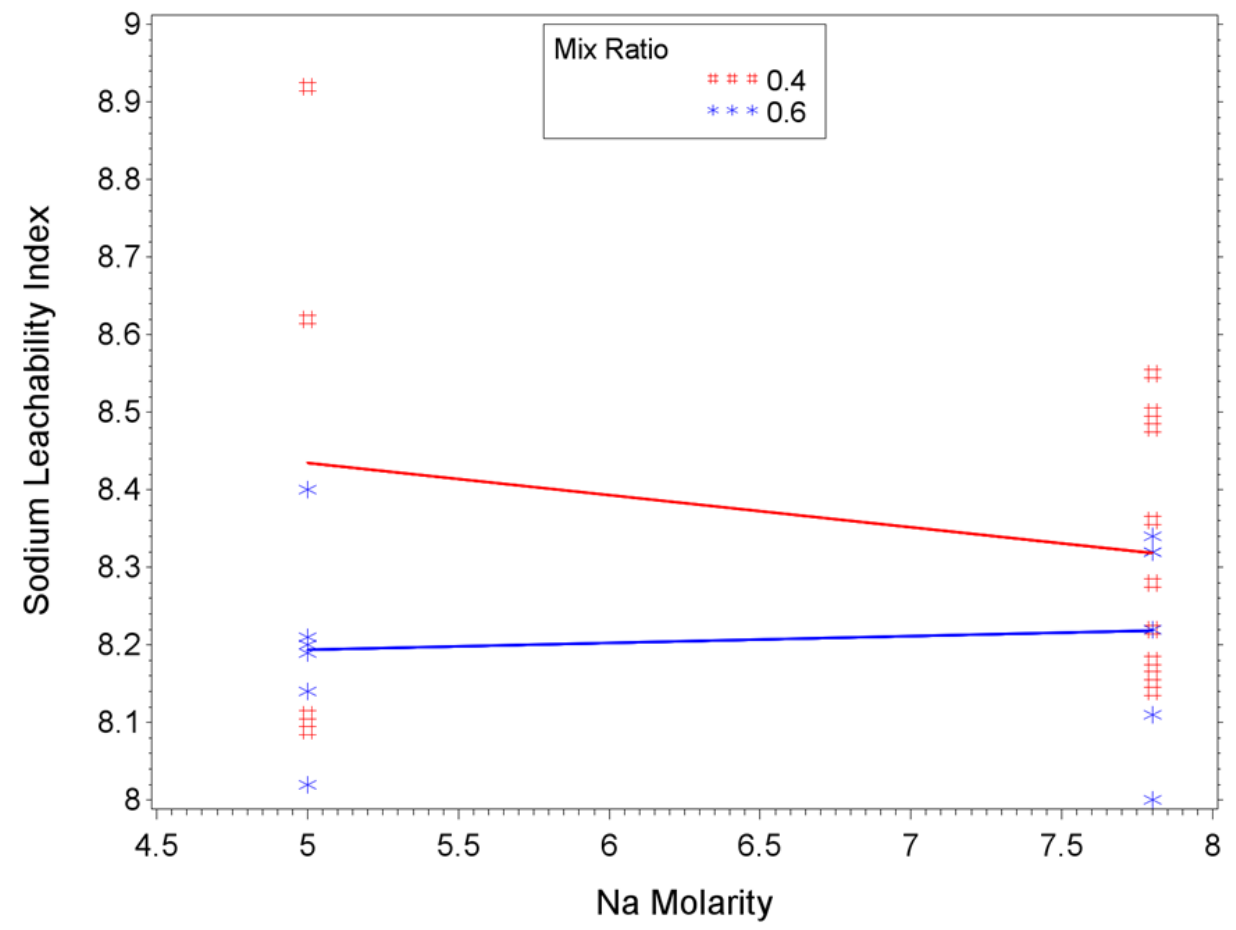

Figure E-45. Data-Interaction Plot for the Effects of Na Molarity and Mix Ratio on Sodium Leachability Index

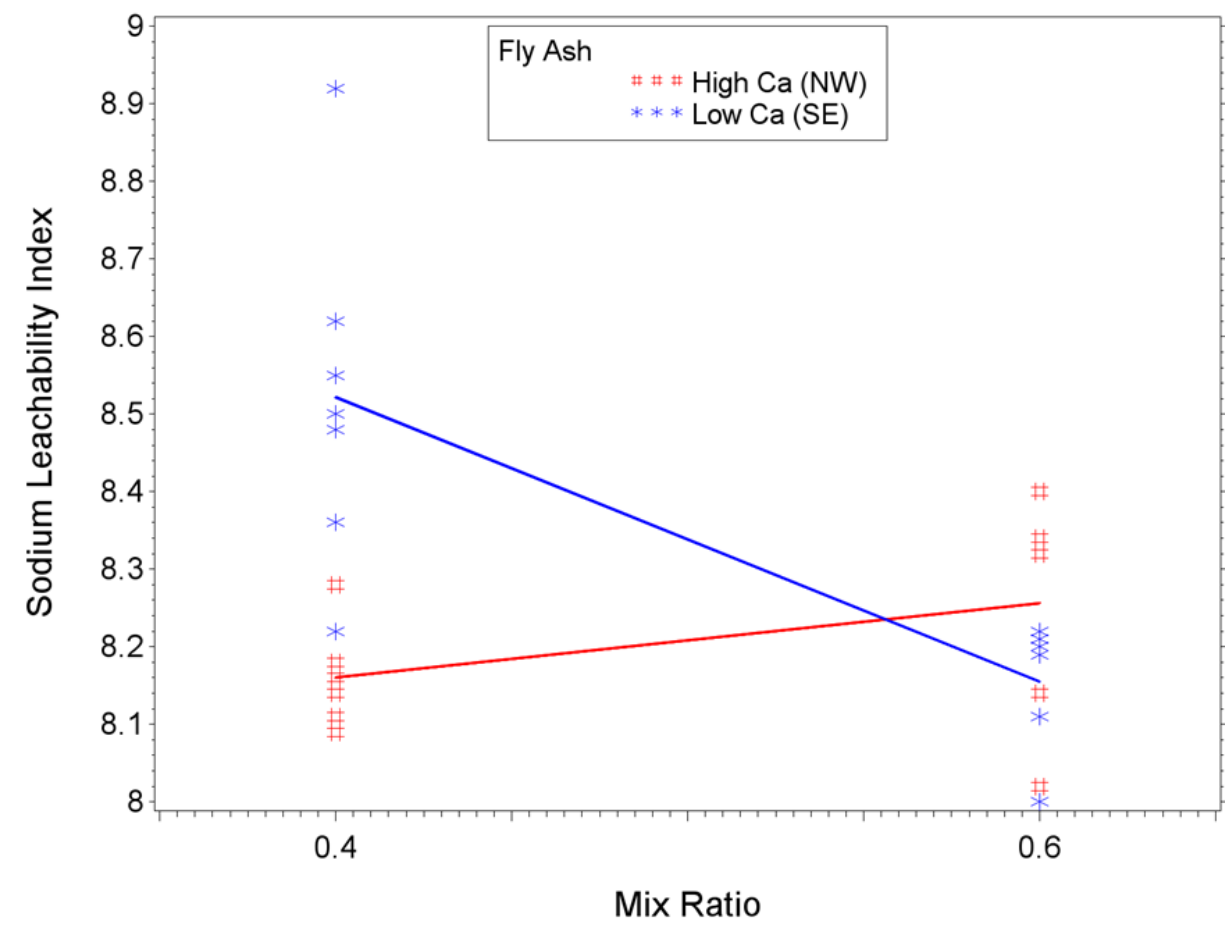

Figure E-46. Data-Interaction Plot for the Effects of Mix Ratio and Fly Ash on Sodium Leachability Index 


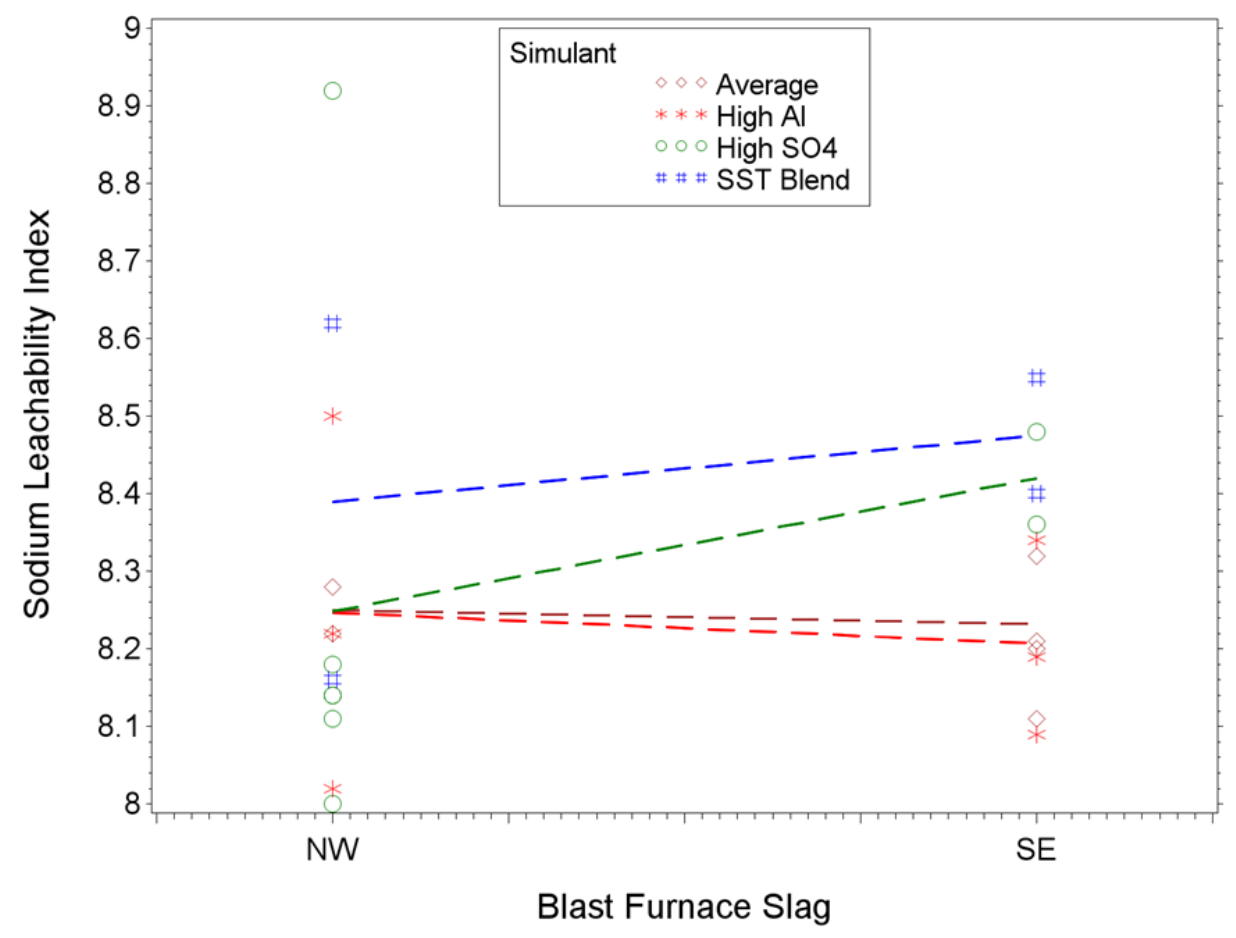

Figure E-47. Data-Interaction Plot for the Effects of Blast Furnace Slag and Simulant on Sodium Leachability Index

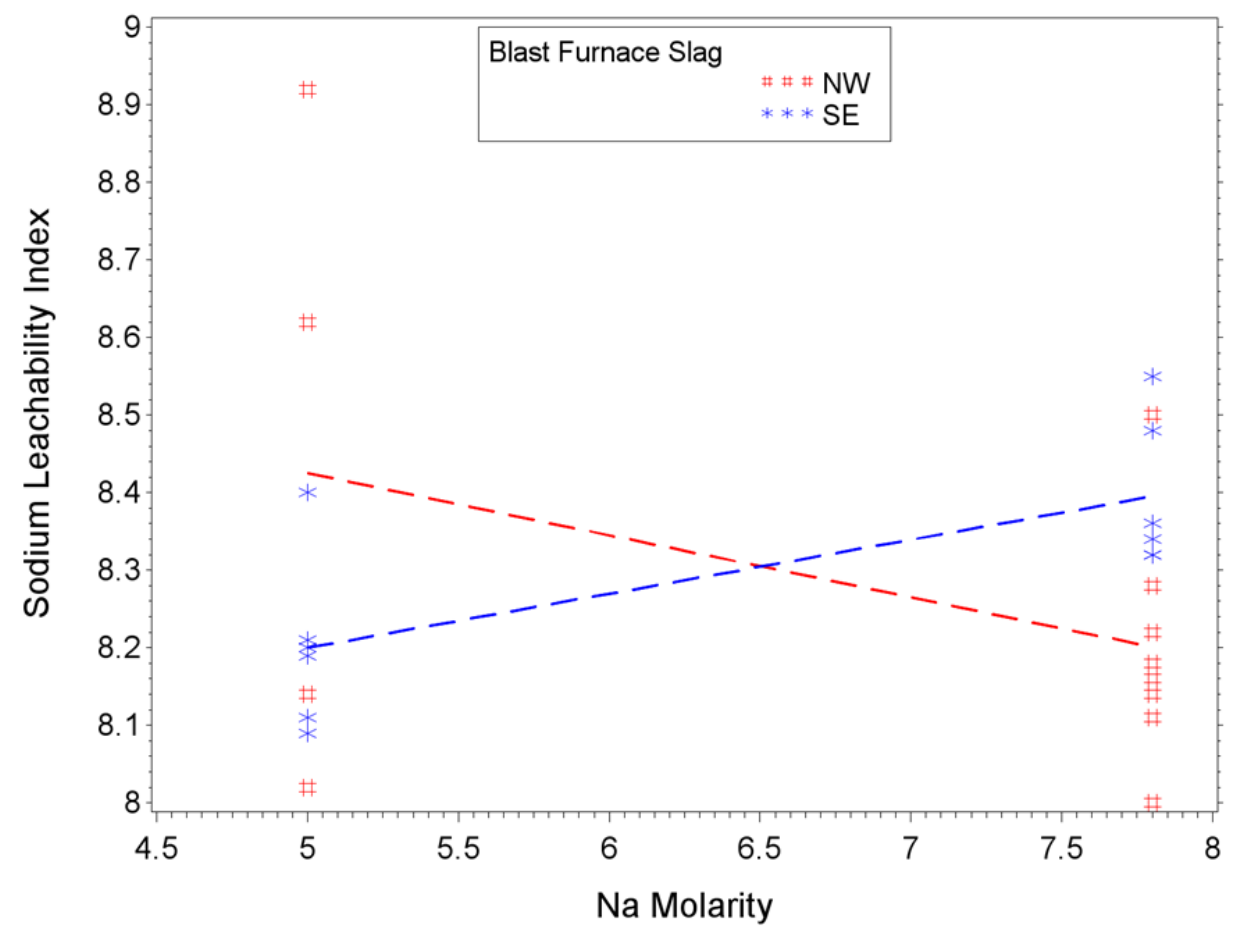

Figure E-48. Data-Interaction Plot for the Effects of Na Molarity and Blast Furnace Slag on Sodium Leachability Index 


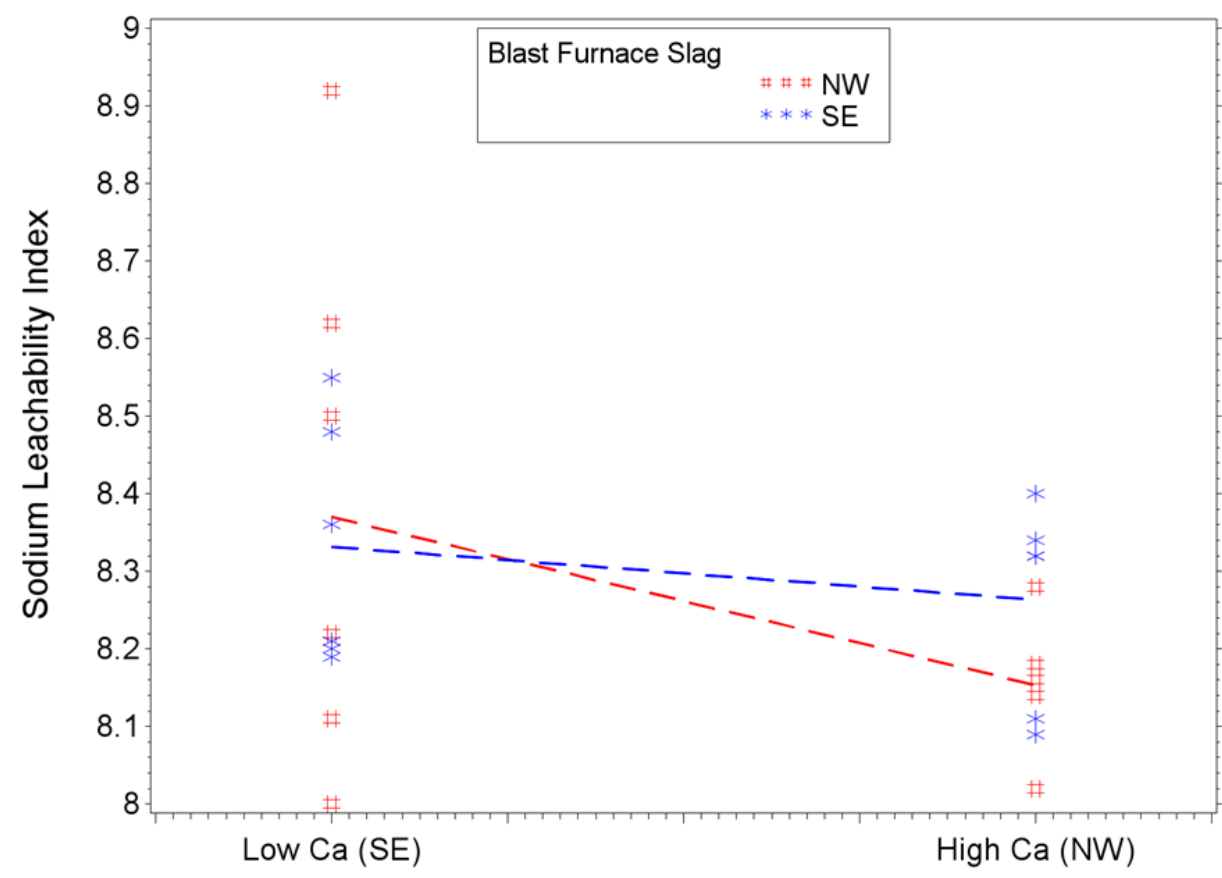

Fly Ash

Figure E-49. Data-Interaction Plot for the Effects of Fly Ash and Blast Furnace Slag on Sodium Leachability Index

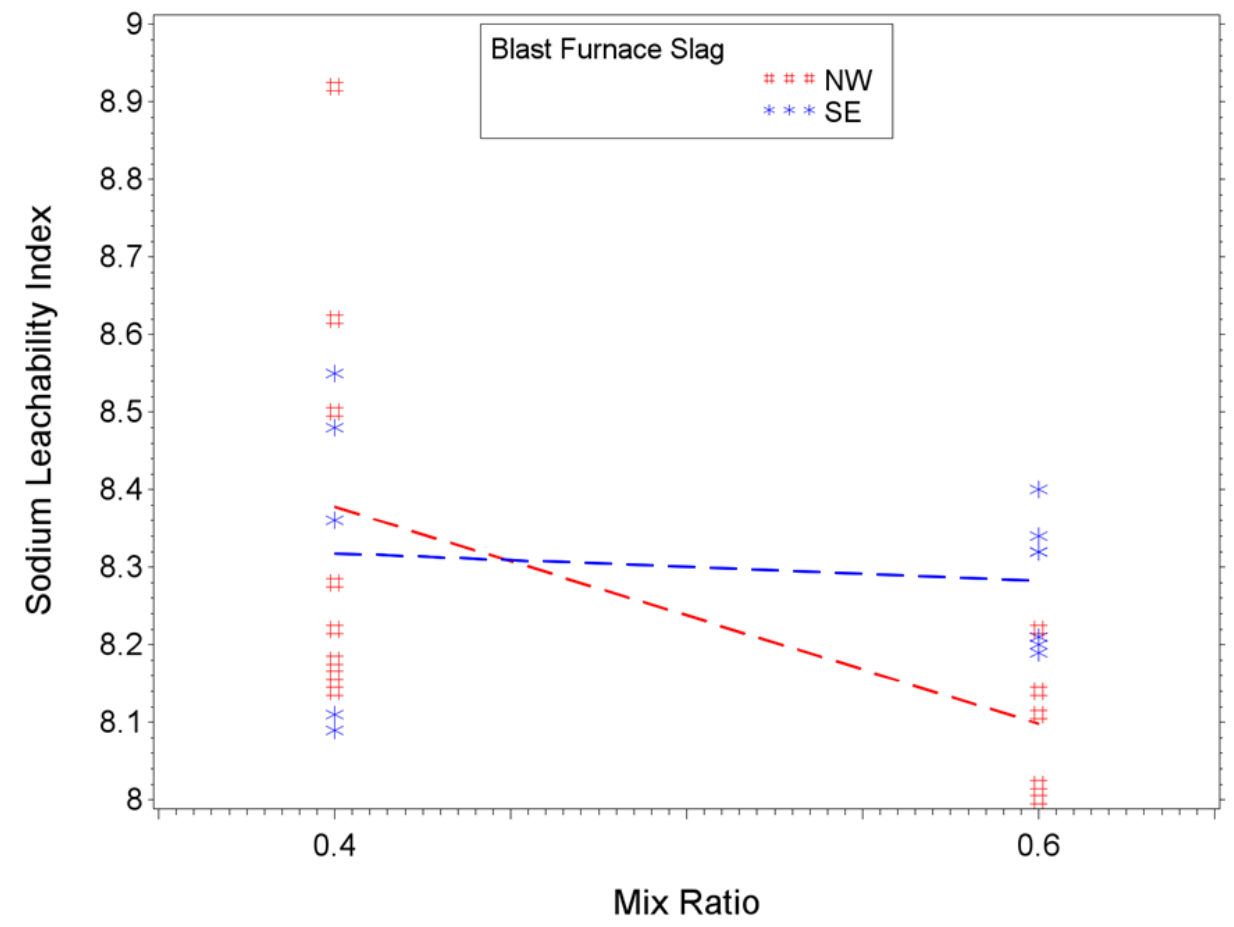

Figure E-50. Data-Interaction Plot for the Effects of Mix Ratio and Blast Furnace Slag on Sodium Leachability Index 
PNNL-22747

SRNL-STI-2013-00465

\section{E.4.2 Nitrate Leachability Index}

Figure E-51 through Figure E-60 display the data-interaction plots for the averaged $\mathrm{NO}_{3} \mathrm{LI}$ of the 26 Cast Stone mixes in the screening text matrix. 


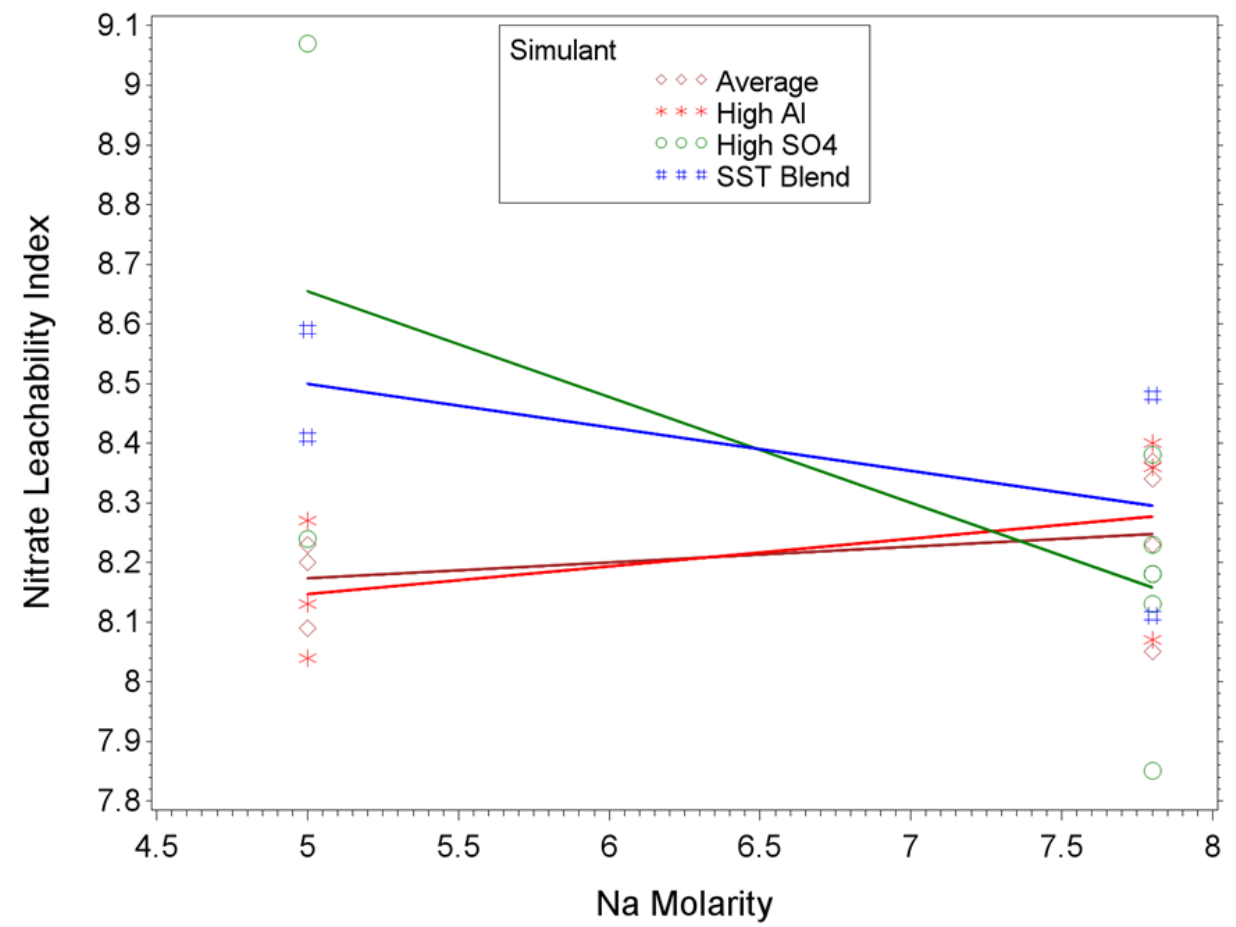

Figure E-51. Data-Interaction Plot for the Effects of Na Molarity and Simulant on Nitrate Leachability Index

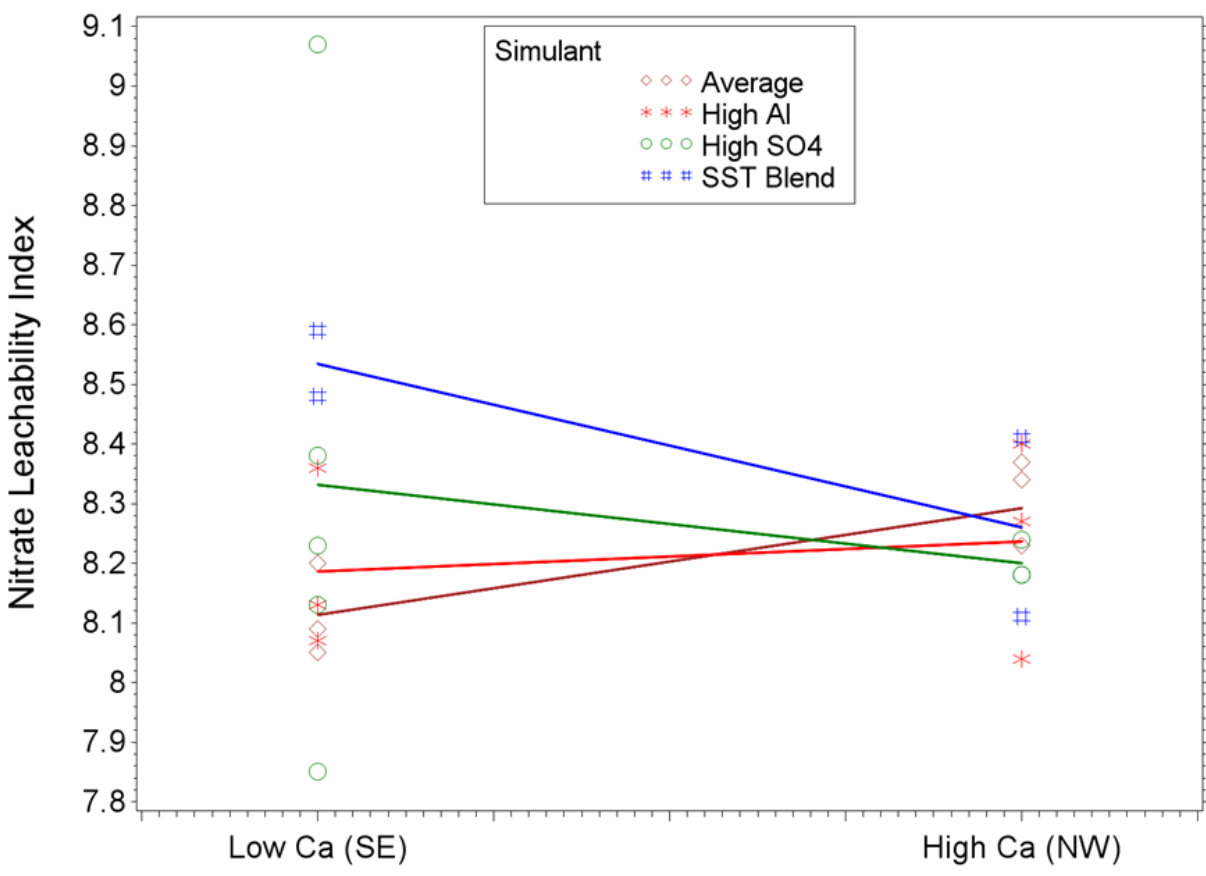

Fly Ash

Figure E-52. Data-Interaction Plot for the Effects of Fly Ash and Simulant on Nitrate Leachability Index 


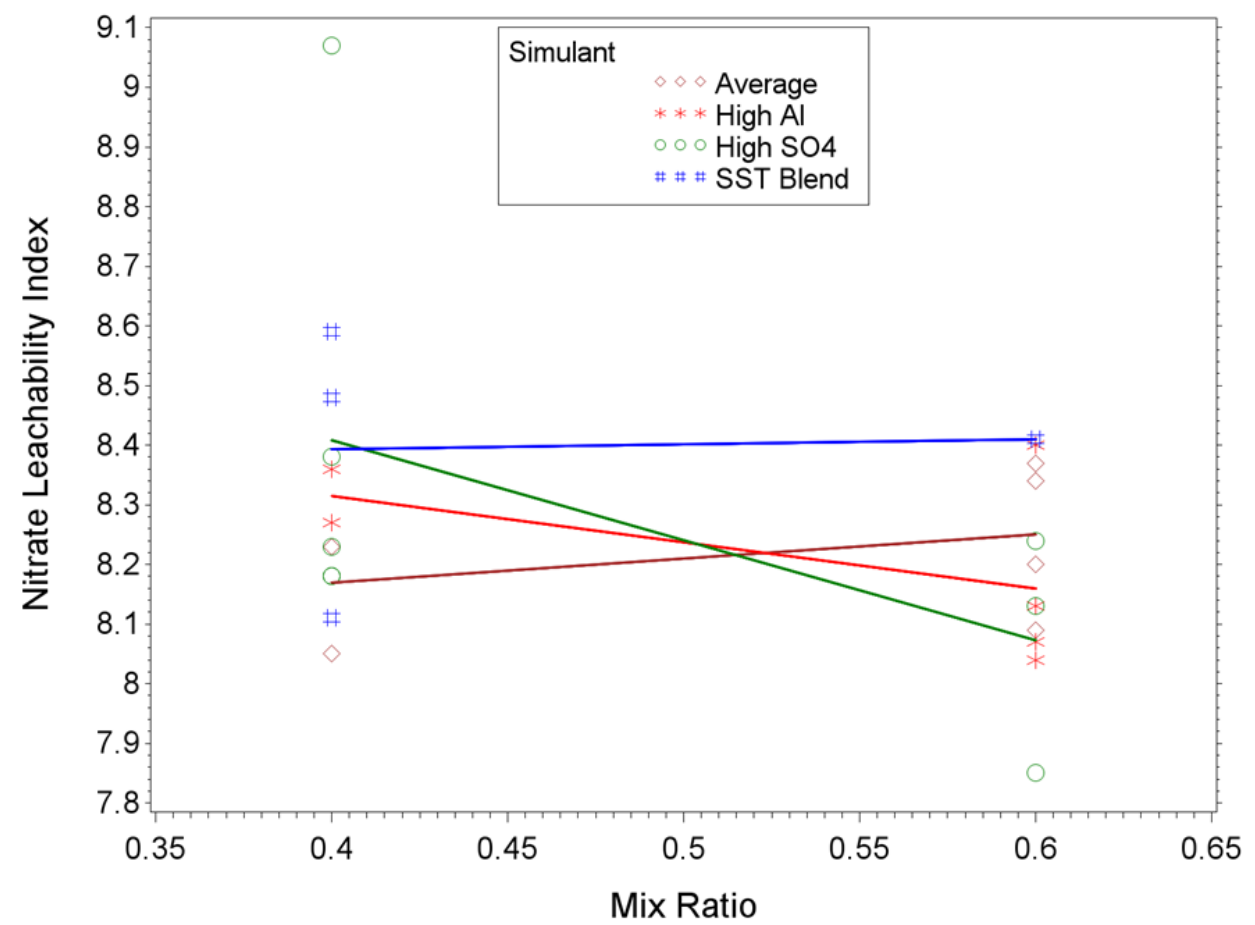

Figure E-53. Data-Interaction Plot for the Effects of Mix Ratio and Simulant on Nitrate Leachability Index

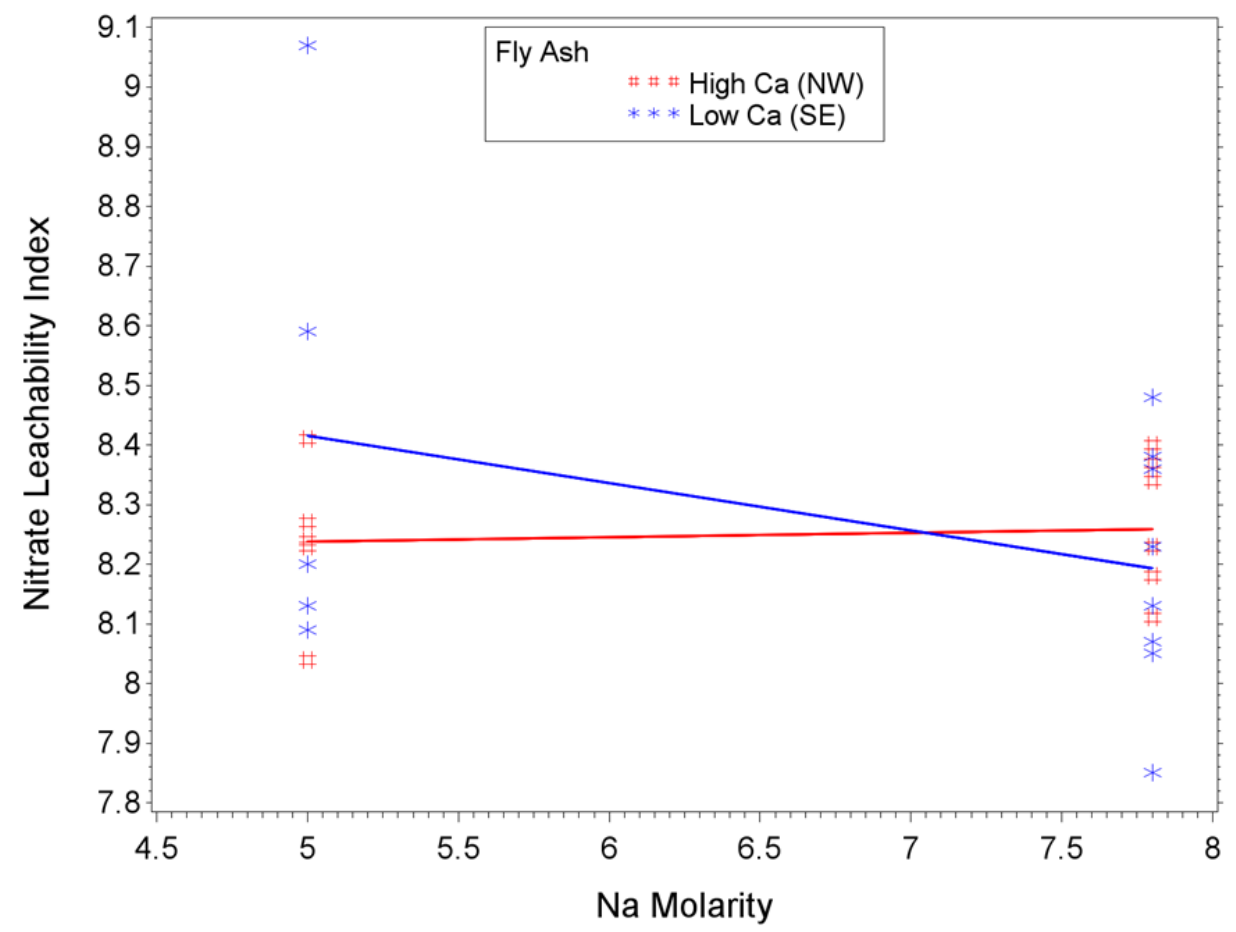

Figure E-54. Data-Interaction Plot for the Effects of Na Molarity and Fly Ash on Nitrate Leachability Index 


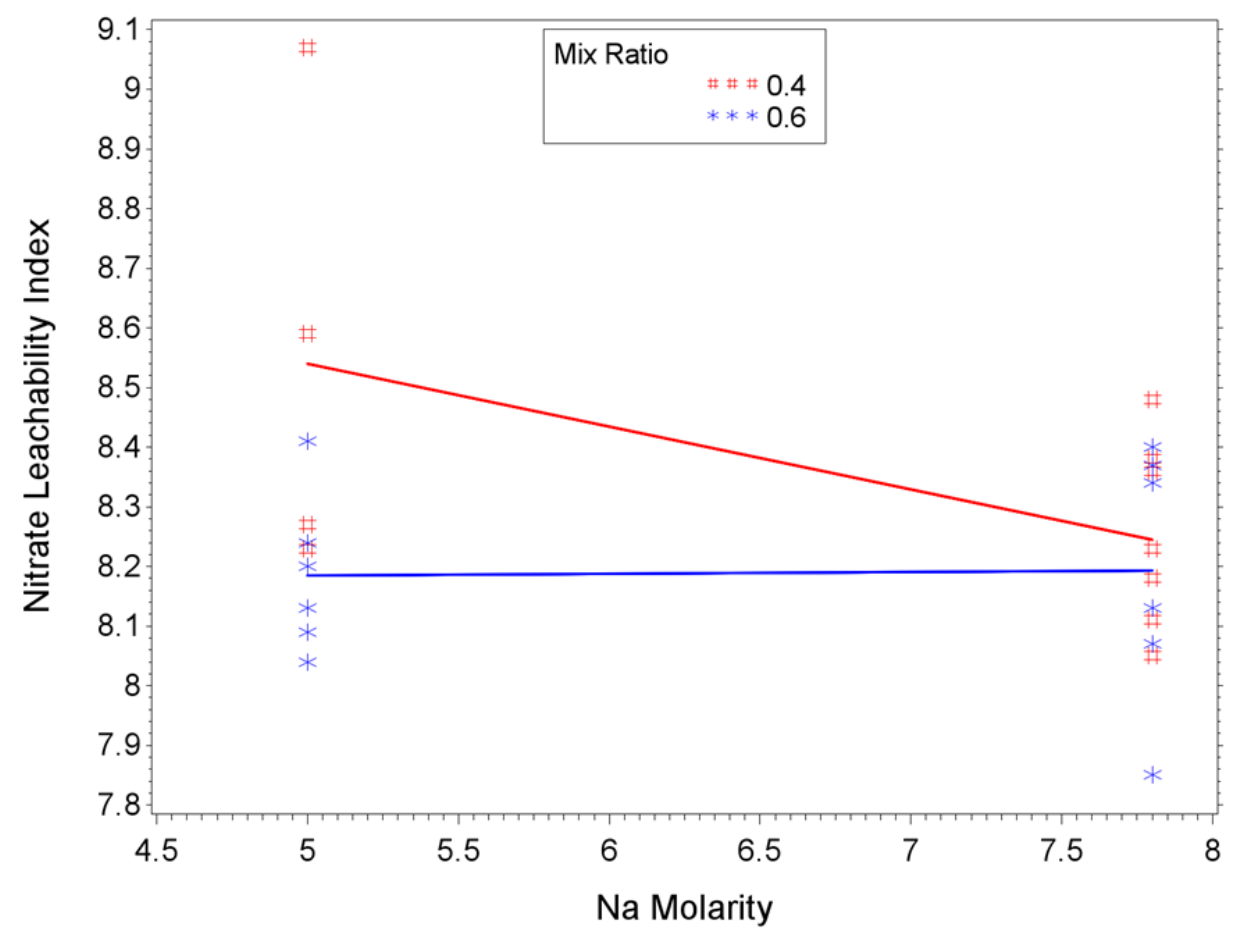

Figure E-55. Data-Interaction Plot for the Effects of Na Molarity and Mix Ratio on Nitrate Leachability Index

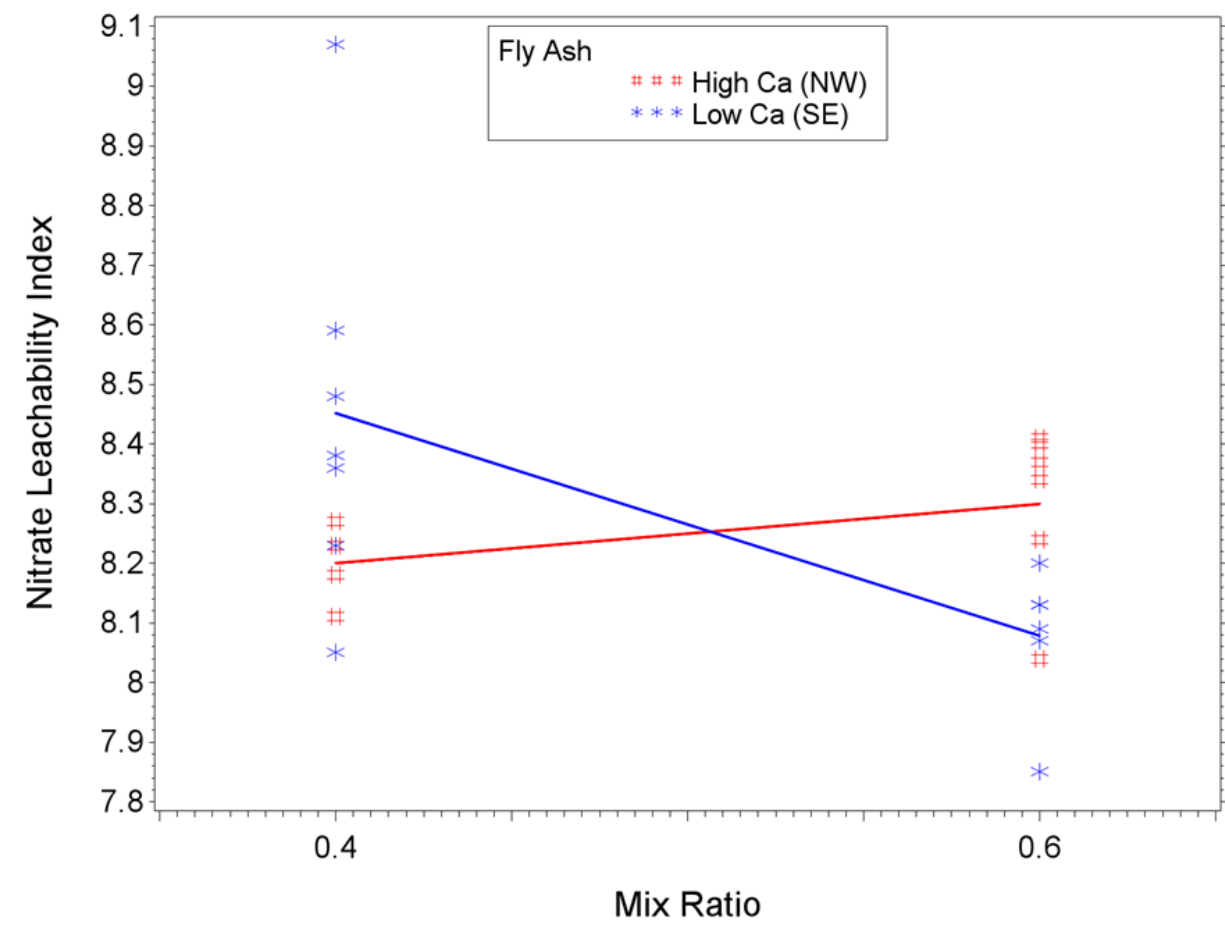

Figure E-56. Data-Interaction Plot for the Effects of Mix Ratio and Fly Ash on Nitrate Leachability Index 


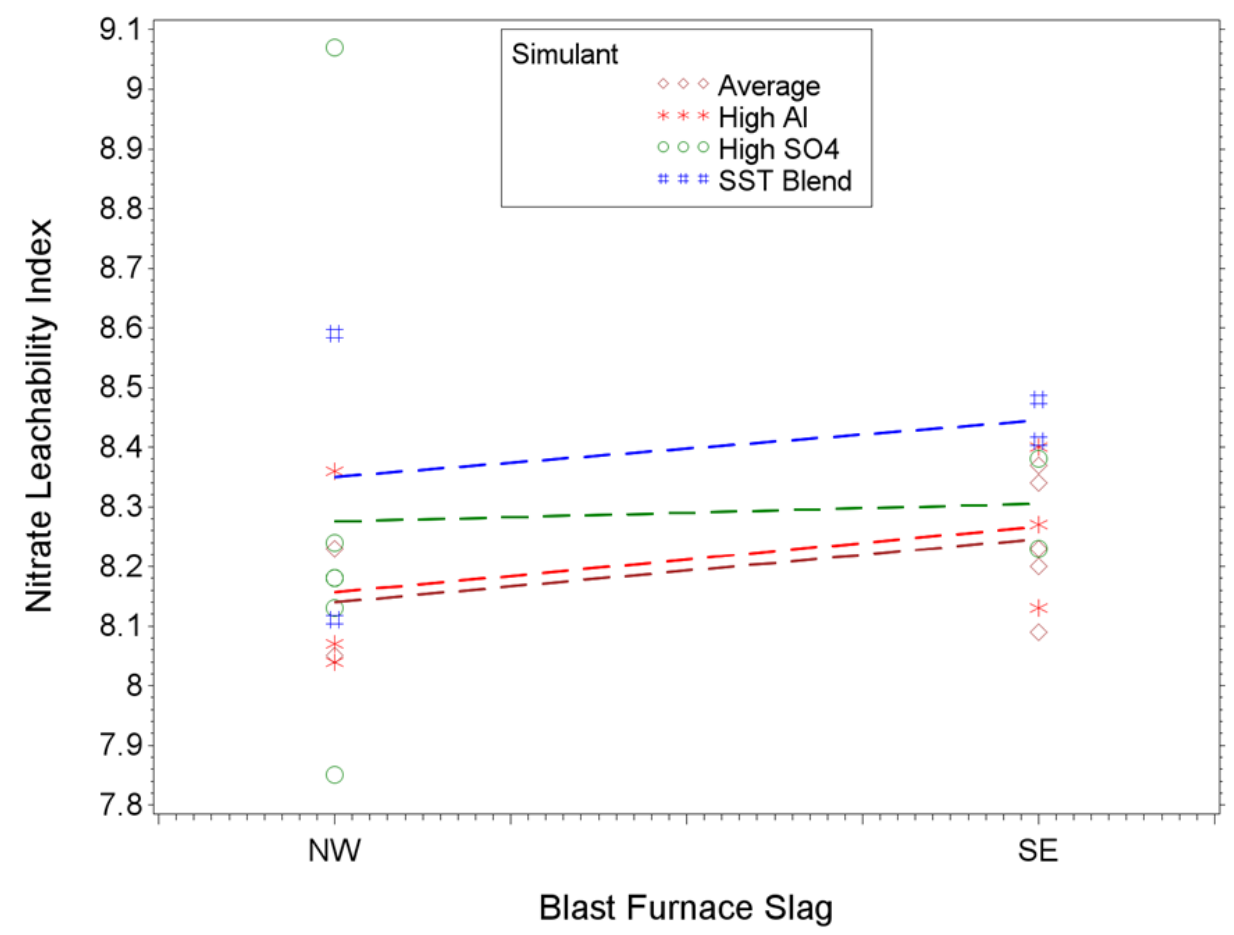

Figure E-57. Data-Interaction Plot for the Effects of Blast Furnace Slag and Simulant on Nitrate Leachability Index

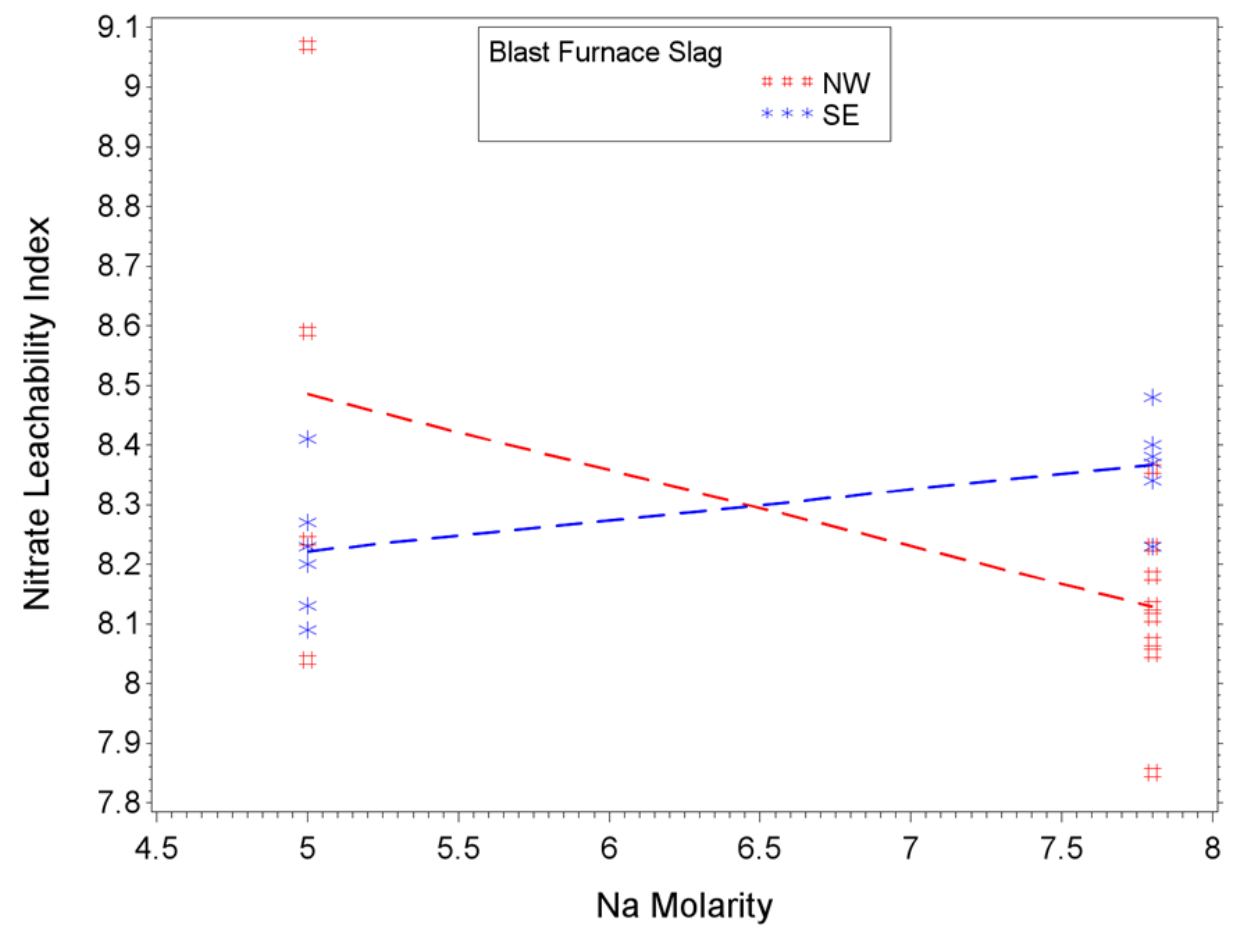

Figure E-58. Data-Interaction Plot for the Effects of Na Molarity and Blast Furnace Slag on Nitrate Leachability Index 


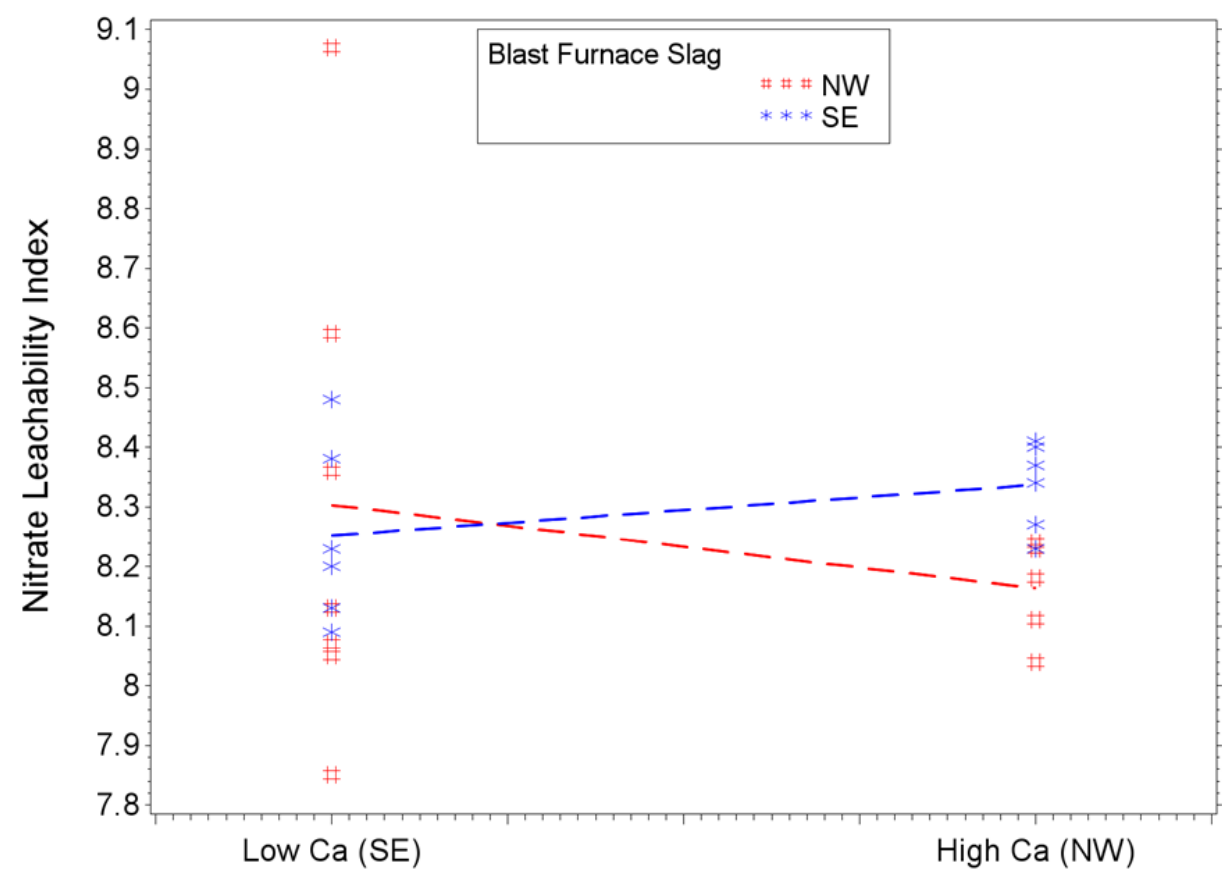

Fly Ash

Figure E-59. Data-Interaction Plot for the Effects of Fly Ash and Blast Furnace Slag on Nitrate Leachability Index

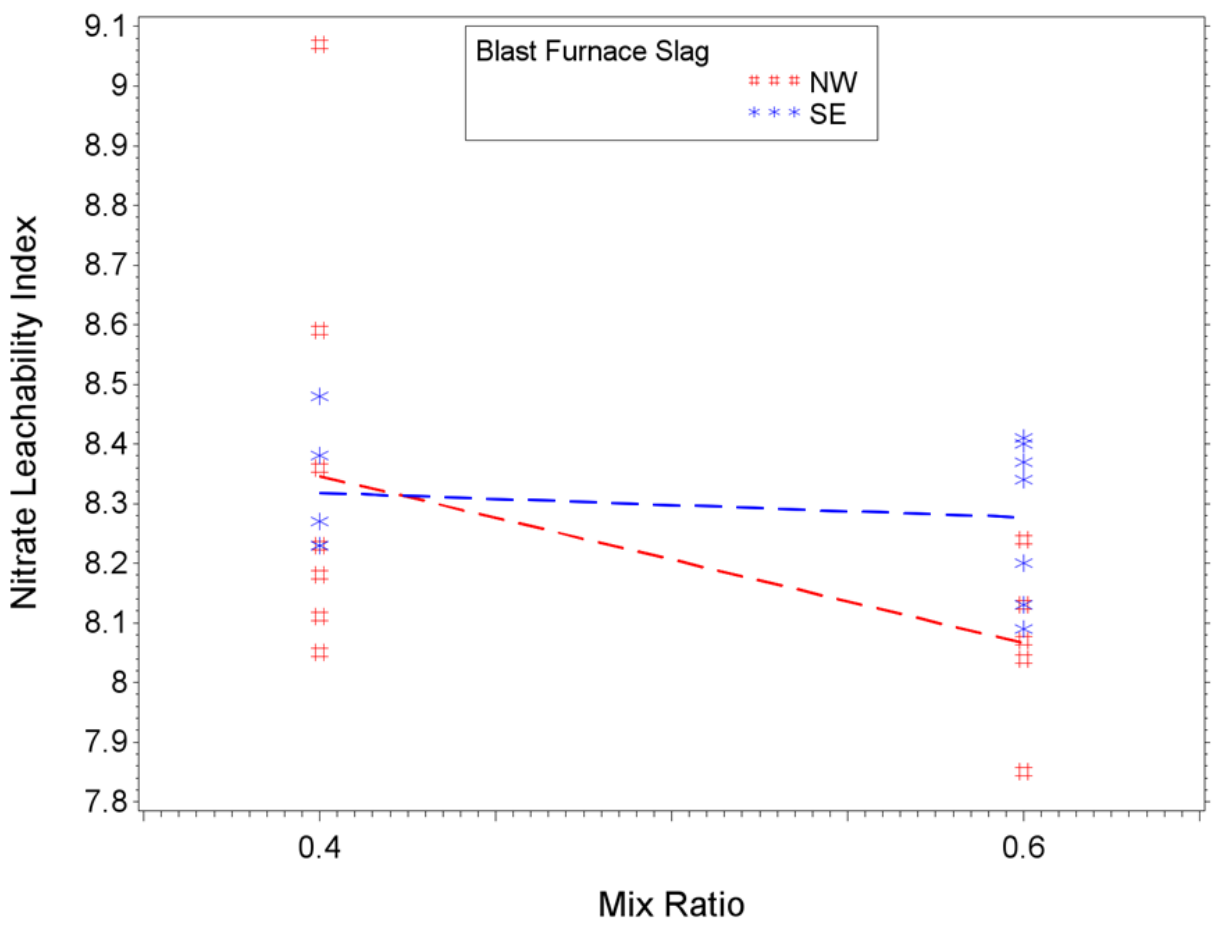

Figure E-60. Data-Interaction Plot for the Effects of Mix Ratio and Blast Furnace Slag on Nitrate Leachability Index 
PNNL-22747

SRNL-STI-2013-00465

\section{E.4.3 Iodine Leachability Index}

Figure E-61 through Figure E-70 display the data-interaction plots for the averaged I LI of the 26 Cast Stone mixes in the screening text matrix. 


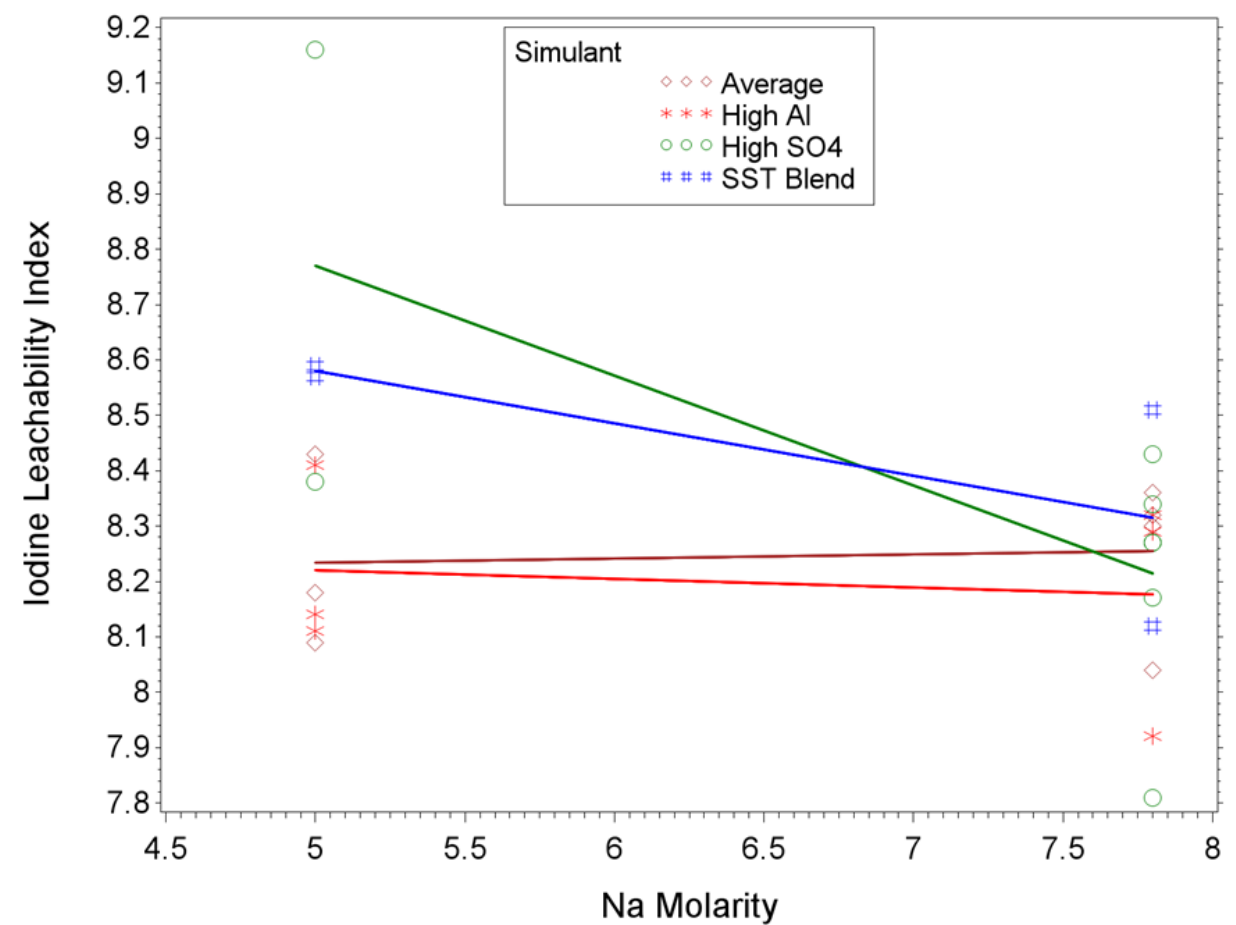

Figure E-61. Data-Interaction Plot for the Effects of Na Molarity and Simulant on Iodine Leachability Index

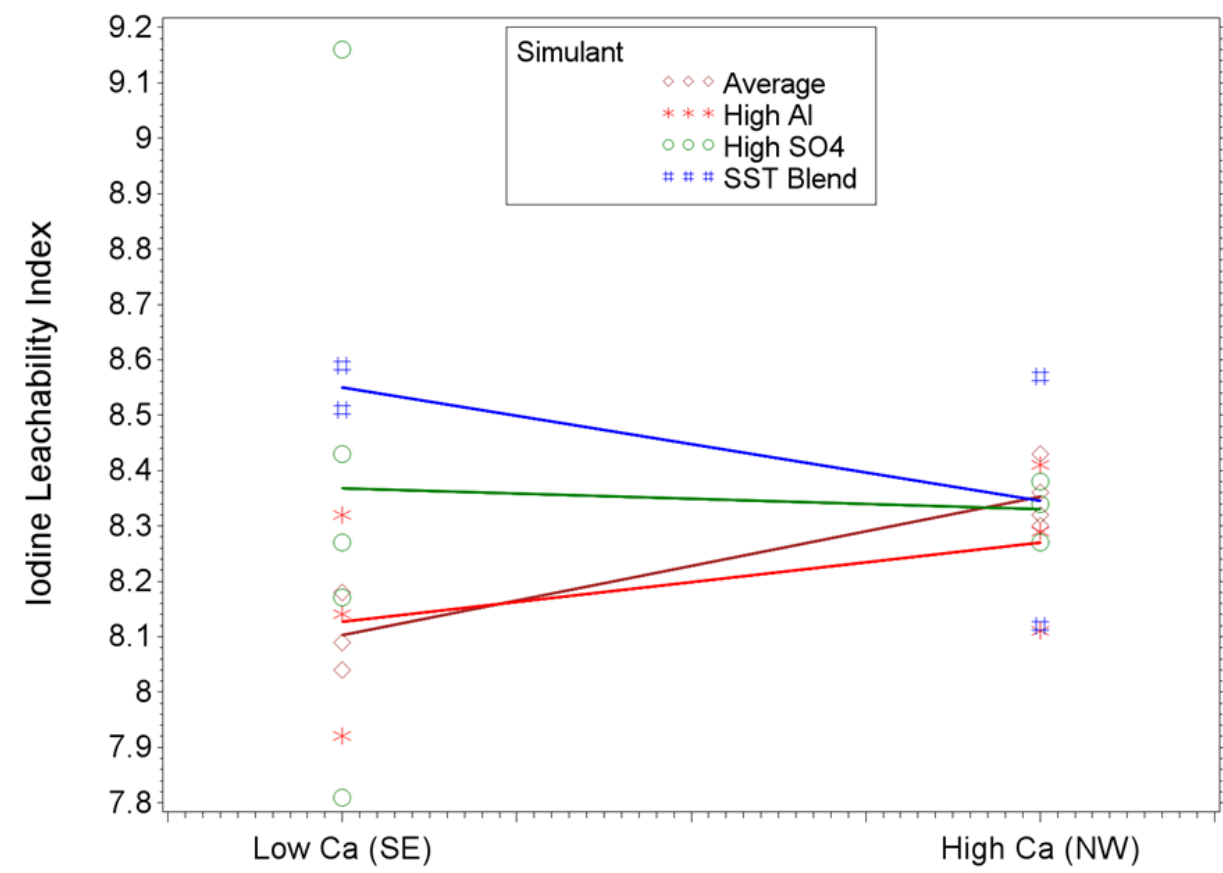

Fly Ash

Figure E-62. Data-Interaction Plot for the Effects of Fly Ash and Simulant on Iodine Leachability Index 


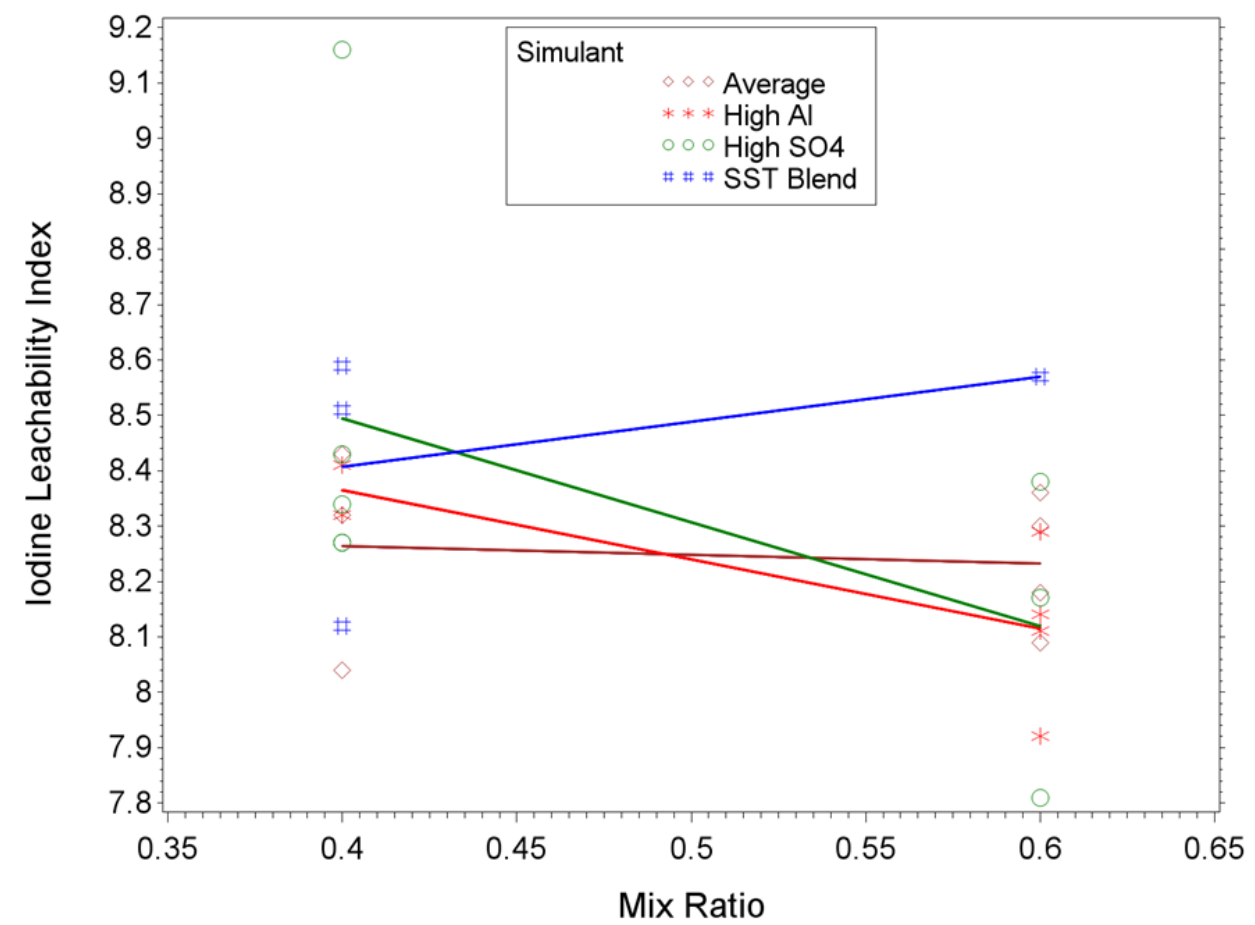

Figure E-63. Data-Interaction Plot for the Effects of Mix Ratio and Simulant on Iodine Leachability Index

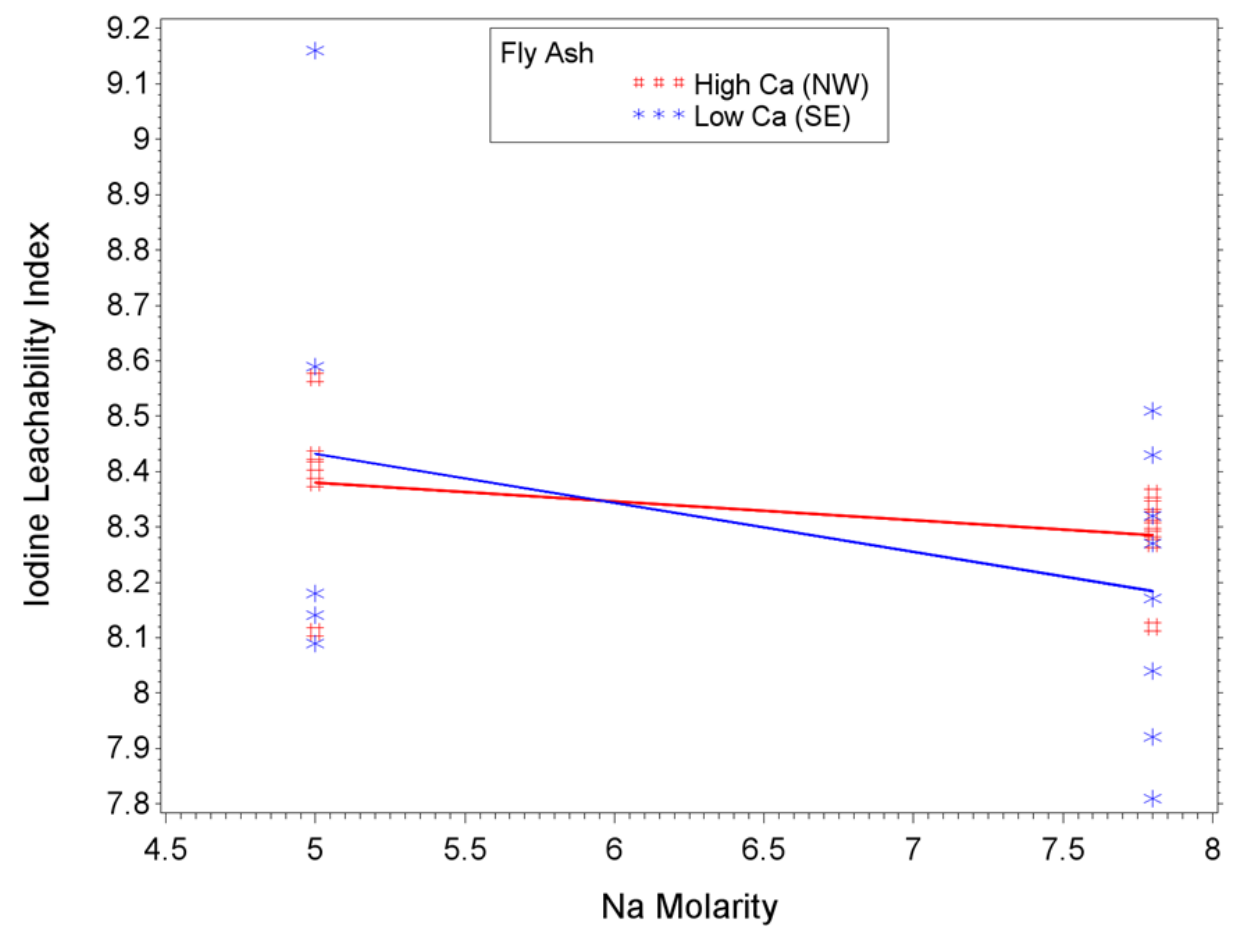

Figure E-64. Data-Interaction Plot for the Effects of Na Molarity and Fly Ash on Iodine Leachability Index 


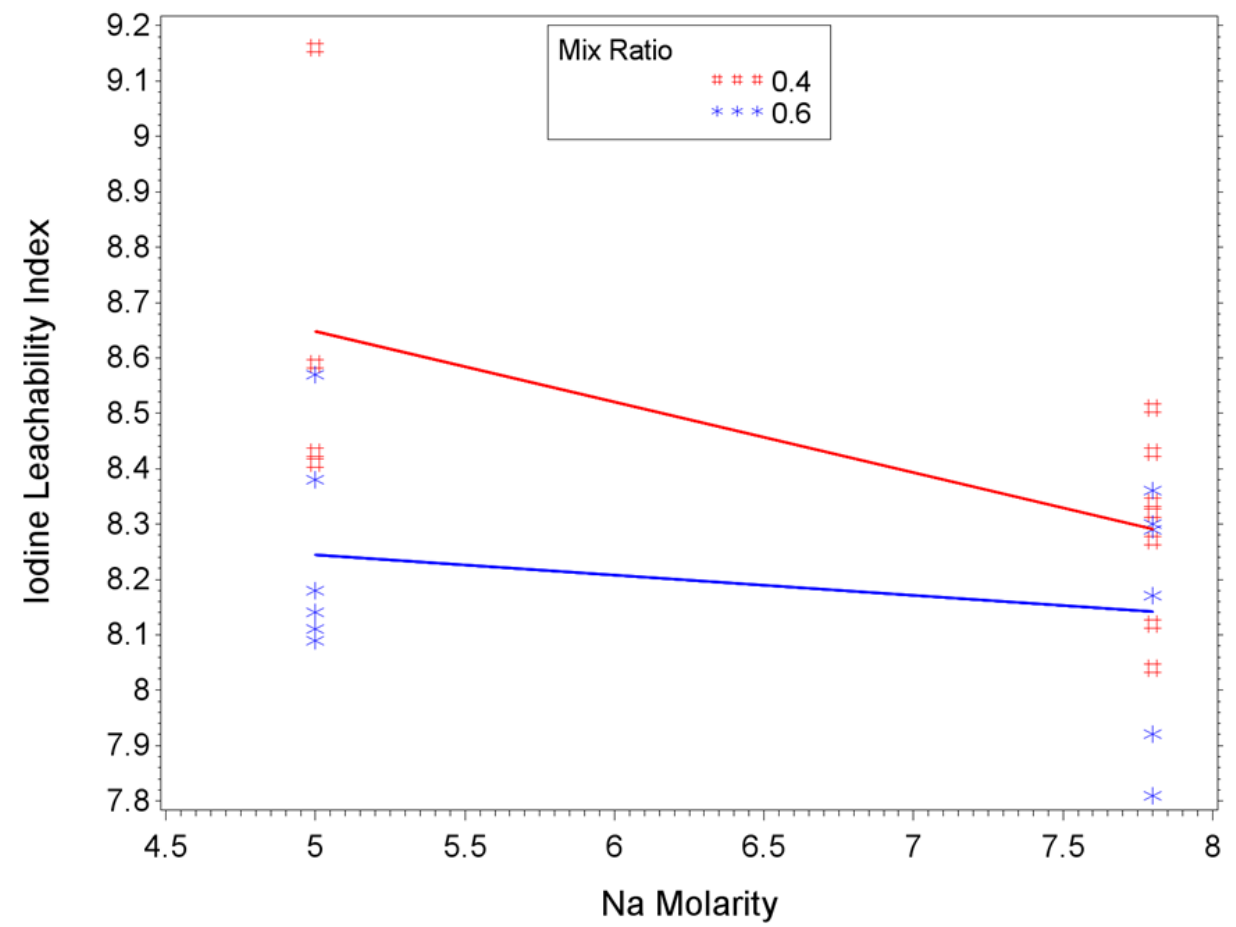

Figure E-65. Data-Interaction Plot for the Effects of Na Molarity and Mix Ratio on Iodine Leachability Index

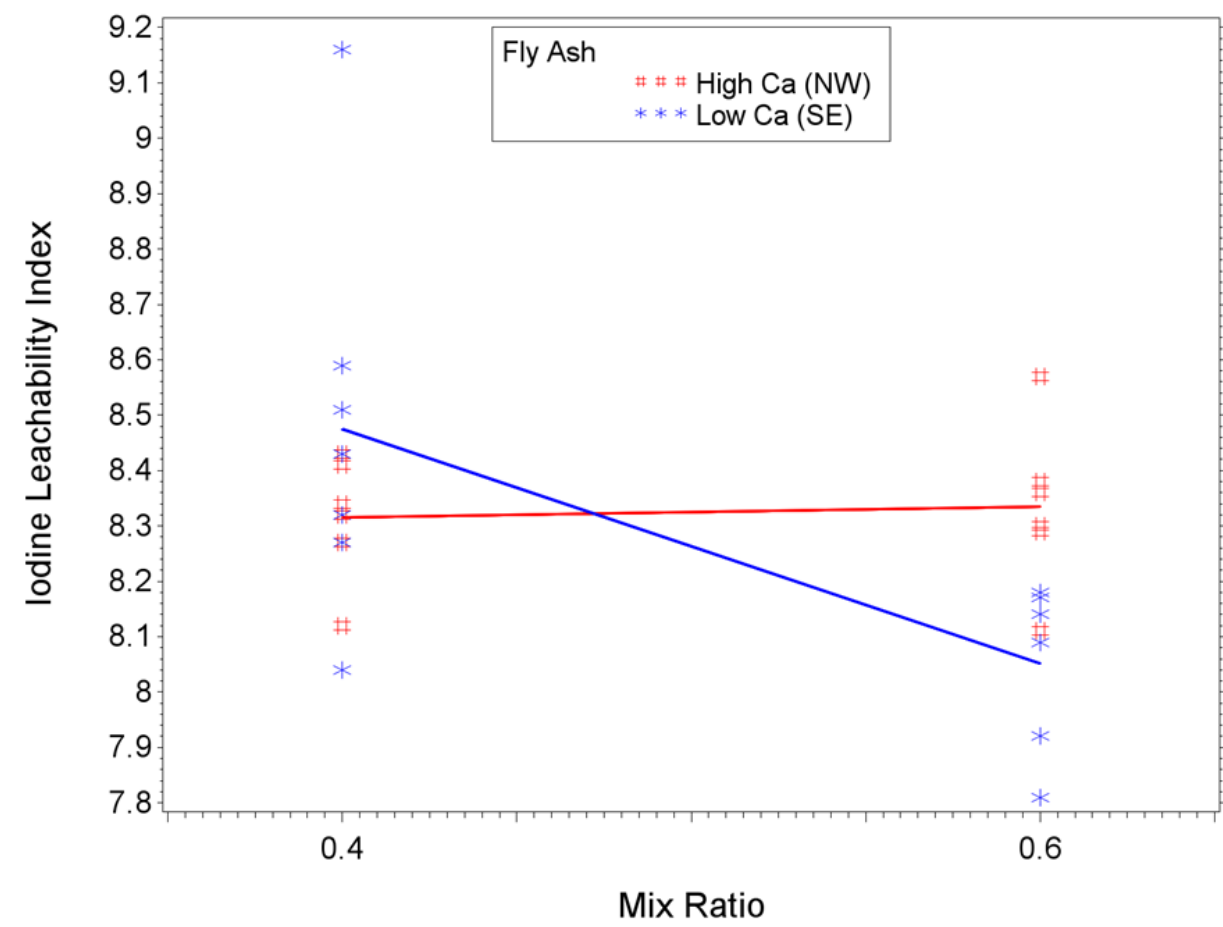

Figure E-66. Data-Interaction Plot for the Effects of Mix Ratio and Fly Ash on Iodine Leachability Index 


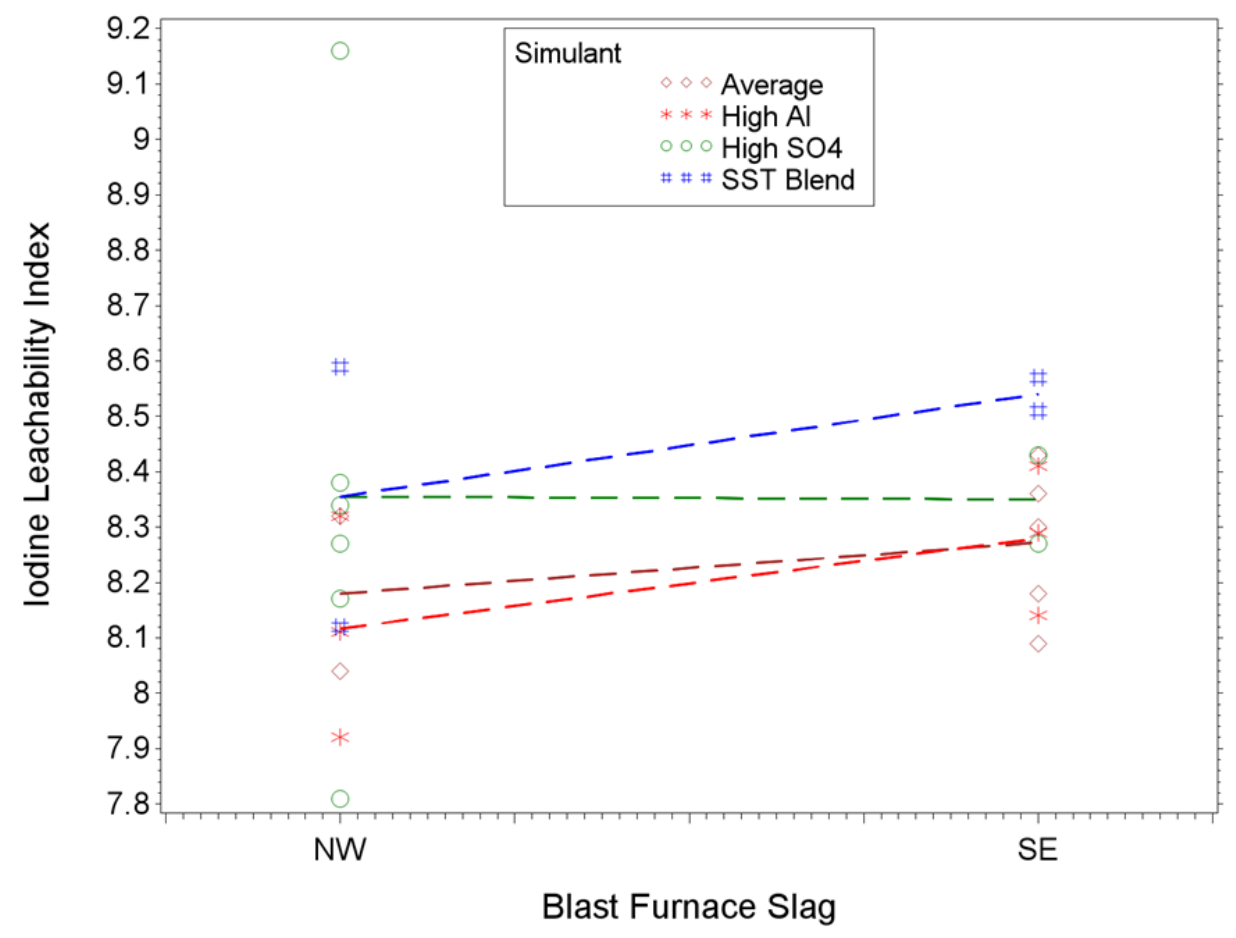

Figure E-67. Data-Interaction Plot for the Effects of Blast Furnace Slag and Simulant on Iodine Leachability Index

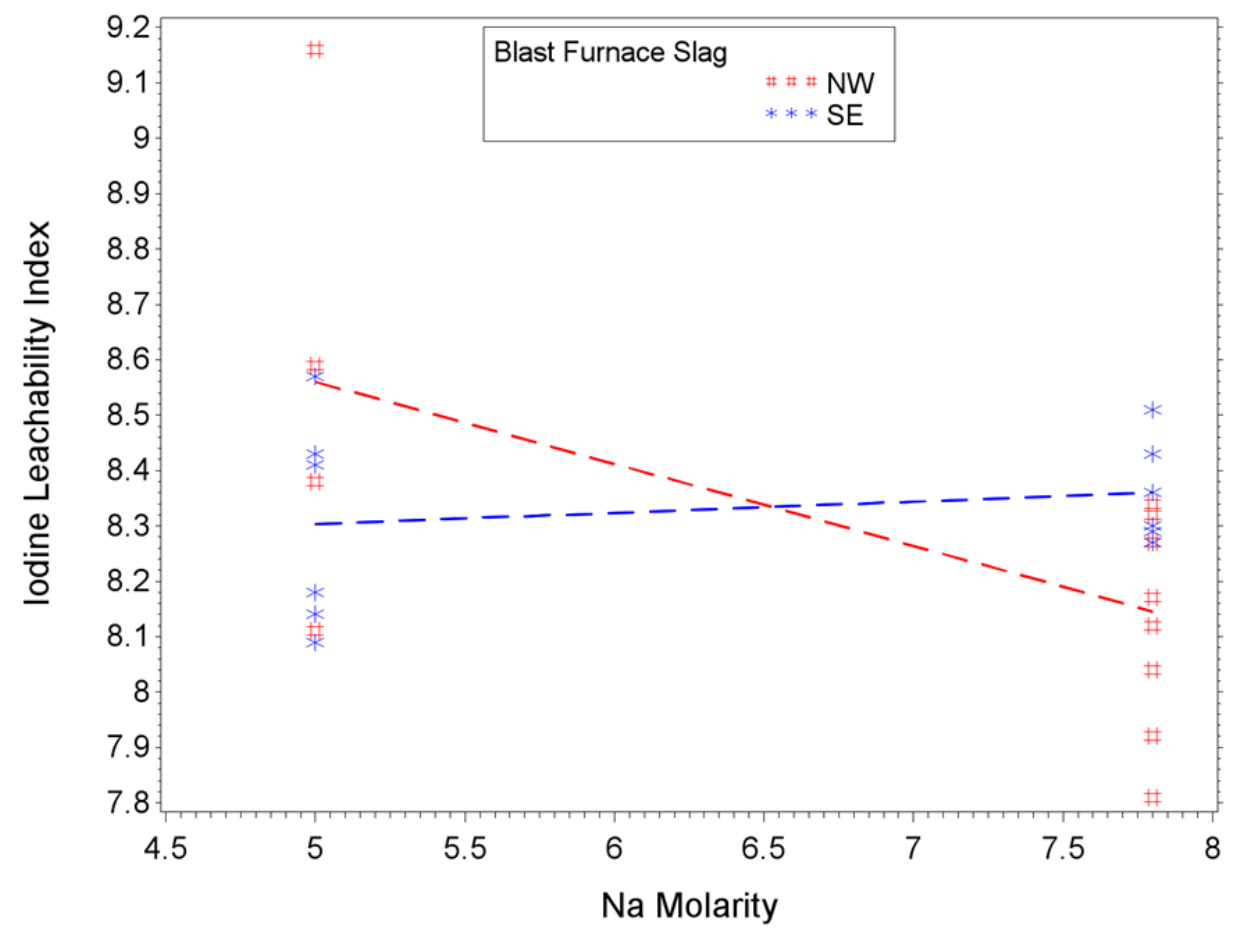

Figure E-68. Data-Interaction Plot for the Effects of Na Molarity and Blast Furnace Slag on Iodine Leachability Index 


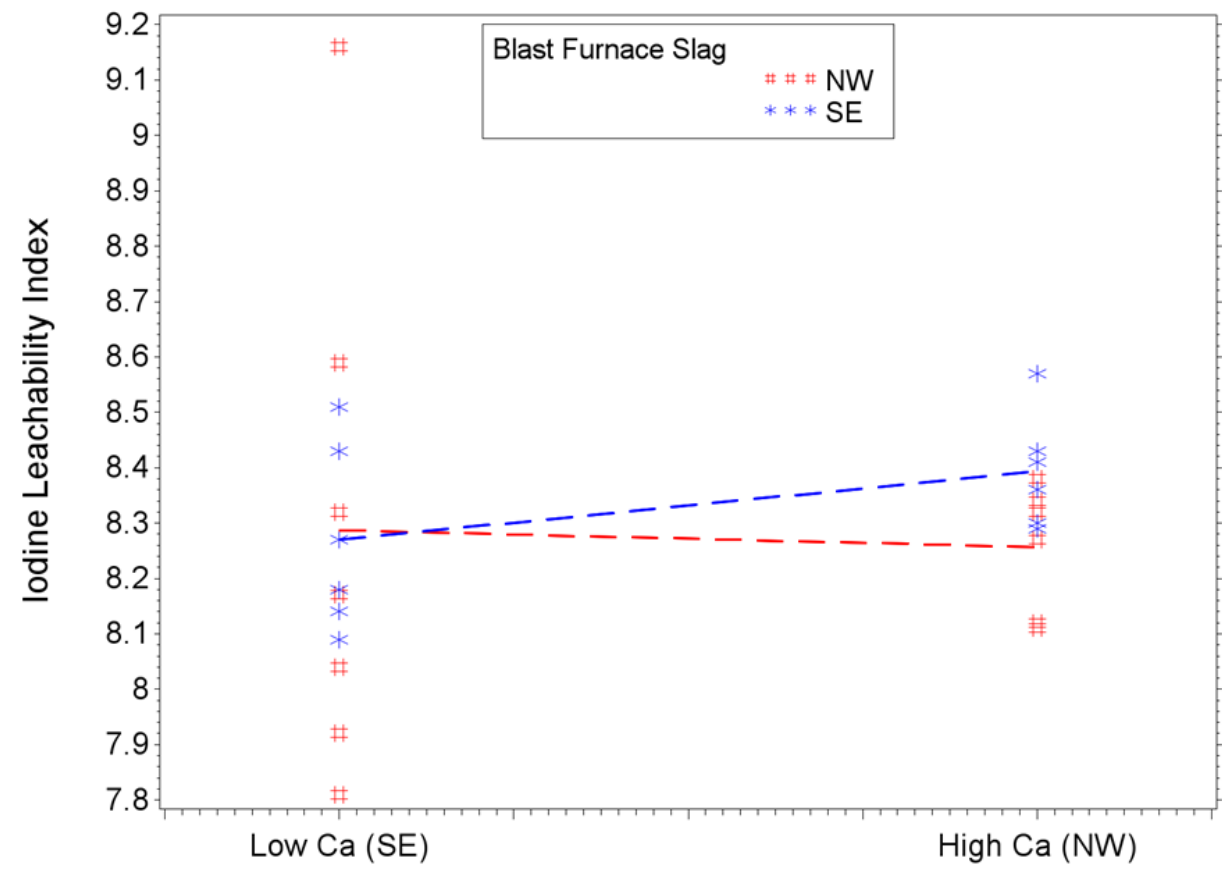

Fly Ash

Figure E-69. Data-Interaction Plot for the Effects of Fly Ash and Blast Furnace Slag on Iodine Leachability Index

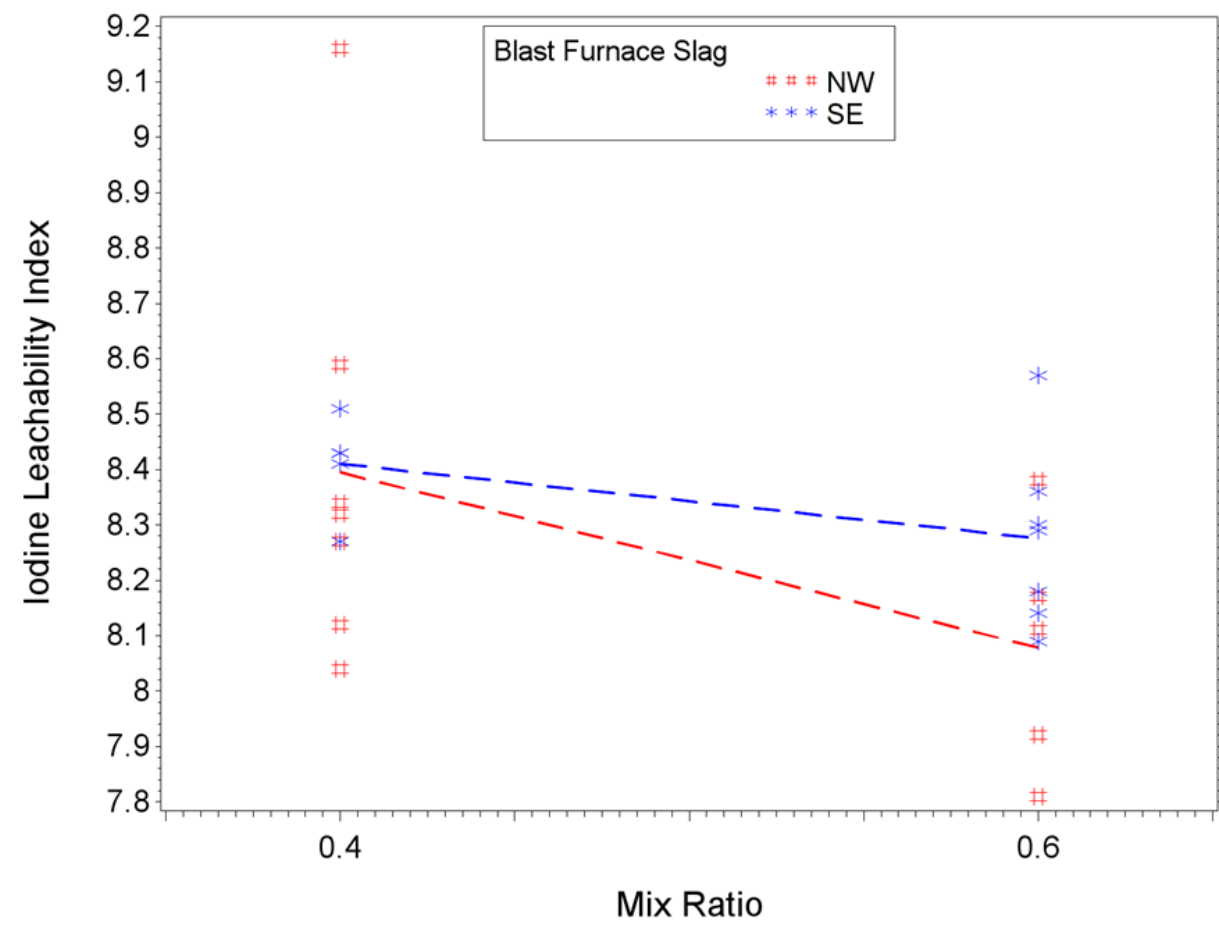

Figure E-70. Data-Interaction Plot for the Effects of Mix Ratio and Blast Furnace Slag on Iodine Leachability Index 
PNNL-22747

SRNL-STI-2013-00465

\section{E.4.4 Technetium Leachability Index}

Figure E-71 through Figure E-80 display the data-interaction plots for the averaged Tc LI of the 26 Cast Stone mixes in the screening text matrix. 


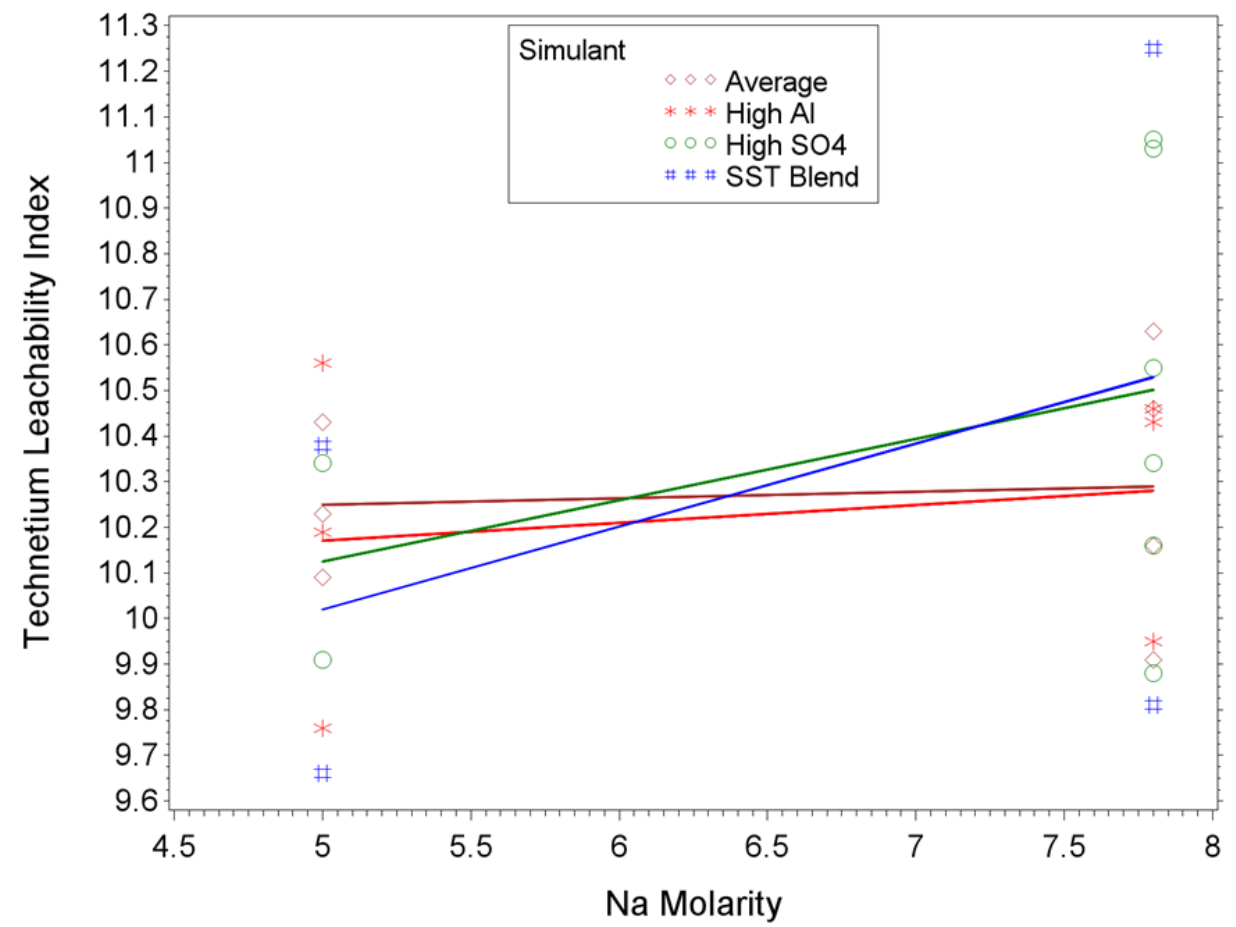

Figure E-71. Data-Interaction Plot for the Effects of Na Molarity and Simulant on Technetium Leachability Index

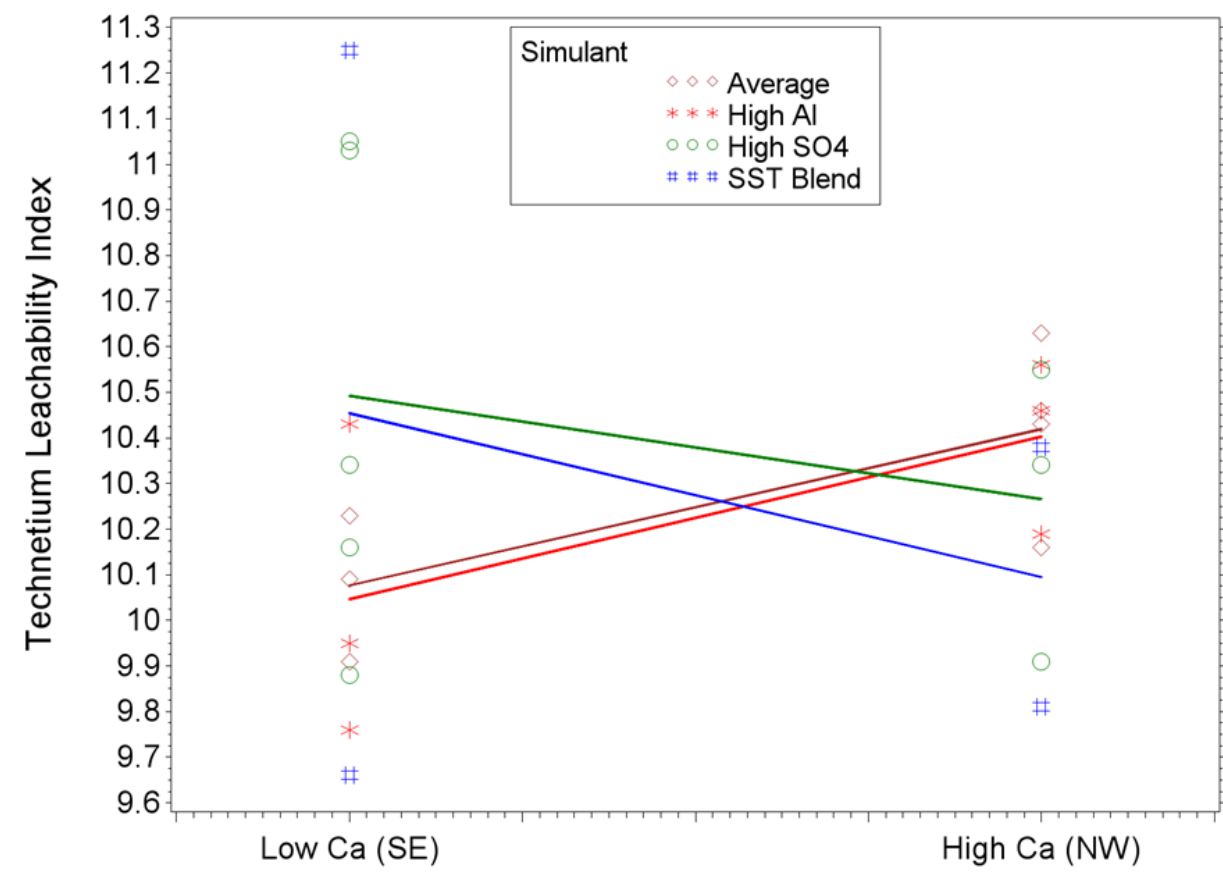

Fly Ash

Figure E-72. Data-Interaction Plot for the Effects of Fly Ash and Simulant on Technetium Leachability Index 


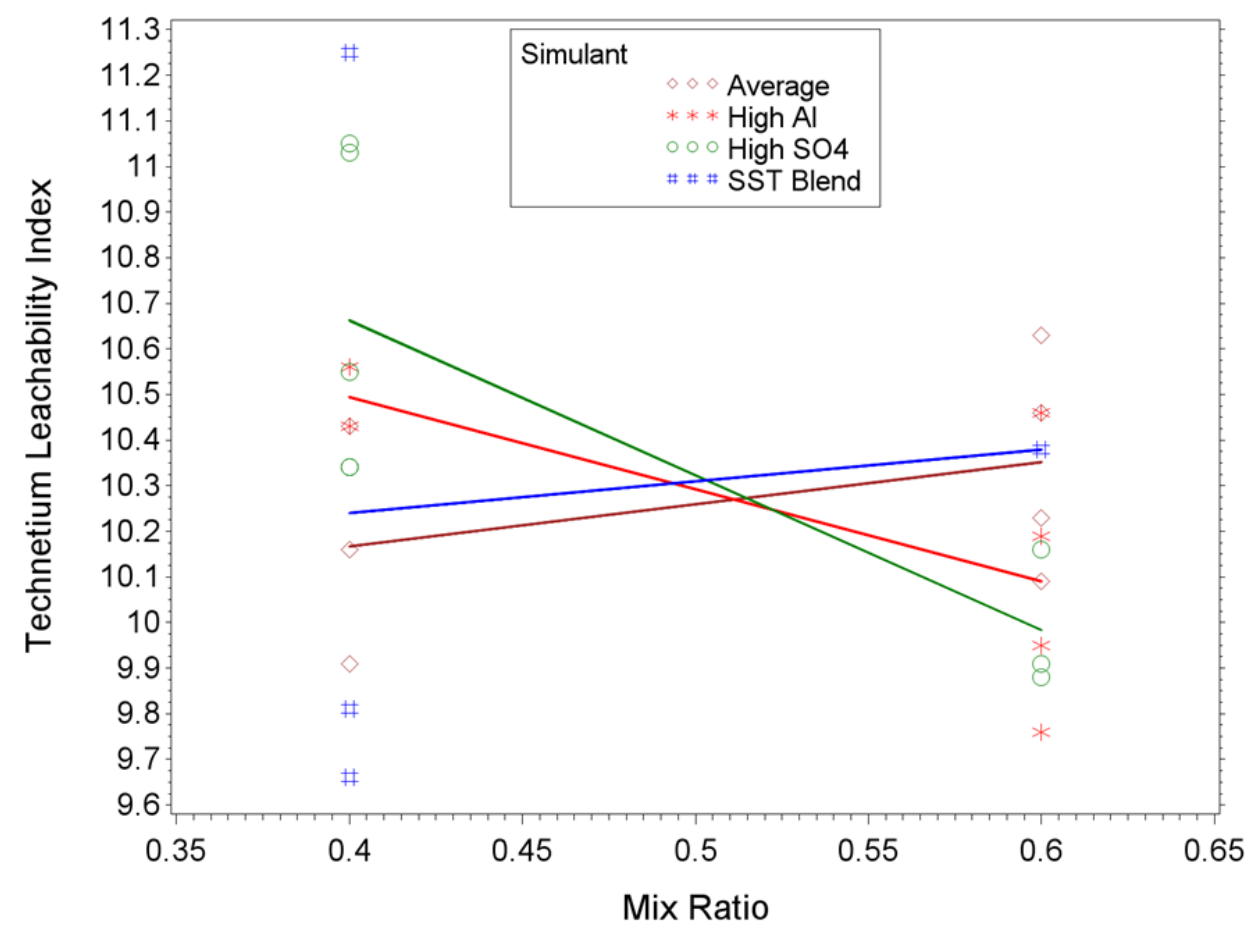

Figure E-73. Data-Interaction Plot for the Effects of Mix Ratio and Simulant on Technetium Leachability Index

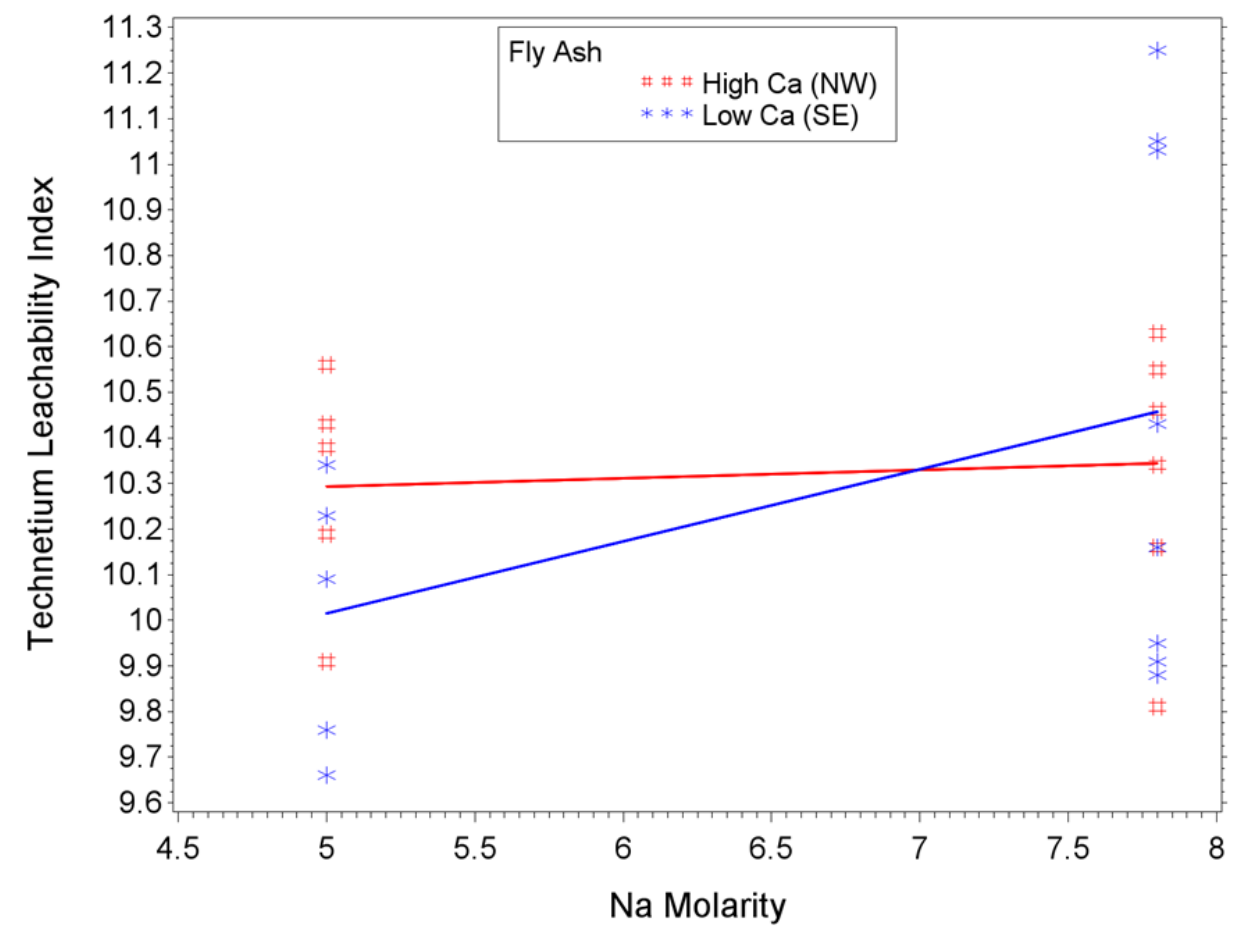

Figure E-74. Data-Interaction Plot for the Effects of Na Molarity and Fly Ash on Technetium Leachability Index 


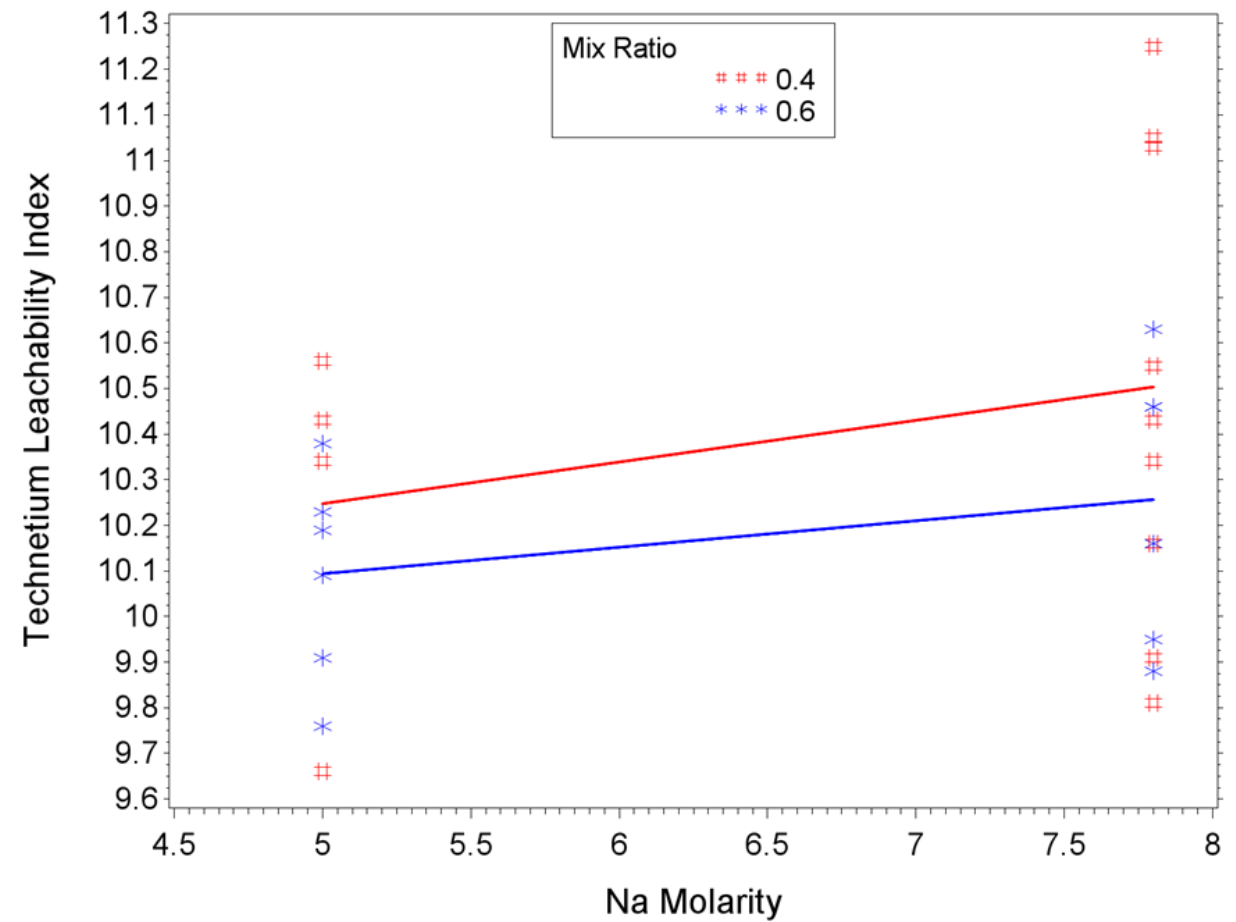

Figure E-75. Data-Interaction Plot for the Effects of Na Molarity and Mix Ratio on Technetium Leachability Index

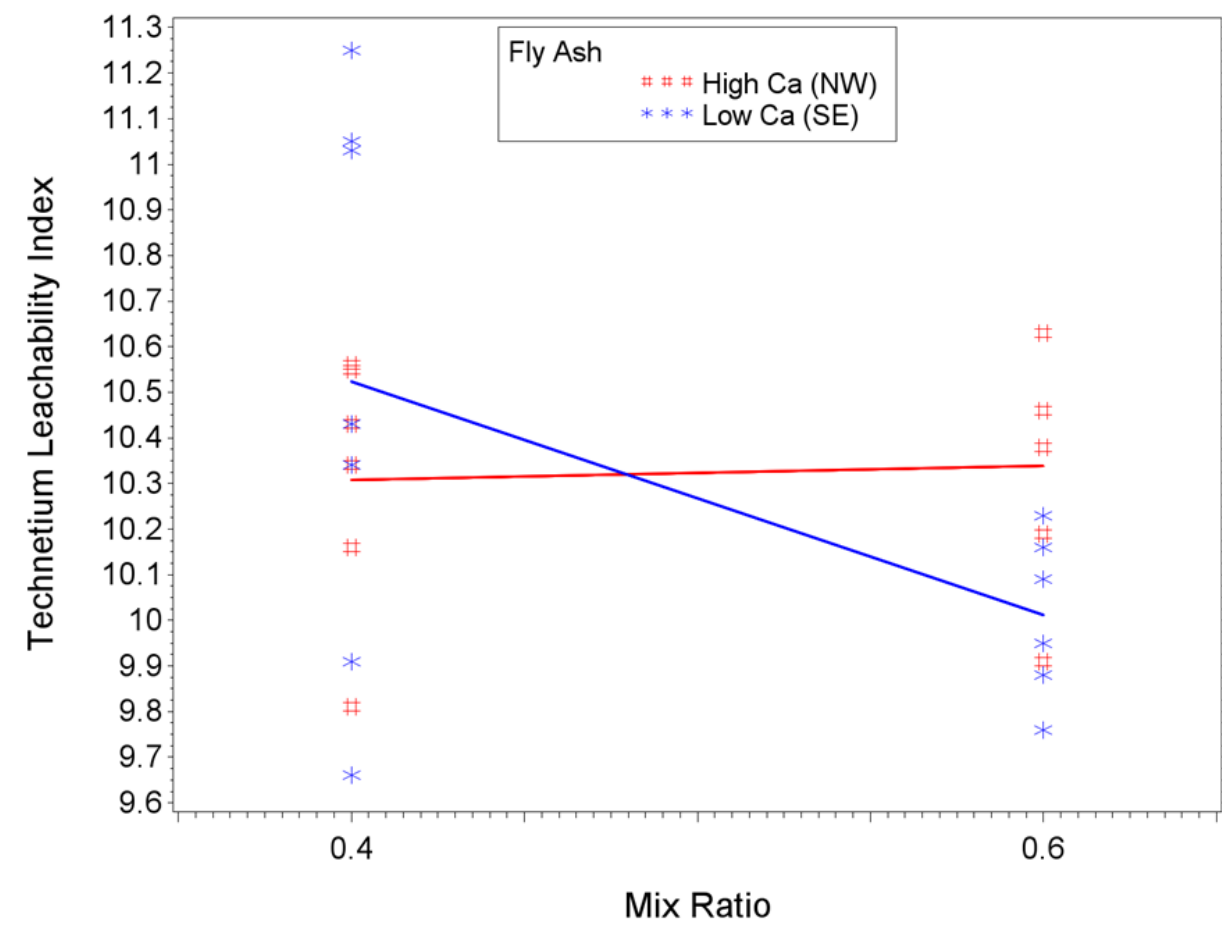

Figure E-76. Data-Interaction Plot for the Effects of Mix Ratio and Fly Ash on Technetium Leachability Index 


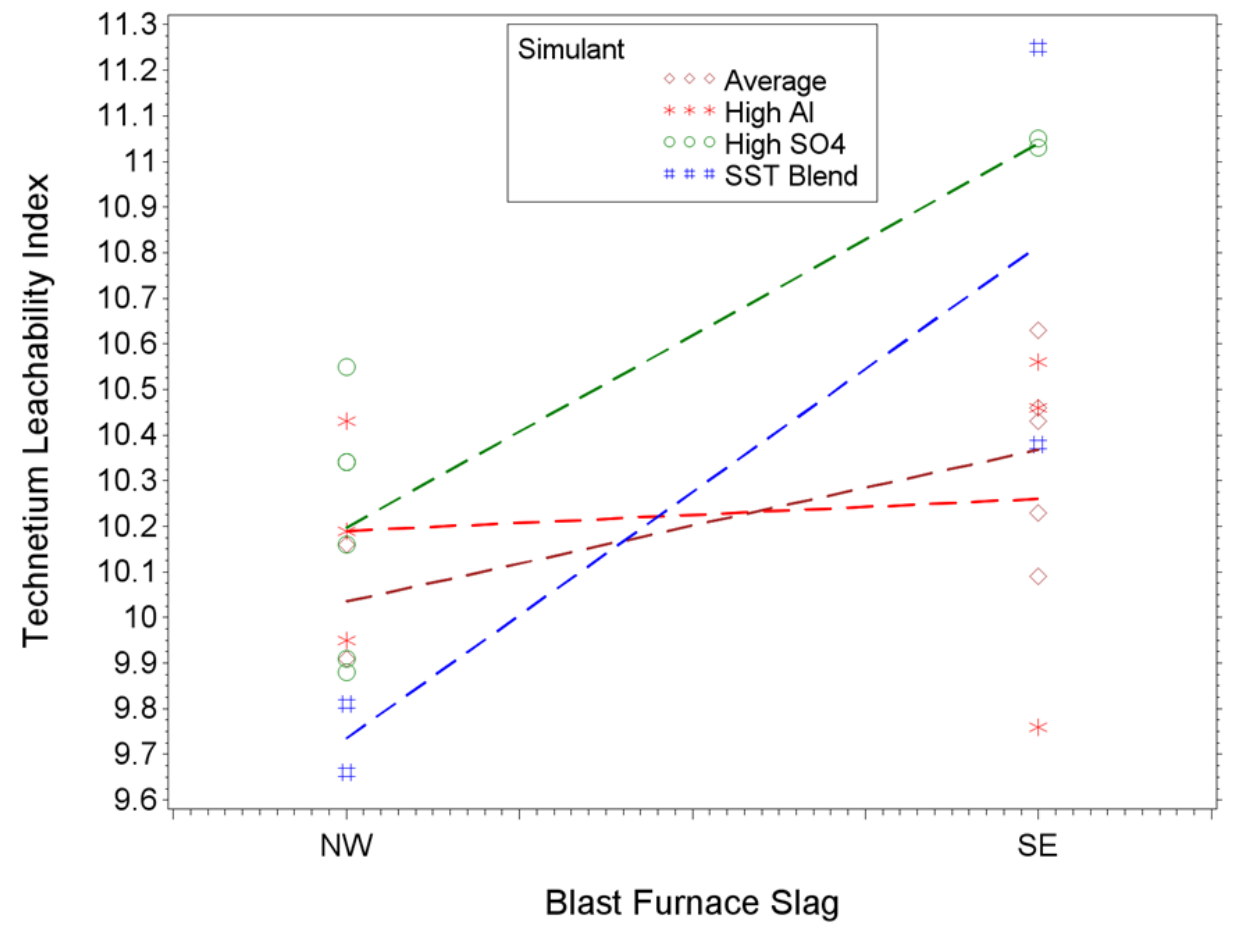

Figure E-77. Data-Interaction Plot for the Effects of Blast Furnace Slag and Simulant on Technetium Leachability Index

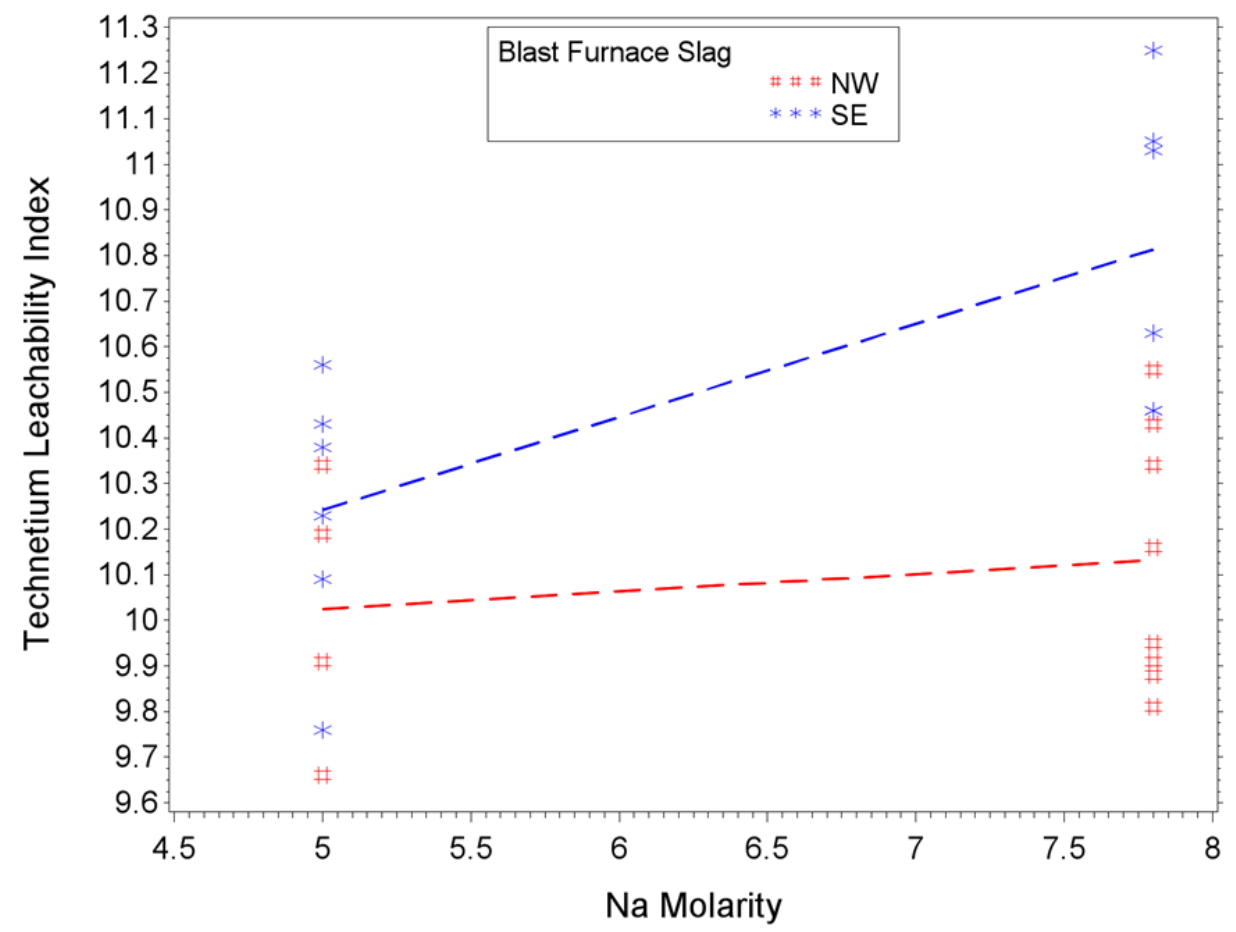

Figure E-78. Data-Interaction Plot for the Effects of Na Molarity and Blast Furnace Slag on Technetium Leachability Index 


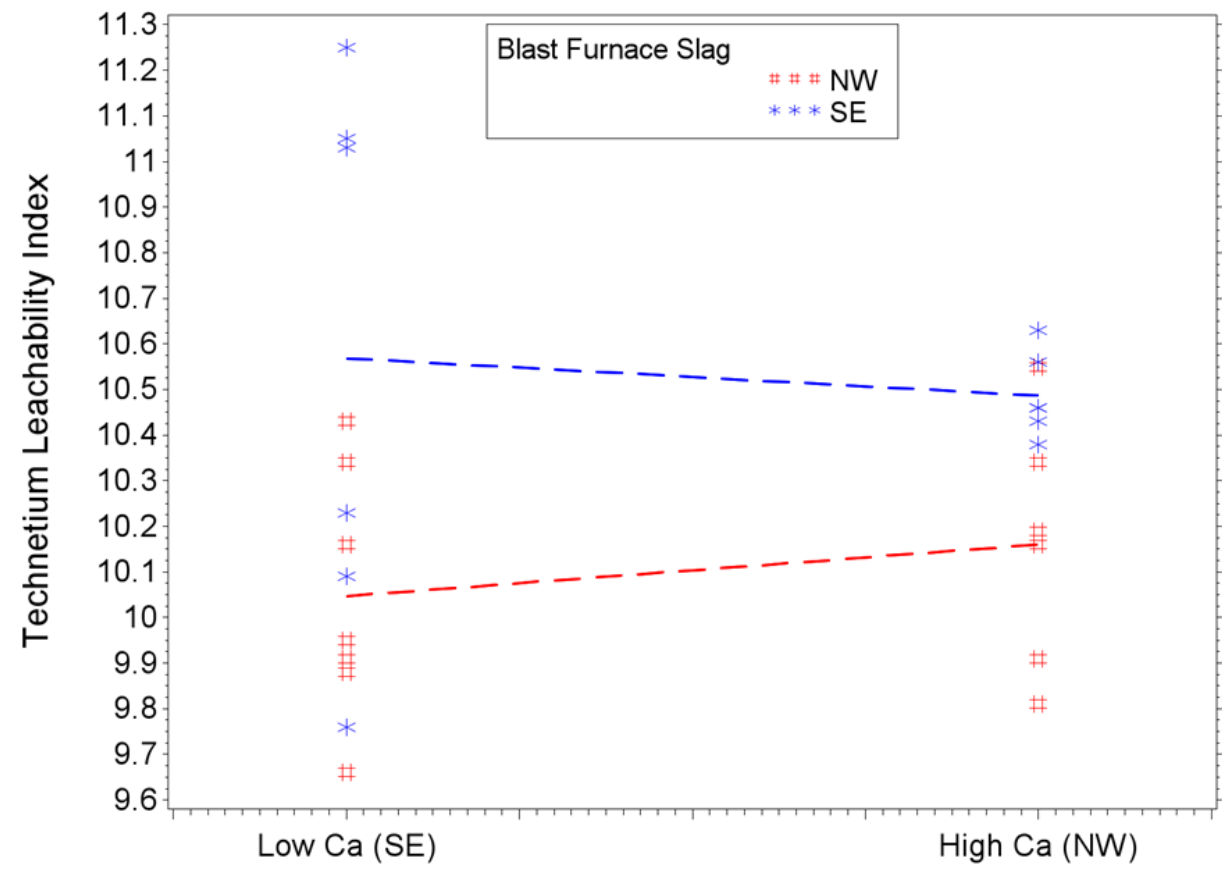

Fly Ash

Figure E-79. Data-Interaction Plot for the Effects of Fly Ash and Blast Furnace Slag on Technetium Leachability Index

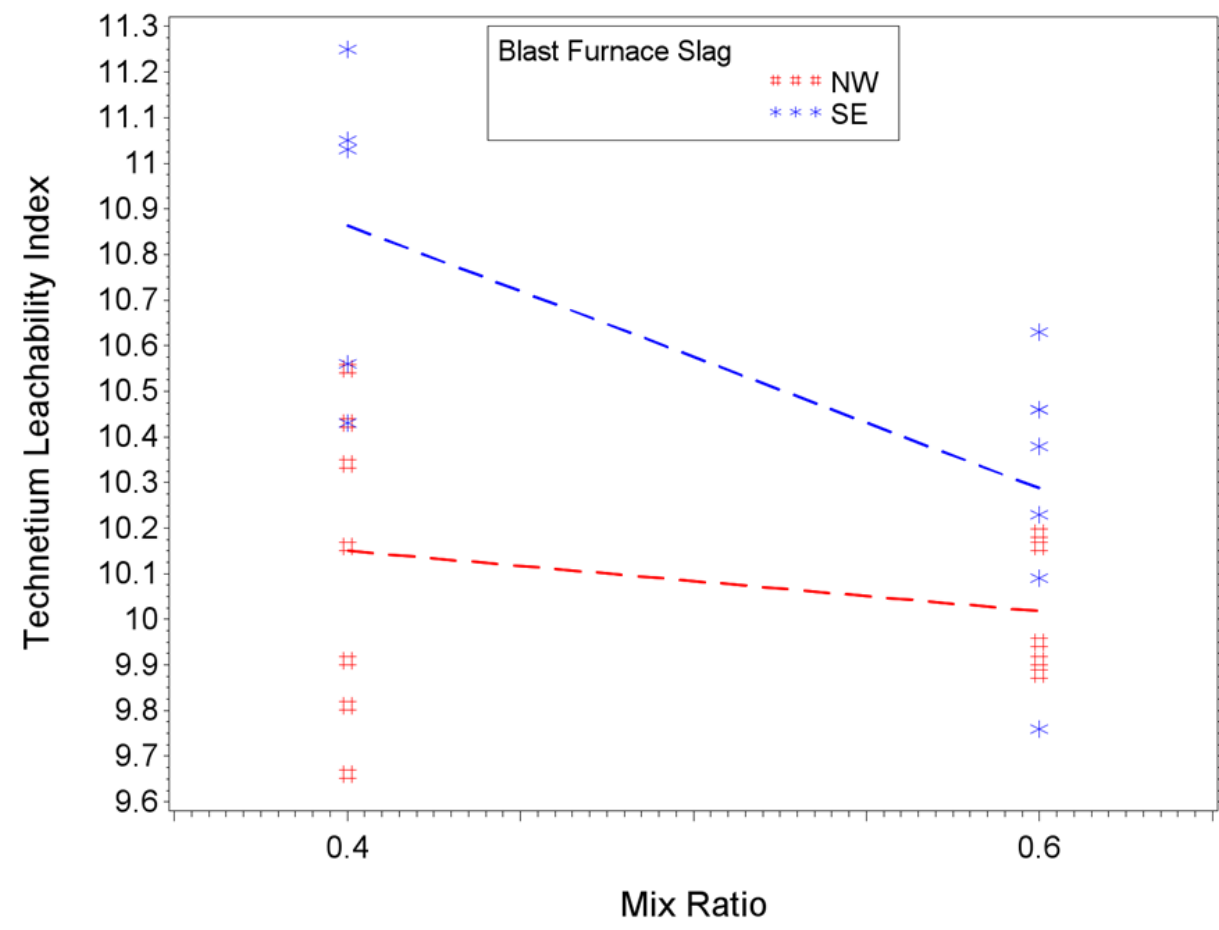

Figure E-80. Data-Interaction Plot for the Effects of Mix Ratio and Blast Furnace Slag on Technetium Leachability Index 
PNNL-22747

SRNL-STI-2013-00465

\section{E.4.5 Chromium Leachability Index}

Figure E-81 through Figure E-90 display the data-interaction plots for the averaged Cr LI of the 26 Cast Stone mixes in the screening text matrix. 


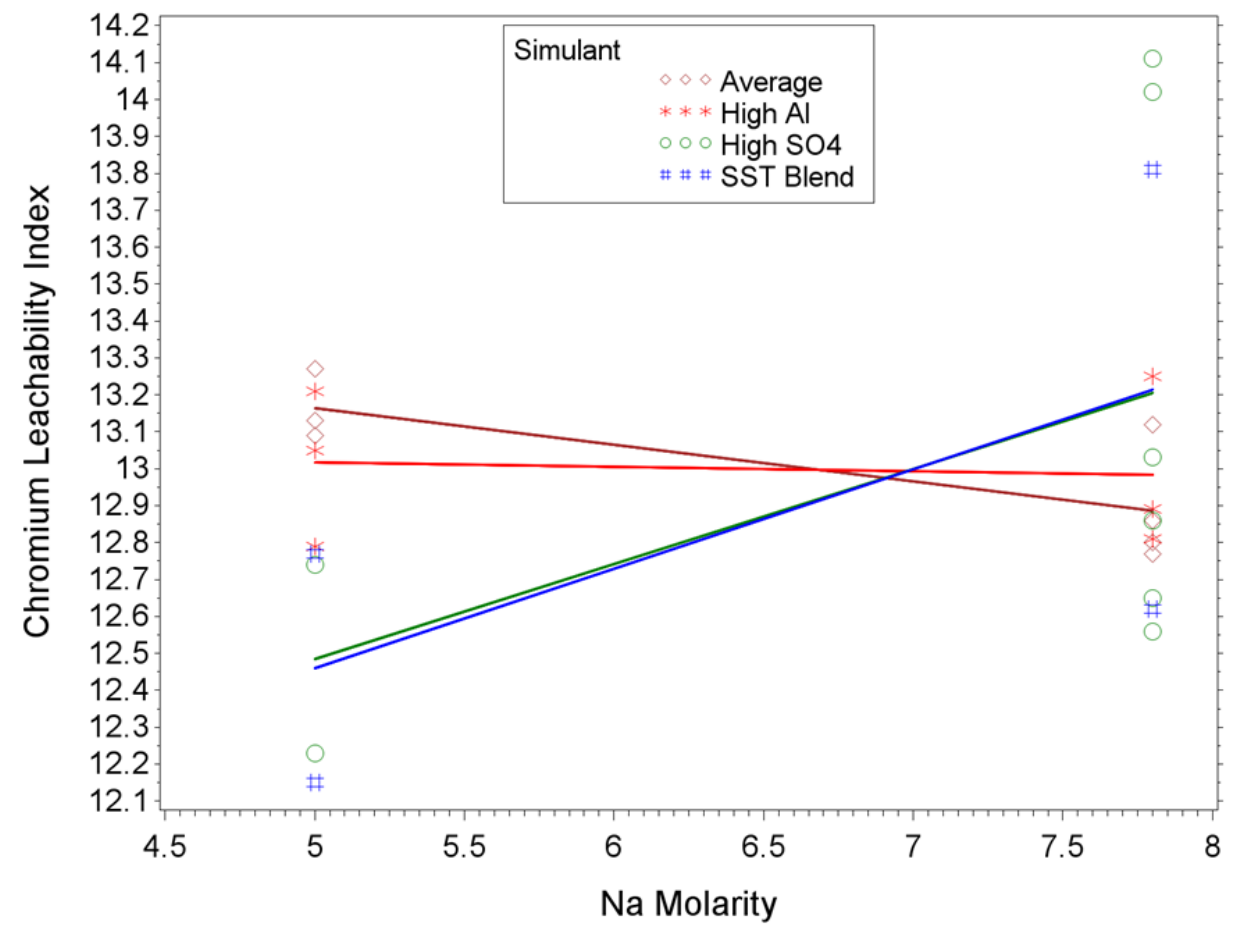

Figure E-81. Data-Interaction Plot for the Effects of Na Molarity and Simulant on Chromium Leachability Index

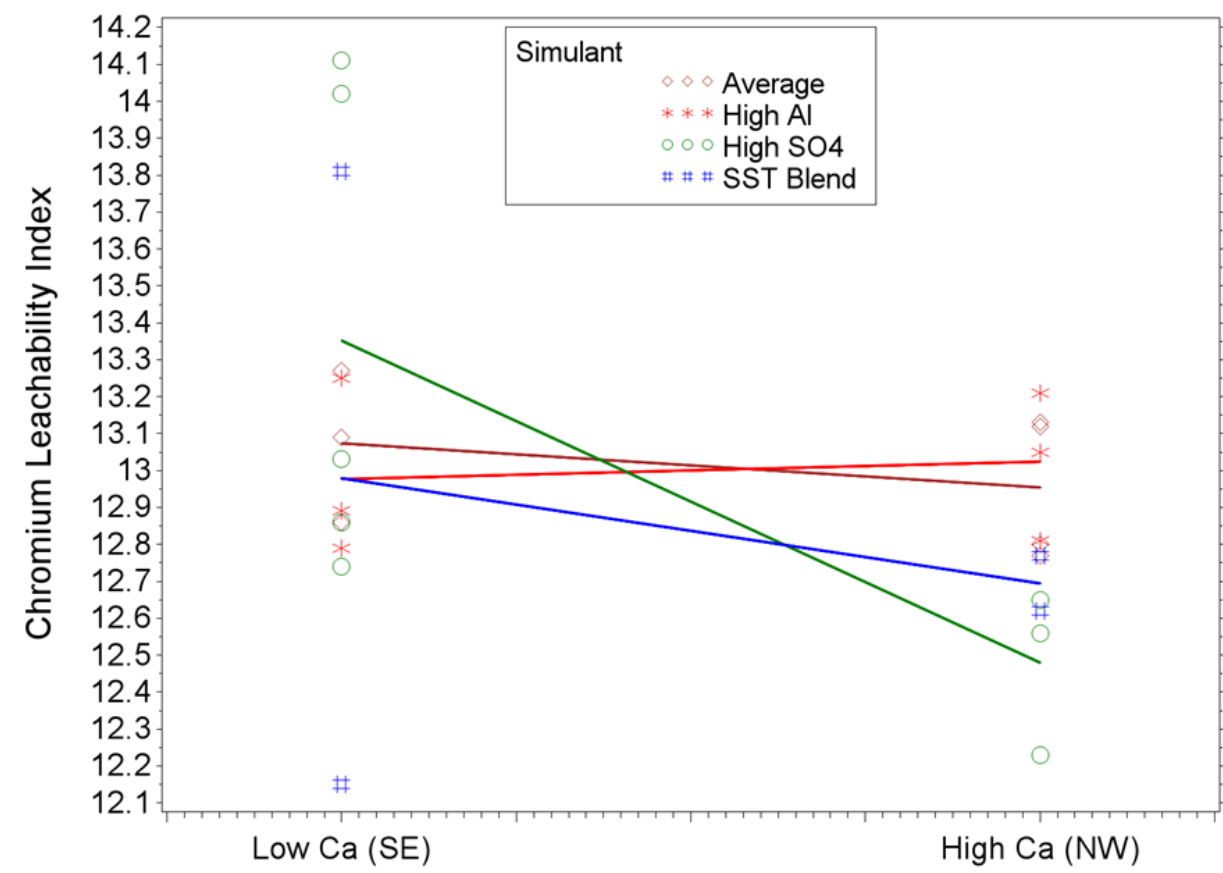

Fly Ash

Figure E-82. Data-Interaction Plot for the Effects of Fly Ash and Simulant on Chromium Leachability Index 


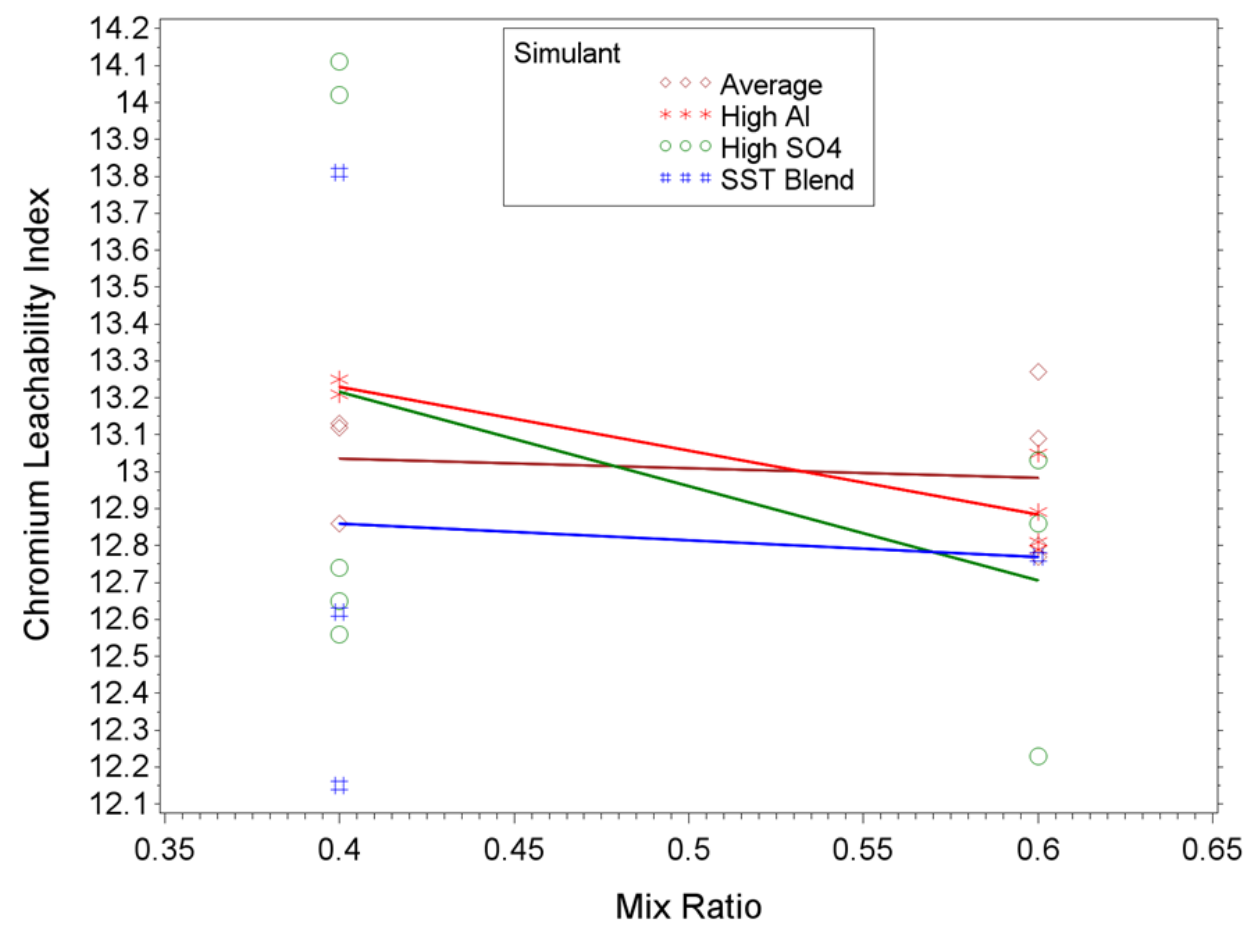

Figure E-83. Data-Interaction Plot for the Effects of Mix Ratio and Simulant on Chromium Leachability Index

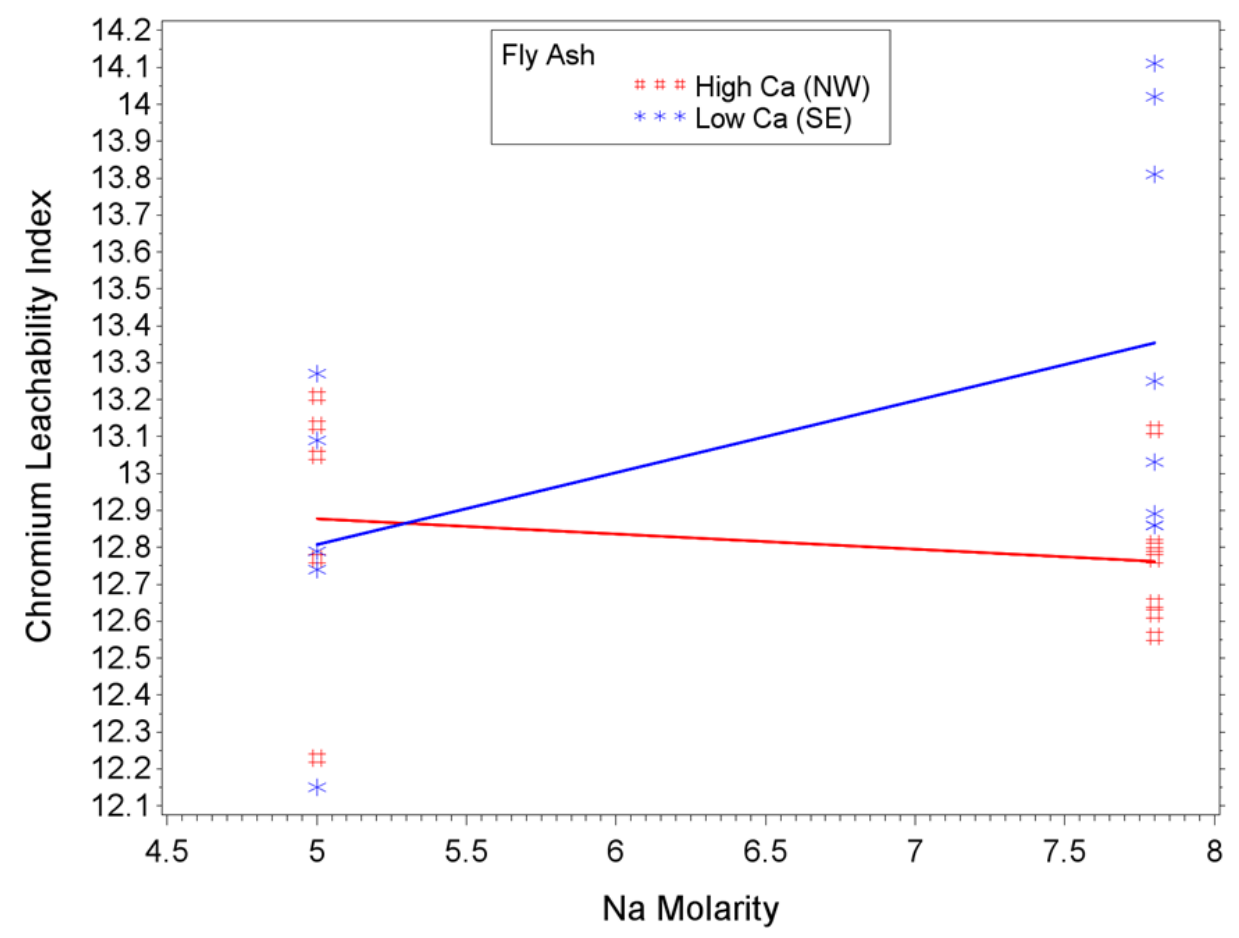

Figure E-84. Data-Interaction Plot for the Effects of Na Molarity and Fly Ash on Chromium Leachability Index 


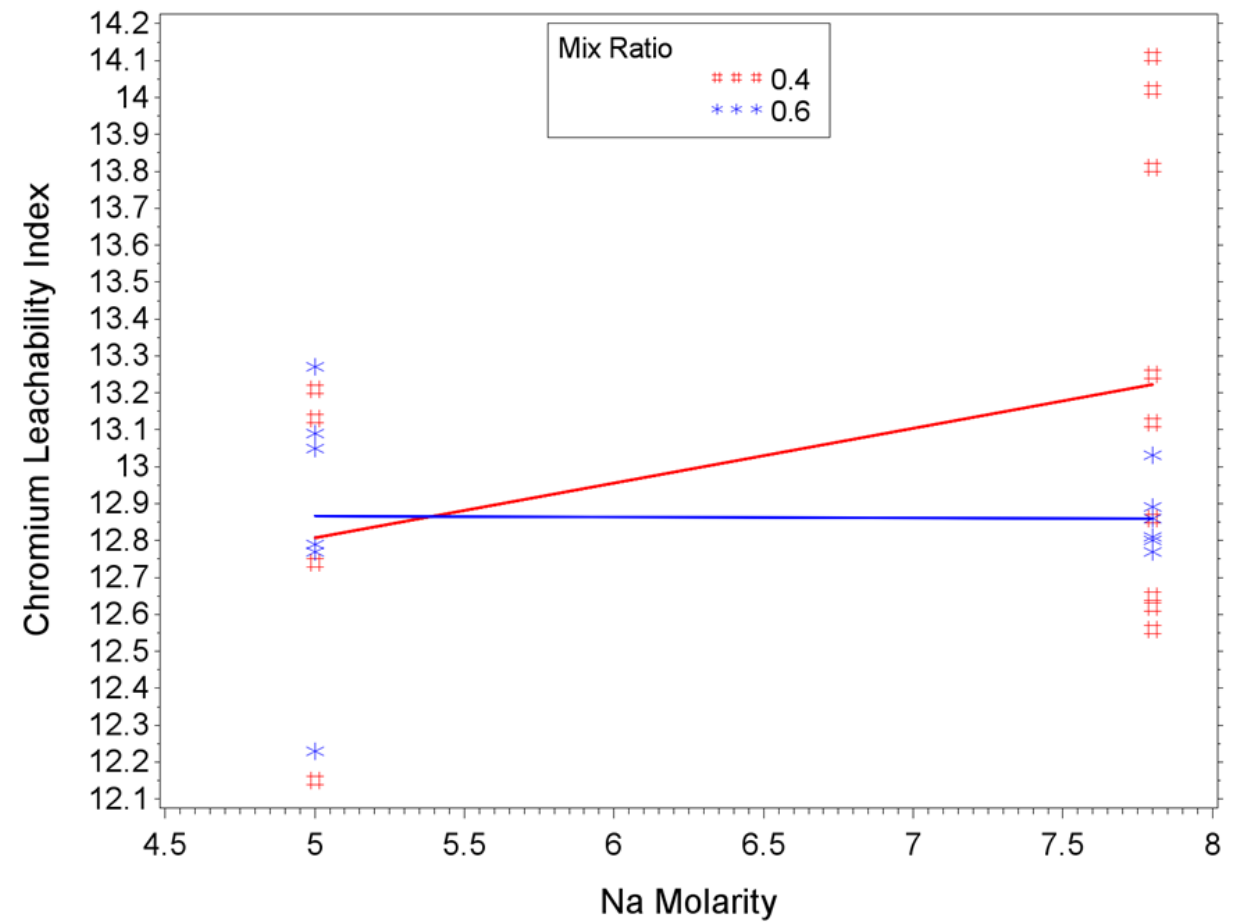

Figure E-85. Data-Interaction Plot for the Effects of Na Molarity and Mix Ratio on Chromium Leachability Index

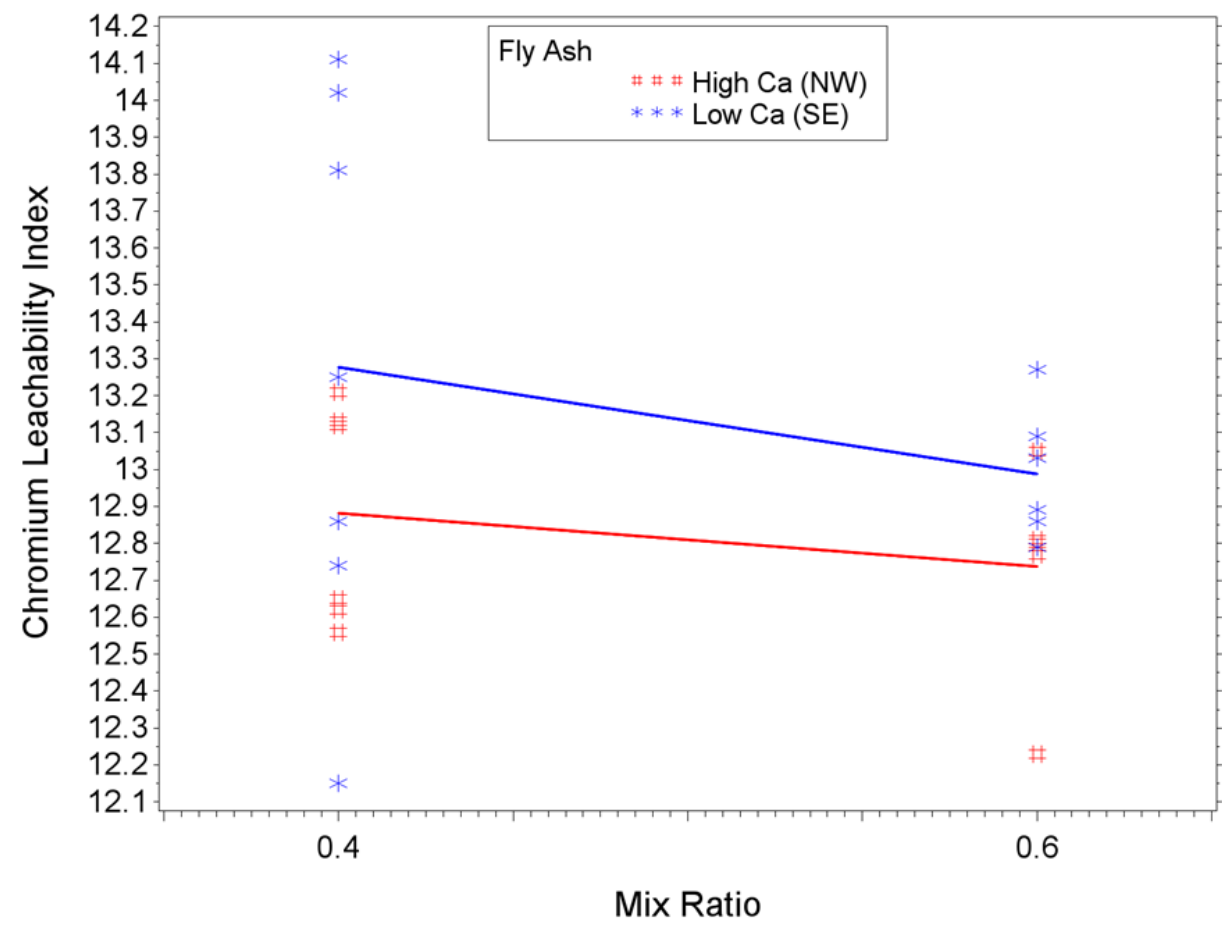

Figure E-86. Data-Interaction Plot for the Effects of Mix Ratio and Fly Ash on Chromium Leachability Index 


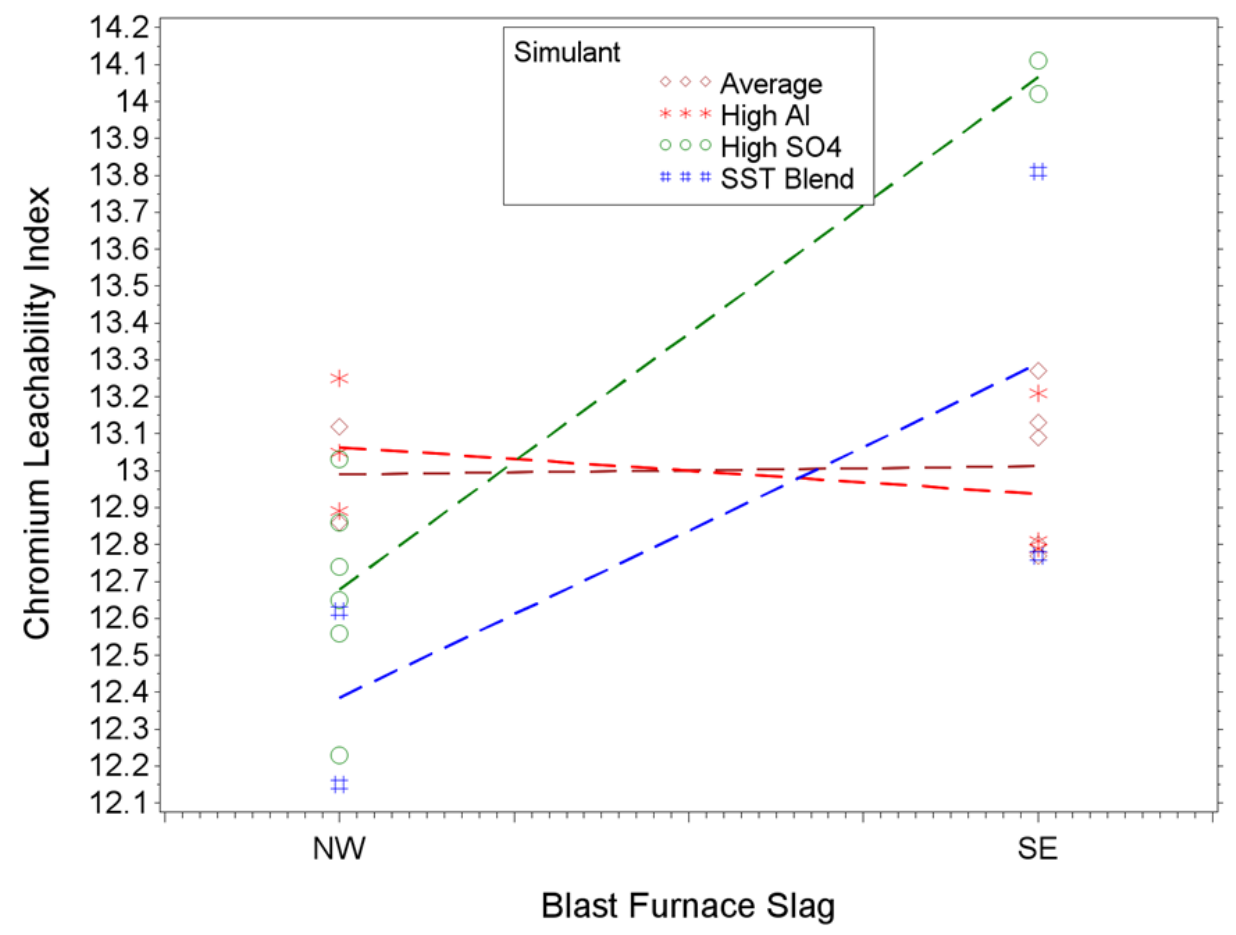

Figure E-87. Data-Interaction Plot for the Effects of Blast Furnace Slag and Simulant on Chromium Leachability Index

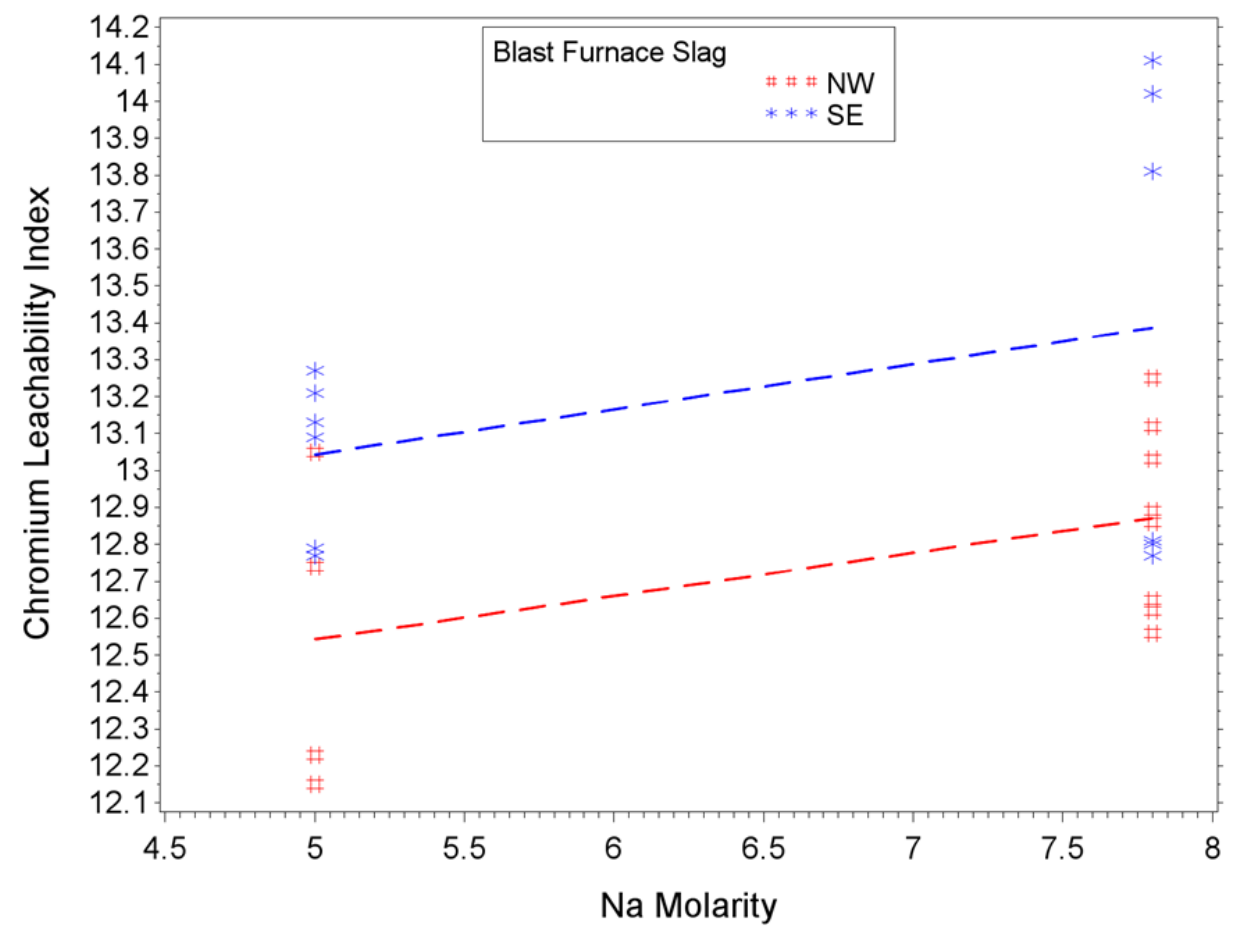

Figure E-88. Data-Interaction Plot for the Effects of Na Molarity and Blast Furnace Slag on Chromium Leachability Index 


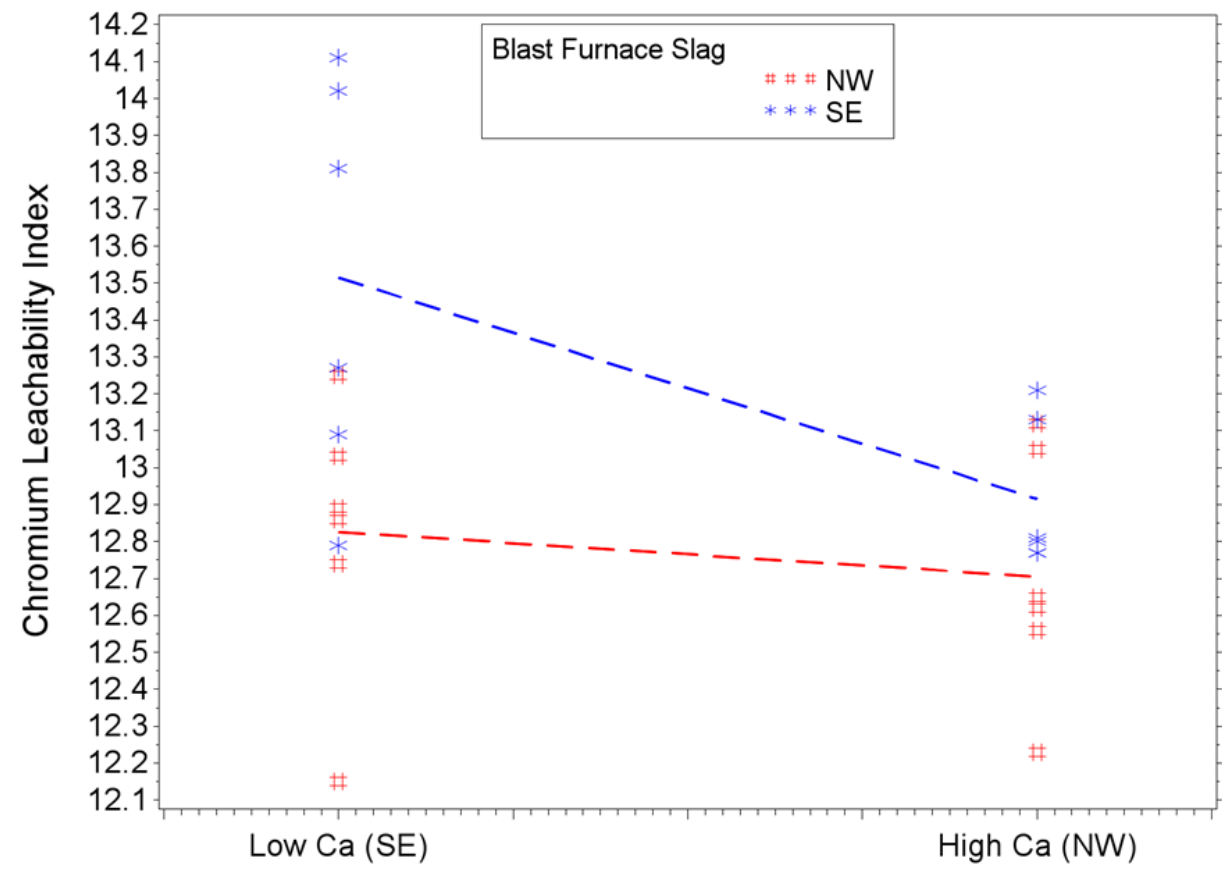

Fly Ash

Figure E-89. Data-Interaction Plot for the Effects of Fly Ash and Blast Furnace Slag on Chromium Leachability Index

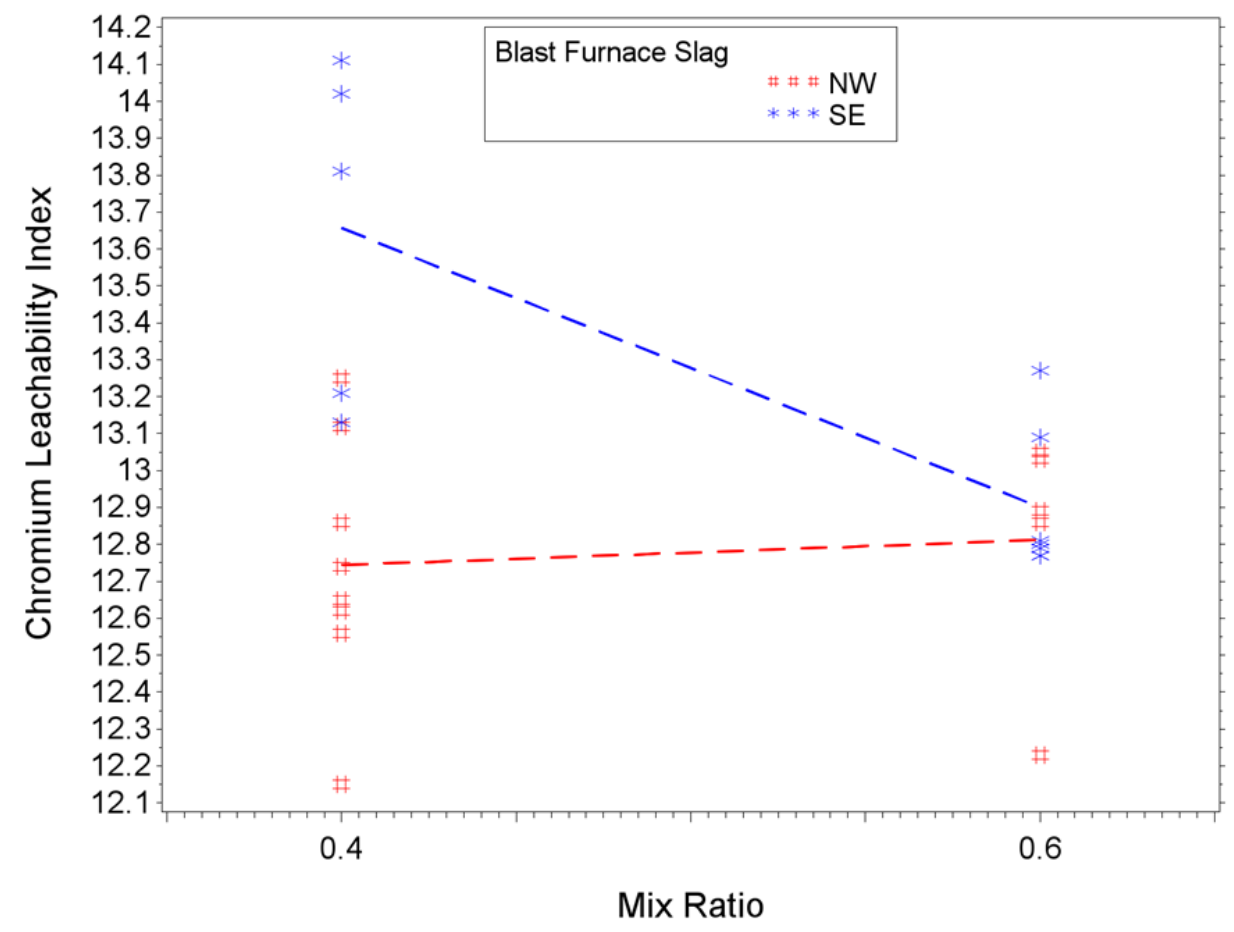

Figure E-90. Data-Interaction Plot for the Effects of Mix Ratio and Blast Furnace Slag on Chromium Leachability Index 
PNNL-22747

SRNL-STI-2013-00465

Appendix F. Material Certification Reports 


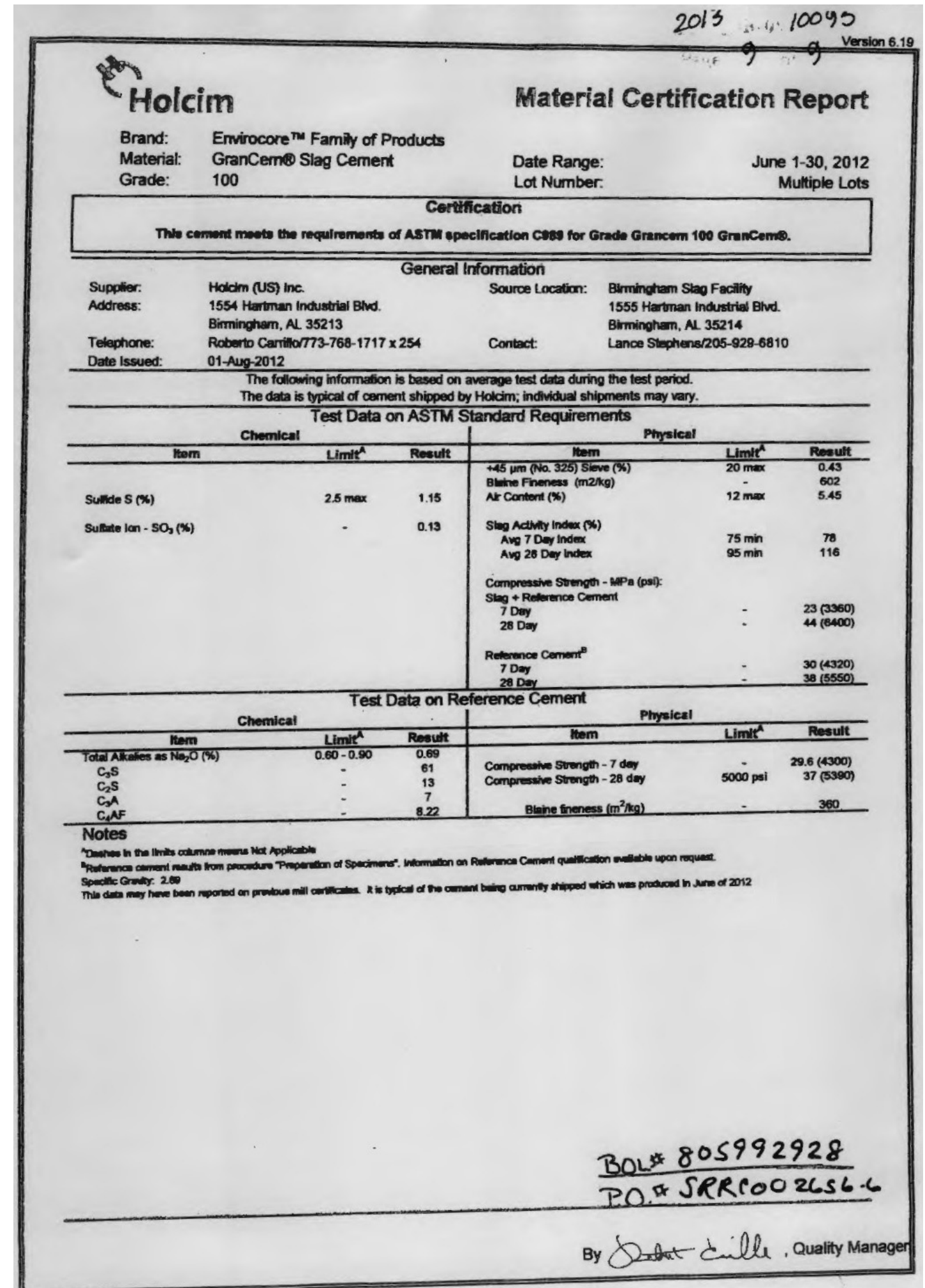




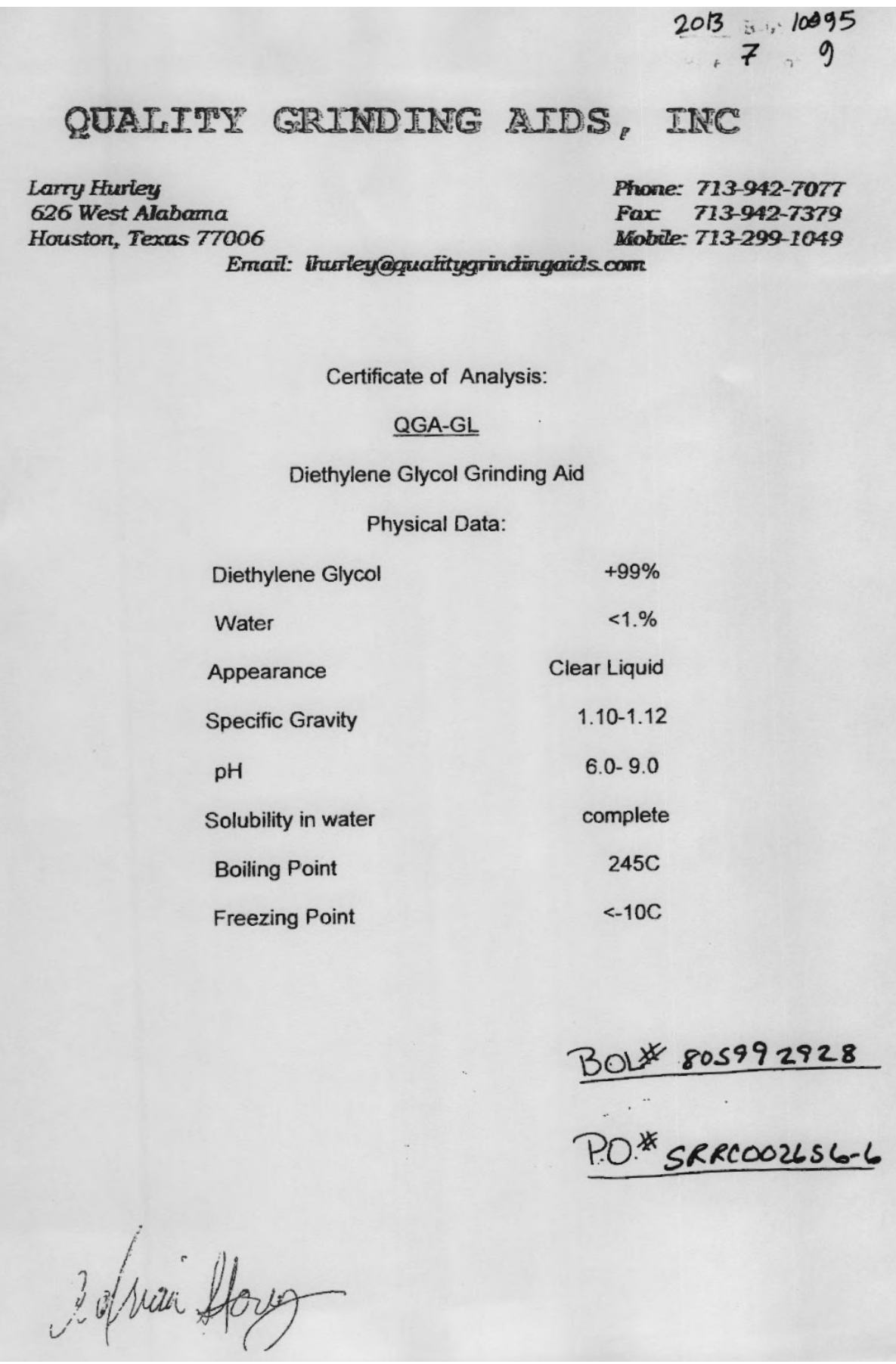




\section{QUAIITY GRINDIIG AIDS, INC}

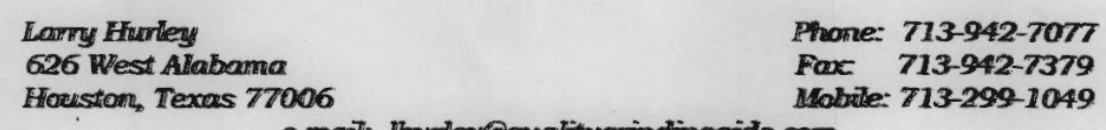

e-mat: tharley@qualitygrindingaids.com

Certificate of Analysis:

\section{QGA-AA}

Amine-Acetate Grinding Aid (50\% Amines reacted with 25\% Glacial Acetic Acid)

Physical Data:
Amine-Acetate

Water

Appearance

Specific Gravity

$\mathrm{pH}$

Solubility in water

Boiling Point

Freezing Point
$75 \%$

$25 \%$

Dark Liquid

1.14-1.16

$6.0-7.0$

complete

$116 \mathrm{C}$

$<-20 C$

\section{BOL 805992928}

P. * sRrcoo2656-6 
PNNL-22747

SRNL-STI-2013-00465

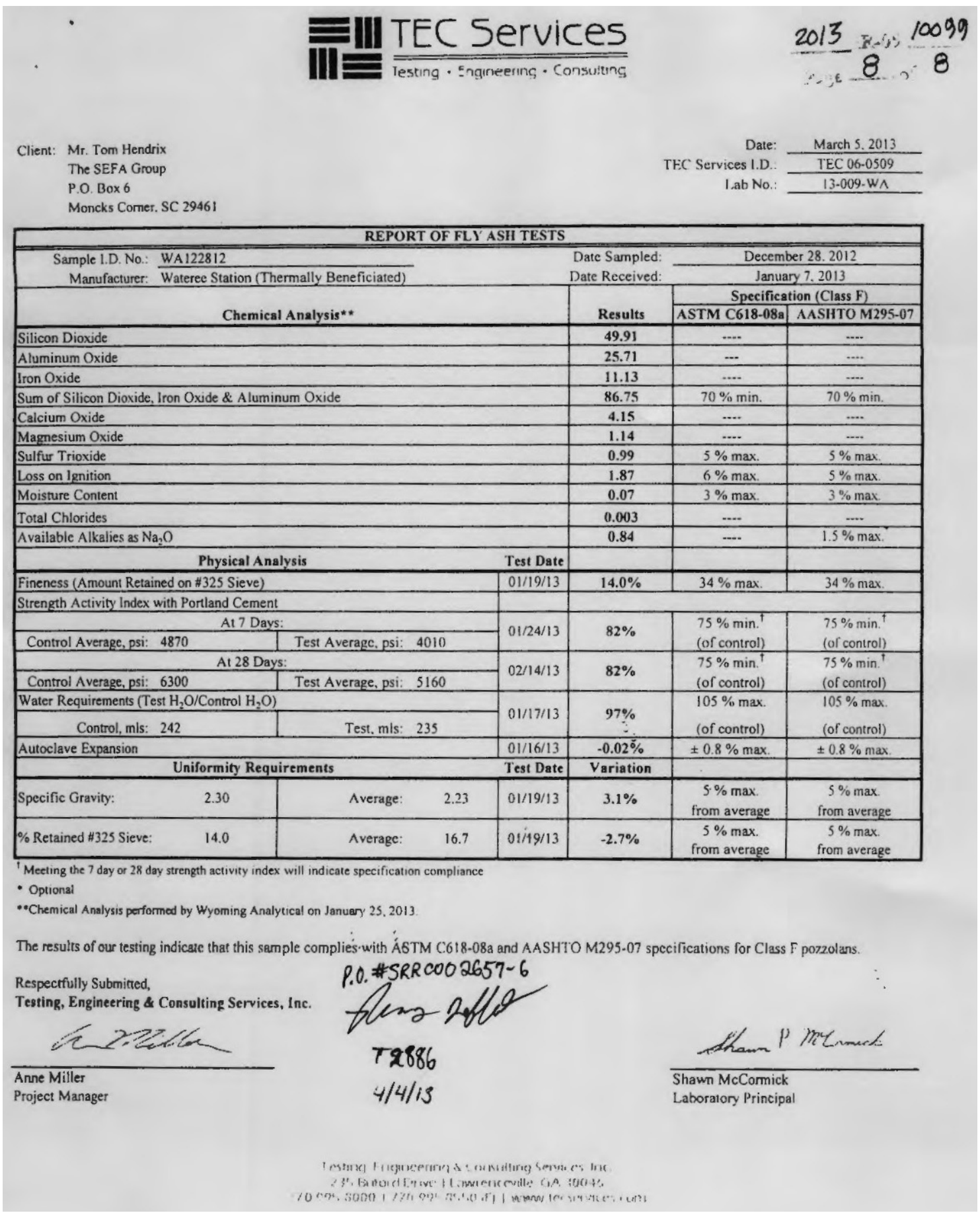


PNNL-22747

SRNL-STI-2013-00465

LAFARGE

Cement

\section{FLY ASH TEST REPORT}

$\begin{array}{ll}\text { Analysis by: } & \text { Lafarge Seattle Concrete Lab } \\ \text { Sample from : } & \text { Centralia Power Plant } \\ \text { Average Analysis: } & \text { August } 1^{\text {st }} \text { - August } 31^{\text {st }} 2012 \\ \text { Test Report Number } & 9-12 \mathrm{~F} \\ & \\ \text { Chemical Analysis } & \end{array}$

Silicon Dioxide $\left(\mathrm{SiO}_{2}\right)$

Results

$54.0 \%$

$16.5 \%$

$6.5 \%$

$77.0 \%$

$0.8 \%$

$12.2 \%$

$4.1 \%$

$0.21 \%$

$0.19 \%$

$1.2 \%$

Available Alkali as Equiv. $\mathrm{Na}_{2} \mathrm{O}$ (previous month's result)

\section{Physical Analysis}

Fineness Retained on 45 um (No. 325 Sieve)

Strength Activity Index with Portland Cement

$\%$ of Control at 7 Days

$\%$ of Control at 28 Days (previous month's result)

Water Requirement, Percent of Control

Autoclave Expansion

Density

Uniformity Requirements

Density, Variation from Average

Fineness $45 \mathrm{um}$ Sieve, Variation from Average

$17.3 \% \quad 34 \%$ Max - ASTM

$80 \% \quad 75 \%$ Min - ASTM

$96 \% \quad 75 \%$ Min - ASTM

$\mathbf{9 8} \% \quad 105 \%$ Max- ASTM

$\mathbf{0 . 0 2} \% \quad 0.8 \%$ Max - ASTM

$2.59 \mathrm{Mg} / \mathrm{m}^{3}$

$\mathbf{0 . 0 0} \% \quad 5 \%$ Max - ASTM

$\mathbf{0 . 0 0} \% \quad 5 \%$ Max - ASTM

We hereby certify that the composite fly ash sample above meets the chemical and physical requirements of ASTM C618-08 and AASHTO M295-07 for class F and C fly ash.

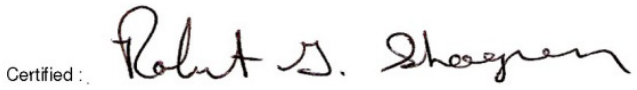

\section{WESTERN REGION}

5400 West Marginal Way SW, Seattle, Washington 98106-1517

Office: 206.923 .0098 or 800.477 .0100 Fax: 206.923 .0388 
PNNL-22747

SRNL-STI-2013-00465

\section{LAFARGE Cement Test Report}

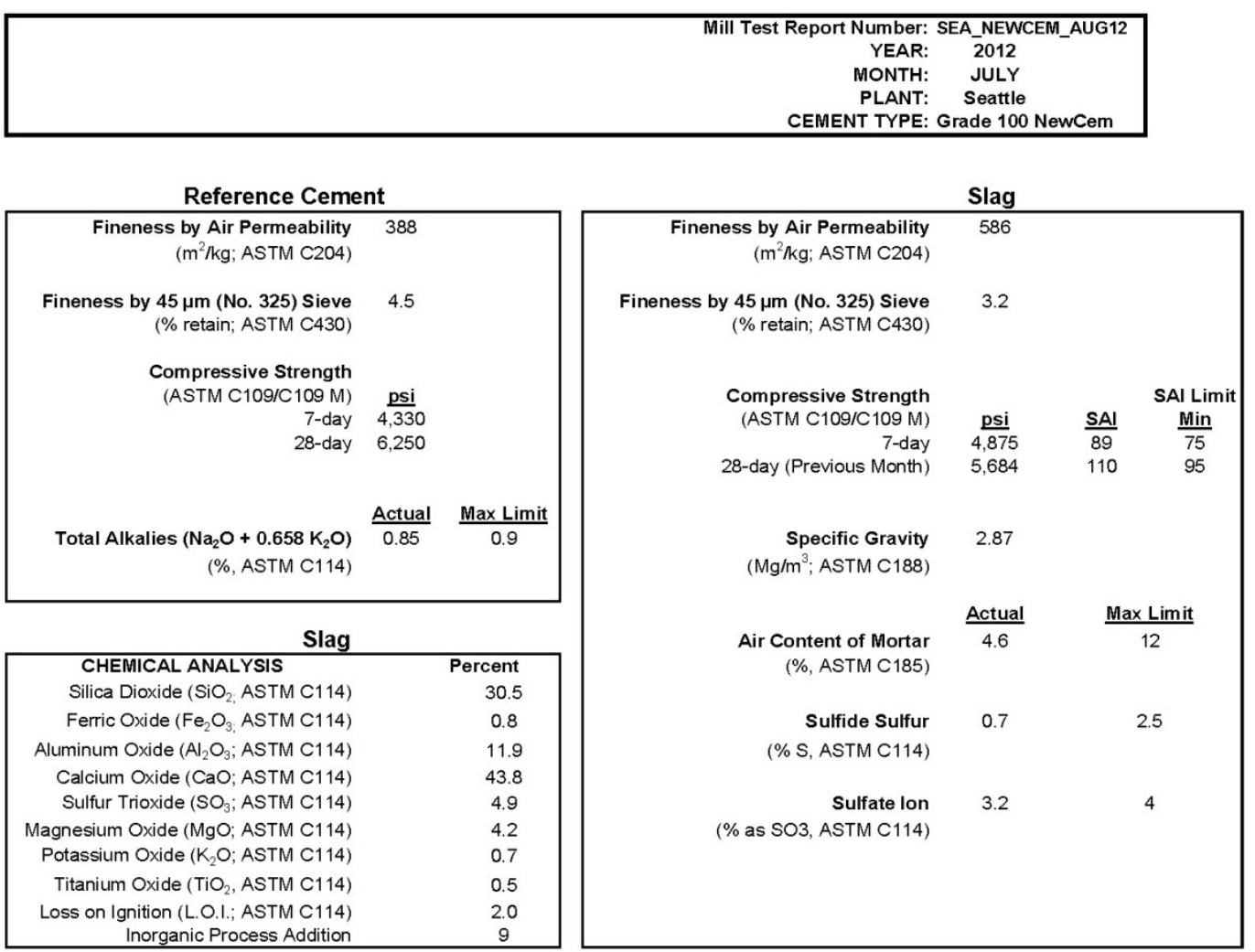

The ground granulated blast furnace slag complies with the current specification of the chemical physical requirement of ASTM C-989, AASHTO M-302 for grade 100 Ground Granulated Blast Furace Slag (GGBFS) and and CSA A3001 Slag.

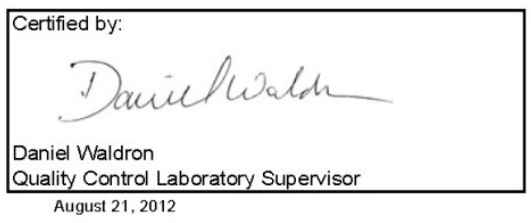

